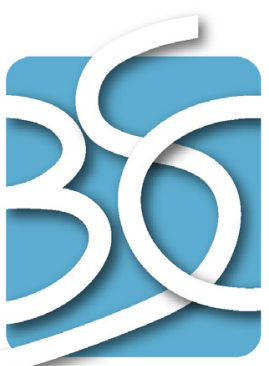

BECHTEL SAIC COMPANYLC
QA: QA

ANL-EBS-MD-000037 REV 04

July 2005

\title{
In-Package Chemistry Abstraction
}

\section{NOTICE OF OPEN CHANGE DOCUMENTS - THIS DOCUMENT IS IMPACTED BY THE LISTED CHANGE DOCUMENT AND CANNOT BE USED WITHOUT IT.}

1) ACN-001, DATED 12/01/2005

Prepared for:

U.S. Department of Energy

Office of Civilian Radioactive Waste Management

Office of Repository Development

1551 Hillshire Drive

Las Vegas, Nevada 89134-6321

Prepared by:

Bechtel SAIC Company, LLC

1180 Town Center Drive

Las Vegas, Nevada 89144

Under Contract Number

DE-AC28-01RW12101 


\section{DISCLAIMER}

This report was prepared as an account of work sponsored by an agency of the United States Government. Neither the United States Government nor any agency thereof, nor any of their employees, nor any of their contractors, subcontractors or their employees, makes any warranty, express or implied, or assumes any legal liability or responsibility for the accuracy, completeness, or any third party's use or the results of such use of any information, apparatus, product, or process disclosed, or represents that its use would not infringe privately owned rights. Reference herein to any specific commercial product, process, or service by trade name, trademark, manufacturer, or otherwise, does not necessarily constitute or imply its endorsement, recommendation, or favoring by the United States Government or any agency thereof or its contractors or subcontractors. The views and opinions of authors expressed herein do not necessarily state or reflect those of the United States Government or any agency thereof. 
QA: QA

In-Package Chemistry Abstraction ANL-EBS-MD-000037 REV 04

July 2005 
2. Type of Mathematical Model

Process Model

凶 Abstraction Model

System Model

Describe Intended Use of Model

\section{Title}

In-Package Chemistry Abstraction

4. DI (including Rev. No.):

ANL-EBS-MD-000037 REV 04

\begin{tabular}{|c|c|c|c|}
\hline & Printed Name & Signature & Date \\
\hline 5. Originator & Emma Thomas & $\sum s t h$ & $7 / 14 / 05$ \\
\hline $\begin{array}{l}\text { 6. Independent Technical } \\
\text { Reviewer }\end{array}$ & Laura Price & SEE NEXT PAGE & \\
\hline 7. Checker & Patricia Bernot & c & $27 / 1410$ \\
\hline 8. QER & Judith Gebhart & $\partial l_{0}$ & $1 / 14 / 0$ \\
\hline 9. Responsible Manager/Lead & James Cunnane & 10 & $3 / 14 / 05$ \\
\hline 10. Responsible Manager & Paul Dixon & & $7-14-0$ \\
\hline
\end{tabular}

Change History

\begin{tabular}{|l|l|}
\hline \multicolumn{1}{|c|}{ 12. Revision No. } & \multicolumn{1}{c|}{ 13. Description of Change } \\
\hline 00 & Initial Issue. \\
\hline 01 & $\begin{array}{l}\text { The entire abstraction model was revised to reflect updated inputs/outputs from } \\
\text { the feed process model AMR (ANL-EBS-MD-000050 REV 01). }\end{array}$ \\
\hline 02 & Complete revision to incorporate new conceptual model. \\
\hline 03 & $\begin{array}{l}\text { Complete revision to support regulatory integration. Change bars were not } \\
\text { used because the changes were too significant. This revision incorporates the } \\
\text { suggestions identified in CR 2065. }\end{array}$ \\
\hline 04 & $\begin{array}{l}\text { Complete revision including updating from Cr(VI) to Cr(III), inclusion of } \\
\text { LaBS glass analysis, and enhanced model validation. Change bars were not } \\
\text { used because the changes were too significant. This revision incorporates the } \\
\text { corrections identified in CRs 4961, 5001, and 5002. }\end{array}$ \\
\hline
\end{tabular}


2. Type of Mathematical Mode

Process Model

$\bigotimes$ Abstraction Model

\section{System Model}

Describe Intended Use of Model

3. Title

In-Package Chemistry Abstraction

4. DI (including Rev. No.):

ANL-EBS-MD-000037 REV 04

\begin{tabular}{|l|l|l|l|}
\hline & Printed Name & Signature & Date \\
\hline 5. Originator & Emma Thomas & & \\
\hline $\begin{array}{l}\text { 6. Independent Technical } \\
\text { Reviewer }\end{array}$ & Laura Price & Launa Prie & $7 / 14 / 05$ \\
\hline 7. Checker & Patricia Bernot & & \\
\hline 8. QER & Judith Gebhart & & \\
\hline 9. Responsible Manager/Lead & James Cunnane & & \\
\hline 10. Responsible Manager & Paul Dixon & & \\
\hline
\end{tabular}

11. Remarks

Appendix F - One (1) CD-ROM

Change History

\begin{tabular}{|l|l|}
\hline \multicolumn{1}{|c|}{ 12. Revision No. } & \multicolumn{1}{c|}{ 13. Description of Change } \\
\hline 00 & Initial Issue. \\
\hline 01 & $\begin{array}{l}\text { The entire abstraction model was revised to reflect updated inputs/outputs from } \\
\text { the feed process model AMR (ANL-EBS-MD-000050 REV 01). }\end{array}$ \\
\hline 02 & Complete revision to incorporate new conceptual model. \\
\hline 03 & $\begin{array}{l}\text { Complete revision to support regulatory integration. Change bars were not } \\
\text { used because the changes were too significant. This revision incorporates the } \\
\text { suggestions identified in CR 2065. }\end{array}$ \\
\hline 04 & $\begin{array}{l}\text { Complete revision including updating from Cr(VI) to Cr(III), inclusion of } \\
\text { LaBS glass analysis, and enhanced model validation. Change bars were not } \\
\text { used because the changes were too significant. This revision incorporates the } \\
\text { corrections identified in CRs 4961, 5001, and 5002. }\end{array}$ \\
\hline
\end{tabular}




\section{ACKNOWLEDGEMENTS}

This model report was developed through the contributions of the following individuals, listed in alphabetical order:

- Sara Arthur, AREVA. Contributor to all prior revisions of this report (REV00 through REV03). Responsible for various sensitivity analyses.

- Patrick Brady, Sandia National Laboratories. Co-author/major contributor to prior revisions of this report (REV00 through REV03). Developed the surface complexation model, and co-developed the batch reactor conceptual model (with Paul Domski).

- Paul Domski, AREVA. Originator, lead author, and major contributor to all prior revisions of this report (REV00 through REV03). Codeveloped the batch reactor conceptual model (with Pat Brady) and developed the model abstraction.

- Susan LeStrange, BSC. Contributor to REV03. Responsible for various sensitivity analyses.

- Clinton Lum, Sandia National Laboratories. Contributor to the REV04. Responsible for the vapor diffusion calculation.

- Paul Mariner, AREVA. Coauthored, and major contributor to previous and current revision of this report (REV03 through REV 04). Responsible for the development of the surface complexation model demonstration.

- Emma Thomas, BSC. Originator and lead author for REV03 and REV04 of this report. Responsible for incorporation of Regulatory Integration Team comments and items in the RIT Action Item Database. 


\section{CONTENTS}

Page

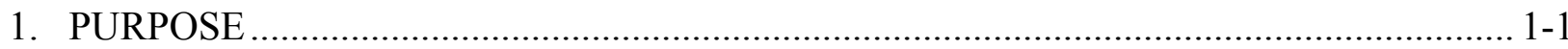

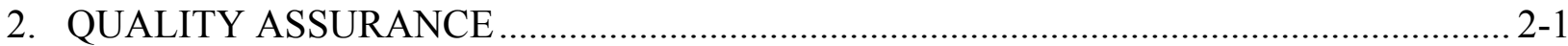

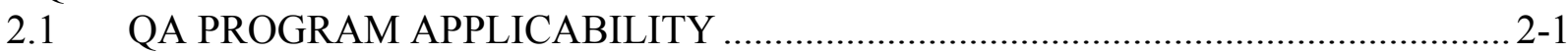

2.2 ELECTRONIC MANAGEMENT OF INFORMATION ............................................. 2-1

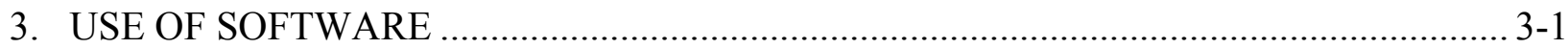

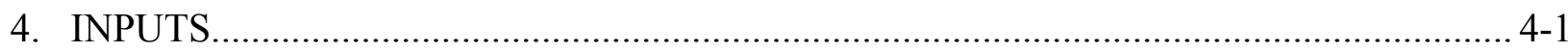

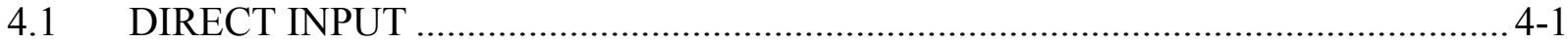

4.1.1 Thermodynamic Database .................................................................. 4-3

4.1.2 Input Water Compositions and Rates ...................................................... 4-3

4.1.3 Waste Forms ……….................................................................................

4.1.4 Waste Package Material Compositions and Rates......................................... 4-11

4.1.5 Atomic Weights ................................................................................... 4-13

4.1.6 Surface Complexation Inputs................................................................. 4-13

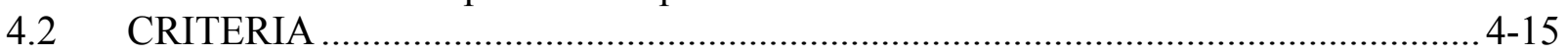

4.3 CODES, STANDARDS, AND REGULATIONS ………..................................... 4-15

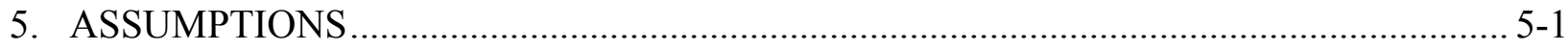

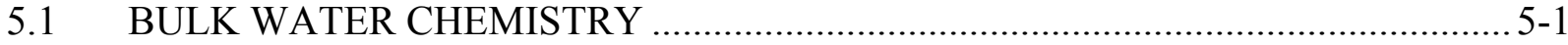

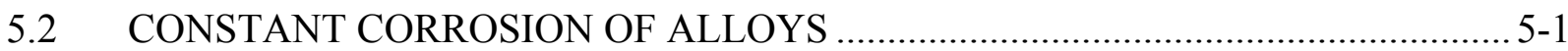

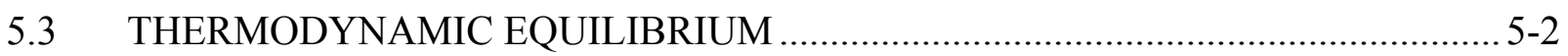

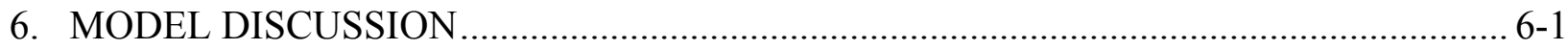

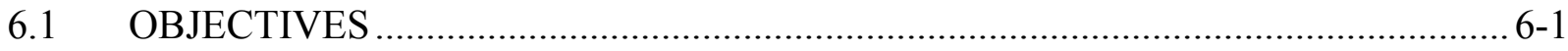

6.2 FEATURES, EVENTS, AND PROCESSES ………........................................ 6-1

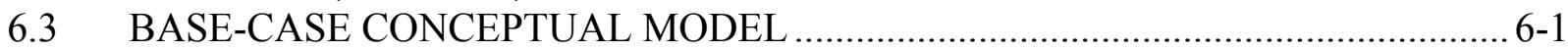

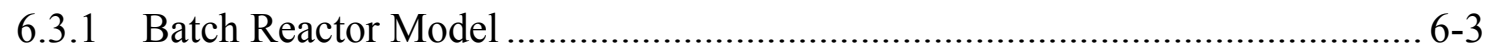

6.3.2 Surface Complexation Model …………................................................ 6-21

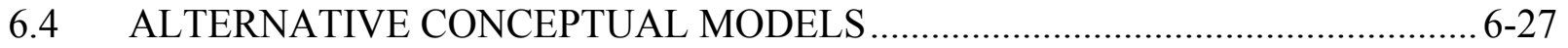

6.4.1 Alternative Conceptual Model I ……………….................................... 6-27

6.4.2 Alternative Conceptual Model II ............................................................... 6-28

6.4.3 Alternative Conceptual Model III - Diffusion of Vapor into the Waste

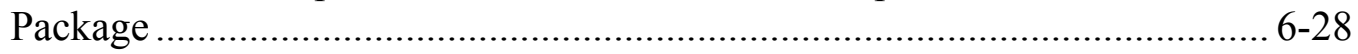

6.5 BATCH-REACTOR BASE-CASE MODEL OUTPUT …………………............ 6-34

6.5.1 Liquid-Influx Case Model Results........................................................ 6-34

6.5.2 Vapor-Influx Model Results ................................................................. 6-47

6.5.3 Conceptual Model Conclusions ...................................................................... 6-54

6.6 BATCH REACTOR SENSITIVITY ANALYSES .............................................. 6-54

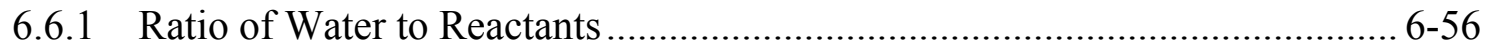

6.6.2 Thermally Perturbed Fluids .................................................................. 6-60

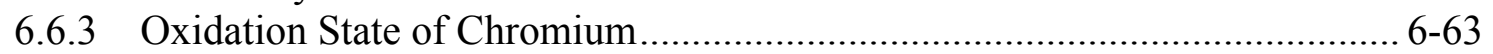


6.6.4 Carbon Dioxide and Oxygen Fugacity ................................................... 6-67

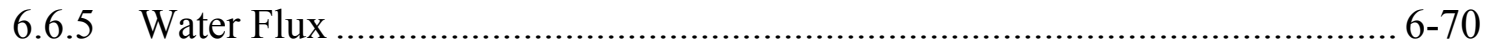

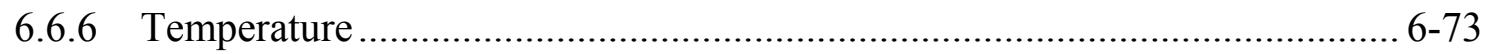

6.6.7 Design Change from Neutronit to NiGd Alloy........................................ 6-77

6.6.8 HLWG Composition Change.................................................................... 6-80

6.6.9 Quantity of Carbon Steel Type A516 in Waste Package Design ................... 6-82

6.6.10 Degradation Rates.............................................................................. 6-84

6.6.11 Hematite versus Goethite................................................................. 6-87

6.6.12 Codisposal Waste Package Containing 5-DHLW Canisters ......................... 6-90

6.6.13 LaBS Glass Composition ................................................................................ 6-92

6.7 SURFACE COMPLEXATION MODEL OUTPUT ............................................. 6-94

6.7.1 pH Buffering During Dissolution of Carbon Steel ..................................... 6-95

6.7.2 pH Buffering During Dissolution of Stainless Steel, Fuel, and HLWG...... 6-100

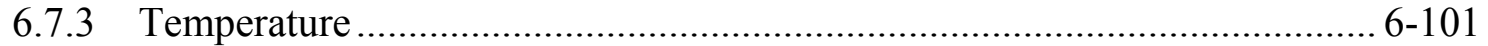

6.8 SURFACE COMPLEXATION DEMONSTRATION ....................................... 6-102

6.8.1 Surface Complexation Reaction Databases ............................................... 6-103

6.8.2 Surface Properties ........................................................................ 6-104

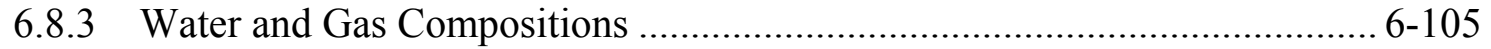

6.8.4 Surface Complexation Calculations......................................................... 6-105

6.9 APPLICATION OF SURFACE COMPLEXATION MODEL TO THE BATCH

REACTOR MODEL RESULTS ....................................................................... 6-107

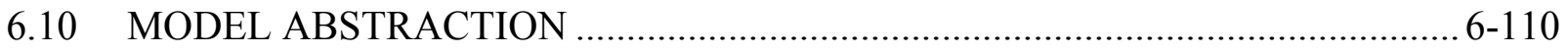

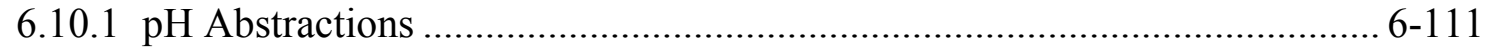

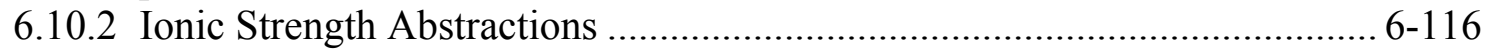

6.10.3 Fluoride Abstractions.................................................................... 6-128

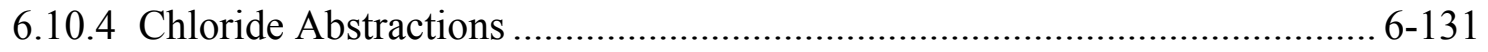

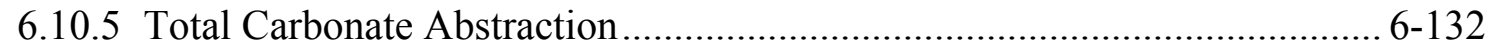

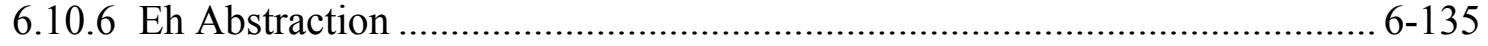

6.10.7 Linking the Vapor-Influx and Liquid-Influx Models for TSPA-LA ........... 6-136

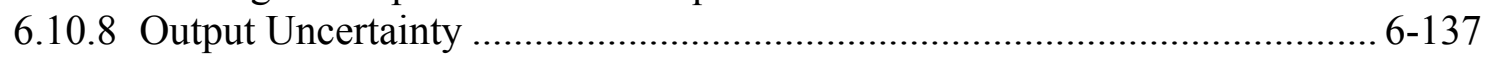

6.10.9 Model Abstraction Conclusions......................................................... 6-137

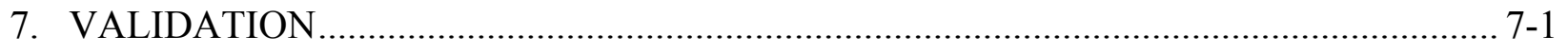

7.1 DOCUMENTED DECISIONS AND ACTIVITIES IMPLEMENTED DURING MODEL DEVELOPMENT PROCESS ................................................................. 7-2

7.2 POST-MODEL DEVELOPMENT VALIDATION METHODS ............................. 7-3

7.3 RATIONALE FOR SELECTION OF VALIDATION METHODS ......................... 7-3

$7.4 \quad$ PH AND IONIC STRENGTH VALIDATION ............................................ $7-4$

7.4.1 Abstraction Validation ............................................................................ 7-4

7.4.2 Fuel-Degradation Model Consistent with Results from Laboratory

Experiments ............................................................................... 7-10

7.4.3 Types of Minerals Formed Consistent with Experimental Results ............... 7-10

7.4.4 Steel-Degradation Model Consistent with Results from Laboratory

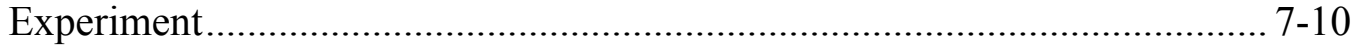

7.4.5 $\mathrm{pH}$ and Ionic Strength Consistent with Natural Analogue Observation......... 7-11 
CONTENTS (Continued)

Page

7.4.6 Relationship Between Ionic Strength and Flow Rate ……............................. 7-13

7.4.7 Surface Complexation Model ................................................................... 7-13

7.5 FLUORIDE VALIDATION ……………....................................................... 7-13

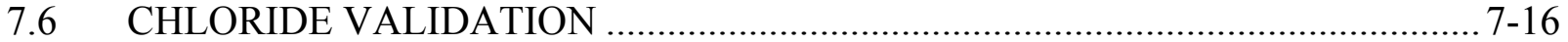

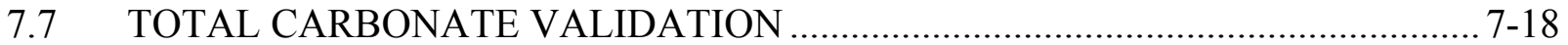

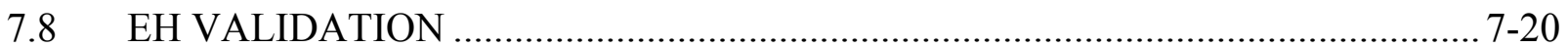

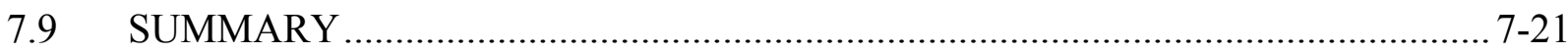

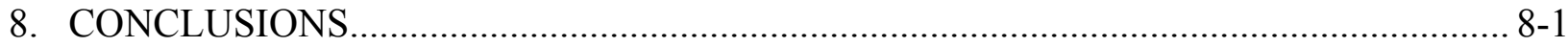

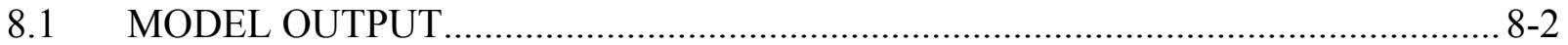

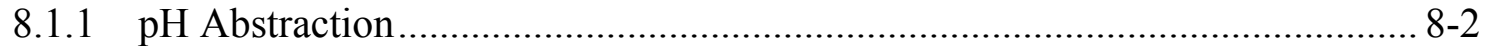

8.1.2 Ionic Strength Abstraction .................................................................... 8-3

8.1.3 Total Carbonate Abstraction.................................................................. 8-5

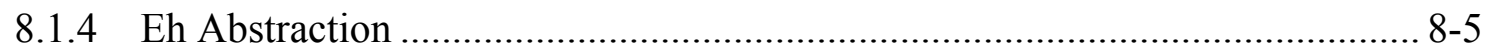

8.1.5 Fluoride and Chloride Abstraction …………........................................ 8-5

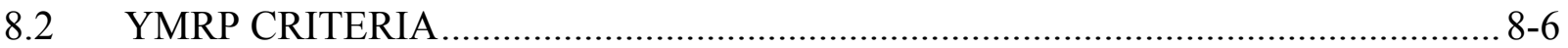

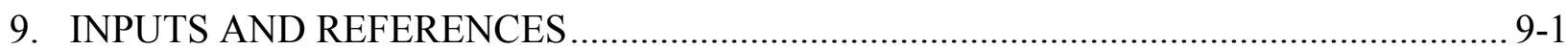

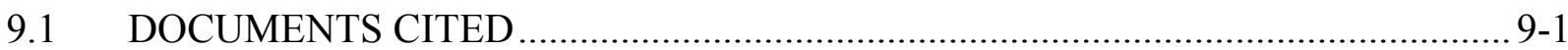

9.2 CODES, STANDARDS, REGULATIONS, AND PROCEDURES ......................... 9-12

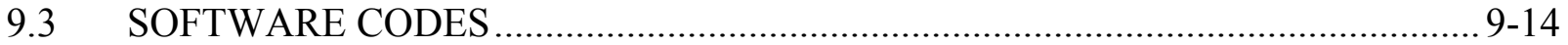

9.4 SOURCE DATA, LISTED BY DATA TRACKING NUMBER ..............................9-14

9.5 OUTPUT DATA, LISTED BY DATA TRACKING NUMBER ............................. 9-15

\section{APPENDICES}

A. ADDITIONAL IN-PACKAGE CHEMISTRY DISCUSSION AND PLOTS ....................... A-1

A.1 CSNF WATER CHEMISTRY EVOLUTION …………………….................... A-3

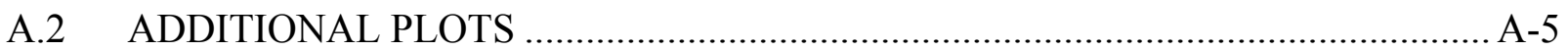

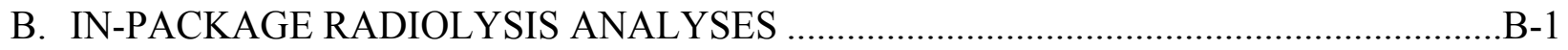

B.1 RADIOLYSIS CONTRIBUTION TO IN-PACKAGE CHEMISTRY ………........... B-3

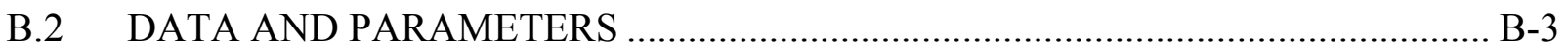

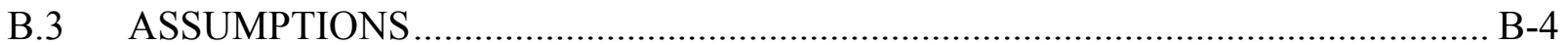

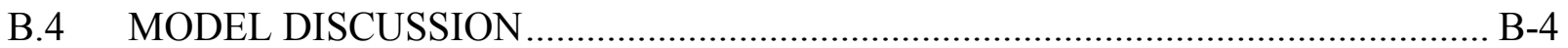

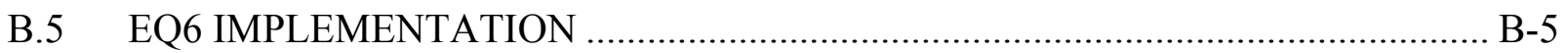

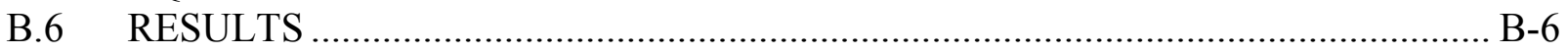

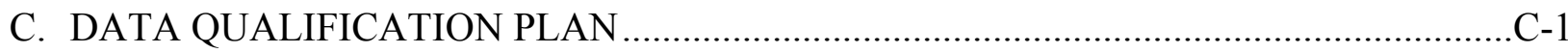

D. QUALIFICATION OF DATA THAT SUPPORTS IN-PACKAGE CHEMISTRY

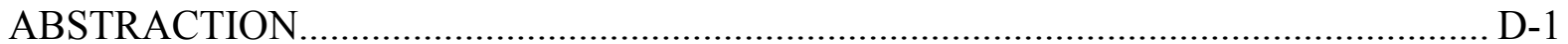

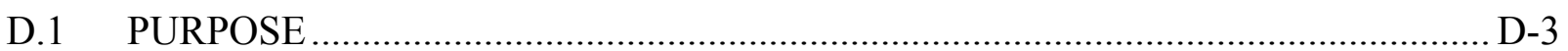

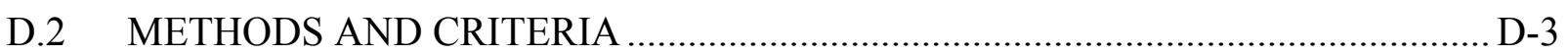




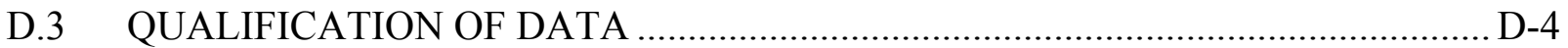

D.3.1 Qualification of Baxter, R.G. 1988 [DIRS 106164] .................................. D-5

D.3.2 Qualification of Langmuir 1997 [DIRS 100051] ..................................... D-5

D.3.3 Qualification of Ball and Nordstrom 1998 [DIRS 163015] ......................... D-6

D.3.4 Qualification of Appelo et al. 2002 [DIRS 168168] .................................... D-6

D.3.5 Qualification of Dzombak and Morel 1990 [DIRS 105483] ......................... D-8

D.4 CONCLUSION ........................................................................................ D-9

E. EVALUATION OF IN-PACKAGE CHEMISTRY SURFACE COMPLEXATION

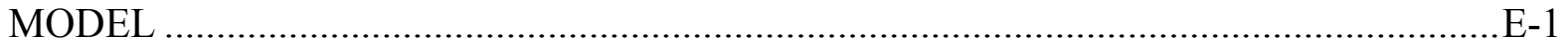

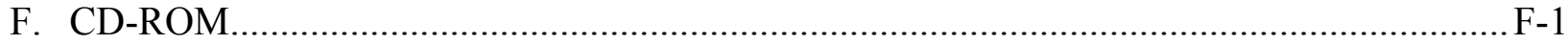

G. LISTING OF FILES ON COMPACT DISC ........................................................... G-1

H. WATER-VAPOR FLUX INTO THE WASTE PACKAGE BASED ON FICK'S FIRST LAW AND STEFAN TUBE EQUATIONS …….......................................... H-1

H.1 WATER VAPOR DIFFUSION FLUX FICK'S FIRST LAW CALCULATION ...... H-3 H.2 WATER VAPOR DIFFUSION FLUX STEFAN TUBE ANALYTIC SOLUTION . H-8 


\section{FIGURES}

Page

Figure 6-1. Vapor Influx Rates for Fick's First Law and Stefan Tube............................... 6-32

Figure 6-2. Temperature versus Relative Humidity for Waste Packages.............................. 6-33

Figure 6-3. CSNF Liquid-Influx Base-Case Reactant Summary and pH Results ................ 6-34

Figure 6-4. CSNF Liquid-Influx Model Results for Various Incoming Water

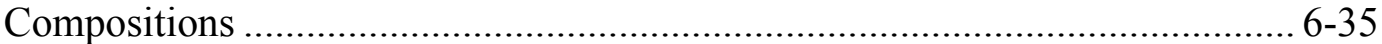

Figure 6-5. CSNF Liquid-Influx Model Mineral Phases for the Base Case.......................... 6-37

Figure 6-6. CSNF Liquid-Influx Model Mineral Phases for Three Seepage

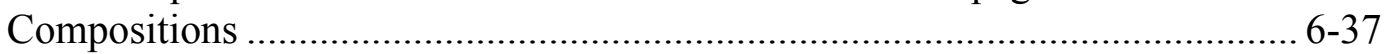

Figure 6-7. CSNF Liquid-Influx Model Aqueous Species for the Base Case...................... 6-39

Figure 6-8. CSNF Liquid-Influx Model Aqueous Species for Three Seepage

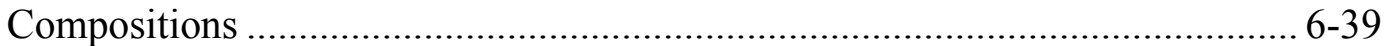

Figure 6-9. CSNF Liquid Influx Base-Case Reactant Summary and Ionic Strength ........... 6-40

Figure 6-10. CSNF Liquid-Influx Model: Eh, Reactant Summary, and Corrosion

Products..................................................................................................... 6-41

Figure 6-11. CSNF Liquid-Influx Model: Eh and $\mathrm{pH}$................................................... 6-42

Figure 6-12. CDSP Liquid-Influx Base Case Reactant Summary and pH Results ................ 6-43

Figure 6-13. CDSP Liquid-Influx Model Mineral Phases for the Base Case.......................... 6-44

Figure 6-14. CDSP Liquid-Influx Model Aqueous Species for the Base Case....................... 6-45

Figure 6-15. CDSP Liquid-Influx Model Aqueous Species for Three Seepage

Compositions ........................................................................................... 6-45

Figure 6-16. CDSP Liquid-Influx Base Case Reactant Summary and Ionic Strength ........... 6-47

Figure 6-17. CSNF Single-Component Vapor Influx pH Outputs ....................................... 6-48

Figure 6-18. CSNF Vapor-Influx Reactant Summary pH Profile ………………................... 6-49

Figure 6-19. CSNF Vapor-Influx Reactant Summary and Ionic Strength ............................. 6-50

Figure 6-20. Comparing the Vapor and Liquid-Influx Cases for CSNF pH ......................... 6-50

Figure 6-21. Comparing the Vapor and Liquid-Influx Cases for CSNF Ionic Strength ........ 6-51

Figure 6-22. CDSP Single-Component Vapor Influx Results.............................................. 6-52

Figure 6-23. CDSP Vapor-Influx Reactant Summary pH Profile ........................................... 6-52

Figure 6-24. CDSP Vapor Influx Reactant Summary and Ionic Strength Profiles ................. 6-53

Figure 6-25. Ratio of Water to Reactants for CSNF: Impact on $\mathrm{pH}$.................................. 6-56

Figure 6-26. Ratio of Water to Reactants for CSNF: Impact on Ionic Strength .................... 6-57

Figure 6-27. Ratio of Water to Reactants for CDSP: Impact on $\mathrm{pH}$...................................... 6-58

Figure 6-28. Ratio of Water to Reactants for CDSP: Impact on Ionic Strength ..................... 6-59

Figure 6-29. $\quad \mathrm{pH}$ Profiles for Thermally Perturbed Compositions for CSNF ......................... 6-61

Figure 6-30. Ionic Strength Profiles for Thermally Perturbed Composition for CSNF ......... 6-61

Figure 6-31. pH Profiles for Thermally Perturbed Compositions for CDSP ......................... 6-62

Figure 6-32. Ionic Strength Profiles for Thermally Perturbed Composition for CDSP ......... 6-62

Figure 6-33. $\quad \mathrm{Cr}(\mathrm{III})$ versus $\mathrm{Cr}(\mathrm{VI})$ for CSNF: Impact on $\mathrm{pH}$............................................. 6-64

Figure 6-34. $\mathrm{Cr}(\mathrm{III})$ versus Cr(VI) for CSNF: Impact on Ionic Strength .............................. 6-65

Figure 6-35. $\quad \mathrm{Cr}(\mathrm{III})$ versus $\mathrm{Cr}(\mathrm{VI})$ for CDSP: Impact on $\mathrm{pH}$............................................ 6-66

Figure 6-36. $\mathrm{Cr}(\mathrm{III})$ versus $\mathrm{Cr}(\mathrm{VI})$ for CDSP: Impact on Ionic Strength ................................ 6-66

Figure 6-37. Variation of $f \mathrm{CO}_{2}$ and $f \mathrm{O}_{2}$ for CSNF: Impact on $\mathrm{pH}$...................................... 6-68

Figure 6-38. Variation of $f \mathrm{CO}_{2}$ and $f \mathrm{O}_{2}$ for CSNF: Impact on Ionic Strength....................... 6-68 


\section{FIGURES (Continued)}

Page

Figure 6-39. Variation of $f \mathrm{CO}_{2}$ and $f \mathrm{O}_{2}$ for CDSP: Impact on $\mathrm{pH}$

Figure 6-40. Variation of $f \mathrm{CO}_{2}$ and $f \mathrm{O}_{2}$ for CDSP: Impact on Ionic Strength.

Figure 6-41. Effect of Water Flux on $\mathrm{pH}$ for CSNF

Figure 6-42.

Effect of Water Flux on Ionic Strength for CSNF....

$6-71$

Figure 6-43.

Effect of Water Flux on $\mathrm{pH}$ for CDSP.

Figure 6-44.

Effect of Water Flux on Ionic Strength for CDSP

$6-72$

Figure 6-45.

Figure 6-46.

Figure 6-47.

Figure 6-48.

Effect of Water Flux on $\mathrm{pH}$ for CSNF (using $\mathrm{Cr}(\mathrm{VI})$ ).

Effect of Increasing Temperature on the $\mathrm{pH}$ for CSNF.

$6-74$

Effect of Increasing Temperature on Ionic Strength for CSNF

$6-75$

Figure 6-49.

Effect of Increasing Temperature on the $\mathrm{pH}$ for CDSP.

Figure 6-50.

Effect of Increasing Temperature on Ionic Strength for CDSP ...

Figure 6-51.

NiGd Alloy Design Change for Liquid-Influx Case: Impact on $\mathrm{pH}$

$6-78$

NiGd Alloy Design Change for Liquid-Influx Case: Impact on Ionic

Strength.... $6-78$

Figure 6-52. NiGd Alloy Design Change for Vapor-Influx Case: Impact on pH 6-79

Figure 6-53. NiGd Alloy Design Change for Vapor-Influx Case: Impact on Ionic

Strength

Figure 6-54. Comparison of HLW Glass Compositions 6-82

Figure 6-55.

Effect of Replacing Carbon Steel Type A516 with Stainless Steel Type 316. $6-83$

Figure 6-56.

Corrosion Rate Comparison for CSNF: pH Profiles.

Figure 6-57.

Corrosion Rate Comparison for CSNF: Ionic Strength Profiles. $6-85$

Figure 6-58.

Corrosion Rate Comparison for CDSP: $\mathrm{pH}$ Profiles.

$6-85$

Figure 6-59.

Corrosion Rate Comparison for CDSP: Ionic Strength Profiles.. $6-86$

Figure 6-60.

Hematite and Goethite Comparison for CSNF: pH Profiles. $6-88$

Figure 6-61.

Figure 6-62.

Hematite and Goethite Comparison for CSNF: Ionic Strength Profiles.

Hematite and Goethite Comparison for CDSP: pH Profiles.

Figure 6-63.

Figure 6-64.

Hematite and Goethite Comparison for CDSP: Ionic Strength Profiles.

$6-89$

Figure 6-65.

$\mathrm{MCO} / 2-\mathrm{DHLW}$ Design versus 5-DHLW/DOE SNF: Impact on $\mathrm{pH}$ $6-91$

$\mathrm{MCO} / 2-\mathrm{DHLW}$ Design versus 5-DHLW/DOE SNF: Impact on Ionic

Strength.

Figure 6-66.

Figure 6-67.

Figure 6-68.

LaBS Glass pH Results

$6-93$

LaBS Glass Ionic Strength Results

Mineral Assemblage for Base Case

Figure 6-69.

Mineral Assemblage for Moderated $\mathrm{pH}$ Case

Figure 6-70.

Figure 6-71.

Figure 6-72.

CSNF Liquid-Influx Model pH Results.

6-112

CDSP Liquid-Influx Model pH Results.

6-114

Comparison of CSNF and CDSP Liquid-Influx $\mathrm{pH}$ Profiles 6-116

Figure 6-73.

CSNF Liquid-Influx Model Ionic Strength Profiles ....

CSNF Liquid-Influx Model Ionic Strengths as a Function of Flux

CSNF Liquid-Influx Model Ionic Strengths as a Function of Mass of

Solvent

Figure 6-76. CSNF Vapor-Influx Model Ionic Strengths as a Function of Flux....... 6-122 
Figure 6-77. CSNF Vapor-Influx Model Ionic Strengths as a Function of Mass of Solvent.....

Figure 6-78. CDSP Liquid-Influx Model Ionic Strength Profiles ....

6-123

Figure 6-79. CDSP Liquid-Influx Model Ionic Strengths as a Function of Flux. 6-124

Figure 6-80.

CDSP Vapor-Influx Model Ionic Strengths as a Function of Flux

Figure 6-81.

CSNF Liquid-Influx Model Fluoride Profiles

Figure 6-82.

Figure 6-83.

Figure 6-84.

CDSP Vapor-Influx Model Fluoride Profiles

CDSP Liquid-Influx Model Fluoride Profiles

$6-130$

Figure 6-85.

CSNF Liquid-Influx Model Chloride Profiles

Figure 7-7.

CDSP Ionic Strength Abstraction Compared to Model Output (1 L/yr) ...

Figure 7-9.

Figure 7-10.

CSNF Fluoride Abstraction Compared to Model Output..

Figure A-3. Thermally Perturbed Composition 20013 (W5) with Ca-porewater (W5) for CSNF.

Figure A-4. Thermally Perturbed Composition 51 (W6) with Na-porewater (W5) for CDSP.

Figure A-5. Thermally Perturbed Composition 10006 (W4) with Na-porewater (W5) for CDSP.

Figure A-6. Corrosion Products and pH with no Sulfur in the Carbon Steel Type A516 Composition.

Figure A-7. Effect of Varying Sulfur Content in Carbon Steel Type A516 on pH.............. A-8 


\section{FIGURES (Continued)}

Page

Figure A-8. Effect of Varying Sulfur Content in Carbon Steel Type A516 on Ionic

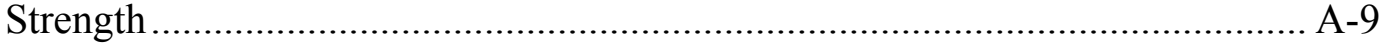

Figure A-9. Effect of Goethite and Hematite on $\mathrm{pH}$.................................................... A-9

Figure A-10. Effect of Goethite and Hematite on Ionic Strength .................................... A-10

Figure B-1. $\quad$ pH Profiles Showing Radiolysis Impacts on $\mathrm{pH}$..............................................

Figure G-1. Directory Structures for Appendix F Zip Files ............................................. G-5

Figure H.1-1. Water Vapor Flux (QTemp $\left.{ }_{i}\right)$ That Enters the Waste Package, Calculated Based on Fick's First Law and for 95 Percent Relative Humidity .................... H-5

Figure H.1-2. Water Vapor Flux Calculated Based on Fick's First Law ................................ H-8

Figure H.2-1. Gas Phase Diffusion of $A$ through Stagnant $B$.............................................. H-9

Figure H.2-2. Water Vapor Flux Calculated Based on Stefan Tube Equations ..................... H-14 


\section{TABLES}

Page

Table 1-1. Upstream and Downstream Documents.......................................................... 1-3

Table 3-1. Computer Software Used .......................................................................... 3-1

Table 3-2. Computers and Operating Systems Used..................................................... 3-2

Table 4-1. Summary of Direct Inputs.............................................................................. 4-1

Table 4-2. Input Water Compositions ........................................................................ 4-3

Table 4-3. Thermally Perturbed Seepage Compositions......................................................... 4-6

Table 4-4. $\quad$ Flux Into Waste Package ......................................................................... 4-7

Table 4-5. High-Level Waste Glass Composition................................................................. 4-9

Table 4-6. Materials Nomenclature and Waste Package Breakdown ................................. 4-11

Table 4-7. Composition of Steel and Aluminum Alloys...................................................... 4-12

Table 4-8. Steel and Alloy Densities and Corrosion Rates .............................................. 4-13

Table 4-9. Surface Complexation Reactions............................................................... 4-14

Table 4-10. Properties of Major Iron Minerals .................................................................. 4-14

Table 6-1. Included FEPs for the In-Package Chemistry Model Report............................... 6-1

Table 6-2. Batch Reactor-Case Nomenclature ……………………............................ 6-10

Table 6-3. EQ6-Input Fluid Compositions ................................................................. 6-11

Table 6-4. Metal Alloy Compositions ............................................................................... 6-13

Table 6-5. Metal Alloy Corrosion Rates ........................................................................ 6-14

Table 6-6. CSNF and N-Reactor Compositions ............................................................... 6-15

Table 6-7. CSNF Transition State Theory Rate Law and Coefficients................................ 6-16

Table 6-8. HLWG Transition State Theory Rate Law and N-Reactor Rate Constants....... 6-16

Table 6-9. Total Surface Areas and Moles for the CSNF and CDSP Waste Packages....... 6-17

Table 6-10. Minerals Suppressed in In-Package Chemistry Model EQ6 Runs ..................... 6-19

Table 6-11. Major Mineral Phases Formed in EQ6 Runs ................................................... 6-20

Table 6-12. Surface Complexation Reactions ............................................................... 6-23

Table 6-13. Results of Accuracy Evaluation.................................................................. 6-26

Table 6-14. Alternative In-Package Chemistry Conceptual Models...................................... 6-28

Table 6-15. HLWG Sensitivity: High-Level Waste Glass Composition .............................. 6-81

Table 6-16. Simplified LaBS Glass Composition.............................................................. 6-93

Table 6-17. Approximation for Charge Balance ................................................................ 6-98

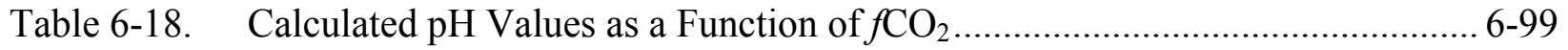

Table 6-19. Initial pH of Waters Prior to Surface Complexation Calculations ................... 6-105

Table 6-20. Equilibrium pH Predicted in Surface Complexation Calculations ................... 6-107

Table 6-21. Mapping of Batch Reactor Cases to Abstractions ......................................... 6-111

Table 6-22. Total Carbonate as a Function of $\mathrm{pH}$............................................................. 6-133

Table 6-23. Log K Values for the Carbonate Species at Temperature................................. 6-133

Table 6-24. Log K Temperature Interpolation Functions for Total Carbonate

Abstraction......................................................................................... 6-134

Table 6-25. Eh as a Function of $\mathrm{pH}, \mathrm{PO}_{2}$, and Absolute Temperature ............................... 6-136

Table 7-1. Validation Criteria, Activities, and Metrics.................................................. 7-3

Table 7-2. Comparison of Total Carbonate Model ........................................................... 7-18

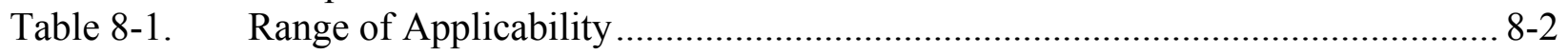

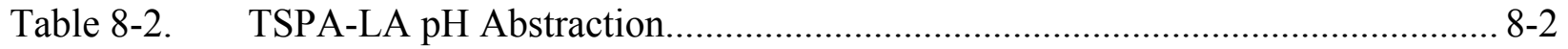


TABLES (Continued)

Page

Table 8-3. $\quad$ Constants for TSPA-LA Ionic Strength Abstraction ...................................... 8-4

Table 8-4. TSPA-LA Total Carbonate Abstraction........................................................... 8-5

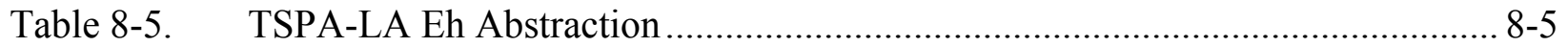

Table 8-6. TSPA-LA Fluoride and Chloride Abstraction ............................................. 8-5

Table A-1. Minor Input Inconsistencies in the EQ3 and EQ6 Input Files ....................... A-10

Table B-1. EQ6 File Names and Nitric Acid and Hydrogen Peroxide Production

Rates.............................................................................................

Table B-2. Chloride, Ferric Iron, and Hydrogen Peroxide Molality....................................6

Table D-1. $\quad$ Sources of Data and Criteria Used to Qualify the Information ........................ D-4

Table H.1-1. Water Vapor Flux (mol/yr) Calculated from Fick's First Law......................... H-6

Table H.2-1. Water Vapor Flux (mol/yr) Calculated by the Stefan Tube Equation .............. H-12 


\section{ACRONYMS}

atm atmospheres

B\&W Babcock and Wilcox

CDSP codisposed

CPU

central processing unit

CSNF

commercial spent nuclear fuel

DOE U.S. Department of Energy

DTN data tracking number

EBS engineered barrier system

FEPs features, events, and processes

GPC glass pour canisters

HFO hydrous ferric oxide

HLW high-level waste

HLWG high-level waste glass

IED information exchange drawing

IEP isoelectric point

MCO multi-canister overpack

PWR pressurized water reactor

Q water flux through the waste package

SNF spent nuclear fuel

SRL Savannah River Laboratory

TMI Three Mile Island

TSPA-LA Total Systems Performance Assessment-License Application

XRD $\quad$ X-ray diffraction

ZPC zero point of charge 


\section{ELEMENTAL SYMBOLS}

Ag Silver

Al Aluminium

Am Americium

$\mathrm{Ba}$ Barium

Be Beryllium

C Carbon

$\mathrm{Ca}$ Calcium

$\mathrm{Cl}$ Chlorine

$\mathrm{Cm}$ Curium

Co Cobalt

$\mathrm{Cr}$ Chromium

Cs Cesium

$\mathrm{Cu}$ Copper

$\mathrm{Eu}$ Europium

$\mathrm{F} \quad$ Fluorine

$\mathrm{Fe} \quad$ Iron

Gd Gadolinium

$\mathrm{H}$ Hydrogen

Ho Holmium

In Indium

K Potassium

$\mathrm{Kr} \quad$ Krypton

La Lanthanum

Li Lithium

$\mathrm{Mg}$ Magnesium

Mn Manganese

Mo Molybdenum

N Nitrogen
$\mathrm{Na}$ Sodium

$\mathrm{Nb}$ Niobium

$\mathrm{Nd}$ Neodymium

$\mathrm{Ni}$ Nickel

$\mathrm{Np} \quad$ Neptunium

$\mathrm{P}$ Phosphorus

$\mathrm{Pa} \quad$ Protactinium

$\mathrm{Pb} \quad$ Lead

Pd Palladium

$\mathrm{Pm}$ Promethium

Pr Praseodymium

Rh Rhodium

Rn Radon

$\mathrm{Ru} \quad$ Ruthenium

$\mathrm{S}$ Sulfur

$\mathrm{Si} \quad$ Silicon

Sm Samarium

Tc Technetium

Th Thorium

Ti Titanium

U Uranium

V Vanadium

W Tungsten

Xe Xenon

Y Yttrium

Zn Zinc

$\mathrm{Zr} \quad$ Zirconium 


\section{PURPOSE}

This report was developed in accordance with the requirements in Technical Work Plan for Postclosure Waste Form Modeling (BSC 2005 [DIRS 173246]). The purpose of the in-package chemistry model is to predict the bulk chemistry inside of a breached waste package and to provide simplified expressions of that chemistry as a function of time after breach to Total Systems Performance Assessment for the License Application (TSPA-LA).

The scope of this report is to describe the development and validation of the in-package chemistry model. The in-package model is a combination of two models, a batch reactor model, which uses the EQ3/6 geochemistry-modeling tool, and a surface complexation model, which is applied to the results of the batch reactor model. The batch reactor model considers chemical interactions of water with the waste package materials, and the waste form for commercial spent nuclear fuel (CSNF) waste packages and codisposed (CDSP) waste packages containing high-level waste glass (HLWG) and DOE spent fuel. The surface complexation model includes the impact of fluid-surface interactions (i.e., surface complexation) on the resulting fluid composition.

The model examines two types of water influx: (1) the condensation of water vapor diffusing into the waste package, and (2) seepage water entering the waste package as a liquid from the drift.

1. Vapor-Influx Case: The condensation of vapor onto the waste package internals is simulated as pure $\mathrm{H}_{2} \mathrm{O}$ and enters at a rate determined by the water vapor pressure for representative temperature and relative humidity conditions.

2. Liquid-Influx Case: The water entering a waste package from the drift is simulated as typical groundwater and enters at a rate determined by the amount of seepage available to flow through openings in a breached waste package.

TSPA-LA uses the vapor-influx case for the nominal scenario for simulations where the waste package has been breached but the drip shield remains intact, so the seepage flow is diverted from the waste package. The chemistry from the vapor-influx case is used to determine the stability of colloids and the solubility of radionuclides available for transport by diffusion, and to determine the degradation rates for the waste forms.

TSPA-LA uses the liquid-influx case for the seismic scenario, where the waste package has been breached and the drip shield has been damaged such that seepage flow is actually directed into the waste package. The chemistry from the liquid-influx case, which is a function of the flow rate, is used to determine the stability of colloids and the solubility of radionuclides available for transport by diffusion and advection, and to determine the degradation rates for the CSNF and HLW glass. TSPA-LA does not use this model for the igneous scenario.

Outputs from the in-package chemistry model implemented inside TSPA-LA include $\mathrm{pH}$, ionic strength, and total carbonate concentration. These inputs to TSPA-LA will be linked to the following processes: dissolution rates of the CSNF and HLWG, dissolved concentrations of radionuclides, and colloid generation. 
Other outputs from the in-package chemistry model used in other models supporting TSPA-LA include Eh (redox potential), chloride, and fluoride concentration. Specific information available in the output files from the batch reactor model includes time series concentrations of the elements and their aqueous complexes constituting the waste package, waste form, seepage, gas composition, and mineralogical phase abundance.

The in-package chemistry model is activated within TSPA-LA when the waste package has been breached and the interior temperature of the waste package is below the boiling temperature of water. References to time within this report refer to the time after waste package breach and after the waste package cools to $100^{\circ} \mathrm{C}$. Liquid water only persists in appreciable quantities when the drift environment has cooled to below approximately $100^{\circ} \mathrm{C}$. While the boiling point of pure water at the repository elevation is approximately $96^{\circ} \mathrm{C}$, the value of $100^{\circ} \mathrm{C}$ is used to reflect possible higher boiling points of liquids containing dissolved solids. The in-package chemistry model is applicable over the water volumetric flux (hereafter referred to as "flux") range from $0.15 \mathrm{~L} / \mathrm{yr}$ to $300 \mathrm{~L} / \mathrm{yr}$ per waste package, a temperature range from $25^{\circ} \mathrm{C}$ to $100^{\circ} \mathrm{C}$, a carbon dioxide partial pressure range of $10^{-5}$ to $10^{-1.5}$ atmospheres (atm), and an oxygen partial pressure up to $0.2 \mathrm{~atm}$. Spatially, the applicability of the in-package chemistry model is limited to the waste package interior.

Limitations to this model include:

- Section 5, Assumption 5.1 discusses the limited availability of data on thin film chemistry.

- Section 5, Assumption 5.2 discusses the limited availability of long-term metal alloy corrosion information such as the evolution of the surface area of the metal waste package components as a function of time.

- Section 6.3.1.1 discusses the limited availability of thermodynamic data for certain elements that constitute the waste package and waste forms (transition metals and radionuclides) that prohibited the use of high-ionic strength solutions as initial starting compositions for the in-package chemistry model (concentrated brines). This data limitation requires the use of the B-dot activity coefficient equation in the EQ3/6 modeling, which is only valid up to ionic strengths of 4 molal (Section 6.3.1.1). This data limitation also influenced the boundary conditions used in the model where the ratio of water to reactants was selected for the base case.

- Section 6.9 addresses not accounting for feedback between the batch reactor and the surface complexation models during modeling since they are implemented in series.

Table 1-1 provides a list of upstream and downstream documents associated with this model. 
Table 1-1. Upstream and Downstream Documents

\begin{tabular}{|c|c|}
\hline $\begin{array}{c}\text { Upstream } \\
\text { Documents } \\
\text { (Providing Directly } \\
\text { Used Inputs to } \\
\text { Develop this Model) }\end{array}$ & $\begin{array}{ll}\text { - } & \text { CSNF Waste Form Degradation: Summary Abstraction (BSC } 2004 \text { [DIRS } \\
& \text { 169987]) } \\
\text { - } & \text { Defense HLW Glass Degradation Model (BSC } 2004 \text { [DIRS 169988]) } \\
\text { - } & \text { EBS Radionuclide Transport Abstraction (BSC } 2004 \text { [DIRS 169868]) } \\
\text { - } & \text { Abstraction of Drift Seepage (BSC } 2004 \text { [DIRS 169131]) } \\
\text { - } & \text { Qualification of Thermodynamic Data for Geochemical Modeling of } \\
& \text { Mineral-Water Interactions in Dilute Systems (BSC 2004 [DIRS 171916]). }\end{array}$ \\
\hline $\begin{array}{l}\text { Downstream } \\
\text { Documents (Using } \\
\text { Output of this Model } \\
\text { for Development ) }\end{array}$ & $\begin{array}{ll}\text { - } & \text { Dissolved Concentration Limits of Radioactive Elements (BSC } 2005 \\
& \text { [DIRS 173873]) } \\
\text { - } & \text { Pitting Model for Zirconium-Alloyed Cladding (BSC } 2004 \text { [DIRS 170043]) } \\
\text { - } & \text { Waste-Form Features, Events, and Processes (BSC } 2004 \text { [DIRS 170020]) } \\
\text { - } & \text { Engineered Barrier System Features, Events, and Processes (BSC 2004 [DIRS } \\
& \text { 169860]) } \\
\text { - } & \text { Clad Degradation - FEPS Screening Arguments (BSC } 2004 \text { [DIRS 170019]). }\end{array}$ \\
\hline
\end{tabular}


INTENTIONALLY LEFT BLANK 


\section{QUALITY ASSURANCE}

\subsection{QA PROGRAM APPLICABILITY}

Development of this report has been determined to be subject to the Yucca Mountain Project's quality assurance (QA) program (BSC 2005 [DIRS 173246], Section 8) because it will be used to support performance assessments. Approved QA procedures identified in the technical work plan (BSC 2005 [DIRS 173246], Section 4) have been used to conduct and document the activities described. This report describes bulk chemistry inside of a breached waste package that affects the following items in Q-List (BSC 2005 [DIRS 171190]): the waste package (including internals), cladding, and waste.

\subsection{ELECTRONIC MANAGEMENT OF INFORMATION}

The technical work plan contains the process control evaluation used to evaluate the control of electronic management of information (BSC 2005 [DIRS 173246], Appendix A) during the modeling and documentation activities, and this evaluation determined that the methods in the implementing procedures are adequate; therefore, no deviations from these methods were necessary. 
INTENTIONALLY LEFT BLANK 


\section{USE OF SOFTWARE}

A list of controlled and baselined software used in this report is provided in Table 3-1, and the operating environments are provided in Table 3-2. The range of use for each piece of software is within that for which it was qualified. Each of the software codes was selected because it is appropriate for use in geochemical modeling, uses the YMP-qualified thermodynamic database, and is subject to no limitations on the outputs due to the selected software (though there are limitations on the thermodynamic database used, which is discussed in more detail in Section 6.3.1.1). The use of the software was consistent with its intended use and within documented validation ranges. No software was used prior to qualification to develop any preliminary output. Microsoft Excel, a commercial off-the-shelf software program, is used in this report; however, the results are not dependent on the software program used, so this software is exempt from requirements in LP-SI.11Q-BSC, Software Management. Section 4 discusses formulas and inputs used in this model for all software. The outputs are discussed in Section 6 . No other information is required for independent reproduction of the work.

Table 3-1. Computer Software Used

\begin{tabular}{|c|c|c|c|c|}
\hline $\begin{array}{l}\text { Software } \\
\text { Name }\end{array}$ & Version & $\begin{array}{c}\text { Software Tracking Number } \\
\text { (Qualification Status) }\end{array}$ & $\begin{array}{l}\text { Description and } \\
\text { Components Used }\end{array}$ & $\begin{array}{l}\text { Input and Output Files }{ }^{a} \\
\text { (Included in Appendix F) }\end{array}$ \\
\hline \multirow[t]{2}{*}{ EQ3/6 } & $7.2 \mathrm{~b}$ & $\begin{array}{l}\text { UCRL-MA-110662 } \\
\text { (LSCR198) } \\
\text { [DIRS 153964] }\end{array}$ & $\begin{array}{l}\text { EQ3NR: a FORTRAN } \\
\text { speciation-solubility code }\end{array}$ & $\begin{array}{ll}\text { input: } & { }^{*} .3 \mathrm{i} \\
\text { output: } & * \text { *.3p, }{ }^{*} .30\end{array}$ \\
\hline & & $\begin{array}{l}\text { (Qualified on Windows } 95 \\
\text { and HP-UX } 10.20 \text { B) }\end{array}$ & $\begin{array}{l}\text { EQPT: a data file } \\
\text { preprocessor in FORTRAN }\end{array}$ & $\begin{array}{ll}\text { input: } & \text { data0.* } \\
\text { output: } & \text { data1.* }\end{array}$ \\
\hline EQ6 & 7.2bLV & $\begin{array}{l}\text { 10075-7.2bLV-02 } \\
\text { [DIRS 159731] } \\
\text { (Qualified on Windows } 2000 \\
\text { and NT 4.0) }\end{array}$ & $\begin{array}{l}\text { EQ6: a reaction path code that } \\
\text { models water-rock interaction } \\
\text { or fluid mixing in either a pure } \\
\text { reaction progress mode or a } \\
\text { time mode }\end{array}$ & $\begin{array}{ll}\text { input: } & { }^{*} .6 \mathrm{i} \\
\text { pickup: } & { }^{*} .6 \mathrm{p} \\
\text { output: } & { }^{*} .6 \mathrm{o} \\
& { }^{*} . \text {.elem_aqu.txt } \\
& { }^{*} . \text { elem_min.txt } \\
& { }^{*} . \text { elem_tot.txt } \\
& { }^{*} . \text { min_info.txt } \\
& { }^{*} . \text {.bin }\end{array}$ \\
\hline GetEQData & 1.0 .1 & $\begin{array}{l}\text { 10809-1.0.1-00 } \\
\text { [DIRS 173680] } \\
\text { (Qualified on Windows 2000, } \\
\text { NT 4.0, 98, and 95) }\end{array}$ & $\begin{array}{l}\text { A Microsoft Excel macro used } \\
\text { to postprocess EQ3/6 output } \\
\text { information }\end{array}$ & $\begin{array}{ll}\text { input: } & { }^{*} .30,{ }^{*} .60 \\
\text { output: } & { }^{*} . x l s\end{array}$ \\
\hline PHREEQC & 2.3 & $\begin{array}{l}\text { 10068-2.3-01 } \\
\text { [DIRS 157837] } \\
\text { (Qualified on Windows 2000) }\end{array}$ & $\begin{array}{l}\text { A code for geochemical } \\
\text { speciation, reaction path } \\
\text { modeling, reactive transport, } \\
\text { and surface-complexation } \\
\text { modeling }\end{array}$ & $\begin{array}{ll}\text { input: } & * \text { (no extension) } \\
\text { output: } & * \text {.out }\end{array}$ \\
\hline transl & 2.0 & $\begin{array}{l}\text { 10251-2.0-00 } \\
\text { [DIRS 155029] } \\
\text { (Qualified on Windows 98) }\end{array}$ & $\begin{array}{l}\text { A code for translating a } \\
\text { nonPitzer EQ3/6 database into } \\
\text { PHREEQC format }\end{array}$ & $\begin{array}{ll}\text { input: } & \text { data0.* } \\
\text { output: } & { }^{*} . \text { dat }\end{array}$ \\
\hline Mathcad & $\begin{array}{l}\text { Version } \\
11\end{array}$ & $\begin{array}{l}\text { Commercial off-the-shelf } \\
\text { software: Exempt }\end{array}$ & $\begin{array}{l}\text { Used in this document for } \\
\text { calculations }\end{array}$ & $\begin{array}{ll}\text { input: } & { }^{*} . \mathrm{mcd} \\
\text { output: } & { }^{*} . \mathrm{mcd},{ }^{*} . \mathrm{xls}\end{array}$ \\
\hline $\begin{array}{l}\text { Microsoft } \\
\text { Excel }\end{array}$ & 97 SR-2 & $\begin{array}{l}\text { Commercial off-the-shelf } \\
\text { software: Exempt }\end{array}$ & $\begin{array}{l}\text { Used in this document for } \\
\text { graphical representation and } \\
\text { arithmetical manipulations }\end{array}$ & $\begin{array}{ll}\text { input: } & { }^{*} .30,{ }^{*} .60 \\
\text { output: } & * \text { *xls }\end{array}$ \\
\hline
\end{tabular}

NOTE: ${ }^{a}$ Files are explained in more detail in Appendix G. 
Table 3-2. Computers and Operating Systems Used

\begin{tabular}{|l|l|l|l|}
\hline \multicolumn{1}{|c|}{ Computer Make } & \multicolumn{1}{|c|}{ CPU \# } & \multicolumn{1}{c|}{ Operating System } & \multicolumn{1}{c|}{ Software Used } \\
\hline Dell Optiplex GX300 & 117728 & Windows 95 & EQ3/6 V7.2b \\
\hline Dell Latitude C610 & $632 \mathrm{MT11}$ & Windows 2000 & $\begin{array}{l}\text { EQ6 V7.2bLV, } \\
\text { GetEQData, Microsoft } \\
\text { Excel }\end{array}$ \\
\hline Dell Optiplex GX260 & 4BPQW11 & Windows 2000 & $\begin{array}{l}\text { PHREEQC, Microsoft } \\
\text { Excel }\end{array}$ \\
\hline Dell Optiplex GX110 & 3YS420B & Windows 98 & transl \\
\hline Dell Optiplex GX260 & 152381 & Windows 2000 & $\begin{array}{l}\text { EQ6 V7.2bLV, Microsoft } \\
\text { Excel }\end{array}$ \\
\hline Dell Optiplex GX260 & 501077 & Windows 2000 & Mathcad V 11 \\
\hline Dell Latitude C640 & YMP000106 & Windows 2000 & $\begin{array}{l}\text { EQ6 V7.2bLV, } \\
\text { GetEQData, Microsoft } \\
\text { Excel }\end{array}$ \\
\hline Dell Optiplex GX400 & 151295 & & $\begin{array}{l}\text { EQ6 V7.2bLV, } \\
\text { GetEQData, Microsoft } \\
\text { Excel }\end{array}$ \\
\hline
\end{tabular}

NOTE: $C P U=$ central processing unit. 


\section{INPUTS}

This section lists the inputs used to develop this report. The information used to develop the model was not used to validate the model.

\subsection{DIRECT INPUT}

The information in the following sections is used as direct input to the in-package chemistry model. Table 4-1 lists the data used in the in-package chemistry model. All the inputs in Table 4-1 are qualified data.

Table 4-1. Summary of Direct Inputs

\begin{tabular}{|c|c|c|c|}
\hline Identifier & Input & Reference & Used in: \\
\hline data0.ymp.R4 & Thermodynamic Data & $\begin{array}{l}\text { DTN: SN0410T0510404.002 [DIRS 172712] } \\
\text { BSC } 2004 \text { [DIRS 171916] }\end{array}$ & $\begin{array}{l}\text { For EQ6 runs and } \\
\text { Sections } 6.3 .1 \\
6.10 .5,6.10 .6\end{array}$ \\
\hline J-13 Well Water & Water Composition & DTN: MO0006J13WTRCM.000 [DIRS 151029] & \multirow{16}{*}{$\begin{array}{l}\text { Section } 6.3 .1, \\
\text { Appendix } \mathrm{F} \\
\text { CDSP.xIs, } \\
\text { CSNF.xIs, and in all } \\
\text { EQ6 input files }\end{array}$} \\
\hline Ca-porewater & Water Composition & DTN: GS020408312272.003 [DIRS 160899] & \\
\hline Na-porewater & Water Composition & DTN: GS020408312272.003 [DIRS 160899] & \\
\hline $51.3 i$ & Water Composition & $\begin{array}{l}\text { DTN: MO0303MWDSCMAB.000 [DIRS 162551], } \\
\text { file: W6_THCabstraction3i3o3pfiles, path: } \\
\text { ESPIJolleylEQ36 for P\&CEITHC } \\
\text { AbstractionIW6ltf4 }\end{array}$ & \\
\hline $10006.3 i$ & Water Composition & $\begin{array}{l}\text { DTN: MO0303MWDSCMAB.000 [DIRS 162551], } \\
\text { file: W4_THCabstraction3i3o3pfiles, path: } \\
\text { ESPIJolleylEQ36 for PCEITHC AbstractionIW4Itf4 }\end{array}$ & \\
\hline $20013.3 i$ & Water Composition & $\begin{array}{l}\text { DTN: MO0303MWDSCMAB.000 [DIRS 162551] } \\
\text { file: W5_THCabstraction3i3o3pfiles, path: } \\
\text { ESPIJolleylEQ36 for P\&CEITHC } \\
\text { AbstractionIW5ltf4 }\end{array}$ & \\
\hline Liquid Entry Rate & Flow Rates & BSC 2004 [DIRS 169131], Tables 6.8-1 and 6.8-2 & \\
\hline Vapor Entry Rate & Flow Rates & BSC 2004 [DIRS 169868], Table 6.6-1 & \\
\hline \multirow[t]{4}{*}{ HLWG } & Reaction Rate & $\begin{array}{l}\text { BSC } 2004 \text { [DIRS 169988], Section 8.1, Equations } \\
50 \text { and 51, Table 8-1 }\end{array}$ & \\
\hline & Density & Baxter 1988 [DIRS 106164], Table 10 & \\
\hline & Composition & $\begin{array}{l}\text { CRWMS M\&O } 2001 \text { [DIRS 153263], Table } 3 \\
\text { (for LaBS glass) Marra, J. and Ebert, W. } 2003 \\
\text { [DIRS 172949] Table 2, column: SRTC Tests, Pu } \\
\text { only }\end{array}$ & \\
\hline & $f_{\text {exposure }}$ & BSC 2004 [DIRS 169988], Table 8-1 & \\
\hline \multirow[t]{2}{*}{ N-Reactor Fuel } & Reaction Rate & DOE 2000 [DIRS 152658], Equation 2-39 & \\
\hline & Composition & DOE 2000 [DIRS 150095], Table 3-1 & \\
\hline \multirow[t]{2}{*}{ CSNF } & Isotopic Inventory & $\begin{array}{l}\text { BSC } 2003 \text { [DIRS 169110], Attachment III Disk } 1 \text { of } \\
\text { 9, ATT III/ LPM1/ uniform_profile/ 3.5/ } \\
\text { ft71-case10.N04 }\end{array}$ & \\
\hline & Reaction Rate & $\begin{array}{l}\text { BSC } 2004 \text { [DIRS 169987], Section 8.1, Tables 8-2 } \\
\text { and 8-3 }\end{array}$ & \\
\hline
\end{tabular}


Table 4-1. Summary of Direct Inputs (Continued)

\begin{tabular}{|c|c|c|c|}
\hline Identifier & Input & Reference & Used in: \\
\hline $\begin{array}{l}\text { 21-PWR CSNF } \\
\text { Waste Package }\end{array}$ & $\begin{array}{l}\text { Waste Package } \\
\text { Component } \\
\text { Dimensions }\end{array}$ & $\begin{array}{l}\text { Punatar } 2001 \text { [DIRS 155635], p. 2-5 } \\
\text { BSC } 2005 \text { [DIRS 173501], Tables } 1 \text { and } 3 \\
\text { BSC } 2004 \text { [DIRS 172214], p. II-2 and II-3 } \\
\text { BSC } 2004 \text { [DIRS 168199] } \\
\text { BSC } 2004 \text { [DIRS 168253] }\end{array}$ & \\
\hline $\begin{array}{l}\text { 2-MCO / 2-DHLW } \\
\text { Waste Package }\end{array}$ & $\begin{array}{l}\text { Waste Package } \\
\text { Component } \\
\text { Dimensions }\end{array}$ & $\begin{array}{l}\text { DOE } 2000 \text { [DIRS 150095], Section } 4 \\
\text { DOE } 1992 \text { [DIRS 102812], Figure } 3.4 .1 \text { and } 3.4 .2 \\
\text { Taylor } 1997 \text { [DIRS 126175] } \\
\text { BSC } 2005 \text { [DIRS 174225], Table 3-1 } \\
\text { BSC } 2005 \text { [DIRS 173501], Table } 1 \text { and } 9 \\
\text { BSC } 2004 \text { [DIRS 172214], p. X-2 and X-3 }\end{array}$ & \multirow[t]{20}{*}{$\begin{array}{l}\text { Section } 6.3 .1 \\
\text { Appendix } \mathrm{F} \\
\text { CDSP.xls, } \\
\text { CSNF.x/s, and in all } \\
\text { EQ6 input files }\end{array}$} \\
\hline Periodic Table & $\begin{array}{l}\text { Atomic Weights of } \\
\text { Elements and } \\
\text { Isotopes }\end{array}$ & $\begin{array}{l}\text { Audi and Wapstra } 1995 \text { [DIRS 149625] } \\
\text { Parrington et al. } 1996 \text { [DIRS 103896] }\end{array}$ & \\
\hline \multirow{3}{*}{$\begin{array}{l}\text { Stainless Steel } \\
\text { Type } 316\end{array}$} & Corrosion rate & DTN: MO0409SPAACRWP.000 [DIRS 172059] & \\
\hline & Density & ASTM G 1-90 1999 [DIRS 103515], Table XI, p. 7 & \\
\hline & Composition & $\begin{array}{l}\text { ASTM A 240/A 240M-03b } 2003 \text { [DIRS 165003], } \\
\text { Table 1, p. } 4\end{array}$ & \\
\hline \multirow{3}{*}{$\begin{array}{l}\text { Stainless Steel } \\
\text { Type 304L }\end{array}$} & Corrosion rate & DTN: MO0409SPAACRWP.000 [DIRS 172059] & \\
\hline & Density & ASTM G 1-90 1999 [DIRS 103515], Table XI, p. 7 & \\
\hline & Composition & $\begin{array}{l}\text { ASTM A 240/A 240M-03b } 2003 \text { [DIRS 165003], } \\
\text { Table 1, p. } 3\end{array}$ & \\
\hline \multirow{3}{*}{$\begin{array}{l}\text { Carbon Steel } \\
\text { Type A516 }\end{array}$} & Corrosion rate & DTN: MO0409SPAACRWP.000 [DIRS 172059] & \\
\hline & Density & $\begin{array}{l}\text { ASTM A 20/A 20M-95a } 1995 \text { [DIRS 104189], } \\
\text { p. Section 14, p. } 8\end{array}$ & \\
\hline & Composition & $\begin{array}{l}\text { ASTM A 516/A 516M-01 } 2001 \text { [DIRS 162723], } \\
\text { Table } 1 \text {, grade } 70,1 / 2 " \text { to } 2 " \text { thickness, product } \\
\text { analysis }\end{array}$ & \\
\hline \multirow{3}{*}{$\begin{array}{l}\text { Aluminum } \\
\text { Alloy } 6061\end{array}$} & Corrosion rate & DTN: MO0409SPAACRWP.000 [DIRS 172059] & \\
\hline & Density & ASTM G 1-90 1999 [DIRS 103515], Table X1.1 & \\
\hline & Composition & ASTM B 209-96 1996 [DIRS 144744], Table 1, p. 7 & \\
\hline \multirow{3}{*}{$\begin{array}{l}\text { Aluminum } \\
\text { Alloy } 1100\end{array}$} & Corrosion rate & DTN: MO0409SPAACRWP.000 [DIRS 172059] & \\
\hline & Density & ASTM G 1-90 1999 [DIRS 103515], Table XI, p. 7 & \\
\hline & Composition & ASTM B 209-96 1996 [DIRS 144744], Table 1, p. 7 & \\
\hline \multirow[t]{2}{*}{ NiGd Alloy } & Corrosion rate & DTN: MO0409SPAACRWP.000 [DIRS 172059] & \\
\hline & $\begin{array}{l}\text { Composition and } \\
\text { density }\end{array}$ & ASTM B 932-04. 2004 [DIRS 168403] & \\
\hline Goethite & Surface properties & Langmuir 1997 [DIRS 100051], Table 10.2, p. 345 & \\
\hline \multirow{2}{*}{$\begin{array}{l}\text { Hydrous Ferric } \\
\text { Oxide (HFO) } \\
\text { Surface } \\
\text { Complexation }\end{array}$} & \multirow{2}{*}{$\begin{array}{l}\text { Surface } \\
\text { Complexation } \\
\text { Reactions }\end{array}$} & Dzombak and Morel 1990 [DIRS 105483] & \multirow{2}{*}{$\begin{array}{l}\text { Sections } 6.3 .2,6.7 \text {, } \\
\text { and } 6.8\end{array}$} \\
\hline & & Appelo et al. 2002 [DIRS 168168] & \\
\hline $\mathrm{Cr}(\mathrm{III})$ solids & $\begin{array}{l}\text { LogK for } \mathrm{Cr}(\mathrm{OH})_{3} \text { and } \\
\text { eskolaite }\end{array}$ & Ball and Nordstrom 1998 [DIRS 163015] & Section 6.6 .3 \\
\hline $\begin{array}{l}\text { Nitric Acid } \\
\text { Production Rate }\end{array}$ & Reaction Rate & BSC 2004 [DIRS 172017], Table 21, p. 33 & \multirow[t]{3}{*}{ Appendix B } \\
\hline $\begin{array}{l}\text { G value of Nitric } \\
\text { Acid Production }\end{array}$ & \multirow{2}{*}{$\begin{array}{l}\text { Used to calculate } \\
\text { hydrogen peroxide } \\
\text { production }\end{array}$} & BSC 2004 [DIRS 172017], p. 27 & \\
\hline $\begin{array}{l}\text { G value of } \\
\text { Hydrogen Peroxide } \\
\text { Production }\end{array}$ & & IAEA 1998 [DIRS 150560], Table 8.2, p. 214 & \\
\hline
\end{tabular}




\subsubsection{Thermodynamic Database}

The in-package chemistry model uses the thermodynamic database, data0.ymp.R4 (DTN: SN0410T0510404.002 [DIRS 172712]), as a necessary component in the execution of the EQ3/6 software. This database used in the in-package chemistry model is qualified for use for temperatures up to $200^{\circ} \mathrm{C}$. The database is appropriate for the in-package chemistry model because it includes the elements that constitute the waste package, waste form, seepage, and gas compositions in the temperature range needed for the model.

The data0.ymp.R4 file was modified to include the following material:

- The CSNF and HLWG (compositions given in Tables 6-6 and 4-5, respectively) were added to the database in order to take advantage of EQ3/6's ability to use a $\mathrm{pH}$ - and carbonate-dependent rate law, using the EQ6 transition state theory formalism to describe the degradation. A range of degradation rates based on $\mathrm{pH}$ can be specified only for reactants entered as "minerals" (solids contained in the database). "Special reactants" (reactants not contained in the database) must have a constant or fixed degradation rate.

- During the qualification of the data0 file, several small errors related to $\log \mathrm{K}$ values (still within the uncertainty range of the data) with their corrections were identified in Qualification of Thermodynamic Data for Geochemical Modeling of Mineral-Water Interactions in Dilute Systems (BSC 2004 [DIRS 171916], Table 6-37). These corrections were added to data0.ymp.R4 in the creation of the data0.cr3 and data0.ert files (Appendix F).

- This report models the oxidation state of chromium in repository conditions as $\mathrm{Cr}(\mathrm{III})$, as justified in Section 6.6.3, so the database was modified to allow the modeling of $\mathrm{Cr}(\mathrm{III})$ by removing all the $\mathrm{Cr}(\mathrm{VI})$ species. Additional information for two $\mathrm{Cr}(\mathrm{III})$ solids from a report by Ball and Nordstrom (1998 [DIRS 163015]) was also added to the database, for $\mathrm{Cr}(\mathrm{OH})_{3}$ and eskolaite.

\subsubsection{Input Water Compositions and Rates}

Table 4-2 summarizes the input water compositions used in the in-package chemistry model as direct input.

Table 4-2. Input Water Compositions

\begin{tabular}{|l|c|c|c|c|}
\hline Parameter & Units & Ca-Porewater $^{\text {a }}$ & Na-Porewater $^{\mathbf{b}}$ & J-13 Well Water $^{{ }^{c}}$ \\
\hline $\mathrm{Ca}^{2+}$ & $\mathrm{mg} / \mathrm{L}$ & 94 & 81 & 13.0 \\
\hline $\mathrm{Mg}^{2+}$ & $\mathrm{mg} / \mathrm{L}$ & 18.1 & 3.3 & 2.01 \\
\hline $\mathrm{Na}^{+}$ & $\mathrm{mg} / \mathrm{L}$ & 39 & 120 & 45.8 \\
\hline $\mathrm{K}^{+}$ & $\mathrm{mg} / \mathrm{L}$ & 7.6 & 6.1 & 5.04 \\
\hline $\mathrm{SiO}_{2}$ & $\mathrm{mg} / \mathrm{L}$ & 42 & 42 & 61.0 \\
\hline $\mathrm{NO}_{3}{ }^{-}$ & $\mathrm{mg} / \mathrm{L}$ & 2.6 & 0.41 & 8.78 \\
\hline $\mathrm{HCO}_{3}{ }^{-}$ & $\mathrm{mg} / \mathrm{L}$ & 397 & 362 & See Section 6.3 .1 .3 .1 \\
\hline $\mathrm{Cl}^{-}$ & $\mathrm{mg} / \mathrm{L}$ & 21 & 24 & 7.14 \\
\hline
\end{tabular}


Table 4-2. Input Water Compositions (Continued)

\begin{tabular}{|l|c|c|c|c|}
\hline Parameter & Units & Ca-Porewater $^{\mathbf{a}}$ & Na-Porewater $^{\mathbf{b}}$ & J-13 Well Water $^{\mathbf{c}}$ \\
\hline $\mathrm{F}^{-}$ & $\mathrm{mg} / \mathrm{L}$ & 3.4 & 6 & 2.18 \\
\hline $\mathrm{SO}_{4}{ }^{2-}$ & $\mathrm{mg} / \mathrm{L}$ & 36 & 31 & 18.4 \\
\hline $\mathrm{pH}$ & $\mathrm{pH}$ & $7.6(8.1)^{\mathrm{d}}$ & $7.4(8.3)^{\mathrm{d}}$ & $7.41(7.8)^{\mathrm{d}}$ \\
\hline
\end{tabular}

Sources: DTNs: GS020408312272.003 [DIRS 160899] ${ }^{\mathrm{a} \text { and }}{ }^{\mathrm{b}}$; MO0006J13WTRCM.000 [DIRS 151029] ${ }^{\mathrm{c}}$.

NOTE: $\quad{ }^{a}$ Sample: ECRB-SYS-CS1000/7.3-7.7/UC (calculated $\mathrm{HCO}_{3}{ }^{-}$value).

bSample: ECRB-SYS-CS2000/16.3-16.5/UC (measured $\mathrm{HCO}_{3}{ }^{-}$value).

${ }^{\mathrm{C}} \mathrm{The} \mathrm{SiO}_{2}$ value is calculated from the $28.5 \mathrm{mg} / \mathrm{L}$ of $\mathrm{Si}$ given in DTN: MO0006J13WTRCM.000.

${ }^{\mathrm{d}}$ The $\mathrm{pH}$ values in parenthesis are the $\mathrm{pH}$ values once the solution is equilibrated to $\log \mathrm{fCO}_{2}=-3.0$.

For simplicity, and based on their calcium and sodium concentrations, samples ECRB-SYS-CS1000/7.3-7.7/UC and ECRB-SYS-CS2000/16.3-16.5/UC were termed "Ca-porewater" and "Na-porewater," respectively.

Three water compositions were used as the initial condition(s) in the liquid-influx model of the in-package chemistry model for water entering a breached waste package. The decision to use these water compositions was based on several lines of reasoning. Although it is not expected to enter the repository, the J-13 well water composition was used for comparison purposes (i.e., to maintain continuity between the current work and past in-package chemistry analyses). The Caand Na-porewater compositions were used because they were obtained from core samples proximal to the repository. These waters are intended to represent seepage compositions that would enter a breached waste package, especially over the long term. The U.S. Geological Survey identified the location of boreholes from which the cores were removed by noting the following in its data spreadsheet (DTN: GS020408312272.003 [DIRS 160899]):

Chemical composition of pore water extracted from cores of 15 ECRB-SYS-CS Series boreholes, USW SD-9, and USW NRG-7/7a, 04/26/2001 to 02/12/2002.

High trace element values created due to reflux as a result of boiling events were not considered in the incoming water compositions, because these effects would be transitory compared to the regulatory timeframe (BSC 2004 [DIRS 169860], Section 6.5.4.2), and the chemistry would quickly revert to compositions similar to that listed in Table 4-2. The term "trace element" is defined in and information about their contents in potential in-drift seepage waters is reviewed in Engineered Barrier System: Physical and Chemical Environment Model (BSC 2004 [DIRS 169860] Section 6.5.4.2). The solute fluoride, often considered a trace element, is included in the input water compositions in Tables 4-2 and 4-3. Several elements generally considered trace elements in natural waters (e.g., Mo, Ni, and B) are found in high concentrations in in-package waters because they are constituents of degrading waste package materials (Figures 6-7, 6-8, 6-14, and 6-15). Other trace elements are considered in the inpackage modeling but are present in only low concentrations in solutions because they form sparingly soluble solids under in-package conditions (Figures 6-5, 6-6, and 6-13). These include $\mathrm{Fe}, \mathrm{Cr}, \mathrm{Al}, \mathrm{Mn}, \mathrm{Gd}$, and $\mathrm{Ru}$.

Section 6.2.2.1 of Drift-Scale THC Seepage Model (BSC 2005 [DIRS 172862]) uses the Ca-porewater (labeled "W5") and another composition (labeled "W4" [ECRB-SYS-CS2000/16.5-21/UC]) also from the U.S. Geological Survey data 
(DTN: GS020408312272.003 [DIRS 160899]) that originates from the next interval in the same core as that from which the Na-porewater was extracted. The composition of the Na-porewater used in the in-package chemistry model differs only slightly from the "W4" composition used in Drift-Scale THC Seepage Model (BSC 2005 [DIRS 172862]). Thus, continuity has been established for key inputs for the in-package chemistry model and the drift scale processes models.

Compared to the J-13 well water composition, the porewater compositions are significantly more concentrated (Table 4-2). Two anions important with regard to steel corrosion (chloride and fluoride) are concentrated in the porewaters by factors of approximately 2 to 3 compared to J-13 well water. Drift-Scale THC Seepage Model (BSC 2005 [DIRS 172862]) states "W5" (Ca-porewater) has the highest $(\mathrm{Ca}+\mathrm{Mg}) /(\mathrm{Na}+\mathrm{K})$ ratio of the ECRB samples, and "W4" (Na-porewater) has the lowest $(\mathrm{Ca}+\mathrm{Mg}) /(\mathrm{Na}+\mathrm{K})$ ratio of the ECRB samples and higher fluoride than other samples. Thus, the two porewaters represent compositional end members and capture the spread of the porewater compositions. A Piper diagram (BSC 2005 [DIRS 172862], Figure 6.2-4) shows these two samples represent compositional end members.

As these samples cover the spectrum of observed porewater compositions sampled, and there is a possibility that waters of similar composition may enter a drift and contact a breached waste package, the use of these compositions is well justified. Furthermore, use of these data in the in-package chemistry model ensures feeds to the TSPA-LA model will reflect the compositional variation of the initial water composition.

Additional water compositions were also used as inputs for sensitivity analyses purposes. The waters from Section 6.6 of Engineered Barrier System: Physical and Chemical Environment Model (BSC 2004 [DIRS 169860]) represent seepage compositions modeled to enter the drift during the postclosure period and those that are thermally perturbed and in equilibrium with higher carbon dioxide fugacities. These include compositions that correspond to thermally perturbed equivalents of the Ca-porewater (W5) and the Na-porewater (W4). A third water composition (W6) from Engineered Barrier System: Physical and Chemical Environment Model (BSC 2004 [DIRS 169860], Section 6.6) was also used to represent a high-temperature composition that could enter a breached waste package. These compositions, along with the temperature and carbon dioxide fugacity, were taken from EQ3 files obtained from DTN: MO0303MWDSCMAB.000 [DIRS 162551] and are listed in Table 4.3.

The input waters selected for sensitivity tests of the in-package model have compositions corresponding to waters that could enter the drift as crown seepage. These compositions were taken from Drift-Scale THC Seepage Model (BSC 2005 DIRS 172862]). The seepage water compositions used as input to the calculations of Engineered Barrier System: Physical and Chemical Environment Model (BSC 2004 [DIRS 169860]) are also based on the results of the THC model. For there to be seepage-as opposed to vapor diffusion-into canisters requires that the drip shields have been breached. In this case, water impinging on the canister will be crown seepage water rather than in-drift waters of the type discussed by Engineered Barrier System: Physical and Chemical Environment Model (BSC 2004 [DIRS 169860]). The in-drift waters can potentially have severe chemistries due to evaporation, and these waters are of concern due to their contact with the waste package, and their potential to enhance corrosion of the waste package. However, the waters that could potentially drip onto the waste package in significant quantities for significant lengths of time will be seeping from rock above the waste package due 
to the forces of gravity, which will be the crown seepage waters and not the in-drift waters. While it is possible that some of the in-drift waters will make their way into the waste package as run off from those components residing above the waste package, the bulk of the waters seeping into the waste packages will be those that drip from above the drift.

Though the input waters do not include the evaporated in-drift waters, the thermally perturbed waters included in Table 4-3 have undergone evaporation; therefore, this model accounts for evaporation for the selected incoming waters.

Table 4-3. Thermally Perturbed Seepage Compositions

\begin{tabular}{|c|c|c|c|c|}
\hline \multicolumn{2}{|c|}{ Source } & \multicolumn{3}{|c|}{ Input File Names } \\
\hline & & 10006 & 20013 & 51 \\
\hline Parameter & Units & \begin{tabular}{|c} 
Cross-drift water \\
CS2000/16.5 \\
thc6_w4_r.xIs \\
TF4 directory \\
\end{tabular} & \begin{tabular}{|c|} 
Cross-drift water \\
CS1000/7.3 \\
thc6_w5_r.xls \\
TF4 directory \\
\end{tabular} & \begin{tabular}{|c|} 
Cross-drift water \\
SD-9/990.4 \\
thc6_w6_r.xls \\
TF4 directory \\
\end{tabular} \\
\hline Temperature & ${ }^{\circ} \mathrm{C}$ & 56.2 & 40.2 & 91.8 \\
\hline $\log \mathrm{fCO}_{2}$ & - & -1.950 & -2.198 & -2.532 \\
\hline $\mathrm{pH}$ & - & 7.78 & 7.94 & 8.14 \\
\hline $\mathrm{HCO}_{3}^{-}$ & Molality & $6.58 \mathrm{E}-03$ & 6.92E-03 & 2.04E-03 \\
\hline $\mathrm{Ca}^{2+}$ & Molality & 4.40E-04 & 5.73E-04 & 7.24E-05 \\
\hline $\mathrm{Cl}^{-}$ & Molality & 7.12E-04 & 5.61E-04 & 7.34E-04 \\
\hline $\mathrm{F}^{-}$ & Molality & 7.81E-04 & $6.43 \mathrm{E}-04$ & 9.77E-04 \\
\hline $\mathrm{K}^{+}$ & Molality & $4.55 \mathrm{E}-04$ & $2.76 \mathrm{E}-04$ & $5.02 \mathrm{E}-04$ \\
\hline $\mathrm{Mg}^{2+}$ & Molality & 5.19E-05 & 8.51E-05 & 2.54E-07 \\
\hline $\mathrm{Na}^{+}$ & Molality & 7.49E-03 & 7.31E-03 & 4.27E-03 \\
\hline $\mathrm{SO}_{4}^{2-}$ & Molality & 3.94E-04 & 3.55E-04 & 1.18E-04 \\
\hline $\mathrm{SiO}_{2}(\mathrm{aq})$ & Molality & $2.43 \mathrm{E}-03$ & 1.79E-03 & 4.15E-03 \\
\hline $\mathrm{NO}_{3}^{-}$ & Molality & 6.58E-05 & 3.97E-05 & 3.10E-04 \\
\hline $\mathrm{NH}_{3}(\mathrm{aq})$ & Molality & 1.00E-12 & 1.00E-12 & $1.00 \mathrm{E}-12$ \\
\hline $\mathrm{Al}^{3+}$ & Molality & 3.73E-09 & 1.50E-09 & 6.09E-08 \\
\hline
\end{tabular}

Source: DTN: MO0303MWDSCMAB.000 [DIRS 162551].

NOTE: $f \mathrm{CO}_{2}$ is carbon dioxide fugacity.

The incoming water composition for the vapor-influx case is pure water, which simulates water vapor entering and then condensing in the waste package.

The potential flow rate for water flux into the waste package is a function of seepage rate, driftwall condensation, condition of the drip shield, and number and types of openings in a breached waste package. The potential flow rate for water vapor flux into the waste package is a function of relative humidity, temperature, and number and types of openings in a breached waste package. To cover the possible range of water fluxes, values from Abstraction of Drift Seepage (BSC 2004 [DIRS 169131]) and EBS Radionuclide Transport Abstraction (BSC 2004 [DIRS 169868]) used as bounding cases are presented in Table 4.4. The seepage values are used to ensure water flow rates considered in this model are sufficient to cover the potential seepage rates to be used by TSPA-LA. TSPA-LA starts with the seepage rates from Abstraction of Drift Seepage (BSC 2004 [DIRS 169131]) and adjusts the rate depending on the condition of the drip shield and the number and types of openings in the breached waste package. The maximum 
seepage flow rate for the purposes of this calculation is the mean seepage rate for the upper-bound scenario with the glacial transition climate in the Tptpmn. The true maximum seepage flow is on the order of $10,000 \mathrm{~kg} / \mathrm{yr}$ per waste package, but the drip shield and the remaining waste package divert most of the seepage flow, so it would not be reasonable to model this flow entering a waste package. Therefore, these rates represent the maximum range of rates that could enter a waste package, and are justified.

The water vapor rates from EBS Radionuclide Transport Abstraction (BSC 2004 [DIRS 169868]) were calculated to provide a range of vapor diffusion rates through stress corrosion cracks for representative temperature and relative humidity conditions, and ranged from 22 moles to 239 moles (which corresponds to 0.4 liters to 4.3 liters). These vapor rates are calculated in an alternative conceptual model (BSC 2004 [DIRS 169868]), and are not actually product output used by TSPA-LA. The use of this data as input is justified by an additional calculation in Appendix H, documented in Section 6.4.3, which corroborates these ranges.

Table 4-4. Flux Into Waste Package

\begin{tabular}{|c|c|c|c|}
\hline Phase & $\begin{array}{l}\text { Minimum Flow Rate } \\
\text { per Waste Package }\end{array}$ & $\begin{array}{c}\text { Maximum Flow Rate } \\
\text { per Waste Package }\end{array}$ & Source \\
\hline $\begin{array}{l}\text { Liquid } \\
\text { (Seepage) }\end{array}$ & $0.0 \mathrm{~kg} / \mathrm{yr}$ & $294.6 \mathrm{~kg} / \mathrm{yr}$ & $\begin{array}{l}\text { BSC } 2004 \text { [DIRS 169131], Table 6.8-1 } \\
\text { and 6.8-2 }\end{array}$ \\
\hline Vapor & $22.1 \mathrm{~mol} \mathrm{H}{ }_{2} \mathrm{O} / \mathrm{yr}$ & $239 \mathrm{~mol} \mathrm{H}{ }_{2} \mathrm{O} / \mathrm{yr}$ & BSC 2004 [DIRS 169868], Table 6.6-1 \\
\hline
\end{tabular}

\subsubsection{Waste Form Compositions and Degradation Rates}

\subsubsection{CSNF}

The source for the composition of the PWR fuel used for the CSNF in the in-package chemistry model is PWR Assembly End-Effect Reactivity Evaluation (BSC 2003 [DIRS 169110]), which starts with fresh fuel $\left(\mathrm{UO}_{2}\right)$ and calculates the composition of the irradiated fuel when it is discharged from the reactor (specified by burnup) and at specified times after discharge. The calculations were performed in that report using the SAS2H sequence and the ORIGEN sequence of the SCALE computer code system. The calculation covers initial enrichment of $2 \mathrm{wt} \%$ to $5 \mathrm{wt} \%$ (fuels less than $2 \%$ enriched are bounded by this calculation) ${ }^{235} \mathrm{U}$, and burnup of 0 to $50 \mathrm{GWd} / \mathrm{MTU}$. The quantity of fuel in one assembly is based on the Babcock and Wilcox $(B \& W) 15 \times 15$-assembly design with the mass of type MK-B2. The MK-B2 design contains the greatest mass of uranium per assembly (CRWMS M\&O 1998 [DIRS 104440], p. 26). The B\&W $15 \times 15$ fuel assembly is one of the most reactive 21-PWR designs (B\&W Fuel Company 1991 [DIRS 104439], p. II 6-6). A representative assembly for CSNF with an initial enrichment of $3.5 \mathrm{wt} \%{ }^{235} \mathrm{U}$ and a burnup of $40 \mathrm{GWd} / \mathrm{MTU}$ was chosen by visual depiction of the central region of the CSNF assembly population illustrated in 21-PWR Waste Package with Absorber Plates Loading Curve Evaluation (BSC 2004 [DIRS 172553], Figure 34).

The recommended CSNF degradation rate law (BSC 2004 [DIRS 169987], Tables 8-2 and 8-3) is $\mathrm{pH}, \mathrm{O}_{2}$ partial pressure, total carbonate, and temperature dependent. This rate, $\log (\mathrm{F} / \mathrm{A})$, is expressed in units of $\mathrm{mg} / \mathrm{m}^{2} / \mathrm{day}$, and is appropriate for temperatures less than $100^{\circ} \mathrm{C}$, and total 
carbonate concentrations greater than $2 \times 10^{-4}$ molar, and an oxygen partial pressure from 0.002 atm to $0.2 \mathrm{~atm}$. For low $f \mathrm{CO}_{2}$ conditions (lower than a total carbonate molar concentration equal to $2 \times 10^{-4}$ molar), the rate described in Equation 4-1 should be used with a total carbonate molar concentration equal to $2 \times 10^{-4}$ molar (BSC 2004 [DIRS 169987], Section 8.2).

For $\mathrm{pH}>6.8$ (BSC 2004 [DIRS 169987], Section 8.1, using Table 8-2):

$$
\begin{gathered}
\log (\mathrm{F})=\log (\mathrm{A})+4.705+(-1,093.826) \times \mathrm{IT}+ \\
(-0.102) \times p \mathrm{CO}_{3}+(-0.338) \times p \mathrm{O}_{2}
\end{gathered}
$$

For $\mathrm{pH} \leq 6.8$ (BSC 2004 [DIRS 169987], Section 8.1, using Table 8-3)

$$
\begin{gathered}
\log (\mathrm{F})=\log (\mathrm{A})+6.60+(-1,093.826) \times \mathrm{IT}+ \\
(-0.338) \times p \mathrm{O}_{2}+(-0.340) \times \mathrm{pH}
\end{gathered}
$$

where

$$
\begin{aligned}
& \log (\mathrm{F})=\log _{10} \text { fractional dissolution rate of the fuel (per day) } \\
& \log (\mathrm{A})=\log _{10} \text { of the fuel effective specific surface area }\left(\mathrm{m}^{2} / \mathrm{mg}\right) \\
& \mathrm{IT} \\
& \mathrm{CCO}_{3}=-\log _{10}(\text { total molar carbonate species concentration) } \\
& \mathrm{pO}_{2}=-\log _{10} \text { (oxygen partial pressure in atmospheres) }
\end{aligned}
$$

This combined rate is appropriate for use for a $\mathrm{pH}$ range from 2 to 10.3 (BSC 2004 [DIRS 169987], Section 8.2).

Summary Report of Commercial Reactor Criticality Data for Crystal River Unit 3 (Punatar 2001 [DIRS 155635], Table 2-2, p. 2-5), IED Waste Package Configuration [Sheet 1 of 1] (BSC 2005 [DIRS 173501], Tables 1 and 3); BSC 2004 [DIRS 172214], p. II-2 and II-3; BSC 2004 [DIRS 168199]; BSC 2004 [DIRS 168253]) provide inputs required to calculate the quantity and surface areas of waste package materials comprising the 21-PWR waste package. These calculations are contained in Appendix F, CSNF.xls. The 21-PWR assembly volume, calculated

in CSNF.xls is corroborated by a volume value of $0.081 \mathrm{~m}^{3}$ from Criticality Evaluation of Degraded Internal Configurations for the PWR AUCF WP Designs (CRWMS M\&O 1997 [DIRS 102824] Table 4.1-1).

\subsubsection{N-Reactor Fuel}

$N$ Reactor (U-Metal) Fuel Characteristics for Disposal Criticality Analysis (DOE 2000 [DIRS 150095], Table 3-1), for Mark IV fuel, provides the N-Reactor fuel composition information, including multi-canister overpack (MCO) dimensions, used in the in-package chemistry model. This reference is an appropriate source for N-Reactor fuel composition and MCO dimensions because the purpose of the report was to document this information and it contains the most detailed information available on the specific MCO dimensions. Praga (1998 [DIRS 172869]) further corroborates the N-Reactor fuel composition and the MCO dimensions information. Due to the poor N-Reactor fuel cladding condition (DOE 2000 [DIRS 152658]), the fuel is always considered $100 \%$ exposed. 
A linear degradation rate (i.e., constant reaction rate) of $1.4 \times 10^{4} \mathrm{mg} /\left(\mathrm{m}^{2} \cdot \mathrm{d}\right)$ is used to describe the dissolution of the N-Reactor fuel. This rate is five times the constant U-metal rate reported in Review of Oxidation Rates of DOE Spent Nuclear Fuel, Part 1: Metallic Fuel (DOE 2000 [DIRS 152658], Equation 2-39). That report (DOE 2000 [DIRS 152658]) contains the $\mathrm{N}$-Reactor fuel degradation rate, which is the property of interest. This reference is an appropriate source for the N-Reactor fuel rate, as it analyzed the linear rate for N-Reactor fuel over a suitable time under conditions relevant to the repository. Gray and Einziger (1998 [DIRS 109691], Section 4.3) document a rate of $1.3 \times 10^{4} \mathrm{mg} /\left(\mathrm{m}^{2} \cdot \mathrm{d}\right)$, thereby corroborating the rate from the DOE (2000 [DIRS 152658]) reported rate. While the TSPA-LA models the dissolution of DSNF as instantaneous (i.e., occurring within one time step), the time steps in TSPA-LA are considerably larger than the time steps within EQ6. The typical TSPA-LA timestep is 100 years or more, and the minimum is 10 years. Using the above rate in EQ6 results in complete dissolution of the DSNF within 15 years, which is essentially the same as TSPA-LA instantaneously degrading the fuel. Because this rate equates to essentially instantaneous degradation of the DSNF, it is also appropriate for the higher temperature runs.

$N$ Reactor (U-Metal) Fuel Characteristics for Disposal Criticality Analysis (DOE 2000 [DIRS 150095], Section 4, pp. 23 and 24) and IED Waste Package Configuration [Sheet 1 of 1] (BSC 2005 [DIRS 173501], Tables 1 and 9), BSC 2004 [DIRS 172214] (p. X-2 and X-3), BSC 2004 [DIRS 168199], and BSC 2004 [DIRS 168253] also provide the inputs required to calculate the quantity and surface areas of the waste package materials for the 2-MCO/2-DHLW waste package (as shown in Appendix F, CDSP.xls).

\subsubsection{HLW Glass}

The simplified HLW glass composition in Table 4-5 is from Table 3 of EQ6 Calculations for Chemical Degradation of $N$ Reactor (U-metal) Spent Nuclear Fuel Waste Packages (CRWMS M\&O 2001 [DIRS 153263]), which cites Defense Waste Processing Facility Wasteform and Canister Description (Baxter 1988 [DIRS 106164], Table 6-8). The Savannah River glass composition was used in the model to maintain continuity with other analyses (CRWMS M\&O 2001 [DIRS 153263]). Furthermore, Savannah River glass has a higher concentration of potassium (about 23 times more than Hanford glass) (CRWMS M\&O 2000 [DIRS 151947], p. 8, Table 5-1). Because of its higher alkali composition (i.e., potassium), the Savannah River glass will produce a broader range of $\mathrm{pH}$ conditions, thus encompassing the range of chemistries generated by more mild glasses such as Handford glass.

Table 4-5. High-Level Waste Glass Composition

\begin{tabular}{|c|c|}
\hline Element & Mol/100 $\mathbf{g}^{*}$ HLWG \\
\hline $\mathrm{O}$ & $2.70 \mathrm{E}+00$ \\
\hline $\mathrm{U}$ & $7.82 \mathrm{E}-03$ \\
\hline $\mathrm{Ba}$ & $1.08 \mathrm{E}-03$ \\
\hline $\mathrm{Al}$ & $8.63 \mathrm{E}-02$ \\
\hline $\mathrm{S}$ & $4.01 \mathrm{E}-03$ \\
\hline $\mathrm{Ca}$ & $1.62 \mathrm{E}-02$ \\
\hline $\mathrm{P}$ & $4.89 \mathrm{E}-04$ \\
\hline $\mathrm{Si}$ & $7.76 \mathrm{E}-01$ \\
\hline $\mathrm{B}$ & $2.91 \mathrm{E}-01$ \\
\hline
\end{tabular}


Table 4-5. High-Level Waste Glass Composition (Continued)

\begin{tabular}{|c|c|}
\hline Element & Mol/100g* HLWG \\
\hline $\mathbf{F}$ & $\mathbf{1 . 6 6 \mathrm { E } - 0 3}$ \\
\hline $\mathrm{Fe}$ & $1.72 \mathrm{E}-01$ \\
\hline $\mathrm{K}$ & $7.51 \mathrm{E}-02$ \\
\hline $\mathrm{Mg}$ & $3.33 \mathrm{E}-02$ \\
\hline $\mathrm{Na}$ & $5.77 \mathrm{E}-01$ \\
\hline
\end{tabular}

Source: CRWMS M\&O 2001 [DIRS 153263], Table 3.

NOTE: * Elemental mole \% of the glass is based on 100 grams of reactant.

The HLWG degradation rate expression (BSC 2004 [DIRS 169988]) follows the transition-state rate law and is dependent on the $\mathrm{pH}$ of the solution. The rate law coefficients provided were deemed the "most probable" in Defense HLW Glass Degradation Model (BSC 2004 [DIRS 169988]). This rate is appropriate for temperatures less than $100^{\circ} \mathrm{C}$. The exposure factor, $\mathrm{f}_{\text {exposure, }}$ is the value that is multiplied by the geometric surface area of the HLW glass to achieve an effective surface area, which includes an increase in surface area due to fractures in the glass. The most likely value for $f_{\text {exposure }}$ is 4, and the maximum value is 17 (BSC 2004 [DIRS 169988], Table 8-1).

For acidic conditions (BSC 2004 [DIRS 169988], Section 8.1, Equation 50):

$$
\text { rate }_{G}=k_{E_{-} \text {acidic }} \times 10^{-0.49 \cdot \mathrm{pH}} \times \exp (-31 \mathrm{~kJ} / \mathrm{mol} / \mathrm{RT})
$$

For alkaline conditions (BSC 2004 [DIRS 169988], Section 8.1, Equation 51):

$$
\text { rate }_{G}=k_{E_{-} \text {alkaline }} \times 10^{0.49 \cdot \mathrm{pH}} \times \exp (-69 \mathrm{~kJ} / \mathrm{mol} / \mathrm{RT})
$$

where (BSC 2004 [DIRS 169988], Section 8.1):

$$
\begin{aligned}
\text { rate }_{G}= & \text { the glass rate law in units of } \mathrm{g} / \mathrm{m}^{2} / \text { day } \\
k_{E_{-} \text {acidic }}= & \text { the glass degradation rate coefficient for acidic solutions: the minimum and } \\
& \text { most probable value of } k_{E_{-} a c i d i c} \text { is } 8.41 \times 10^{3} \mathrm{~g} /\left(\mathrm{m}^{2} \cdot \mathrm{d}\right), \text { and the maximum } \\
& \text { value of } k_{E_{-} \text {acidic }} \text { is } 1.15 \times 10^{7} \mathrm{~g} /\left(\mathrm{m}^{2} \cdot \mathrm{d}\right) \\
k_{E_{-} \text {alkaline }}= & \text { the glass degradation rate coefficient for alkaline solutions: the minimum } \\
& \text { and most probable value of } k_{E_{a} \text { alkaline }} \text { are } 2.82 \times 10^{1} \mathrm{~g} /\left(\mathrm{m}^{2} \cdot \mathrm{d}\right), \text { and the } \\
& \text { maximum value of } k_{E_{-} \text {alkaline }} \text { is } 3.47 \times 10^{4} \mathrm{~g} /\left(\mathrm{m}^{2} \cdot \mathrm{d}\right) .
\end{aligned}
$$

IED Waste Package Configuration [Sheet 1 of 1] (BSC 2005 [DIRS 173501], Tables 1 and 9), BSC 2004 [DIRS 172214] (p. X-2 and X-3), BSC 2004 [DIRS 168199], and Design and Engineering, Spread Ring Sub-Assembly (BSC 2004 [DIRS 168253]) provide the inputs required to calculate the waste package material quantity and surface areas comprising the 2-MCO/2-DHLW waste package (as shown in Appendix F, CDSP.xls).

Taylor (1997 [DIRS 126175]) and Characteristics of Potential Repository Wastes (DOE 1992 [DIRS 102812], Figure 3.4.2) provide direct input dimensions (for increased length and thickness) of the glass pour canisters (GPC), which DOE and Commercial Waste Package System Description Document (BSC 2005 [DIRS 174225], Table 3-1) corroborates. The DOE 
(1992 [DIRS 102812]) report contains the properties of interest, which are the GPC dimensions. This reference is an appropriate source for these dimensions because the purpose of the report was to document this information and it contains the most detailed information available on the specific dimensions of the MCO.

\subsubsection{Waste Package Material Compositions and Degradation Rates}

Table 4-6 contains the names and shorthand names used in this model and waste package type for the metal alloys used throughout this document.

Table 4-6. Materials Nomenclature and Waste Package Breakdown

\begin{tabular}{|c|c|c|c|}
\hline \multirow[b]{2}{*}{ Material Nomenclature } & \multirow[b]{2}{*}{ Shorthand } & \multicolumn{2}{|c|}{ Waste Package Type } \\
\hline & & CSNF & CDSP \\
\hline Alloy 22 (UNS N06022) & Alloy 22 & $\mathrm{X}$ & $\mathrm{X}$ \\
\hline SA-240 (UNS S31600) Stainless Steel & Stainless Steel Type 316 & $\mathrm{X}$ & $\mathrm{X}$ \\
\hline SA-240 S30403 Stainless Steel & Stainless Steel Type 304L & & $\mathrm{X}$ \\
\hline SA-516 Grade 70 Carbon Steel & Carbon Steel Type A516 & $\mathrm{X}$ & $\mathrm{X}$ \\
\hline SB-209 6061 T4 & Aluminum Alloy Type 6061 & $\mathrm{X}$ & \\
\hline Aluminum Alloy-1100 & Aluminum Alloy Type 1100 & & $\mathrm{X}$ \\
\hline Alloy (UNS N06464) & NiGd Alloy & $\mathrm{X}$ & \\
\hline Neutronit A978 & Neutronit $^{\mathrm{a}}$ & $x$ & \\
\hline
\end{tabular}

NOTE: $\quad{ }^{a}$ Neutronit, a borated stainless steel, was replaced by NiGd alloy in the latest CSNF design, and is only presented here for comparison.

The CSNF 21-PWR absorber plate waste package components use the following materials: Alloy 22 for the outer corrosion barrier; Stainless Steel Type 316 for the inner vessel; Carbon Steel Type A516 for the basket guides, stiffeners, and fuel basket tubes; and Aluminum Alloy Type 6061 and NiGd Alloy for the fuel basket plates (BSC 2004 [DIRS 172214], p. II-2 and II-3). The main CDSP waste package (N Reactor) components use the following materials: Alloy 22 for the outer corrosion barrier, Stainless Steel Type 316 for the inner vessel, Carbon Steel Type A516 for the divider plate fuel support plate assemblies (BSC 2004 [DIRS 172214], p. X-2 and X-3), Stainless Steel Type 304L for the multicanister overpack (MCO) (DOE 2000 [DIRS 150095], Section 4) and glass pour canisters (GPC) (BSC 2005 [DIRS 174225], Table 3-1), and Aluminum Alloy Type 1100 for the MCO spacer (DOE 2000 [DIRS 150095], Section 4).

Table 4-7 summarizes the composition of the steel and aluminum alloys present in the CSNF and CDSP waste packages. While there may be some variability in the composition of the alloys used in the construction of the waste packages, the values in Table 4-7 are ASTM standards, which vendors are required to meet with little variation. However, a sensitivity analysis is conducted in Section 6.6.9 that varies the composition of Carbon Steel Type A516 to show the effect on the model response. The alloy compositions represent the best available information on the materials that will be used in the construction of the waste package. 
Table 4-7. Composition of Steel and Aluminum Alloys

\begin{tabular}{|c|c|c|c|c|c|c|c|}
\hline Element & \begin{tabular}{|c|} 
Carbon \\
Steel Type \\
A516 \\
(wt \%) \\
\end{tabular} & $\begin{array}{c}\begin{array}{c}\text { Neutronit } \\
\text { (wt \%) }\end{array} \\
\text { (wt }\end{array}$ & $\begin{array}{c}\text { Aluminum } \\
\text { Alloy } 6061 \\
\text { (wt \%) }\end{array}$ & $\begin{array}{c}\text { Stainless } \\
\text { Steel Type } \\
316 \\
(w t \%) \\
\end{array}$ & $\begin{array}{c}\text { Aluminum } \\
\text { Alloy } 1100 \\
\text { (wt \%) }\end{array}$ & \begin{tabular}{|c|} 
Stainless \\
Steel Type \\
$304 \mathrm{~L}$ \\
$(w \mathrm{t} \%)$ \\
\end{tabular} & \begin{tabular}{|c} 
NiGd Alloy \\
$(w \mathrm{t} \%)$
\end{tabular} \\
\hline C & $0.28^{a}$ & 0.04 & - & 0.08 & - & 0.03 & 0.01 \\
\hline Mn & $\begin{array}{c}0.85 \text { to } 1.2 \\
(1.025)^{\mathrm{b}}\end{array}$ & - & 0.15 & 2.00 & 0.05 & 2.00 & 0.5 \\
\hline$P$ & 0.035 & - & - & 0.045 & - & 0.045 & 0.005 \\
\hline$S$ & 0.035 & - & - & 0.03 & - & 0.03 & 0.005 \\
\hline $\mathrm{Si}$ & $\begin{array}{c}0.13 \text { to } 0.45 \\
(0.29)^{b}\end{array}$ & - & $\begin{array}{c}0.40 \text { to } 0.8 \\
(0.60)^{b}\end{array}$ & 0.75 & $\begin{array}{c}0.95(\mathrm{Si}+\mathrm{Fe}) \\
0.45\end{array}$ & 0.75 & 0.08 \\
\hline $\mathrm{Cr}$ & - & 18.5 & $\begin{array}{c}0.04 \text { to } 0.35 \\
(0.195)^{b}\end{array}$ & $\begin{array}{c}16.0 \text { to } 18.0 \\
(17.00)^{\mathrm{b}}\end{array}$ & - & $\begin{array}{c}18.0 \text { to } 20.0 \\
(19.00)^{\mathrm{b}}\end{array}$ & $\begin{array}{c}14.5-\text { to } 17.1 \\
(15.8)^{\mathrm{b}}\end{array}$ \\
\hline $\mathrm{Ni}$ & - & 13 & - & $\begin{array}{c}10.0 \text { to } 14.0 \\
(12.0)^{) b}\end{array}$ & - & $\begin{array}{l}8.0 \text { to } 12.0 \\
\left(10.00^{\mathrm{b}}\right.\end{array}$ & $64.035^{d}$ \\
\hline Co & - & 0.2 & - & - & - & - & 2 \\
\hline Mo & - & 2.2 & - & $\begin{array}{c}2.00 \text { to } 3.00 \\
\left(2.50^{\mathrm{b}}\right.\end{array}$ & - & - & $\begin{array}{c}13.1 \text { to } 16.0 \\
(14.55)^{\mathrm{b}}\end{array}$ \\
\hline $\mathrm{N}$ & - & - & - & 0.1 & - & 0.10 & 0.01 \\
\hline $\mathrm{Fe}$ & $98.3^{d}$ & 64.815 & 0.7 & $65.495^{d}$ & $\begin{array}{c}0.95(\mathrm{Si}+\mathrm{Fe}) \\
0.50\end{array}$ & $68.045^{d}$ & 1 \\
\hline B & - & $\begin{array}{c}0.75 \text { to } 1.74^{\mathrm{c}} \\
(1.245)^{\mathrm{b}}\end{array}$ & - & - & - & - & - \\
\hline $\mathrm{Zn}$ & - & - & 0.25 & - & 0.10 & - & - \\
\hline $\mathrm{Cu}$ & - & - & $\begin{array}{c}0.15 \text { to } 0.40 \\
(0.275)^{\mathrm{b}} \\
\end{array}$ & - & $\begin{array}{c}0.05 \text { to } 0.20 \\
(0.125)^{\mathrm{b}}\end{array}$ & - & - \\
\hline $\mathrm{Mg}$ & - & - & $\begin{array}{l}0.8 \text { to } 1.2 \\
(1.0)^{\mathrm{b}}\end{array}$ & - & - & - & - \\
\hline $\mathrm{Ti}$ & - & - & 0.15 & - & - & - & - \\
\hline $\mathrm{Al}$ & - & - & $96.68^{d}$ & - & $98.78^{d}$ & - & - \\
\hline$G d$ & - & - & - & - & - & - & $\begin{array}{c}1.9 \text { to } 2.1 \\
2.0^{\mathrm{b}}\end{array}$ \\
\hline 0 & - & - & - & - & - & - & 0.005 \\
\hline Total & 100.0 & 100.0 & 100.0 & 100.0 & 100.0 & 100.0 & 100.0 \\
\hline
\end{tabular}

Source: Table 4-1.

NOTE: $\quad{ }^{a}$ Value is for Grade 70 thicknesses between $1 / 2$ in to 2 in.

${ }^{\mathrm{b}}$ Represents the average of the range specified in source.

${ }^{\mathrm{C}}$ Ranges for types B3, B4, and B6.

${ }^{\mathrm{d}}$ Balance values calculated based on the averaged values.

${ }^{\mathrm{e}}$ Neutronit is presented in this table for comparison purposes only; its composition is not a direct input to this report, as this material has been changed to NiGd alloy. The reference for the Neutronit composition is Kügler 1996 [DIRS 107760]; for B content, ASTM A 887-89 2000 [DIRS 154062],

Table 1, S30463, S30464, and S30466.

Table 4-8 provides the densities and corrosion rates for the waste package metal alloys described in Table 4-7. 
Table 4-8. Steel and Alloy Densities and Corrosion Rates

\begin{tabular}{|c|c|c|c|c|c|c|c|}
\hline & \begin{tabular}{|c|} 
Carbon \\
Steel Type \\
A516 \\
\end{tabular} & Neutronit $^{\mathrm{b}}$ & $\begin{array}{l}\text { Aluminum } \\
\text { Alloy } 6061 \\
\end{array}$ & $\begin{array}{c}\text { Stainless } \\
\text { Steel Type } \\
316 \\
\end{array}$ & $\begin{array}{l}\text { Aluminum } \\
\text { Alloy } 1100 \\
\end{array}$ & $\begin{array}{c}\text { Stainless } \\
\text { Steel Type } \\
\text { 304L } \\
\end{array}$ & NiGd Alloy \\
\hline Density $\left(\mathrm{g} / \mathrm{cm}^{3}\right)$ & 7.85 & 7.76 & 2.70 & 7.98 & 2.71 & 7.94 & 8.76 \\
\hline $\begin{array}{c}\text { Minimum } \\
\text { Corrosion Rate } \\
(\mu \mathrm{m} / \mathrm{yr})\end{array}$ & 3.69 & 0.001 & 0.4 & 0.0014 & 0.4 & 0.001 & $0.0528^{a}$ \\
\hline $\begin{array}{c}\text { Maximum } \\
\text { Corrosion Rate } \\
(\mu \mathrm{m} / \mathrm{yr})\end{array}$ & 130.7 & 29.2 & 110.9 & 14.8 & 110.9 & 39.1 & 0.0774 \\
\hline
\end{tabular}

Source: Table 4-1.

NOTE: $\quad{ }^{a}$ Average Rate from DTN: MO0409SPAACRWP.000 [DIRS 172059].

${ }^{\text {b}}$ Neutronit (Kügler 1996 [DIRS 107760]) is presented in this table for comparison purposes only; its composition is not a direct input to this report, since this material has been changed to the NiGd Alloy.

The corrosion rates used in this model encompass the ranges provided in DTN: MO0409SPAACRWP.000 [DIRS 172059] for temperatures from $25^{\circ} \mathrm{C}$ to $90^{\circ} \mathrm{C}$. The corrosion rates used are justified because they consider the full range intended to encompass the possible range of degradation rates for the materials that make up the waste package as documented by Probability Analysis of Corrosion Rates for Waste Package Materials (BSC 2004 [DIRS 169982], p. 1-1).

The base case reflects the use of the NiGd alloy as a neutron absorber within the CSNF waste package. Previously, the design had called for Neutronit as the neutron absorber (BSC 2004 [DIRS 170710]). Section 6.6.7 contains a sensitivity analysis comparing the base-case CSNF (containing NiGd Alloy) with the old design that included Neutronit. This analysis demonstrates that, although the change in design results in a minor change of overall chemistry, the resulting $\mathrm{pH}$ and ionic strength of the solutions are still within the abstracted range provided to TSPA-LA by the base analysis.

\subsubsection{Atomic Weights}

Atomic weights of the elements and radionuclide isotopes used were taken from Atomic Mass Adjustment, Mass List for Analysis (Audi and Wapstra 1995 [DIRS 149625]) and Nuclides and Isotopes, Chart of the Nuclides (Parrington et al. 1996 [DIRS 103896], p. 50). These documents have been used as a source for this information throughout the Yucca Mountain Project and are appropriate as a source for atomic weights in this analysis. The atomic weights of the elements are used to convert the weight percent of the elements in the metal alloys to moles of elements in the metal alloys used as input in the EQ6 files.

\subsubsection{Surface Complexation Inputs}

The surface complexation reactions and the associated equilibrium constants (log K) presented in Table 4-9 are used to estimate the $\mathrm{pH}$-buffering effects in the analytical surface complexation model developed in Sections 6.3.2 and 6.7. These reactions and $\log \mathrm{K}$ values are internally consistent (Appelo et al. 2002 [DIRS 168168], p. 3,097). 
Table 4-9. Surface Complexation Reactions

\begin{tabular}{|c|c|}
\hline Reaction & $\log K$ \\
\hline $\mathrm{HFO} \_\mathrm{sOH}+\mathrm{H}^{+}=\mathrm{HFO} \_\mathrm{sOH}_{2}{ }^{+}$ & $7.29^{a}$ \\
\hline $\mathrm{HFO} \_\mathrm{wOH}+\mathrm{H}^{+}=\mathrm{HFO} \_\mathrm{wOH}_{2}{ }^{+}$ & $7.29^{a}$ \\
\hline $\mathrm{HFO} \_\mathrm{sOH}=\mathrm{HFO} \_\mathrm{sO}^{-}+\mathrm{H}^{+}$ & $-8.93^{b}$ \\
\hline Reaction & $\log K$ \\
\hline $\mathrm{HFO} \_w O H=H F O \_w O^{-}+\mathrm{H}^{+}$ & $-8.93^{b}$ \\
\hline $\mathrm{HFO} \_\mathrm{wOH}+\mathrm{CO}_{3}^{2-}+2 \mathrm{H}^{+}=\mathrm{HFO} \_\mathrm{wHCO}_{3}+\mathrm{H}_{2} \mathrm{O}$ & $20.37^{\circ}$ \\
\hline $\mathrm{HFO} \_\mathrm{wOH}+\mathrm{CO}_{3}{ }^{2-}+\mathrm{H}^{+}=\mathrm{HFO} \_\mathrm{wCO}_{3}{ }^{-}+\mathrm{H}_{2} \mathrm{O}$ & $12.78^{\mathrm{c}}$ \\
\hline
\end{tabular}

Sources: ${ }^{\mathrm{a} D z o m b a k}$ and Morel 1990 [DIRS 105483], Table 5.7, Equation 5.2.

${ }^{\mathrm{b}}$ Dzombak and Morel 1990 [DIRS 105483], Table 5.7, Equation 5.3.

${ }^{\mathrm{c}}$ Appelo et al. 2002 [DIRS 168168], p. 3,097.

NOTE: $\quad H F O=$ hydrous ferric oxide. HFO_s and HFO_w represent adsorption sites, strong (s) and weak (w), respectively.

The equilibrium constant $(\mathrm{K})$ is defined as the product of the concentration of the product divided by the concentrations of the reactants.

Surface properties of iron corrosion products are presented in Table 4-10. The isoelectric point $\left(\mathrm{pH}_{\mathrm{IEP}}\right)$ is the $\mathrm{pH}$ at which the surface has a net neutral charge. It is also called the pristine point of zero charge ( $\mathrm{pH}_{\mathrm{PPZC}}$ ) (Langmuir 1997 [DIRS 100051], p. 350). Various formulae have been assigned to amorphous ferric hydroxide due to its variable hydration state. Dzombak and Morel (1990 [DIRS 105483]) treat this phase using a molecular weight that is nearly equivalent to that of goethite $(\mathrm{FeOOH})$ when expressed in a per mol of Fe basis, but it has also been described as $\mathrm{Fe}(\mathrm{OH})_{3}$.

Table 4-10. Properties of Major Iron Minerals

\begin{tabular}{|l|l|l|l|l|}
\hline \multicolumn{1}{|c|}{ Mineral } & \multicolumn{1}{|c|}{$\begin{array}{c}\text { Surface Area } \\
\left(\mathbf{m}^{2} / \mathbf{g m}\right)\end{array}$} & \multicolumn{1}{|c|}{$\begin{array}{c}\text { Site Density } \\
\text { (sites/area or wt) }\end{array}$} & \multicolumn{1}{c|}{$\begin{array}{c}\text { Sites } \\
\text { (mol/mol Fe) }\end{array}$} & $\begin{array}{c}\text { Isoelectric Point } \\
\text { (pH }\end{array}$ \\
\hline Goethite $(\mathrm{FeOOH})$
\end{tabular}

Sources: Langmuir 1997 [DIRS 100051], pp. 345 and 351, Tables 10.2 and 10.3 (unless otherwise noted) a'Stumm (1992 [DIRS 141778], p. 54)

${ }^{\mathrm{b}} \mathrm{HFO}$ (Dzombak and Morel 1990 [DIRS 105483], p. 95)

${ }^{C}$ Approximate median value chosen by Dzombak and Morel (1990 [DIRS 105483], p. 94).

NOTES: ${ }^{d}$ Calculated from 0.2 moles sites/mole $\mathrm{Fe}$ and a formula weight of $89 \mathrm{~g}$ ferrihydrite/mol Fe ${ }^{e}$ Calculated using the formula given in Langmuir 1997 [DIRS 100051], p. 346: Sites (mol/mol Fe) $=$ Site Density $\times$ Surface Area $\times 10^{18} \mathrm{~nm}^{2} / \mathrm{m}^{2} \times 89 \mathrm{~g}$ ferrihydrite/mol Fe/Avogadro's number $(6.022 \mathrm{E} 23 \mathrm{sites} / \mathrm{mol}$ of sites)

${ }^{\mathrm{f}}$ These numbers are presented for comparison purposes only and are not direct inputs to this report.

The surface complexation inputs are justified for use because they are representative of the best available data on surface complexation. 


\subsection{CRITERIA}

Work described in this document supports the following criteria from Yucca Mountain Review Plan, Final Report (NRC 2003 [DIRS 163274]) as described in Technical Work Plan for Postclosure Waste Form Modeling (BSC 2005 [DIRS 173246]). The full text of these criteria is quoted in Section 8.2 along with a detailed explanation of how this document addresses those criteria and the location where the appropriate information can be found.

- Quantity and Chemistry of Water Contacting Waste Packages and Waste Forms, Acceptance Criteria (NRC 2003 [DIRS 163274], Section 2.2.1.3.3)

- AC1-System Description and Model Integration are Adequate

- AC2-Data are Sufficient for Model Justification

- AC3-Data Uncertainty is Characterized and Propagated Through the Model Abstraction

- AC4-Model Uncertainty is Characterized and Propagated Through the Model Abstraction

- AC5-Model Abstraction Output is Supported by Objective Comparisons

\subsection{CODES, STANDARDS, AND REGULATIONS}

Standard Practice for Prediction of the Long-Term Behavior of Materials, Including Waste Forms, Used in Engineered Barrier Systems (EBS) for Geological Disposal of High-Level Radioactive Waste (ASTM C 1174-97 [DIRS 105725]), is used to support the model development methodology, categorize the models developed with respect to their usage for long-term total system performance assessment, and relate the information or data used to develop the model to the requirements of the standard. 
INTENTIONALLY LEFT BLANK 


\section{ASSUMPTIONS}

\subsection{BULK WATER CHEMISTRY}

Assumption: In the absence of a thin film model, it is assumed the bulk water chemistry calculated by this batch reactor model is applicable to thin films of water.

Rationale: For liquid films thicker than 8 to 20 monolayers, the behavior is similar to bulk water (Sposito 1984 [DIRS 127253]). This observation is supported by Franks 1975 [DIRS 173728], which indicated that for films with thicknesses greater than $10 \mathrm{~nm}$ (equivalent to approximately thirty monolayers) the film behaves as bulk water.

1. The $\mathrm{OH}$ bond distance in a water molecule is $\sim 0.1 \mathrm{~nm}$; the length of a hydrogen bond between water molecules is $\sim 0.3 \mathrm{~nm}$ (Stumm and Morgan 1996 [DIRS 125332], p. 7).

2. The effect of a cation on the structure of bulk water is localized to a suite of no more than 6 to 20 water solvation molecules (Sposito 1984 [DIRS 127253], p. 57). About 10 molecular layers of water on clay minerals exist at humidities of $98 \%$ (Sposito 1984 [DIRS 127253], p. 61). The spatial extent of adsorbed water on a phyllosilicate surface is, conservatively, whatever is included in the region bounded by a plane about $1.0 \mathrm{~nm}$ from the basal plane of the clay mineral. The bounding plane at $1.0 \mathrm{~nm}$ is expected to include all but a few percent of the siloxane surface effects on water structure (Sposito 1984 [DIRS 127253], pp. 69 to 70). A 1-nm layer of water is roughly 4 to 10 water molecules, depending on how they are arranged, so an 8- to 20 -water molecule layer is, therefore, around $2 \mathrm{~nm}$. In addition, cation hydration is similar to hydration of surface complexation sites (Sposito 1984 [DIRS 127253], p. 64). The above clay observations and the magnitude of cation hydration shell radii both suggest that $1 \mathrm{~nm}$ to $2 \mathrm{~nm}$ of surface associated water is not structurally different than bulk water (Sposito 1984 [DIRS 127253], pp. 57, 61, 64, 69, and 70).

3. Experimental studies of a 20-nm-thick water layer adsorbed onto metal plates indicate that its physical characteristics are consistent with bulk water (Zang and Grischokowsky 2004 [DIRS 173729]).

Confirmation Status: This modeling assumption, when combined with the diffusion implementation of the EBS radionuclide transport model (BSC 2004 [DIRS 169868]) within TSPA-LA, is conservative in its estimation of radionuclide release and is, therefore, justified, and does not require confirmation.

Use in the Model: This assumption is used throughout Section 6 in the development of the conceptual model.

\subsection{CONSTANT SURFACE AREA AND CORROSION RATES OF ALLOYS}

Assumption: In the absence of a surface area function within a geochemistry-modeling tool, the surface areas of the reactants are fixed and assumed not to vary with time. 
Rationale: As a material degrades, its surface area will certainly change, but how it varies with time and degree of degradation is extremely complex. Though the actual surface area will increase with time, the effective surface area will decrease due to the formation of a protective layer of corrosion products. The corrosion rate itself also decreases with time due to the formation of oxide layers (DTN: MO0409SPAACRWP.000 [DIRS 172059]). However, the constant surface area simplification can only result in faster degradation, which maximizes the impact of the degradation on the solution chemistry. Also, the EQ6 code does not have the ability to implement a surface area function.

Confirmation Status: The impact of this simplification is that reactants may not degrade as quickly as modeled, but this difference is accounted for by varying the range of degradation rates over three orders of magnitude (Section 6.6.10) and is, therefore, justified and requires no further confirmation.

Use in the Model: This assumption is used in Sections 6.3.

\subsection{THERMODYNAMIC EQUILIBRIUM}

Assumption: In the absence of data on the long-term behavior of man-made materials in the waste package for the regulatory period, it is assumed that all homogeneous solution and gas reactions, and all heterogeneous gas-solution reactions are reversible and at equilibrium. Heterogeneous reactions between solutions and precipitating solids are also assumed to be at equilibrium except for those by which waste and waste-package components degrade and dissolve in the in-package fluids. These reactions are irreversible and described by various expressions for reaction kinetics. These assumptions are implicit in the EQ3/EQ6 reaction and reaction path codes used to model the evolution of the in-package chemistry. Some exceptions to this assumption are the suppression of certain minerals known only to form at high temperatures (as discussed in Section 6.3.1.3.5), and that the oxidation state of chromium is limited to $\mathrm{Cr}(\mathrm{III})$.

Rationale: The justification for equilibrium between solution and precipitating solids is because some solids might require longer times to reach equilibrium (even longer than the times considered in the modeling). These solids, which include high-temperature minerals, are explicitly excluded from consideration as described in Section 6.3.1.1. In this model, kinetic factors do not control the reactions, even though it is unlikely all reactions will actually reach equilibrium, even over the regulatory period.

Confirmation Status: This assumption is justified because it does not lead to nonconservatisms (such as moderate $\mathrm{pH}$ values that would lead to lower solubilities, or moderate ionic strengths $(>0.05)$ that would destabilize colloids [BSC 2004 [DIRS 170025]]). The impact of kinetic control for several species is examined in sensitivity studies in Section 6.6 and is shown to result in chemistries within the predicted ranges provided to TSPA-LA; therefore, no further confirmation is required.

Use in the Model: This assumption is used in Sections 6.3. 


\section{MODEL DISCUSSION}

\subsection{OBJECTIVES}

The objective of the in-package chemistry model is to predict the possible bulk water chemistry within a breached waste package and to provide simplified expressions of the chemistry as a function of time after breach to TSPA-LA. This chemistry is simplified in the form of abstractions for $\mathrm{pH}\left(\mathrm{pH}=-\log \left[\mathrm{H}^{+}\right]\right.$), ionic strength, Eh (redox potential), total carbonate (i.e., sum of aqueous carbonate species), chloride, and fluoride concentration. Ionic strength is defined as a measure of interionic effect resulting primarily from electrical attraction and repulsions between the various ions; $I=1 / 2 \Sigma_{\mathrm{i}} \mathrm{c}_{\mathrm{i}} \mathrm{Z}_{\mathrm{i}}^{2}$, where $\mathrm{c}_{\mathrm{i}}$ is the ion concentration, and $\mathrm{Z}_{\mathrm{i}}$ is the ion charge. The summation is carried out for all cations and anions in solution (Stumm and Morgan 1996 [DIRS 125332], p. 101).

The $\mathrm{pH}$, ionic strength, and total carbonate abstractions are used by TSPA-LA in conjunction with the other models to determine the stability of colloids, the solubility of radionuclides, and the degradation rates of the waste forms. The fluoride abstraction is not directly used by TSPA-LA, but is used by Dissolved Concentration Limits of Radioactive Elements (BSC 2005 [DIRS 173873]) to ensure predicted solubilities are valid over the range of fluoride concentrations possible in waste packages.

\subsection{FEATURES, EVENTS, AND PROCESSES}

Table 6-1 provides a list of "included" FEPs determined to be related to the in-package chemistry model (DTN: MO0407SEPFEPLA.000 [DIRS 170760]). The table also indicates where within this report the indicated FEP is addressed. The discussion of these FEPs, in the indicated sections, provides a summary of how the respective FEP is treated within TSPA-LA.

Table 6-1. Included FEPs for the In-Package Chemistry Model Report

\begin{tabular}{|l|l|l|}
\hline FEP Number & \multicolumn{1}{|c|}{ FEP Name } & \multicolumn{1}{c|}{ Addressed In } \\
\hline $2.1 .01 .02 .0 \mathrm{~B}$ & Interactions between co-disposed waste & Sections 6.5.1.2, 6.5.3, 6.6.13, 6.10.9 \\
\hline $2.1 .02 .09 .0 \mathrm{~A}$ & Chemical effects of void space in waste package & Sections 6.5.3, 6.6.1, 6.6.4, 6.10.9 \\
\hline 2.1.09.01.0B & Chemical characteristics of water in waste package & Sections 6.5.3, 6.7.1, 6.10.9 \\
\hline $2.1 .09 .06 .0 \mathrm{~A}$ & Reduction-oxidation potential in waste package & Sections 6.5.1.1.3, 6.5.3, 6.6.4, 6.10.9 \\
\hline $2.1 .09 .07 .0 \mathrm{~A}$ & Reaction kinetics in waste package & $\begin{array}{l}\text { Sections 6.5.1.1, 6.5.1.2, 6.5.3, 6.6.3, } \\
\text { 6.6.4, 6.6.10, 6.10.9 }\end{array}$ \\
\hline 2.1.09.02.0A & Chemical interaction with corrosion products & $\begin{array}{l}\text { Sections 6.3.2, 6.5.1.1, 6.5.2.2, 6.5.3, } \\
6.7 .1,6.10 .9\end{array}$ \\
\hline 2.1.11.08.0A & $\begin{array}{l}\text { Thermal effects on chemistry and microbial activity in } \\
\text { the EBS }\end{array}$ & $\begin{array}{l}\text { Sections 6.5.1.1, 6.5.3, 6.6.6, 6.7.3, } \\
6.10 .9\end{array}$ \\
\hline 2.2.08.12.0B & Chemistry of water flowing into the waste package & Sections 6.5.1.1, 6.5.3, 6.6.2, 6.10.9 \\
\hline
\end{tabular}

\subsection{BASE-CASE CONCEPTUAL MODEL}

The base-case conceptual model is a combination of a batch reactor model with a surface complexation model. The batch reactor portion of the model combines water, oxygen, carbon 
dioxide, waste forms, and metal alloys. The system is in equilibrium with atmospheric conditions, and the reactants degrade in the presence of water according to a rate determined by the physical properties and the exposed surface area of each reactant. For each reactant, a mass per time rate is selected based on experimental measurements, and the surface area available to react is calculated based on the dimensions of the waste package internals. During reaction progress, metal (hydr)oxide corrosion products and secondary mineral phases precipitate from solution, waste forms and metal alloys are consumed, and water changes in its initial composition and mass due to these reactions. The corrosion products are generally less dense than the starting metals and waste forms, so as the reactions progress, the volume of the system increases. The surface complexation portion of the model examines the effects of the contact of the solution with corrosion product surfaces. An overall model limitation is that these two portions of the model are implemented in series by applying the surface complexation effects to the output of the batch reactor model; when in fact, surface complexation occurs as the reactants are degrading. However, the impact of this simplification is considered in the uncertainty of the output abstractions and is discussed in Section 6.9.

The base case is divided into two water cases: (1) water enters the waste package as a vapor and condenses, and (2) water enters the waste package as a liquid.

1. Vapor-Influx Case: The condensation of vapor onto the waste package internals is simulated as pure $\mathrm{H}_{2} \mathrm{O}$ and enters at a rate determined by the water vapor pressure for representative temperature and relative humidity conditions.

2. Liquid-Influx Case: The water entering a waste package from the drift is simulated as typical groundwater and enters at a rate determined by the amount of seepage available to flow through openings in a breached waste package.

TSPA-LA uses the vapor-influx case for simulations where the waste package has been breached and the drip shield remains intact, so all seepage flow is diverted from the waste package. In this case, the driving force for water vapor condensation onto surfaces inside the breached waste package is the lowering of the water activity as a result of sorption and dissolution of soluble materials released in the corrosion of the waste forms and other materials inside the waste package. These driving forces are counteracted by evaporation when the waste form and other surfaces are hotter than other locations in the drift environment. The combined effects of temperature and solutes on water film accumulation on surfaces inside the breached waste packages are not modeled explicitly. Instead, the amount of water potentially available for sorption and condensation is calculated from the upper-bound rate of diffusion of water vapor into the breached waste packages (Section 6.4.3). Uncertainties in the effects of the actual water accumulation rate are addressed by assessing the sensitivity of the in-package chemistry to the water flux into the breached waste packages (Section 6.6.5). The chemistry from the vaporinflux case is used to determine the stability of colloids and the solubility of radionuclides available for transport by diffusion, and to determine the degradation rates for the waste forms. TSPA-LA uses the liquid-influx case when simulating a seismic event in which the waste package has been breached and the drip shield has been damaged such that seepage flow is actually directed into the waste package. The chemistry from the liquid-influx case, which is a function of the flow rate, is used to determine the stability of colloids, the solubility of radionuclides available for transport by diffusion and advection, and the degradation rates for the 
waste forms. For the vapor-influx and the liquid-influx cases, the batch reactor model considers bulk water, but varies the total quantity of water from a bathtub configuration all the way down the least amount of water, which can still enable the code to run within its range of validation (Section 6.6.1). TSPA-LA applies the chemistry from the batch reactor model to thin films of water. This issue is discussed in Section 5.1.

The chemical processes considered in the model include:

- Reaction-path tracing of the in-package chemical system

- Conservation of mass

- Kinetic dissolution of the waste package components and spent nuclear fuel (N-Reactor fuel) using linear rate laws

- Kinetic dissolution of waste forms (CSNF and HLWG) using transition-state theory rate laws (i.e., nonlinear rate laws, which are dependent on the fluid chemistry)

- Equilibrium precipitation and dissolution of metal corrosion products and complex mineral phases

- Thermal (i.e., temperature) effects on fluid chemistry

- Equilibrium oxidation and reduction reactions

- Chemical interaction of input solution with codisposed waste (DSNF with HLWG)

- Effect of variable input water compositions on the resulting fluid composition

- Chemical effects of void space (proximity of waste package components with atmospheric conditions)

- Influence of surface complexation on the fluid $\mathrm{pH}$.

The physical processes considered in the model include:

- Water ingress and egress (egress for the liquid influx only) through the waste package

- Mixing of water in contact with waste package components.

\subsubsection{Batch Reactor Model}

\subsubsection{Batch Reactor Modeling Concepts and Assumptions}

Thermodynamic Equilibrium - A thermodynamic chemical equilibrium approach is used for aqueous species in this report. The main justification for the use of the thermodynamic chemical equilibrium approach is the extended period of concern mandated by the regulations. Although the use of kinetic factors would be appropriate, such an approach cannot be used with the limited 
available data. The effects of kinetically controlled reactions would be a more-neutral $\mathrm{pH}$ and lower ionic strengths. The $\mathrm{pH}$ and ionic strength ranges projected by the thermodynamic equilibrium approach is wide enough to encompass the $\mathrm{pH}$ and ionic strength ranges that would be projected by a kinetic approach, as shown in the sensitivity analyses in Section 6.6.3. The uncertainty ranges for the ionic strength model passed to TSPA-LA favor lower ionic strengths that account for the effect of the surface complexation model on ionic strength, as well as the effect of kinetics.

A good example of the thermodynamic-versus-kinetic approach is the treatment of sulfur. The complete oxidation of sulfur to $\mathrm{SO}_{4}{ }^{2-}$ is a conservative way to examine the effects of corrosion on $\mathrm{pH}$. At thermodynamic equilibrium, the $\mathrm{S}, \mathrm{N}$, and $\mathrm{P}$ in the steels will be oxidized to the acid anions $\mathrm{SO}_{4}{ }^{2-}, \mathrm{NO}_{3}{ }^{-}$, and $\mathrm{PO}_{4}{ }^{3-}$. Even if there are kinetic barriers to the completion of these oxidation reactions, modeling their equilibria leads to more extreme chemistries; lower $\mathrm{pH}$ values, and higher ionic strengths. To balance this treatment, the surface complexation model adds more realism to the model by buffering $\mathrm{pH}$ (Section 6.3.2).

The exception to thermodynamic equilibrium is the treatment of chromium. Allowing $\mathrm{Cr}$ to oxidize to $\mathrm{Cr}(\mathrm{VI})$ leads to artificially high ionic strengths. Therefore, this model limits the oxidation state of $\mathrm{Cr}$ to $\mathrm{Cr}$ (III) rather than $\mathrm{Cr}(\mathrm{VI})$. Other examples of elements that oxidize due to the thermodynamic equilibrium model include $\mathrm{C}$ and $\mathrm{B}$, but the amount of these elements in the composition of the waste package components is not significant enough to impact the results.

$\mathrm{CO}_{2}$ and $\mathrm{O}_{2}$ Partial Pressure - Oxygen and carbon dioxide maintain equilibrium with the waste package solution and the ambient atmosphere outside of the waste package. The partial pressure of $\mathrm{CO}_{2}$ and $\mathrm{O}_{2}$ of the ambient repository atmosphere are set to $10^{-3.0}$ and $0.2 \mathrm{~atm}$, respectively $\left(\log f \mathrm{CO}_{2}=-3\right.$ and $\left.\log f \mathrm{O}_{2}=-0.7\right)$. The oxygen partial pressure is set to equal atmospheric pressure (Weast 1977 [DIRS 106266], p. F-210). The carbon dioxide pressure is set higher than the atmospheric value because ambient fluids drawn from boreholes near the repository horizon appear to be in equilibrium with above-atmospheric carbon dioxide levels (Yang et al. 1996 [DIRS 100194], Table 8). Sensitivity analyses of the model response to the $\mathrm{CO}_{2}$ and $\mathrm{O}_{2}$ partial pressure are discussed in Section 6.6.4. Nitrogen and minor and trace gases in the atmosphere were not included in the model as gases because they are either inert or of such low concentration to be of no consequence on the model results.

Evaporation - The effects of evaporation inside of the waste package are not modeled explicitly for the liquid-influx case. In addition, the model does not explicitly account for the possibility of seepage concentrated via evaporative processes entering the waste package. Another assumption implicit in the "no-evaporation" assumption is that water will condense in the waste package when the waste package is breached; this assumption is required in order to have an in-package chemistry model.

There will be a period immediately after waste package breach (when water first enters and the relative humidity increases) where evaporation inside a waste package will be high, but this phenomenon was not included in the EQ6 modeling of the in-package chemistry. At high flux values, the effect of early-time evaporative processes is likely to have a negligible impact on the model results because the humidity inside of the breached waste package would increase quickly and the high water flux would diminish any evaporative effects on the fluid composition. At low 
water flux values, the opposite would be true. Humidity would increase slowly, and low water flux would have less of a dilution effect.

Engineered Barrier System: Physical and Chemical Environment (BSC 2004 [DIRS 169860]) examines the effects of evaporation on crown seepage waters of the chemistries used as input to this model. For evaporated seepage waters, the results show that after minimal evaporation to $\mathrm{RH}$ values of no lower than $95 \%$ to $98 \%$, the waters have reached ionic strengths exceeding 1 molal (BSC 2004 [DIRS 169860], Figures 6.13-2 to 6.13-12). Such water would be unsuitable for use as input water for the liquid-influx case because the EQ3/6 codes and database used for the in-package modeling are not intended for use with waters of ions strengths above 1 molal (Section 6.10.2). The version of EQ3/6 database for use at high ionic strengths (the Pitzer version) could not be used because at the time Engineered Barrier System: Physical and Chemical Environment (BSC 2004 [DIRS 169860]) and the in-package modeling were done, the available Pitzer database (DTN: SN0302T0510102.002 [DIRS 162572]) lacked parameters for such important constituents of in-package materials such as U, Ni, Mo, and Gd. However, these and additional elements have since been added to the database (DTN: SN0504T0502404.011 [DIRS 173493]). In addition, the principal solutes following evaporation will be those of soluble salts (such as $\mathrm{Cl}, \mathrm{Na}, \mathrm{Mg}$, etc.). Figures 6-7 and 6-8, for CSNF (Section 6.5.1.1), and Figures 614 and 6-15 for CDSP (Section 6.5.1.2), illustrate that changes in the concentrations of solutes such as $\mathrm{Na}$ do not affect solutes derived from the waste package. As stated in Section 4.1.2, the crown seepage waters, rather than the in-drift waters, are the waters more likely to enter the waste package in any significant quantity; and the use of the thermally perturbed seepage waters (Table 4-3) do account for evaporation.

Therefore, the effects of evaporation in the EQ6 modeling are accounted for by the broad uncertainty range for the ionic-strength abstraction, and effects of the evaporation of the incoming waters are accounted for by use of the thermally perturbed seepage waters. Evaporation is examined in more detail in Sections 6.5.1.1.2 and 6.10.2.

Well-Mixed Batch Reactor-The reactants in the batch reactor are well mixed. Because the waste package components are evenly distributed and in proximity to one another inside of the waste package, and an important aspect of the model is to investigate the effects of the interactions of the various components, the well-mixed concept is justified. In addition, the waste package will be cooling slowly over time, so the temperature gradients within the waste package will contribute to convective flow that will further mix the contents of the waste package. Localized effects (small areas with reducing conditions and more extreme $\mathrm{pH}$ values and ionic strengths) will occur, but these will be transient and not significant enough to alter model results.

Approximately half of the waste package (CSNF or CDSP) volume is taken up with the waste form and structural components and the rest of the waste package is empty. This empty space is referred to as the void space and can fill with water. The waste package is tightly packed (there are no large gaps of space), but individual components are relatively thin sheets of metal or small pellets of fuel packed tightly together, so available space for water is spread throughout the waste package. This spatial configuration is further justification for a well-mixed model. 
Scaling to One Liter-The waste package is represented in the EQ6 input file as amounts, compositions, and surface areas of the major materials, such as carbon and stainless steel, aluminum or other alloys, and different fuel types. Each material is also assigned a reaction rate that EQ6 combines with the surface area to determine the actual rate at which the material degrades. The water influx rate is calculated to provide a representative quantity of water to interact with the waste package components at a rate corresponding to the rate at which seepage water could enter a waste package, or the rate at which vapor could enter a waste package and condense.

EQ6 works on a per liter basis; therefore, all of the reactants and the water flow rate are scaled accordingly. To maintain the proper ratio of each of the materials to each other, the reactants are scaled based on the total surface area of all of the waste package materials. The ratio of the waste package components to the amount of water that they come in contact with is treated as a variable in this model. For one case, the ratio is such that the materials of the waste package are in contact with a volume of water equal to that of the void space. This case is referred to as the "bathtub" model and has the highest ratio of water to waste package materials. Other ratios are examined in which less water is considered. By lowering the ratio of water to reactants, more reactants are available to react that approximates the effects of capillary forces distributing the water to the tight spaces in the waste package, even if the waste package is not completely filled. The base case uses a ratio of water to reactants that is half of the "bathtub" model to examine a lower ratio. The impact of varying this ratio is examined in a sensitivity analysis in Section 6.6.1.

As the ratio of water to reactants is decreased, the ionic strength of the solution increases. As described in the B-dot discussion below, this model is appropriate for use up to about 4 molal. The lowest ratio of water to reactants used in this model approaches this limit, so that a lower ratio could not be examined without exceeding the 4-molal limit. Because ionic strength is an output of this model and this high ionic strength boundary condition affects radionuclide solubility, this 4-molal boundary condition is discussed in greater detail below. The base case uses a ratio of water to reactants that is half of the "bathtub" model to examine a lowest possible ratio.

The highest ionic strengths predicted by the in-package chemistry models are 3 to 4 molal. This upper limit captures the maximum concentrations that would be expected in the aqueous solution because as ionic strength gets above about 1 molal, a "salting out" effect starts to occur, in which cations get less soluble as the ionic strength increases. As an explanation, reactions that control solubility are written in terms of activity, where activity $(a)$ is the molal concentration of the species $(m)$ times the activity coefficient $(\gamma), a=m \times \gamma$ (Langmuir 1997 [DIRS 100051], Equation 4.1). Figure 4.2 of Langmuir (1997 [DIRS 100051]) shows that for cations, as the ionic strength increases above about 1 to 2 molal, the activity coefficient increases. For a set activity value, when the activity coefficient increases, the concentration of dissolved cations decreases.

Dissolved Concentration Limits of Radioactive Elements (BSC 2005 [DIRS 173873], Section 6.3.3.4) also notes, at high ionic strengths activity, coefficients calculated using the algorithm in EQ3/6 v. 7.2b diverge from those calculated from experimental data. In that report (BSC 2005 [DIRS 173873]), the influence of this divergence on solubilities is not expressed by decreasing the solubilities to reflect the salting out effect because the species dominating the solubilities in some cases are anions, which do not exhibit the salting out effect. Instead, the uncertainties of 
solubilities modeled at ionic strengths above 1 molal are increased by an amount corresponding to the maximum divergence in the ionic strengths shown in Figures 6.3-4 and 6.3-5 of Dissolved Concentration Limits of Radioactive Elements (BSC 2005 [DIRS 173873]).

The surface area of the CSNF and N-Reactor fuel are treated as the geometric surface area because the rates reported in Section 4.1.3 are given in terms of geometric surface area. A sensitivity study in Section 6.6.10 examines the use of specific surface area for the CSNF. Similarly, the measured rates of the steels are based on a geometric surface area. The surface area of the HLWG is the geometric surface area multiplied by the exposure factor (BSC 2004 [DIRS 169988]).

Waste Package Materials not Included in the EQ6 Input File-The waste package outer barrier is constructed of Alloy 22, and the fuel cladding is made of Zircaloy, both of which degrade slowly compared to the other materials in the waste package. These two materials are not included in the EQ6 input file because they would react so slowly that the effect on the results would be negligible. The corrosion rate for Zircaloy is low (BSC 2004 [DIRS 169982], Section 6.2.5) and the probability of Alloy 22 corroding quickly is low as stated in of General Corrosion and Localized Corrosion of Waste Package Outer Barrier (BSC 2004 [DIRS 169984], Section 8.1).

In the EQ6 input file, only the inside surface area of the Stainless Steel Type 316 inner vessel is modeled because only the inside of the vessel is in contact with the solution. The gap between the inner vessel and the outer barrier is small and, even if water did manage to enter this gap, it would be a small quantity and would not contact the solution inside the inner vessel. Only the outside surface area of the glass pour canisters was used because they are filled with glass, so the majority of the surface area exposed to water will be the outside of the canister.

Codisposal Waste Packages-The N-Reactor spent nuclear fuel was chosen to represent all DOE spent nuclear fuel because it accounts for about 85 percent of the total metric tons of heavy metal of DOE spent nuclear fuel (DOE 2002 [DIRS 158405]). This selection was deemed appropriate by a sensitivity in Section 6.6.13 that examines the behavior of a waste package containing five HLWG canisters and one DOE canister containing one assembly of Three Mile Island (TMI) SNF (waste package type: 5-DHLW long), and the results are similar.

Corrosion-Long-term corrosion of the internal waste package components may proceed in a nonlinear fashion, where corrosion of fresh surfaces would be rapid and then decrease as corrosion product buildup limits corrosion by impeding oxygen and water diffusion. At some future time, if a mechanism to expose fresh metal surfaces were in action, such as a "sloughing off" mechanism, corrosion could again proceed unimpeded until a new layer of corrosion products formed. Under static conditions, with only gravity acting, the frequency of "sloughing off" could be envisioned to be partially a function of the orientation of a particular component (i.e., angle to vertical and the mass of corrosion product present on a surface). In a dynamic system, an outside force, such as a seismic event, acting on the waste package could also expose fresh metal surfaces. In essence, this model combines two events, sloughing off under gravity and sloughing off under an outside force; the timing of neither is predictable. It is a conservatism that the surface is continually reacting until all of the steels are fully corroded (Section 5.2). However, the range of corrosion rates examined account for this slowing down of corrosion. 
The corrosion rates considered for this report are aqueous corrosion rates. Atmospheric rates can be higher or lower than aqueous rates (DTNs: MO0407SPAPCEML.005 [DIRS 172097] and MO0409SPAACRWP.000 [DIRS 172059]). The use of aqueous rates for this model is justified because the intent of this model is to examine the chemistry generated by water interacting inside a waste package. Additionally, sensitivity studies were performed (Section 6.6.10) to examine the effect of increasing and decreasing the corrosion rates.

Code Implementation - The EQ6 code simulates a titration in which reactants are added to the system according to their kinetic rate and surface area exposed. For the vapor-influx case, the water is simply entered as one of the reactants with a rate corresponding to the maximum diffusion rate of vapor through openings in a breached waste package. For the liquid-influx case, the water is entered as a "displacer" reactant type that takes advantage of the solid center flow through capability of EQ6, at a rate corresponding to seepage water entering a waste package.

The calculation that determines the vapor influx rate into a waste package (BSC 2004 [DIRS 169868], Table 6.6-1; Appendix H) is based on the assumption that the incoming vapor is immediately consumed by the corrosion processes, which maintains a 0-percent relative humidity in the waste package and is, thus, the driving force for more vapor to enter the waste package. This conceptualization is intended to maximize the amount of vapor that can diffuse into a waste package for the purposes of determining a bounding vapor-influx rate for a given set of temperature and relative humidity conditions. For the modeling case in EQ6 to actually mimic the 0-percent relative humidity conditions, the incoming vapor influx rate would have to exactly equal the rate at which the water is consumed, which would be based on the corrosion rates of all of the materials in the waste package. Different materials have different corrosion rates, so as some of the materials are depleted, the overall water consumption rate will decrease. However, the vapor-influx cases modeled in this report used constant vapor-influx rates, allowing for the potential of water to accumulate if the vapor-influx rate exceeds the rate at which the water is consumed. In addition, EQ6 works on the basis of one liter of water, which already exceeds the 0 -percent relative humidity basis for the vapor-influx calculation. To assess the impacts of this excess water, a sensitivity study was conducted in Section 6.6.1, which shows that the excess water has minimal impact on $\mathrm{pH}$, but directly affects the ionic strength. Therefore, additional discussion about the treatment of this issue is provided in ionic strength abstraction, in Section 6.10.2.

The physical system modeled in the batch reactor model differs slightly from the implementation in TSPA-LA. For the vapor-influx case, the rate at which the water enters is sometimes greater than the rate at which the water is consumed in corrosion reactions, depending on which reactants are still degrading in the system. For example, the Carbon Steel Type A516 degrades quickly and consumes water in the process, so during its lifespan, no water accumulates in the system. But once it has fully degraded, water can begin to accumulate in the system. TSPA-LA applies the chemistry of the vapor-influx case to a continuous water film that coats the waste package internals and transports radionuclides and colloids by diffusion across that film, so no water is accumulated. This difference is studied in a sensitivity analysis that looks at the effects of accumulating water in the system in Section 6.6.1.

If the waste package breaches, the quantity of water required by the EQ6 model (1 liter) is instantly present. In actuality, after the waste package breaches, water would enter the waste package and take a certain amount of time to accumulate. This amount of time for accumulation 
is difficult to quantify, and would only result in a delay in radionuclide transport, so for the purposes of this model, the water is instantly available. The impact of this modeling simplification is explored in a sensitivity analysis in Section 6.6.1 and discussed in Section 6.10.2.

Applicability of the B-dot Equation-The thermodynamic database used in this report, SN0410T0510404.002 [DIRS 172712], is for dilute solutions and is used with the B-dot equation within the EQ3/6 software. The B-dot equation is defined and carefully examined in Dissolved Concentration Limits of Radioactive Elements (BSC 2005 [DIRS 173873], Section 6.3.3.4). For the purposes of the in-package chemistry model, EQ3/6 results generated using the B-dot activity coefficient equation for solutions with ionic strength greater than 1 molal and up to 4 molal are sufficiently accurate for the intent of this calculation (mainly to estimate $\mathrm{pH}$ ). Experimental data (in sulfate, nitrate, and chloride solutions) show that EQ3/6 results using the B-dot activity coefficient equation can be used qualitatively up to an ionic strength of about 4 molal to indicate the general nature of the reactions that would actually occur (CRWMS M\&O 1997 [DIRS 100222], Appendix D). Dissolved Concentration Limits of Radioactive Elements (BSC 2005 [DIRS 173873]) adds an uncertainty term to the solubilities if the ionic strength of the solution is between 1 and 3 molal, and does not provide solubilities if the ionic strength is greater than 3 molal, because of the applicability of the B-dot equation. The in-package chemistry model extends the range of applicability of the B-dot equation because the purpose of this model is to predict bulk chemistry properties such as $\mathrm{pH}$ and ionic strength, as opposed to Dissolved Concentration Limits of Radioactive Elements (BSC 2005 [DIRS 173873]), which predicts more precise solubility values.

\subsubsection{Batch Reactor Base-Case Runs}

For the vapor-influx case, several runs include only a single reactant, in addition to the complete runs that contain all of the components. The incoming water in the vapor-influx case is pure water, simulating water vapor that enters a waste package and condenses. These runs examine the chemistry and the contribution of each of the reactants and reactant combinations to the in-package chemistry.

For the liquid-influx case, a series of model runs was conducted in which key inputs were varied across their expected input range to generate a broad range of model response. The key parameters include water flux, fuel exposure (clad failure), initial water composition, temperature, $f \mathrm{O}_{2}, f \mathrm{CO}_{2}$, degradation rates of reactants, amount of water in the system, and the major iron mineral that forms. Many of these input parameters are also input variables in the total system performance assessment to the in-package chemistry model. Other model inputs were varied in sensitivity analyses (Section 6.6) to expand the applicability of the model abstraction for TSPA-LA implementation and to quantify model uncertainty.

Table 6-2 shows the input filenames and the varied associated parameters. Each case uses the base-case values for the other inputs: a flux of $1 \mathrm{~L} / \mathrm{yr}$, median rates for all of the alloys and fuels, $\mathrm{J}-13$ well water, $25^{\circ} \mathrm{C}, \log f \mathrm{CO}_{2}=-3$, and $\log f \mathrm{O}_{2}=-0.7,100 \%$ cladding exposure (for CSNF), and the most likely fracture factor for HLWG (for CDSP). 
Table 6-2. Batch Reactor-Case Nomenclature

\begin{tabular}{|c|c|c|c|}
\hline \multicolumn{2}{|r|}{ CSNF } & \multicolumn{2}{|r|}{ CDSP } \\
\hline Filename & Values Used & Filename & Values Used \\
\hline 316_Max & Maximum 316 rate & 304L_Max & Maximum 316 rate \\
\hline 316_Min & Minimum 316 rate & 304L_Min & Minimum 316 rate \\
\hline $50 C$ & $50^{\circ} \mathrm{C}$ & 316_Max & Maximum 316 rate \\
\hline $90 \mathrm{C}$ & $90^{\circ} \mathrm{C}$ & 316_Min & Minimum 316 rate \\
\hline A516_Min & Minimum A516 rate & $50 \mathrm{C}$ & $50^{\circ} \mathrm{C}$ \\
\hline Al_Max & Maximum Al-6061 rate & $90 \mathrm{C}$ & $90^{\circ} \mathrm{C}$ \\
\hline Al_Min & Minimum Al-6061 rate & A516_Min & Minimum 316 rate \\
\hline BaseCase & $\begin{array}{l}\text { Base Case } \\
(1 \text { significant figure })\end{array}$ & Al_Max & Maximum Al-1100 rate \\
\hline Bathtub & Bathtub quantity of water & Al_Min & Minimum Al-1100 rate \\
\hline Ca_Pore & Ca-porewater & BaseCase & $\begin{array}{l}\text { Base case } \\
(1 \text { significant figure })\end{array}$ \\
\hline Clad_1 & $1 \%$ Clad exposure & Bathtub & Bathtub quantity of water \\
\hline Clad_10 & $10 \%$ Clad exposure & Ca_pore & Ca-porewater \\
\hline CSNF_Max & Maximum 316 rate & fCO2_1_5 & $\log \mathrm{fCO}_{2}=-1.5$ \\
\hline CSNF_Min & Minimum 316 rate & fCO2_5_0 & $\log \mathrm{fCO}_{2}=-5.0$ \\
\hline $\mathrm{fCO} 2 \_1 \_5$ & $\log \mathrm{fCO}_{2}=-1.5$ & ff_Max & Maximum fracture factor \\
\hline $\mathrm{fCO} 2 \_5 \_0$ & $\log \mathrm{fCO}_{2}=-5.0$ & fO2_-17 & $\log f_{2}=-17$ \\
\hline $\mathrm{fO} 2 \_-17$ & $\log \mathrm{fO}_{2}=-17$ & fO2__-69 & $\log f_{2}=-69$ \\
\hline $\mathrm{fO} 2 \_-69$ & $\log \mathrm{fO}_{2}=-69$ & fO2_Eh & Log $\mathrm{fO}_{2}=-8.7349$ (Adjusted Eh) \\
\hline fO2_Eh & Log $\mathrm{fO}_{2}=-8.7349$ (Adjusted Eh) & Goethite & Hematite is suppressed \\
\hline Goethite & Hematite is suppressed & HLWG_Max & Maximum HLWG rate \\
\hline Na_Pore & Na-porewater & LaBS_GI & LaBS Glass composition \\
\hline NiGd_Max & Maximum NiGd rate & LaBS_Max & $\begin{array}{l}\text { LaBS Glass composition with max } \\
\text { HLWG rate. }\end{array}$ \\
\hline NiGd_Min & Minimum NiGd rate & $\mathrm{Na}$ _pore & Na-porewater \\
\hline pw_10006 & Porewater 10006 & pw_10006 & Porewater 10006 \\
\hline pw_20013 & Porewater 20013 & pw_20013 & Porewater 20013 \\
\hline pw_51 & Porewater 51 & pw_51 & Porewater 51 \\
\hline SigFig & $\begin{array}{l}\text { Base case with } 3 \text { significant } \\
\text { figures }\end{array}$ & SigFig & $\begin{array}{l}\text { Base case with } 3 \text { significant } \\
\text { figures }\end{array}$ \\
\hline
\end{tabular}

NOTE: The values used for these cases can be found in Sections 6.3.1.3 and 6.6.

\subsubsection{Batch Reactor Model Inputs}

The inputs to the EQ3/6 input files are in terms of moles, centimeters, and seconds. The amounts and compositions of reactants are converted to moles, the surface areas are converted to $\mathrm{cm}^{2}$, and the degradation and flow rates are converted to moles per second. During the checking process, some minor inconsistencies were identified in the input files, and these inconsistencies are documented in Table A-2. 


\subsection{Water Compositions and Influx Rates}

The water compositions listed in Tables 4-2 and 4-3 were used as input into EQ3NR. The output from EQ3NR, the "pickup" (*.3p) file, is used as an integral part of each EQ6 input file. EQ3NR recasts the reported concentrations from Table 4-2 into molal units that are the working units of EQ6. The modeling was conducted at the temperatures presented in Table 6-3.

For the J-13 well water composition, the measured $\mathrm{pH}$ of 7.41 from Table 4-2 was changed to 7.0 based on work reported by Harrar et al. (1990 ([DIRS 100814], p. 4-9) that contains measured values of $\mathrm{pH}: 6.9$ to 7.1. The $\mathrm{HCO}_{3}{ }^{-}$was used to charge balance the solution in the EQ3 input file.

Table 6-3 provides the EQ3NR output molal concentrations of the elements used in the EQ6 input files. For code stability, each of the elements contained in the composition of any of the reactants must also be modeled as present in the fluid composition; therefore, certain elements are present in concentrations of $1.00 \mathrm{E}-16$ molal. The $\mathrm{pH}$ of the $\mathrm{J}-13$ well water is set at approximately the mean field measurement of 7 (Harrar et al. 1990 [DIRS 100814], p. 4-9). Many of the $\mathrm{pH}$ values included in that report are lab measurements typically higher than field measurements, likely due to loss of dissolved $\mathrm{CO}_{2}$ (Harrar et al. 1990 [DIRS 100814], p. 4-9).

The diffusion flux of water vapor into a breached waste package used for the base case is a range from 0.1 to 10 liters per year per waste package; this range is based on the potential range of rates depending on the temperature and $\mathrm{RH}$ in the drift. The diffusion flux of water vapor into a waste package was calculated (BSC 2004 [DIRS 169868], Table 6.6-1) to determine ingress of water vapor through stress corrosion cracks ranged from 22 moles to 239 moles (which corresponds to 0.4 liters to 4.3 liters) per year per waste package. An alternative conceptual model is developed in Section 6.4.3 to examine the relationship between the vapor influx rate and the temperature and $\mathrm{RH}$ of the drift, and the possibility of implementing this relationship in TSPA-LA. This alternative conceptual model also provides a basis for the range of vapor influx rates. The results of this alternative conceptual model build confidence in the range of rates selected for the vapor-influx case.

The range of seepage rates into a breached waste package used for the base case in this report is $0.001 \mathrm{~L} / \mathrm{yr}$ to $1,000 \mathrm{~L} / \mathrm{yr}$. These rates are based on the total potential seepage and drift wall condensation presented in Table 4-4, but only a fraction of these will actually enter a breached waste package, a fraction that is varied inside the TSPA-LA.

Table 6-3. EQ6-Input Fluid Compositions

\begin{tabular}{|l|c|c|c|c|c|c|c|}
\hline $\begin{array}{c}\text { Constituent } \\
\text { (molal) }^{\mathbf{a}}\end{array}$ & Ca-Porewater & Na-Porewater & $\begin{array}{c}\text { J-13 Well } \\
\text { Water }^{\mathbf{b}}\end{array}$ & Pure Water $^{\mathbf{c}}$ & $\mathbf{5 1}^{\mathbf{d}}$ & $\mathbf{1 0 0 0 6}^{\mathbf{d}}$ & $\mathbf{2 0 0 1 3}^{\mathbf{d}}$ \\
\hline Temperature & $25^{\circ} \mathrm{C}$ & $25^{\circ} \mathrm{C}$ & $25^{\circ} \mathrm{C}^{\mathrm{e}}$ & $25^{\circ} \mathrm{C}$ & $91.8^{\circ} \mathrm{C}$ & $56.2^{\circ} \mathrm{C}$ & $40.2^{\circ} \mathrm{C}$ \\
\hline lonic Strength & 0.011 & 0.012 & 0.0035 & N/A & $5.00 \mathrm{E}-03$ & $1.00 \mathrm{E}-02$ & $1.00 \mathrm{E}-02$ \\
\hline $\mathrm{pH}$ & 7.6 & 7.4 & 7.0 & 5.4 & 8.14 & 7.78 & 7.94 \\
\hline $\mathrm{O}$ & $5.55 \mathrm{E}+01$ & $5.55 \mathrm{E}+01$ & $5.55 \mathrm{E}+01$ & $5.55 \mathrm{E}+01$ & $5.55 \mathrm{E}+01$ & $5.55 \mathrm{E}+01$ & $5.55 \mathrm{E}+01$ \\
\hline $\mathrm{Al}$ & $1.00 \mathrm{E}-16$ & $1.00 \mathrm{E}-16$ & $1.00 \mathrm{E}-16$ & $1.00 \mathrm{E}-16$ & $6.09 \mathrm{E}-08$ & $3.73 \mathrm{E}-09$ & $1.50 \mathrm{E}-09$ \\
\hline $\mathrm{B}$ & $1.00 \mathrm{E}-16$ & $1.00 \mathrm{E}-16$ & $1.00 \mathrm{E}-16$ & $1.00 \mathrm{E}-16$ & $1.00 \mathrm{E}-16$ & $1.00 \mathrm{E}-16$ & $1.00 \mathrm{E}-16$ \\
\hline $\mathrm{Ba}$ & $1.00 \mathrm{E}-16$ & $1.00 \mathrm{E}-16$ & $1.00 \mathrm{E}-16$ & $1.00 \mathrm{E}-16$ & $1.00 \mathrm{E}-16$ & $1.00 \mathrm{E}-16$ & $1.00 \mathrm{E}-16$ \\
\hline
\end{tabular}


Table 6-3. EQ6-Input Fluid Compositions (Continued)

\begin{tabular}{|c|c|c|c|c|c|c|c|}
\hline $\begin{array}{c}\text { Constituent } \\
\text { (molal) }^{\mathrm{a}}\end{array}$ & Ca-Porewater & Na-Porewater & $\begin{array}{c}\text { J-13 Well } \\
\text { Water }\end{array}$ & Pure Water ${ }^{c}$ & $51^{\mathrm{d}}$ & $10006^{d}$ & $20013^{d}$ \\
\hline $\mathrm{Ca}$ & $2.35 \mathrm{E}-03$ & $2.02 \mathrm{E}-03$ & $3.24 \mathrm{E}-04$ & $1.00 \mathrm{E}-16$ & $7.24 \mathrm{E}-05$ & $4.40 \mathrm{E}-04$ & $5.73 \mathrm{E}-04$ \\
\hline $\mathrm{Cl}$ & 5.92E-04 & $6.77 \mathrm{E}-04$ & $2.01 \mathrm{E}-04$ & $1.00 \mathrm{E}-16$ & $7.34 \mathrm{E}-04$ & $7.12 \mathrm{E}-04$ & $5.61 \mathrm{E}-04$ \\
\hline Co & $1.00 \mathrm{E}-16$ & $1.00 \mathrm{E}-16$ & $1.00 \mathrm{E}-16$ & $1.00 \mathrm{E}-16$ & $1.00 \mathrm{E}-16$ & $1.00 \mathrm{E}-16$ & $1.00 \mathrm{E}-16$ \\
\hline $\mathrm{Cr}$ & $1.00 \mathrm{E}-16$ & $1.00 \mathrm{E}-16$ & $1.00 \mathrm{E}-16$ & $1.00 \mathrm{E}-16$ & $1.00 \mathrm{E}-16$ & $1.00 \mathrm{E}-16$ & $1.00 \mathrm{E}-16$ \\
\hline Cs & $1.00 \mathrm{E}-16$ & $1.00 \mathrm{E}-16$ & $1.00 \mathrm{E}-16$ & $1.00 \mathrm{E}-16$ & $1.00 \mathrm{E}-16$ & $1.00 \mathrm{E}-16$ & $1.00 \mathrm{E}-16$ \\
\hline $\mathrm{Cu}$ & $1.00 \mathrm{E}-16$ & $1.00 \mathrm{E}-16$ & $1.00 \mathrm{E}-16$ & $1.00 \mathrm{E}-16$ & $1.00 \mathrm{E}-16$ & $1.00 \mathrm{E}-16$ & $1.00 \mathrm{E}-16$ \\
\hline $\mathrm{F}$ & 1.79E-04 & $3.16 \mathrm{E}-04$ & 1.15E-04 & $1.00 \mathrm{E}-16$ & 9.77E-04 & 7.81E-04 & 6.43E-04 \\
\hline $\mathrm{Fe}$ & $1.00 \mathrm{E}-16$ & $1.00 \mathrm{E}-16$ & $1.00 \mathrm{E}-16$ & $1.00 \mathrm{E}-16$ & $1.00 \mathrm{E}-16$ & $1.00 \mathrm{E}-16$ & $1.00 \mathrm{E}-16$ \\
\hline $\mathrm{Gd}$ & $1.00 \mathrm{E}-16$ & $1.00 \mathrm{E}-16$ & $1.00 \mathrm{E}-16$ & $1.00 \mathrm{E}-16$ & $1.00 \mathrm{E}-16$ & $1.00 \mathrm{E}-16$ & $1.00 \mathrm{E}-16$ \\
\hline $\mathrm{H}$ & $1.11 \mathrm{E}+02$ & $1.11 \mathrm{E}+02$ & $1.11 \mathrm{E}+02$ & $1.11 \mathrm{E}+02$ & $1.11 \mathrm{E}+02$ & $1.11 \mathrm{E}+02$ & $1.11 \mathrm{E}+02$ \\
\hline$C$ & $6.76 \mathrm{E}-03$ & $8.62 \mathrm{E}-03$ & $2.49 \mathrm{E}-03$ & $3.79 \mathrm{E}-05$ & $2.04 \mathrm{E}-03$ & $6.58 \mathrm{E}-03$ & $6.92 \mathrm{E}-03$ \\
\hline $\mathrm{P}$ & $1.00 \mathrm{E}-16$ & $1.00 \mathrm{E}-16$ & $1.00 \mathrm{E}-16$ & $1.00 \mathrm{E}-16$ & $1.00 \mathrm{E}-16$ & $1.00 \mathrm{E}-16$ & $1.00 \mathrm{E}-16$ \\
\hline $\mathrm{I}$ & $1.00 \mathrm{E}-16$ & $1.00 \mathrm{E}-16$ & $1.00 \mathrm{E}-16$ & $1.00 \mathrm{E}-16$ & $1.00 \mathrm{E}-16$ & $1.00 \mathrm{E}-16$ & $1.00 \mathrm{E}-16$ \\
\hline $\mathrm{K}$ & 1.94E-04 & 1.56E-04 & $1.29 \mathrm{E}-04$ & $1.00 \mathrm{E}-16$ & 5.02E-04 & 4.55E-04 & 2.76E-04 \\
\hline $\mathrm{Li}$ & $1.00 \mathrm{E}-16$ & $1.00 \mathrm{E}-16$ & $1.00 \mathrm{E}-16$ & $1.00 \mathrm{E}-16$ & $1.00 \mathrm{E}-16$ & $1.00 \mathrm{E}-16$ & $1.00 \mathrm{E}-16$ \\
\hline $\mathrm{Mg}$ & 7.45E-04 & 1.36E-04 & 8.27E-05 & $1.00 \mathrm{E}-16$ & $2.54 \mathrm{E}-07$ & 5.19E-05 & 8.51E-05 \\
\hline $\mathrm{Mn}$ & $1.00 \mathrm{E}-16$ & $1.00 \mathrm{E}-16$ & $1.00 \mathrm{E}-16$ & $1.00 \mathrm{E}-16$ & $1.00 \mathrm{E}-16$ & $1.00 \mathrm{E}-16$ & $1.00 \mathrm{E}-16$ \\
\hline Mo & $1.00 \mathrm{E}-16$ & $1.00 \mathrm{E}-16$ & $1.00 \mathrm{E}-16$ & $1.00 \mathrm{E}-16$ & $1.00 \mathrm{E}-16$ & $1.00 \mathrm{E}-16$ & $1.00 \mathrm{E}-16$ \\
\hline $\mathrm{N}$ & 4.19E-05 & $6.61 \mathrm{E}-06$ & 1.42E-04 & $1.00 \mathrm{E}-16$ & $3.10 \mathrm{E}-04$ & $6.58 \mathrm{E}-05$ & 3.97E-05 \\
\hline $\mathrm{Na}$ & $1.70 \mathrm{E}-03$ & $5.22 \mathrm{E}-03$ & $1.99 \mathrm{E}-03$ & $1.00 \mathrm{E}-16$ & $4.29 \mathrm{E}-03$ & $7.48 \mathrm{E}-03$ & $7.31 \mathrm{E}-03$ \\
\hline $\mathrm{Ni}$ & $1.00 \mathrm{E}-16$ & $1.00 \mathrm{E}-16$ & $1.00 \mathrm{E}-16$ & $1.00 \mathrm{E}-16$ & $1.00 \mathrm{E}-16$ & $1.00 \mathrm{E}-16$ & $1.00 \mathrm{E}-16$ \\
\hline $\mathrm{Np}$ & $1.00 \mathrm{E}-16$ & $1.00 \mathrm{E}-16$ & $1.00 \mathrm{E}-16$ & $1.00 \mathrm{E}-16$ & $1.00 \mathrm{E}-16$ & $1.00 \mathrm{E}-16$ & $1.00 \mathrm{E}-16$ \\
\hline $\mathrm{Pb}$ & $1.00 \mathrm{E}-16$ & $1.00 \mathrm{E}-16$ & $1.00 \mathrm{E}-16$ & $1.00 \mathrm{E}-16$ & $1.00 \mathrm{E}-16$ & $1.00 \mathrm{E}-16$ & $1.00 \mathrm{E}-16$ \\
\hline $\mathrm{Pu}$ & $1.00 \mathrm{E}-16$ & $1.00 \mathrm{E}-16$ & $1.00 \mathrm{E}-16$ & $1.00 \mathrm{E}-16$ & $1.00 \mathrm{E}-16$ & $1.00 \mathrm{E}-16$ & $1.00 \mathrm{E}-16$ \\
\hline $\mathrm{Ru}$ & $1.00 \mathrm{E}-16$ & $1.00 \mathrm{E}-16$ & $1.00 \mathrm{E}-16$ & $1.00 \mathrm{E}-16$ & $1.00 \mathrm{E}-16$ & $1.00 \mathrm{E}-16$ & $1.00 \mathrm{E}-16$ \\
\hline$S$ & 3.75E-04 & 3.23E-04 & 1.92E-04 & $1.00 \mathrm{E}-16$ & 1.18E-04 & 3.94E-04 & 3.55E-04 \\
\hline $\mathrm{Si}$ & 6.99E-04 & 6.99E-04 & $1.02 \mathrm{E}-03$ & $1.00 \mathrm{E}-16$ & $4.15 E-03$ & 2.43E-03 & 1.79E-03 \\
\hline Tc & $1.00 \mathrm{E}-16$ & $1.00 \mathrm{E}-16$ & $1.00 \mathrm{E}-16$ & $1.00 \mathrm{E}-16$ & $1.00 \mathrm{E}-16$ & $1.00 \mathrm{E}-16$ & $1.00 \mathrm{E}-16$ \\
\hline $\mathrm{Ti}$ & $1.00 \mathrm{E}-16$ & $1.00 \mathrm{E}-16$ & $1.00 \mathrm{E}-16$ & $1.00 \mathrm{E}-16$ & $1.00 \mathrm{E}-16$ & $1.00 \mathrm{E}-16$ & $1.00 \mathrm{E}-16$ \\
\hline U & $1.00 \mathrm{E}-16$ & $1.00 \mathrm{E}-16$ & $1.00 \mathrm{E}-16$ & $1.00 \mathrm{E}-16$ & $1.00 \mathrm{E}-16$ & $1.00 \mathrm{E}-16$ & $1.00 \mathrm{E}-16$ \\
\hline $\mathrm{Zn}$ & $1.00 \mathrm{E}-16$ & $1.00 \mathrm{E}-16$ & $1.00 \mathrm{E}-16$ & $1.00 \mathrm{E}-16$ & $1.00 \mathrm{E}-16$ & $1.00 \mathrm{E}-16$ & $1.00 \mathrm{E}-16$ \\
\hline $\mathrm{Zr}$ & $1.00 \mathrm{E}-16$ & $1.00 \mathrm{E}-16$ & $1.00 \mathrm{E}-16$ & $1.00 \mathrm{E}-16$ & $1.00 \mathrm{E}-16$ & $1.00 \mathrm{E}-16$ & $1.00 \mathrm{E}-16$ \\
\hline
\end{tabular}

Sources: ${ }^{a}$ EQ3NR pickup file "Ca_trc.3p", "Na_trc.3p", "J13_trc.3p", "pure_trc.3p" (Appendix F).

${ }^{\mathrm{b}} \mathrm{C}$ levels calculated from charge balance are in agreement with measured alkalinity.

${ }^{\mathrm{C}}$ EQ3NR pickup file (Appendix F). Pure water in contact with atmospheric carbon dioxide is mildly acidic.

dDTN: MO0303MWDSCMAB.000 [DIRS 162551], 51.3p: Cross-drift water CS1000/7.3 thc6_w5_r.x/s, 10006.3p: Cross-drift water CS1000/7.3 thc6_w5_r.x/s, and 20013.3p: Cross-drift water SD-9/990.4 thc6_w6_r.x/s (TF4 directory).

${ }^{\mathrm{e}} \mathrm{J}-13$ water temperature for the is $31^{\circ} \mathrm{C}$ in the EQ3 input file, but the EQ6 run is conducted at $25^{\circ} \mathrm{C}$.

The representativeness of these incoming waters is described in more detail in Section 4.1.2 and the effects of evaporation are described in Section 6.3.1.1. 


\subsection{Metal Alloy Composition and Corrosion Rates}

The in-package chemistry model represents the metal alloys as "special reactants," in the EQ6 input files, with the compositions provided in Table 6-4 (converted to units appropriate for EQ6 in Appendix F, CSNF.xls and CDSP.xls). The steel corrosion rates given in Table 6-5 (from Table 4-8, converted to units appropriate to EQ6) represent values for the temperature range from $25^{\circ} \mathrm{C}$ to $90^{\circ} \mathrm{C}$. The values are supported by the data in DTN: MO0409SPAACRWP.000 [DIRS 172059], which cover a range of temperatures and corroding water compositions.

Table 6-4. Metal Alloy Compositions

\begin{tabular}{|c|c|c|c|c|c|c|c|}
\hline Element & $\begin{array}{c}\text { Carbon } \\
\text { Steel Type } \\
\text { A516 } \\
\text { (moles) } \\
\end{array}$ & $\begin{array}{c}\text { Neutronit } \\
\text { (moles) }\end{array}$ & $\begin{array}{c}\text { Aluminum } \\
\text { Alloy } 6061 \\
\text { (moles) }\end{array}$ & $\begin{array}{c}\text { Stainless } \\
\text { Steel } \\
\text { Type } 316 \\
\text { (moles) }\end{array}$ & $\begin{array}{c}\text { Aluminum } \\
\text { Alloy } 1100 \\
\text { (moles) }\end{array}$ & $\begin{array}{c}\text { Stainless } \\
\text { Steel Type } \\
\text { 304L } \\
\text { (moles) } \\
\end{array}$ & $\begin{array}{c}\text { NiGd } \\
\text { Alloy } \\
\text { (moles) }\end{array}$ \\
\hline$C$ & 2.33E-02 & 3.33E-03 & & 6.66E-03 & & 2.50E-03 & 8.33E-04 \\
\hline $\mathrm{Mn}$ & 1.87E-02 & & 2.73E-03 & $3.64 \mathrm{E}-02$ & 9.10E-04 & $3.64 \mathrm{E}-02$ & $9.10 \mathrm{E}-03$ \\
\hline $\mathrm{P}$ & 1.13E-03 & & & 1.45E-03 & & 1.45E-03 & 1.61E-04 \\
\hline S & 1.09E-03 & & & 9.36E-04 & & 9.36E-04 & 1.56E-04 \\
\hline $\mathrm{Si}$ & 1.03E-02 & & 2.14E-02 & 2.67E-02 & 1.60E-02 & 2.67E-02 & 2.85E-03 \\
\hline $\mathrm{Cr}$ & & 3.56E-01 & 3.75E-03 & 3.27E-01 & & 3.65E-01 & 3.04E-01 \\
\hline $\mathrm{Ni}$ & & 2.21E-01 & & 2.04E-01 & & 1.70E-01 & $1.09 \mathrm{E}+00$ \\
\hline Co & & 3.39E-03 & & & & & 3.39E-02 \\
\hline Mo & & 2.29E-02 & & 2.61E-02 & & & 1.52E-01 \\
\hline $\mathrm{N}$ & & & & 7.14E-03 & & 7.14E-03 & 7.14E-04 \\
\hline $\mathrm{Fe}$ & $1.76 \mathrm{E}+00$ & $1.16 \mathrm{E}+00$ & 1.25E-02 & 1.17E+00 & 8.95E-03 & $1.22 \mathrm{E}+00$ & 1.79E-02 \\
\hline $\mathrm{B}$ & & 1.15E-01 & & & & & \\
\hline$Z n$ & & & 3.82E-03 & & 1.53E-03 & & \\
\hline $\mathrm{Cu}$ & & & 4.33E-03 & & 1.97E-03 & & \\
\hline $\mathrm{Mg}$ & & & 4.11E-02 & & & & \\
\hline $\mathrm{Ti}$ & & & $3.13 \mathrm{E}-03$ & & & & \\
\hline $\mathrm{Al}$ & & & $3.58 \mathrm{E}+00$ & & $3.66 \mathrm{E}+00$ & & \\
\hline Gd & & & & & & & 1.27E-02 \\
\hline o & & & & & & & 3.13E-04 \\
\hline
\end{tabular}

Source: Appendix F, CSNF.Xls and CDSP.xIs, "Materials" worksheet.

NOTE: Elemental mole \% of the reactant is calculated based on 100 grams of reactant. 
Table 6-5. Metal Alloy Corrosion Rates

\begin{tabular}{|l|c|c|c|c|c|c|c|c|}
\hline $\begin{array}{c}\text { Corrosion } \\
\text { Rate }\end{array}$ & Units & $\begin{array}{c}\text { Carbon } \\
\text { Steel Type } \\
\text { A516 }\end{array}$ & Neutronit & $\begin{array}{c}\text { Aluminum } \\
\text { Alloy 6061 }\end{array}$ & $\begin{array}{c}\text { Stainless } \\
\text { Steel Type } \\
\mathbf{3 1 6}\end{array}$ & $\begin{array}{c}\text { Aluminum } \\
\text { Alloy 1100 }\end{array}$ & $\begin{array}{c}\text { Stainless } \\
\text { Steel Type } \\
\text { 304L }\end{array}$ & $\begin{array}{c}\text { NiGd } \\
\text { Alloy }\end{array}$ \\
\hline \multirow{2}{*}{ Minimum } & $\mu \mathrm{m} / \mathrm{yr}$ & 3.69 & 0.001 & 0.4 & 0.0014 & 0.4 & 0.001 & 0.0528 \\
\cline { 2 - 9 } & $\mathrm{moles} / \mathrm{s}-\mathrm{cm}^{2}$ & $9 \mathrm{E}-13$ & $2.46 \mathrm{E}-16$ & $3 \mathrm{E}-14$ & $4 \mathrm{E}-16$ & $3 \mathrm{E}-14$ & $3 \mathrm{E}-16$ & $1 \mathrm{E}-14$ \\
\hline \multirow{2}{*}{ Maximum } & $\mu \mathrm{m} / \mathrm{yr}$ & 130.7 & 29.2 & 110.9 & 14.8 & 110.9 & 39.1 & 0.0774 \\
\cline { 2 - 9 } & $\mathrm{moles} / \mathrm{s}-\mathrm{cm}^{2}$ & $4 \mathrm{E}-11$ & $7.18 \mathrm{E}-12$ & $9 \mathrm{E}-12$ & $4 \mathrm{E}-12$ & $9 \mathrm{E}-12$ & $1 \mathrm{E}-11$ & $2 \mathrm{E}-14$ \\
\hline \multirow{2}{*}{ Mean } & $\mu \mathrm{m} / \mathrm{yr}$ & 102.7 & 0.1 & 12.95 & 1.94 & 12.95 & 11.44 & 0.0528 \\
\cline { 2 - 9 } & $m o l e s / s-\mathrm{cm}^{2}$ & $3 \mathrm{E}-11$ & $2.54 \mathrm{E}-14$ & $1 \mathrm{E}-12$ & $5 \mathrm{E}-13$ & $1 \mathrm{E}-12$ & $3 \mathrm{E}-12$ & $1 \mathrm{E}-14$ \\
\hline
\end{tabular}

Source: Appendix F, CSNF.XIs and CDSP.xIs, worksheet "Rates."NOTE: $\quad{ }^{a}$ Neutronit, a borated stainless steel, was replaced by NiGd alloy in the latest CSNF design, and is only presented here for comparison.

The corrosion rates used for the base case are those within the range provided in DTN: MO0409SPAACRWP.000 [DIRS 172059]. The results show that different rates do not affect the range of the model output (maximum or minimum $\mathrm{pH}$ or ionic strength). Changes in these rates only affect the timing of the $\mathrm{pH}$ or ionic strength responses that occur when a reactant is depleted. Since the output is not time-dependent, the timing of the shifts in $\mathrm{pH}$ or ionic strength does not impact the results. The rates in Table 6-5 were compared to the atmospheric rates given in DTN: MO0407SPAPCEML.005 [DIRS 172097], spreadsheet atmospheric.xls. For the Carbon Steel Type A516, some of the atmospheric rates were higher $(1,057.18 \mu \mathrm{m} / \mathrm{yr})$ than the $130.7 \mu \mathrm{m} / \mathrm{yr}$ value given in Table 6-5. For Aluminum Alloy Types 1100 and 6061, the atmospheric rates are lower than the minimum rate given in Table 6-5. For Stainless Steel Type 316, some of the atmospheric rates were higher $(53 \mu \mathrm{m} / \mathrm{yr})$ than the $14.8 \mu \mathrm{m} / \mathrm{yr}$ value provided in Table 6-5.

The amount of metal alloy that EQ6 "adds" to the reaction during a run (moles) is the product of the coefficients (moles $/ \mathrm{s}-\mathrm{cm}^{2}$ ) in Table 6-5, the duration of the EQ6 time step(s), and the surface area $\left(\mathrm{cm}^{2}\right)$ of the reactant. Therefore, the amount of reactant added per time step $=$ moles $/ \mathrm{s}-\mathrm{cm}^{2} \times \mathrm{s} \times \mathrm{cm}^{2}$. The duration of the EQ6 time step varies depending on how quickly the given reactions reach equilibrium.

\subsection{SNF and HLWG Composition and Reaction Rates}

For EQ6 runs, the CSNF was specified to have $3.5 \mathrm{wt} \%{ }^{235} \mathrm{U}$ enrichment, $40 \mathrm{GWd} / \mathrm{MTU}$ fuel burnup, and 10,000 years of decay time BSC 2003 [DIRS 169110]. The number of elements in the fuel composition was reduced to allow EQ6 to run more efficiently. EQ6 run time increases rapidly and nonlinearly as the number of elements is increased. Therefore, the moles of $\mathrm{Ru}$ in Table 6-6 include the moles of $\mathrm{Ru}, \mathrm{Rh}, \mathrm{Pd}$, and $\mathrm{Ag}$, and the moles of $\mathrm{Gd}$ in Table 6-6 include the moles of $\mathrm{Gd}, \mathrm{Y}, \mathrm{Pr}, \mathrm{Nd}, \mathrm{Pm}, \mathrm{Sm}, \mathrm{Eu}$, and Ho in the CSNF composition (BSC 2003 [DIRS 169110]). The combined elements are expected to behave in a similar manner due to their position in the periodic table. The elements not included in the fuel composition used in the model are $\mathrm{Th}, \mathrm{Pa}, \mathrm{Am}, \mathrm{Cm}, \mathrm{Li}, \mathrm{Be}, \mathrm{As}, \mathrm{Kr}, \mathrm{Nb}$, and $\mathrm{Xe}$. The concentration of the elements excluded from the CSNF composition are estimated to be below levels which have influence over the calculated in-package chemistry; thus, their exclusion does not impact the results of the in-package chemistry model. 
Table 6-6 summarizes the composition of the CSNF and N-Reactor fuels, respectively. The CSNF is an oxide fuel while the N-Reactor fuel is a uranium metal-type fuel.

Table 6-6. CSNF and N-Reactor Compositions

\begin{tabular}{|c|c|c|}
\hline Element & $\begin{array}{c}\text { CSNF } \\
\text { (Moles/100g) }\end{array}$ & $\begin{array}{l}\text { N Reactor } \\
\text { (Moles/100g) }\end{array}$ \\
\hline U & 0.3617 & 0.420 \\
\hline $\mathrm{Np}$ & 0.0009 & $\mathrm{~N} / \mathrm{A}$ \\
\hline $\mathrm{Pu}$ & 0.0027 & $\mathrm{~N} / \mathrm{A}$ \\
\hline $\mathrm{Zr}$ & 0.0005 & $\mathrm{~N} / \mathrm{A}$ \\
\hline Mo & 0.0009 & $\mathrm{~N} / \mathrm{A}$ \\
\hline Tc & 0.0008 & $\mathrm{~N} / \mathrm{A}$ \\
\hline $\mathrm{Ru}$ & 0.0020 & $\mathrm{~N} / \mathrm{A}$ \\
\hline Cs & 0.0013 & $\mathrm{~N} / \mathrm{A}$ \\
\hline $\mathrm{Ba}$ & 0.0010 & $\mathrm{~N} / \mathrm{A}$ \\
\hline Gd & 0.0035 & $\mathrm{~N} / \mathrm{A}$ \\
\hline 0 & 0.7385 & $\mathrm{~N} / \mathrm{A}$ \\
\hline \multicolumn{3}{|l|}{ Source: } \\
\hline \multicolumn{3}{|c|}{$\begin{array}{l}\text { NOTE: Elemental mole \% of the reactant are calculated based on } \\
100 \text { grams of reactant. }\end{array}$} \\
\hline
\end{tabular}

For input into EQ6, the simplified HLWG formula is used based on $100 \mathrm{~g}$ from Table 4-5. As described in EQ6 Calculations for Chemical Degradation of N Reactor (U-metal) Spent Nuclear Fuel Waste Packages (CRWMS M\&O 2001 [DIRS 153263]), to arrive at this simplified composition, several elements in the glass composition from Defense Waste Processing Facility Wasteform and Canister Description (Baxter 1988 [DIRS 106164], Table 10), were:

- Decayed to other elements $\left({ }^{238} \mathrm{Pu}\right.$ to $\left.{ }^{234} \mathrm{U}\right)$

- Combined with other elements (Li added to $\mathrm{Na}$ ) or

- Excluded to reduce the number of elements for ease in running EQ6.

The elements not included in the model of the glass composition were $\mathrm{Ag}, \mathrm{Cs}, \mathrm{Cu}, \mathrm{Mn}, \mathrm{Cl}, \mathrm{Ni}$, $\mathrm{Pb}, \mathrm{Th}$, and Ti. These elements occur in such low quantities $(<0.2 \mathrm{wt} \%)$ that their omission has no impact on the modeling results. These minor changes were made to the basic composition to increase the efficiency of the calculations, to decrease the EQ6 run time, and to allow the use of a $\mathrm{pH}$ dependent rate law. The simplified glass composition was included in the EQ6 database as a mineral named 'SRL_Bulk' (Stoichiometric fractions less than 0.0001 moles/100 g are not read by EQ3/6).

Table 6-7 provides the CSNF reaction rate constants at various temperatures for the equations provided in CSNF Waste Form Degradation: Summary Abstraction (BSC 2004 [DIRS 169987]). The two equations in Section 4.1.3 for the dissolution of CSNF were combined into a single closed-form expression for use in EQ6. The CSNF reaction rate is a transition state theory rate law that is dependent on temperature, $\mathrm{pH}$, and bicarbonate concentration. The bicarbonate concentration is used rather than total carbonate because the CSNF rate law is insensitive to carbonate concentration in the output $\mathrm{pH}$ range (3 to 8) of the model. Figure A-1 of Appendix A 
shows the CSNF total degradation constant as a function of $\mathrm{pH}$ and derived in terms of total carbonate and $\mathrm{HCO}_{3}{ }^{-}$. This figure shows that from $\mathrm{pH} 2$ to about $\mathrm{pH} 10$, the total degradation constant is not sensitive to carbonate, but above $\mathrm{pH} 10$ the degradation constant is sensitive to carbonate. The geometric surface area (the $\log (\mathrm{A})$ term) was varied from the minimum to the maximum values provided in CSNF Waste Form Degradation: Summary Abstraction (BSC 2004 [DIRS 169987]). The first rate mechanism (described with $\mathrm{k}_{1}$ ) in Table 6-8 is dominant at $\mathrm{pH}$ values less than or equal to 6.8 , while the second rate mechanism (described with $\mathrm{k}_{2}$ ) is dominant at $\mathrm{pH}$ values greater 6.8. The rate constants in Table 6-7 were calculated using an oxygen partial pressure of 0.2 atmospheres.

Table 6-7. CSNF Transition State Theory Rate Law and Coefficients

\begin{tabular}{|c|c|c|c|c|}
\hline \multicolumn{5}{|c|}{ Total Degradation Rate Constant $=\mathrm{k}_{1}\left[\mathrm{H}^{+}\right]^{0.34}+\mathrm{k}_{2}\left[\mathrm{HCO}_{3}\right]^{0.10}\left(\mathrm{~mol} / \mathrm{cm}^{2} \cdot \mathrm{s}\right)$} \\
\hline Temperature $\left({ }^{\circ} \mathrm{C}\right)$ & $\%$ Clad Failure & $\log (A)$ & $\begin{array}{c}\text { Rate Constant } \\
\left(\mathbf{k}_{1}\right)\end{array}$ & $\begin{array}{l}\text { Rate Constant } \\
\left(\mathbf{k}_{2}\right)\end{array}$ \\
\hline \multirow[t]{9}{*}{25} & & Minimum & $2.9 \mathrm{E}-10$ & 3.7E-12 \\
\hline & & Apex & 1.1E-09 & $1.5 \mathrm{E}-11$ \\
\hline & 1 & Maximum & 2.3E-08 & $2.9 \mathrm{E}-10$ \\
\hline & & Minimum & $2.9 \mathrm{E}-09$ & 3.7E-11 \\
\hline & & Apex & $1.1 \mathrm{E}-08$ & $1.5 \mathrm{E}-10$ \\
\hline & 10 & Maximum & 2.3E-07 & $2.9 \mathrm{E}-09$ \\
\hline & & Minimum & 1.4E-08 & $1.8 \mathrm{E}-10$ \\
\hline & & Apex & $5.7 \mathrm{E}-08$ & 7.3E-10 \\
\hline & 100 & Maximum & $1.1 \mathrm{E}-06$ & $1.5 \mathrm{E}-08$ \\
\hline 40 & 100 & Apex & 8.6E-08 & 1.1E-09 \\
\hline 50 & 100 & Apex & 1.1E-07 & 1.4E-09 \\
\hline 90 & 100 & Apex & $2.6 \mathrm{E}-07$ & $3.3 \mathrm{E}-09$ \\
\hline
\end{tabular}

Source: Appendix F, CSNF.x/s.

The glass dissolution rate law is the $\mathrm{pH}$-dependent, transition state theory rate law provided in Defense HLW Glass Degradation Model (BSC 2004 [DIRS 169988], Section 8.1, Equations 40a and 40b). The first rate mechanism (described with $\mathrm{k}_{1}$ ) in Table 6-8 is dominant at $\mathrm{pH}$ values greater than or equal to 7.1, while the second rate mechanism (described with $\mathrm{k}_{2}$ ) is dominant at $\mathrm{pH}$ values below 7.1. The rate constants for various temperatures are given in Table 6-8.

Table 6-8. HLWG Transition State Theory Rate Law and N-Reactor Rate Constants

\begin{tabular}{|c|c|c|}
\hline \multicolumn{3}{|c|}{ HLWG } \\
\hline \multicolumn{3}{|c|}{ Total Degradation Rate Constant $=\mathrm{k}_{1}[\mathrm{H}+]^{-0.49}+\mathrm{k}_{2}[\mathrm{H}+]^{0.49}\left(\mathrm{~mol} / \mathrm{cm}^{2} \cdot \mathrm{s}\right)$} \\
\hline Temperature $\left({ }^{\circ} \mathrm{C}\right)$ & Rate Constant $\left(\mathbf{k}_{1}\right)$ & Rate Constant $\left(\mathbf{k}_{2}\right)$ \\
\hline 25.0 & 2.7E-22 & $3.6 \mathrm{E}-13$ \\
\hline 40.2 & 1.0E-21 & $6.6 \mathrm{E}-13$ \\
\hline 50.0 & $2.3 E-21$ & $9.5 \mathrm{E}-13$ \\
\hline 56.2 & 3.7E-21 & $1.2 \mathrm{E}-12$ \\
\hline 90.0 & $3.9 \mathrm{E}-20$ & $3.4 \mathrm{E}-12$ \\
\hline 91.8 & 4.3E-20 & 3. $6 \mathrm{E}-12$ \\
\hline
\end{tabular}


Table 6-8. HLWG Transition State Theory Rate Law and N-Reactor Rate Constants (Continued)

\begin{tabular}{|c|c|}
\hline \multicolumn{2}{|r|}{ N Reactor ${ }^{a}$} \\
\hline Temperature $\left({ }^{\circ} \mathrm{C}\right)$ & Total Degradation Constant $\mathrm{K}\left(\mathrm{mol} / \mathrm{cm}^{2} \cdot \mathrm{s}\right)$ \\
\hline 25.0 & $1.6 \mathrm{E}-10$ \\
\hline 50.0 & 1.3E-09 \\
\hline 90.0 & $2.0 \mathrm{E}-08$ \\
\hline
\end{tabular}

Source: Appendix F, CDSP.x/s, worksheet: "CDSP Rates."

NOTE: ${ }^{a}$ The $25^{\circ} \mathrm{C}$ rate for CDSP was used for all EQ6 runs (the high-temperature rates were not used in any runs).

\subsection{Waste Package Components Total Surface Areas and Moles}

Table 6-9 presents the total surface areas and moles of reactants for the waste packages as calculated in CSNF.xls and CDSP.xls. The dimensions and masses of components from the IED (BSC 2005 [DIRS 173501]) were used to calculate surface areas and amounts that were then converted into $\mathrm{cm}^{2}$ and moles for use by the EQ6 code. The methodology for these calculations is described in the associated spreadsheets (Appendix F, CSNF.xls, and CDSP.xls).

For the HLWG, the exposure factors given in Section 4.1.3.3 are: $f_{\text {exposure }}=4$ (most likely) and 17 (maximum).

Table 6-9. Total Surface Areas and Moles for the CSNF and CDSP Waste Packages

\begin{tabular}{|l|c|c|l|c|c|}
\hline \multicolumn{1}{|c|}{ Material } & $\begin{array}{c}\text { Moles per } \\
\text { Waste Package }\end{array}$ & $\begin{array}{c}\text { Surface Area } \\
\left(\mathbf{c m}^{2} \text { ) per Waste }\right. \\
\text { Package }\end{array}$ & \multicolumn{1}{c|}{ Material } & $\begin{array}{c}\text { Moles per } \\
\text { Waste Package }\end{array}$ & $\begin{array}{c}\text { Surface Area } \\
\left(\mathbf{c m}^{2}\right) \text { per Waste } \\
\text { Package }\end{array}$ \\
\hline $\begin{array}{l}\text { Carbon Steel } \\
\text { Type A-516 }\end{array}$ & 55,996 & $2,390,930$ & $\begin{array}{l}\text { Carbon Steel } \\
\text { Type A-516 }\end{array}$ & 16,510 & 331,210 \\
\hline NiGd & 21,216 & 436,275 & $\begin{array}{l}\text { Stainless Steel } \\
\text { Type 304L }\end{array}$ & 57,532 & 631,626 \\
\hline $\begin{array}{l}\text { Aluminum Type } \\
6061\end{array}$ & 4,384 & 255,701 & $\begin{array}{l}\text { Aluminum Type } \\
1100\end{array}$ & 1,245 & 92,038 \\
\hline $\begin{array}{l}\text { Stainless Steel } \\
\text { Type 316 }\end{array}$ & 107,199 & 286,237 & $\begin{array}{l}\text { Stainless Steel } \\
\text { Type 316 }\end{array}$ & 116,065 & 310,960 \\
\hline CSNF & 110,453 & $5,034,310$ & N-Reactor fuel & 136,818 & $9,577,260$ \\
\hline & & $\begin{array}{l}\text { HLWG } \\
\text { (most probable } \\
f_{\text {exposure }}\end{array}$ & 68,821 & 680,000 \\
\end{tabular}

Source: Appendix F, CSNF.xls, and CDSP.xls.

\subsection{Vapor-Influx Case: Model Inputs}

The vapor-influx cases include single component runs that examine the interactions of water with a single waste package component and the base case, which includes all of the waste package components. The vapor-influx cases use a low ratio of water to reactants to simulate vapor condensing over a large surface area. For simplicity and comparison purposes, each of the single component runs considers the liter of water to be in contact with $4,000 \mathrm{~cm}^{2}$ of available surface area $(4,000=1$ liter of water, spread over each reactant $0.25 \mathrm{~cm}$ thick). The single 
component and the water flow rate are scaled to the surface area of $4,000 \mathrm{~cm}^{2}$. The scaling calculations for the vapor-influx cases are provided in Appendix F, CSNF.xls and CDSP.xls.

\subsection{Liquid-Influx Case: Model Inputs}

The total moles and reactants for the liquid-influx models are scaled to one liter of water. The ratio of water to reactants for the liquid-influx cases is approximately half of what the ratio would be in a bathtub model. This ratio was selected to generate a model more representative than the bathtub model and more closely aligned to the conceptual implementation of the model within TSPA-LA. TSPA-LA applies the output of this model to a continuous film over the waste package interior available to transport radionuclides. The reactants are scaled to one liter of water and the total surface area. Different exposures of fuel result in different total surface areas, so each fuel exposure case is scaled differently. The water flow rates are also scaled to the total surface area. The scaling calculations for the liquid-influx cases are provided in Appendix $\mathrm{F}$, CSNF.xls and CDSP.xls.

\subsection{Mineral Controls}

In the in-package chemistry model, the minerals that precipitate from solution during an EQ6 run are determined by the code in accordance with the thermodynamics of the chemical system. Based on the modeled conditions, only certain minerals will precipitate from solution. For EQ6 to choose "realistic" precipitation phases, the analyst must assume that the database includes data for all possible relevant phases. There is no test of completeness in the construction or qualification of the database. In using the EQ6 software the analyst must decide, on the basis of prior knowledge related to the phenomena, that mineral phases will not be allowed to form in a simulation; this is called mineral "suppression." Table 6-10 lists the mineral phases suppressed in the EQ6 runs. By deciding which minerals to suppress, the analyst is implicitly deciding which minerals will form. Trial runs are often performed to allow the analyst to see first hand what minerals are forming and what minerals should be suppressed. By suppressing a phase, a decision is made based on knowledge of a phase's mode of occurrence and the relative kinetics of formation. Table 6-11 provides a list of the major minerals that were not suppressed and were observed to precipitate in the EQ6 runs for the in-package chemistry model. Phases in abundance of greater than $10^{-4}$ moles over the 20,000-year model period are included in the list.

The corrosion product assemblage is likely to be made up of some mixture of hematite, goethite, and ferrihydrite (Section 6.3). From a modeling point of view, hematite was the primary ferric iron phase allowed to form in the batch reactor simulations because it is the most thermodynamically stable mineral. Because EQ6 is a thermodynamic equilibrium code, the use of hematite over goethite leads to the lowest dissolved iron concentrations. However, goethite also requires consideration because it is kinetically favored, so goethite formation was also allowed in some cases and its impact on the in-package chemistry is examined in Section 6.6.11. Ferrihydrite is not modeled in the batch reactor simulations because it has limited thermodynamic data. The fact that the $\mathrm{pH}$ predicted by the goethite and hematite simulations are similar to each other indicates ferrihydrite use would also be similar. 


\begin{tabular}{|c|c|c|}
\hline Mineral & Chemical Formula & Justification \\
\hline Quartz & $\mathrm{SiO}_{2}$ & $\begin{array}{l}\text { Quartz is formed at higher temperatures (around } 573^{\circ} \mathrm{C} \text { ), but its extremely simple elemental makeup makes it resistant to } \\
\text { corrosion, allowing it to exist widespread as a detrital fragment in many sedimentary rocks, which is why it has been noted in so } \\
\text { many sedimentary deposits. However, other forms of } \mathrm{SiO}_{2} \text { can form as primary sedimentary minerals at low temperatures (such } \\
\text { as chalcedony) (Klein and Hurlbut } 1985 \text { [DIRS } 105907], \text { pp. } 441 \text { to } 442 \text { ). Therefore, the mineral quartz has been suppressed in } \\
\text { the EQ6 runs, allowing the lower temperature varieties of } \mathrm{SiO}_{2} \text { to form. }\end{array}$ \\
\hline Goethite & $\alpha-\mathrm{FeOOH}$ & $\begin{array}{l}\text { Goethite }(\alpha-\mathrm{FeOOH}) \text { and hematite }\left(\alpha-\mathrm{Fe}_{2} \mathrm{O}_{3}\right) \text { are the two most thermodynamically stable Fe minerals under oxidizing conditions } \\
\text { (Schwertmann and Taylor } 1995 \text { [DIRS 105959]). Goethite was suppressed in the EQ6 runs, however, suppressing goethite had } \\
\text { no effect on the results of the model as hematite is more-thermodynamically stable than goethite, and EQ6 would not allow } \\
\text { goethite to form unless hematite was suppressed. Sensitivity runs were performed where hematite was suppressed and } \\
\text { goethite allowed to form; the results are included in Section } 6.6 .11 \text { and the conclusion drawn, therein, was that the chemistry of } \\
\text { the system was largely independent of which phase was allowed to form, either goethite or hematite. }\end{array}$ \\
\hline Tridymite & $\mathrm{SiO}_{2}$ & $\begin{array}{l}\text { Tridymite exists as both } \alpha \text { and } \beta \text { types. The low-temperature } \alpha \text {-tridymite forms only from preexisting } \beta \text {-tridymite that forms in the } \\
\text { temperature range of } 870^{\circ} \mathrm{C} \text { to } 1,470^{\circ} \mathrm{C} \text { (Roberts et al. } 1990 \text { [DIRS 107105], pp. } 881 \text { to 882). }\end{array}$ \\
\hline Muscovite & $\mathrm{KAl}_{2}\left(\mathrm{Si}_{3} \mathrm{Al}\right) \mathrm{O}_{10}(\mathrm{OH}, \mathrm{F})_{2}$ & $\begin{array}{l}\text { Occurs in high temperature and/or pressure mineral assemblages and as a detrital mineral in sedimentary rocks (Roberts et al. } \\
1990 \text { [DIRS 107105], p. 586). }\end{array}$ \\
\hline Celadonite & $\mathrm{K}\left(\mathrm{Mg}, \mathrm{Fe}^{2+}\right)\left(\mathrm{Fe}^{3+}, \mathrm{Al}\right) \mathrm{Si}_{4} \mathrm{O}_{10}(\mathrm{OH})_{2}$ & $\begin{array}{l}\text { Celadonite is found in altered volcanic rocks (Roberts et al. } 1990 \text { [DIRS 107105], p. 149). Celadonite can form at low } \\
\text { temperatures, but this is due to either diagenesis of preexisting material, low-grade metamorphic processes, or concentration of } \\
\text { the liquid environment through evaporation (Li et al. } 1997 \text { [DIRS 159034]). }\end{array}$ \\
\hline Annite & $\mathrm{KFe}_{3}{ }^{2+} \mathrm{AlSi}_{3} \mathrm{O}_{10}(\mathrm{OH}, \mathrm{F})_{2}$ & Synthesized, natural occurrence uncertain (Roberts et al. 1990 [DIRS 107105], p. 32). \\
\hline Dolomite & $\mathrm{CaMg}\left(\mathrm{CO}_{3}\right)_{2}$ & $\begin{array}{l}\text { Dolomite is usually derived by secondary mineralization, from the replacement of calcium for magnesium in the calcite crystal } \\
\text { structure in Mg-rich waters (Klein and Hurlbut } 1985 \text { [DIRS 105907], p. 340). Because it rarely occurs as a primary mineral, } \\
\text { dolomite was also suppressed. }\end{array}$ \\
\hline Andradite & $\mathrm{Ca}_{3} \mathrm{Fe}_{2}\left(\mathrm{SiO}_{4}\right)_{3}$ & $\begin{array}{l}\text { Andradite is a high pressure-temperature mineral found in metamorphic and igneous rocks (Deer et al. } 1966 \text { [DIRS 102773], } \\
\text { p. 30). }\end{array}$ \\
\hline Phlogopite & $\mathrm{KMg}_{3} \mathrm{AlSi}_{3} \mathrm{O}_{10}(\mathrm{OH}, \mathrm{F})_{2}$ & Occurs chiefly in metamorphic limestones and ultrabasic rocks (Roberts et al. 1990 [DIRS 107105], p. 671). \\
\hline Talc & $\mathrm{Mg}_{3} \mathrm{Si}_{4} \mathrm{O}_{10}(\mathrm{OH})_{2}$ & $\begin{array}{l}\text { Talc is characteristically associated with low-grade metamorphic rock and hydrothermal alteration of ultrabasic rocks (Kerr } 1977 \\
\text { [DIRS 161606], p. 450). }\end{array}$ \\
\hline $\begin{array}{l}\text { Ferrite-Ca } \\
\text { Ferrite-Mg }\end{array}$ & $\begin{array}{l}\mathrm{CaFe}_{2} \mathrm{O}_{4} \\
\mathrm{MgFe}_{2} \mathrm{O}_{4}\end{array}$ & $\begin{array}{l}\text { Magnesioferrite has been found in sintered magnesite of furnace linings and other refractories (Palache et al. } 1944 \\
\text { [DIRS 163604], p. 705); not expected to form at low temperatures. }\end{array}$ \\
\hline Zircon & $\mathrm{ZrSiO}_{4}$ & $\begin{array}{l}\text { High pressure-temperature mineral. Found in sedimentary deposits as a detrital mineral (Roberts et al. } 1990 \text { [DIRS 107105], } \\
\text { p. 975). }\end{array}$ \\
\hline Soddyite & $\left(\mathrm{UO}_{2}\right)_{2} \mathrm{SiO}_{4}: 2 \mathrm{H}_{2} \mathrm{O}$ & $\begin{array}{l}\text { Suppression of soddyite had no effect on the results of this model report, since this mineral is fairly soluble under the conditions } \\
\text { simulated by the model, and it would not have precipitated in any of the EQ6 runs even if its formation had not been suppressed. } \\
\text { This suppression is discussed in more detail in Table A-1. }\end{array}$ \\
\hline $\mathrm{PuO}_{2}$ & $\mathrm{PuO}_{2}$ & $\begin{array}{l}\text { The measured solubilities of solid Pu(IV) oxide/hydroxide scatter within several orders of magnitude because of the difficulties of } \\
\text { establishing equilibrium of Pu(IV), polymerization and disproportionation reactions and the strong sorption capacities of } \mathrm{Pu}^{4+} \\
\text { (Runde } 1999 \text { [DIRS 144800]). Experimental plutonium solution concentrations during } \mathrm{PuO}_{2} \text { or } \mathrm{PWR}_{\mathrm{SNF}} \text { degradation have } \\
\text { been shown to be between the solubility of } \mathrm{PuO}_{2} \text { and that of a more soluble phase, } \mathrm{Pu}(\mathrm{OH})_{4}\left(\text { or } \mathrm{PuO}_{2} \cdot 2 \mathrm{H}_{2} \mathrm{O} \text { ) (Rai and }\right. \\
\text { Ryan } 1982 \text { [DIRS 112060]; Wilson and Bruton } 1989 \text { [DIRS 137607], Section } 3.1 \text { and Table 3). }\end{array}$ \\
\hline
\end{tabular}




\begin{tabular}{|c|c|c|}
\hline Mineral & Chemical Formula & Justification \\
\hline Hematite & $\alpha-\mathrm{Fe}_{2} \mathrm{O}_{3}$ & $\begin{array}{l}\text { Goethite }(\alpha-\mathrm{FeOOH}) \text { and hematite }\left(\alpha-\mathrm{Fe}_{2} \mathrm{O}_{3}\right) \text { are the two most-thermodynamically stable and most-widespread Fe minerals under oxidizing } \\
\text { condition. Hematite is usually found in tropical and subtropical regions where higher temperatures and lower water activities aid in its } \\
\text { formation. Hematite needs a precursor such as ferrihydrite from which it forms through dehydration and rearrangement (Schwertmann and } \\
\text { Taylor } 1995 \text { [DIRS 105959]). }\end{array}$ \\
\hline Pyrolusite & $\mathrm{MnO}_{2}$ & $\begin{array}{l}\text { Secondary mineral forming from alteration of manganite or other manganese-bearing minerals. (Roberts et al. 1990 [DIRS 107105], p. 704). } \\
\text { Manganite forms as a low-temperature hydrothermal vein mineral; in circulating meteoric water; or bog, lacustrine, or shallow marine } \\
\text { deposits (Roberts et al. } 1990 \text { [DIRS 107105], p. 524). Found as a secondary mineral in the oxidation zone at the Morro de Ferro site in } \\
\text { Brazil (Waber } 1991 \text { [DIRS } 126924]) \text {. Formed in the system } \mathrm{Mn}-\mathrm{O}_{2}-\mathrm{H}_{2} \mathrm{O} \text { at } 25^{\circ} \mathrm{C} \text { and one atmosphere (Bricker } 1965 \text { [DIRS 157873], Table 1). }\end{array}$ \\
\hline Trevorite & $\mathrm{NiFe}_{2} \mathrm{O}_{4}$ & $\begin{array}{l}\text { High pressure-temperature mineral (Roberts et al. } 1990 \text { [DIRS 107105], p. 881). Trevorite was allowed to form since nickel-substituted } \\
\text { goethite, hematite, and } \mathrm{NiFe}_{2} \mathrm{O}_{4} \text { can be synthesized at low pressure and temperature (Cornell et al. } 1992 \text { [DIRS 164025]), and Ni-substituted } \\
\text { iron oxides are not in the EQ6 database. }\end{array}$ \\
\hline Powellite & $\mathrm{Ca}(\mathrm{Mo}, \mathrm{W}) \mathrm{O}_{4}$ & $\begin{array}{l}\text { Occurs as a secondary mineral in the oxidation zones of ore deposits (Roberts et al. } 1990 \text { [DIRS 107105], p. 692). Secondary mineral, often } \\
\text { by the alteration of molybdenite, in copper deposits; deposits encountering contact metamorphism (Palache et al. } 1951 \text { [DIRS 162280], } \\
\text { p. 1,080). }\end{array}$ \\
\hline Tenorite & $\mathrm{CuO}$ & $\begin{array}{l}\text { Occurs chiefly in the oxidation zone of copper deposits, often associated with other secondary minerals. Also occurs as a sublimation } \\
\text { product deposited on lavas in volcanic regions (Roberts et al. } 1990 \text { [DIRS 107105], p. 856; Palache et al. } 1944 \text { [DIRS 163604], p. 509). } \\
\text { CuO is a component of patina formed in atmospheric and aqueous corrosion of copper alloys, though not specifically given the mineral } \\
\text { name, tenorite (Sequeira } 2000 \text { [DIRS 162970]). }\end{array}$ \\
\hline Schoepite & $\mathrm{UO}_{3}: 2 \mathrm{H}_{2} \mathrm{O}$ & $\begin{array}{l}\text { Alteration product of uraninite }\left(\mathrm{UO}_{2}\right) \text {; associated with bequerelite, curite and other secondary minerals of uranium (Palache et al. } 1944 \\
\text { [DIRS 163604], p. 628). The phase Na-boltwoodite was observed to form in some simulations where it was typically below } 10^{-4} \text { moles. It is } \\
\text { a phase expected to be stable in the corroding waste package environment (BSC } 2005 \text { [DIRS 173873], Section 6.7.2). }\end{array}$ \\
\hline Gibbsite & $\mathrm{Al}(\mathrm{OH})_{3}$ & $\begin{array}{l}\left.\text { Most common } \mathrm{Al}(\mathrm{OH})_{3} \text { polymorph (Hsu } 1995[\mathrm{DIRS} 105875]\right) . \mathrm{AlOOH} \text { are rarer than hydroxides and are considered the product of } \\
\text { weathering (Allen and Hajek } 1995 \text { [DIRS 159372]) so the } \mathrm{Al}(\mathrm{OH})_{3} \text { polymorphs are the primary ones expected to form in the waste package. }\end{array}$ \\
\hline Kaolinite & $\mathrm{Al}_{2} \mathrm{Si}_{2} \mathrm{O}_{5}(\mathrm{OH})_{4}$ & $\begin{array}{l}\text { Most common kaolin, formation at } 25^{\circ} \mathrm{C} \text { is usually slow, however it can crystallize easily from the alteration of smectites (Dixon } 1995 \\
\text { [DIRS 159374]). }\end{array}$ \\
\hline Nontronite & $\begin{array}{c}\mathrm{Na}_{0.33} \mathrm{Fe}_{2} \\
(\mathrm{Si}, \mathrm{Al})_{4} \mathrm{O}_{10}(\mathrm{OH})_{2}: \mathrm{nH}_{2} \mathrm{O}\end{array}$ & $\begin{array}{l}\text { One of the three most common smectite minerals found in soils. Smectites are common in temperate and cold climates, but may form or be } \\
\text { preserved in tropical environments where leaching is limited or drainage is restricted (Allen and Hajek } 1995 \text { [DIRS 159372]). }\end{array}$ \\
\hline $\begin{array}{l}\text { Gadolinium } \\
\text { phosphate }\end{array}$ & $\mathrm{GdPO}_{4}: 10 \mathrm{H}_{2} \mathrm{O}$ & $\begin{array}{l}\text { Gadolinium phosphate hydrates are insoluble in near-neutral } \mathrm{pH} \text { solutions (Firsching and Brune } 1991 \text { [DIRS 106357]). Monazite type } \\
\text { minerals, of which } \mathrm{GdPO}_{4} \text { is one, is usually formed under hydrothermal conditions, but studies have indicated the formation of monazites at } \\
\text { low temperatures }\left(\mathrm{Spahiu} \text { and Bruno } 1995 \text { [DIRS 103804]), and the formation of } \mathrm{GdPO}_{4}: 10 \mathrm{H}_{2} \mathrm{O} \text { is consistent with the formation of }\right. \\
\left(\mathrm{UO}_{2}\right)_{3}\left(\mathrm{PO}_{4}\right)_{2}: \mathrm{xH}_{2} \mathrm{O} \text {. }\end{array}$ \\
\hline $\begin{array}{l}\text { Uranyl } \\
\text { phosphates }\end{array}$ & $\left(\mathrm{UO}_{2}\right)_{3}\left(\mathrm{PO}_{4}\right)_{2}: \mathrm{xH}_{2} \mathrm{O}$ & $\begin{array}{l}\text { NOTE: } \mathrm{x}=4 \text { or } 6 .\left(\mathrm{UO}_{2}\right)_{3}\left(\mathrm{PO}_{4}\right)_{2}: 4 \mathrm{H}_{2} \mathrm{O} \text { is a stable phase under oxidizing conditions, low temperature, and pH values relevant for natural } \\
\text { water systems ( } \mathrm{Sandino} 1991 \text { [DIRS } 113307], \mathrm{pp} .16 \text { to } 17) \text {. }\left(\mathrm{UO}_{2}\right)_{3}\left(\mathrm{PO}_{4}\right)_{2}: 6 \mathrm{H}_{2} \mathrm{O} \text { was also allowed to form since uranyl phosphates are } \\
\text { associated with a wide range of weathered uranium deposits (Finch and Murakami } 1999 \text { [DIRS 145442]), but few uranyl phosphates are } \\
\text { included in the EQ6 database. }\end{array}$ \\
\hline Chalcedony & $\mathrm{SiO}_{2}$ & $\begin{array}{l}\text { Chalcedony readily precipitates from aqueous solutions and is frequently found lining or filling cavities in rocks (Klein and Hurlbut } 1985 \\
\text { [DIRS 105907], pp. } 441 \text { to 442). }\end{array}$ \\
\hline Baddeleyite & $\mathrm{ZrO}_{2}$ & $\begin{array}{l}\text { High-pressure-temperature mineral, found in sedimentary deposits as a detrital mineral (Roberts et al. } 1990 \text { [DIRS 107105], p. 62), also } \\
\text { formed in metamict zircon (Deer et al. } 1966 \text { [DIRS 102773], p. 15). Baddeleyite was allowed to form in the waste package as hydrolysis of } \\
\text { Zr salts leads to precipitation of poorly crystalline oxides at low temperatures (Milnes and Fitzpatrick } 1995 \text { [DIRS 105911], pp. 1,189 to } \\
1,190) \text {, and soluble Zr may be incorporated in or sorb on clay mineral surfaces (Milnes and Fitzpatrick } 1995 \text { [DIRS } 105911 \text { ], pp. } 1,185 \text { to } \\
1,186) \text {. So, it is likely that some of the zirconium released by degradation of waste package components will precipitate or be sorbed. }\end{array}$ \\
\hline
\end{tabular}




\subsubsection{Surface Complexation Model}

The surface complexation model examines the effects of the contact of the solution predicted by the batch reactor model (Section 6.3.1) with corrosion product surfaces. Waste form and waste package degradation will involve oxidation and hydration of fuel elements and steels. Carbon Steel Type A516 corrosion will be particularly rapid relative to fuel oxidation and will result in large accumulations of ferric (hydr)oxide corrosion products inside the waste package, where (hydr)oxide means any oxide, hydroxide, or oxyhydroxide that has ferric iron in it. Because there is substantially more iron in the waste packages than $U$ - the most abundant radionuclide it is reasonable to expect ferric (hydr)oxides to be the single most abundant phase in degraded waste packages.

Although the formation of large masses of ferric (hydr)oxide corrosion products is inevitable, it is difficult to predict which one will dominate the mineralogy of the whole. Goethite and hematite are expected to eventually be the most abundant iron oxides in corrosion products (Schwertmann and Cornell 1991 [DIRS 144629], Section 4.2.2). Poorly crystalline solids such as ferrihydrite $\left(\mathrm{Fe}_{5} \mathrm{HO}_{8} \cdot 4 \mathrm{H}_{2} \mathrm{O}\right)$ and $\mathrm{Fe}(\mathrm{OH})_{3}$ that form during rapid oxidation of $\mathrm{Fe}(\mathrm{II})$ and hydrolysis of $\mathrm{Fe}(\mathrm{III})$, will probably be present throughout the period of steel degradation in the waste package (Schwertmann and Cornell 1991 [DIRS 144629], Sections 1.3 and 8.1). These poorly crystalline iron oxides are unstable with respect to hematite and goethite, but their transformation is significantly inhibited or retarded by their adsorption or structural substitution, or both, of silicate, phosphate, and $\mathrm{Cr}$ (III), which are common components of the waste package solution. To summarize, the corrosion product assemblage is likely to be made up of some mixture of hematite, goethite, and ferrihydrite. However, the batch reactor model uses hematite in the base case and goethite in a sensitivity study in Section 6.6.11, as described in Section 6.3.1.3.5, but the surface complexation uses ferric (hydr)oxides, as explained in Sections 6.7 and 6.8. Properties of these phases are presented in Table 4-10.

In natural systems, less crystalline ferric (hydr)oxides appear to control the surface chemistry of soils and aquifers by coating the surfaces of other more abundant minerals. The observation that "surface coatings on larger mineral grains in soils and sediments may exhibit site densities per unit mass within the range similar to ferrihydrite even though present as fine-grained crystalline material" (Davis et al. 2002 [DIRS 168855]) is routinely observed for natural systems. Specifically, surface coatings of natural minerals appear to possess the site densities per unit mass of amorphous materials (Davis et al. 1998 [DIRS 154436]; Waite et al. 2000 [DIRS 168856]). Consequently, the surface chemistry of natural sediments is routinely modeled by assuming that the surface area of the sediments is composed entirely of ferrihydrite (Waite et al. 2000 [DIRS 168856]). The present state of knowledge suggests that a reasonable approach to approximating the buffering of $\mathrm{pH}$ by ferric (hydr)oxide corrosion products inside of breached waste packages is to estimate quantitatively the properties and effects of the resulting ferric (hydr)oxide surfaces. Thus, similar to those described by Waite et al. (2000 [DIRS 168856]), surface complexation reactions in the waste packages are treated as if they are entirely due to ferrihydrite coatings.

Reported isoelectric points ( $\mathrm{pH}_{\mathrm{IEP}}$ ) of ferric (hydr)oxides are listed in Table 4-10. The $\mathrm{pH}_{\text {IEP }}$ values from Chemistry of the Solid-Water Interface, Processes at the Mineral-Water and Particle-Water Interface in Natural Systems (Stumm 1992 [DIRS 141778]) and Surface 
Complexation Modeling, Hydrous Ferric Oxidei (Dzombak and Morel 1990 [DIRS 105483]) are considered more reliable measurements than those tabulated by Langmuir (1997 [DIRS 100051]) because Stumm (1992 [DIRS 141778]) and Dzombak and Morel (1990 [DIRS 105483]) works are devoted solely to the topic of adsorption. These $\mathrm{pH}_{\text {IEP }}$ values range from 7.3 to 8.7 (Table 4-10). Iron corrosion results in a mixture of amorphous and crystalline iron phases (Schwertmann and Cornell 1991 [DIRS 144629], Sections 4.2.1 and 4.2.2). However, the amorphous iron phases will likely dominate the surface reactions in the waste package due to their higher surface-site concentrations per mass of water. Ferrihydrite, therefore, is a good choice as an iron corrosion product to represent the mixture of iron corrosion products. This choice is consistent with the findings of Schwertmann and Cornell (1991 [DIRS 144629]) and Waite et al. (2000 [DIRS 168856]). Another reasonable choice is goethite because of its relatively high specific surface area and comparable surface site density (Table 4-10).

Based on work by Stumm (1992 [DIRS 141778]) and Dzombak and Morel (1990 [DIRS 105483]), the isoelectric points of ferrihydrite and goethite are between 7 to 8 (Table 4-10), indicating the predominant surfaces in the waste package tends to buffer the $\mathrm{pH}$ in the near-neutral range, adsorbing protons as $\mathrm{pH}$ values decrease and releasing protons as $\mathrm{pH}$ values increase. Considerable departures from the near-neutral $\mathrm{pH}$ range (i.e., outside the 5 to $9 \mathrm{pH}$ value range) have the potential of increasing radionuclide solubilities. Therefore, steps must be taken to prevent overstating the potential effects of surface reactions. This concern is addressed in Sections 6.7 and 6.8.

A calculation shows that between 10 and 40 moles of ferric (hydr)oxides (ferrihydrite, goethite, or hematite) will form per kilogram of water in almost all runs due to the degradation of Carbon Steel Type A516 and Stainless Steel Type 316 (Appendix F, CSNF.xls, "Moles Corrosion Products" tab). Roughly $30 \%$ of the ferric (hydr)oxides appears in the first 100 years due to the degradation of Carbon Steel Type A516. The batch reactor model calculates the formation of ferric (hydr)oxides and accounts for their presence in, for example, the calculation of dissolved Fe levels. Nevertheless, the batch reactor model does not consider the ability of iron(III) mineral surfaces to control in-package $\mathrm{pH}$ through the acquisition or loss of protons at low and high $\mathrm{pH}$ values, respectively. The latter effect is likely to be large as there are from 0.02 to 0.9 moles of reactive sites per mole of $\mathrm{Fe}(\mathrm{III})$ precipitated as goethite or ferrihydrite (Table 4-10, 0.02 rounded up from 0.017 ). The total amount of reactive sites available for $\mathrm{pH}$ buffering is between 0.2 moles $(10$ moles $\times 0.02)$ and 36 moles $(40$ moles $\times 0.09)$ per liter of void space. Compare this to maximal estimated acid and base loads of the batch reactor model (respectively, $\sim 10^{-3}$ moles of protons per liter [corresponds to $\mathrm{pH} \sim 3$ ] and $10^{-4}$ hydroxyls per liter [corresponds to $\mathrm{pH} \sim 10])$.

The approach is then to consider the chemical reactivity of the fuel and steel components in isolation and in combination in order to bound the fluid compositions produced by oxidation, as modeled in the batch reactor model (Section 6.3.1) and to then consider the degree to which ferric (hydr)oxide surface will affect their chemistry.

The above discussion addresses the subject matter of "Included" FEP 2.1.09.02.0A (Chemical interaction with corrosion products) and indicates how that subject matter has been included and addressed within TSPA-LA. Corrosion products are generated during the degradation of the metal alloys that make up the waste package components. Therefore, the effect of the corrosion 
products on the in-package chemistry is directly handled by the in-package surface complexation model that accounts for the effects of surface complexation of the in-package fluids with the corrosion products.

\subsubsection{Development of the Surface Complexation Demonstration Database}

The surface complexation demonstration database for hydrous ferric oxide (HFO) is developed in this section. This database is used in the surface complexation demonstration in Section 6.8, and is solely intended to build confidence in the surface complexation model discussed in Section 6.3.2, and is not an actual technical product of this model.

The data to be evaluated are the surface complexation reactions and log $\mathrm{K}$ values in Table 4-12 and include data by Dzombak and Morel (1990 [DIRS 105483]). Surface Complexation Modeling, Hydrous Ferric Oxide (Dzombak and Morel 1990 [DIRS 105483]) is a widely acclaimed treatise on surface complexation modeling for HFO.

A diffuse-layer surface complexation model for hydrous ferric oxide (HFO) is used in this report to demonstrate the adsorption effects predicted by the in-package chemistry model. Dzombak and Morel (1990 [DIRS 105483]) develop and document the model in detail in one of several adsorption models available within PHREEQC. The diffuse layer surface model was selected because it has the largest thermodynamic database for support.

The thermodynamic database used for the surface complexation demonstration is provided in Table 6-12 for ferrihydrite, in addition to the data provided in Table 4-9. The data in Tables 4-9 and 6-12 are internally consistent. These data are used as input to develop a surface complexation database. They are also used to develop a PHREEQC database for the adsorption demonstrations. In addition, several of these reactions are used to explain $\mathrm{pH}$-buffering effects.

Table 6-12. Surface Complexation Reactions

\begin{tabular}{|c|c|c|}
\hline Reaction & $\log \mathrm{K}$ & Location \\
\hline $\mathrm{HFO} \_\mathrm{sOH}+\mathrm{Ca}^{2+}=\mathrm{HFO} \_\mathrm{sOHCa}^{2+}$ & 4.97 & Table 10.1 \\
\hline $\mathrm{HFO} \_\mathrm{wOH}+\mathrm{Ca}^{2+}=\mathrm{HFO} \_\mathrm{WOCa}^{+}+\mathrm{H}^{+}$ & -5.85 & Table 10.1 \\
\hline $\mathrm{HFO} \_\mathrm{sOH}+\mathrm{Cd}^{2+}=\mathrm{HFO} \_\mathrm{sOCd} d^{+}+\mathrm{H}^{+}$ & 0.47 & Table 10.2 \\
\hline HFO_wOH $+\mathrm{Cd}^{2+}=$ HFO_wOCd ${ }^{+}+\mathrm{H}^{+}$ & -2.9 & Table 10.2 \\
\hline $\mathrm{HFO} \_\mathrm{sOH}+\mathrm{Cr}^{3+}+\mathrm{H}_{2} \mathrm{O}=\mathrm{HFO} \_\mathrm{sOCrOH}{ }^{+}+2 \mathrm{H}^{+}$ & 2.06 & Table 10.3 (and 6.43) ${ }^{\mathrm{a}}$ \\
\hline $\mathrm{HFO} \_\mathrm{sOH}+\mathrm{Cu}^{2+}=\mathrm{HFO} \_\mathrm{sOCu}{ }^{+}+\mathrm{H}^{+}$ & 2.89 & Table 10.2 \\
\hline $\mathrm{HFO} \_\mathrm{wOH}+\mathrm{Cu}^{2+}=\mathrm{HFO} \_\mathrm{wOCu}^{+}+\mathrm{H}^{+}$ & 0.6 & Table 10.5 \\
\hline $\mathrm{HFO} \_\mathrm{sOH}+\mathrm{Ni}^{2+}=\mathrm{HFO} \_\mathrm{sONi} i^{+}+\mathrm{H}^{+}$ & 0.37 & Table 10.2 \\
\hline $\mathrm{HFO} \_\mathrm{wOH}+\mathrm{Ni}^{2+}=\mathrm{HFO} \_\mathrm{wONi}{ }^{+}+\mathrm{H}^{+}$ & -2.5 & Table 10.5 \\
\hline $\mathrm{HFO} \_\mathrm{sOH}+\mathrm{Pb}^{2+}=\mathrm{HFO} \_\mathrm{sOPb}{ }^{+}+\mathrm{H}^{+}$ & 4.65 & Table 10.2 \\
\hline HFO_wOH $+\mathrm{Pb}^{2+}=$ HFO_wOPb ${ }^{+}+\mathrm{H}^{+}$ & 0.3 & Table 10.5 \\
\hline $\mathrm{HFO} \_\mathrm{sOH}+\mathrm{Sr}^{2+}=\mathrm{HFO} \_\mathrm{sOHSr}{ }^{2+}$ & 5.01 & Table 10.1 \\
\hline $\mathrm{HFO} \_\mathrm{wOH}+\mathrm{Sr}^{2+}=\mathrm{HFO} \_\mathrm{wOSr} r^{+}+\mathrm{H}^{+}$ & -6.58 & Table 10.1 \\
\hline $\mathrm{HFO} \_\mathrm{wOH}+\mathrm{Sr}^{2+}+\mathrm{H}_{2} \mathrm{O}=\mathrm{HFO} \_\mathrm{wOSrOH}+2 \mathrm{H}^{+}$ & -17.6 & Table 10.1 \\
\hline $\mathrm{HFO} \_\mathrm{sOH}+\mathrm{Zn}^{2+}=\mathrm{HFO} \_\mathrm{sOZn}{ }^{+}+\mathrm{H}^{+}$ & 0.99 & Table 10.2 \\
\hline $\mathrm{HFO} \_\mathrm{wOH}+\mathrm{Zn}^{2+}=\mathrm{HFO} \_\mathrm{wOZn}{ }^{+}+\mathrm{H}^{+}$ & -1.99 & Table 10.2 \\
\hline $\mathrm{HFO} \_\mathrm{wOH}+\mathrm{B}(\mathrm{OH})_{3}=\mathrm{HFO} \_\mathrm{wH}_{2} \mathrm{BO}_{3}+\mathrm{H}_{2} \mathrm{O}$ & 0.62 & Table 10.7 \\
\hline
\end{tabular}


Table 6-12. Surface Complexation Reactions (Continued)

\begin{tabular}{|c|c|c|}
\hline Reaction & $\log K$ & Location \\
\hline $\mathrm{HFO} \_\mathrm{wOH}+\mathrm{CrO}_{4}^{2-}+\mathrm{H}^{+}=\mathrm{HFO} \_\mathrm{wCrO}_{4}^{-}+\mathrm{H}_{2} \mathrm{O}$ & 10.85 & Table 10.8 \\
\hline $\mathrm{HFO} \_\mathrm{wOH}+\mathrm{CrO}_{4}{ }^{2-}=\mathrm{HFO} \_\mathrm{wOHCrO}_{4}{ }^{2-}$ & 3.9 & Table 10.10 \\
\hline $\mathrm{HFO} \_\mathrm{wOH}+\mathrm{SeO}_{3}{ }^{2-}+\mathrm{H}^{+}=\mathrm{HFO} \_\mathrm{wSeO}_{3}{ }^{-}+\mathrm{H}_{2} \mathrm{O}$ & 12.69 & Table 10.8 \\
\hline $\mathrm{HFO} \_\mathrm{wOH}+\mathrm{SeO}_{3}^{2-}=\mathrm{HFO} \_\mathrm{wOHSeO}_{3}^{2-}$ & 5.17 & Table 10.8 \\
\hline $\mathrm{HFO} \_\mathrm{wOH}+\mathrm{SeO}_{4}{ }^{2-}+\mathrm{H}^{+}=\mathrm{HFO} \_\mathrm{wSeO}_{4}{ }^{-}+\mathrm{H}_{2} \mathrm{O}$ & 7.73 & Table 10.8 \\
\hline $\mathrm{HFO} \_\mathrm{wOH}+\mathrm{SeO}_{4}^{2-}=\mathrm{HFO} \_\mathrm{wOHSeO}_{4}^{2-}$ & 0.8 & Table 10.8 \\
\hline $\mathrm{HFO} \_\mathrm{wOH}+\mathrm{SO}_{4}{ }^{2-}+\mathrm{H}^{+}=\mathrm{HFO} \_\mathrm{wSO}_{4}^{-}+\mathrm{H}_{2} \mathrm{O}$ & 7.78 & Table 10.8 \\
\hline $\mathrm{HFO} \_\mathrm{wOH}+\mathrm{SO}_{4}{ }^{2-}=\mathrm{HFO} \_\mathrm{wOHSO}_{4}{ }^{2-}$ & 0.79 & Table 10.8 \\
\hline $\mathrm{HFO} \_\mathrm{sOH}+\mathrm{Ba}^{2+}=\mathrm{HFO} \_\mathrm{sOHBa}{ }^{2+}$ & 5.46 & Table 10.1 \\
\hline $\mathrm{HFO} \_\mathrm{wOH}+\mathrm{Ba}^{2+}=\mathrm{HFO} \_\mathrm{wOBa}^{+}+\mathrm{H}^{+}$ & -7.2 & Table 10.5 \\
\hline $\mathrm{HFO} \_\mathrm{sOH}+\mathrm{Co}^{2+}=\mathrm{HFO} \_\mathrm{sOCo}++\mathrm{H}^{+}$ & -0.46 & Table 10.2 \\
\hline $\mathrm{HFO} \_\mathrm{wOH}+\mathrm{Co}^{2+}=\mathrm{HFO} \_\mathrm{WOCo}^{+}+\mathrm{H}^{+}$ & -3.01 & Table 10.2 \\
\hline HFO_sOH $+\mathrm{Hg}^{2+}=$ HFO_sOHg ${ }^{+}+\mathrm{H}^{+}$ & 7.76 & Table 10.2 \\
\hline $\mathrm{HFO} \_\mathrm{wOH}+\mathrm{Hg}^{2+}=\mathrm{HFO} \_\mathrm{wOHg}{ }^{+}+\mathrm{H}^{+}$ & 6.45 & Table 10.2 \\
\hline $\mathrm{HFO} \_\mathrm{wOH}+\mathrm{Mg}^{2+}=\mathrm{HFO} \_\mathrm{wOMg}^{+}+\mathrm{H}^{+}$ & -4.6 & Table 10.5 \\
\hline $\mathrm{HFO} \_\mathrm{sOH}+\mathrm{Mn}^{2+}=\mathrm{HFO} \_\mathrm{sOMn}{ }^{+}+\mathrm{H}^{+}$ & -0.4 & Table 10.5 \\
\hline $\mathrm{HFO}_{-} \mathrm{wOH}+\mathrm{Mn}^{2+}=\mathrm{HFO} \_\mathrm{wOMn}^{+}+\mathrm{H}^{+}$ & -3.5 & Table 10.5 \\
\hline $\mathrm{HFO} \_\mathrm{sOH}+\mathrm{NpO}_{2}{ }^{2+}=\mathrm{HFO} \_\mathrm{sONpO}_{2}{ }^{+}+\mathrm{H}^{+}$ & 5.9 & Table 10.5 \\
\hline $\mathrm{HFO} \_\mathrm{wOH}+\mathrm{NpO}_{2}{ }^{2+}=\mathrm{HFO} \_\mathrm{wONpO}_{2}{ }^{+}+\mathrm{H}^{+}$ & 3.6 & Table 10.5 \\
\hline $\mathrm{HFO} \_\mathrm{sOH}+\mathrm{PuO}_{2}^{2+}=\mathrm{HFO} \_\mathrm{sOPuO}_{2}^{+}+\mathrm{H}^{+}$ & 5.4 & Table 10.5 \\
\hline $\mathrm{HFO} \_\mathrm{wOH}+\mathrm{PuO}_{2}{ }^{2+}=\mathrm{HFO} \_\mathrm{wOPuO}_{2}{ }^{+}+\mathrm{H}^{+}$ & 3 & Table 10.5 \\
\hline $\mathrm{HFO} \_\mathrm{sOH}+\mathrm{UO}_{2}^{2+}=\mathrm{HFO} \_\mathrm{sOUO}_{2}{ }^{+}+\mathrm{H}^{+}$ & 5.2 & Table 10.5 \\
\hline $\mathrm{HFO} \_\mathrm{wOH}+\mathrm{UO}_{2}^{2+}=\mathrm{HFO} \_\mathrm{wOUO}_{2}{ }^{+}+\mathrm{H}^{+}$ & 2.8 & Table 10.5 \\
\hline $\mathrm{HFO} \_\mathrm{wOH}+\mathrm{AsO}_{4}{ }^{3-}=\mathrm{HFO} \_\mathrm{wOHAsO}_{4}{ }^{3-}$ & 10.58 & Table 10.6 \\
\hline $\mathrm{HFO} \_\mathrm{wOH}+\mathrm{AsO}_{4}{ }^{3-}+2 \mathrm{H}^{+}=\mathrm{HFO} \_\mathrm{wHAsO}_{4}^{-}+\mathrm{H}_{2} \mathrm{O}$ & 23.51 & Table 10.6 \\
\hline $\mathrm{HFO} \_\mathrm{wOH}+\mathrm{AsO}_{4}{ }^{3-}+3 \mathrm{H}+=\mathrm{HFO} \_\mathrm{wH}_{2} \mathrm{AsO}_{4}+\mathrm{H}_{2} \mathrm{O}$ & 29.31 & Table 10.6 \\
\hline $\mathrm{HFO} \_\mathrm{wOH}+\mathrm{F}^{-}+\mathrm{H}^{+}=\mathrm{HFO} \_\mathrm{wF}+\mathrm{H}_{2} \mathrm{O}$ & 8.7 & Table 10.10 \\
\hline HFO_wOH + F'= HFO_wOHF & 1.6 & Table 10.10 \\
\hline $\mathrm{HFO} \_\mathrm{wOH}+\mathrm{H}_{3} \mathrm{AsO}_{3}=\mathrm{HFO} \_\mathrm{wH}_{2} \mathrm{AsO}_{3}+\mathrm{H}_{2} \mathrm{O}$ & 5.41 & Table 10.7 \\
\hline $\mathrm{HFO} \_\mathrm{wOH}+\mathrm{PO}_{4}{ }^{3-}+2 \mathrm{H}^{+}=\mathrm{HFO} \_\mathrm{wHPO}_{4}^{-}+\mathrm{H}_{2} \mathrm{O}$ & 25.39 & Table 10.6 \\
\hline $\mathrm{HFO} \_\mathrm{wOH}+\mathrm{PO}_{4}{ }^{3-}+3 \mathrm{H}+=\mathrm{HFO} \_\mathrm{wH}_{2} \mathrm{PO}_{4}+\mathrm{H}_{2} \mathrm{O}$ & 31.29 & Table 10.6 \\
\hline $\mathrm{HFO} \_\mathrm{wOH}+\mathrm{PO}_{4}{ }^{3-}+\mathrm{H}^{+}=\mathrm{HFO} \_\mathrm{wPO}_{4}{ }^{2-}+\mathrm{H}_{2} \mathrm{O}$ & 17.72 & Table 10.6 \\
\hline $\mathrm{HFO} \_\mathrm{wOH}+\mathrm{SiO}_{3}{ }^{2-}+\mathrm{H}^{+}=\mathrm{HFO} \_\mathrm{wSiO}_{3}^{-}+\mathrm{H}_{2} \mathrm{O}$ & 15.9 & Table 10.10 \\
\hline $\mathrm{HFO} \_\mathrm{wOH}+\mathrm{SiO}_{3}{ }^{2-}=\mathrm{HFO} \_\mathrm{wOHSiO}_{3}{ }^{2-}$ & 8.3 & Table 10.10 \\
\hline $\mathrm{H}_{2} \mathrm{SiO}_{3}^{0}=\mathrm{HSiO}_{3}^{-}+\mathrm{H}^{+}$ & -9.86 & Table 10.9 \\
\hline $\mathrm{HSiO}_{3}{ }^{-}=\mathrm{SiO}_{3}{ }^{2-}+\mathrm{H}^{+}$ & -13.1 & Table 10.9 \\
\hline
\end{tabular}

Source: Dzombak and Morel 1990 [DIRS 105483].

NOTE: $\quad{ }^{a}$ There is a charge balance error in the reaction described by Dzombak and Morel (1990 [DIRS 105483], Table 10.3). Reaction is taken from Table 6.43 instead.

\subsection{Evaluation of Experimental Data}

Dzombak and Morel (1990 [DIRS 105483], Chapter 4) dedicate an entire chapter to the careful and thorough compilation of experimental data. Dzombak and Morel (1990 [DIRS 105483]) established a rigorous, systematic procedure to identify and collect all available adsorption data from refereed papers, books, technical reports, and dissertations. These data were then scrutinized for the critical information needed to determine whether to accept or reject the data 
for the purpose of deriving surface complexation model reactions. The decision to accept or reject a given data set was based on reliability and/or usefulness of the data. Critical information included (Dzombak and Morel (1990 [DIRS 105483], p. 66):

- Method of preparation of the HFO

- Composition of the electrolyte solution

- Temperature

- Type of reaction vessel

- Methods employed to avoid carbonate contamination

- Sorbate/sorbent ratio

- Equilibration time

- Method of solid-liquid separation

- Analytical methods

- Method for controlling $\mathrm{pH}$

- Other potentially important factors.

Experimental details for each data set, whether accepted or rejected, are included in Surface Complexation Modeling, Hydrous Ferric Oxide (Dzombak and Morel (1990 [DIRS 105483], Appendix A).

Dzombak and Morel (1990 [DIRS 105483]) did not include carbonate as one of the sorbates in their model. The carbonate adsorption reactions in Table 4-9 are obtained from work by Appelo et al. (2002 [DIRS 168168]). These reactions were derived from experimental data presented in a paper by Zachara et al. (1987 [DIRS 105963]), one work Dzombak and Morel (1990 [DIRS 105483]) accepted for its experimental chromate adsorption data. Based on the critical information necessary to accept or reject the data set (as outlined above), carbonate adsorption data from the report by Zachara et al. (1987 [DIRS 105963]) was found to satisfy the data criterion.

Several of the sorbates and their adsorption reactions in Tables 4-9 and 6-12 are estimated based on linear free energy relationships (Dzombak and Morel 1990 [DIRS 105483], Chapter 10). Their effects are reflected in this report's results (Section 6.8.4).

\subsection{Evaluation of Accuracy of Derived Surface Complexation Reactions}

The accuracy of the surface complexation database is evaluated by comparing model predictions to the experimental data (i.e., to those presented by Dzombak and Morel 1990 [DIRS 105483] and Appelo et al. 2002 [DIRS 168168]).

Surface complexation reactions were considered acceptable if:

- Predictions of percent adsorbed within 20\% (absolute) of experimental data for at least $90 \%$ of the experimental data for a given sorbate

- $\mathrm{pH}$ predicted within $0.5 \mathrm{pH}$ unit for at least $90 \%$ of the surface hydrolysis experimental data. 
The percentage of experimental data within these limits was determined for each sorbate by examining the graphs presented by Dzombak and Morel (1990 [DIRS 105483]) and Appelo et al. (2002 [DIRS 168168]). On each graph by Dzombak and Morel (1990 [DIRS 105483]), the differences between predictions and measurements were determined by comparing the data points to the dashed lines. The dashed lines represent predictions based on the derived surface complexation database. The comparisons were performed vertically to determine the differences between predicted and measured adsorption for the known parameter on the $\mathrm{x}$-axis, usually $\mathrm{pH}$. For carbonate adsorption, experimental data were vertically compared to predictions represented by the solid lines in the graph presented by Appelo et al. (2002 [DIRS 168168], p. 3,097). The results are summarized in Table 6-13 for the sorbates with experimental adsorption data.

Table 6-13. Results of Accuracy Evaluation

\begin{tabular}{|c|c|c|c|c|c|}
\hline Sorbate & $\begin{array}{l}\text { Accuracy } \\
\text { Criterion }\end{array}$ & Location & Sorbate & $\begin{array}{l}\text { Accuracy } \\
\text { Criterion }\end{array}$ & Location \\
\hline $\mathrm{Pb}^{2+}$ & Met & pp. 108 to 109 & $\mathrm{H}^{+}$ & Met & pp. 96 to 100 \\
\hline $\mathrm{Zn}^{2+}$ & Met & pp. 113 to 123 & $\mathrm{PO}_{4}{ }^{3-}$ & Not Met $^{a}$ & pp. 195 to 199 \\
\hline $\mathrm{Cd}^{2+}$ & Met & pp. 127 to 138 & $\mathrm{AsO}_{4}{ }^{2-}$ & Not Met & pp. 202 to 204 \\
\hline $\mathrm{Hg}^{2+}$ & Not Met & pp. 145 to 147 & $\mathrm{VO}_{4}{ }^{3-}$ & Met & pp. 207 to 212 \\
\hline $\mathrm{Cu}^{2+}$ & Met & pp. 150 to 154 & $\mathrm{AsO}_{3}{ }^{2-}$ & Not Met & pp. 214 to 216 \\
\hline $\mathrm{Ag}^{+}$ & Not Met & pp. 156 to 158 & $\mathrm{~B}(\mathrm{OH})_{3}$ & Met & p. 218 \\
\hline $\mathrm{Ni}^{2+}$ & Met & p. 160 & $\mathrm{SO}_{4}{ }^{2-}$ & Met & p. 220 \\
\hline $\mathrm{Co}^{2+}$ & Not Met & pp. 166 to 169 & $\mathrm{SeO}_{4}{ }^{2-}$ & Met & pp. 222 to 225 \\
\hline $\mathrm{Cr}^{3+}$ & Met & pp. 171 to 172 & $\mathrm{SeO}_{3}{ }^{2-}$ & Met & p. 227 \\
\hline $\mathrm{Ca}^{2+}$ & Met & pp. 174 to 178 & $\mathrm{~S}_{2} \mathrm{O}_{3}{ }^{2-}$ & Met & p. 229 \\
\hline $\mathrm{Sr}^{2+}$ & Met & pp. 181 to 186 & $\mathrm{CrO}_{4}{ }^{2-}$ & Met & pp. 232 to 238 \\
\hline $\mathrm{Ba}^{2+}$ & Not Met & pp. 188 to 190 & $\mathrm{CO}_{3}^{2-}$ & Met & p. $3,097^{\mathrm{b}}$ \\
\hline Source: & \multicolumn{5}{|c|}{ Dzombak and Morel 1990 [DIRS 105483]. } \\
\hline NOTES: & \multicolumn{5}{|c|}{$\begin{array}{l}\text { a No graphs provide percent adsorbed versus } \mathrm{pH} \text { for } \mathrm{PO}_{4}{ }^{3-} \text {. } \\
{ }^{b} \text { From Appelo et al. } 2002 \text { [DIRS 168168]. }\end{array}$} \\
\hline
\end{tabular}

\subsubsection{Thermodynamic Database for PHREEQC}

YMP_R3.dat is the thermodynamic database developed for the PHREEQC calculations performed in Section 6.8. This database is developed in this section and documented in DTN: MO0403SPAYMPR3.000. This DTN is used in the surface complexation demonstration in Section 6.8, and is solely intended to build confidence in the surface complexation model discussed in Section 6.3.2, and is not an actual technical product of this model. It is nearly identical to the data0.ymp.R2 database for EQ3/6, except for the following:

- It is in PHREEQC database format

- It only has equilibrium constants for $25^{\circ} \mathrm{C}$ and, therefore, is only valid for calculations at $25^{\circ} \mathrm{C}$

- The error in the $\log \mathrm{K}$ value and formula of solid $\mathrm{PuO}_{2}(\mathrm{OH})_{2} \cdot \mathrm{H}_{2} \mathrm{O}$ was corrected 
- Acetic acid, ethane, formate, formaldehyde, formic acid, methane, methanol, $\mathrm{H}_{2} \mathrm{O}_{2}$, and $\mathrm{HO}_{2}{ }^{-}$have been removed

- Nine $\mathrm{CaO}-\mathrm{Al}_{2} \mathrm{O}_{3}$ minerals, $1.7 \mathrm{Ca}(\mathrm{OH})_{2} \mathrm{SiO}_{2} \cdot 0.917 \mathrm{H}_{2} \mathrm{O}, \mathrm{Be}_{13} \mathrm{U}$, friedl salt, hydrogarnet, and $\mathrm{U}_{3} \mathrm{P}_{4}$ have been removed

- USe, $\mathrm{USe}_{2}$ (alpha), $\mathrm{USe}_{2}$ (beta), and $\mathrm{USe}_{3}$ mineral phases have been renamed to $\mathrm{SeU}$, $\mathrm{Se}_{2} \mathrm{U}\left(\right.$ alpha), $\mathrm{Se}_{2} \mathrm{U}($ beta $)$, and $\mathrm{Se}_{3} \mathrm{U}$

- Surface complexation reactions documented in DTN: MO0403SPASURCR.000 have been added to the database.

Other minor additions and modifications (due to differences in how the EQ3/6 and PHREEQC codes work) are documented in the comment lines of the YMP_R3.dat file.

This database was initially translated from the data0.ymp.R2 database in DTN: MO0210SPATHDYN.000 [DIRS 160229]. First, EQPT from EQ3/6, version 7.2b (STN: UCRL-MA-110662), was used on a personal computer using Windows 95 operating system to generate a datalf.ymp file from the data0.ymp.R2 database. To translate this file to the PHREEQC format, the organic species and reactions listed above were removed and transl (transl V2.0, STN: 10251-2.0-00 [DIRS 155029]) was then used to perform the translation on a personal computer using Windows 98 operating system. The translation produced files named phreeqc.ymp (the database translation into PHREEQC) and fix_redox.out (a list of redox reactions requiring correction in the phreeqc.ymp file. As instructed in the transl software management report (BSC 2001 [DIRS 154880]), the first file was corrected based on the redox comments in the second file. These files can be found in Appendix F.

Two additional steps were involved in the final production of the $Y M P_{-}$R3. dat database. First, the phreeqc.ymp file described above (YMP_R3.dat database in this step) was updated to match the changes made in the final data0.ymp.R2 EQ3/6 database (DTN: MO0302SPATHDYN.000 [DIRS 161756]) and to correct the error in the log $\mathrm{K}$ value and formula of solid $\mathrm{PuO}_{2}(\mathrm{OH})_{2} \mathrm{H}_{2} \mathrm{O}$. Second, the surface complexation reactions documented in DTN: MO0403SPASURCR.000 were added to the database.

The complete YMP_R3.dat database, which includes the surface complexation database for HFO, is documented in DTN: MO0403SPAYMPR3.000.

\subsection{ALTERNATIVE CONCEPTUAL MODELS}

\subsubsection{Alternative Conceptual Model I}

The interior of a waste package is spatially heterogeneous with respect to composition; therefore, a stream of water traveling vertically downward through the cross-sectional interior of a waste package would encounter different materials at different times. Along this flow path and at a given time, water molecules would react with the solid or solids to which they were immediately adjacent, resulting in a water stream with a variable composition along its flow path. This conceptual model could be viewed as a one-dimensional column composed of $n$ cells in which the reactants in each cell represent the waste package components in vertical cross section of the 
waste package - this model would eliminate the constraint of the EQ6 solid-centered flow-through mode, used in the in-package chemistry model, of a well-mixed batch reactor. This alternative conceptual model would also provide spatial information on the chemistry inside of a breached waste package, information not used by the total system performance assessment for the license application.

The vapor-influx model results showed (Section 6.5.1) the mixing model actually provides a good alternative to the more-complex Alternative Conceptual Model I, as the waste package materials tend to have an overwhelming effect on the in-package chemistry regardless of mixing.

\subsubsection{Alternative Conceptual Model II}

Seepage entering a breached waste package is likely to vary in composition as a function of time (i.e., as the prevailing conditions in the drift and engineered barrier system (EBS) vary over time). Therefore, a conceptual model that implemented a continuously varying input fluid composition would be more representative than the current in-package chemistry model, in which the input fluid compositions are constant over time. The liquid-influx model showed model response was largely insensitive to input water composition because the effect of the waste package materials on the in-package chemistry exerted much more control than the input water composition (Section 6.5.2). The alternative conceptual models are listed in Table 6-14.

Table 6-14. Alternative In-Package Chemistry Conceptual Models

\begin{tabular}{|l|l|l|}
\hline Alternative Conceptual Model & \multicolumn{1}{|c|}{ Key Features } & \multicolumn{1}{|c|}{ Screening Assessment and Basis } \\
\hline Alternative Conceptual Model I & $\begin{array}{l}\text { Waste package is compositionally } \\
\text { heterogeneous }\end{array}$ & $\begin{array}{l}\text { Vapor-influx model showed resulting } \\
\text { chemical effects of individual waste } \\
\text { package components were comparable to } \\
\text { those of their ensembles (Section 6.5.1) }\end{array}$ \\
\hline Alternative Conceptual Model II & $\begin{array}{l}\text { Composition of seepage entering a } \\
\text { waste package is likely to vary as } \\
\text { a function of changing conditions } \\
\text { in the unsaturated zone and drift } \\
\text { environments }\end{array}$ & $\begin{array}{l}\text { The liquid-influx model showed wide } \\
\text { compositional ranges in the seepage } \\
\text { composition had little influence on the } \\
\text { resulting in-package chemistry } \\
\text { (Section 6.5.2) }\end{array}$ \\
\hline
\end{tabular}

Although these alternative models have been considered, this report demonstrates the current base-case model is sufficient, robust, and adequate for its intended purpose.

\subsubsection{Alternative Conceptual Model III - Diffusion of Vapor into the Waste Package}

These calculations determine the amount of water available for sorption and precipitation in the waste package from diffusion of water vapor through stress corrosion cracks. The alternative conceptual model is developed here to lay the foundation for a future model in which the vapor influx ionic strength abstraction can be implemented within TSPA-LA as a function relative humidity and temperature. This calculation is also performed to show that the range of values for vapor influx ( 0.1 to 10 liter $\mathrm{H}_{2} \mathrm{O} / \mathrm{yr}$ per waste package) presented in Section 6.10 .2 is reasonable and valid. To ensure this range is defensible, two methods of calculation were used. The rate of diffusion of water vapor through the stress corrosion cracks into the waste package was calculated using Fick's First Law (Bird et al. 1960 [DIRS 103524], p. 503) and Stefan Tube Equations (Cutlip and Shacham 2000 [DIRS 163339], pp. 259 to 263). For both methodologies, 
the rate of diffusion is calculated over the range of relative humidity and temperature in which diffusion of water vapor into the package is expected to occur. A range of water fluxes can then be determined based on the anticipated waste package temperature and relative humidity provided by Multiscale Thermohydrologic Model (BSC 2005 [DIRS 173944], Figure 6.3-69).

For both calculations, the humidity is assumed to be zero inside the waste package. This maximizes the water vapor concentration gradient between the exterior and interior of the waste package, and considers all humidity entering the waste package is immediately consumed by corrosion reactions. Because this assumption maximizes the amount of water available within the waste package available for reactions and transport, it is, therefore, bounding. The assumption of zero relative humidity inside the waste package in this section is only for the purposes of maximizing the calculated water vapor fluxes; in the EQ6 modeling, ample water is available to react with the degrading materials, allowing in-package chemistry to be modeled. The amount of water available to react in the EQ6 modeling as it pertains to this vapor influx calculation is discussed in more detail in Section 6.3.1.1 (Scaling to 1 Liter and Code Implementation).

\subsubsection{Fick's First Law Diffusion Calculation}

Fick's First Law can be applied to calculate the diffusion of water vapor through stagnant air in the stress corrosion cracks. As shown by Equation 1, Fick's First Law states species A diffuses (moves relative to the mixture) in the direction of the decreasing mole fraction of A, just as heat flows by conduction in the direction of decreasing temperature (Bird et al. 1960 [DIRS 103524], pp. 502 to 503). The calculation of water vapor flux through the stress corrosion crack is described in detail in EBS Radionuclide Transport Abstraction (BSC 2004 [DIRS 169868], Section 6.6.2).

The rate of diffusion for Fick's First Law for a binary system with constant molar density is (BSC 2004 [DIRS 169868], Section 6.6.2):

$$
\begin{gathered}
q=D_{A B} A_{S C C} \frac{\partial C_{W V}}{\partial x} \\
=D_{A B} A_{S C C} \frac{C_{W V}}{\Delta x}
\end{gathered}
$$

where,

$$
\begin{aligned}
q= & \text { diffusive flux }\left(\mathrm{mol} \mathrm{s}^{-1}\right) \text { of water vapor into the waste package } \\
A= & \text { water vapor } \\
B= & \text { air } \\
D_{A B}= & \text { diffusion coefficient }\left(\mathrm{cm}^{2} \mathrm{~s}^{-1}\right) \text { of water vapor in air } \\
A_{S C C}= & \text { cross-sectional area }\left(\mathrm{cm}^{2}\right) \text { of stress corrosion cracks through which water vapor } \\
& \text { can diffuse }
\end{aligned}
$$


$C_{W V}=$ concentration of water vapor in air outside the waste package $\left(\mathrm{mol} / \mathrm{cm}^{3}\right)$

$\Delta x=$ diffusion distance $(2.54 \mathrm{~cm})$ for the thickness of the waste package outer lid (BSC 2004 [DIRS 170710], Detail A).

As described in EBS Radionuclide Transport Abstraction (BSC 2004 [DIRS 169868], Section 6.6.2) and in Appendix $\mathrm{H}$, the parameters $D_{A B}$ and $C_{W V}$ are dependent on temperature and relative humidity.

\subsubsection{Stefan Tube Diffusion Calculations}

In contrast to Fick's First Law that calculates the flux solely due to diffusion, a Stefan Tube calculation determines the flux based on diffusion and bulk flow (Bird et al. 1960 [DIRS 103524], pp. 519 - 526; Cutlip and Shacham 2000 [DIRS 163339], pp. 259 - 261). A Stefan Tube calculation is used to calculate flux for situations with fast evaporation and potentially concentrated solutions (Cussler, 1997 [DIRS 111468] p. 58). It is commonly referred to as "diffusion through a stagnant gas film," and has been commonly used for experimental determination of gas diffusivities (Bird et al. 1960 [DIRS 103524] Section 17.2).

$$
\begin{aligned}
& \underbrace{N_{A}}_{\text {flux }}=\underbrace{-D_{A B} C \frac{d x_{A}}{d z}}_{\text {diffusion }+ \text { bulk flow (convection) }}+\underbrace{\frac{C_{A}}{C}\left(N_{A}+N_{B}\right)} \\
& \text { flow }
\end{aligned}
$$

where,

$$
\begin{aligned}
& A=\text { water vapor } \\
& B=\text { air } \\
& N_{A}=\text { flux of } A \text { normalized to } 1 \mathrm{~cm}^{2}\left(\mathrm{~mol} / \mathrm{cm}^{2} \cdot \mathrm{s}\right) \\
& C=\text { total concentration }\left(\mathrm{mol} / \mathrm{cm}^{3}\right) \\
& \mathrm{x}_{\mathrm{A}}=\text { mole fraction of species A } \\
& D_{A B}=\text { diffusion coefficient }\left(\mathrm{cm}^{2} \mathrm{~s}^{-1}\right) \text { of water vapor in air } \\
& C_{A}=\text { concentration of } A\left(\mathrm{~mol} / \mathrm{cm}^{3}\right) \\
& N_{B}=\text { flux of } B\left(\mathrm{~mol} / \mathrm{cm}^{2} \cdot \mathrm{s}\right)
\end{aligned}
$$

The derivation of the analytical solution to this equation is documented by Bird et al. (1960 [DIRS 103524], pp. 522 to 526) and Cutlip and Shacham (2000 [DIRS 163339], pp. 260 to 261). The water vapor flux for the Stefan Tube based on the analytical solution is provided below and described in Appendix H. 
The entire system is presumed to be at constant temperature and pressure. Gases A and B are assumed to be ideal; the total concentration, $C$, constant; and component $\mathrm{B}$ stagnant. The analytical solution for the fluxes (Bird et al. 1960 [DIRS 103524], Eq. 17.2-15):

$$
\left.N_{A z}\right|_{z=z 1}=\frac{D_{A B} C}{\left(z_{2}-z_{1}\right)\left(x_{B}\right)_{l m}}\left(x_{A 1}-x_{A 2}\right)
$$

where,

$$
\left(x_{B}\right)_{l m}=\frac{\left(x_{B 2}-x_{B 1}\right)}{\ln \left(x_{B 2} / x_{B 1}\right)}=\frac{\left(x_{A 1}-x_{A 2}\right)}{\ln \left[\left(1-x_{A 2}\right) /\left(1-x_{A 1}\right)\right]}
$$

where,

$$
\begin{aligned}
& D_{A B} \text { and } C=\text { as defined in Equation 6-2. } \\
& z_{1}=\begin{array}{l}
\text { distance just above the liquid or vapor reservoir (the external environment outside } \\
\text { the package) }
\end{array} \\
& z_{2}=\text { distance of the end of the Stefan Tube (the interior of the waste package) } \\
& x_{A 1}=\text { concentration of gas A at location } z_{1} \\
& x_{A 2}=\text { concentration of gas A at location } z_{2} .
\end{aligned}
$$

Cutlip and Shacham (2000 [DIRS 163339], Figure 7-1) illustrated the relationship between the location point and concentration of A.

\subsubsection{Results}

The results of the Fick's First Law and Stefan Tube calculations are shown in Figure 6-1. For both methodologies, the vapor flux was calculated for a temperature range of $30^{\circ} \mathrm{C}$ to $96^{\circ} \mathrm{C}$ and a range of relative humidity from 30 to 100 percent. Comparing the results of the two methodologies shows that low temperatures flux values calculated using the Stefan Tube are less than those calculated using Fick's First Law. However, as shown at high relative humidities 80, 90,95 , and 100 at high temperatures $94^{\circ} \mathrm{C}, 91^{\circ} \mathrm{C}, 89^{\circ} \mathrm{C}$, and $88^{\circ} \mathrm{C}$, respectively, the Stefan Tube calculated fluxes cross over and become higher than the values calculated based on Fick's First Law. This can be confirmed by comparing the tabulated results for the fluxes provided in Tables H.1-1 and H.2-1. 


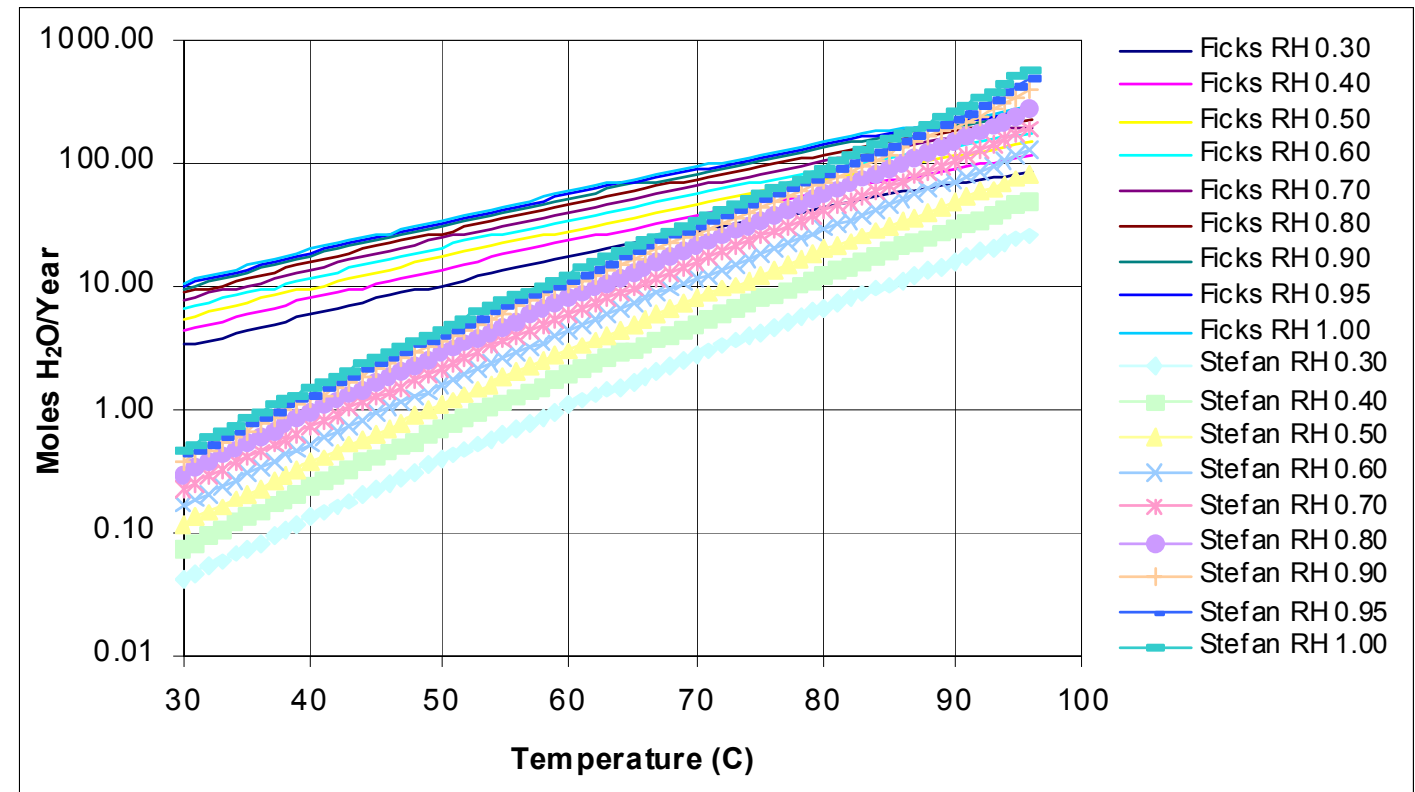

Source: Fick's vs Stefan Tube - Flux vs Temp.xls.xls.xls (Appendix F ISpreadsheets)

Figure 6-1. Vapor Influx Rates for Fick's First Law and Stefan Tube

Multiscale Thermohydrologic Model (BSC 2005 [DIRS 173944], Figure 6.3-69) illustrates the range of temperature and relative humidity anticipated outside a cooling waste package. As shown in Figure 6-2, four points that bounded the observed range in temperature and humidity were selected. These bounding points were then used to calculate the vapor diffusion flux. Because these bounding four points bracket the range of observed variation in temperature and humidity, they also bound the range of water vapor flux.

Figure 6-2 shows the calculated water vapor flux bounding the range of temperature versus relative humidity trajectories for all waste packages during cooldown, accounting for uncertainty in host-rock thermal conductivity and percolation flux. Higher vapor influx rates correspond to high temperatures and relative humidity (upper right of the bounded region of Figure 6-2), while lower influx rates are observed for low temperatures and relative humidity. At $95^{\circ} \mathrm{C}$ and $95 \%$ to $35 \%$ relative humidity, all calculated vapor fluxes, based on either Fick's First Law or Stefan Tube, fall above the minimum vapor influx of 0.1 liter/year (Section 6.10.2). However, at $40^{\circ} \mathrm{C}$, the values calculated based on Fick's First Law exceed the minimum vapor influx, while the Stefan Tube-calculated values do not. At $40^{\circ} \mathrm{C}$ and $100 \%$ relative humidity, an influx rate of $0.03 \mathrm{~L} / \mathrm{yr}$ is calculated, and at $60 \%$ relative humidity, a influx rate of $0.01 \mathrm{~L} / \mathrm{yr}$ is calculated. These influx rates are below the modeled minimum vapor influx of $0.1 \mathrm{~L} / \mathrm{yr}$. 


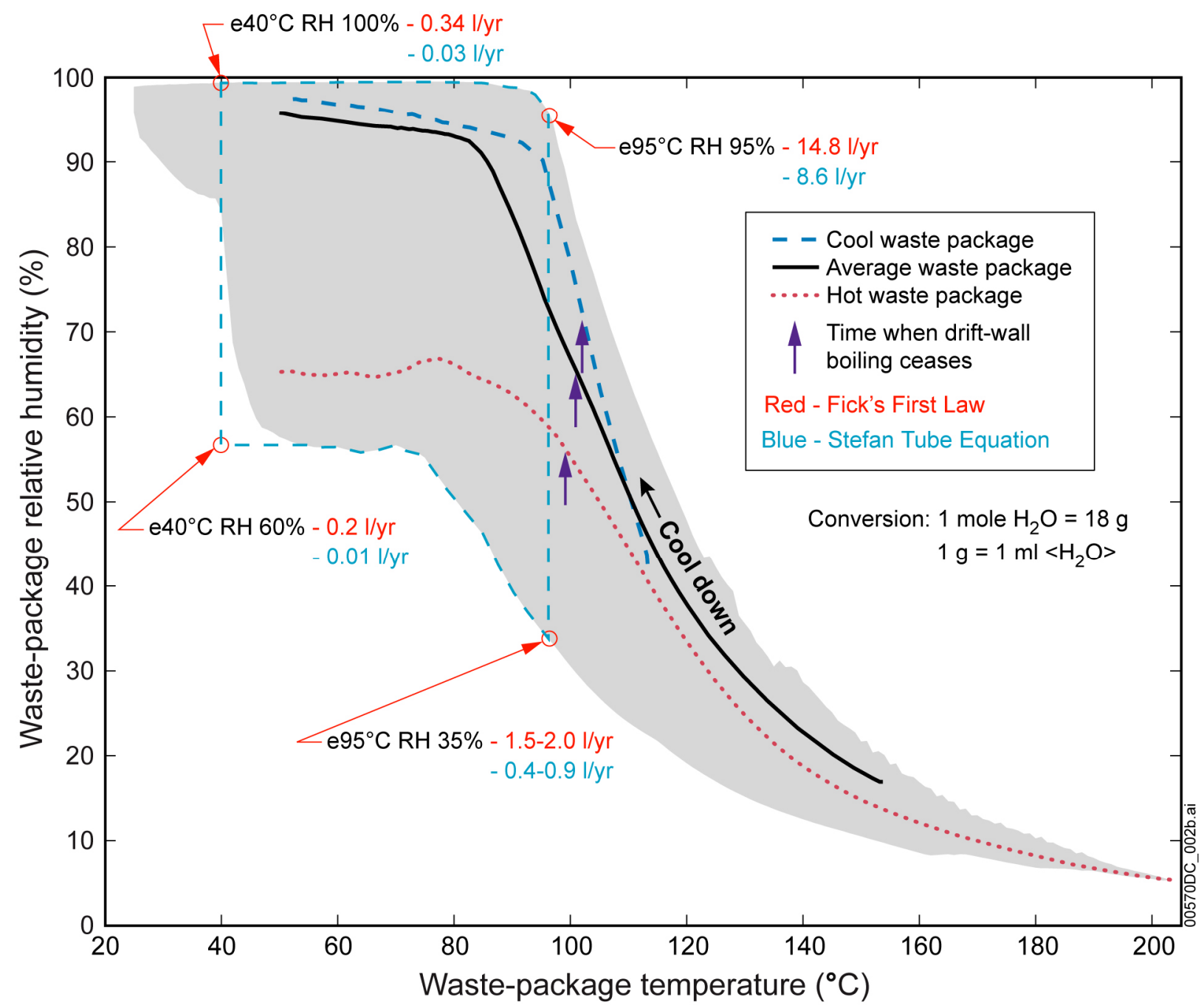

Source: BSC 2005 [DIRS 173944], Figure 6.3-69 updated to include the flux values calculated in this alternative conceptual model from Fick's vs Stefan Tube - Flux vs Temp.xIs.xls (Appendix F ISpreadsheets).

Figure 6-2. Temperature versus Relative Humidity for Waste Packages

However, as indicated by the lines indicating the cool, average, and hot waste package with time, the waste package temperature will decrease along the lines in the direction of the "cooldown arrow." Therefore, the overall time-integrated path of the waste package will experience higher temperatures and, thus, greater water vapor influxes during its cooldown history. Therefore, based on the higher influx rates calculated based on Fick's First Law and for the Stefan Tube higher-temperature history for the waste package, the range of water vapor influx $(0.1 \mathrm{~L} / \mathrm{yr}$ to $10 \mathrm{~L} / \mathrm{yr}$ ) presented in Section 6.10.2 is deemed to be valid and appropriate.

\subsubsection{Thermal Diffusion}

As discussed and illustrated by Bird et al. (1960 [DIRS 103524], pp. 564 to 565 and Table 18.4-1), there are two "driving forces" affecting diffusive mass flux. The first is due to concentration gradients and has been investigated by the application of Fick's First Law and Stefan Tube equations. The second (called the "Soret effect" or "thermal-diffusion effect") is 
due to temperature gradients. However, the effect of the "thermal-diffusion effect" was not calculated or determined, as its contribution to mass flux is secondary to concentration gradients (Bird et al. 1960 [DIRS 103524], p. 567; Housiadas et al. 2002 [DIRS 173263], p. 814).

\subsection{BATCH-REACTOR BASE-CASE MODEL OUTPUT}

This section provides the output from the batch reactor model runs. The $\mathrm{pH}$ value ranges from the surface complexation model are shown in some of these plots, but implementation of the surface complexation model is actually discussed in Section 6.9.

The "time" on the x-axis for all plots refers to the time after both the breach of the waste package has occurred and temperature in the repository has dropped below $100^{\circ} \mathrm{C}$, at which time, liquid water can exist.

\subsubsection{Liquid-Influx Case Model Results}

\subsubsection{CSNF Output}

\subsubsection{1 pH}

The history of the reactants and $\mathrm{pH}$ values is plotted for the base case in Figure 6-3. The base case considers a reasonable representation of inputs by using median or most likely values: a flux of $1 \mathrm{~L} / \mathrm{yr}$, median rates for all of the alloys and fuels, and $100 \%$ cladding exposure at $\log f \mathrm{CO}_{2}=$ -3 , and $\log f \mathrm{O}_{2}=-0.7$. The incoming water composition is $\mathrm{J}-13$, and the runs were conducted at $25^{\circ} \mathrm{C}$.

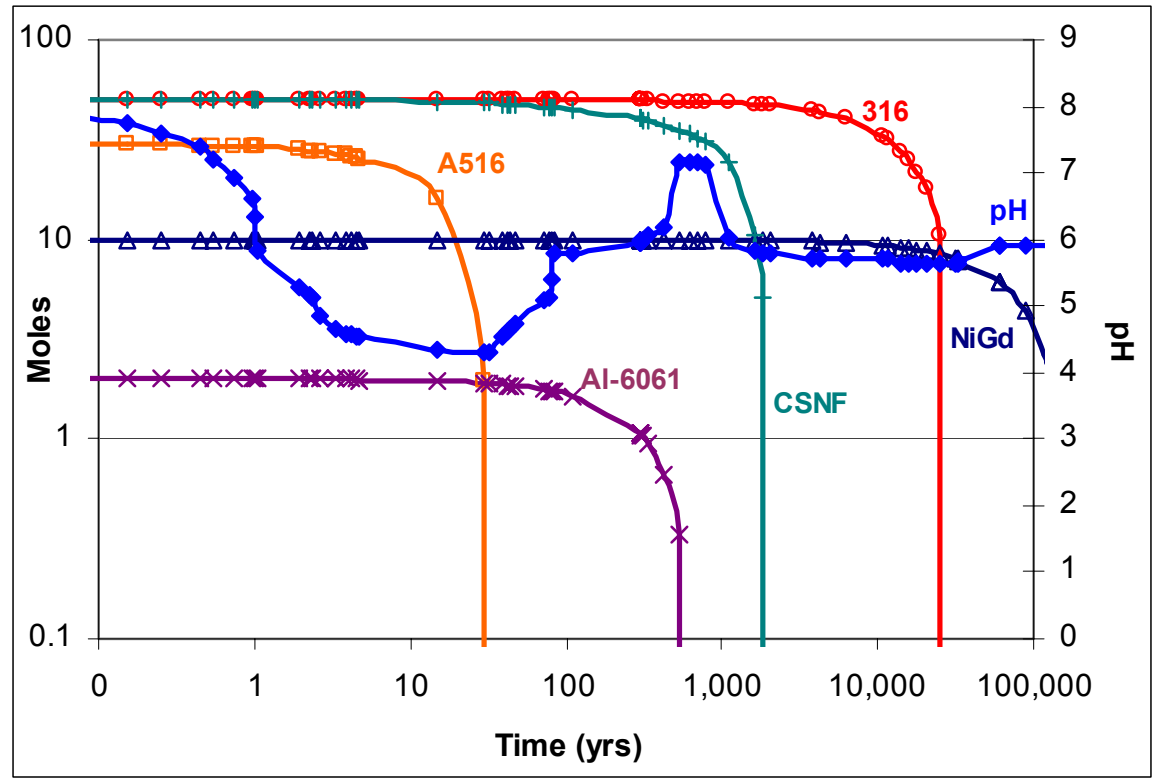

Source: CSNF Liquid Influx Model Output.xIs (Appendix F ISpreadsheets).

NOTE: $\quad$ Time refers to time after waste package breach ( 0 on the $x$-axis refers to 0.1 years).

Figure 6-3. CSNF Liquid-Influx Base-Case Reactant Summary and pH Results 
Figure 6-4 shows the $\mathrm{pH}$ history for different seepage compositions. The EQ6 results plotted in Figure 6-4 reflect only the physical chemistry of the system; the surface complexation model is not represented in this plot. The evolution of the $\mathrm{pH}$ in a CSNF waste package is complex and is controlled by the precipitation and dissolution of many phases. The following section provides a brief explanation for the trends in $\mathrm{pH}$ for this representative CSNF case, but a detailed discussion is provided in Appendix $\mathrm{A}$. The $\mathrm{pH}$ reaches a minimum at around 30 years due to the rapid degradation of the A516, which releases sulfur and phosphorus that drive down the $\mathrm{pH}$ as they oxidize. With the A516 depleted, the $\mathrm{pH}$ increases sharply from $\sim 30$ to 100 years, and then more gradually until about 300 years. Shortly after 300 years, the $\mathrm{pH}$ increases again sharply until about 600 years. When the $\mathrm{pH}$ exceeds 7 , saponite-tri solid solution $\left(\mathrm{Ca}_{0.5}, \mathrm{H}, \mathrm{K}, \mathrm{Mg}_{0.5}, \mathrm{Na}_{0.33} \mathrm{Mg}_{3}\right.$ $\left.\mathrm{Al}_{0.33} \mathrm{Si}_{3.67} \mathrm{O}_{10}(\mathrm{OH})_{2}\right)$ begins to precipitate up until the Al-6061 is depleted. Once the source for the Al has been depeleted, the saponite-tri solid solution begins to dissolve. When the saponite-tri solid solution is exhausted at about 1000 years, the $\mathrm{pH}$ drops. At about 2300 years, the CSNF is exhausted and kaolinite begins to precipitate, after which the $\mathrm{pH}$ remains virtually constant at about 6 .

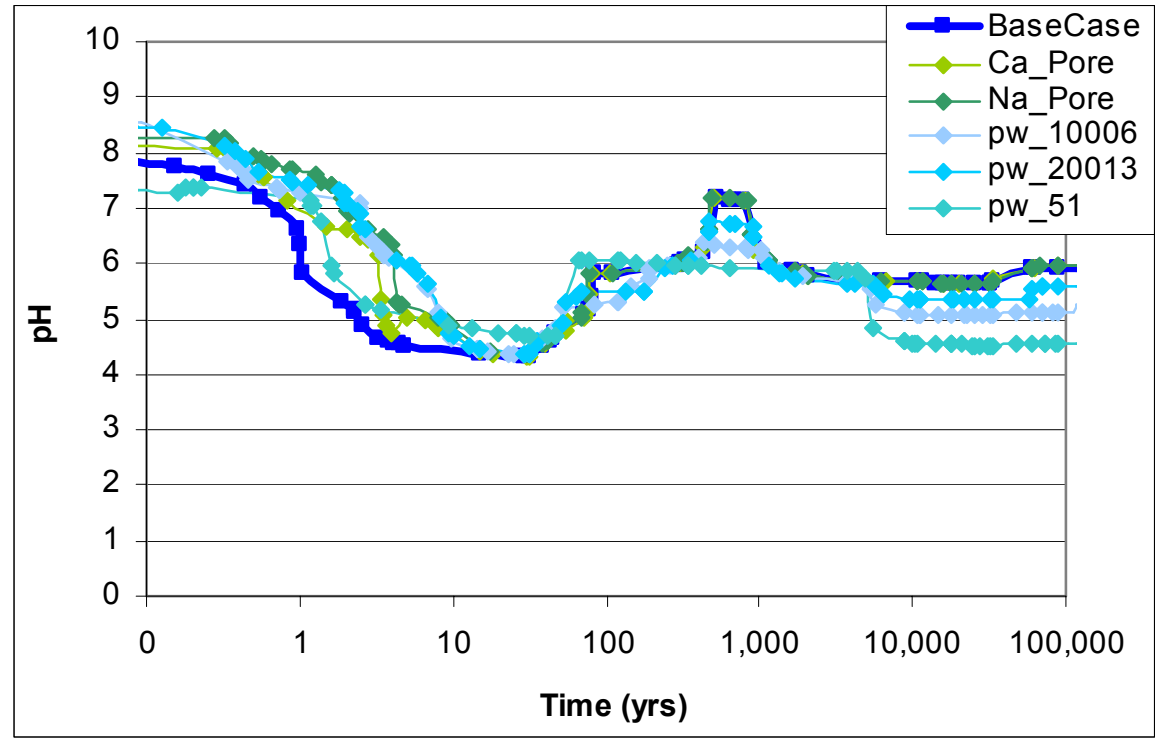

Source: $\quad$ CSNF Liquid Influx Model Output.xls (Appendix F ISpreadsheets).

NOTE: $\quad$ Time refers to time after waste package breach ( 0 on the $x$-axis refers to 0.1 years).

Figure 6-4. CSNF Liquid-Influx Model Results for Various Incoming Water Compositions

Figure 6-4 emphasizes composition of the seepage (Tables 4-2 and 4-3) has little effect on the $\mathrm{pH}$ profile. The most notable effect is for the long-term $\mathrm{pH}$ for the high-temperature waters (pw_51 is $91.8^{\circ} \mathrm{C}$, pw_10006 is $56.2^{\circ} \mathrm{C}$, and pw_20013 is $40.2^{\circ} \mathrm{C}$ ). The separation in the early-time (less than approximately 0.5 years after waste package breach) $\mathrm{pH}$ profiles is a function of the seepage chemistry. However, this difference dissipates in approximately 10 years, and the $\mathrm{pH}$ profiles become nearly identical. The above discussion addresses the subject matter of "Included" FEP 2.2.08.12.0B (Chemistry of water flowing into the waste package) and indicates how that subject matter has been included and addressed within TSPA-LA. Thus, the composition of the water flowing into the EBS has a negligible impact on the in-package chemistry $\mathrm{pH}$. The in-package chemistry model uses the results of cases examining the three seepage compositions, so the effect of the chemistry of the water flowing 
into the EBS is included in the feed to TSPA-LA. (Even though the abstractions passed to TSPA-LA from this model are not defined in terms of the incoming water composition). These results show that the model is robust with respect to Alternative Conceptual Model II. If the liquid-influx model had been sensitive to the input water composition, then an alternative conceptual model with time-varying composition would be needed.

As described in Section 4.1.2, the model does not consider the possibility of seepage concentrated via evaporative processes entering the waste package. However, if small quantities of these in-drift waters did enter the waste package, as run off from some of the components located above the waste package, the additional incoming crown seepage water dripping from the drift ceiling and the waste package environment itself would tend to overwhelm the chemistry of concentrated solutions. Additionally, the principal solutes following evaporation will be those of soluble salts like $\mathrm{Cl}, \mathrm{Na}, \mathrm{Mg}$, etc. Figures 6-6 and 6-8 illustrate that changes in the concentrations of solutes like $\mathrm{Na}$ do not affect solutes derived from the waste package.

Further examination of Figure 6-3 shows reactants dissolve as a function of time (i.e., they are kinetic reactants). Their effect on the in-package chemistry is explicitly modeled in the in-package chemistry model and, thus, is carried over to TSPA-LA. The above discussion addresses the subject matter of "Included" FEP 2.1.09.07.0A (Reaction kinetics in waste package) and indicates how that subject matter has been included and addressed within TSPA-LA.

Figure 6-5 displays mineral phases that precipitated from solution for the base case. Hematite, gibbsite, schoepite, pyrolusite, and trevorite constitute the five most abundant phases, all of which are expected to form in the oxidizing waste package environment (Table 6-11). The large amount of gibbsite $\left(\mathrm{Al}(\mathrm{OH})_{3}\right)$ that formed in these runs is due to the relatively low amount of available silica in the incoming waters and waste package components. Had more silica been available, greater quantities of aluminum-silicate phases would then have formed with proportionately less gibbsite formation within the near-neutral $\mathrm{pH}$ range. The silica phases that do form include kaolinite, nontronite- $\mathrm{Mg}$, and nontronite-Ca, all of which are clay minerals. In addition to these most-abundant phases, some other phases of interest (actinides or neutron absorbers) that form in smaller quantities include: $\mathrm{PuO}_{2}(\mathrm{OH})_{2}: \mathrm{H}_{2} \mathrm{O}, \mathrm{GdPO}_{4}: 10 \mathrm{H}_{2} \mathrm{O}, \mathrm{RuO}_{2}$, $\mathrm{Gd}_{2}\left(\mathrm{CO}_{3}\right)_{3}, \mathrm{NpO}_{2},\left(\mathrm{UO}_{2}\right)_{3}\left(\mathrm{PO}_{4}\right)_{2}: 4 \mathrm{H}_{2} \mathrm{O}$, and uranophane(alpha). The mineral assemblage plots (Figures 6-5 and 6-6) support that the composition of the seepage has little influence over which minerals formed and their amounts. The J-13 well water minerals show some variability compared to the other water compositions; however, the major phases are present in nearly identical amounts. Differences in input water chemistry do not change the identities of minerals formed during waste-package degradation, but may lead to differences in the amounts of some minerals formed. For example, less powellite $\left(\mathrm{CaMoO}_{4}\right)$ forms from base case water than from either $\mathrm{Ca}$ - or Na-porewater. This is because the $\mathrm{Ca}$ contents of both these waters are higher than that of the base case water (Table 4-2). 


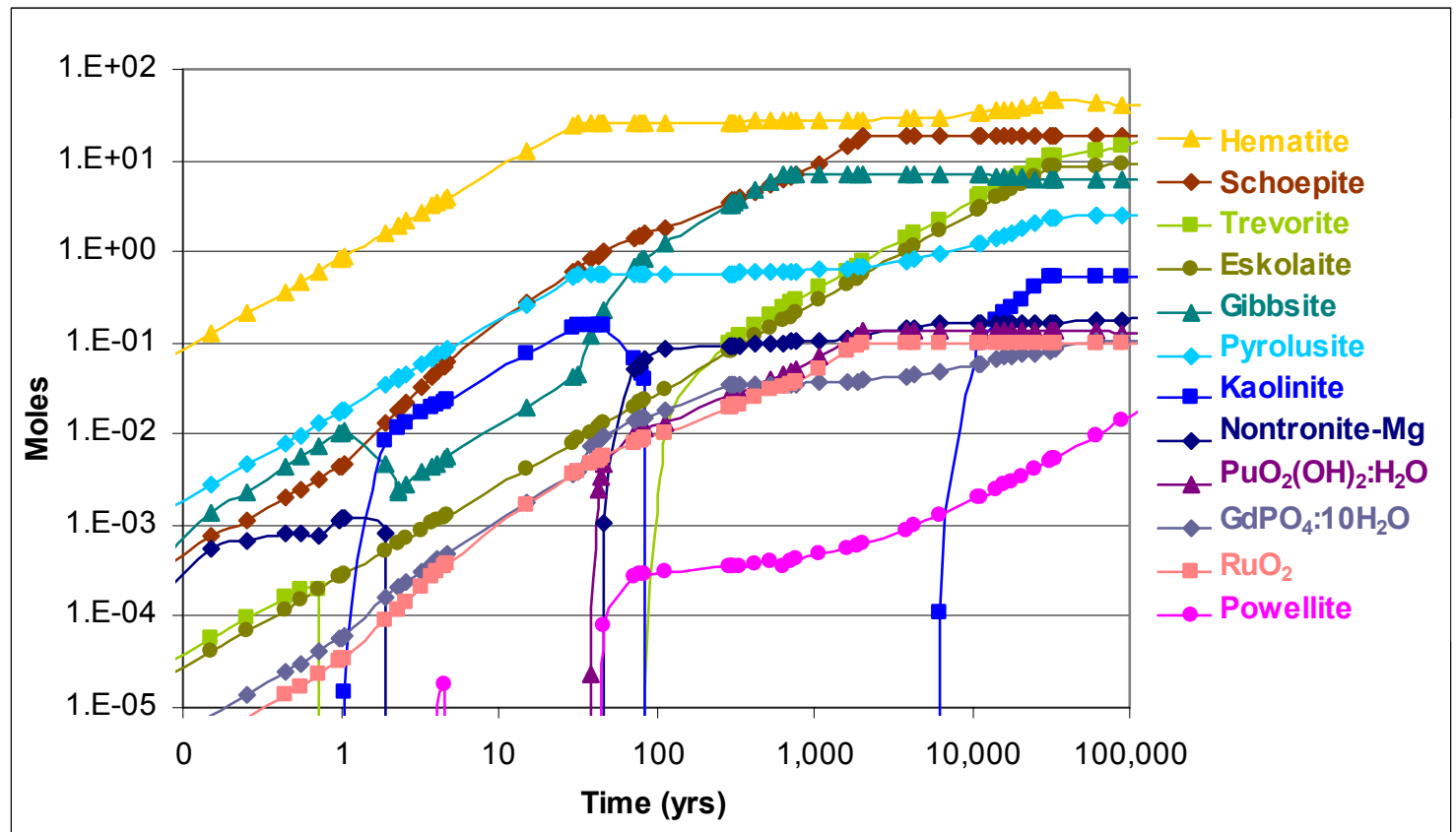

Source: CSNF Liquid Influx Model Output.xIs (Appendix F ISpreadsheets).

NOTE: Time refers to time after waste package breach ( 0 on the $x$-axis refers to 0.1 years).

Figure 6-5. CSNF Liquid-Influx Model Mineral Phases for the Base Case

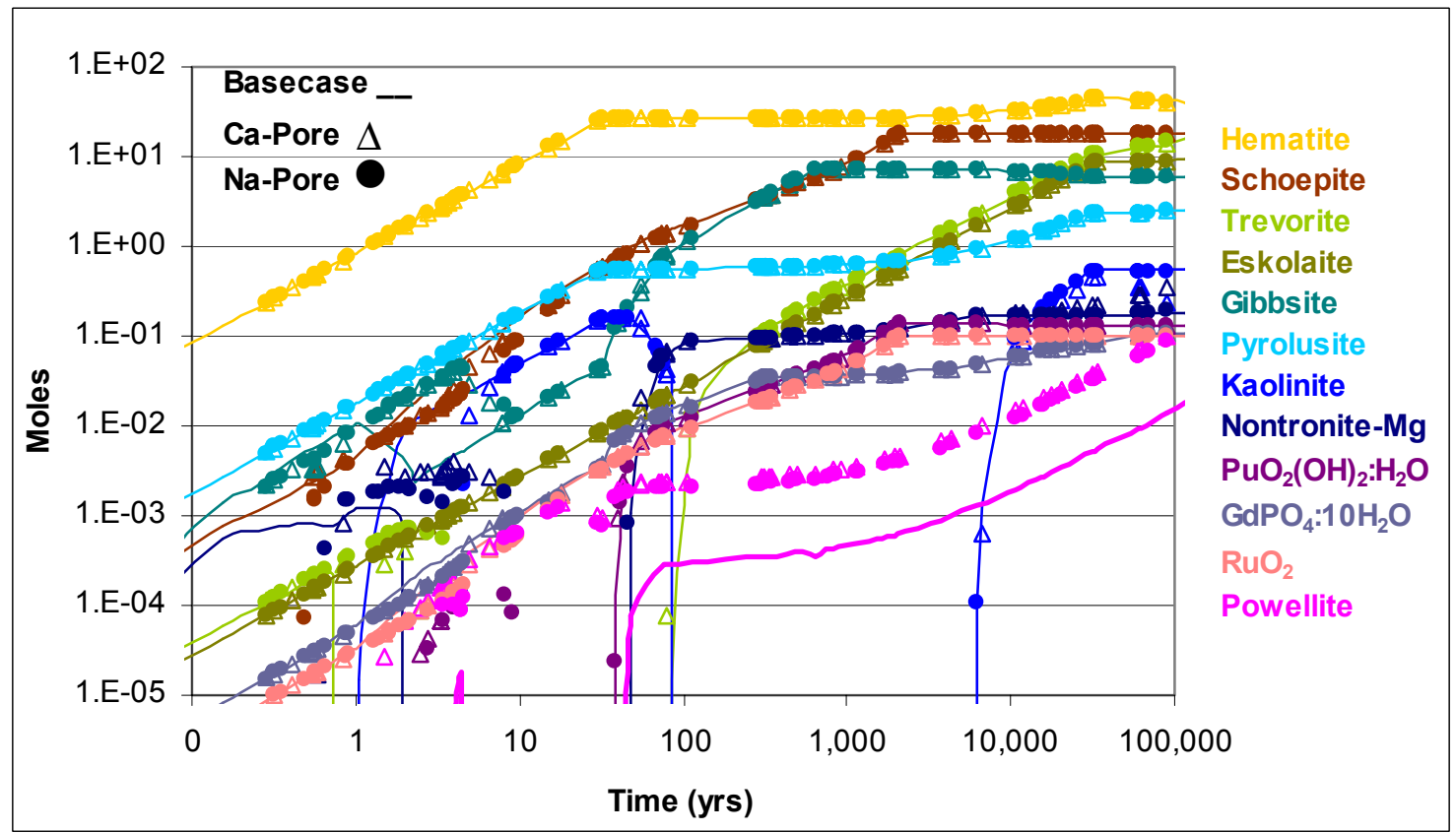

Source: CSNF Liquid Influx Model Output.xls (Appendix F ISpreadsheets).

NOTE: Time refers to time after waste package breach ( 0 on the $x$-axis refers to 0.1 years).

Figure 6-6. CSNF Liquid-Influx Model Mineral Phases for Three Seepage Compositions

Figures 6-7 and 6-8 display aqueous species for the runs with various input water compositions. Figure 6-8 shows the in-package chemical environment control elements not present in the initial 
water compositions (Table 4-2). In other words, elements originating from the waste package and waste forms have aqueous species concentrations nearly identical and independent of the initial water composition for the duration of the simulations. Examples include $\mathrm{Ni}$ and $\mathrm{Mo}$, which originate from oxidation of the metal waste package components. Elements present in the initial water composition and involved in reactions in the waste package also have similar aqueous species concentrations. For example, sulfur, which was present in all of the water compositions as sulfate $\left(\mathrm{SO}_{4}{ }^{2-}\right)$, shows similar concentration trends in the simulations, independent of the starting water composition, due to the sulfur contained in the Carbon Steel Type A516 that dominates the sulfate concentration trends observed in Figures 6-7 and 6-8. Figures 6-7 and 6-8 show that, depending on the initial fluid composition, there is a small degree of variability in the minerals and aqueous species of the reacted fluid chemistry that may exit a breached waste package. However, this variability is slight and is captured in the overall uncertainty treatment in the $\mathrm{pH}$ and ionic strength of the reacted solutions.

Several of the porewaters are high-temperature seepage waters, and these cases were run using EQ6 at the corresponding higher temperatures using the temperature-appropriate CSNF degradation rates (Table 6-7). The metal alloy corrosion rates are the same as those used for the $25^{\circ} \mathrm{C}$ runs, because these rates are provided in DTN: MO0409SPAACRWP.000 [DIRS 172059] as appropriate over this range of temperatures and because many of the experimental rates were measured at higher temperatures. The thermodynamic database includes high temperature data for most mineral and aqueous species; therefore, the reacted solution chemistry and precipitated mineral phases are temperature appropriate.

Higher temperature $\left(>25^{\circ} \mathrm{C}\right)$ runs achieve an overall lower $\mathrm{pH}$ profile at long time periods (as shown in Figure 6-4 and discussed further in Section 6.6.6) and slight variations in the stable mineral assemblages compared with the results at $25^{\circ} \mathrm{C}$. Since several simulations are carried out at above ambient temperatures and the in-package chemistry model results reflect the increased thermal conditions, the TSPA-LA feed also reflects the increased thermal conditions. The above discussion addresses the thermal effects on chemistry portion of the subject matter of "Included" FEP 2.1.11.08.0A (Thermal effects on chemistry and microbial activity in the EBS) and indicates how that subject matter has been included and addressed within TSPA-LA. The microbial activity in the EBS subject matter is described in FEP 2.1.10.01.0A as documented in Engineered Barrier System Features, Events, and Processes (BSC 2004 [DIRS 169898]). The effect of temperature on the surface complexation model is discussed in Section 6.7.3. 


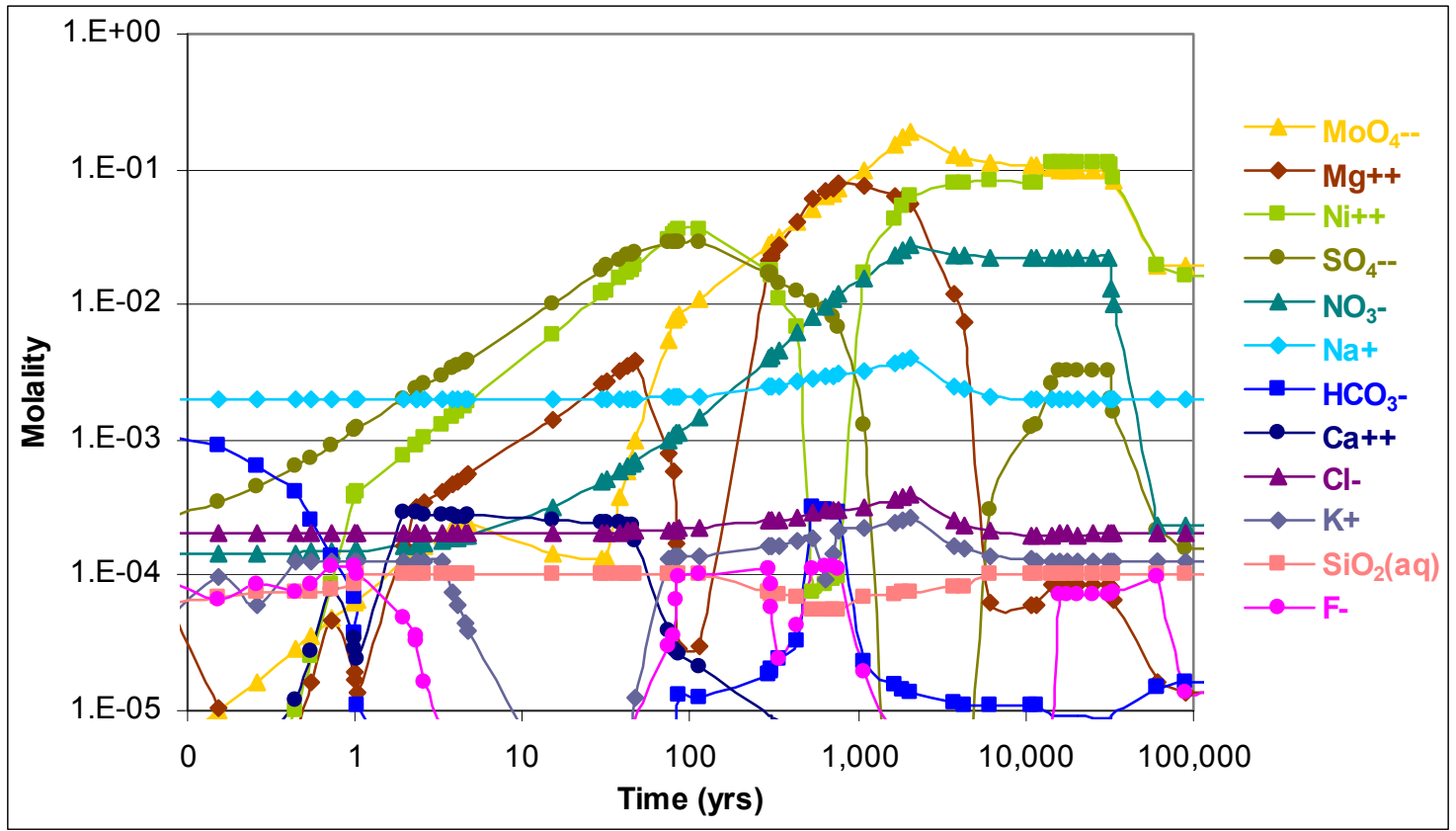

Source: CSNF Liquid Influx Model Output.x/s (Appendix F ISpreadsheets).

NOTE: $\quad$ Time refers to time after waste package breach ( 0 on the $x$-axis refers to 0.1 years).

Figure 6-7. CSNF Liquid-Influx Model Aqueous Species for the Base Case

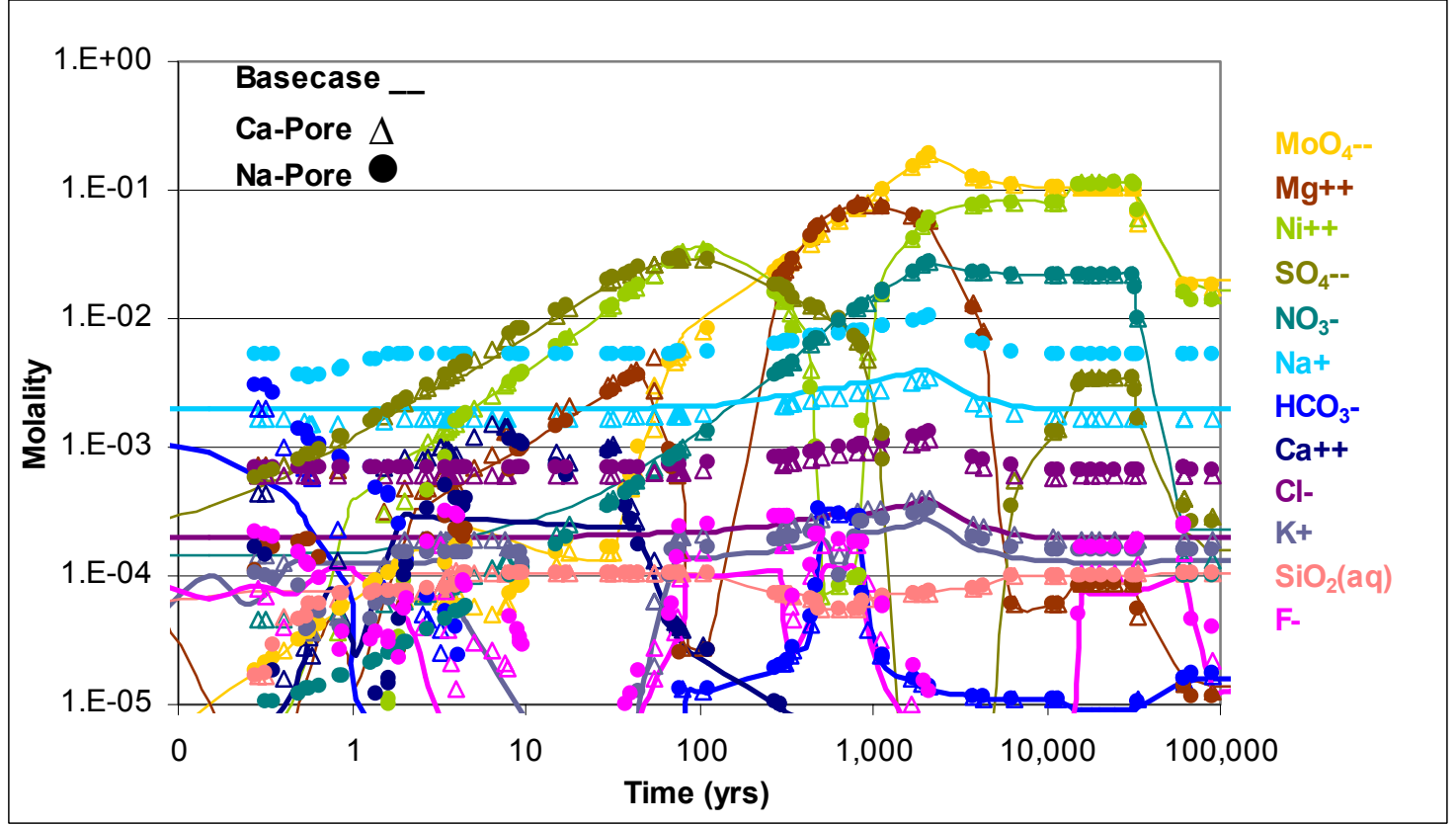

Source: CSNF Liquid Influx Model Output.xIs (Appendix F ISpreadsheets).

NOTE: Time refers to time after waste package breach ( 0 on the x-axis refers to 0.1 years).

Figure 6-8. CSNF Liquid-Influx Model Aqueous Species for Three Seepage Compositions 


\subsection{Ionic Strength}

Figure 6-9 displays the ionic strength profiles for the CSNF base case. The base case considers a reasonable representation of inputs: a flux of $1 \mathrm{~L} / \mathrm{yr}$, median rates for all of the alloys and fuels, $\mathrm{J}-13$ well water, and $100 \%$ cladding exposure, at $25^{\circ} \mathrm{C}, \log f \mathrm{CO}_{2}=-3$, and $\log f \mathrm{O}_{2}=-0.7$. The ionic strength abstraction is used by the Colloids and Dissolved Concentration Limits of Radioactive Elements submodels in the TSPA-LA. The colloidal suspensions are unstable at ionic strength values above $0.05 \mathrm{~mol} / \mathrm{L}$ (BSC 2004 [DIRS 170025]), so for the colloid submodel, the significance of exceeding the limits of the B-dot activity coefficient equation is diminished. For the Dissolved Concentration Limits of Radioactive Elements model (BSC 2005 [DIRS 173873]), TSPA-LA applies an additional uncertainty term to the concentrations if the ionic strengths is greater than one molal, so the significance of exceeding the limits $(\sim 4$ molal $)$ of the B-dot activity coefficient equation is already captured.

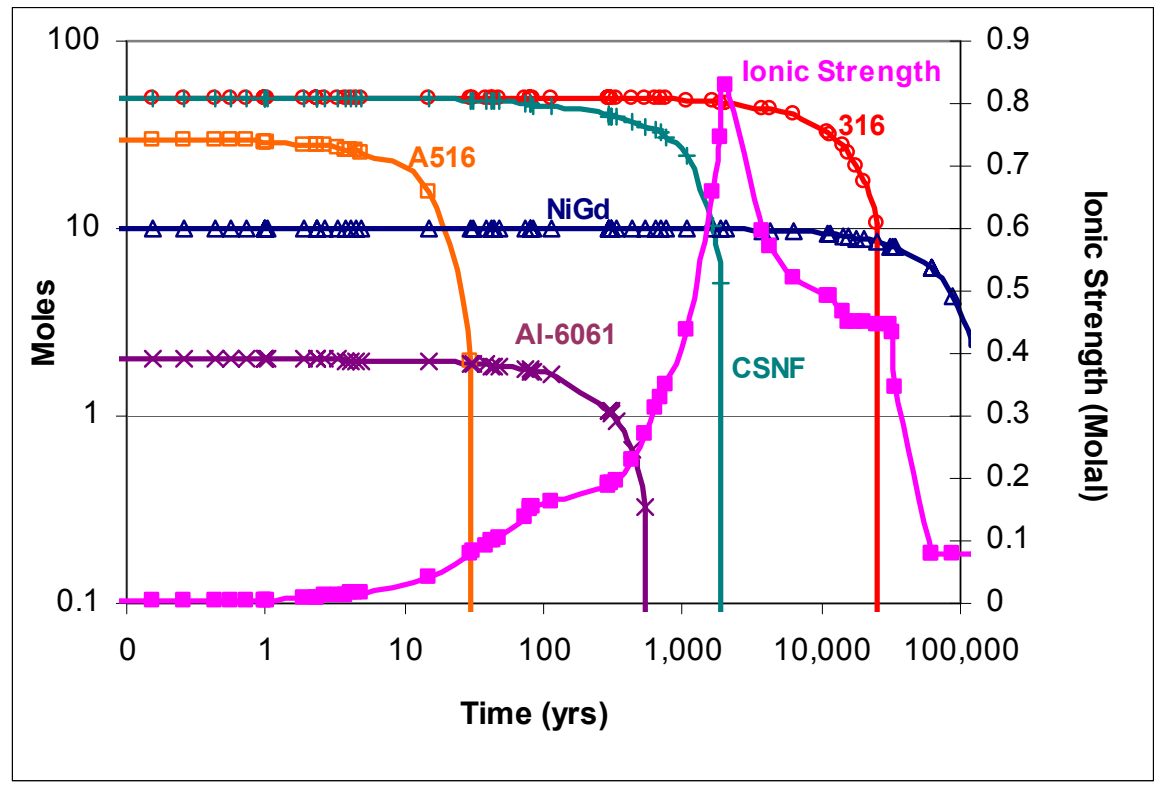

Source: CSNF Liquid Influx Model Output.xIs (Appendix F ISpreadsheets).

NOTE: $\quad$ Time refers to time after waste package breach ( 0 on the $x$-axis refers to 0.1 years).

Figure 6-9. CSNF Liquid Influx Base-Case Reactant Summary and lonic Strength

Figure 6-9 shows ionic strength results with the reactant summary. The ionic strength curve shows cusps as a response to the depletion of each of the reactants; the most noticeable cusps occurring after the depletion of CSNF fuel and then Stainless Steel Type 316.

As described in Section 4.1.2, the model does not consider the possibility of seepage concentrated via evaporative processes entering the waste package. However, if small quantities of these in-drift waters did enter the waste package, as run off from some of the components located above the waste package, the additional incoming crown seepage water dripping from the drift ceiling and the waste package environment itself would tend to overwhelm the chemistry of concentrated solutions. The principal solutes following evaporation will be those of soluble salts like $\mathrm{Cl}, \mathrm{Na}, \mathrm{Mg}$, which could increase the ionic strength of the in-package solution. This effect 
is accounted for in the ionic strength abstraction, and is described in more detail in Section 6.10 .2 .

\subsection{Eh}

Figure 6-10 displays Eh (a measure of the redox potential) and oxidation products for the CSNF base-case run. The base case considers a reasonable representation of inputs: a flux of $1 \mathrm{~L} / \mathrm{yr}$, median rates for all of the alloys and fuels, J-13 well water, and $100 \%$ cladding exposure, at $25^{\circ} \mathrm{C}, \log f \mathrm{CO}_{2}=-3$, and $\log f \mathrm{O}_{2}=-0.7$. The Eh, given in terms of the standard hydrogen electrode scale, varies between approximately 0.8 to 1.0 volts. The modeled conditions are uniformly oxidizing, so Eh changes only in response to $\mathrm{pH}$ changes, as shown in Figure 6-11. In reality, the presence of abundant reduced material and the ability of corrosion products to limit the access of water and oxygen are likely to cause substantial lowering of the in-package Eh. A lower Eh would lead toward more neutral $\mathrm{pH}$ values and more moderate ionic strengths, but because this effect cannot be quantified, uniformly oxidizing Eh value is used for the model, and sensitivity studies were conducted under less oxidizing conditions to determine the impact (Section 6.6.4).

Since metal oxide corrosion products are precipitating from a solution in contact with the waste form and waste package components, the corrosion products have a first-order influence on the in-package chemistry. The above discussion addresses the subject matter of "Included" FEPs 2.1.09.02.0A (Chemical interaction with corrosion products) and 2.1.09.06.0A (Reduction-oxidation potential in waste package) and indicates how that subject matter has been included and addressed within TSPA-LA.

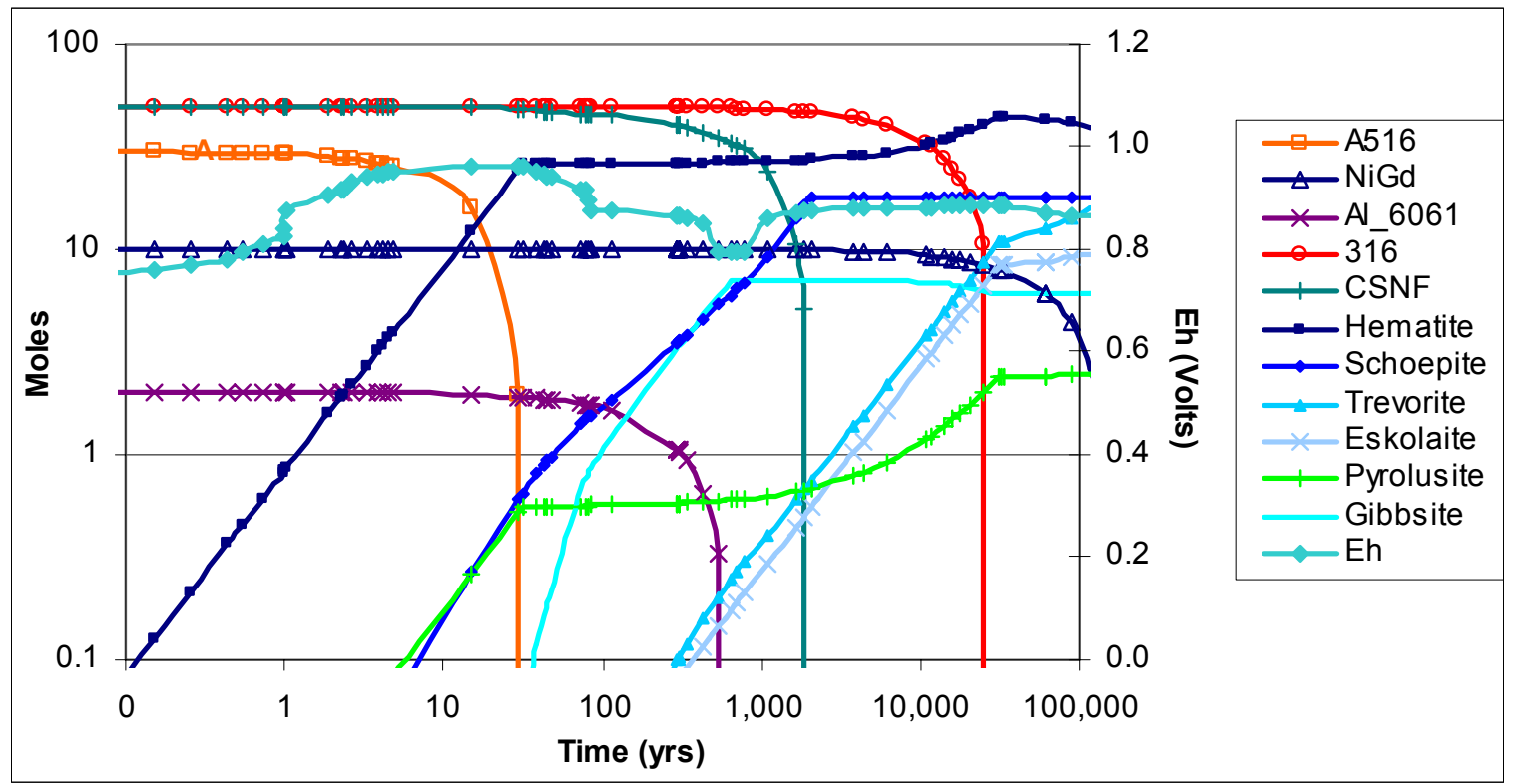

Source: CSNF Liquid Influx Model Output.xls (Appendix F ISpreadsheets).

NOTE: $\quad$ Time refers to time after waste package breach ( 0 on the $x$-axis refers to 0.1 years).

Figure 6-10. CSNF Liquid-Influx Model: Eh, Reactant Summary, and Corrosion Products 


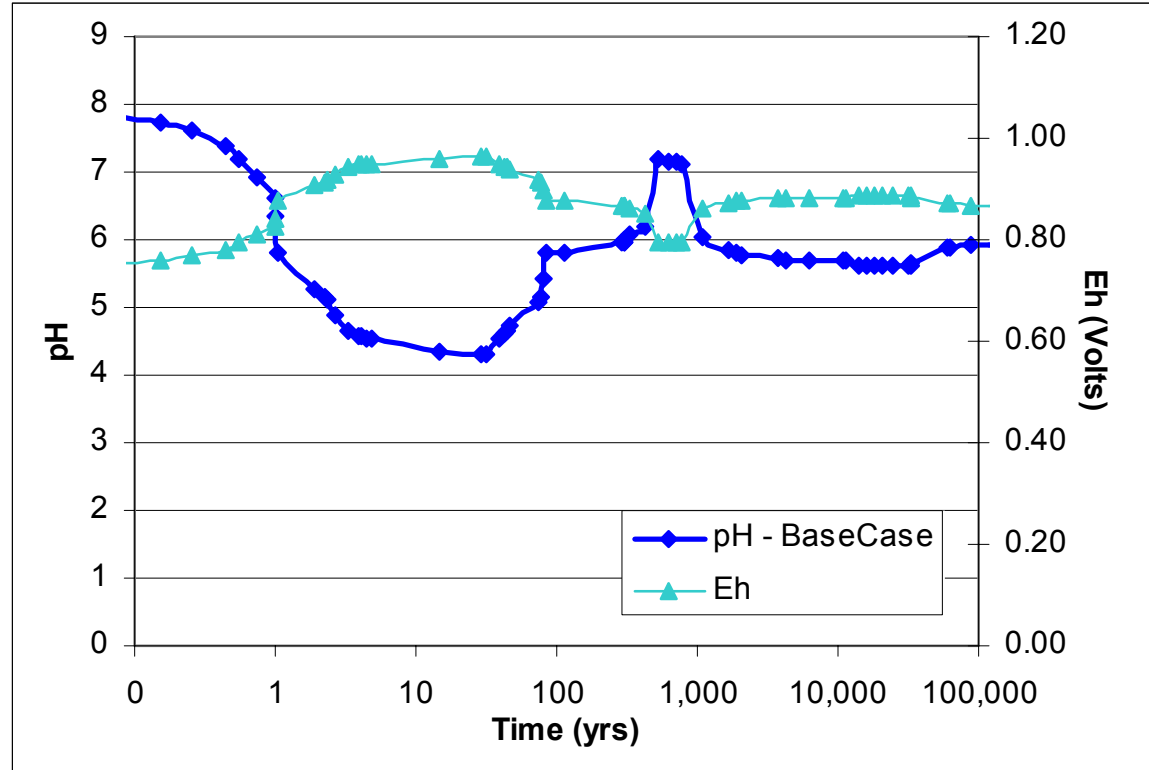

Source: $\quad$ CSNF Liquid Influx Model Output.xls (Appendix F ISpreadsheets).

NOTE: $\quad$ Time refers to time after waste package breach ( 0 on the $x$-axis refers to 0.1 years).

Figure 6-11. CSNF Liquid-Influx Model: Eh and pH

\subsubsection{CDSP Output}

\subsubsection{1 pH}

The history of the reactants and the $\mathrm{pH}$ is plotted for the base case in Figure 6-12. The base case considers a reasonable representation of inputs by using median or most likely values: a flux of $1 \mathrm{~L} / \mathrm{yr}$, median rates for all of the alloys and fuels at $\log f \mathrm{CO}_{2}=-3$, and $\log f \mathrm{O}_{2}=-0.7$. The incoming water composition is $\mathrm{J}-13$, and the runs were conducted at $25^{\circ} \mathrm{C}$. 


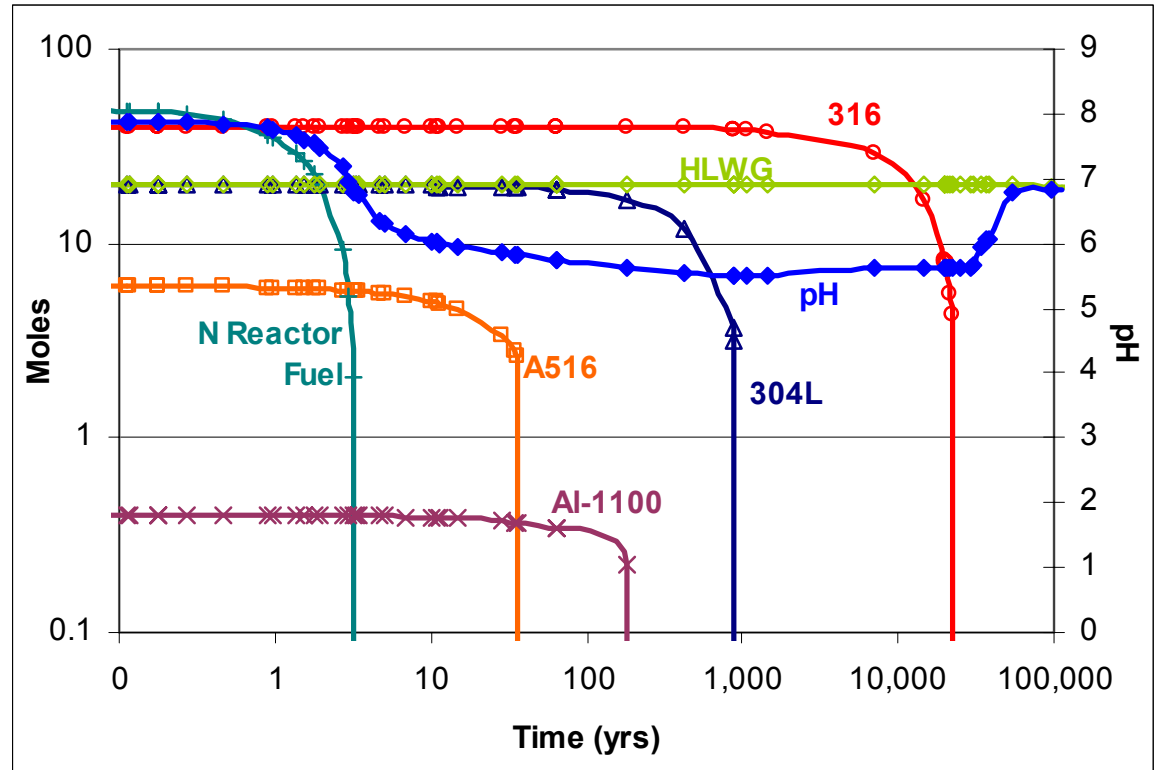

Source: CDSP Liquid Influx Model Output.xIs (Appendix F ISpreadsheets).

NOTE: Time refers to time after waste package breach ( 0 on the $x$-axis refers to 0.1 years).

Figure 6-12. CDSP Liquid-Influx Base Case Reactant Summary and pH Results

The most outstanding feature in Figure 6-12 is the reactant summary for the N-Reactor fuel. The figure shows that the N-Reactor fuel dissolves over a short duration of just a few years. The rapid $\mathrm{N}$-Reactor fuel dissolution diminishes the importance of the $\mathrm{N}$-Reactor fuel to the overall in-package chemistry contribution. However, the large quantity of schoepite precipitated in the waste package influences the in-package chemistry for an extended duration by buffering $\mathrm{pH}$ in the near-neutral range.

Another important feature of the $\mathrm{pH}$ profiles in Figure 6-12 is the absence of a period of sustained high $\mathrm{pH}$ that might be expected from the dissolution of the HLWG, except at times greater than 100,000 years, after the steels have degraded, and the glass is the only remaining reactant in the system (as shown in the far right side of the plot). The single-component CDSP vapor-influx model predicted high $\mathrm{pH}$ conditions are possible in the absence of an acid producing reactant (i.e., steel alloy). However, in the liquid-influx model, seepage is allowed to "stream" through the waste package reacting with waste package components. It is unlikely seepage that has reacted with HLWG could exit a waste package without contacting a steel component, or schoepite from N-Reactor fuel degradation, along its flow path (both having the capacity to buffer the $\mathrm{pH}$ in the neutral range). 


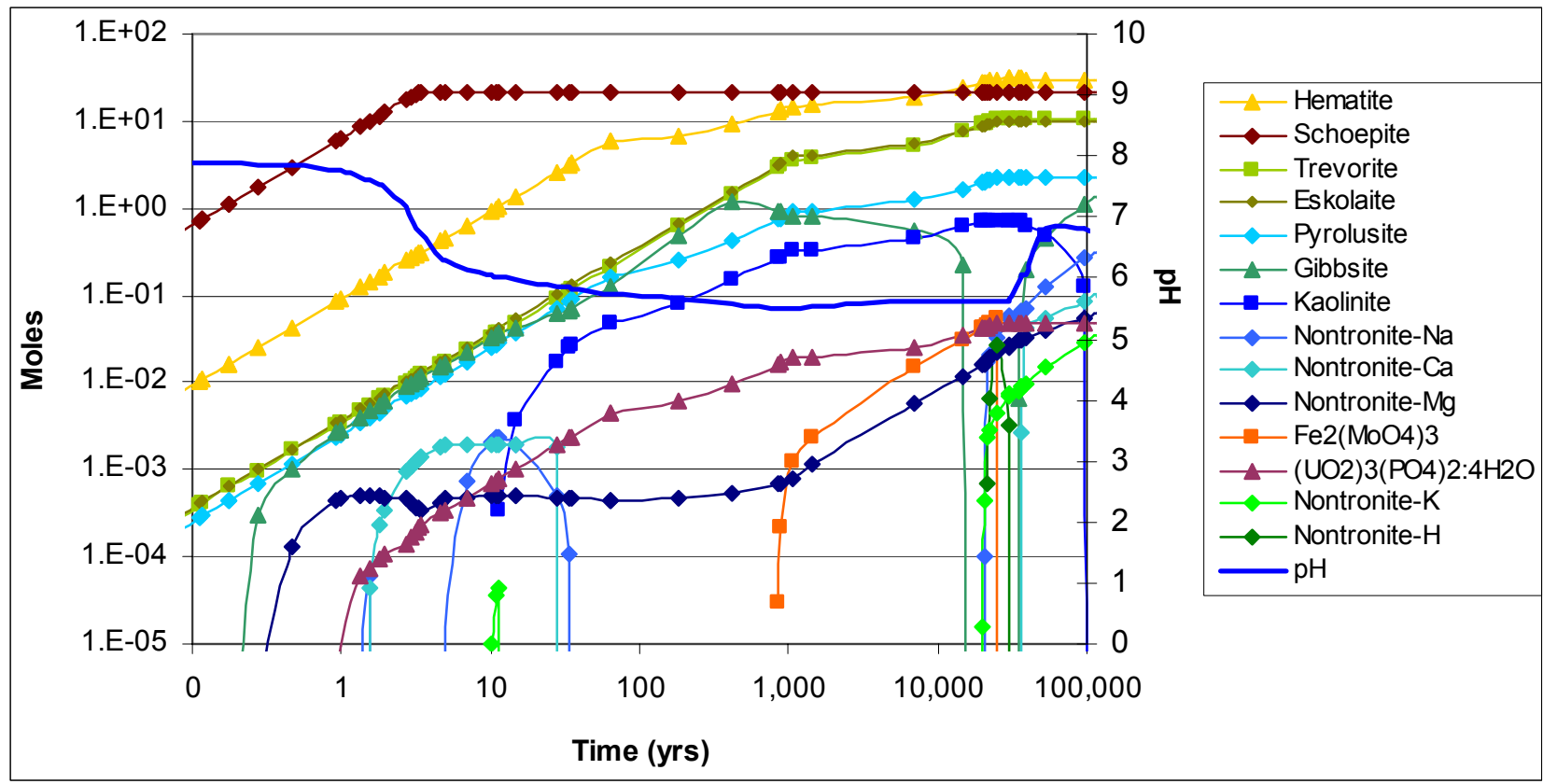

Source: CDSP Liquid Influx Model Output.xIs (Appendix F ISpreadsheets).

NOTE: $\quad$ Time refers to time after waste package breach ( 0 on the $x$-axis refers to 0.1 years).

Figure 6-13. CDSP Liquid-Influx Model Mineral Phases for the Base Case

Figure 6-13 shows the minerals that formed for the CDSP liquid-influx model. This plot shows that hematite, schoepite, trevorite, eskolaite, pyrolusite, and gibbsite constitute the most abundant mineral phases that form from the degradation of a CDSP waste package. The abundance of schoepite $\left(\mathrm{UO}_{3}: 2 \mathrm{H}_{2} \mathrm{O}\right)$ results from the complete reaction of the uranium metal N-Reactor fuel, while the hematite, trevorite and gibbsite are products of steel and aluminum alloys dissolution, respectively. Over the duration of the simulations, less gibbsite forms in CDSP runs compared to CSNF runs (Figure 6-5), while greater amounts of the nontronite clay minerals form in CDSP runs compared to CSNF runs. This occurs because silica is more available in CDSP compared to CSNF waste packages as a result of the presence and degradation of HLWG. This additional silica leads to greater amounts of nontronite formation in CDSP waste packages. In addition to these most abundant phases, some other phases of interest (actinides) that form in smaller quantities include: Boltwoodite-Na, $\left(\mathrm{UO}_{2}\right)_{3}\left(\mathrm{PO}_{4}\right)_{2}: 4 \mathrm{H}_{2} \mathrm{O}$, and Uranophane(alpha). 


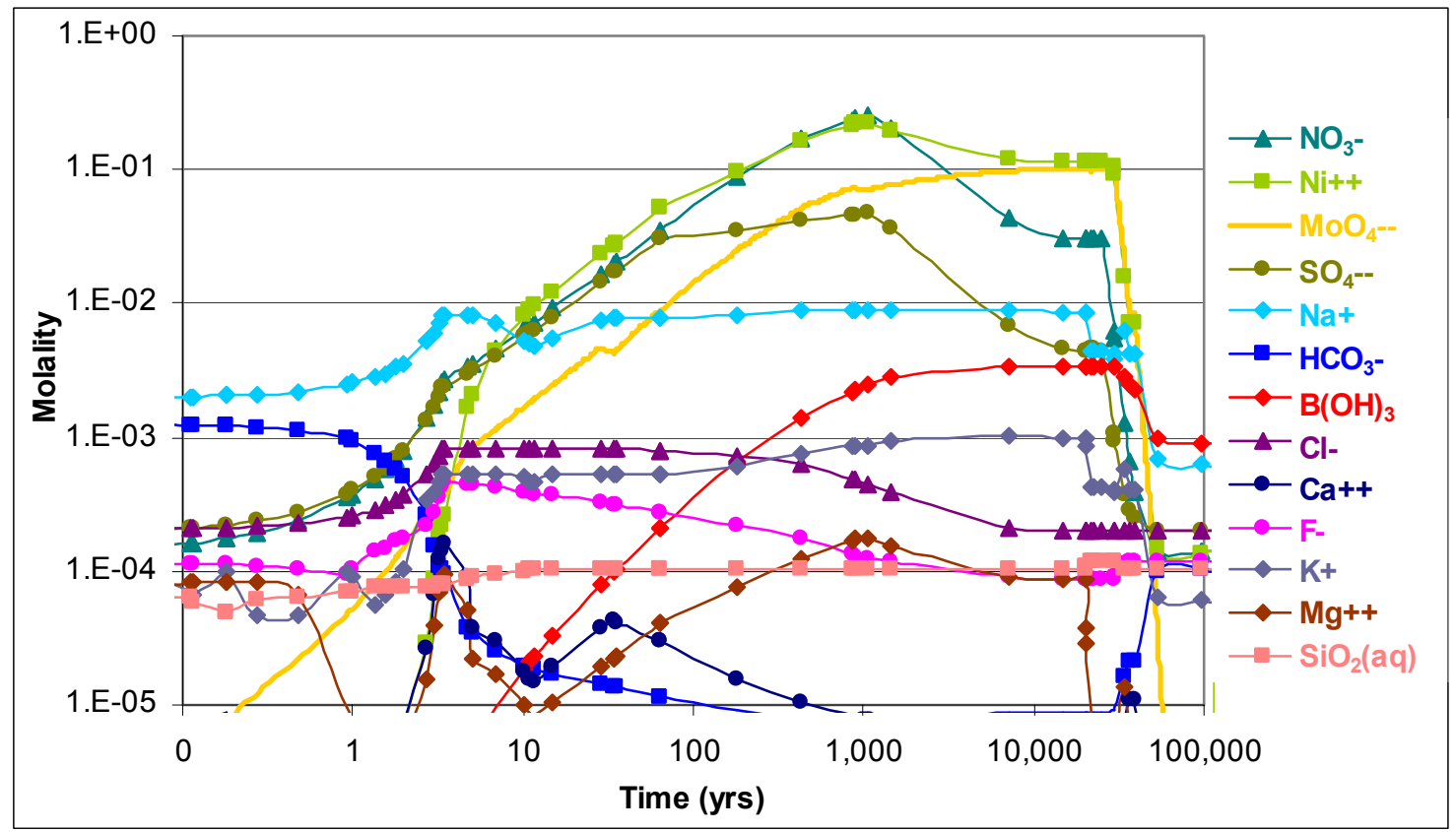

Source: CDSP Liquid Influx Model Output.xIs (Appendix F ISpreadsheets).

NOTE: Time refers to time after waste package breach ( 0 on the $x$-axis refers to 0.1 years).

Figure 6-14. CDSP Liquid-Influx Model Aqueous Species for the Base Case

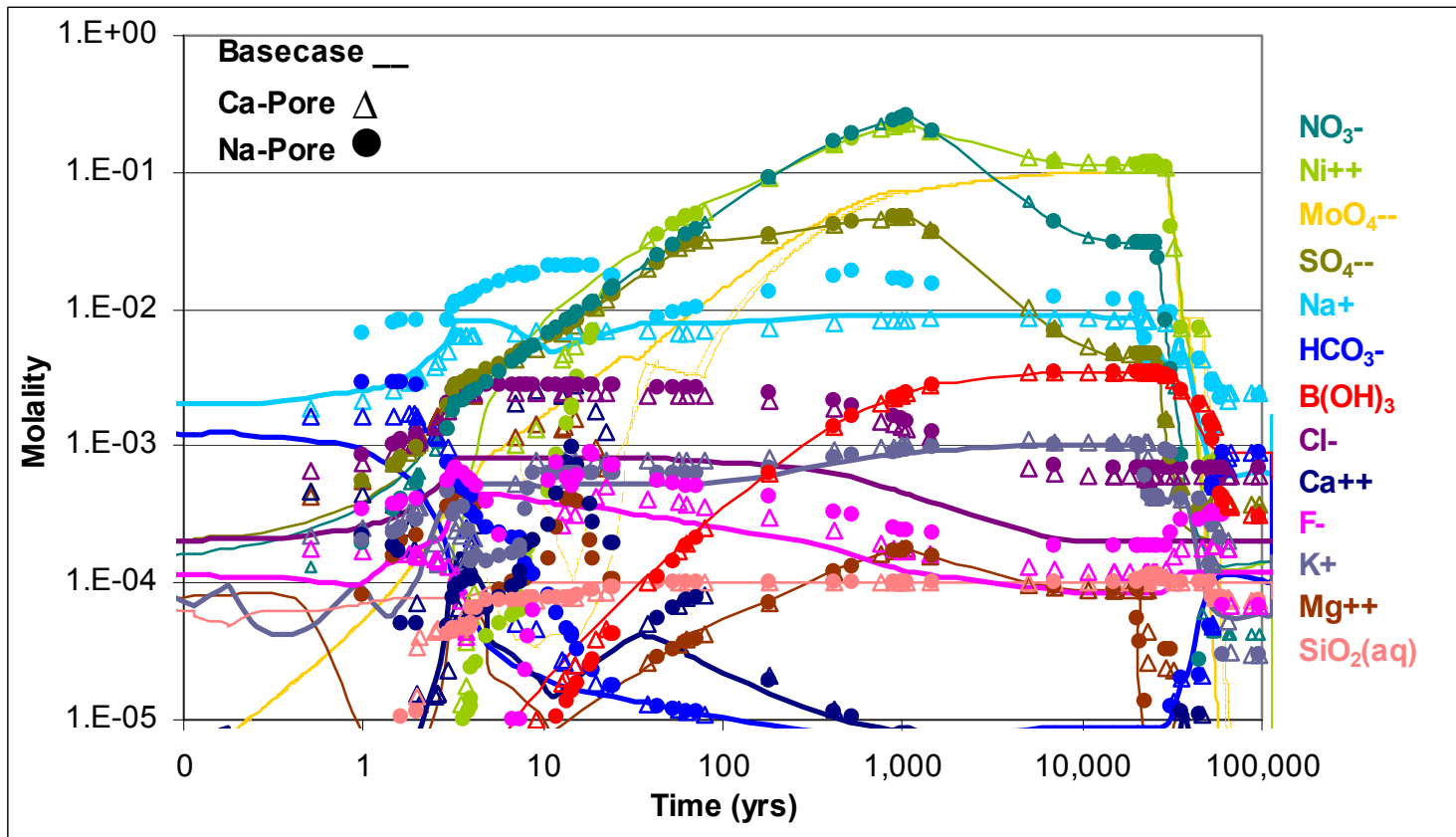

Source: CDSP Liquid Influx Model Output.xIs (Appendix F ISpreadsheets).

NOTE: Time refers to time after waste package breach ( 0 on the $x$-axis refers to 0.1 years).

Figure 6-15. CDSP Liquid-Influx Model Aqueous Species for Three Seepage Compositions 
Figures 6-14 and 6-15 display the aqueous species for the CDSP base case and for three seepage compositions respectively. Similar to CSNF, Figures 6-14 and 6-15 also show elements that were not present in the initial water compositions (Table 4-2) (i.e., those elements originating from the waste package and waste forms) have aqueous species concentrations nearly identical, and independent of the initial water composition, for the duration of the simulations. Nickel, sodium and boron have the highest concentrations, and either originated from HLWG dissolution or from the oxidation of the metal waste package components (in the case of nickel). Elements not originating from the waste form or package components and not participating in the formation of minerals will have aqueous species concentrations set by the incoming water composition (e.g., chloride).

Further examination of Figure 6-14 shows that the reactants dissolve as a function of time (i.e., kinetic reactants) and their effect on the in-package chemistry is explicitly modeled in the in-package chemistry model and, thus, is carried over to TSPA-LA. The above discussion addresses the subject matter of "Included" FEP 2.1.09.07.0A (Reaction kinetics in waste package) and indicates how that subject matter has been included and addressed within TSPA-LA.

\subsection{Ionic Strength}

Figure 6-16 displays the ionic strength profiles for the CDSP base case. The base case considers a reasonable representation of inputs: a flux of $1 \mathrm{~L} / \mathrm{yr}$, median rates for all of the alloys and fuels and $\mathrm{J}-13$ well water, at $25^{\circ} \mathrm{C}, \log f \mathrm{CO}_{2}=-3$, and $\log f \mathrm{O}_{2}=-0.7$. The ionic strength abstraction is used by the colloid and Dissolved Concentration Limits of Radioactive Elements submodels in the TSPA-LA. The colloidal suspensions are unstable at ionic strength values above $0.05 \mathrm{~mol} / \mathrm{L}$ (BSC 2004 [DIRS 170025]). For the Dissolved Concentration Limits of Radioactive Elements model (BSC 2005 [DIRS 173873]), TSPA-LA applies an additional uncertainty term to the concentrations if the ionic strengths is greater than one molal. 


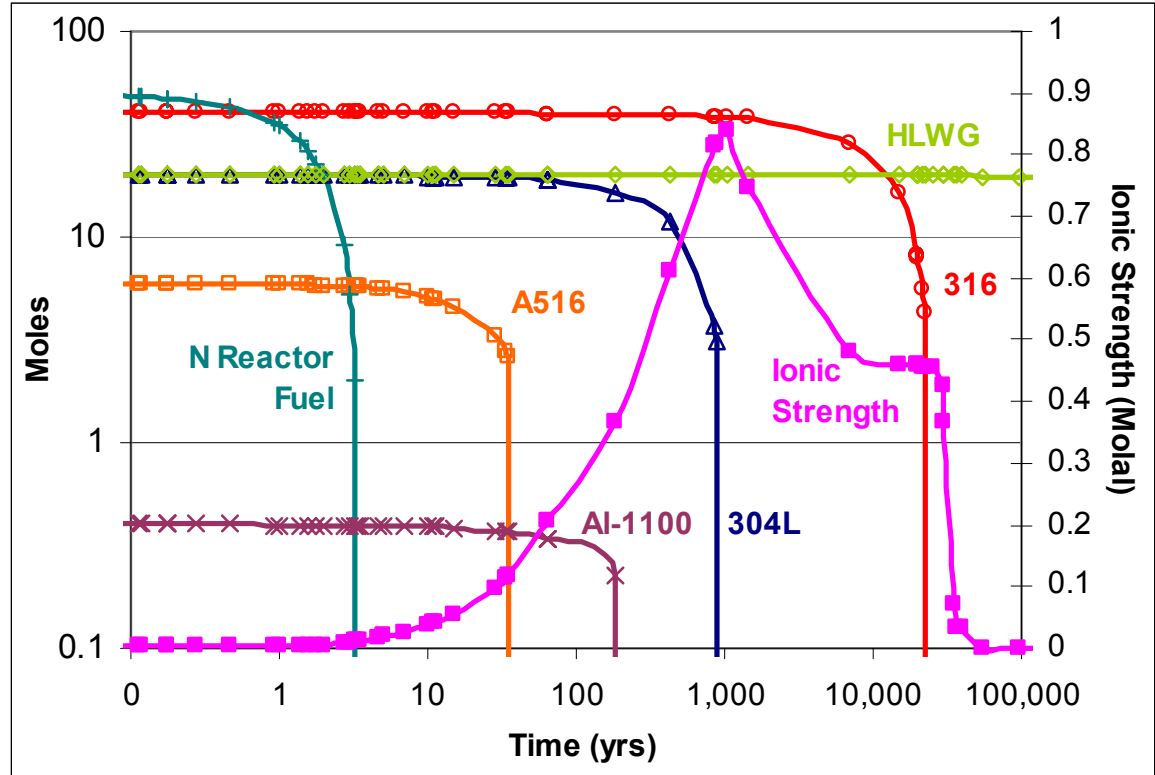

Source: CDSP Liquid Influx Model Output.xIs (Appendix F ISpreadsheets).

NOTE: $\quad$ Time refers to time after waste package breach ( 0 on the $x$-axis refers to 0.1 years).

Figure 6-16. CDSP Liquid-Influx Base Case Reactant Summary and lonic Strength

Figure 6-16 shows ionic strength results with the reactant summary. The ionic strength curve shows cusps as a response to the depletion of each of the reactants; the most noticeable cusps occurring after the depletion of Stainless Steel Type 304L, and then Stainless Steel Type 316.

\subsubsection{Vapor-Influx Model Results}

For simplicity and comparison purposes, each of the single component runs considers the liter of water to be in contact with $4,000 \mathrm{~cm}^{2}$ of available surface area $(4,000=1$ liter of water, spread over each reactant $0.25 \mathrm{~cm}$ thick). One exception to this surface area is for the aluminum alloy (Aluminum Alloy 6061 and Aluminum Alloy 1100) single component cases, which use a surface area of $2,000 \mathrm{~cm}^{2}$. Modifying the surface area for this run does not impact the results because the single component runs were conducted to examine the steady state chemistry generated by each reactant. Therefore, the relative degradation rate is not important for this case. The main mineral that forms in the aluminum alloy single component runs is gibbsite, and the formation of gibbsite consumes more water that any of the other minerals, such as hematite and schoepite. When the runs were conducted with a surface area of $4,000 \mathrm{~cm}^{2}$, the water was being consumed much faster than it was entering, so the surface area was divided in half to allow the runs to converge. However, the steady state $\mathrm{pH}$ and ionic strength for both runs are exactly the same (e.g., the steady state $\mathrm{pH}$ for Al-1100 is 6.70 and the ionic strength is 0.0001156 molal (see Appendix F/Spreadsheets/CDSP Vapor Influx Model Output.xls in).

\subsubsection{CSNF Output}

Figure 6-17 displays the EQ6 results of the CSNF single component runs. The pH profiles in Figure 6-17 are plotted as a function of reaction progress (the EQ6 zi $(\xi)$ variable is moles reacted) rather than time elapsed. Plotting the results in this manner allows reactants' different 
degradation rates to be compared with each other. This figure provides information on how each waste package component contributes to the in-package $\mathrm{pH}$ and shows the upper- and lower-pH bounds for the components in the CSNF package.

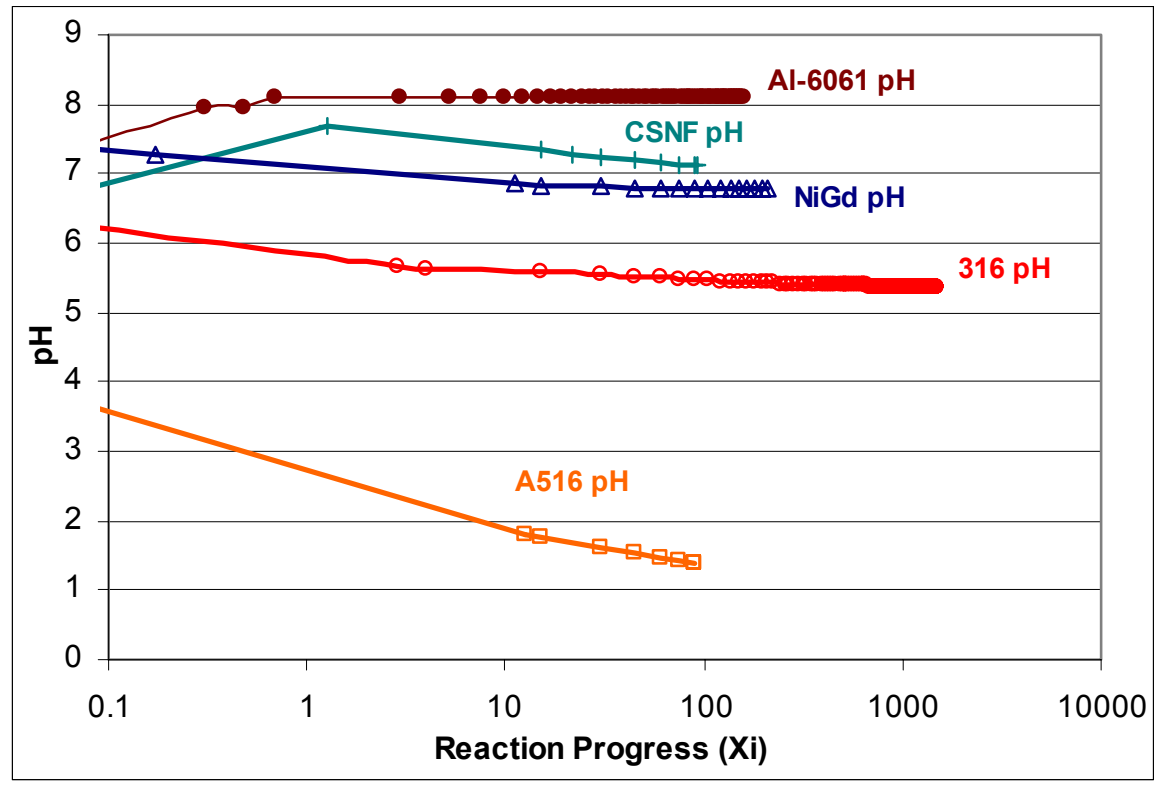

Source: $\quad$ CSNF Vapor Influx Model Output.xls in Appendix F.

Figure 6-17. CSNF Single-Component Vapor Influx pH Outputs

The low $\mathrm{pH}$ resulting from Carbon Steel Type A516 corrosion is due to the combination of oxidation of sulfur, the large quantity of Carbon Steel Type A516, and its high corrosion rate relative to the other waste package components. When the surface complexation model is applied to the batch reactor results, $\mathrm{pH}$ values do not reduce below 4.5. In addition, the oxidation layer that would form on degrading steels would also slow degradation and further buffer the $\mathrm{pH}$, though this effect is not modeled (Section 5.2). Aluminum Alloy 6061 and CSNF have neutral to slightly basic $\mathrm{pH}$ profiles, while Stainless Steel Type 316 and NiGd alloy have slightly acidic $\mathrm{pH}$ profiles. The trends observed in the $\mathrm{pH}$ are a function of the mineral phases becoming saturated and then precipitating as more and more reactant is added to solution.

The CSNF vapor-influx base case is shown in Figure 6-18. The base case considers a reasonable representation of inputs by using median or most likely values: a flux of $1 \mathrm{~L} / \mathrm{yr}$, median rates for the alloys and fuels, and $100 \%$ cladding exposure at $\log f \mathrm{CO}_{2}=-3$, and $\log f \mathrm{O}_{2}=-0.7$. The incoming water composition is deionized water and the runs were conducted at $25^{\circ} \mathrm{C}$.

The most acid-producing profiles include those for the single component run Carbon Steel Type A516 profile shown in Figure 6-17 and in the base case, during the 0- to 600-year period in Figure 6-18, while the Carbon Steel Type A516 is degrading. The early-time $\mathrm{pH}(<100$ years) is controlled by Carbon Steel Type A516 dissolution, the middle period (100 to 1,000 years) by Aluminum Alloy 6061 dissolution, and greater than 1,000 years by equilibrium with the corrosion products. The peak in $\mathrm{pH}$ at around 1,000 years also occurs in the liquid-influx case, and is explained in detail in Section 6.5.1.1.1 and in Appendix A. 
Figure 6-19 displays the ionic strength profiles for the CSNF vapor-influx base case. Under vapor influx conditions, the interior of the waste package is dry at the moment of waste package breach. With time, the humidity of the interior of the waste package will equilibrate to the ambient drift conditions and water will begin to adsorb or condense to the interior waste package components. The ratio of water to reactants is initially small and increases with time, so the ionic strength will initially be high and decrease with time as more water enters the system. This effect is not captured by the vapor influx EQ6 model because the batch reactor model considers the water needed for the model to be instantly available once the waste package breaches, rather than the water taking time to accumulate in the waste package (Section 6.3.1.1). However, this effect is accounted for in the ionic strength model abstraction (Section 6.10.2).

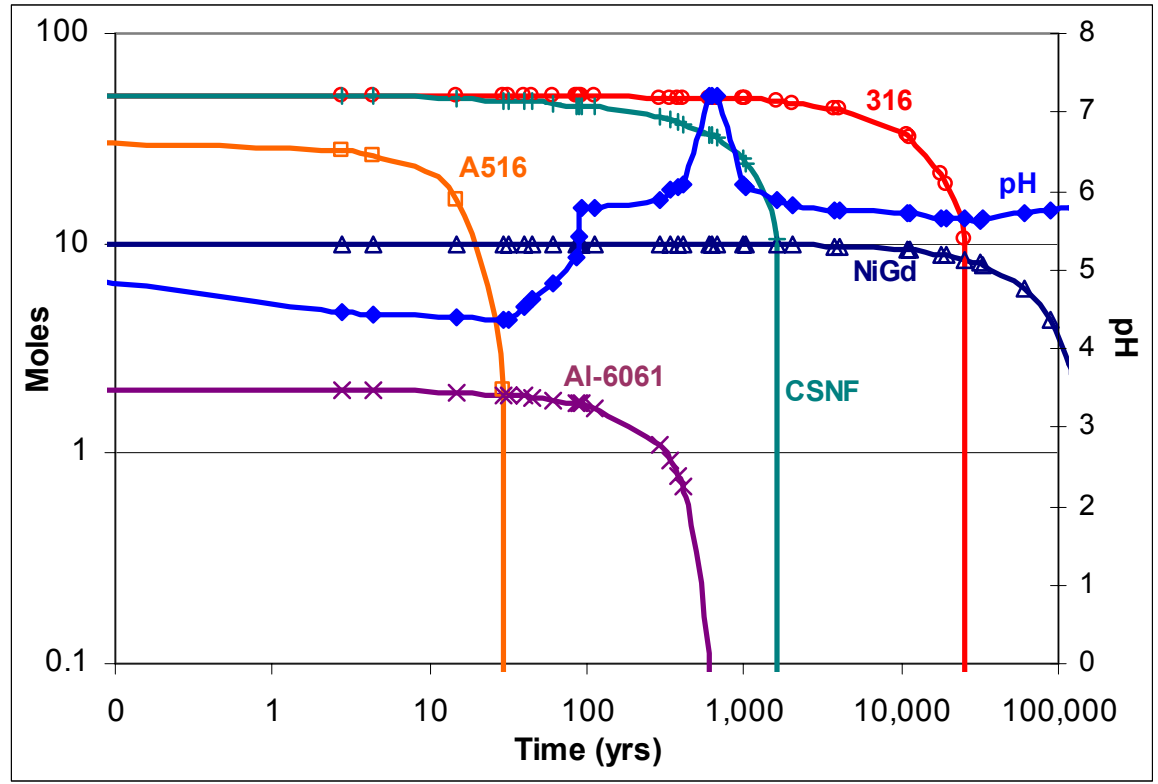

Source: $\quad$ CSNF Vapor Influx Model Output.xls in Appendix F.

NOTE: $\quad$ Time refers to time after waste package breach ( 0 on the $x$-axis refers to 0.1 years).

Figure 6-18. CSNF Vapor-Influx Reactant Summary pH Profile 


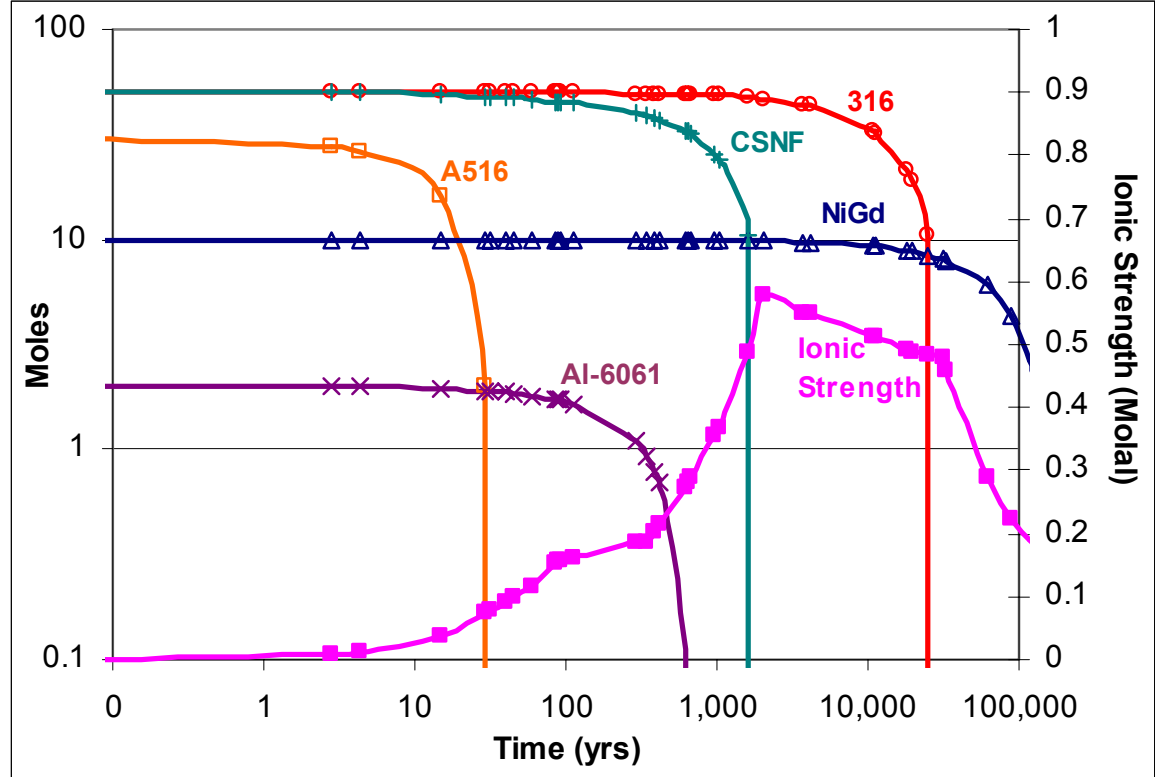

Source: CSNF Vapor Influx Model Output.xIs (Appendix F ISpreadsheets).

NOTE: Time refers to time after waste package breach ( 0 on the $x$-axis refers to 0.1 years).

Figure 6-19. CSNF Vapor-Influx Reactant Summary and lonic Strength

Figure 6-20 compares the vapor influx base-case model and the liquid-influx model $\mathrm{pH}$ values. This figure shows that the two cases are similar, except for the $\mathrm{pH}$ values at early times, due to the use of deionized water as opposed to J-13 well water in the vapor-influx case. Also, the $\mathrm{pH}$ is different at later times due to the accumulation of water described in Section 6.3.1.1.

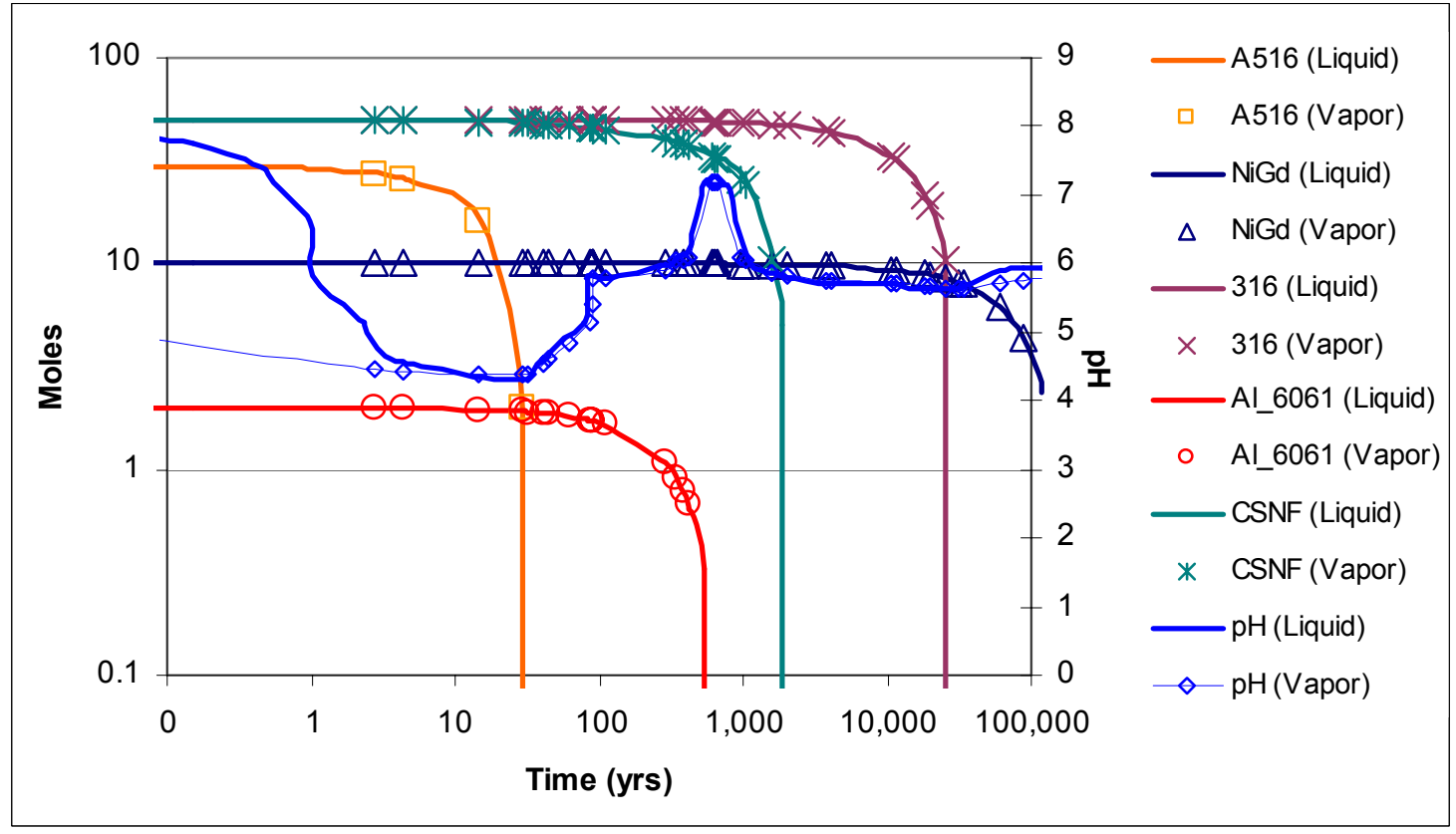

Source: $\quad$ CSNF Water Influx Model Output.xIs (Appendix F ISpreadsheets).

NOTE: $\quad$ Time refers to time after waste package breach ( 0 on the $x$-axis refers to 0.1 years).

Figure 6-20. Comparing the Vapor and Liquid-Influx Cases for CSNF pH 


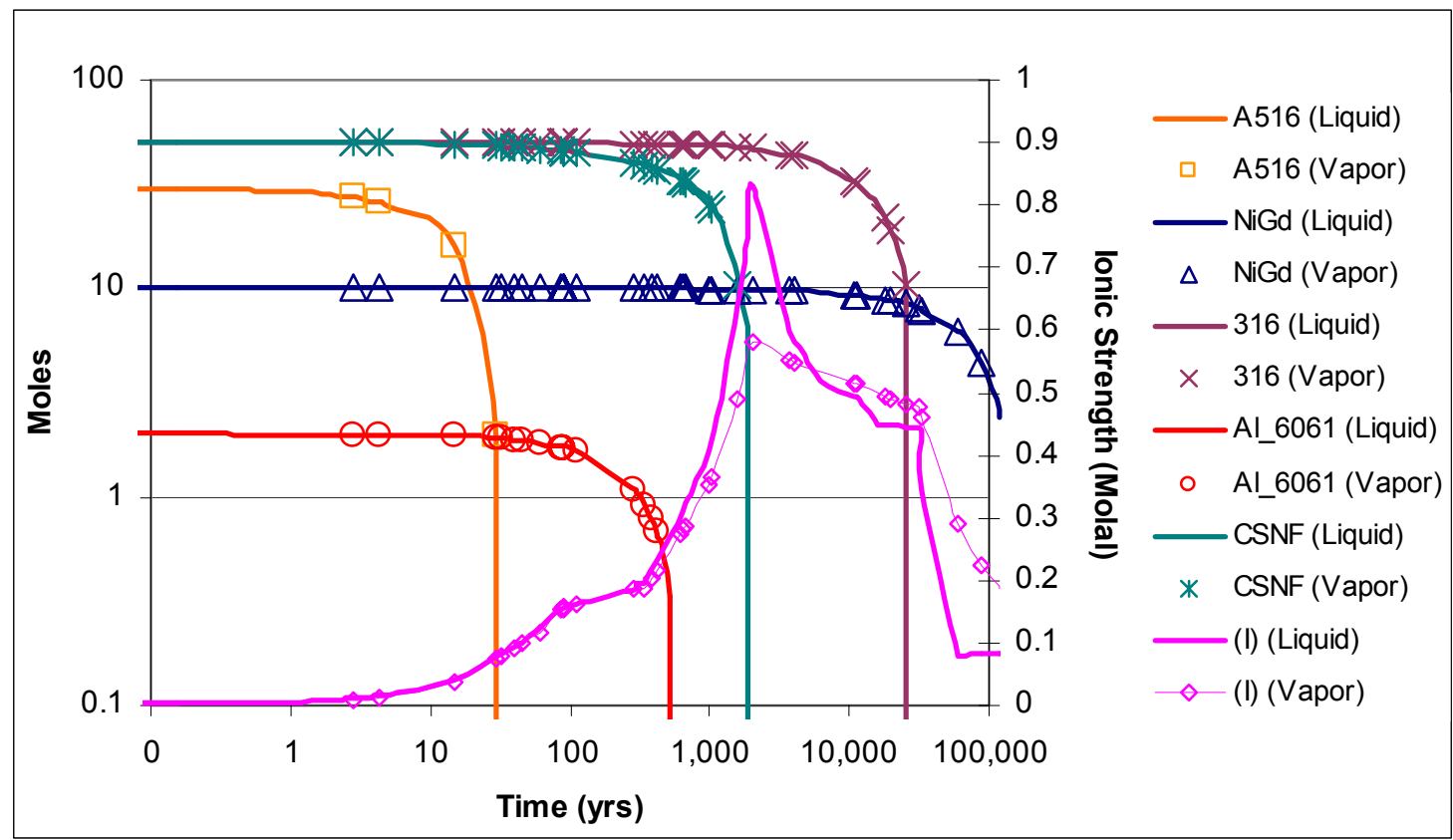

Source: CSNF Water Influx Model Output.xls (Appendix F ISpreadsheets).

NOTE: Time refers to time after waste package breach ( 0 on the $x$-axis refers to 0.1 years).

Figure 6-21. Comparing the Vapor and Liquid-Influx Cases for CSNF Ionic Strength

Figure 6-21 compares the ionic strength for the vapor-influx base-case model and the liquidinflux model. This figure shows that the two cases are similar, except that the ionic strength for the vapor-influx case is lower at later times due to the accumulation of water described in Section 6.3.1.1.

\subsubsection{CDSP Output}

Figure 6-22 displays the EQ6 output-pH profiles for the CDSP waste package components. The $\mathrm{pH}$ profiles in Figure 6-22 are plotted as a function of reaction progress (the EQ6 zi $(\xi)$ variable is moles reacted) rather than time elapsed. Plotting the results in this manner allows reactants' different degradation rates to be compared with each other. The CDSP waste package displays a much wider variation in $\mathrm{pH}$ compared to the CSNF waste package (Figure 6-17). HLWG generates high-pH conditions due the high concentrations of sodium and potassium. Aluminum Alloy 1100, Stainless Steel Types 316 and 304L, and N-Reactor fuel fall in the middle of the $\mathrm{pH}$ range at approximately 5.7 to 6.2. Carbon Steel Type A516 is a strong acid generator at $\mathrm{pH}$ values of 1.5 to 2 .

The CDSP base-case results, which include all of the waste package components, are displayed in Figure 6-23. The CDSP vapor-influx base case considers a reasonable representation of inputs by using median or most likely values: a flux of $1 \mathrm{~L} / \mathrm{yr}$, median rates for all of the alloys and fuels at $\log f \mathrm{CO}_{2}=-3$, and $\log f \mathrm{O}_{2}=-0.7$. The incoming water composition is deionized water and the runs were conducted at $25^{\circ} \mathrm{C}$. The low end of the $\mathrm{pH}$ range in Figure 6-22 is not reproduced in the base-case results (Figure 6-23). The low $\mathrm{pH}$ generated by the Carbon Steel Type A516 (Figures 6-22 and 6-23) is mitigated due to the pH-buffering capacity that HLWG and N-Reactor fuel provide. 


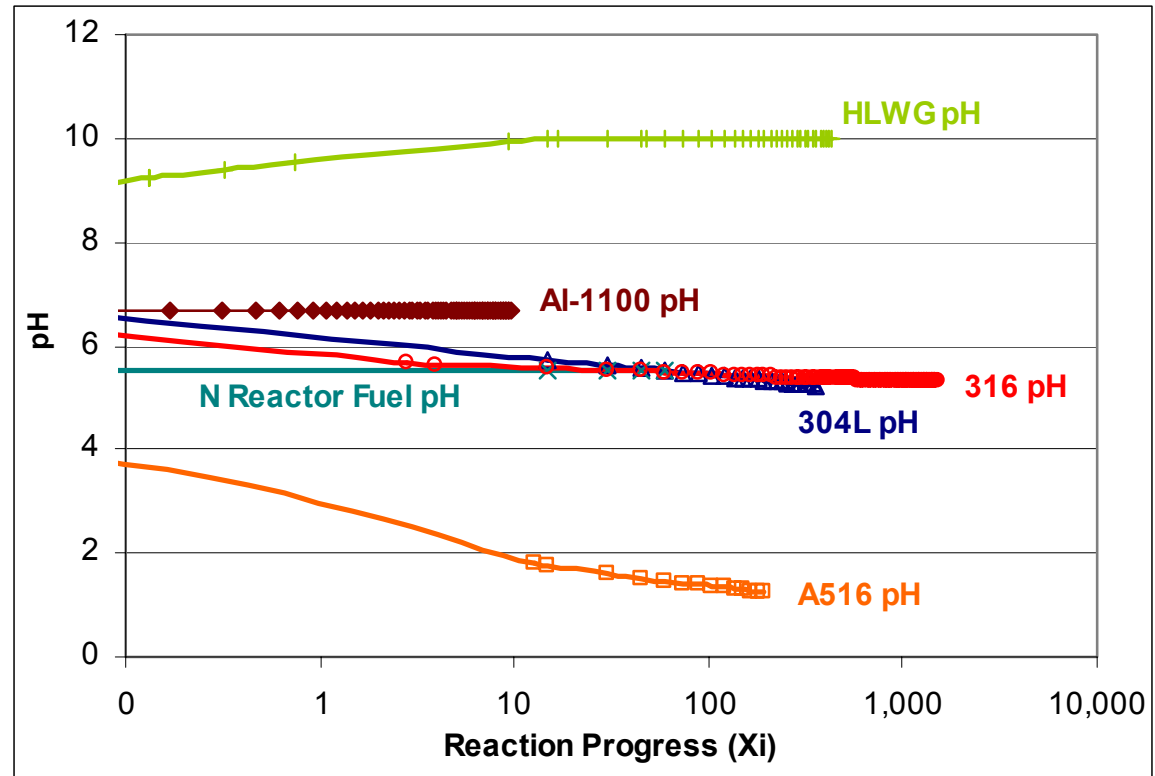

Source: $\quad$ CDSP Vapor Influx Model Output.xls (Appendix F).

NOTE: $\quad$ Time refers to time after waste package breach ( 0 on the $x$-axis refers to 0.1 years).

Figure 6-22. CDSP Single-Component Vapor Influx Results

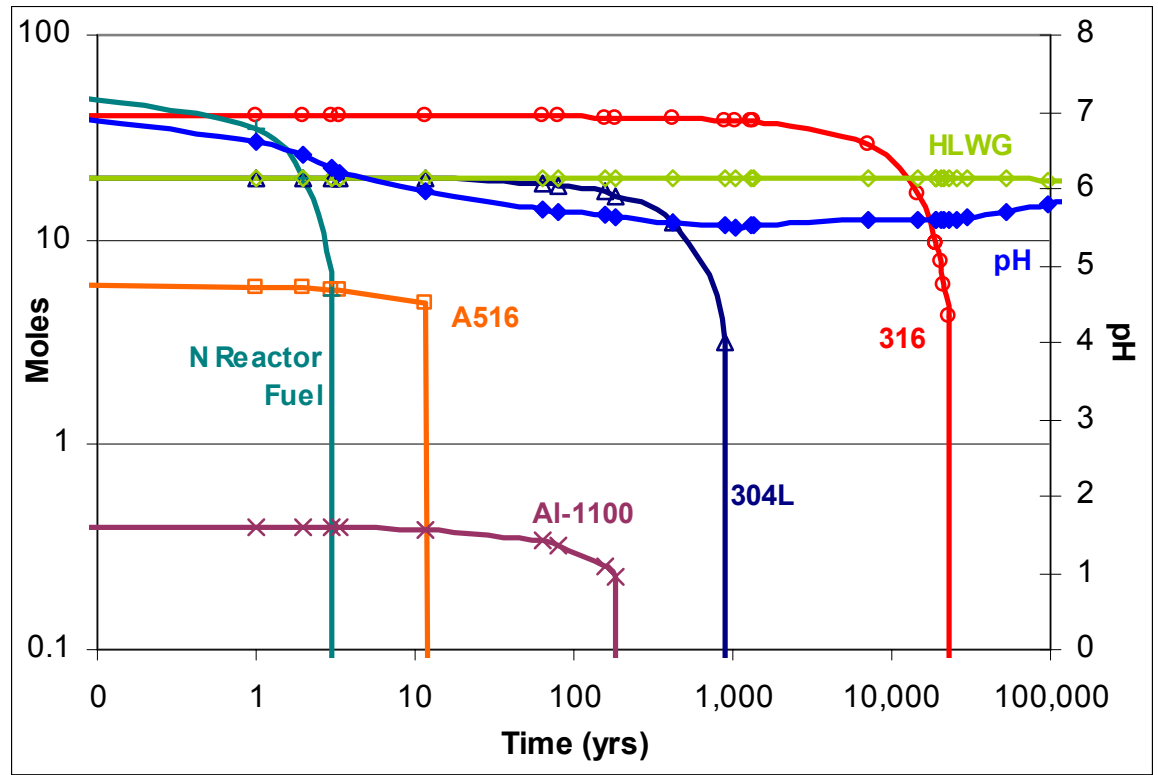

Source: $\quad$ CDSP Vapor Influx Model Output.xls (Appendix F).

NOTE: $\quad$ Time refers to time after waste package breach ( 0 on the $x$-axis refers to 0.1 years).

Figure 6-23. CDSP Vapor-Influx Reactant Summary pH Profile

The base case includes HLWG and N-Reactor fuels as reactants; thus, the resulting chemistry of the reacted solutions $(\mathrm{pH} \cong 6)$ reflects interactions between the codisposed waste, the waste package components that are not spent nuclear fuel, the liquid phase water, and the atmosphere 
in the voids in the waste package and drift. The above discussion addresses the subject matter of "Included" FEP 2.1.01.02.0B (Interactions between co-disposed waste) and indicates how that subject matter has been included and addressed within TSPA-LA. In addition, the fuel and metal alloys are kinetic reactants that undergo oxidation and precipitate corrosion products that are in contact with the liquid phase water, thereby having a first order influence on the chemistry. The above discussion addresses the subject matter of "Included" FEP 2.1.09.02.0A (Chemical interaction with corrosion products) and indicates how that subject matter has been included and addressed within TSPA-LA.

High-pH conditions are only realized in the single-component simulation for HLWG. In the base case, after the metal alloys have been exhausted, the $\mathrm{pH}$ starts to increase slowly due to the HLWG, but even at 100,000 years, $\mathrm{pH}$ is still below 6 because the glass dissolution rate is slow. HLWG is contained in Stainless Steel Type 304L canisters in which the steels will moderate the basic conditions generated by HLWG dissolution and maintain neutral-pH conditions inside the waste package, well past 20,000 years. The presence of schoepite, resulting from N-Reactor fuel degradation, and large quantity of steel in the waste package limits the potential of generating high-pH conditions in the CDSP waste package.

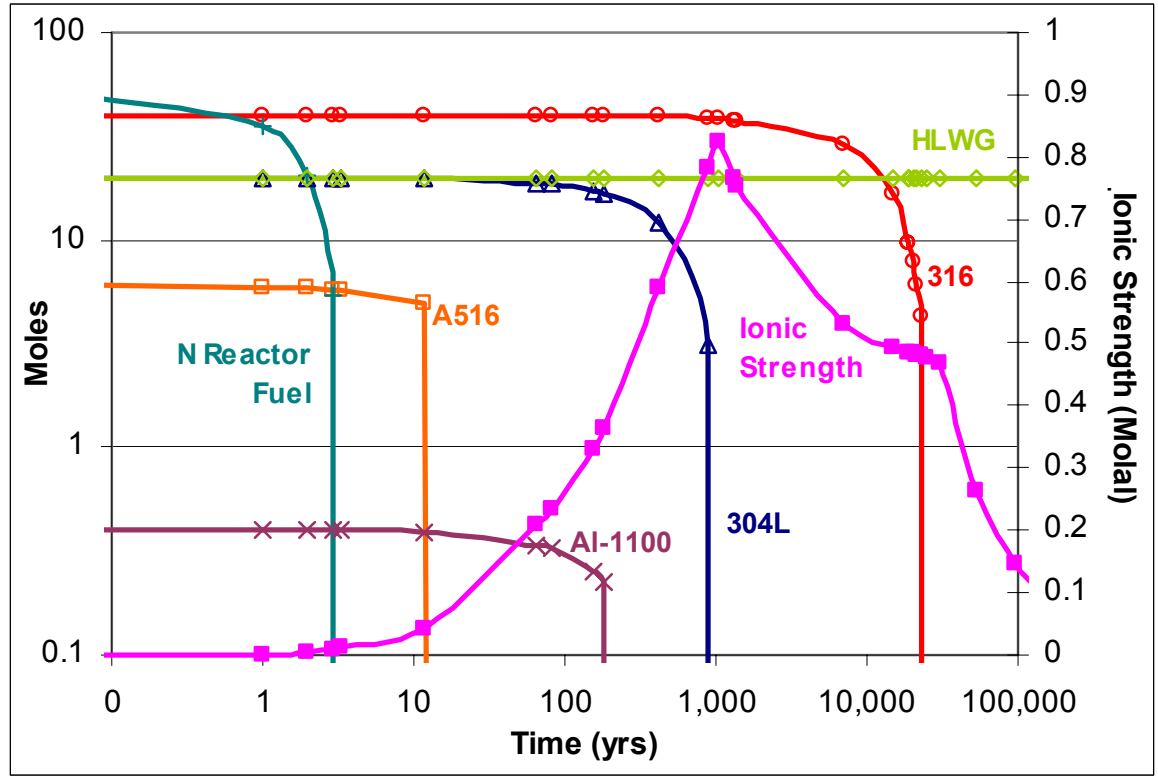

Source: $\quad$ CDSP Vapor Influx Model Output.x/s (Appendix F).

NOTE: $\quad$ Time refers to time after waste package breach ( 0 on the $x$-axis refers to 0.1 years).

Figure 6-24. CDSP Vapor Influx Reactant Summary and lonic Strength Profiles

Figure 6-24 displays the ionic strength profiles for the CDSP vapor-influx model. Under vapor influx conditions, the interior of the waste package is dry at the moment of waste package breach. With time, the humidity of the interior of the waste package will equilibrate to the ambient drift conditions and water will begin to adsorb or condense to the interior waste package components. The ratio of water to reactants is initially small and increases with time, so the ionic strength will initially be high and decrease with time as more water enters the system. This effect is not captured by the vapor influx EQ6 model, because the batch reactor model considers 
the water needed for the model to be instantly available when the waste package breaches, rather than the water taking time to accumulate in the waste package (Section 6.3.1.1). However, this effect is accounted for in the ionic strength model abstraction (Section 6.10.2).

\subsubsection{Conceptual Model Conclusions}

The CSNF vapor-influx and liquid-influx models reacted solutions results reflect interactions between CSNF, waste package components, liquid-phase water, and the atmosphere in the voids in the waste package and drift. In addition, the reactants are kinetic reactants, the metal alloys undergo oxidation and precipitate corrosion products in contact with the liquid phase water (thereby, having a first order influence on the chemistry) and increased temperature was investigated. The above discussion addresses the subject matter of the following "Included FEPs," and indicates how that subject matter has been included and addressed within TSPA-LA:

- 2.1.02.09.0A, Chemical effects of void space in waste package

- 2.1.09.01.0B, Chemical characteristics of water in the waste package

- 2.1.09.02.0A, Chemical interaction with corrosion products

- 2.1.09.06.0A, Reduction - oxidation potential in waste package

- 2.1.09.07.0A, Reaction kinetics in waste package

- 2.1.11.08.0A, Thermal effects on chemistry and microbial activity in the EBS

- $2.2 .08 .12 .0 \mathrm{~B}, \mathrm{Chemistry}$ of water flowing into the waste package.

The CDSP vapor-influx and liquid-influx model runs include high-level radioactive waste and N-Reactor fuels as reactants; thus, the resulting chemistry of the reacted solutions reflects interactions between codisposed waste, the nonspent nuclear fuel waste package components, the liquid phase water, and the atmosphere in the voids in the waste package and drift. In addition, the reactants are kinetic (the fuel and metal alloys undergo oxidation and precipitate corrosion products in contact with the liquid phase water); thereby, having a first order influence on the chemistry. The above discussion addresses the subject matter of the following "Included FEPs," and indicates how that subject matter has been included and addressed within TSPA-LA:

- 2.1.01.02.0B, Interactions between codisposed waste

- 2.1.02.09.0A, Chemical effects of void space in waste package

- 2.1.09.01.0B, Chemical characteristics of water in the waste package

- 2.1.09.02.0A, Chemical interaction with corrosion products

- 2.1.09.07.0A, Reaction kinetics in waste package

- $2.2 .08 .12 .0 \mathrm{~B}, \mathrm{Chemistry}$ of water flowing into the waste package.

\subsection{BATCH REACTOR SENSITIVITY ANALYSES}

Sensitivity analyses were performed to:

1. Determine uncertainty ranges

2. Demonstrate how various inputs (waste package design configuration, water to reactant ratio) impact the model output. 
The sensitivity analyses consider that variations in a model input will translate to the model output independent of the modeled scenario. For example, decreasing the corrosion rate of the steels used in the waste package for a specific fuel exposure-flux scenario has the effect of delaying the timing of a $\mathrm{pH}$ response. Therefore, it is expected that an equivalent model response will occur for a different fuel exposure-flux scenario.

The sensitivities in this section are all compared to the liquid-influx base-case model described in Section 6.5. Based on Figures 6-20 and 6-21, which show similar results for the liquid-influx and vapor-influx models, the liquid-influx model base case can be considered representative of the vapor-influx model for the purposes of these sensitivities. The base case considers a reasonable representation of inputs by using median or most-likely values: a flux of $1 \mathrm{~L} / \mathrm{yr}$, median rates for all of the alloys and fuels, and $100 \%$ cladding exposure, at $\log f \mathrm{CO}_{2}=-3$, and $\log f \mathrm{O}_{2}=-0.7$. The incoming water composition is $\mathrm{J}-13$, and the runs were conducted at $25^{\circ} \mathrm{C}$.

Some of the sensitivities were not updated from Rev 03 of this report, so for these cases Cr(VI) was allowed to form instead of $\mathrm{Cr}(\mathrm{III})$. The source for the input to these sensitivities is documented in Rev03 of this report, and the figures can be found in DTN: MO0411SPAMOICA.000 [DIRS 172244]. These sensitivities include Sections 6.6.1, 6.6.8, and 6.6.12. The rationale and impacts of using $\mathrm{Cr}$ (III) versus $\mathrm{Cr}$ (VI) are discussed in Section 6.6.3. The purpose of a sensitivity analysis is to observe the model response to varying certain inputs. For example, Section 6.6.1 examines different ratios of water to reactants and shows that increasing the ratio of water to reactants changes neither the minimum or maximum $\mathrm{pH}$ observed nor the shape of the $\mathrm{pH}$ profile, but increasing this ratio delays the timing of the minimum or maximum $\mathrm{pH}$. This sort of trend is important in assessing which factors to include in the model abstraction. In this example, because the $\mathrm{pH}$ abstraction is not time dependent, and the ratio of water to reactants does not impact the range of $\mathrm{pH}$, the ratio of water to reactants is not included in the model abstraction. If this sensitivity study were to be conducted using $\mathrm{Cr}$ (III) instead of $\mathrm{Cr}(\mathrm{VI})$, the series of $\mathrm{Cr}(\mathrm{III})$ results would show a more-moderate $\mathrm{pH}$ profile than the $\mathrm{Cr}(\mathrm{VI})$ results. However, the trends of interest-that increasing the ratio of water to reactants results in the same $\mathrm{pH}$ range and profile shape, but the timing of the $\mathrm{pH}$ response is delayed-would be the same for both the $\mathrm{Cr}(\mathrm{III})$ and the $\mathrm{Cr}(\mathrm{VI})$ sensitivities. Likewise, for the other two sensitivity analyses that use Cr(VI), the change in HLWG composition, and the 5-DHLW/DOE SNF waste package design, the trends of interest shown in the sensitivity analyses-that altering the HLWG composition has very little impact on $\mathrm{pH}$, or that the 5-DHLW/DOE SNF waste package design does result in a lower $\mathrm{pH}$, but this $\mathrm{pH}$ is still within the range of $\mathrm{pH}$ values predicted by the model abstraction-using $\mathrm{Cr}(\mathrm{VI})$ would also be supported by sensitivity analyses using $\mathrm{Cr}$ (III). This logic also applies to the trends observed in ionic strength results. For this reason, results using $\mathrm{Cr}(\mathrm{VI})$ results are still credible for showing model response, and the use of the superceded DTN: MO0411SPAMOICA.000 [DIRS 172244] is justified. The sensitivity runs from Rev 03 were executed using the Ca-porewater, median seepage flux-fuel exposure case (filename: $\mathrm{C} 22 \mathrm{C} 25$ ) at $25^{\circ} \mathrm{C}$, with an equivalent set of runs executed for the codisposed case (filename: D23C25).

The sensitivity analyses in this section do not include the effects of the surface complexation model. The results of applying the surface complexation model to the batch reactor model are discussed in Section 6.9 with results shown in the plots. 


\subsubsection{Ratio of Water to Reactants}

The following runs were conducted to see the impact of varying the ratio of water to reactants. The highest ratio is that of the "bathtub," where all of the void space is filled with water. This ratio is decreased, and the impact on the $\mathrm{pH}$ and ionic strength are presented in Figures 6-25 and 6-26. The ratio of water to reactants is varied based on the surface area. For the "bathtub" case, if the liter of water were spread evenly over the scaled surface areas of the reactants, that layer of water would be approximately $0.58-\mathrm{cm}$ thick for the CSNF waste package and 0.69-cm thick for the CDSP waste package. In this sensitivity analysis, this ratio of water to reactants is examined based on the thickness of the layer of water that would result from one liter of water spread over the scaled surface areas for each case. For more details on the scaling used in this sensitivity, see CSNF.xls or CDSP.xls in DTN: MO0411SPAMOICA.000 [DIRS 172244].

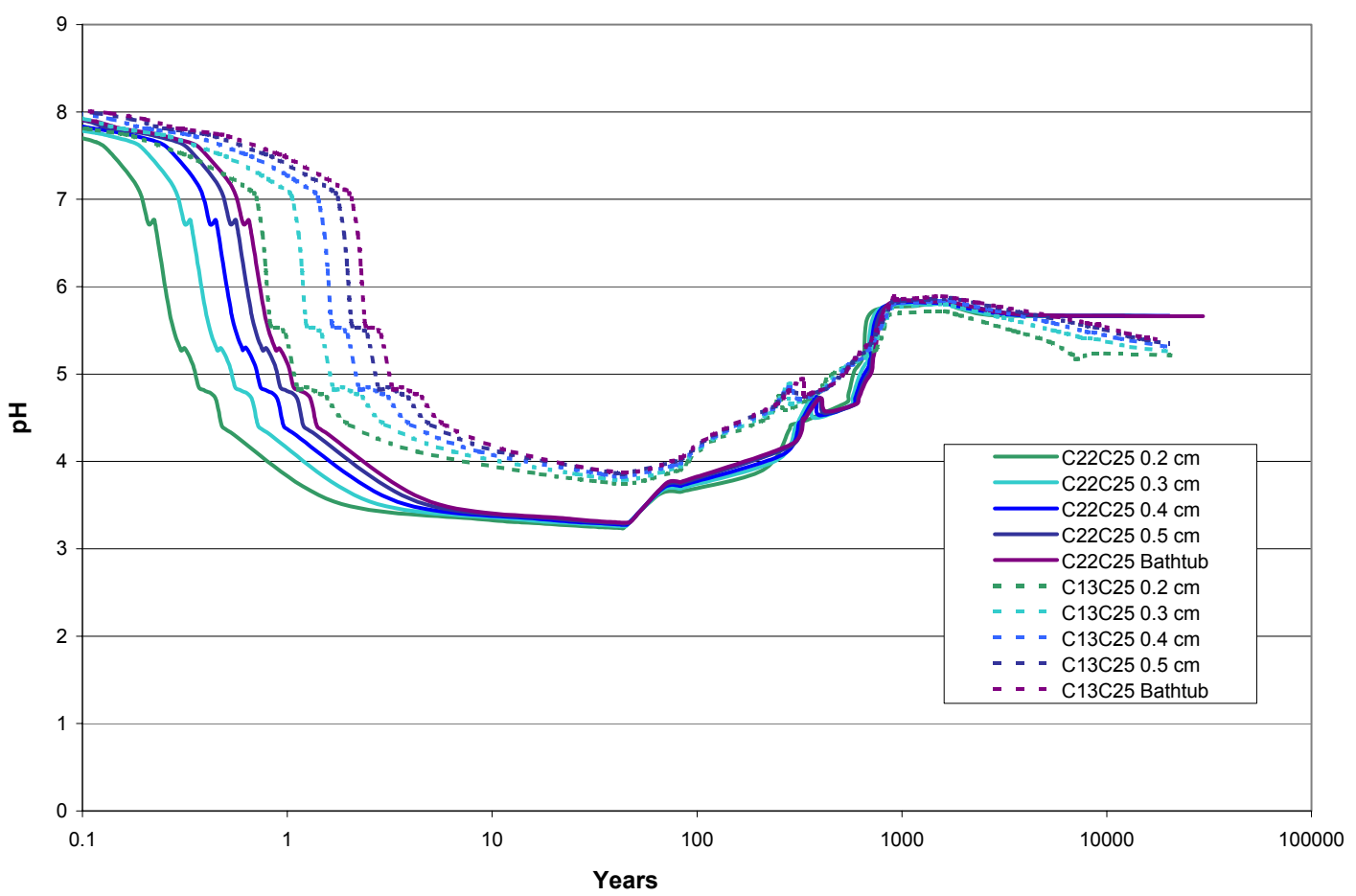

Source: $\quad$ CSNF_Water Ratio Sensitivity.xIs (DTN: MO0411SPAMOICA.000 [DIRS 172244]).

Note: $\quad$ Time refers to time after waste package breach. This sensitivity uses $\mathrm{Cr}(\mathrm{VI})$ rather than $\mathrm{Cr}(\mathrm{III})$.

Figure 6-25. Ratio of Water to Reactants for CSNF: Impact on $\mathrm{pH}$

Figures 6-25 and 6-27 show the ratio of water to reactants has little effect on the overall $\mathrm{pH}$ of the system for the CSNF and CDSP waste packages. The most notable effect is lower ratios of water-to-reactants see the $\mathrm{pH}$ values decrease earlier than the cases with a higher ratio, but the minimum and steady-state $\mathrm{pH}$ values are similar. This sensitivity uses $\mathrm{Cr}(\mathrm{VI})$ rather than $\mathrm{Cr}$ (III), but because all of these cases use the same oxidation state for chromium, $\mathrm{Cr}(\mathrm{VI})$, the important $\mathrm{pH}$ trends discussed above are a function of the quantity of water in the system and not the chromium oxidation state. The impacts of Cr(III) versus Cr(VI) are shown in Section 6.6.3. 
For the CSNF case, the water ratio sensitivity analysis also examined $\mathrm{C} 13 \mathrm{C} 25$ that uses the lowest water flux with the highest fuel exposure $(0.15 \mathrm{~L} / \mathrm{yr}$ and $100 \% \mathrm{CSNF}$ exposure) to maximize the impact to the chemistry. In addition, sensitivity also uses a case with the median seepage flux-fuel exposure case $\mathrm{C} 22 \mathrm{C} 25$ at $25^{\circ} \mathrm{C}$ (the representative case used for the sensitivities from Rev 03). For all cases, the results also show the same trend in $\mathrm{pH}$; the lower ratios of water to reactants see the $\mathrm{pH}$ values decrease earlier, but the minimum and steady-state $\mathrm{pH}$ values are similar. These results show that additional water in the system has minimal impact on $\mathrm{pH}$, which addresses two points dealing with the quantity of water that were raised while discussing code implementation in Section 6.3.1.1. In the vapor-influx case, where water accumulates in the EQ6 model (as opposed to the implementation in TSPA-LA with no accumulation of water), the impacts of this accumulating water on $\mathrm{pH}$ are minimal. In addition, the immediate availability of water in the described batch reactor model also has minimal impact on the $\mathrm{pH}$ value of the system. Therefore, the difference between the batch reactor modeling, and the conceptualization of the vapor influx within TSPA-LA has minimal impact.

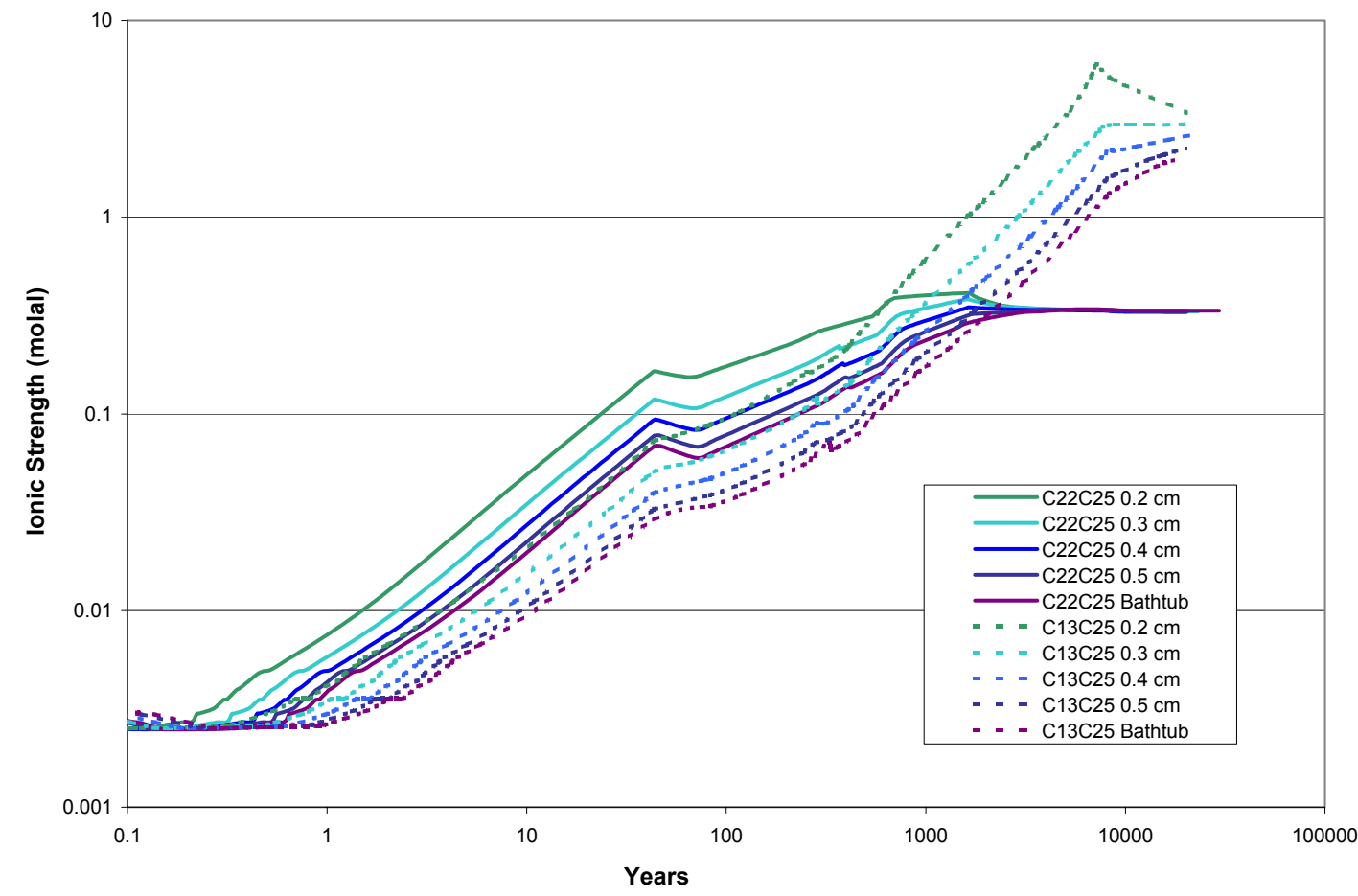

Source: CSNF_Water Ratio Sensitivity.xIs (DTN: MO0411SPAMOICA.000 [DIRS 172244]).

Note: $\quad$ Time refers to time after waste package breach. This sensitivity uses $\mathrm{Cr}(\mathrm{VI})$ rather than $\mathrm{Cr}(\mathrm{III})$.

Figure 6-26. Ratio of Water to Reactants for CSNF: Impact on lonic Strength 
D23C25

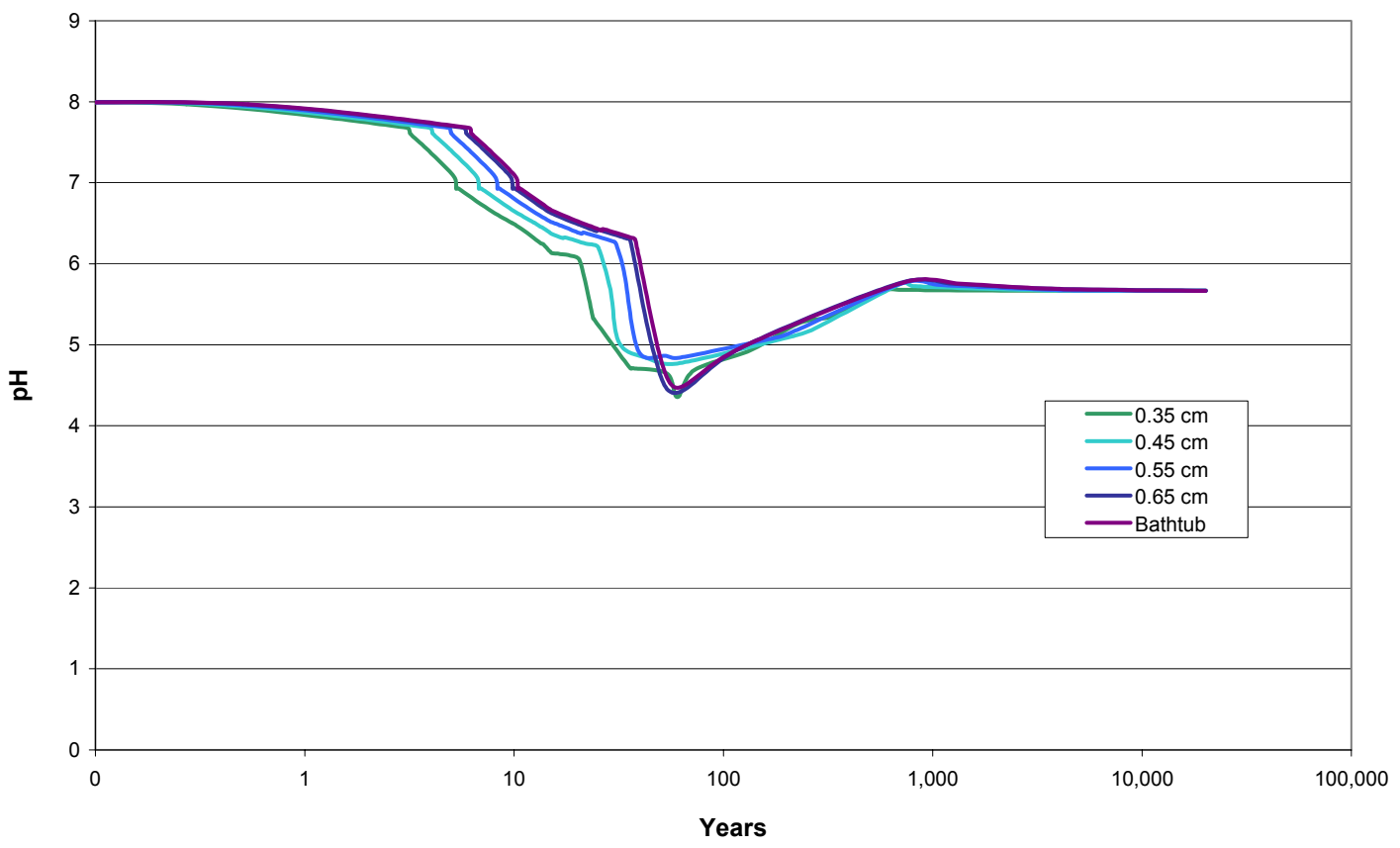

Source: $\quad$ CDSP_Water Ratio Sensitivity.xIs (DTN: MO0411SPAMOICA.000 [DIRS 172244]).

Note: $\quad$ Time refers to time after waste package breach ( 0 on the $x$-axis refers to 0.1 years).

This sensitivity uses $\mathrm{Cr}(\mathrm{VI})$ rather than $\mathrm{Cr}(\mathrm{III})$.

Figure 6-27. Ratio of Water to Reactants for CDSP: Impact on pH 


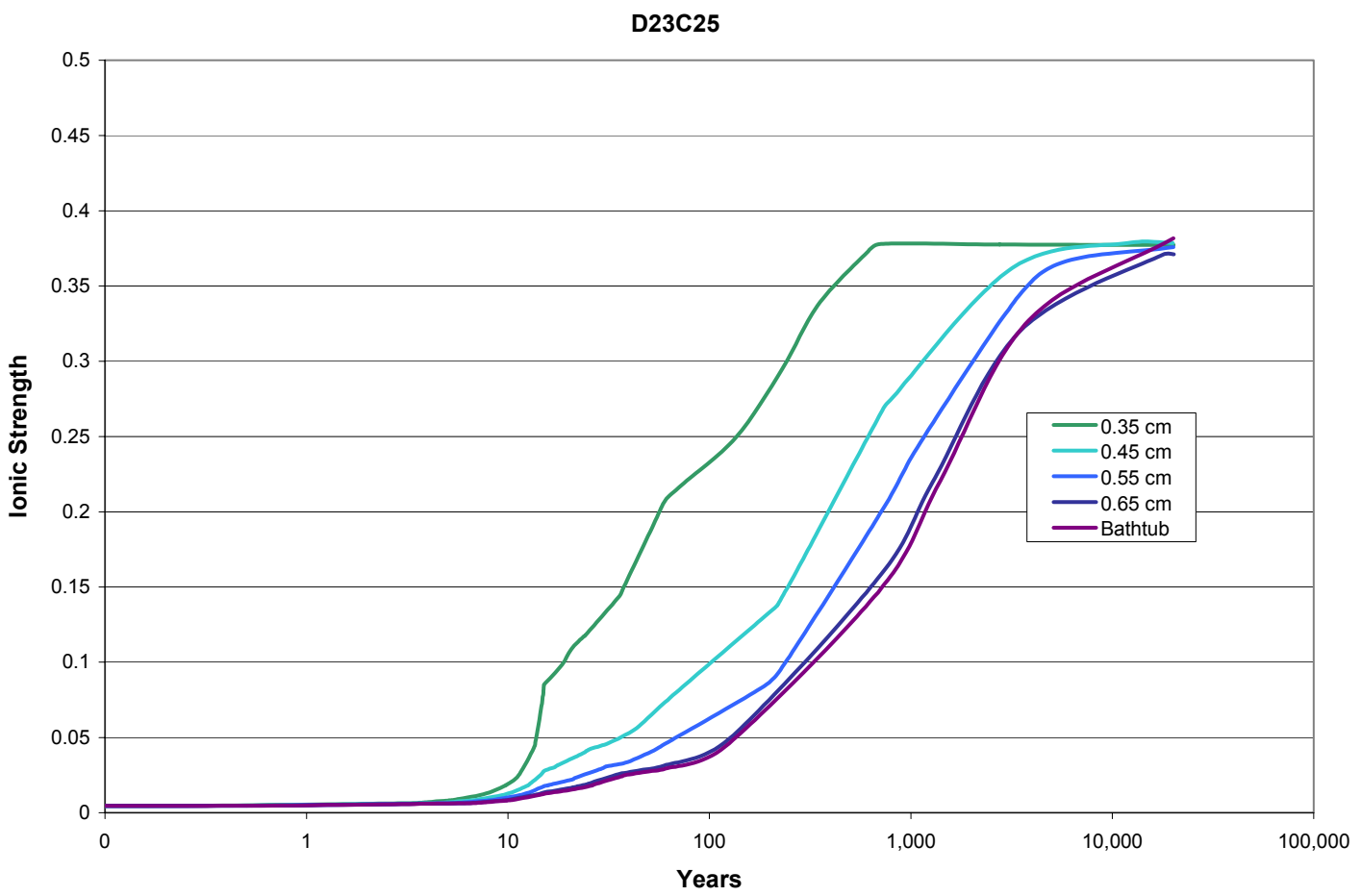

Source: CDSP_Water Ratio Sensitivity.xIs (DTN: MO0411SPAMOICA.000 [DIRS 172244]).

Note: $\quad$ Time refers to time after waste package breach ( 0 on the $x$-axis refers to 0.1 years).

This sensitivity uses $\mathrm{Cr}(\mathrm{VI})$ rather than $\mathrm{Cr}(\mathrm{III})$.

Figure 6-28. Ratio of Water to Reactants for CDSP: Impact on lonic Strength

The important trend shown in Figures 6-26 and 6-28 is the ratio of water to reactants affects the timing of the ionic strength response; lower ratios of water to reactants see the ionic strength increase earlier than the cases with a higher ratio, but the ionic strength maximum are similar. This sensitivity uses $\mathrm{Cr}(\mathrm{VI})$ rather than $\mathrm{Cr}(\mathrm{III})$; however, because all of these cases use the same oxidation state for chromium, $\mathrm{Cr}(\mathrm{VI})$, the ionic strength trends discussed above are due to the ratio of water to reactants, not the oxidation state of chromium, and are, therefore, still valuable.

The water ratios examined in this section use the base-case quantity of water as the minimum, and increase the ratio of water from there. If the quantity of water were decreased much lower than the base case, the ionic strength increases dramatically, well beyond the valid range of the model. For this reason, the ionic strength model includes additional uncertainty to account for the potential variation in water-to-reactants ratio. For the two points dealing with the quantity of water (raised in the code implementation discussion in Section 6.3.1.1), the effects of water accumulation on ionic strength must be addressed. The difference between the EQ6 batch reactor model and the conceptualization of the vapor-influx case within TSPA-LA is more significant for the ionic strength than for $\mathrm{pH}$. This difference leads to lower modeled ionic strengths at later times (due to accumulating water), and the immediate availability of water in the batch reactor model leads to lower modeled ionic strengths at early times.

Low ionic strengths $(<0.05 \mathrm{~mol} / \mathrm{L})$ are conservative for the TSPA-LA relative to colloid stability because colloids are stable and can transport radionuclides when the ionic strength is less than 
$0.05 \mathrm{~mol} / \mathrm{L}$ (BSC 2004 [DIRS 170025]). High ionic strengths ( $>1$ molal) are conservative for the TSPA-LA relative to the dissolved concentrations of radionuclides because the TSPA-LA increases the uncertainty applied to the Dissolved Concentration Limits of Radioactive Elements (BSC 2005 [DIRS 173873]), increasing the concentrations of radionuclides in solution. Ionic strengths between 0.05 and 1 molal are the least conservative to the TSPA-LA relative to the transport of radionuclides. Therefore, the uncertainty applied to the ionic strength should be broad enough to encompass extreme ionic strengths resulting in an overall representative output to the TSPA-LA that does not minimize risk.

The above discussion addresses the subject matter of "Included" FEP 2.1.02.09.0A (Chemical effects of void space in waste package) and indicates how that subject matter has been included and addressed within TSPA-LA.

\subsubsection{Thermally Perturbed Fluids}

This section uses three thermally perturbed fluid compositions abstracted in Engineered Barrier System: Physical and Chemical Environment Model (BSC 2004 [DIRS 169860], Section 6.6) as input for the in-package chemistry model.

The three waters have different carbon dioxide fugacity $\left(f \mathrm{CO}_{2}\right)$ and temperatures (Table 4-3: ( $p w \_51$ is $91.8^{\circ} \mathrm{C}, p w_{-} 10006$ is $56.2^{\circ} \mathrm{C}$, and $p w_{-} 20013$ is $40.2^{\circ} \mathrm{C}$ ). The EQ6 runs were set up to reflect increased temperature and $f \mathrm{CO}_{2}$, and CSNF (Table 6-7) and HLWG (Table 6-8) kinetic rate constants were recalculated at the new temperatures. EQ6 runs were executed at these conditions using the thermally perturbed seepage compositions; Na-porewater and Ca-porewater were plotted with the results for comparative purposes.

Figures 6-29 and 6-30 are sample outputs and show the results for CSNF, and Figures 6-31 and 6-32 show the results for CDSP. The simulation results for the various water compositions are in close agreement for each case, even though their initial compositions were different, which implies that incoming water composition has little influence over the in-package $\mathrm{pH}$ and ionic strength. 


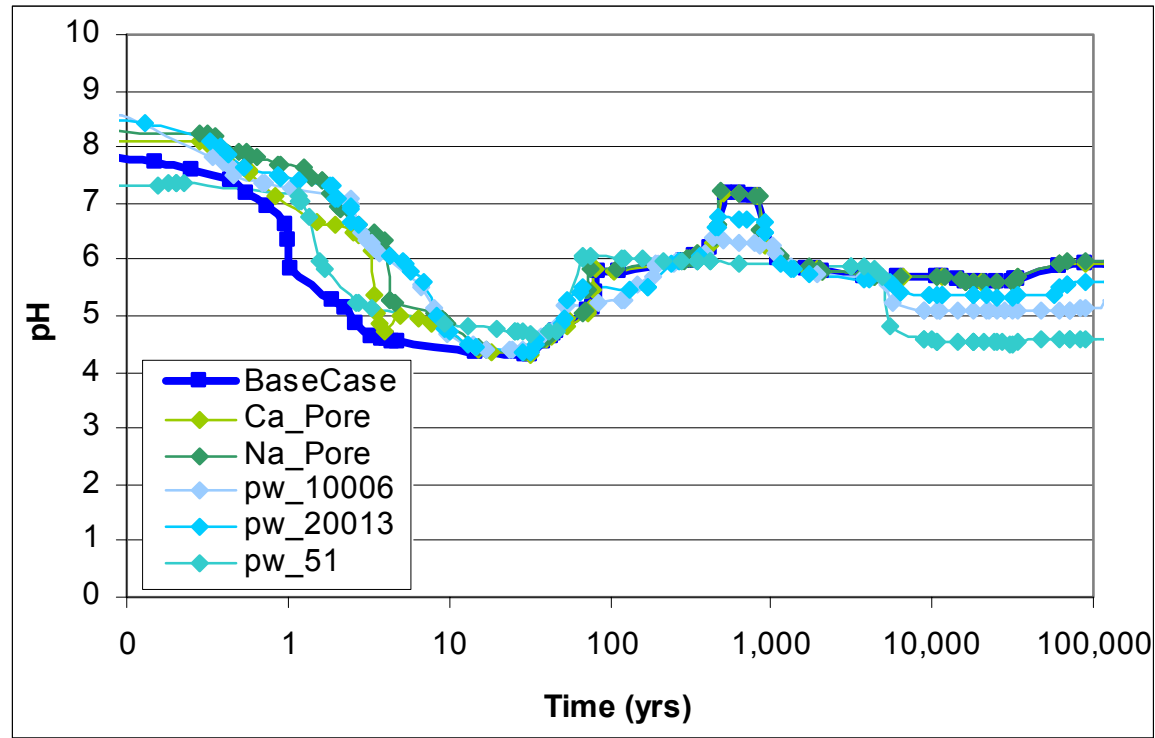

Source: $\quad$ CSNF Liquid Influx Model Output.xIs (Appendix F ISpreadsheets).

NOTE: $\quad$ Time refers to time after waste package breach ( 0 on the $x$-axis refers to 0.1 years).

Figure 6-29. $\mathrm{pH}$ Profiles for Thermally Perturbed Compositions for CSNF

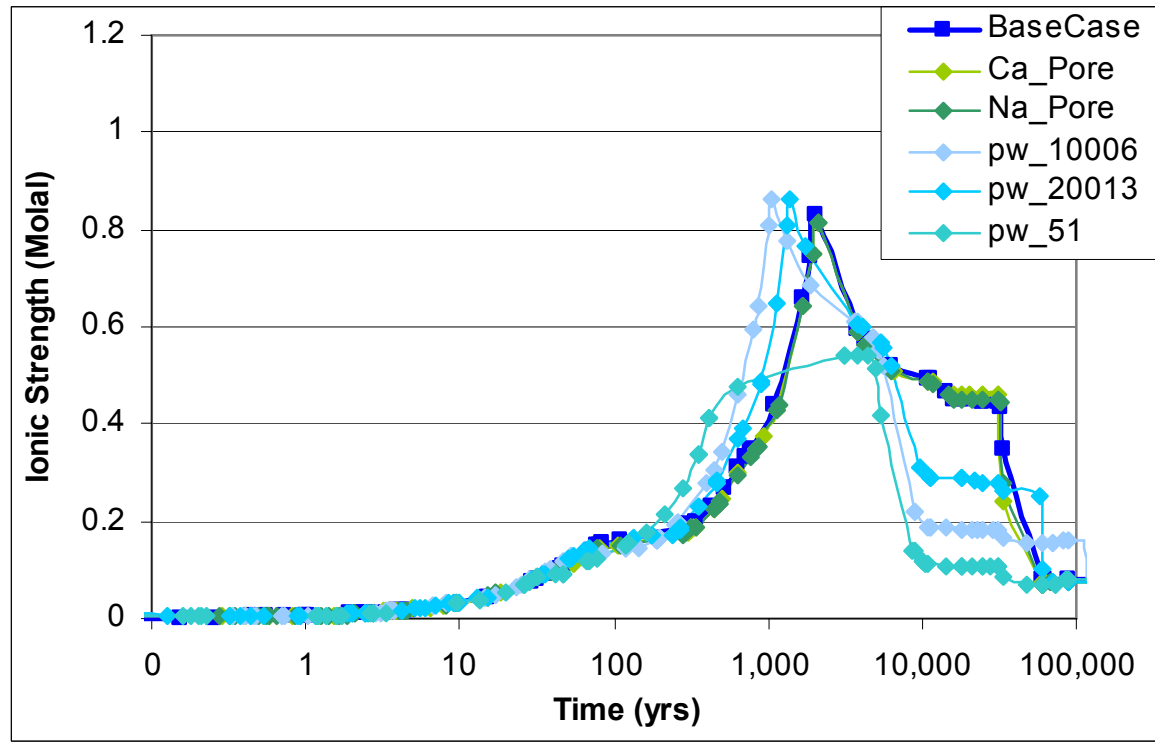

Source: $\quad$ CSNF Liquid Influx Model Output.xIs (Appendix F ISpreadsheets).

NOTE: $\quad$ Time refers to time after waste package breach ( 0 on the $x$-axis refers to 0.1 years).

Figure 6-30. Ionic Strength Profiles for Thermally Perturbed Composition for CSNF 


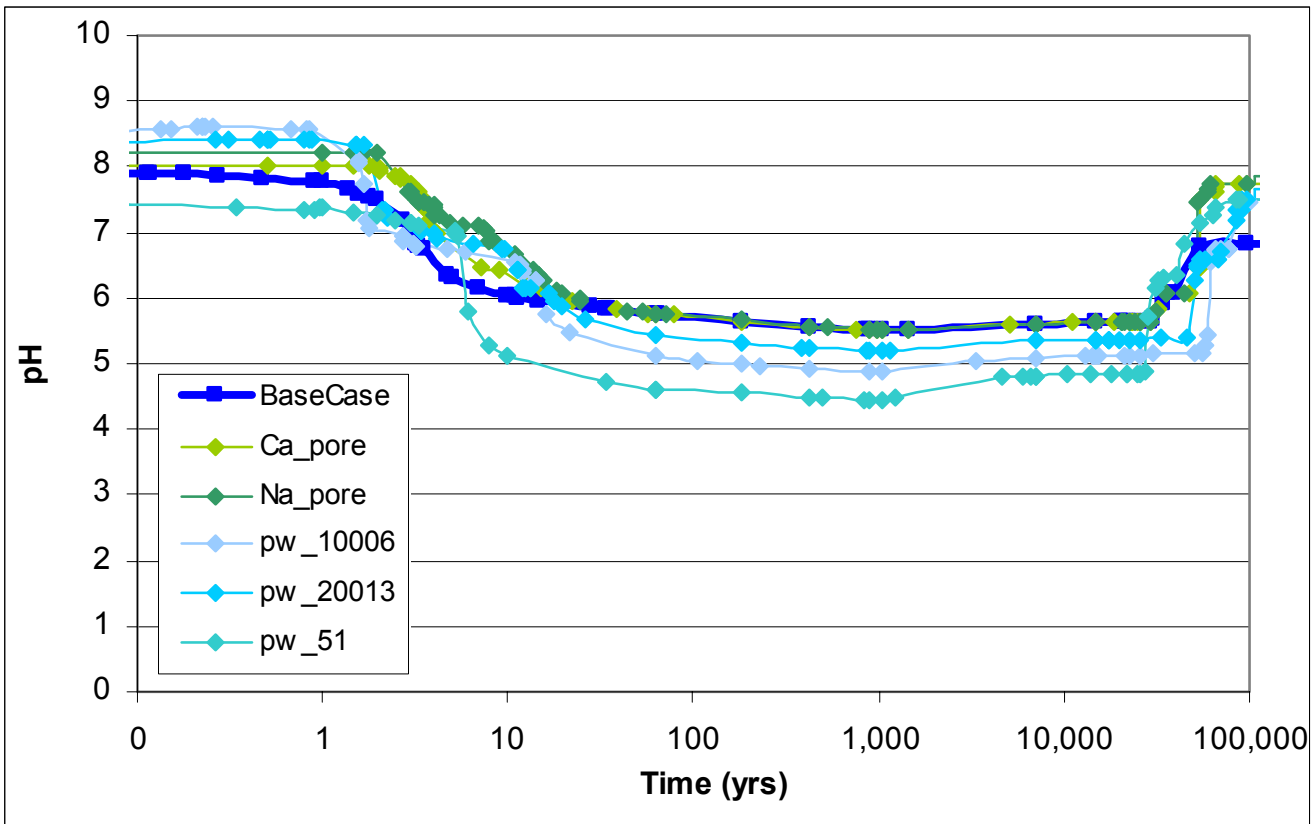

Source: $\quad$ CDSP Liquid Influx Model Output.xIs (Appendix F ISpreadsheets).

NOTE: $\quad$ Time refers to time after waste package breach ( 0 on the $x$-axis refers to 0.1 years).

Figure 6-31. pH Profiles for Thermally Perturbed Compositions for CDSP

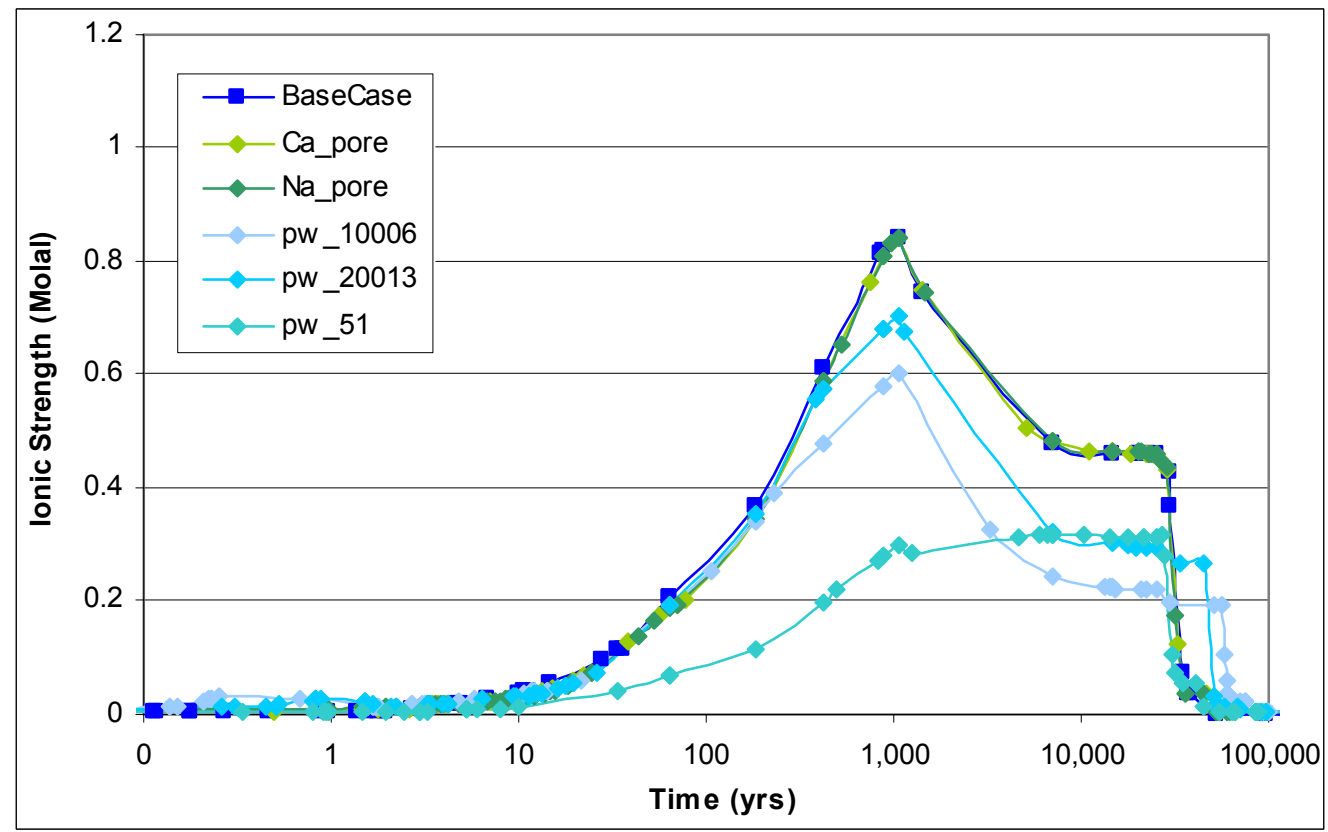

Source: CDSP Liquid Influx Model Output.x/s (Appendix F ISpreadsheets).

NOTE: $\quad$ Time refers to time after waste package breach ( 0 on the $x$-axis refers to 0.1 years).

Figure 6-32. Ionic Strength Profiles for Thermally Perturbed Composition for CDSP 
It is expected that surface complexation, which will occur during the first 600 years (Section 6.9), will have little impact on the conclusions drawn regarding thermally perturbed waters. This is because variations in the bulk fluid composition would be negligible for elements originating in the waste package, and only slight variations are expected for elements peculiar to the water composition; therefore, these compositional variations are anticipated to have no impact on the results of the model.

The above discussion addresses the subject matter of "Included" FEP 2.2.08.12.0B (Chemistry of water flowing into the waste package) and indicates how that subject matter has been included and addressed within the TSPA-LA.

\subsubsection{Oxidation State of Chromium}

The element chromium $(\mathrm{Cr})$ is a major constituent of several of the stainless steels and alloys used in the construction of the CSNF and CDSP waste packages (Table 4-7). A sensitivity analysis was performed to determine the influence of the Cr oxidation state (kinetic control), on the in-package $\mathrm{pH}$.

Revision 03 of the in-package chemistry model report allowed complete oxidation of chromium to $\mathrm{Cr}(\mathrm{VI})$, but Engineered Barrier System: Physical and Chemical Environment [Model] (BSC 2004 [DIRS 169860], Section 6.8.2), and the current version of the in-package chemistry model report limit the oxidation of chromium to $\mathrm{Cr}$ (III). Justification for the selection of the Cr(III) oxidation state from Engineered Barrier System: Physical and Chemical Environment [Model] (BSC 2004 [DIRS 169860]), which is also applicable to this model, is provided below:

Selection of $\mathrm{Cr}(\mathrm{III})$ over that of the more soluble $\mathrm{Cr}(\mathrm{VI})$ species is based on experimentally observed corrosion products, and on the kinetics and conditions required to obtain the fully oxidized Cr(VI) state (Smith and Purdy 1995 [DIRS 162976]). Smith and Purdy's examination of the actual chromium speciation as a result of corrosion of $316 \mathrm{~L}$ stainless steel demonstrated a predominance of the less soluble $\mathrm{Cr}$ (III) species, except under the conditions of hot concentrated nitric acid $\left(111^{\circ} \mathrm{C}\right.$ and $>7$ molal $\mathrm{HNO}_{3}$, see Smith and Purdy 1995, Figure 6).

The choice of $\mathrm{Cr}(\mathrm{VI})$ in Rev 03 had been based on thermodynamic equilibrium, as described in Section 6.3.1.1, for the purpose of modeling the most extreme chemistries (Cr(VI) lead to higher ionic strengths and lower $\mathrm{pH}$ values). The choice of $\mathrm{Cr}(\mathrm{VI})$ was also based on the predominance of manganese as a component of the steels (Table 4-7), which when oxidized to either $\mathrm{MnO}_{2}$ (pyrolusite), or to $\mathrm{MnOOH}$ (manganite) (Eary and Rai 1987 [DIRS 105780]; Johnson and Xyla 1991 [DIRS 105878]), tends to favor the Cr(VI) oxidation state.

Results are shown for $\mathrm{pH}$ and ionic strength for $\mathrm{Cr}(\mathrm{III})$ and $\mathrm{Cr}(\mathrm{VI})$ for CSNF in Figures 6-33 and 6-34. The $\mathrm{pH}$ and ionic strength results for CDSP are shown in Figures 6-35 and 6-36. The plots showing $\mathrm{pH}$ values indicate the $\mathrm{Cr}$ (III) oxidation state has more moderate $\mathrm{pH}$ values. The figures show the $\mathrm{Cr}$ (III) system significantly reduces the ionic strength. The reason for the decreased ionic strength is the presence of several $\mathrm{Cr}$ (III) solids in the database that precipitate and remove chromium from solution. 
As shown in Figures 6-33 and 6-35, the oxidation state of chromium has a significant impact on $\mathrm{pH}$, with the $\mathrm{Cr}(\mathrm{VI})$ case resulting in a much lower long term $\mathrm{pH}$ due to the formation of chromic acid from the $\mathrm{Cr}(\mathrm{VI})$ released from the degradation of the stainless steels and the NiGd. When using $\mathrm{Cr}(\mathrm{VI})$, there is a strong effect on the $\mathrm{pH}$ for the Stainless Steel Type 304L single-component run; the differences between the $\mathrm{pH}$ produced by the two stainless steel types are due to the chromium-to-nickel ratio in the alloys, as shown in CDSP Stainless Steel $p H$ $\mathrm{Cr}_{-} \mathrm{Ni}$ ratio.xls (Appendix $\mathrm{F} \backslash$ Spreadsheets). For molar ratios of chromium to nickel greater than or equal to two, as in the case of Stainless Steel Type 304L, the pH of the solution after 15 moles have reacted is less than two. For chromium-to-nickel ratios below two, as in the case of the Stainless Steel Type 316, the $\mathrm{pH}$ is above five. For the $\mathrm{Cr}$ (III) system, the ratio of chromium-to-nickel is lower than for the $\mathrm{Cr}(\mathrm{VI})$ system, because the $\mathrm{Cr}$ (III) in solution precipitates as a solid, so the extreme low $\mathrm{pH}$ is never realized (Figure 6-22).

The above discussion addresses the kinetics of the $\mathrm{Cr}$ species that is the subject matter of "Included" FEP 2.1.09.07.0A (Reaction kinetics in waste package) and indicates how that subject matter has been included and addressed within TSPA-LA.

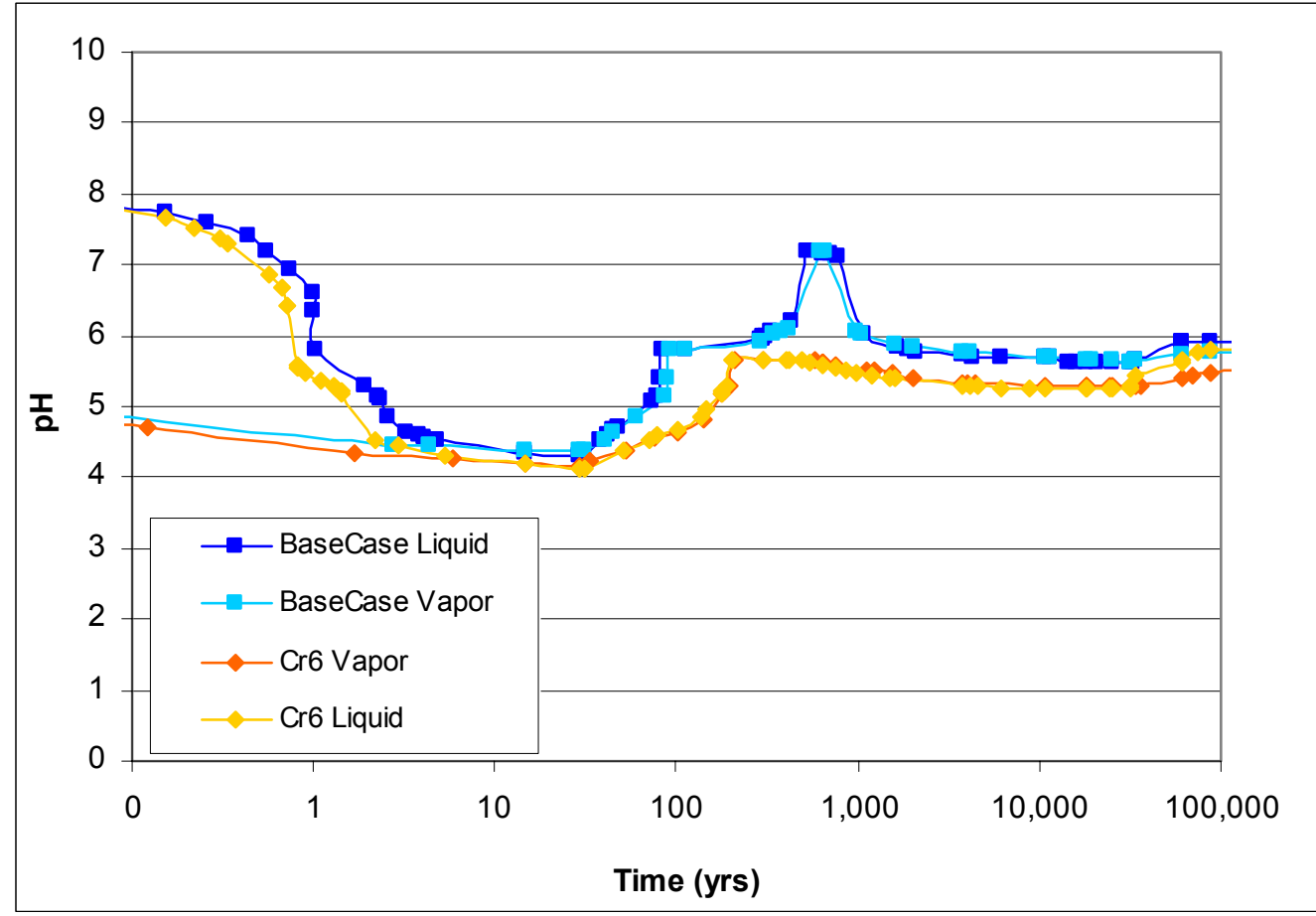

Source: $\quad$ CSNF Liquid Influx Model Output.xls (Appendix F ISpreadsheets).

NOTE: $\quad$ Time refers to time after waste package breach ( 0 on the $x$-axis refers to 0.1 years).

Figure 6-33. $\mathrm{Cr}(\mathrm{III})$ versus $\mathrm{Cr}(\mathrm{VI})$ for CSNF: Impact on $\mathrm{pH}$ 


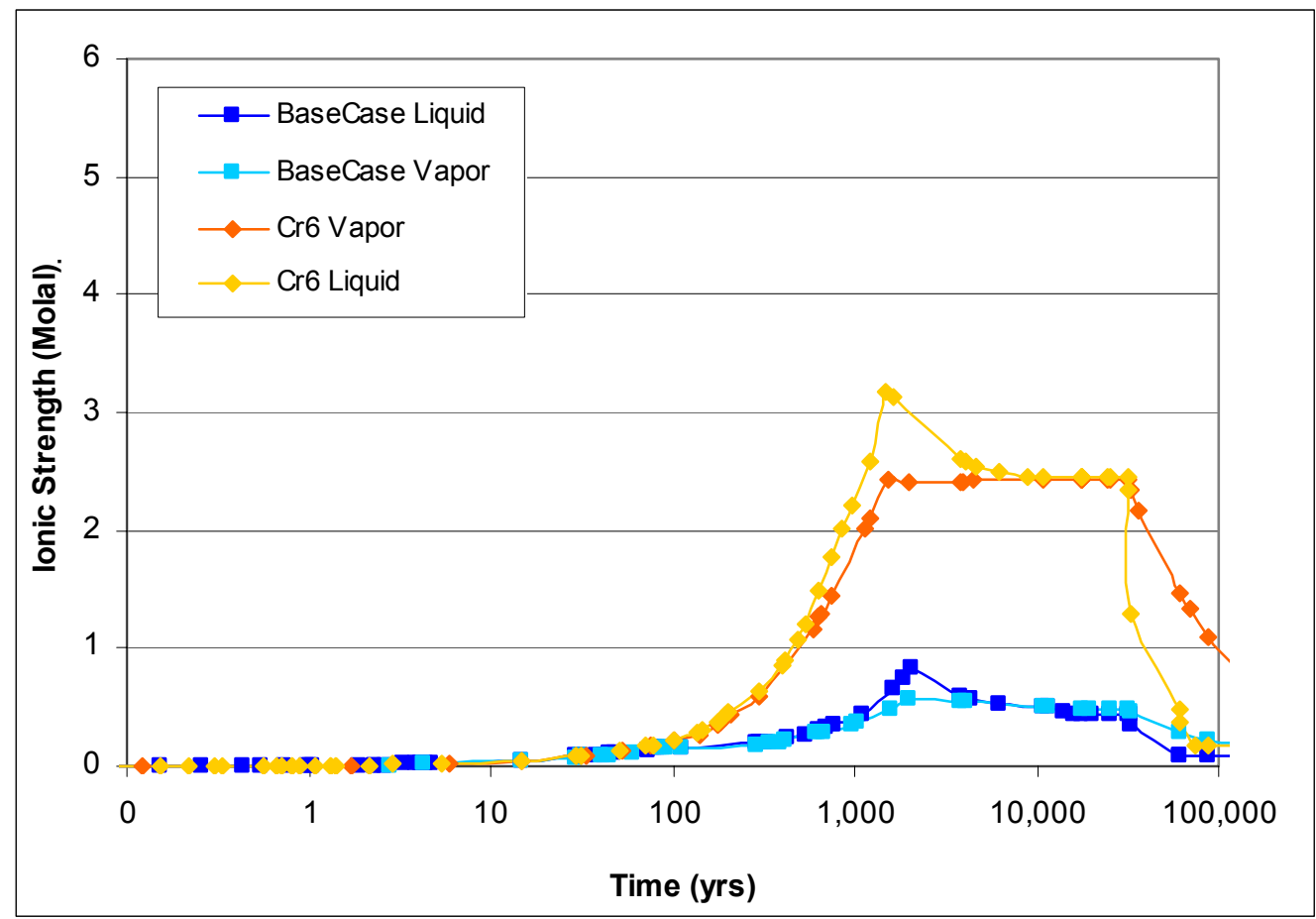

Source: CSNF Liquid Influx Model Output.xIs (Appendix F ISpreadsheets).

NOTE: Time refers to time after waste package breach ( 0 on the $x$-axis refers to 0.1 years).

Figure 6-34. $\mathrm{Cr}(\mathrm{III})$ versus $\mathrm{Cr}(\mathrm{VI})$ for CSNF: Impact on lonic Strength 


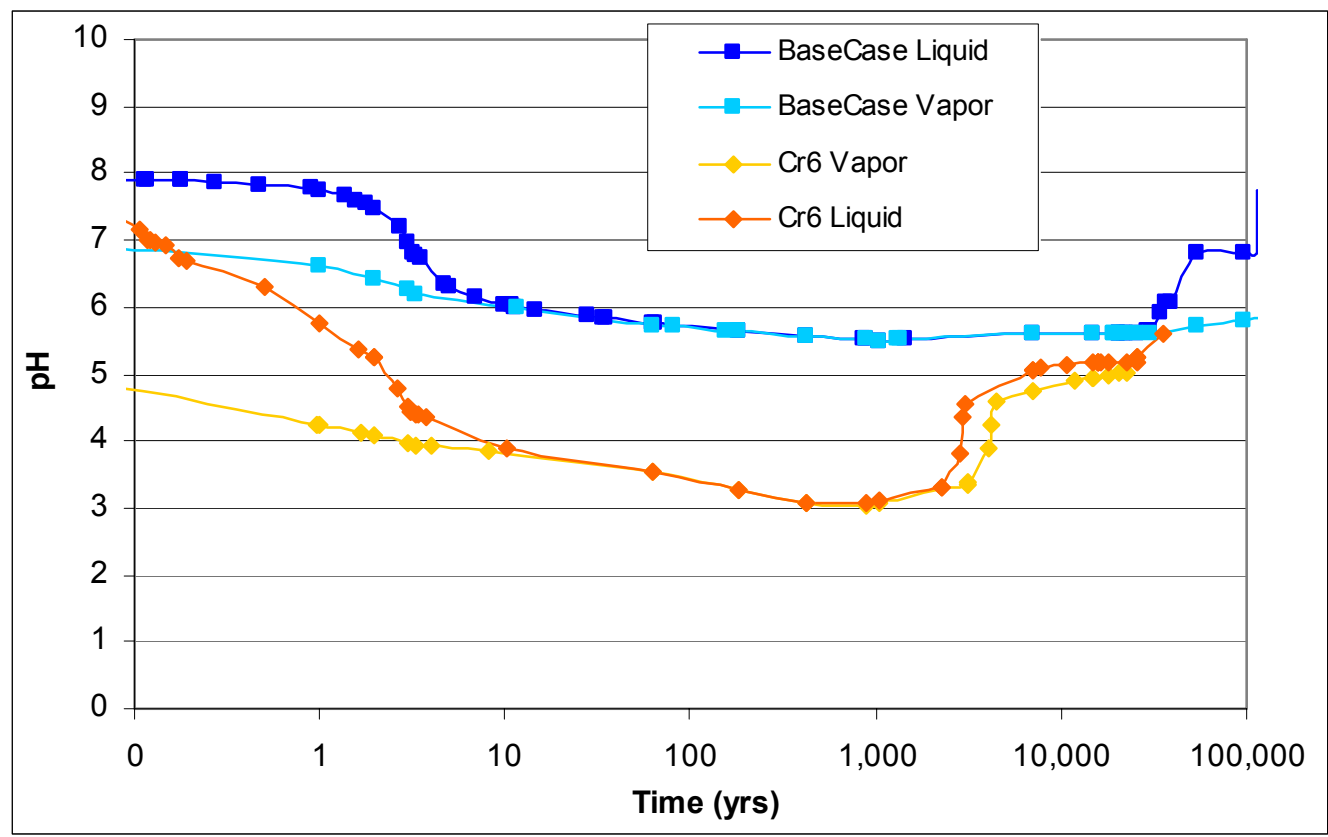

Source: CDSP Liquid Influx Model Output.xIs (Appendix F ISpreadsheets).

NOTE: $\quad$ Time refers to time after waste package breach ( 0 on the $x$-axis refers to 0.1 years).

Figure 6-35. $\mathrm{Cr}(\mathrm{III})$ versus $\mathrm{Cr}(\mathrm{VI})$ for $\mathrm{CDSP}$ : Impact on $\mathrm{pH}$

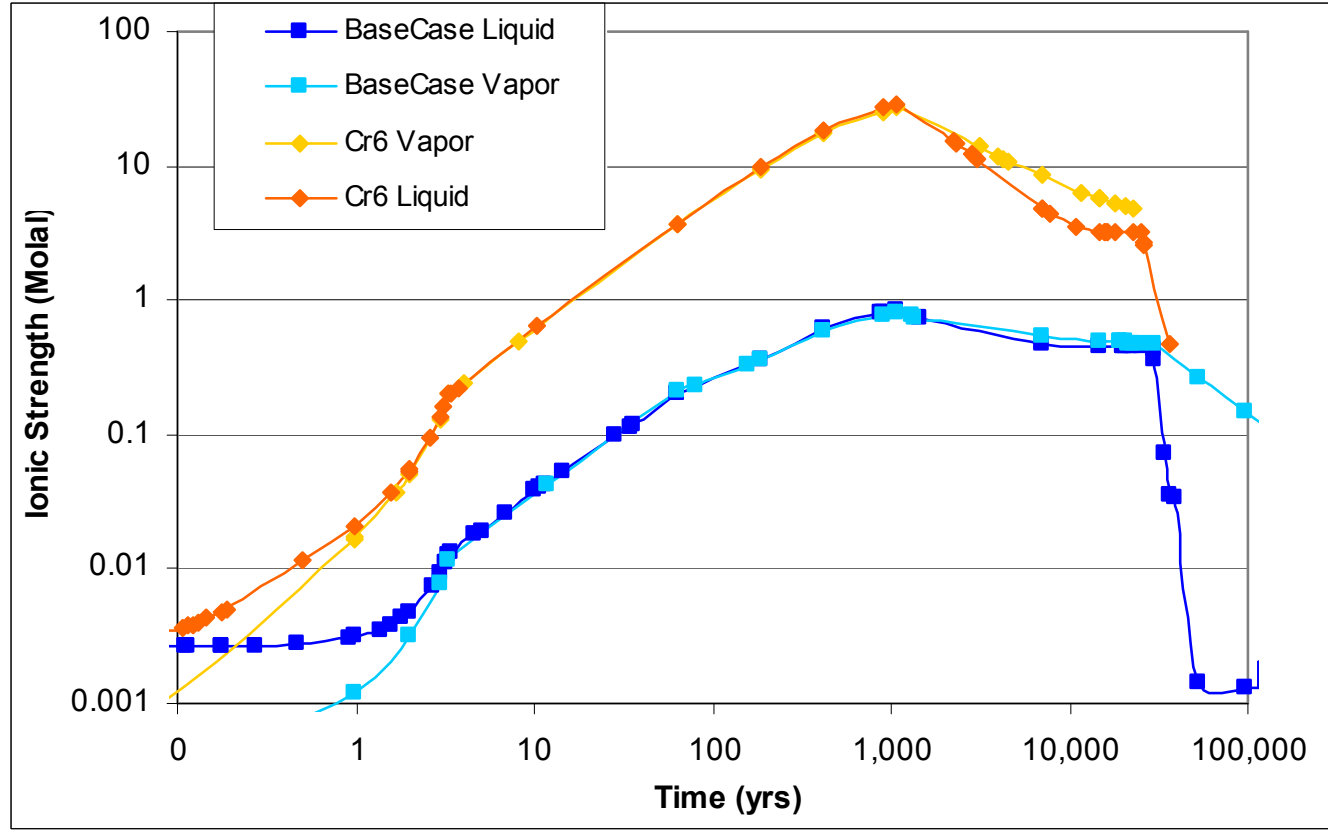

Source: CDSP Liquid Influx Model Output.xIs (Appendix F ISpreadsheets).

NOTE: $\quad$ Time refers to time after waste package breach ( 0 on the $x$-axis refers to 0.1 years).

Figure 6-36. $\mathrm{Cr}(\mathrm{III})$ versus $\mathrm{Cr}(\mathrm{VI})$ for CDSP: Impact on lonic Strength 
The ionic strength for the $\mathrm{Cr}(\mathrm{VI}) \mathrm{CDSP}$ case is high, higher than the range of validation for the thermodynamic database; therefore the results of the $\mathrm{Cr}(\mathrm{VI})$ cases should not be used quantitatively, but are only presented here for comparison purposes. The reason for the high ionic strength is that there are no stable $\mathrm{Cr}(\mathrm{VI})$ solid species in the thermodynamic database, so all of the chromium that comes out of the stainless steels remains in solution, driving up the ionic strength.

\subsubsection{Carbon Dioxide and Oxygen Fugacity}

The sensitivity studies in this section vary the $\log f \mathrm{CO}_{2}$ from -5.0 to -1.5 and the $\log f \mathrm{O}_{2}$ from -69 to -0.7 . Because $\mathrm{EQ} 3 / 6$ is a thermodynamic code, to actually model conditions other than fully oxidizing, the $\log f \mathrm{O}_{2}$ must be set to a very low value. The CSNF rate constants used in this sensitivity are from Table 6-7, which were calculated using an oxygen partial pressure of 0.2 atmospheres, even though calculating the rates at lower $f \mathrm{O}_{2}$ values would have resulted in lower rates or even non-existent rates (meaning that no degradation occurs). However, the purpose of this sensitivity is to examine the effects of lower $f \mathrm{O}_{2}$ on the system, and the degradation of the CSNF has a strong influence on the chemistry of the system, so the faster rates were retained. For total carbonate concentrations less than $2 \times 10^{-4}$ molar, the recommended CSNF degradation rate (BSC 2004 [DIRS 169987]) is to use Equation 4-1 with the total carbonate concentration set to $2 \times 10^{-4}$ molar. This rate was compared to the rate that would be calculated by EQ6 using Equation 4-1 with lower total carbonate concentrations, and the two rates were similar, with the EQ6 rate slightly higher (as shown in Appendix F, Total Carbonate and Eh Abstractions.xls in Appendix F). The code calculates the rate of the CSNF based on the $\mathrm{pH}$ and total carbonate of the system for each time step. Since the total carbonate is above the $2 \times 10^{-4}$ molar limit for the majority of the run, this sensitivity uses the same transition state theory formalism (described in Section 4.1.1) as the base case (rather than trying to decouple the CSNF rate from the total carbonate for the brief period when the total carbonate drops below $2 \times 10^{-4}$ molar).

The following plots (Figures 6-37 through 6-40) show the results of varying carbon dioxide fugacity on the $\mathrm{pH}$ and ionic strength. 


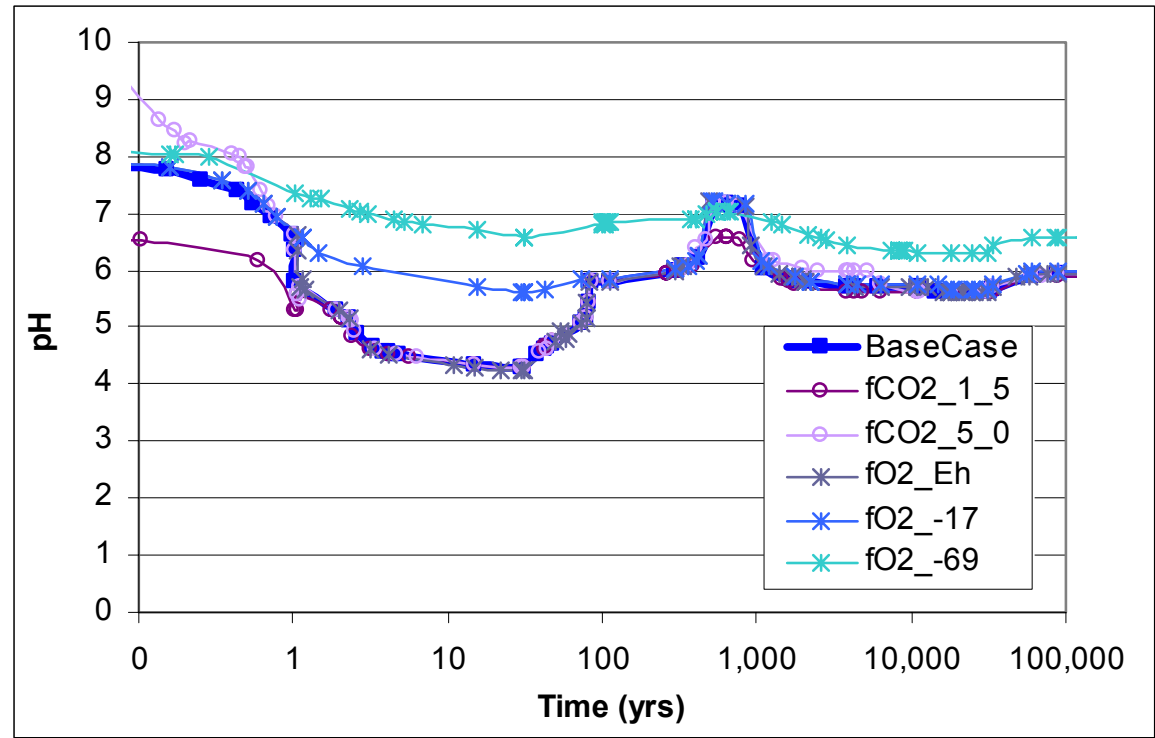

Source: $\quad$ CSNF Liquid Influx Model Output.xIs (Appendix F ISpreadsheets).

NOTE: $\quad$ Time refers to time after waste package breach ( 0 on the $x$-axis refers to 0.1 years).

Figure 6-37. Variation of $\mathrm{fCO}_{2}$ and $\mathrm{fO}_{2}$ for CSNF: Impact on $\mathrm{pH}$

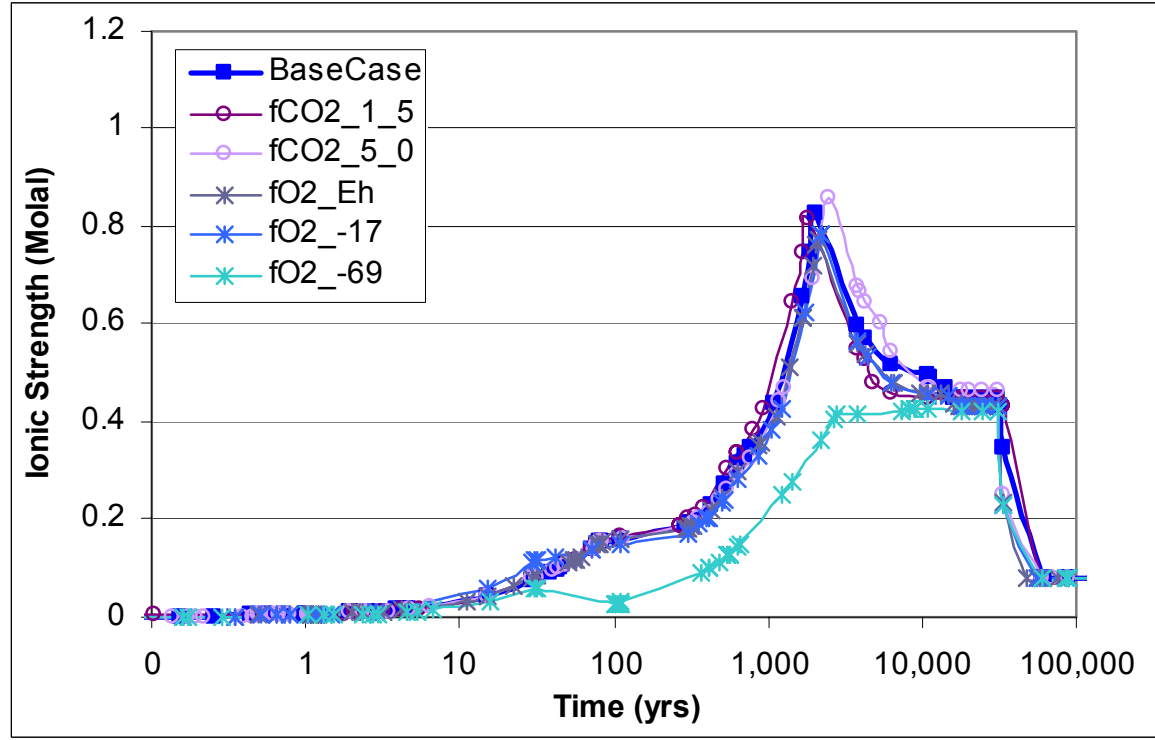

Source: $\quad$ CSNF Liquid Influx Model Output.xls (Appendix F ISpreadsheets).

NOTE: $\quad$ Time refers to time after waste package breach ( 0 on the $x$-axis refers to 0.1 years).

Figure 6-38. Variation of $\mathrm{fCO}_{2}$ and $\mathrm{fO}_{2}$ for CSNF: Impact on lonic Strength 


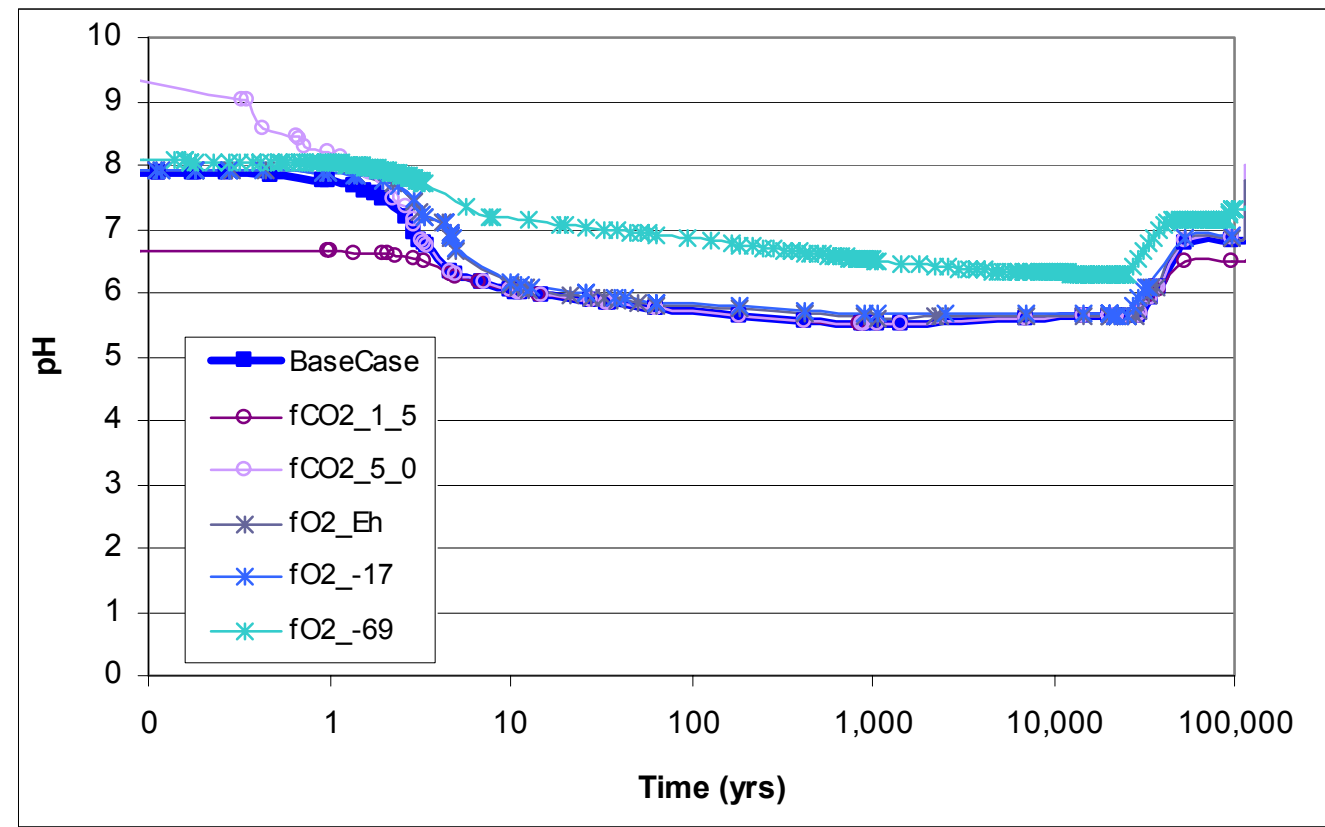

Source: $\quad$ CDSP Liquid Influx Model Output.xIs (Appendix F ISpreadsheets).

NOTE: $\quad$ Time refers to time after waste package breach ( 0 on the $x$-axis refers to 0.1 years).

Figure 6-39. Variation of $\mathrm{fCO}_{2}$ and $\mathrm{fO}_{2}$ for CDSP: Impact on $\mathrm{pH}$

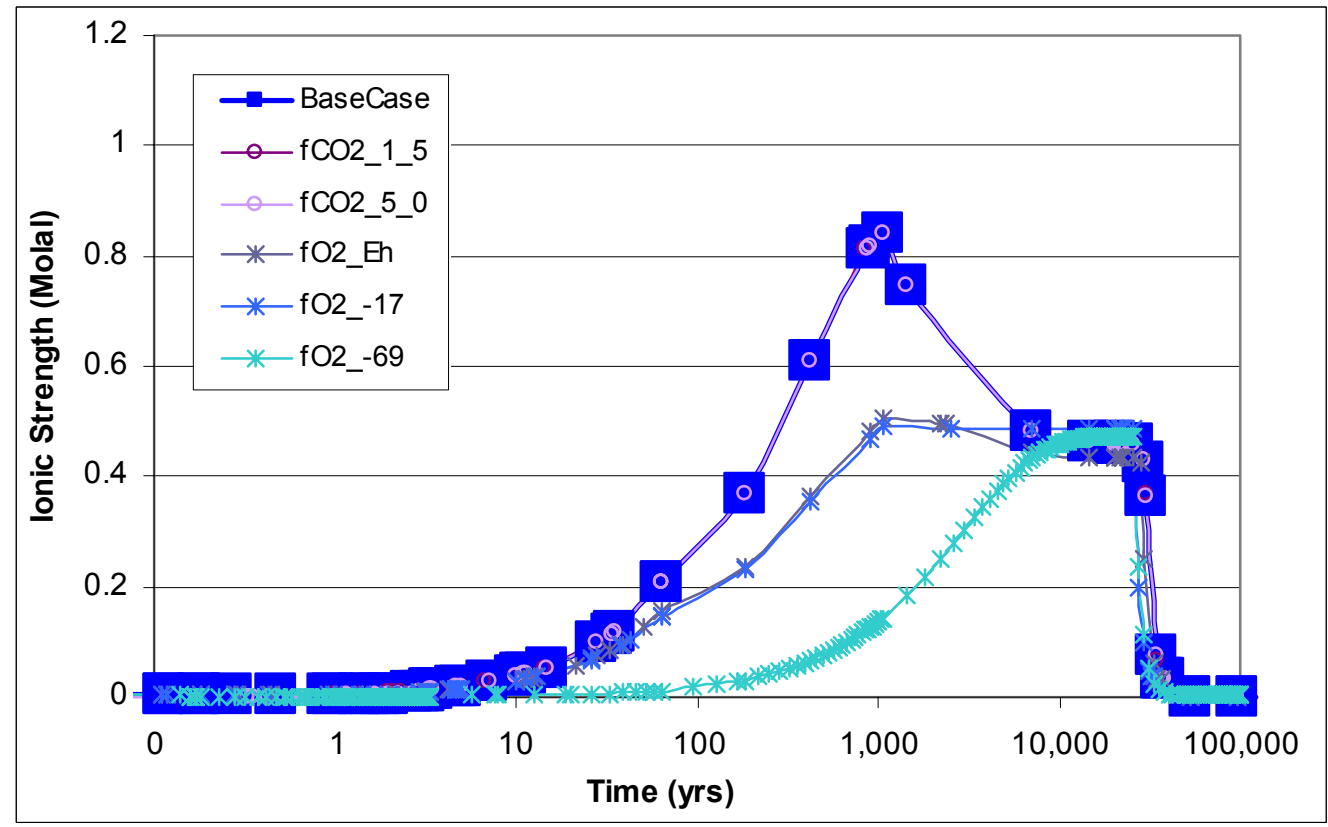

Source: CDSP Liquid Influx Model Output.xIs (Appendix F ISpreadsheets).

NOTE: $\quad$ Time refers to time after waste package breach ( 0 on the $x$-axis refers to 0.1 years).

Figure 6-40. Variation of $\mathrm{fCO}_{2}$ and $\mathrm{fO}_{2}$ for CDSP: Impact on lonic Strength

The results show for CSNF and CDSP, neither $\mathrm{pH}$ nor ionic strength is affected by increasing $\log f \mathrm{CO}_{2}$ to a value of -1.5 . However, decreasing $\log f \mathrm{CO}_{2}$ to -5.0 results in a high initial $\mathrm{pH}$ 
The high $\mathrm{pH}$ for the $\log f \mathrm{CO}_{2}=-5.0$ case is not considered, because the initial high $\mathrm{pH}$ is only a function of the solution being equilibrated with that low $f \mathrm{CO}_{2}$, and is short lived (one year) and quickly overwhelmed by the corrosion of the waste package internals.

The lack of variation in system $\mathrm{pH}$ as the carbon dioxide fugacity was increased (up to $\left.\log f \mathrm{CO}_{2}=-1.5\right)$ renders it possible to use $\mathrm{pH}$ as a means of calculating total carbonate (Section 6.10.5) over a wide range of $f \mathrm{CO}_{2}$ values. In the surface complexation model (Section 6.8), the CSNF pH distribution is cast as a function of $f \mathrm{CO}_{2}$; thus, allowing the formation of carbonate surface complexes. As the carbon dioxide is fixed at a given value in the batch reactor modeling runs, the carbonate species in the bulk in-package fluid will reequilibrate in accordance with the relationships provided in Section 6.10.5.

The results shown in Figures 6-37 and 6-39 show that using the adjusted Eh (Eh $=1.1-0.0592 \times$ pH) from Dissolved Concentration Limits of Radioactive Elements (BSC 2005 [DIRS 173873]) provides results similar to the base case. Eh was calculated at the $\mathrm{pH}$ value of the incoming water, applied to the entire run, and did not vary with $\mathrm{pH}$. The results of this sensitivity show similar $\mathrm{pH}$ and ionic strength results. More-significant decreases in the $f \mathrm{O}_{2}$ (i.e., lower than the adjusted-Eh value) tend to raise $\mathrm{pH}$ and lower ionic strength; however, all of the results shown in Figures 6-37 through 6-40 are within the range of values provided to TSPA-LA.

These sensitivities vary the composition of air in contact with the waste package internals. In addition, this sensitivity examines various states of kinetic equilibrium with the atmosphere by varying the $f \mathrm{CO}_{2}$ and $f \mathrm{O}_{2}$. The results of these sensitivities are used to broaden the range of applicability of this model and used in the model abstraction.

The above discussion addresses the subject matter of "Included" FEPs 2.1.02.09.0A (Chemical effects of void space in waste package), 2.1.09.06.0A (Reduction-oxidation potential in waste package), and 2.1.09.07.0A (Reaction kinetics in waste package) and indicates how that subject matter has been included and addressed within TSPA-LA.

\subsubsection{Water Flux}

The flux of water through a waste package has direct impacts on the chemistry of the water exiting the package. The lower the influx rate the longer the residence time of the water in the package and greater the extent of the reaction between the water and the waste package components. There must exist an upper limit to flux at which there is virtually no reaction between the water and the waste package components.

This was confirmed as displayed in the following plots (Figures 6-41 through 6-44) where the $\mathrm{pH}$ and ionic strength approach that of the incoming fluid as the flux was increased. As the flux increases, the chemistry stabilizes in a shorter time frame and the run terminates. 


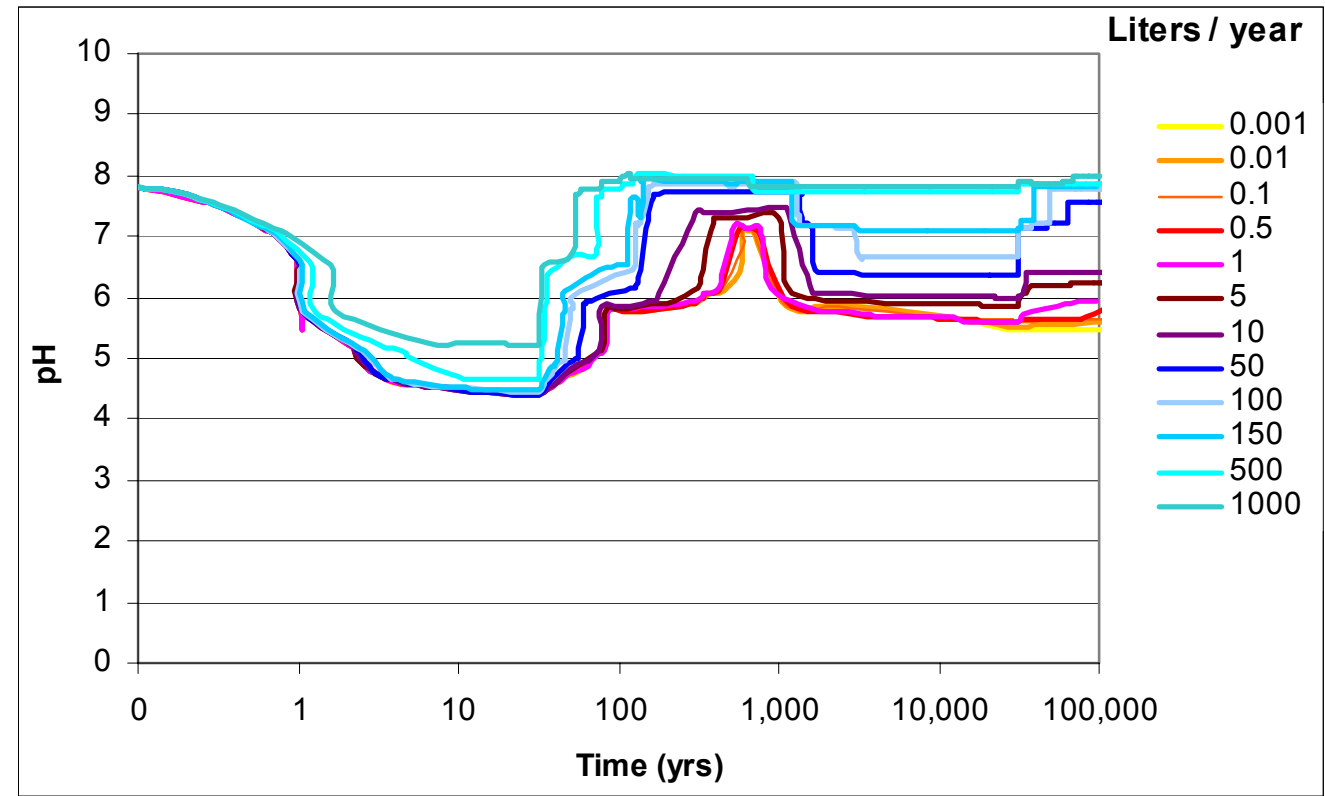

Source: (I) Abstraction CSNF Liquid Influx.xIs (Appendix F /Spreadsheets).

NOTE: $\quad$ Time refers to time after waste package breach ( 0 on the $x$-axis refers to 0.1 years).

Figure 6-41. Effect of Water Flux on $\mathrm{pH}$ for CSNF

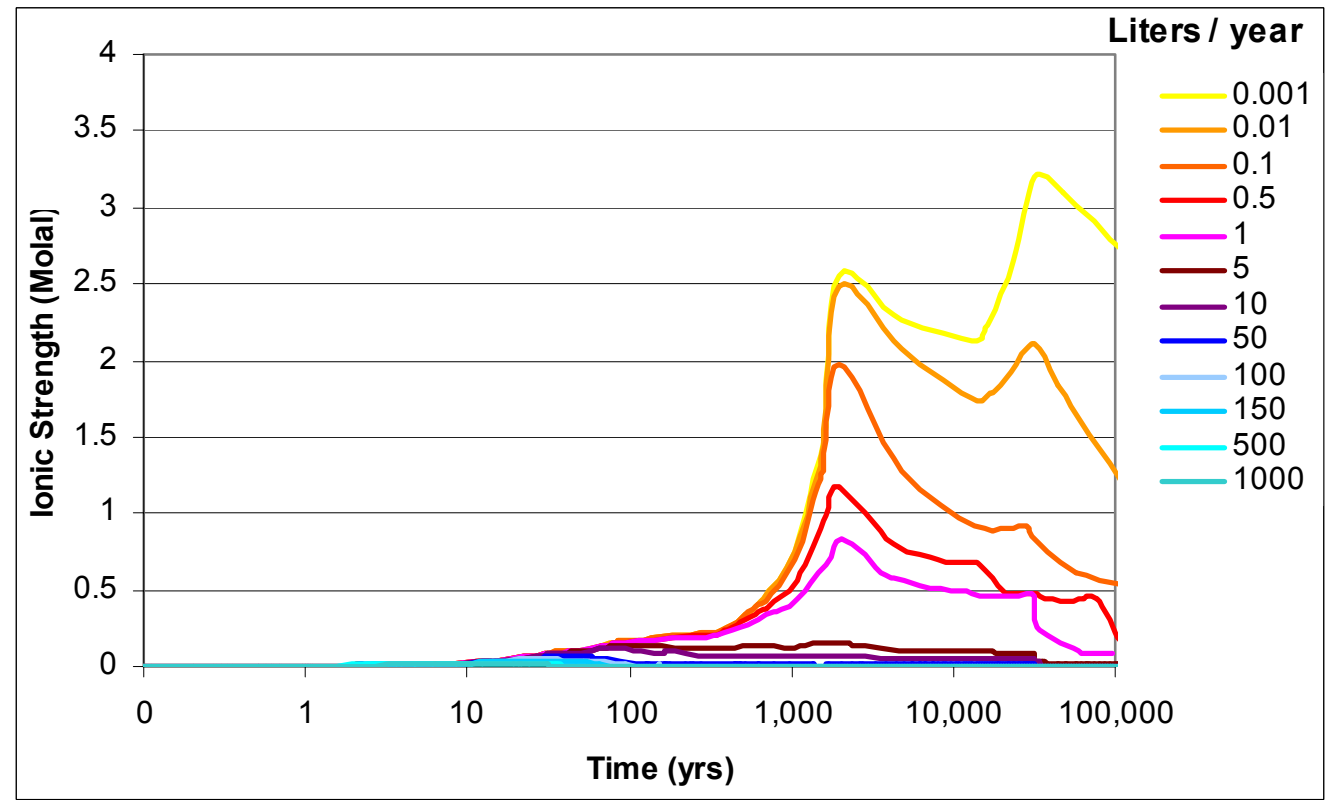

Source: (I) Abstraction CSNF Liquid Influx.xIs (Appendix F /Spreadsheets).

NOTE: $\quad$ Time refers to time after waste package breach ( 0 on the $x$-axis refers to 0.1 years).

Figure 6-42. Effect of Water Flux on lonic Strength for CSNF 


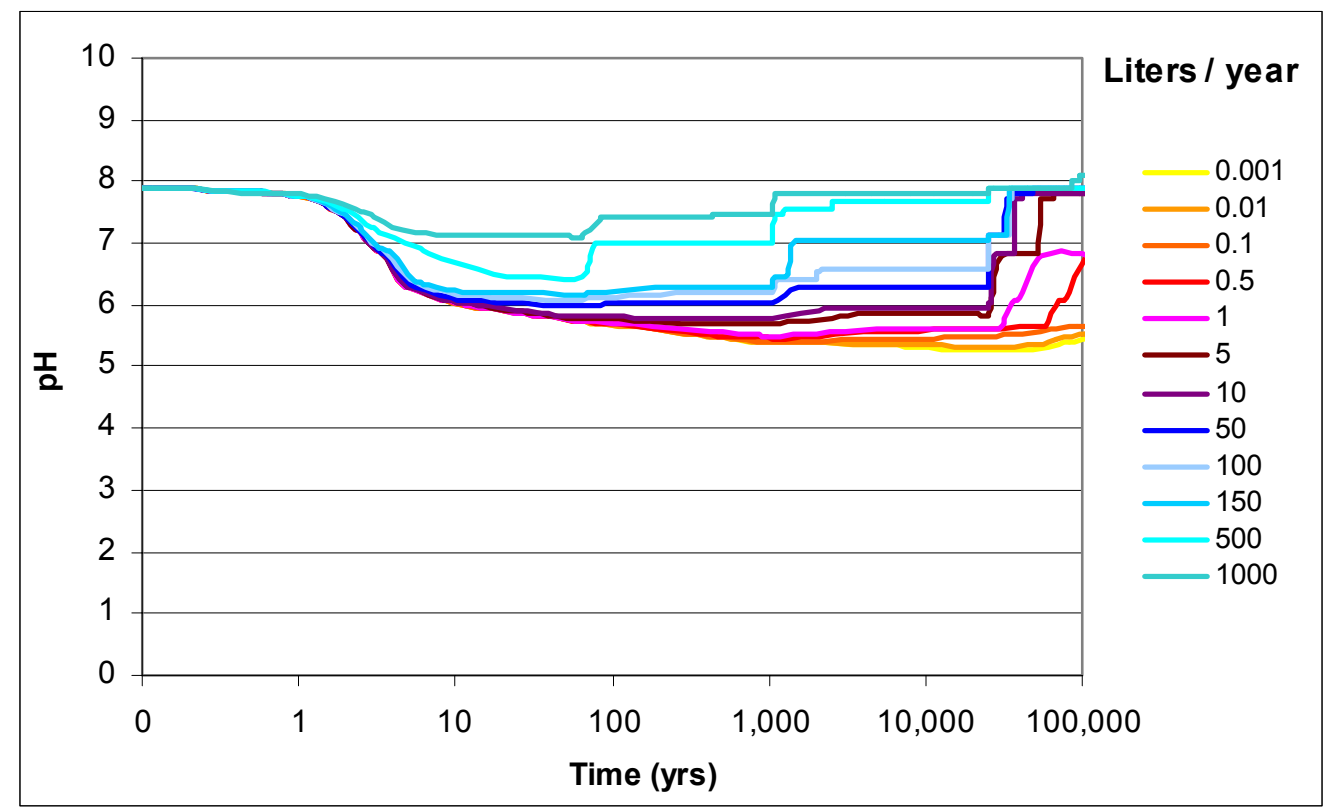

Source: (I) Abstraction CDSP Liquid Influx.xIs (Appendix F /Spreadsheets).

NOTE: $\quad$ Time refers to time after waste package breach ( 0 on the $x$-axis refers to 0.1 years).

Figure 6-43. Effect of Water Flux on $\mathrm{pH}$ for CDSP

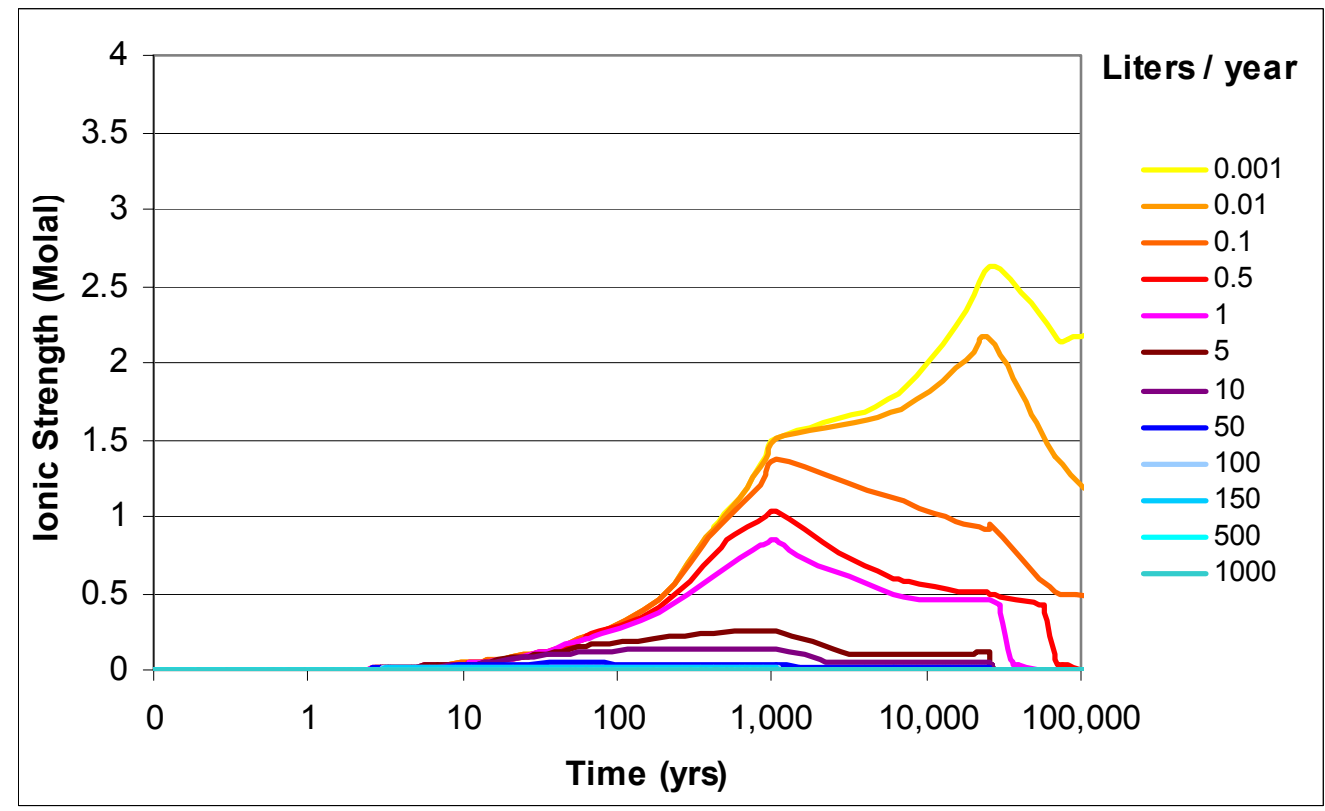

Source: (I) Abstraction CDSP Liquid Influx.x/s (Appendix F /Spreadsheets).

NOTE: $\quad$ Time refers to time after waste package breach ( 0 on the $x$-axis refers to 0.1 years).

Figure 6-44. Effect of Water Flux on lonic Strength for CDSP 
Because influx has such an impact on the in-package chemistry, the ionic strength abstraction is determined as a function of flux. Section 6.10.2 develops the ionic strength abstraction varying the water flux over the full range for the liquid influx and vapor-influx cases. For comparison and historical purposes, Figure 6-45 shows the $\mathrm{Cr}(\mathrm{VI}) \mathrm{pH}$ history from Rev 03 of this document, for various fluxes for the CSNF waste package, and the results show the same trend seen in the $\mathrm{Cr}(\mathrm{III})$.

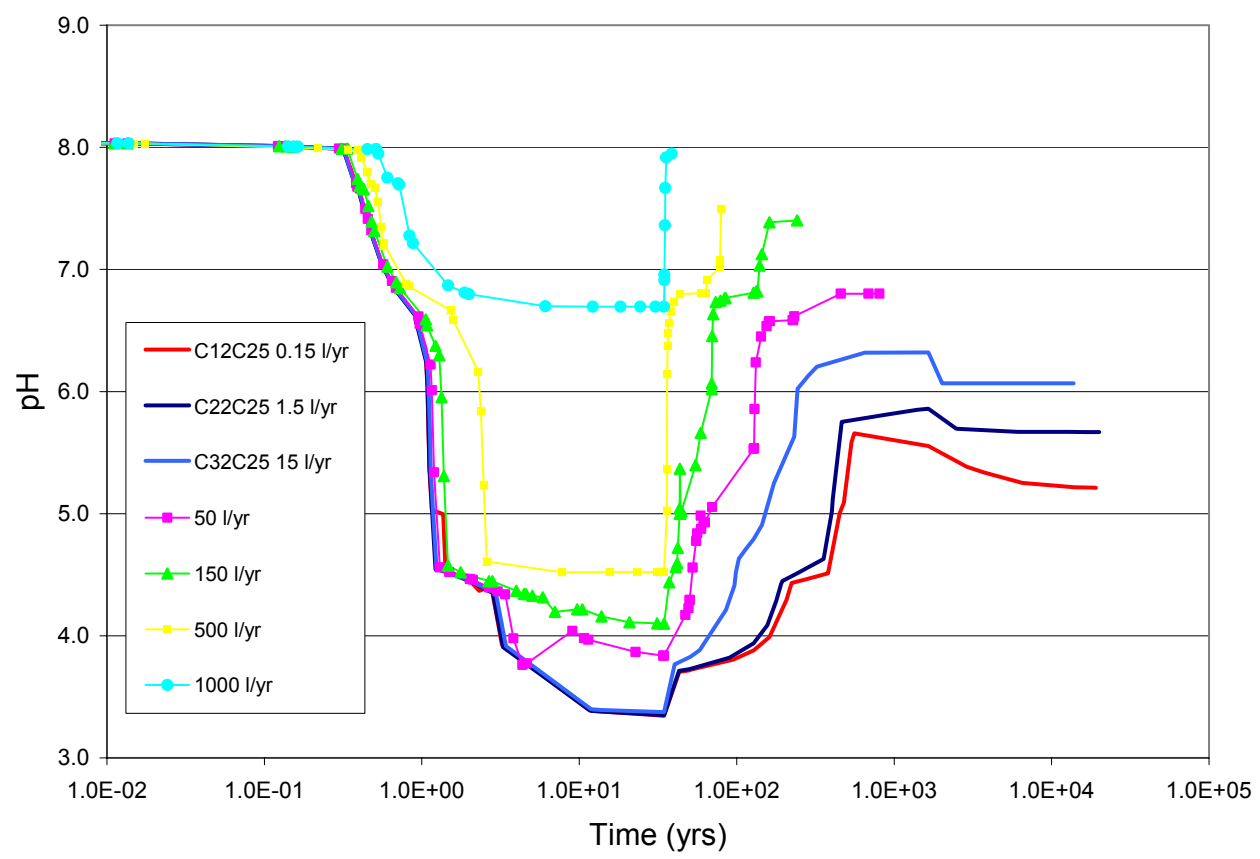

Source: CSNF_Sensitivity.xIs (DTN: MO0411SPAMOICA.000 [DIRS 172244]).

Note: $\quad$ Time refers to time after waste package breach. This sensitivity uses $\mathrm{Cr}(\mathrm{VI})$ rather than $\mathrm{Cr}(\mathrm{III})$.

Figure 6-45. Effect of Water Flux on pH for CSNF (using $\mathrm{Cr}(\mathrm{VI})$ )

\subsubsection{Temperature}

The temperature of the waste package receiving seepage could vary significantly depending on the timing of waste package breach and seepage ingress. In addition to the sensitivity analysis that examines the type of fluids expected at high temperatures (the thermally perturbed fluid compositions), a set of simulations was performed at $50^{\circ} \mathrm{C}$ and $90^{\circ} \mathrm{C}$ with the base-case waters. Also included in this sensitivity are the thermally perturbed waters, since they are high-temperature runs ( $\mathrm{pw} 51$ is $91.8^{\circ} \mathrm{C}$, pw_10006 is $56.2^{\circ} \mathrm{C}$, and pw_20013 is $40.2^{\circ} \mathrm{C}$ ). The coefficients for the CSNF- and HLWG-rate expressions were recalculated at the temperature of the run (Tables 6-7 and 6-8). 


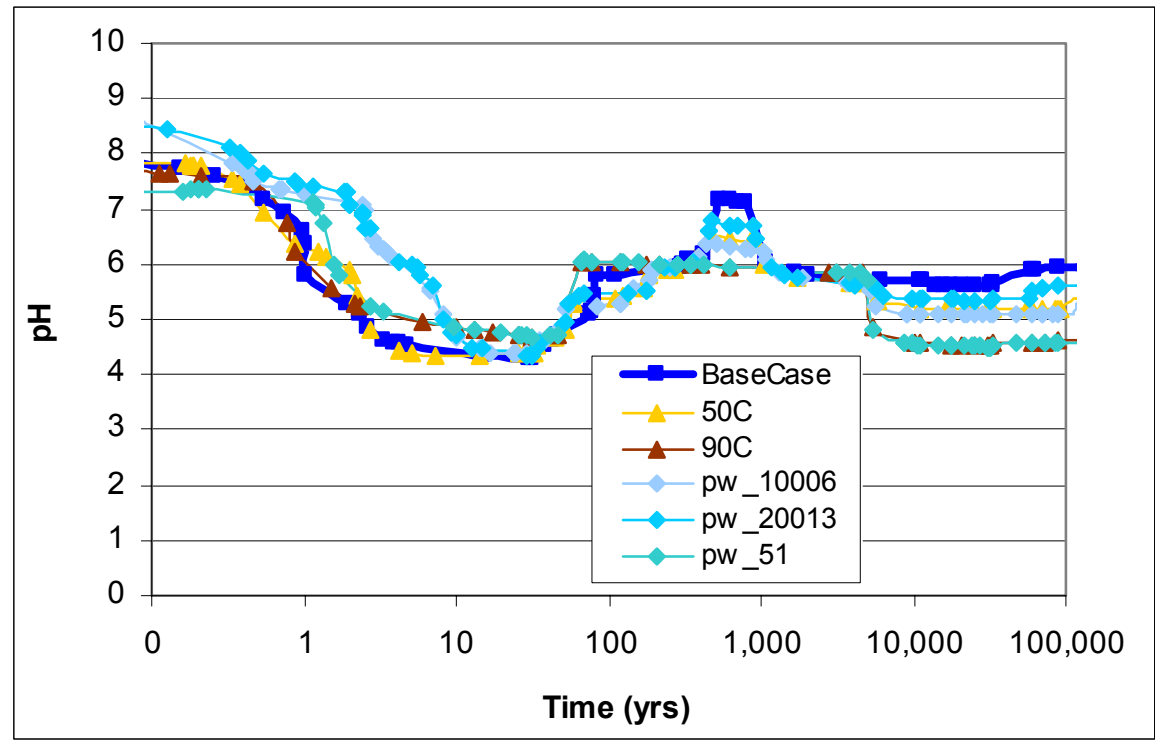

Source: $\quad$ CSNF Liquid Influx Model Output.xIs (Appendix F ISpreadsheets).

NOTE: $\quad$ Time refers to time after waste package breach ( 0 on the $x$-axis refers to 0.1 years).

Figure 6-46. Effect of Increasing Temperature on the $\mathrm{pH}$ for CSNF

Figure 6-46 shows increasing the temperature lowers late-time $\mathrm{pH}$ for the CSNF runs. One reason for the decreasing $\mathrm{pH}$ values at high temperature is the decrease in the dissociation constant of water with increased temperature.

Figure 6-47 shows the ionic strength results of EQ6 simulations at higher temperatures for CSNF waste packages. The results plotted in Figure 6-47 show temperature had a minor influence on ionic strength, and this effect is even more pronounced for high temperatures. Although evaporation from the interior of the waste package is not expected to be great, due to high humidity in the waste package interior, evaporation could still influence the ionic strength as temperature increases. 


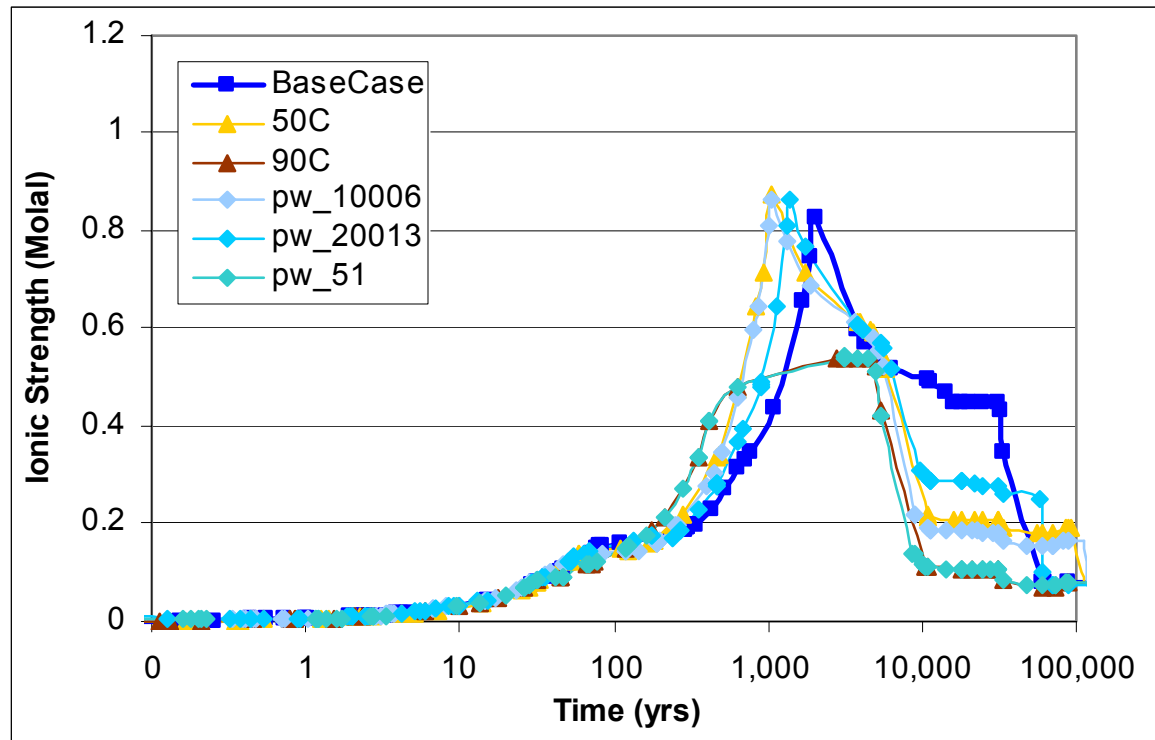

Source: $\quad$ CSNF Liquid Influx Model Output.xIs (Appendix F ISpreadsheets).

NOTE: Time refers to time after waste package breach ( 0 on the $x$-axis refers to 0.1 years).

Figure 6-47. Effect of Increasing Temperature on lonic Strength for CSNF

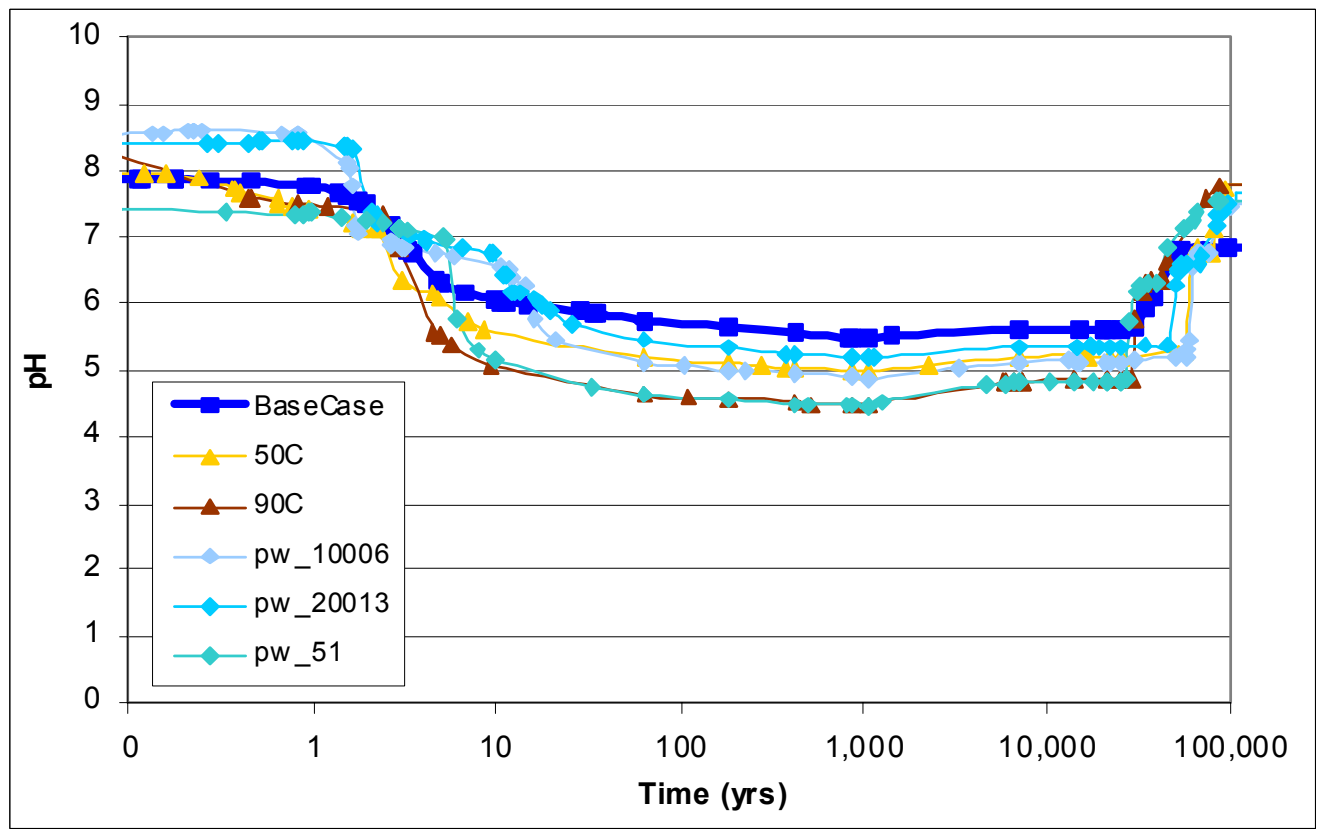

Source: CDSP Liquid Influx Model Output.xls (Appendix FISpreadsheets).

NOTE: $\quad$ Time refers to time after waste package breach ( 0 on the $x$-axis refers to 0.1 years).

Figure 6-48. Effect of Increasing Temperature on the $\mathrm{pH}$ for CDSP

Figure 6-48 shows increasing the temperature lowers the late-time $\mathrm{pH}$ for the CDSP runs. One reason for decreasing $\mathrm{pH}$ at high temperature is the decrease in the dissociation constant of water with increased temperature. The HLWG is more-quickly depleted at higher temperatures because of the higher rate constants (Table 6-8) at elevated temperature. The batch reactor runs 
at higher temperatures use a temperature-appropriate HLWG-degradation rate (Table 6-8). The metal alloy corrosion rates for the high temperature runs are the same as those used for the $25^{\circ} \mathrm{C}$ runs; however, these rates are also considered appropriate for higher temperatures because many of the experiments that generated the data for these rates were conducted at higher temperatures. As shown in the corrosion rate DTN (MO0409SPAACRWP.000 [DIRS 172059]), the degradation rates at $25^{\circ} \mathrm{C}$ are similar to those at $90^{\circ} \mathrm{C}$. In addition, sensitivity studies were conducted that examined the impact of varying the corrosion rates over several orders of magnitude (Section 6.6.10). The thermodynamic database includes high temperature data for most mineral and aqueous species; therefore, the reacted solution chemistry and precipitated mineral phases are temperature appropriate.

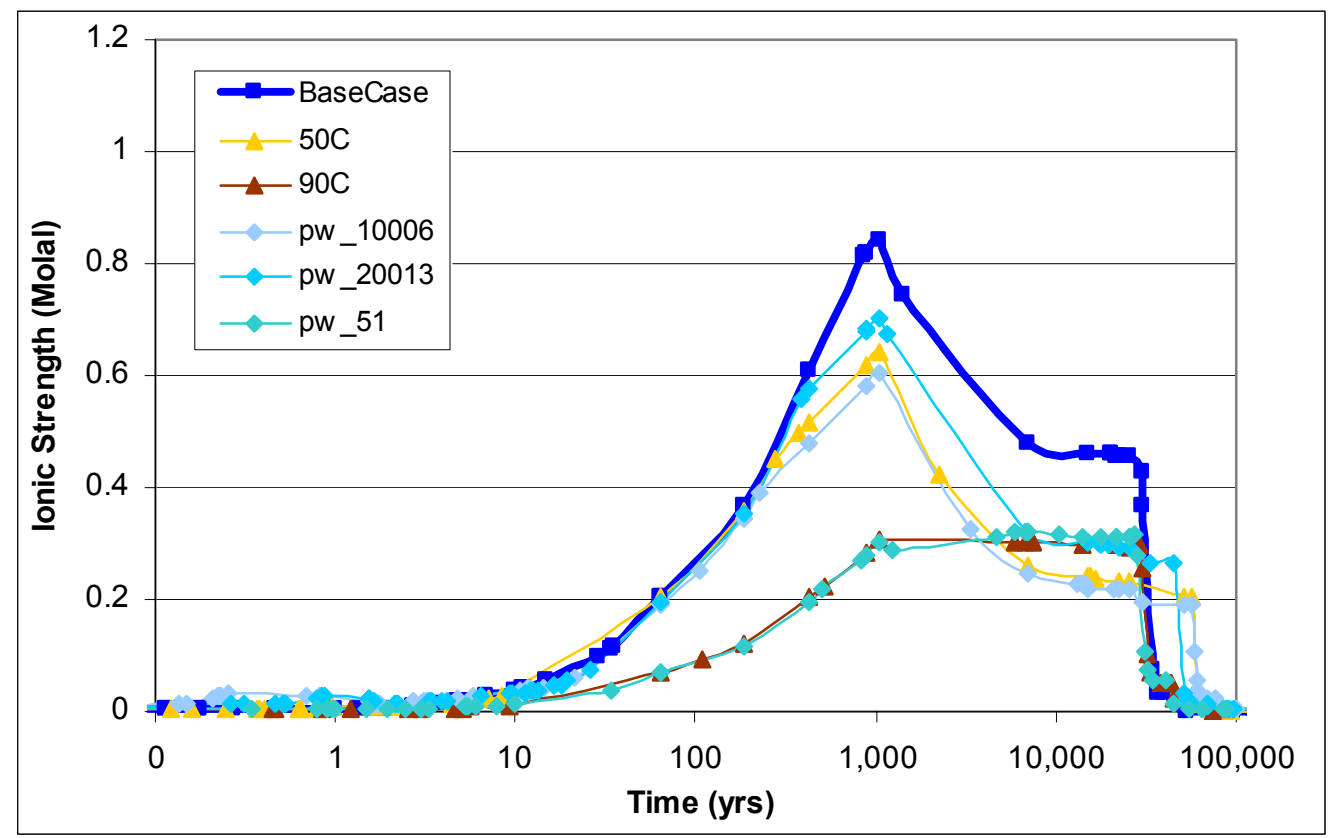

Source: CDSP Liquid Influx Model Output.x/s (Appendix F /Spreadsheets).

NOTE: $\quad$ Time refers to time after waste package breach ( 0 on the $x$-axis refers to 0.1 years).

Figure 6-49. Effect of Increasing Temperature on lonic Strength for CDSP

The results plotted in Figure 6-49 show temperature had a minor influence on steady-state ionic strength. The effects of evaporation inside of the waste package are not modeled explicitly, but the effects are accounted for by the broad uncertainty range for the ionic strength abstraction.

Although the simulations depicted in Figures 6-46 through 6-49 were run at a maximum of $90^{\circ} \mathrm{C}$, the results of these high-temperature simulations have been used to extend the temperature limit of the $\mathrm{pH}$ and ionic strength abstractions (Sections 6.10.1 and 6.10.2) up to $100^{\circ} \mathrm{C}$. The temperature effect on $\mathrm{pH}$ from $50^{\circ} \mathrm{C}$ to $90^{\circ} \mathrm{C}$ is small enough to conclude that the additional ten degrees will have little impact on lowering the late-time $\mathrm{pH}$ for either CSNF or CDSP waste packages, because TSPA-LA, and this model consider the transition from water to steam occurs at $100^{\circ} \mathrm{C}$.

The high-temperature runs achieve an overall higher $\mathrm{pH}$ profile at long time periods and slight variations in the stable mineral assemblages compared with the results at $25^{\circ} \mathrm{C}$. Since several of 
the runs are carried out at above ambient temperatures and the in-package chemistry model results reflect the increased thermal conditions, the TSPA-LA feed also reflects the increased thermal conditions. The effect of temperature on the surface complexation model is discussed in Section 6.7.3. The above discussion addresses the thermal effects on chemistry portion of the subject matter of "Included" FEP 2.1.11.08.0A (Thermal effects on chemistry and microbial activity in the EBS) and indicates how that subject matter has been included and addressed within TSPA-LA. The microbial activity in the EBS subject matter is described in FEP 2.1.10.01.0A and documented in Engineered Barrier System Features, Events, and Processes (BSC 2004 [DIRS 169898]).

\subsubsection{Design Change from Neutronit to NiGd Alloy}

The impact of replacing the Neutronit with NiGd alloy in the CSNF waste package (Section 4.1.4) was examined in Rev 03 of this report, and is presented here for historical purposes. The files associated with this sensitivity can be found in DTN: MO0411SPAMOICA.000 [DIRS 172244]. The quantity (moles) and surface area for the NiGd alloy are modeled as the same as the Neutronit values. Two corrosion rates for the NiGd alloy are used: one run considers $0.052 \mu \mathrm{m} / \mathrm{yr}(52 \mathrm{~nm} / \mathrm{yr}$ ) from Table 4-8, and the second case uses $1 \mu \mathrm{m} / \mathrm{yr}$ for the first ten years, followed by $90 \mathrm{~nm} / \mathrm{yr}$ (BSC 2004 [DIRS 168434]) for the remainder of the run. The second rate case was examined to factor in the potential that the initial rate could be as high as $1 \mu \mathrm{m} / \mathrm{yr}$, but could slow down due to the passive layer that forms.

A CSNF run containing Neutronit with a mean flux value and mean fuel exposure $(\mathrm{Q}=1.5 \mathrm{~L} / \mathrm{yr}$ and $10 \%$ exposed) was used as the base case for this sensitivity. Because chromium is a major component of the NiGd alloy, and also has a great impact on the chemistry of the system, this sensitivity also examines the $\mathrm{Cr}(\mathrm{III})$ and $\mathrm{Cr}(\mathrm{VI})$ oxidation states for each run. The results are presented in Figures 6-50 through 6-53. 


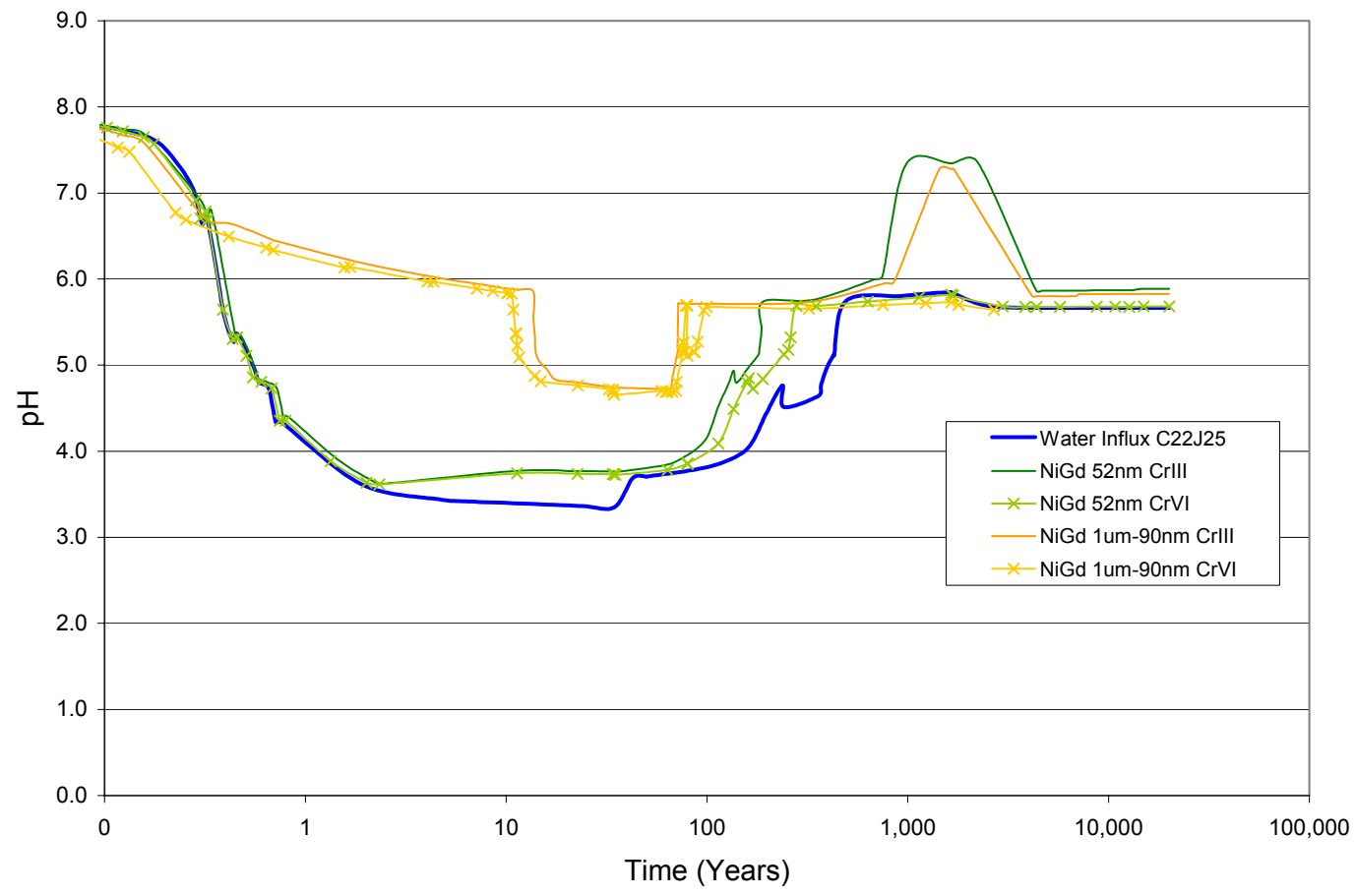

Source: CSNF_NiGd Sensitivity.xIs (DTN: MO0411SPAMOICA.000 [DIRS 172244]).

NOTE: Time refers to time after waste package breach ( 0 on the $x$-axis refers to 0.1 years).

Figure 6-50. NiGd Alloy Design Change for Liquid-Influx Case: Impact on $\mathrm{pH}$

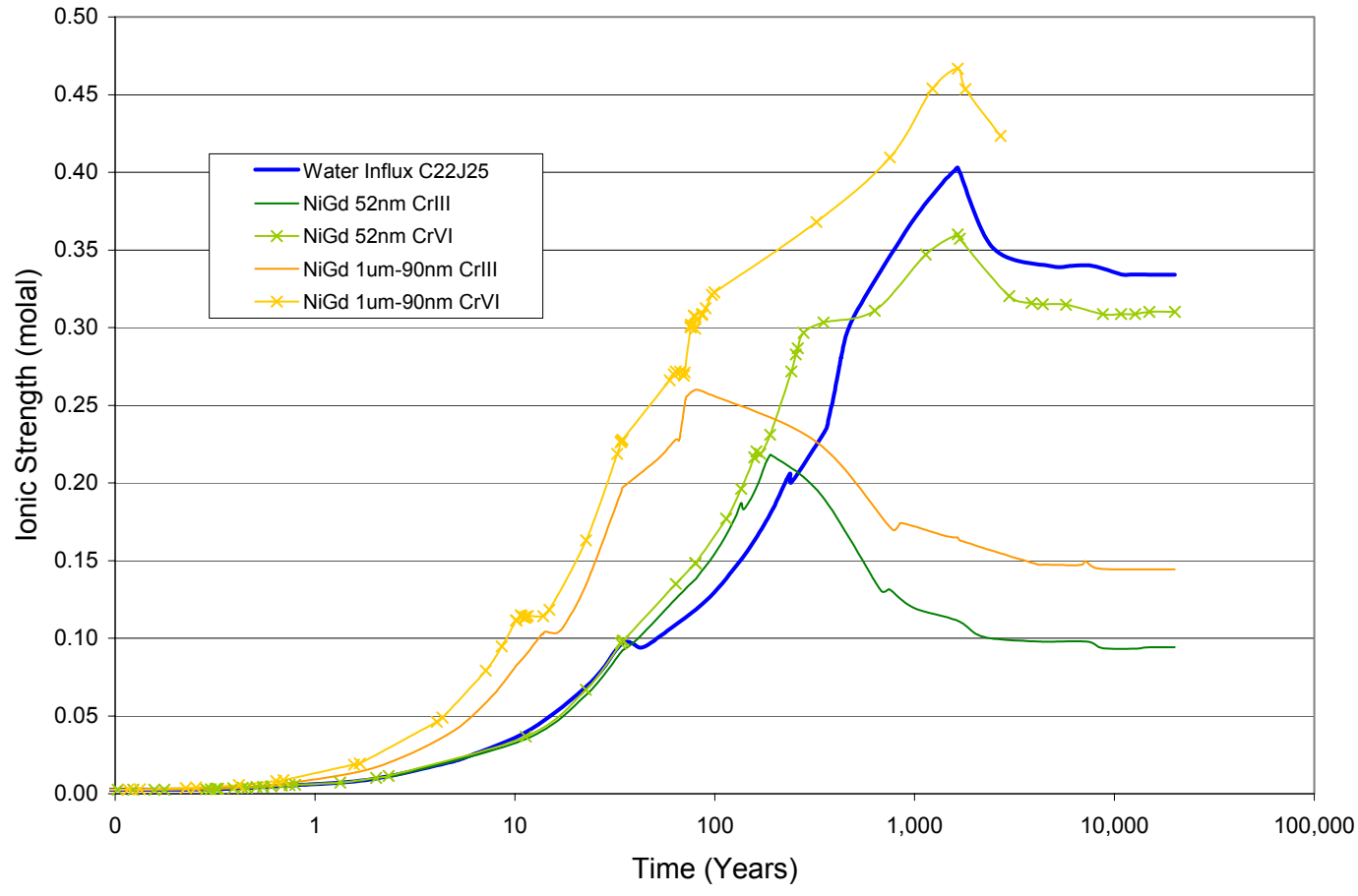

Source: CSNF_NiGd Sensitivity.xIs (DTN: MO0411SPAMOICA.000 [DIRS 172244]).

Figure 6-51. NiGd Alloy Design Change for Liquid-Influx Case: Impact on lonic Strength 


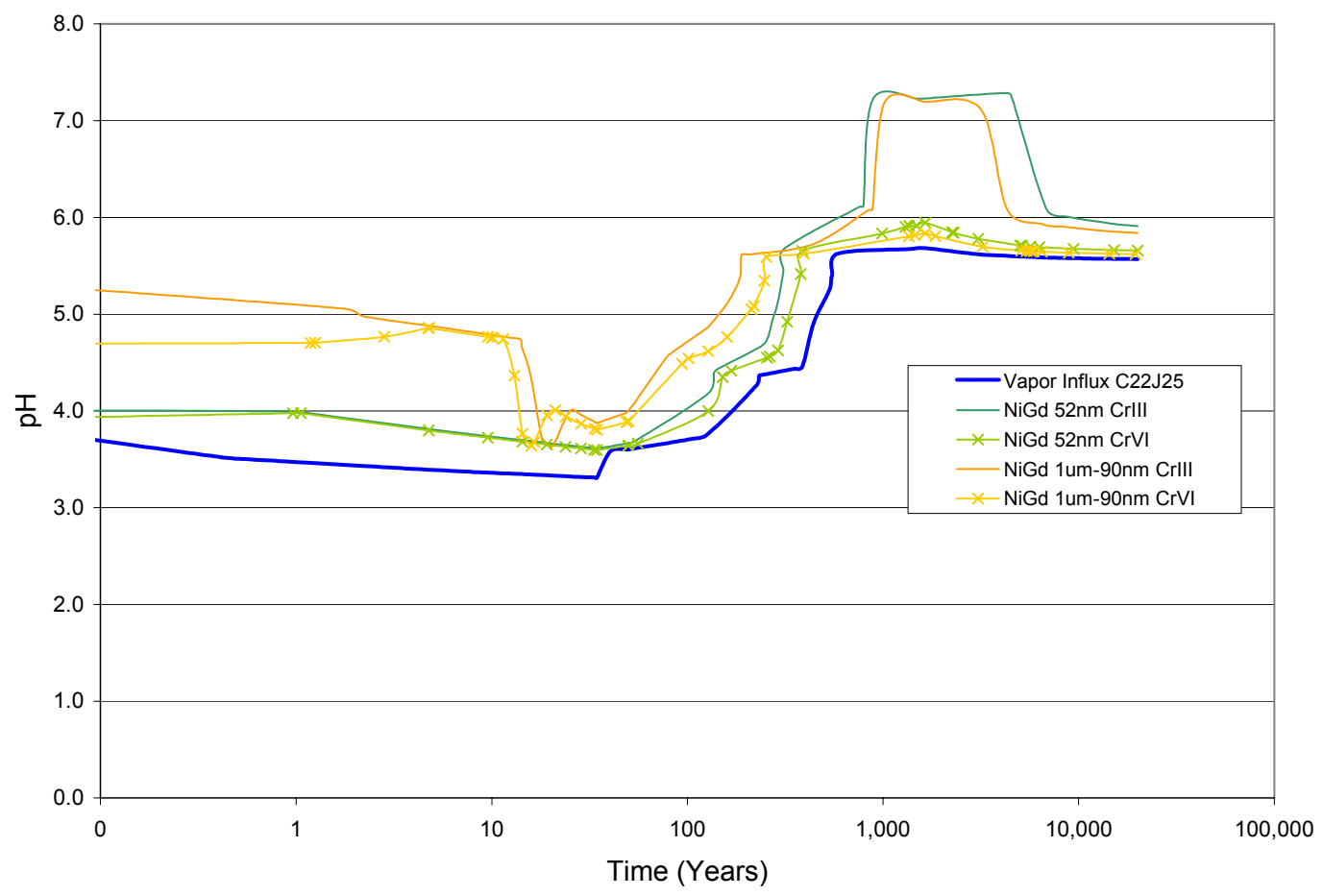

Source: CSNF_NiGd Sensitivity.xIs (DTN: MO0411SPAMOICA.000 [DIRS 172244]).

NOTE: Time refers to time after waste package breach ( 0 on the $x$-axis refers to 0.1 years).

Figure 6-52. NiGd Alloy Design Change for Vapor-Influx Case: Impact on pH 


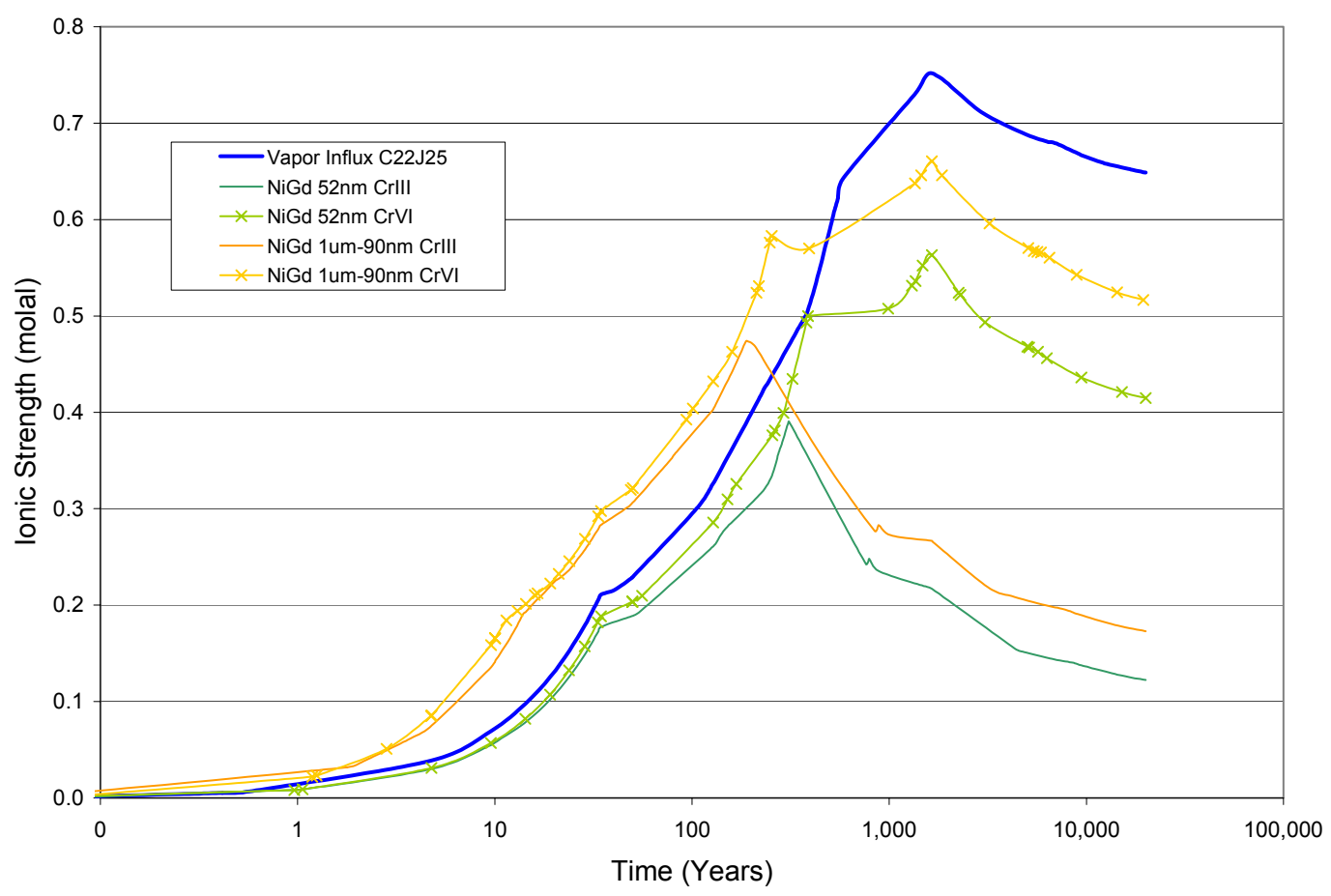

Source: CSNF_NiGd Sensitivity.xIs (DTN: MO0411SPAMOICA.000 [DIRS 172244]).

NOTE: $\quad$ Time refers to time after waste package breach ( 0 on the $x$-axis refers to 0.1 years).

Figure 6-53. NiGd Alloy Design Change for Vapor-Influx Case: Impact on lonic Strength

The NiGd alloy runs have a slightly higher $\mathrm{pH}$ than the base case for early times that is more pronounced for the higher NiGd alloy rates, but the stabilized, long-term $\mathrm{pH}$ is similar for all the cases. The $\mathrm{Cr}(\mathrm{VI})$ runs exhibit a high $\mathrm{pH}$ between 1,000 and 10,000 years as shown in the $\mathrm{Cr}$ sensitivity.

The ionic strength profiles for the NiGd alloy runs are similar to the base case, but are slightly higher than the base case for the liquid-influx case, and slightly lower than the base case for the vapor-influx case, as shown by comparing Figures 6-51 and 6-53. The ionic strength effects are more impacted by the Cr oxidation state than the presence of NiGd alloy instead of Neutronit.

The results of this sensitivity show that the change in design to NiGd alloy does impact the chemistry, but that the resulting $\mathrm{pH}$ and ionic strength are still within the abstracted range provided to TSPA-LA (Section 8.1.2).

\subsubsection{HLWG Composition Change}

The impact of the HLWG composition on the in-package chemistry was evaluated in Rev 03 of this report by replacing the simplified glass composition described in Table 4-5 with two alternate glass compositions and running the CDSP liquid-influx case. The D23C25 case was chosen because it has the highest glass exposure (100\%) and since this run was used to assess several other sensitivities. The inputs associated with this sensitivity are documented in Rev 03 of this report, and the files can be found in DTN: MO0411SPAMOICA.000 [DIRS 172244]. 
The sources for the "raw" HLWG chemical composition used for these sensitivity runs are "Waste Treatment and Immobilization Plant (WTP) High-Level Waste (HLW) Canister Production Estimates to Support Analyses by the Yucca Mountain Project" (Hamel 2003 [DIRS 164947], Table 1) and Projected Glass Composition and Curie Content of Canisters from the Savannah River Site (U) (Allison 2004 [DIRS 168734], Attachment I). The specific glass compositions chosen from these sources contain high concentrations of alkali metals ( $\mathrm{Na}$ and $\mathrm{K}$ ), which increase solution $\mathrm{pH}$ during glass dissolution (which was the Waste Acceptance Product Specifications Low Viscosity Purex Only Glass Composition for the SRL_new glass composition, and the WTP Technology Case for the Hanford glass composition).

For input into EQ6, several elements in the glass composition from Hamel (2003 [DIRS 164947], Table 1) and Allison (2004 [DIRS 168734], Attachment I) were simplified in a manner similar to the base-case glass presented in Table 4-5, and described in CRMWS M\&O 2001 [DIRS 153263]. The simplification is presented in detail in CDSP_HLWG_Sensitivity.xls in DTN: MO0411SPAMOICA.000 [DIRS 172244]. These minor changes were made to the basic composition to increase the efficiency of the calculations, to decrease the EQ6 run time, and to allow the use of a $\mathrm{pH}$-dependent rate law. These simplified glass compositions were calculated in CDSP_HLWG_Sensitivity.xls (DTN: MO0411SPAMOICA.000 [DIRS 172244]). These simplified glass compositions were also included in the EQ6 database as the minerals 'SRL_New' and 'HanfordTC' (Stoichiometric fractions less than 0.0001 moles/100 g are not read by EQ3/6). The resulting simplified HLWG formula based on $100 \mathrm{~g}$ is in Table 6-15. The base-case composition is also presented for comparison purposes.

Table 6-15. HLWG Sensitivity: High-Level Waste Glass Composition

\begin{tabular}{|c|c|c|c|}
\hline Element & $\begin{array}{c}\text { Base Case } \\
\text { Moles/100g HLWG }\end{array}$ & $\begin{array}{c}\text { SRL_New } \\
\text { Moles/100g HLWG }\end{array}$ & $\begin{array}{c}\text { HanfordTC } \\
\text { Moles/100g HLWG }\end{array}$ \\
\hline $\mathrm{O}$ & 2.7038 & 2.6338 & 2.5781 \\
\hline$U$ & 0.0078 & 0.0102 & 0.0107 \\
\hline $\mathrm{Ba}$ & 0.0011 & 0.0017 & 0.0018 \\
\hline $\mathrm{Al}$ & 0.0863 & 0.0578 & 0.2537 \\
\hline$S$ & 0.0040 & 0.0028 & 0.0048 \\
\hline $\mathrm{Ca}$ & 0.0162 & 0.0182 & 0.0217 \\
\hline $\mathrm{P}$ & 0.0005 & 0.0003 & 0.0186 \\
\hline $\mathrm{Si}$ & 0.7765 & 0.7400 & 0.6068 \\
\hline$B$ & 0.2912 & 0.2895 & 0.1845 \\
\hline $\mathrm{Fe}$ & 0.1722 & 0.2064 & 0.1364 \\
\hline $\mathrm{K}$ & 0.0752 & 0.0751 & 0.0059 \\
\hline $\mathrm{Mg}$ & 0.0333 & 0.0327 & 0.0060 \\
\hline $\mathrm{Na}$ & 0.5767 & 0.5931 & 0.8907 \\
\hline \multicolumn{4}{|c|}{$\begin{array}{ll}\text { Source: } & \text { CDSP_HLWG_Sensitivity.xIs (DTN: MO0411SPAMOICA.000 } \\
& \text { [DIRS 172244]). }\end{array}$} \\
\hline NOTE: & $\begin{array}{l}\text { tal mole } \% \text { of the re } \\
\text { tant. } \\
\text { Savannah River Lab }\end{array}$ & $\begin{array}{l}\text { ctant are calculated } \\
\text { ratory }\end{array}$ & ased on 100 grams \\
\hline
\end{tabular}

The results of the sensitivity runs with the alternate glass compositions, Figure 6-54, show only small differences in $\mathrm{pH}$ or ionic strength. This sensitivity uses $\mathrm{Cr}$ (VI) rather than $\mathrm{Cr}$ (III), but 
because these cases use the same oxidation state for chromium, $\mathrm{Cr}(\mathrm{VI})$, the important $\mathrm{pH}$ and ionic strength trends shown in this sensitivity are impacts caused by the differences in the base-case glass composition and the new SRL and Hanford glass compositions. Because this sensitivity used $\mathrm{Cr}(\mathrm{VI})$ instead of $\mathrm{Cr}(\mathrm{III})$, the ionic strengths shown in Figure 6-54 are higher than they would be if $\mathrm{Cr}(\mathrm{III})$ had been used. The impacts of $\mathrm{Cr}(\mathrm{VI})$ versus $\mathrm{Cr}$ (III) are described in more detail in Section 6.6.3.

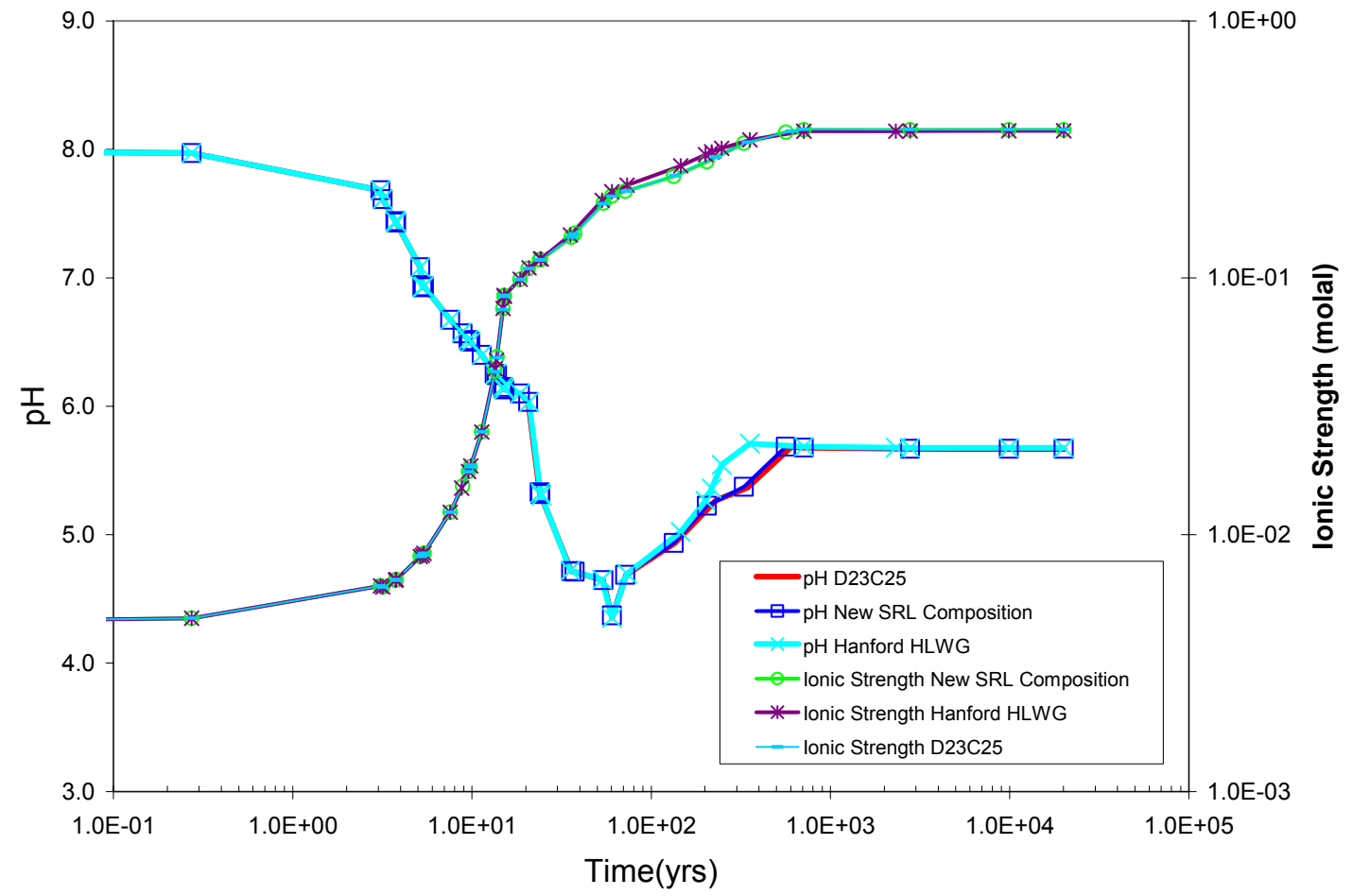

Source: CDSP_HLWG_Composition Sensitivity.xIs (DTN: M00411SPAMOICA.000 [DIRS 172244]).

Note: $\quad$ Time refers to time after waste package breach. This sensitivity uses $\mathrm{Cr}(\mathrm{VI})$ rather than $\mathrm{Cr}(\mathrm{III})$.

Figure 6-54. Comparison of HLW Glass Compositions

\subsubsection{Quantity of Carbon Steel Type A516 in Waste Package Design}

The impact of the Carbon Steel Type A516 on the in-package chemistry was evaluated by replacing the Carbon Steel Type A516 with an equivalent amount of Stainless Steel Type 316 (filename: NoA516), decreasing the amount of sulfur in the A516 by a factor of ten (filename: LowA516), and running the CSNF liquid-influx model.

The effect of the fuel exposure on the $\mathrm{pH}$ is direct, in that increasing the fuel exposure buffers the $\mathrm{pH}$ due the acid neutralizing capacity of the CSNF via the reaction:

$$
\mathrm{UO}_{2}+1 / 2 \mathrm{O}_{2}+2 \mathrm{H}^{+} \rightarrow \mathrm{UO}_{2}{ }^{2+}+\mathrm{H}_{2} \mathrm{O}
$$

where $\mathrm{UO}_{2}$ represents the CSNF. Thus, dissolution of $\mathrm{UO}_{2}$ consumes hydrogen ion $\left(\mathrm{H}^{+}\right)$and moderates the $\mathrm{pH}$ towards a more neutral value. 
The results of the run in which Carbon Steel Type A516 was replaced by Stainless Steel Type 316 are displayed in Figure 6-55. As would be expected, the low-pH conditions observed in the base-case run in the first 100 years are not observed in the run in which Carbon Steel Type A516 is replaced with Stainless Steel Type 316. The reason for the moderation in the $\mathrm{pH}$ between the two runs is the lower corrosion rate, nearly three orders of magnitude, of Stainless Steel Type 316 compared to the Carbon Steel Type A516 steel. The slower corrosion of Stainless Steel Type 316 translates to a decrease in the amount of oxidized sulfur released into the aqueous phase as a function of time and, thus, the $\mathrm{pH}$ remains closer to neutral. At times greater than about 600 years (Figure 6-55), the $\mathrm{pH}$ is less for the Stainless Steel Type 316 case than for the base case due to the excess chromium in solution from the additional stainless steel.

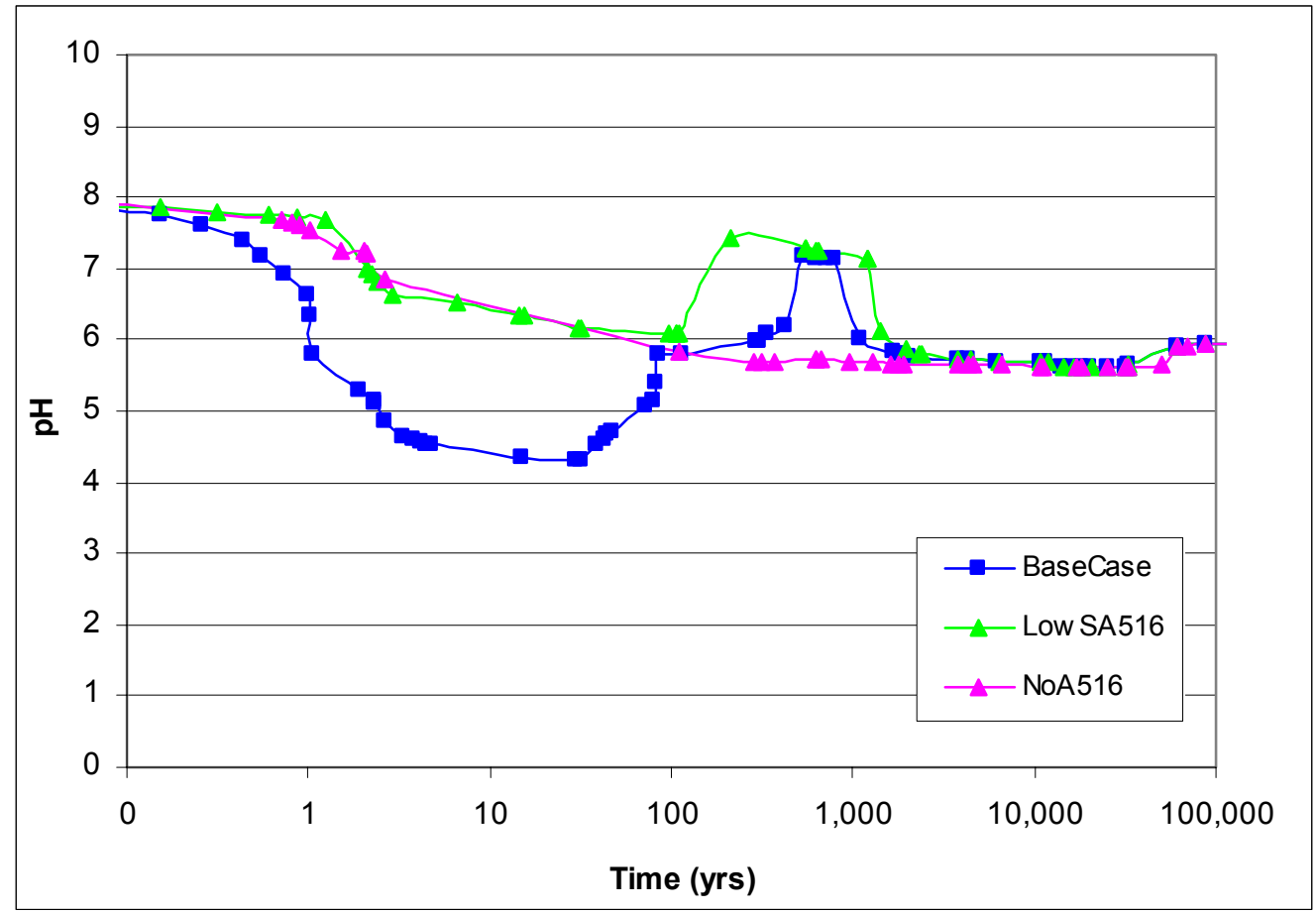

Source: CSNF Liquid Influx Model Output.xIs (Appendix F ISpreadsheets).

Note: $\quad$ Time refers to time after waste package breach.

Figure 6-55. Effect of Replacing Carbon Steel Type A516 with Stainless Steel Type 316

The implication of replacing the Carbon Steel Type A516 with stainless steel in the CSNF waste package is a more moderate $\mathrm{pH}$ condition during the period when Carbon Steel Type A516 would be corroding. Thus, with less-extreme $\mathrm{pH}$ conditions, the CSNF dissolution that increases at low $\mathrm{pH}$ would also be lower. Additionally, it would be expected for waste packages that do not contain Carbon Steel Type A516, the low-pH conditions would not develop. For example, for the naval waste packages, McKenzie (2002 [DIRS 165219], p. 9 of 47) states :

Spacers are used for some basket designs to fill the internal length of the canister. Canister, basket, and spacer materials are stainless steels (including material dual certified as Type 316 and 316L stainless, Nitronic 50 and Nitronic 60) and Zircaloy. Hastelloy alloy C-22 may be used in future designs. 
For the waste packages that do not contain Carbon Steel Type A516 in their design, the expected $\mathrm{pH}$ profiles would be near those displayed in Figure 6-55.

\subsubsection{Degradation Rates}

To account for the full possible range of corrosion rates for all the materials in the waste package, a series of sensitivity runs was conducted to examine the minimum and maximum rates for the alloys and fuels from Tables 6-5, 6-7, and 6-8. In addition, the CSNF cladding exposure and the HLWG fracture factor were varied.

The results of these runs are presented in Figures 6-56 through 6-59.

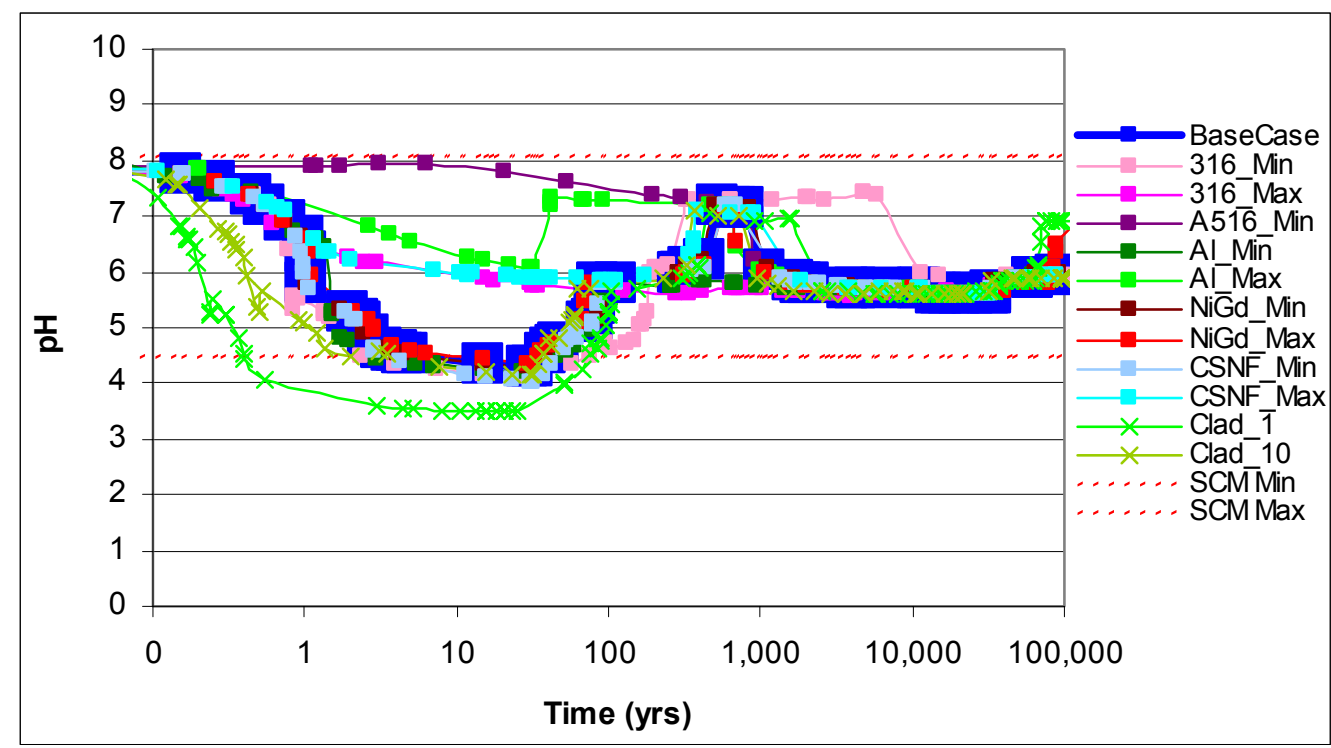

Source: CSNF Liquid Influx Model Output.xIs (Appendix F ISpreadsheets).

NOTE: $\quad$ Time refers to time after waste package breach ( 0 on the $x$-axis refers to 0.1 years). The dotted red lines indicate the minimum and maximum $\mathrm{pH}$ values after the surface complexation model has been applied.

Figure 6-56. Corrosion Rate Comparison for CSNF: pH Profiles 


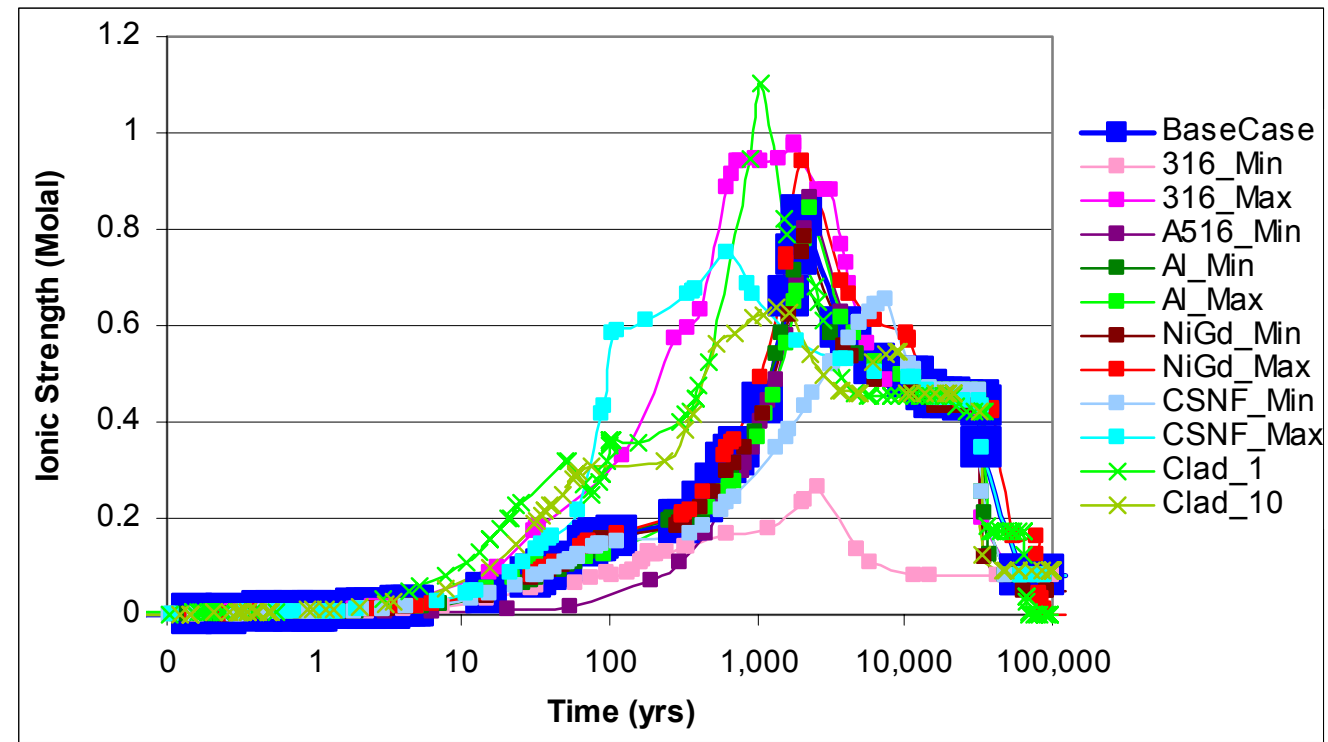

Source: CSNF Liquid Influx Model Output.xls (Appendix F ISpreadsheets).

NOTE: Time refers to time after waste package breach ( 0 on the $x$-axis refers to 0.1 years).

Figure 6-57. Corrosion Rate Comparison for CSNF: Ionic Strength Profiles

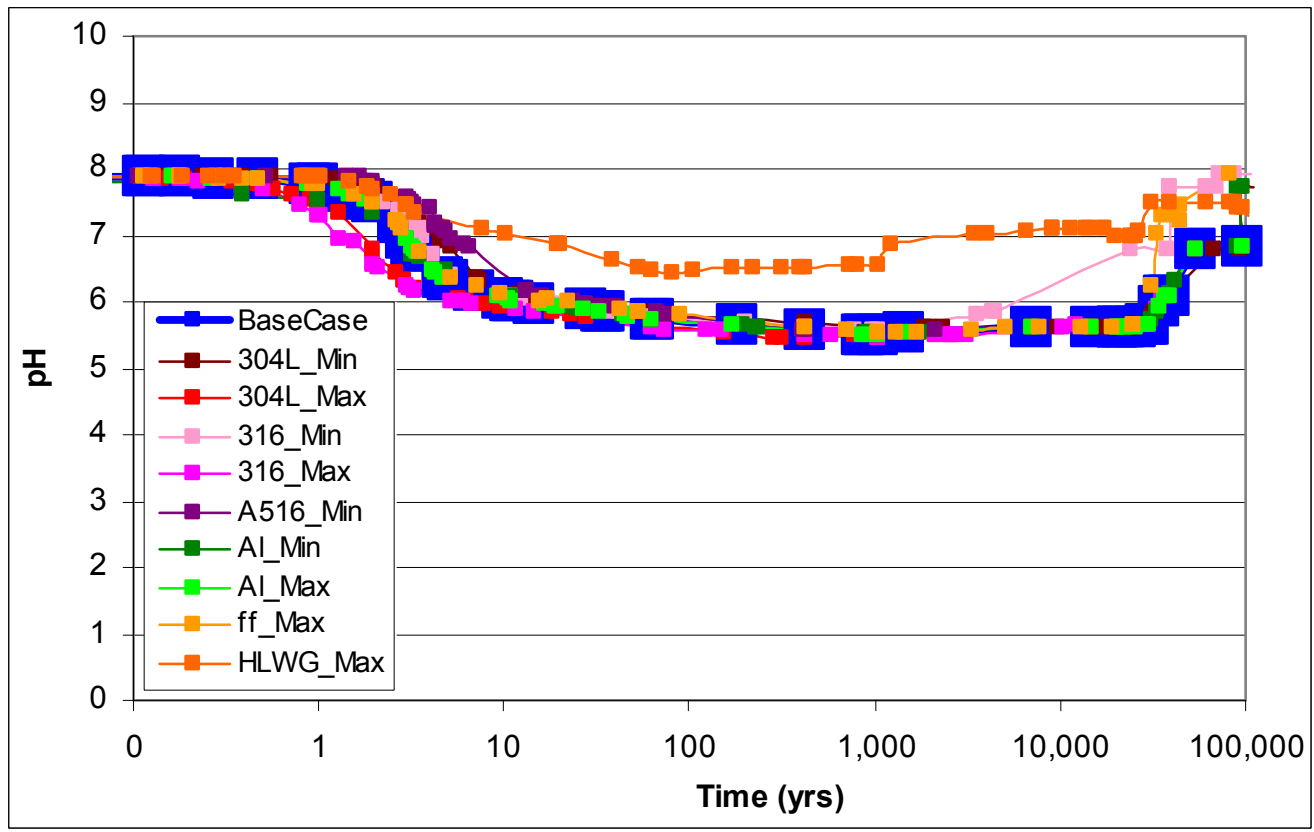

Source: CDSP Liquid Influx Model Output.xIs (Appendix F ISpreadsheets).

NOTE: Time refers to time after waste package breach ( 0 on the $x$-axis refers to 0.1 years).

Figure 6-58. Corrosion Rate Comparison for CDSP: pH Profiles 


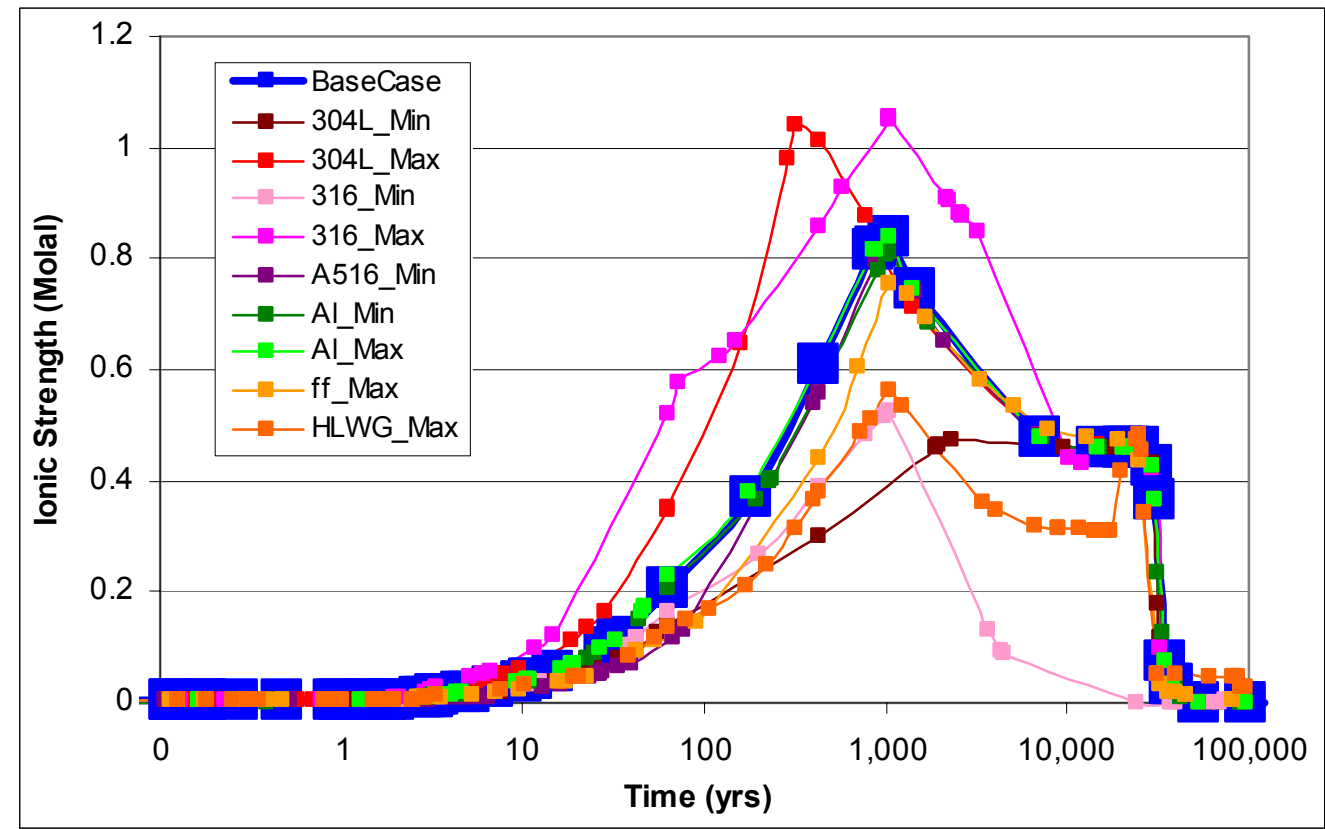

Source: CDSP Liquid Influx Model Output.xIs (Appendix F ISpreadsheets).

NOTE: $\quad$ Time refers to time after waste package breach ( 0 on the $x$-axis refers to 0.1 years).

Figure 6-59. Corrosion Rate Comparison for CDSP: Ionic Strength Profiles

The results in Figures 6-56 and 6-58 show that $\mathrm{pH}$ and ionic strength are sensitive to the corrosion rates used. The $\mathrm{pH}$ responses occur as a reactant is depleted and when that reactant no longer impacts the chemistry. The CSNF $\mathrm{pH}$ curves are slightly different, and the faster rates correspond to a lower $\mathrm{pH}$ minimum. A comparison of the CSNF runs shows $\mathrm{pH}$ values (by up to $4 \mathrm{pH}$ units) and timing of the $\mathrm{pH}$ response can vary by up to 1,000 years. However, these variations are accounted for in the $\mathrm{pH}$ abstraction that samples the $\mathrm{pH}$ between 4.5 and 7 or 8 , depending on the waste package and the $f \mathrm{CO}_{2}$ (Section 6.10.1). The effects of the surface complexation model are plotted in Figure 6-56 to indicate that even though the results of the EQ6 model show a $\mathrm{pH}$ minimum of less than 4 , the output of this model gives a $\mathrm{pH}$ minimum of 4.5 due to the effects of the surface complexation model. The CDSP $\mathrm{pH}$ curves show little change in $\mathrm{pH}$; the most notable changes are the increase in $\mathrm{pH}$ with an increase in the HLWG rate. For CDSP runs, over the full range of rates, $\mathrm{pH}$ values drop only by one $\mathrm{pH}$ unit (the minimum $\mathrm{pH}$ drops from $\sim 5.5$ to $\sim 4.0$ ).

The results in Figures 6-57 and 6-59 indicate that cases using higher corrosion rates result in higher ionic strengths for both CSNF and CDSP waste packages. The higher ionic strength is a result of the steel corrosion; the faster the elements are released from the steel, the higher the resulting ionic strength. Sensitivity cases using the highest rates result in ionic strengths approaching 1 molal for both the CSNF and CDSP cases.

The above discussion addresses the subject matter of "Included" FEP 2.1.09.07.0A (Reaction kinetics in waste package) and indicates how that subject matter has been included and addressed within TSPA-LA. 
The CSNF rate equation (BSC 2004 [DIRS 169987], Tables 8-2 and 8-3) includes a term, $\log (\mathrm{A})$, that factors in geometric surface area and surface area of cracks in the fuel. The $\log (\mathrm{A})$ term was calculated using the mass of CSNF fuel for the most likely or apex distribution $(\log (\mathrm{A})=-6.7)$ and the maximum distribution $(\log (\mathrm{A})=-5.4)$.

The results for the CSNF rates used show the maximum rate results in a higher $\mathrm{pH}$ for the first hundred years, but shows the same steady-state $\mathrm{pH}$ value. The maximum rate also results in a higher initial ionic strength, but similar long-term ionic strengths.

The HLWG rate has a high uncertainty applied to the glass degradation rate coefficient $\left(\mathrm{k}_{\mathrm{E}}\right.$ term) of the rate equation (Section 4.1.3). The base case uses the most probable values for $\mathrm{k}_{\mathrm{E}}: k_{E_{-} \text {acidic }}$ $\left(8.41 \times 10^{3} \mathrm{~g} /\left(\mathrm{m}^{2} \cdot \mathrm{d}\right)\right)$, and $k_{E_{\text {alkaline }}}\left(2.82 \times 10^{1} \mathrm{~g} /\left(\mathrm{m}^{2} \cdot \mathrm{d}\right)\right)$. The sensitivity uses the maximum values for $\mathrm{k}_{\mathrm{E}}\left(k_{E_{\text {accidic }}}=1.15 \times 10^{7} \mathrm{~g} /\left(\mathrm{m}^{2} \cdot \mathrm{d}\right)\right.$ and $\left.k_{E_{-} \text {alkaline }}=3.47 \times 10^{4} \mathrm{~g} /\left(\mathrm{m}^{2} \cdot \mathrm{d}\right)\right)$. These results show a considerably higher $\mathrm{pH}$ and ionic strength profile for the higher HLWG rate.

The exposure factor, $f_{\text {exposure }}$, is the value multiplied by the geometric surface area of the HLWG to achieve an effective surface area, which includes an increase in surface area due to fractures in the glass. Defense HLW Glass Degradation Model (BSC 2004 [DIRS 169988, Table 8-1) provides a minimum and most-likely value of the exposure factor equal to 4 and a maximum of 17. Figure 6-58 shows the $\mathrm{pH}$ is about $1 / 2 \mathrm{pH}$ unit lower for the lower-exposure factor case. These results do not reflect the surface complexation effects expected to buffer the $\mathrm{pH}$ in the first few hundred years. As shown in Section 6.8.4, solutions with $\mathrm{pH}$ values from 3 to 4 are buffered to $\mathrm{pH}$ values from 7 to 8 when contacted with iron oxides.

\subsubsection{Hematite versus Goethite}

Which ferric (hydr)oxide phase will form in a degrading waste package is uncertain. Section 6.3.2 provides information that suggests there is a time dependency where poorly crystalline ferrihydrite may initially dominate with a slow transformation, depending on the system chemistry to goethite and hematite. The likely outcome is a mixture of these three phases in varying proportions. In the EQ6 modeling included in this report, the runs were executed such that hematite was the ferric phase allowed to precipitate from solution, while the surface complexation model (Sections 6.7 and 6.8) uses goethite as the ferric phase active in the complexation of aqueous species.

To examine the influence of the ferric (hydr)oxide on the CSNF batch reactor model $\mathrm{pH}$ and ionic strength predictions, runs were completed where goethite was allowed to form in place of hematite, and the results are shown in Figures 6-60 through 6-63. It was not possible to test the effect of ferrihydrite formation because it is not included in the thermodynamic database. However, based on its similarities to goethite, the conclusion drawn from this sensitivity can also be applied to ferrihydrite formation. 


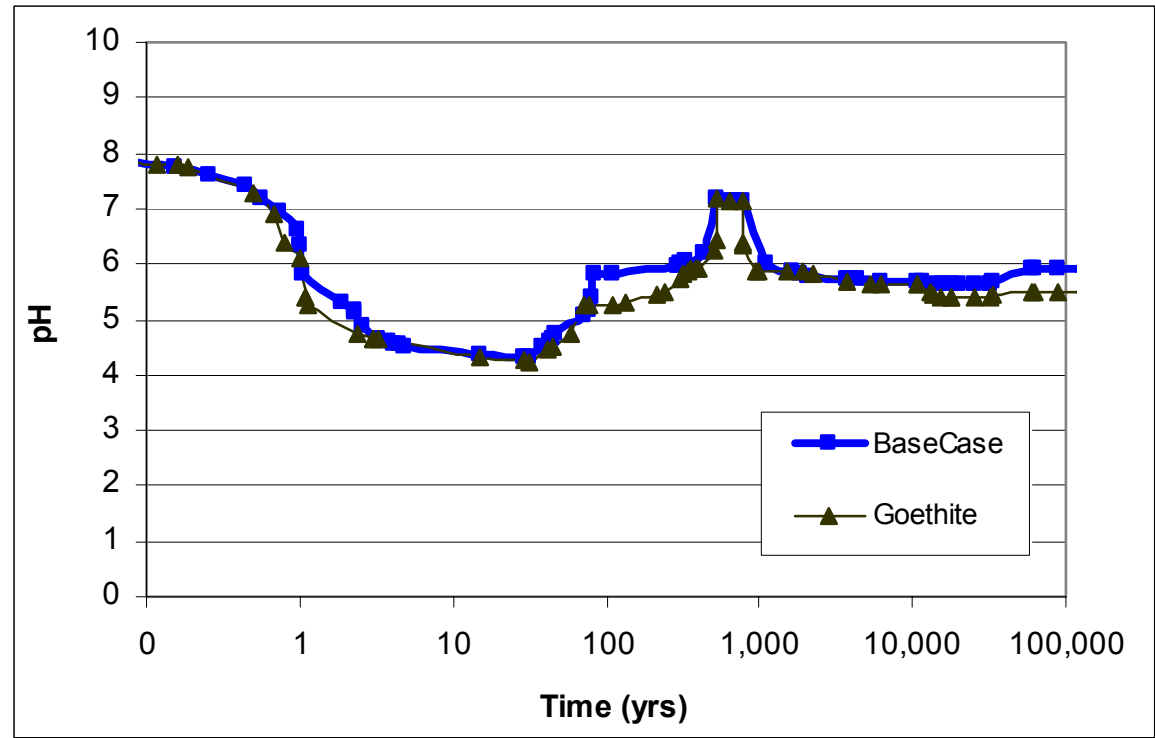

Source: CDSP Liquid Influx Model Output.xIs (Appendix F ISpreadsheets).

NOTE: $\quad$ Time refers to time after waste package breach ( 0 on the $x$-axis refers to 0.1 years).

Figure 6-60. Hematite and Goethite Comparison for CSNF: pH Profiles

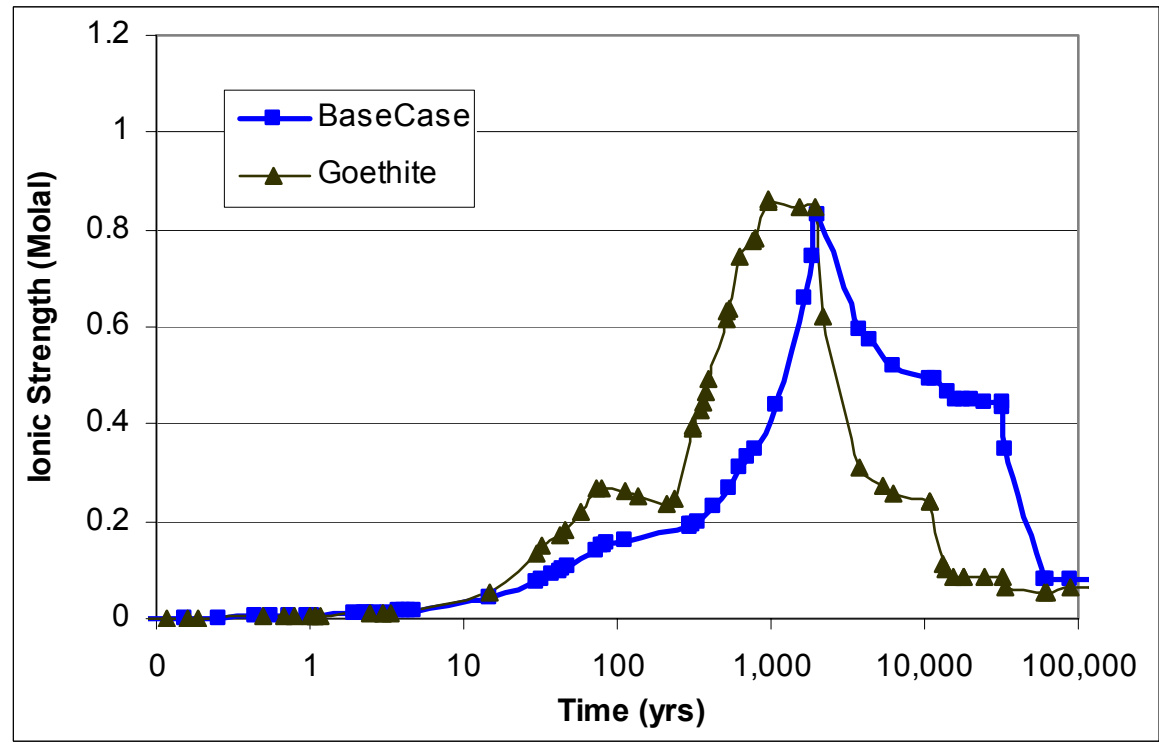

Source: $\quad$ CDSP Liquid Influx Model Output.xls (Appendix F ISpreadsheets).

NOTE: $\quad$ Time refers to time after waste package breach ( 0 on the $x$-axis refers to 0.1 years).

Figure 6-61. Hematite and Goethite Comparison for CSNF: Ionic Strength Profiles 


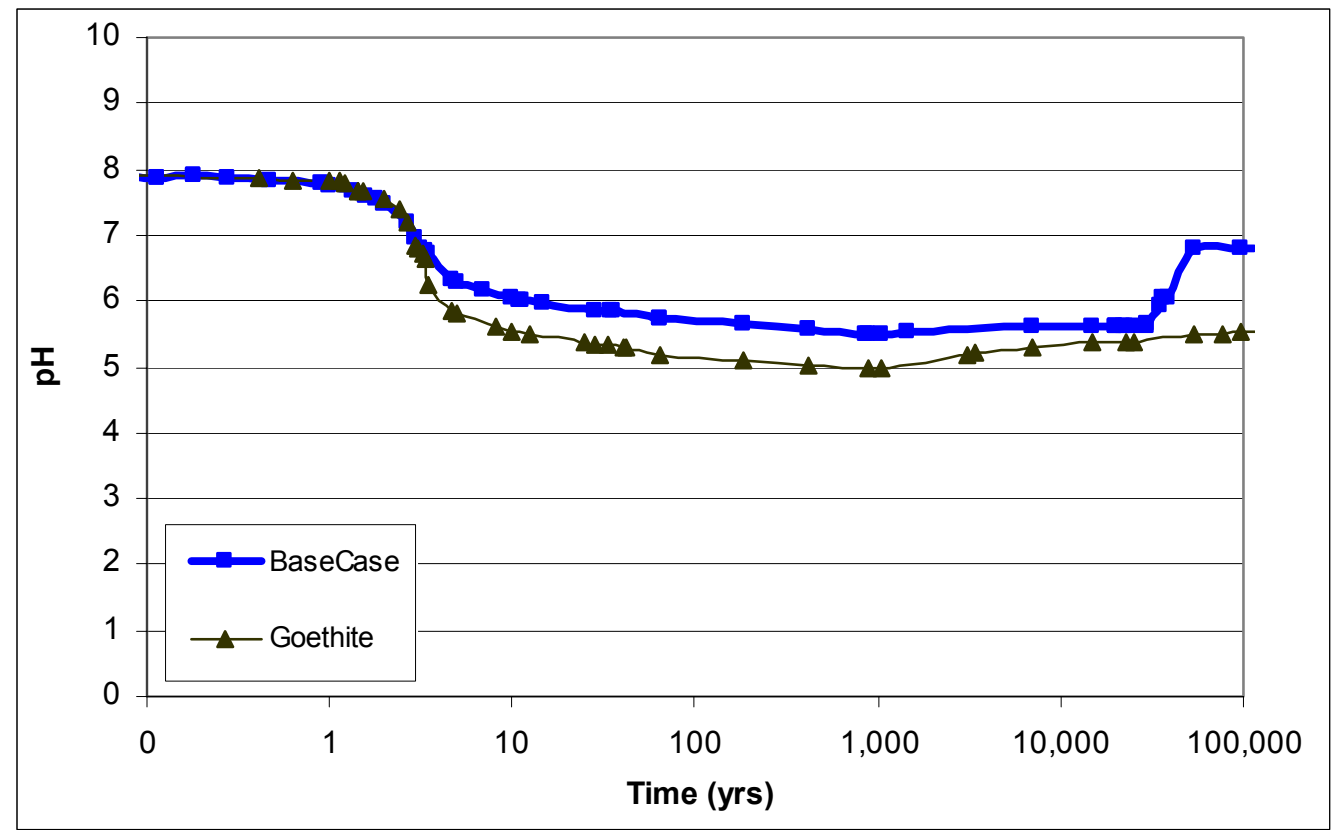

Source: $\quad$ CDSP Liquid Influx Model Output.xIs (Appendix F ISpreadsheets).

NOTE: $\quad$ Time refers to time after waste package breach ( 0 on the $x$-axis refers to 0.1 years).

Figure 6-62. Hematite and Goethite Comparison for CDSP: pH Profiles

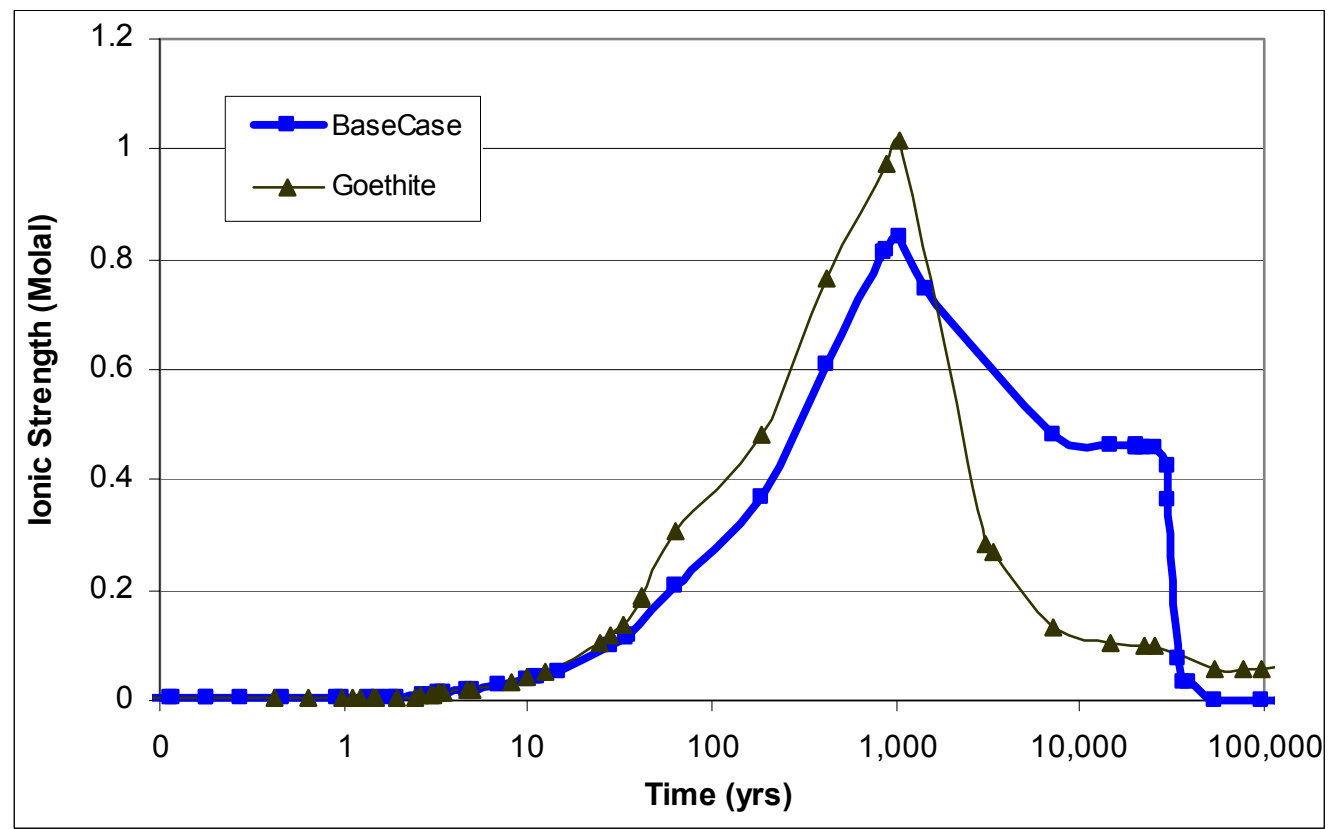

Source: CDSP Liquid Influx Model Output.xIs (Appendix F ISpreadsheets).

NOTE: $\quad$ Time refers to time after waste package breach ( 0 on the $x$-axis refers to 0.1 years).

Figure 6-63. Hematite and Goethite Comparison for CDSP: Ionic Strength Profiles

Additional results are plotted in Appendix A (Figure A-13 for $\mathrm{pH}$ profiles and Figure A-14 for ionic strength profiles). As shown in Figures 6-60 and 6-62, the $\mathrm{pH}$ results for the hematite and 
goethite cases are similar for the CSNF and CDSP cases, with the goethite runs about $0.5 \mathrm{pH}$ units lower than those of the hematite runs. This $0.5-\mathrm{pH}$ difference is insignificant and within the uncertainty of the model.

There is a slight difference in the ionic strength between 10 and 1,000 years (for both the CSNF and CDSP cases) where the goethite runs have higher ionic strength because the formation of goethite consumes more water than does hematite. This difference is insignificant in terms of performance because the ionic strength for goethite and hematite are above the $0.05-\mathrm{mol} / \mathrm{L}$ colloid threshold (BSC 2004 [DIRS 170025]) for this entire period.

This sensitivity analysis has shown the results of the batch reactor model are largely independent of which ferric (hydr)oxide mineral is allowed to form in the simulations. Therefore, the use of ferrihydrite, which is similar to goethite, in the surface complexation model is acceptable because it would not cause unusual excursions in the chemistry of the batch reactor model that used hematite as the primary phase. In addition to the similarities, there are also some differences between ferrihydrite and goethite, such as their surface areas. To account for this difference, the treatment of the ferric (hydr)oxide site density is varied by an order of magnitude, as described in Section 6.7.1 (Table 6-18).

\subsubsection{Codisposal Waste Package Containing 5-DHLW Canisters}

The CDSP base case considers codisposal waste packages contain N-Reactor fuel (2-MCO/2-DHLW). In addition to this type of waste package, the repository is expected to contain other waste packages containing the 5-DHLW/DOE SNF waste package design (BSC 2004 [DIRS 173501], Table 12). The 5-DHLW/DOE SNF waste package design contains five HLWG canisters (5-DHLW waste package) and one DOE canister containing DOE SNF. A sensitivity analysis was conducted in Rev 03 of this report to determine the impact on the in-package chemistry of the degradation of the 5-DHLW/DOE SNF waste package under the same conditions as the base-case N-Reactor D23C25 EQ6 run. The inputs to this sensitivity are documented in Rev 03 of this report, and files associated with this sensitivity can be found in DTN: MO0411SPAMOICA.000 [DIRS 172244].

The 5-DHLW/DOE SNF waste package design has a short waste package and a long waste package. This sensitivity examines the long waste package design because that is the design that will be used with the Three Mile Island (TMI) fuel. The EQ6 batch reactor model, liquid-influx case, was run for a codisposal waste package containing five HLWG canisters (5-DHLW long waste package) and one DOE canister containing one assembly of TMI SNF. TMI SNF was chosen because it is chemically similar to the N-Reactor fuel, and the purpose of this sensitivity is to examine the impact of the 5-DHLW/DOE SNF design. Using a drastically different fuel composition would have masked any differences due to the waste package design. The TMI SNF also represents a significant number of DOE canisters expected at the repository (DOE 2004 [DIRS 170071], Table A-2, "LEU oxide"). Two EQ6 calculations were run using the same drip rate, degradation rates (except fuel), temperature, and water composition as case D23C25. Two fuel degradation rates were used for these runs. Since the TMI fuel is a uranium oxide, the rates used in the EQ6 simulations were set equal to the CSNF rate and $100 \times$ the CSNF surface area, as recommended for DOE UO $\mathrm{U}_{2}$-type SNF in (DOE 2002 [DIRS 158405], Section 6.8). 
The results of the sensitivity runs with the TMI codisposal waste package are shown in Figure 6-64. The $\mathrm{pH}$ is lower in the first few hundred years. However, these results do not reflect the surface complexation effects expected to buffer the $\mathrm{pH}$ in the first few hundred years. As shown in Section 6.8.4, solutions with a $\mathrm{pH}$ value of 3 to 4 are buffered to a $\mathrm{pH}$ value of 7 to 8 when contacted with iron oxides. Therefore, due to the influence of the surface complexation, no significant $\mathrm{pH}$ change would be expected with water contacting a breached TMI codisposal waste package as opposed to an N-Reactor codisposal waste package.

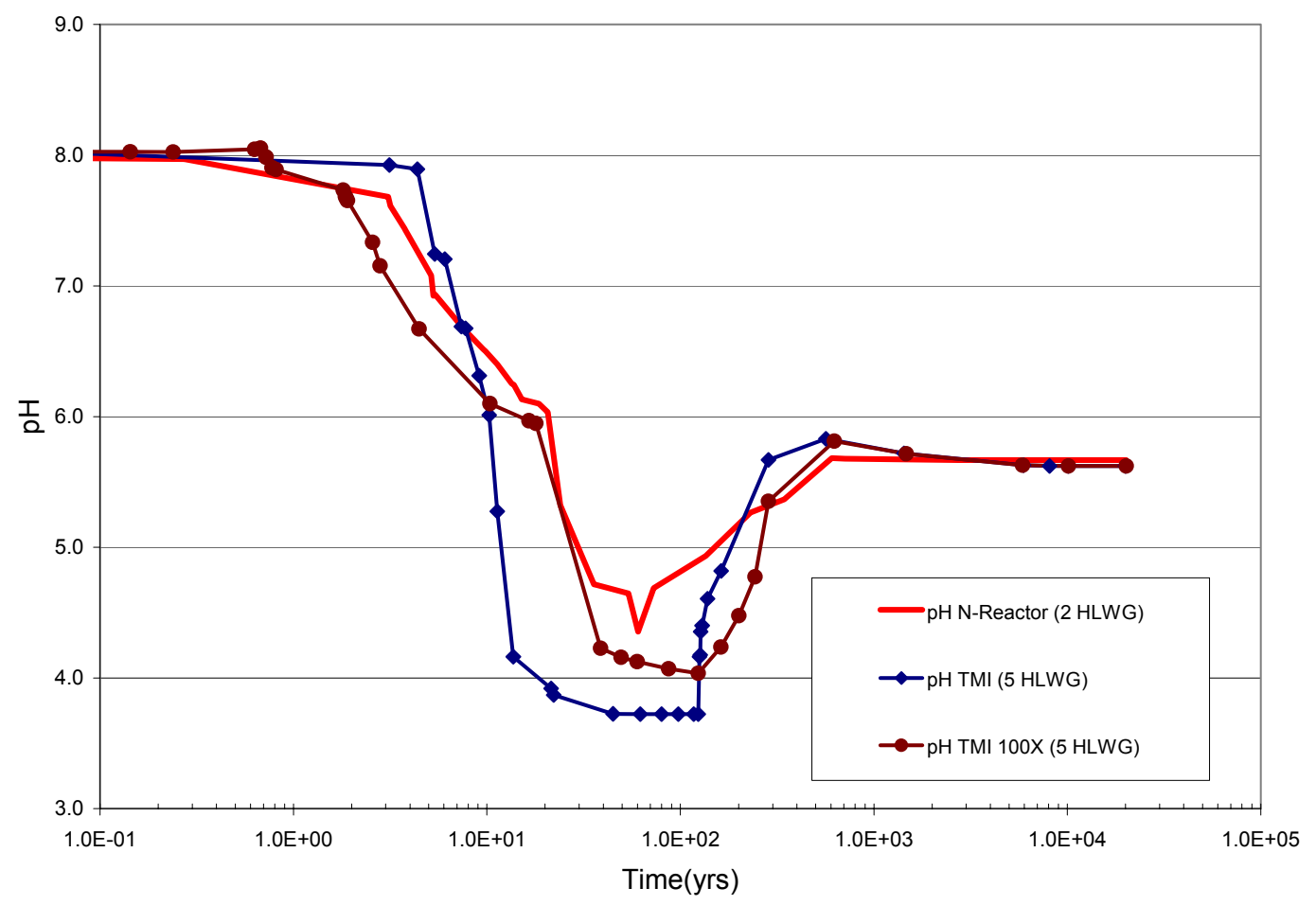

Source: CDSP_5_DHLWG WP Sensitivity.xIs (DTN: MO0411SPAMOICA.000 [DIRS 172244]).

Note: $\quad$ Time refers to time after waste package breach. This sensitivity uses $\mathrm{Cr}(\mathrm{VI})$ rather than $\mathrm{Cr}(\mathrm{III})$.

Figure 6-64. MCO/2-DHLW Design versus 5-DHLW/DOE SNF: Impact on pH

Figure 6-65 shows the range of ionic strength values for the TMI codisposal waste package is similar to the N-Reactor codisposal waste package, except for slightly higher values after 4,000 years. The maximum increase in ionic strength, from 0.38 to 0.57 molal at 20,000 years, is small compared to the variation in ionic strength due to the influence of other variables in the system, such as the drip rate (Section 6.5.2.2.2). Therefore, the degradation of the TMI codisposal waste package is not expected to have a significant impact on the ionic strength of the solution compared to the N-Reactor codisposal waste package. Therefore, the different waste package configurations expected in the repository are sufficiently characterized by this model. 


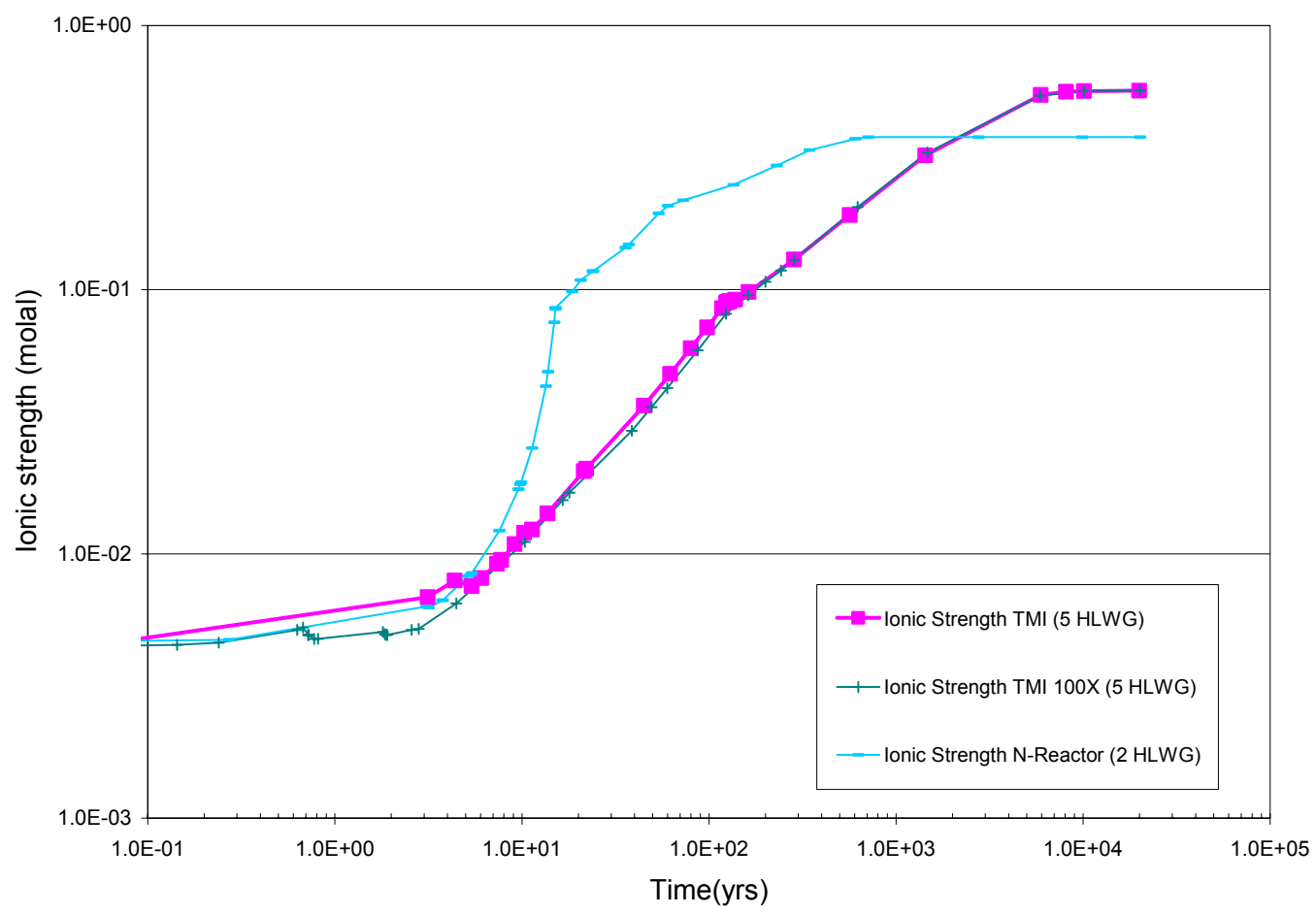

Source: CDSP_5_DHLWG WP Sensitivity.xIs (DTN: MO0411SPAMOICA.000 [DIRS 172244]).

Note: $\quad$ Time refers to time after waste package breach. This sensitivity uses $\mathrm{Cr}(\mathrm{VI})$ rather than $\mathrm{Cr}(\mathrm{III})$.

Figure 6-65. MCO/2-DHLW Design versus 5-DHLW/DOE SNF: Impact on lonic Strength

This sensitivity uses $\mathrm{Cr}(\mathrm{VI})$ rather than $\mathrm{Cr}(\mathrm{III})$, but because all of these cases use the same oxidation state for chromium, $\mathrm{Cr}(\mathrm{VI})$, the important $\mathrm{pH}$ and ionic strength trends shown in this sensitivity are impacts caused by differences in the waste package design, not the oxidation state of the chromium. Using $\mathrm{Cr}(\mathrm{VI})$ instead of $\mathrm{Cr}(\mathrm{III})$ means that the ionic strengths are higher than they would be if $\mathrm{Cr}$ (III) had been used. The impacts of $\mathrm{Cr}(\mathrm{VI})$ versus $\mathrm{Cr}(\mathrm{III})$ are described in more detail in Section 6.6.3.

The above discussion addresses the subject matter of "Included" FEP 2.1.01.02.0B (Interactions between co-disposed waste) and indicates how that subject matter has been included and addressed within TSPA-LA.

\subsubsection{LaBS Glass Composition}

This sensitivity study examines the impact of using LaBS glass in a CDSP waste package. The composition of the LaBS glass is described by Marra and Ebert (2003 [DIRS 172949], Table 2, column: SRTC Tests, Pu only), and is provided in the Table 6-16. This sensitivity uses the most probably HLWG rate and $f_{\text {exposure }}$ from Section 4.1.3.3, (Equations 4-3 and 4-4) for the LaBS glass. 
Table 6-16. Simplified LaBS Glass Composition

\begin{tabular}{|l|c|}
\hline \multicolumn{1}{|c|}{ Element } & $\begin{array}{c}\text { LaBS Glass } \\
\text { Moles/100g HLWG }\end{array}$ \\
\hline $\mathrm{Al}$ & 0.3657 \\
\hline $\mathrm{B}$ & 0.2921 \\
\hline $\mathrm{Gd}$ & 0.0408 \\
\hline $\mathrm{La}$ & 0.0693 \\
\hline $\mathrm{Nd}$ & 0.0610 \\
\hline $\mathrm{Pu}$ & 0.0333 \\
\hline $\mathrm{Si}$ & 0.4945 \\
\hline $\mathrm{Sr}$ & 0.0210 \\
\hline $\mathrm{Zr}$ & 0.0087 \\
\hline $\mathrm{O}$ & 2.3540 \\
\hline
\end{tabular}

Source: CDSP_LaBS_Sensitivity.xIs

(Appendix F).

NOTE: Elemental mole \% of the reactant are calculated based on 100 grams of reactant.

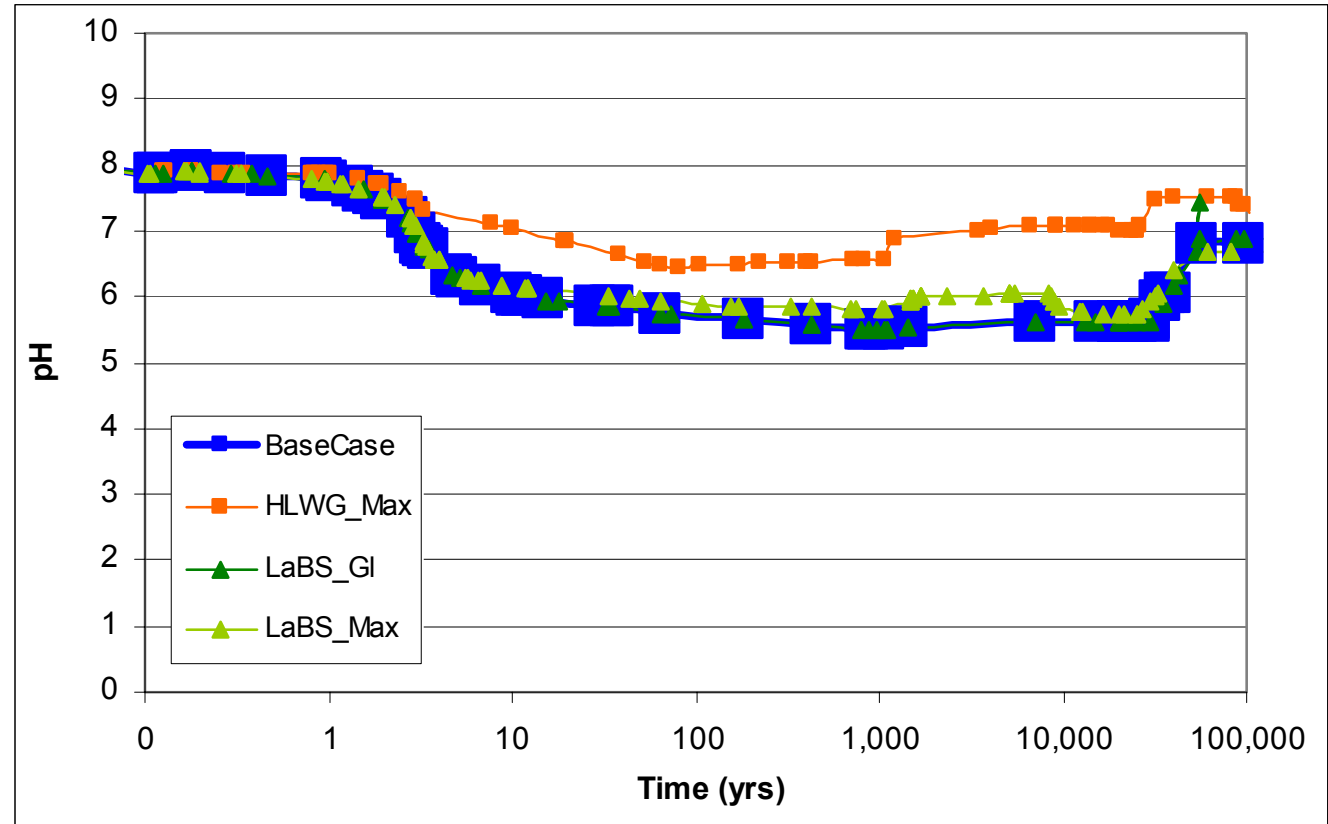

Source: CDSP Liquid Influx Model Output.xls (Appendix F).

NOTE: $\quad$ Time refers to time after waste package breach ( 0 on the $x$-axis refers to 0.1 years).

Figure 6-66. LaBS Glass pH Results 


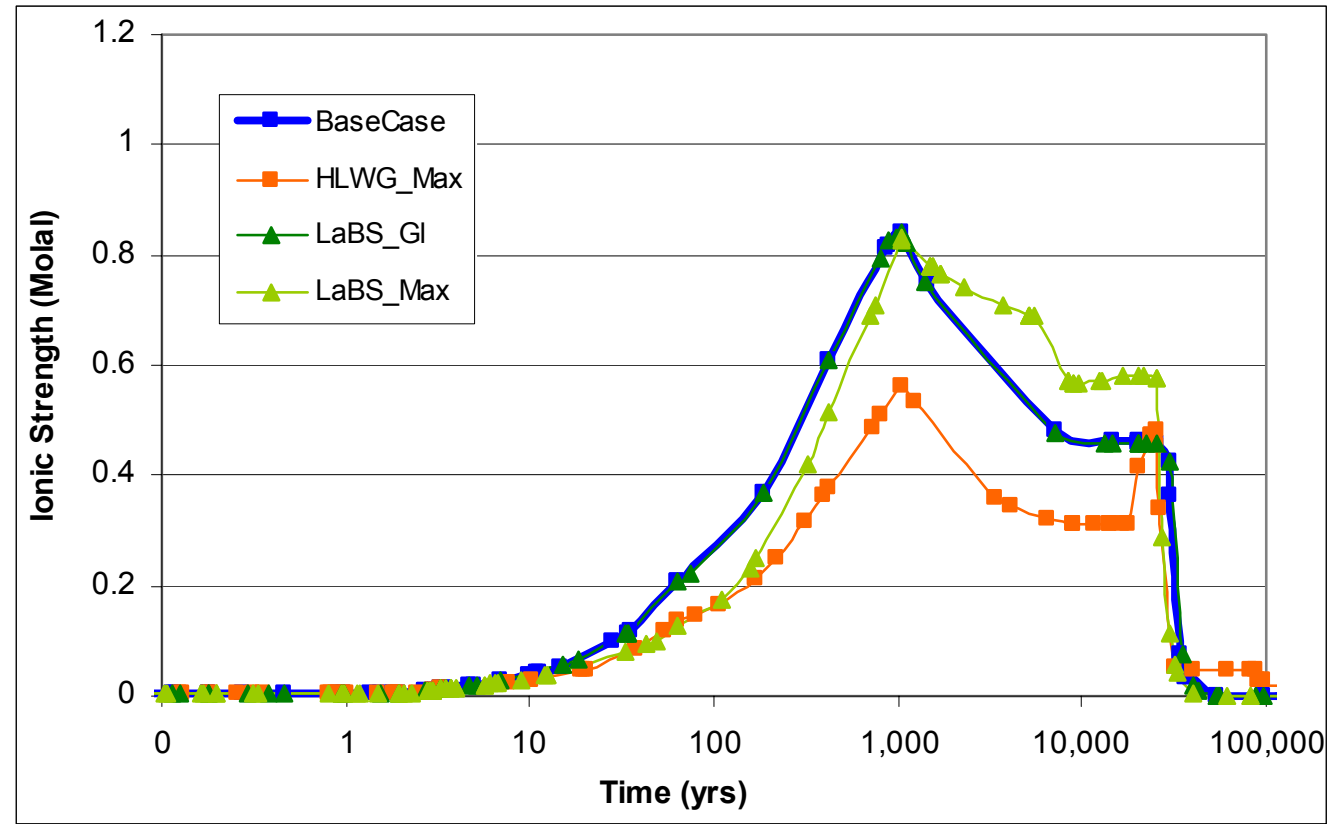

Source: CDSP Liquid Influx Model Output.xls (Appendix F).

NOTE: $\quad$ Time refers to time after waste package breach ( 0 on the $x$-axis refers to 0.1 years).

Figure 6-67. LaBS Glass Ionic Strength Results

As shown in Figures 6-66 and 6-67, the results of this sensitivity indicate that the LaBS glass has less of an impact on chemistry than the existing HLWG. The two cases that use the most probably rates ("BaseCase" and "LaBS_Gl") are identical for the HLWG and the LaBS glass for $\mathrm{pH}$ and ionic strength. For the two cases that use the high glass degradation rate ("HLWG_Max" and "LaBS_Max"), the case with HLWG has a higher $\mathrm{pH}$ than the case with the LaBS glass, as shown in Figure 6-66, but the LaBS glass case has a higher ionic strength than the HLWG case, as shown in Figure 6-67.

\subsection{SURFACE COMPLEXATION MODEL OUTPUT}

An analytical model is developed in this section using inputs from Section 4.1.6 to account for the $\mathrm{pH}$ buffering effects of iron corrosion product surfaces. The results of this analytical model are applied to the results of the batch reactor model in Section 6.9. As discussed in Section 6.3.2, ferric hydr(oxide) corrosion products such as ferrihydrite, goethite, and hematite will be present in abundance in the waste package in the short and long term (Schwertmann and Cornell 1991 [DIRS 144629]). Justification is made in Section 6.3.2 for using either ferrihydrite or goethite as the representative iron corrosion product as long as the concentration of surface sites is not overestimated. Therefore, for the analytical model developed here, a compromise is made to use a thermodynamic database for hydrous ferric oxide (HFO) while using the surface properties of goethite (i.e., specific surface area and specific site density). While there are differences in complexation reactions between HFO and goethite (Appelo et al. 2002 [DIRS 168168]), these differences are small compared to those in specific surface areas of HFO and goethite, and especially between these minerals and hematite (Section 6.3.2). Choosing the lower surface site concentrations of goethite helps to decrease the modeled concentration of adsorption sites per liter water and ensure the effects of complexation with iron corrosion 
product surfaces are not overestimated in the model. The modeled adsorption site concentration is determined in Section 6.7.1.

Studies have shown that the surface chemistry of natural sediments can be successfully modeled using the surface complexation approach by assuming that ferrihydrite is the dominant adsorbent in natural sediments or that the surface area of the sediments is composed entirely of ferrihydrite (Payne and Waite 1991 [DIRS 168860]; Waite et al. 2000 [DIRS 168856]). Ferrihydrite is equated with HFO in Dzombak and Morel (1990 [DIRS 105483]). The general formula for HFO is $\mathrm{Fe}_{2} \mathrm{O}_{3} \cdot \mathrm{nH}_{2} \mathrm{O}$ (Dzombak and Morel 1990 [DIRS 105483], p. 90); however, the bulk structure is uncertain and gradually changes from highly amorphous to more crystalline structures with age (Dzombak and Morel 1990 [DIRS 105483], p. 90). Ferrihydrite is predicted to occur in abundance in the waste package at early times and persist over the long term (Schwertmann and Cornell 1991 [DIRS 144629]), and it will continue to form as a product of steel corrosion. This knowledge and the studies cited above justify the use of the HFO surface complexation approach for the analytical model developed in Section 6.7.1.

\subsection{1 pH Buffering During Dissolution of Carbon Steel}

In a multireactant system, such as the waste package interior, the evolution of the chemistry is most influenced by reactants that react rapidly, contain elements with the potential to perturb the ambient chemical conditions, and are present in large enough quantities to exert a chemical change on the system. For these reasons, Carbon Steel Type A516 is considered to be of primary importance because it has a high corrosion rate (Table 4-8) relative to the other reactants, its composition (which includes reduced sulfur which lowers system $\mathrm{pH}$ when oxidized), and its abundance in the waste package. During the period of rapid corrosion of Carbon Steel Type A516, a large quantity of ferric (hydr)oxides will accumulate in the waste packages in a relatively short period of about 200 years, and the oxidation of sulfur will tend to lower the system $\mathrm{pH}$. Occurring simultaneously with Carbon Steel Type A516 corrosion are corrosion and degradation of the other waste package metal alloys and waste forms, albeit at much slower rates than Carbon Steel Type A516. While the system chemistry would be dominated by Carbon Steel Type A516 corrosion, the complexity of the system chemistry would be increased by the corrosion or degradation of the other waste package components. The stainless steel components would form ferric (hydr)oxides and other metal corrosion products (e.g., pyrolusite), the aluminum alloys (6061 and 1100) would form gibbsite and clay minerals, and while the spent nuclear fuel would form primarily schoepite, the HLWG would form clays (as shown in Figure 6-5 for CSNF and Figure 6-13 for CDSP). Nearly all of the degradation products of the waste package component materials other than Carbon Steel Type A516 are phases with surface complexation properties (e.g., Langmuir 1997 [DIRS 100051] p. 351). Considering only the reaction of Carbon Steel Type A516 would tend to underestimate the total number of surface sites available for the surface complexation reactions, as well as the nature of the sites (e.g., site density) because the surface sites of other materials and corrosion products (e.g., gibbsite, clays) would be ignored.

It is during the 0 - to 600-year period after waste package breach that the analytic surface complexation model developed in this section was used to predict the in-package $\mathrm{pH}$. The reasons for limiting the application of the surface complexation model to this period are: 1) increasing uncertainty in the ferric (hydr)oxide mineral assemblage as a function of time; and 
2) this relatively brief period of low $\mathrm{pH}$, as predicted by the EQ6 batch reactor model, would be most influenced by the presence of surface complexation reactions.

The model is restricted to $25^{\circ} \mathrm{C}$ simply because the surface complexation database is restricted to this temperature. After waste package breach, and water is present in the waste package, the temperature can still range up to the boiling point of water. Temperatures above $25^{\circ} \mathrm{C}$ tend to decrease the $\mathrm{pH}_{\mathrm{zpc}}$, the $\mathrm{pH}$ of zero surface charge, for oxides and hydroxides (Brady 1992 [DIRS 154467], p. 2,941 and Table 1). This relationship implies that an increase in temperature increases the deprotonation of surface sites, resulting in a reduction in $\mathrm{pH}$. The magnitude of this effect can only be determined by additional modeling because there are numerous side effects associated with an increase in temperature. For example, the $\log \mathrm{K}$ of the dissociation of water increases from -14 to -13 as temperature increases from $25^{\circ} \mathrm{C}$ to $60^{\circ} \mathrm{C}$ (DTN: SN0410T0510404.002 [DIRS 172712]). Cation adsorption also tends to increase as temperature increases (Brady 1992 [DIRS 154467], p. 2,941). Temperature also affects aqueous and waterair equilibria of numerous potential adsorbates (e.g., carbonate, radionuclides, etc.) in various ways. Without carefully modeling all of the effects of temperature, the only assertion that can be made is that higher temperatures may moderate (or augment) the $\mathrm{pH}$-buffering effects of the surface sites in the waste package. However, regardless of temperature effects, surface complexation will markedly buffer $\mathrm{pH}$ in the waste package, which is the primary point of this exercise.

A mole of Carbon Steel Type A516 dissolves into neutral and subneutral solutions as (Table 6-4):

$$
\begin{gathered}
\mathrm{Fe}_{1.76} \mathrm{Mn}_{0.019} \mathrm{C}_{0.0233} \mathrm{Si}_{0.0103} \mathrm{P}_{0.00113} \mathrm{~S}_{0.00109}+m \mathrm{H}_{2} \mathrm{O}+q \mathrm{O}_{2} \rightarrow \\
0.00109 \mathrm{SO}_{4}{ }^{2-}+0.00113\left(\mathrm{H}_{3} \mathrm{PO}_{4}+\mathrm{H}_{2} \mathrm{PO}_{4}{ }^{-}+\mathrm{HPO}_{4}{ }^{2-}\right)+0.0103 \mathrm{H}_{4} \mathrm{SiO}_{4}+ \\
0.0233\left(\mathrm{H}_{2} \mathrm{CO}_{3}+\mathrm{HCO}_{3}{ }^{-}\right)+0.019 \mathrm{MnO}_{2}+1.76 \mathrm{FeOOH}+n \mathrm{H}^{+}
\end{gathered}
$$

where $m, n$, and $q$ are positive numbers that depend ultimately on the $\mathrm{pH}$ of the solution (at $25^{\circ} \mathrm{C}$, $\mathrm{HCO}_{3}{ }^{-}$is the predominant carbonate species above $\mathrm{pH} 6.3 ; \mathrm{H}_{2} \mathrm{PO}_{4}{ }^{-}$is the dominant $\mathrm{P}$ species between $\mathrm{pH} 2.4$ and 7; $\mathrm{H}_{3} \mathrm{PO}_{4}$ is the dominant species below $\mathrm{pH}$ 2.4). The choice of goethite $(\mathrm{FeOOH})$ as the iron corrosion product is irrelevant to the value of $n$. Goethite is used here and in Section 6.8.2 simply because the surface site concentrations of goethite are used. Charge balance requires that $n$, the amount of acid produced in the reaction, be equal to $2\left(\mathrm{SO}_{4}{ }^{2-}\right)+\left(\mathrm{H}_{2} \mathrm{PO}_{4}{ }^{-}\right)+2\left(\mathrm{HPO}_{4}{ }^{2-}\right)+\left(\mathrm{HCO}_{3}{ }^{-}\right)$where the bracketed terms denote amounts added from Carbon Steel Type A516 dissolution (moles). The acid input and the resulting $\mathrm{pH}$ can be estimated for when a liter of water reacts with a mole of Carbon Steel Type A516 as:

$$
n=0.00218+0.00113+0+0=0.00331 \mathrm{~mol} / \mathrm{L} \mathrm{H}^{+}
$$

which, when used in a solution charge balance equation, corresponds to a $\mathrm{pH}$ of $\sim 2.5$ (assuming that all of $\mathrm{C}$ reacts to carbonic acid). 0.1 moles of Carbon Steel Type A516 dissolution would result in $n=0.000331$ and a solution with a $\mathrm{pH}$ of $\sim 3.5$. The $\mathrm{pH}$ derived analytically for Carbon Steel Type A516 dissolution is close to the output $\mathrm{pH}$ calculated by EQ6. For example, Figure 6-4 shows the $\mathrm{pH}$ profiles for the three water compositions, and the stabilized $\mathrm{pH}$ when 
Carbon Steel Type A516 dominates the system chemistry at about ten years is $\sim 3.5$. The high initial $\mathrm{pH}$ values of around $\mathrm{pH}=8$ (Figure 6-56), 0.1 to 10 years, reflects the chemistry of the starting solutions and a finite amount of reaction needs to occur to overcome the buffer capacity of the water before the low pH (3.5) of Carbon Steel Type A516 is realized.

The analytic equation (Eq. 6-6) and the EQ6 calculations neglect the tendency for iron hydroxide corrosion product surfaces to buffer $\mathrm{pH}$ in the near-neutral range through the following surface reactions (Table 4-9):

$$
\begin{aligned}
& >\mathrm{Fe}-\mathrm{OH}_{2}{ }^{+} \leftrightarrow>\mathrm{Fe}-\mathrm{O}-\mathrm{H}+\mathrm{H}^{+} \quad \mathrm{K}_{1}=[>\mathrm{Fe}-\mathrm{O}-\mathrm{H}]\left[\mathrm{H}^{+}\right] /\left[>\mathrm{Fe}-\mathrm{OH}_{2}^{+}\right]=10^{-7.29} \\
& >\mathrm{Fe}-\mathrm{OH} \leftrightarrow>\mathrm{Fe}-\mathrm{O}^{-}+\mathrm{H}^{+} \quad \mathrm{K}_{2}=\left[>\mathrm{Fe}-\mathrm{O}^{-}\right]\left[\mathrm{H}^{+}\right] /[>\mathrm{Fe}-\mathrm{OH}]=10^{-8.93}
\end{aligned}
$$

$>\mathrm{Fe}^{-}$is a general representation of an adsorption site at the iron (hydr)oxide-solution interface. The values of the equilibrium constants in this section are for $25^{\circ} \mathrm{C}$. For the HFO reactions in Table 4-9, HFO_s (strong site) and HFO_w (weak site) represent the adsorption sites. Sorbed bicarbonate also appears through (Table 4-9):

$$
>\mathrm{Fe}-\mathrm{O}-\mathrm{H}+\mathrm{H}^{+}+\mathrm{CO}_{3}{ }^{2-} \leftrightarrow>\mathrm{Fe}-\mathrm{CO}_{3}{ }^{-}+\mathrm{H}_{2} \mathrm{O}
$$

where

$$
\mathrm{K}_{\mathrm{CO} 3}=\left[\mathrm{Fe}-\mathrm{CO}_{3}{ }^{-}\right] \mathrm{a}_{\mathrm{H}_{2} \mathrm{O}} /[>\mathrm{Fe}-\mathrm{OH}]\left[\mathrm{H}^{+}\right]\left[\mathrm{CO}_{3}{ }^{2-}\right]=10^{12.78}
$$

Brackets in the above equations indicate activities. For surface species, activities are treated as equivalent to concentrations. The activity of an aqueous species is equivalent to the species concentration multiplied by the species activity coefficient, which is a function of ionic strength.

To account for the surface effect, the Carbon Steel Type A516 dissolution reaction must be expanded to:

$$
\begin{gathered}
\mathrm{Fe}_{1.76} \mathrm{Mn}_{0.019} \mathrm{C}_{0.0233} \mathrm{Si}_{0.0103} \mathrm{P}_{0.00113} \mathrm{~S}_{0.00109}+m \mathrm{H}_{2} \mathrm{O}+q \mathrm{O}_{2} \rightarrow \\
0.00109 \mathrm{SO}_{4}{ }^{2-}+0.00113\left(\mathrm{H}_{3} \mathrm{PO}_{4}+\mathrm{H}_{2} \mathrm{PO}_{4}{ }^{-}+\mathrm{HPO}_{4}{ }^{2-}\right)+0.0103 \mathrm{H}_{4} \mathrm{SiO}_{4}+ \\
0.0233\left(\mathrm{H}_{2} \mathrm{CO}_{3}+\mathrm{HCO}_{3}{ }^{-}\right)+0.019 \mathrm{MnO}_{2}+(1.76-\mathrm{X}) \mathrm{FeOOH}+ \\
\mathrm{X}\left(>\mathrm{Fe}-\mathrm{O}-\mathrm{H}+>\mathrm{Fe}-\mathrm{O}-\mathrm{H}_{2}{ }^{+}+>\mathrm{Fe}-\mathrm{O}^{-}+>\mathrm{Fe}-\mathrm{CO}_{3}{ }^{-}\right)+n \mathrm{H}^{+} .
\end{gathered}
$$

where $\mathrm{X}$ is the amount of $\mathrm{Fe}$ in FeOOH (moles) exposed to solution.

The approximations applied to solving the charge balance equation for the expanded reaction above are listed and justified in Table 6-17. Specifically, since the output $\mathrm{pH}$ is calculated to be between $\mathrm{pH} 2.4$ (no surface effect) and $\sim \mathrm{pH} 8$ (surfaces considered), the magnitude of the charged species are calculated at these two end members. The sulfate contribution to the charge balance is $\sim 0.002 \mathrm{~mol} / \mathrm{L}$; species whose concentrations are less than a factor of 10 of this will tend to have a minor effect on the charge-balance calculation. 
Table 6-17. Approximation for Charge Balance

\begin{tabular}{|l|l|l|}
\hline \multicolumn{1}{|c|}{ Approximation } & \multicolumn{1}{c|}{ Justification } & \multicolumn{1}{c|}{ Notes } \\
\hline $\begin{array}{l}\text { Dissolved Mn can be } \\
\text { neglected }\end{array}$ & $\begin{array}{l}\mathrm{MnO}_{2} \text { growth limits } \\
\text { dissolved } \mathrm{Mn} \text { to low levels }\end{array}$ & $\begin{array}{l}\text { EQ3/6 runs show pyrolusite to limit } \\
\text { dissolved Mn to low levels over the } \\
\mathrm{pH} \text { range of interest }\end{array}$ \\
\hline $\begin{array}{l}\text { Deprotonated Si species do } \\
\text { not contribute to charge } \\
\text { balance }\end{array}$ & $\begin{array}{l}\text { Deprotonated Si species } \\
\text { only form at } \mathrm{pH}>9\end{array}$ & $\begin{array}{l}\text { At pH } 7\left[\mathrm{H}_{3} \mathrm{SiO}_{4}\right] \sim 10^{-4} \mathrm{~mol} / \mathrm{L} \mathrm{At} \mathrm{pH} \\
2.4\left[\mathrm{H}_{3} \mathrm{SiO}_{4}\right]=3.2 \times 10^{-10} \mathrm{~mol} / \mathrm{L}\end{array}$ \\
\hline $\begin{array}{l}\mathrm{OH}^{-} \text {can be neglected in the } \\
\text { charge balance }\end{array}$ & $\begin{array}{l}\text { OH' levels will always be } \\
\text { much less than sulfate levels } \\
\text { below pH } 9\end{array}$ & $\begin{array}{l}\text { At pH } 8\left[\mathrm{OH}^{-}\right]=10^{-6} \mathrm{~mol} / \mathrm{L} \\
\text { At pH } 2.4\left[\mathrm{OH}^{-}\right]=2.5 \times 10^{-12} \mathrm{~mol} / \mathrm{L}\end{array}$ \\
\hline $\begin{array}{l}\mathrm{HSO}_{4}^{-} \text {can be neglected in } \\
\text { the charge balance }\end{array}$ & $\begin{array}{l}\mathrm{HSO}_{4}^{-} \text {only exceeds } \mathrm{SO}_{4}{ }^{2-} \\
\text { levels below } \mathrm{pH} 2\end{array}$ & $\begin{array}{l}\text { At pH } 8\left[\mathrm{HSO}_{4}\right]=10^{-9} \mathrm{~mol} / \mathrm{L} \\
\text { At pH } 2.4\left[\mathrm{HSO}_{4}\right]=4 \times 10^{-4} \mathrm{~mol} / \mathrm{L}\end{array}$ \\
\hline
\end{tabular}

Given a value of $\mathrm{X}=0.176(10 \%$ of reacted Fe become surface sites - a lower-end value for goethite, Table 4-10) - for dissolution of 1 mole of Carbon Steel Type A516 into a near-neutral solution: $n=2\left(\mathrm{SO}_{4}{ }^{2-}\right)+\left(\mathrm{H}_{2} \mathrm{PO}_{4}^{-}\right)+2\left(\mathrm{HPO}_{4}{ }^{-2}\right)+\left(\mathrm{HCO}_{3}{ }^{-}\right)+\left(>\mathrm{Fe}-\mathrm{O}^{-}\right)+\left(>\mathrm{Fe}-\mathrm{CO}_{3}{ }^{-}\right)-$ $\left(>\mathrm{Fe}-\mathrm{O}-\mathrm{H}_{2}{ }^{+}\right)$. Similarly, charge balance for a solution in contact with carbon dioxide gas at $0.001 \mathrm{~atm}$ and into which 1 mole of Carbon Steel Type A516 was dissolved would be:

$$
\begin{gathered}
\left(\mathrm{H}^{+}\right)+\left(>\mathrm{Fe}-\mathrm{O}-\mathrm{H}_{2}^{+}\right)=2\left(\mathrm{SO}_{4}^{-2}\right)+\left(\mathrm{H}_{2} \mathrm{PO}_{4}^{-}\right)+2\left(\mathrm{HPO}_{4}^{-2}\right) \\
+\left(\mathrm{HCO}_{3}^{-}\right)+\left(>\mathrm{Fe}-\mathrm{O}^{-}\right)+\left(>\mathrm{Fe}-\mathrm{CO}_{3}^{-}\right)
\end{gathered}
$$

The two phosphate terms can be manipulated with the equilibrium constant for their conversion to give: $\left(\mathrm{H}_{2} \mathrm{PO}_{4}{ }^{-}\right)=0.00113 /\left(1+10^{-7.2} \gamma_{\mathrm{H}_{2} \mathrm{PO}_{4}}-/\left[\mathrm{H}^{+}\right]\right)$and $\left(\mathrm{HPO}_{4}^{-2}\right)=0.00113\left(1-1 /\left(1+10^{-7.2}\right.\right.$ $\left.\left.\gamma_{\mathrm{H}_{2} \mathrm{PO}_{4}}-\left[\mathrm{H}^{+}\right]\right)\right)$. Similarly, mass action expressions for $\left(\mathrm{OH}^{-}\right)+\left(\mathrm{HCO}_{3}^{-}\right)$can be manipulated to show they are equal to $10^{-14} /\left[\mathrm{H}^{+}\right] / \gamma_{\mathrm{OH}^{-}}$and $10^{-7.82} \mathrm{PCO}_{2} /\left[\mathrm{H}^{+}\right] / \gamma_{\mathrm{HCO}_{3}}{ }^{-}$, respectively (DTN: MO0302SPATHDYN.000 [DIRS 161756]). Substituting these expressions, carbonate equilibrium constants, the surface equilibria above, and rearranging to solve for $\mathrm{pH}$ gives:

$$
\begin{gathered}
\left(\mathrm{H}^{+}\right)=0.00218+0.00113 /\left(1+10^{-7.2} \gamma_{\mathrm{H}_{2} \mathrm{PO}_{4}}-/\left[\mathrm{H}^{+}\right]\right)+0.00226\left(1-1 /\left(1+10^{-7.2} \gamma_{\mathrm{H}_{2} \mathrm{PO}_{4}^{-}} /\left[\mathrm{H}^{+}\right]\right)\right)+ \\
10^{-14} /\left[\mathrm{H}^{+}\right] / \gamma_{\mathrm{OH}^{-}}+10^{-7.82} \mathrm{PCO}_{2} /\left[\mathrm{H}^{+}\right] / \gamma_{\mathrm{HCO}_{3}}{ }^{-}+[>\mathrm{Fe}-\mathrm{O}-\mathrm{H}]\left(10^{-8.93} /\left[\mathrm{H}^{+}\right]+\right. \\
\left.\mathrm{PCO}_{2} 10^{-5.36} /\left[\mathrm{H}^{+}\right]-10^{7.29}\left[\mathrm{H}^{+}\right]\right)
\end{gathered}
$$

Note: $\mathrm{PCO}_{2}$ is the partial pressure of $\mathrm{CO}_{2}$

where, because of surface site mole balance, the site master-species concentration $[>\mathrm{Fe}-\mathrm{O}-\mathrm{H}]$ at $25^{\circ} \mathrm{C}$ can be approximated by:

$$
[>\mathrm{Fe}-\mathrm{O}-\mathrm{H}]=0.176 /\left(1+10^{-8.93} /\left[\mathrm{H}^{+}\right]+\mathrm{PCO}_{2} 10^{-5.36} /\left[\mathrm{H}^{+}\right]+10^{7.29}\left[\mathrm{H}^{+}\right]\right)
$$

Equations 6-14 and 6-15 can be solved for $\mathrm{pH}$ as a function of fixed partial pressure of $\mathrm{CO}_{2}$ (Table 6-18). These $\mathrm{pH}$ calculations are insensitive to the number of moles of Carbon Steel 
Type A516 that corrodes per $\mathrm{kg}$ of water as long as corrosion exceeds 0.1 moles per $\mathrm{kg}$ of water. This is the case for each Carbon Steel Type A516 corrosion calculation in this report. The $\mathrm{pH}$ is calculated using a site density of 0.1 moles of sites per mole of iron. The most significant input to the surface complexation model is the site density of the iron mineral. Due to the potential uncertainty on the site density, an additional calculation shows the resulting $\mathrm{pH}$ if the site density were a 0.01 moles of sites per mole of iron, as shown in Table 6-18. Using one tenth the site density only results in slightly less $\mathrm{pH}$ buffering, $0.4 \mathrm{pH}$ units at the higher $\mathrm{pH}$ values, and 0.2 $\mathrm{pH}$ units at the lower $\mathrm{pH}$ values. These results show significant $\mathrm{pH}$ buffering, even when using a low site density.

The results in Table 6-18 are for an ionic strength of 0.1 molal. At this ionic strength, activity coefficients in equation 6-14 are in the range of 0.76 to 0.83 (Stumm and Morgan 1996 [DIRS 125332] p. 104). Concentrated solutions with high ionic strengths could result in a relatively negligible change in $\mathrm{pH}$ (negligible $\mathrm{pH}$ buffering). Moreover, the $\mathrm{pHs}$ were calculated for each fixed $f \mathrm{CO}_{2}$ conditions. Thus, ionic strength has a negligible effect on the calculated $\mathrm{pH}$ values relative to the site density and partial pressure of carbon dioxide.

Table 6-18. Calculated pH Values as a Function of $\mathrm{fCO}_{2}$

\begin{tabular}{|c|c|c|}
\hline $\begin{array}{c}\text { Log } \mathrm{fCO}_{2} \\
(\mathbf{a t m})\end{array}$ & $\begin{array}{c}\mathbf{0 . 1} \text { moles of } \\
\text { sites/mole of } \mathrm{Fe} \\
(\mathbf{p H})\end{array}$ & $\begin{array}{c}\mathbf{0 . 0 1} \text { moles of } \\
\text { sites/mole of } \mathrm{Fe} \\
(\mathbf{p H})\end{array}$ \\
\hline-5.0 & 8.1 & 7.7 \\
\hline-4.5 & 8.1 & 7.7 \\
\hline-4.0 & 8.0 & 7.6 \\
\hline-3.5 & 7.9 & 7.6 \\
\hline-3.0 & 7.7 & 7.5 \\
\hline-2.5 & 7.5 & 7.3 \\
\hline-2.0 & 7.3 & 7.1 \\
\hline-1.5 & 7.0 & 6.8 \\
\hline \multicolumn{2}{|c|}{ Source: SCM analytical.x/s in Appendix $\mathrm{F}}$. \\
\hline
\end{tabular}

To simplify the calculation, adsorption of phosphate, uranium, nickel, chromate, sulfate, and other sorbates was neglected. Under favorable conditions, these sorbates, if abundant, could have a noticeable impact on the final $\mathrm{pH}$ values calculated. As a check on the potential effects of these sorbates, surface complexation reactions involving the entire database in Table 4-9 are performed in Section 6.8.

The greater the number of surface sites, the greater is the tendency for surface reactions to resist acid production from the steel and instead to maintain the $\mathrm{pH}$ near 7.6 (for dissolution of 1 mole of Carbon Steel Type A516 to produce a pH below 7 at $\mathrm{PCO}_{2}=0.001$ atm requires fewer than $1.5 \%$ of the Fe sites to be exposed). The calculations above were done without activity corrections for aqueous or surface species - so they are somewhat approximate. Nevertheless, they suggest that degradation of Carbon Steel Type A516 will result in solution $\mathrm{pH}$ values close to 7 to 8 because of corrosion product surface chemistry. The output $\mathrm{pH}$ values shown in Table 6-18 depend simply on interaction of produced acidity with near-neighbor Fe sites and not transport and mixing of fluids. 
The effect of corrosion products on the $\mathrm{pH}$ of the in-package environment is a first-order process that the surface complexation model provides as input to TSPA-LA. The above discussion addresses the subject matter of "Included" FEPs 2.1.09.02.0A (Chemical interaction with corrosion products) and 2.1.09.01.0B (Chemical characteristics of water in waste package) and indicates how that subject matter has been included and addressed within TSPA-LA.

\subsection{2 pH Buffering During Dissolution of Stainless Steel, Fuel, and HLWG}

Over time periods greater than a thousand years, the primary reactions affecting $\mathrm{pH}$ are dissolution of Stainless Steel Types 316 and 304L, spent fuel and alteration products (schoepite) and, in codisposal packages, HLWG. Simplified dissolution reactions for each are written below. Minor components have been left out of the respective compositions. The approximated compositions provide a sufficiently clear picture of the degree to which each reaction affects proton balances in solution. $\mathrm{SiO}_{2}$ refers either to aqueous silica or silica solid (e.g., chalcedony).

\section{Schoepite}

$$
\begin{array}{lc}
\boldsymbol{p H} \leq \mathbf{5 . 5} & \mathrm{UO}_{3} \cdot 2 \mathrm{H}_{2} \mathrm{O}+2 \mathrm{H}^{+} \leftrightarrow \mathrm{UO}_{2}{ }^{2+}+3 \mathrm{H}_{2} \mathrm{O} \\
\boldsymbol{p H}>\text { 7-7.5 } & \mathrm{UO}_{3} \cdot 2 \mathrm{H}_{2} \mathrm{O}+3 \mathrm{HCO}_{3}{ }^{-} \leftrightarrow \mathrm{UO}_{2}\left(\mathrm{CO}_{3}\right)_{3}{ }^{4-}+\mathrm{H}^{+}+3 \mathrm{H}_{2} \mathrm{O}
\end{array}
$$

NOTE: Schoepite stability for $5.5 \leq \mathrm{pH} \leq 7-7.5$ is dependent on $\mathrm{fCO}_{2}$.

\section{Stainless Steel Type 304L}

$$
\begin{gathered}
\text { pH } \leq .5 \quad \mathrm{Fe}_{1.22} \mathrm{Cr}_{0.365} \mathrm{Ni}_{0.17} \mathrm{Si}_{0.0267} \mathrm{Mn}_{0.0364}+1.6106 \mathrm{O}_{2}+0.805 \mathrm{H}_{2} \mathrm{O} \rightarrow \\
1.22 \mathrm{FeOOH}+0.365 \mathrm{HCrO}_{4}{ }^{-}+0.17 \mathrm{Ni}^{2+}+ \\
0.0267 \mathrm{SiO}_{2}+0.0364 \mathrm{MnO}_{2}+0.025 \mathrm{H}^{+} \\
\boldsymbol{p H}>\mathbf{6 . 5} \quad \mathrm{Fe}_{1.22} \mathrm{Cr}_{0.365} \mathrm{Ni}_{0.17} \mathrm{Si}_{0.0267} \mathrm{Mn}_{0.0364}+1.6106 \mathrm{O}_{2}+0.805 \mathrm{H}_{2} \mathrm{O} \rightarrow \\
1.22 \mathrm{FeOOH}+0.365 \mathrm{CrO}_{4}{ }^{2-}+0.17 \mathrm{Ni}^{2+}+ \\
0.0267 \mathrm{SiO}_{2}+0.0364 \mathrm{MnO}_{2}+0.39 \mathrm{H}^{+}
\end{gathered}
$$

\section{Stainless Steel Type 316}

$$
\begin{gathered}
\text { pH } \leq \text { 6.5 } \\
\mathrm{Fe}_{1.17} \mathrm{Ni}_{0.2} \mathrm{Cr}_{0.33} \mathrm{Mo}_{0.03} \mathrm{Si}_{0.03}+1.5475 \mathrm{O}_{2}+0.745 \mathrm{H}_{2} \mathrm{O}+0.01 \mathrm{H}^{+} \rightarrow \\
1.17 \mathrm{FeOOH}+0.03 \mathrm{SiO}_{2}+0.2 \mathrm{Ni}^{2+}+0.33 \mathrm{HCrO}_{4}{ }^{-}+0.03 \mathrm{MoO}_{4}{ }^{2-} \\
\boldsymbol{p H}>\mathbf{6 . 5} \\
\mathrm{Fe}_{1.17} \mathrm{Ni}_{0.2} \mathrm{Cr}_{0.33} \mathrm{Mo}_{0.03} \mathrm{Si}_{0.03}+1.5475 \mathrm{O}_{2}+0.745 \mathrm{H}_{2} \mathrm{O} \rightarrow \\
1.17 \mathrm{FeOOH}+0.03 \mathrm{SiO}_{2}+0.2 \mathrm{Ni}^{2+}+0.33 \mathrm{CrO}_{4}{ }^{2-}+0.03 \mathrm{MoO}_{4}{ }^{2-}+0.32 \mathrm{H}^{+}
\end{gathered}
$$

\section{HLWG}

$$
\begin{gathered}
\mathrm{Na}_{0.577} \mathrm{Si}_{0.776} \mathrm{~B}_{0.291} \mathrm{O}_{2.277}+0.577 \mathrm{H}^{+}+0.148 \mathrm{H}_{2} \mathrm{O} \rightarrow \\
0.577 \mathrm{Na}^{+}+0.776 \mathrm{SiO}_{2}+0.291 \mathrm{~B}(\mathrm{OH})_{3}
\end{gathered}
$$


Schoepite and iron corrosion products dominate the composition of the alteration products from time periods of 500 years and beyond, and the schoepite dissolves at acid $\mathrm{pH}$ to consume protons and at above neutral $\mathrm{pH}$ to produce protons. These two reactions, thus, constitute a negative feedback that resists $\mathrm{pH}$ excursions to high or low $\mathrm{pH}$, and ultimately anchors $\mathrm{pH}$ values near the schoepite solubility minimum - pH 6.5 to 7, depending on the ambient carbon dioxide pressure. The EQ6 output supports the buffering of the $\mathrm{pH}$ near neutral by schoepite (see, for example Figure 6-23).

Considering the steels and glass in isolation from the schoepite points to another mechanism by which alkalinity increases from HLWG dissolution are resisted - namely above $\mathrm{pH} 6.5 \mathrm{Cr}$ oxidizes to $\mathrm{CrO}_{4}{ }^{2-}$, whereas below it forms $\mathrm{HCrO}_{4}^{-}$. This means ambient $\mathrm{pH}$ has an important effect on proton production by steel degradation. Specifically, at $\mathrm{pH} \leq 6.5$, steel degradation either consumes protons or produces relatively small amounts of them; whereas, at $\mathrm{pH}>6.5$, degradation of Stainless Steel Types 304L and 316 produces relatively large amounts of protons. This has the effect of anchoring $\mathrm{pH}$ values close to 6.5 and consuming proton consumption by glass degradation. Equilibrium surface reactions will also buffer $\mathrm{pH}$ (e.g., $>\mathrm{Fe}-\mathrm{OH}=>\mathrm{Fe}-\mathrm{O}^{-}+$ $\mathrm{H}^{+}$and $>\mathrm{Fe}-\mathrm{HCO}_{3}=>\mathrm{Fe}-\mathrm{CO}_{3}^{-}+\mathrm{H}^{+}$).

As proton consumption prevails at $\mathrm{pH} \leq 6.5$, but proton production amplifies when $\mathrm{pH}>6.5$, indicates long-term $\mathrm{pH}$ values will converge towards 6.5 as long as sufficient steel and HLWG exists in the package. There is over twice as much Stainless Steel Type 316 as HLWG and roughly 20\% more Stainless Steel Type 304L than HLWG, so the presence of the degrading stainless steel will tend to keep the $\mathrm{pH}$ from going too high due to the effects of the degrading HLWG. As shown in Figure 6-58, if the highest HLWG rate is used, the resulting $\mathrm{pH}$ is about a unit higher than the other cases. A potential case examining the highest HLWG combined with low degradation rates for the stainless steels could result in an even higher $\mathrm{pH}$, but that resulting $\mathrm{pH}$ would also be in contact with significant quantities of schoepite, according to the well-mixed batch reactor (Section 6.3.1.1), and the buffering effects of the schoepite would prevent the $\mathrm{pH}$ from going much higher than neutral. The most reasonable high-end $\mathrm{pH}$ for packages containing HLWG is, therefore, 6.5 to 7. FeOOH corrosion products will also be abundant in codisposal packages, from steel degradation and from the earlier dissolution of the Carbon Steel Type A516.

To summarize, over the first hundred years when the degraded waste form consists primarily of Carbon Steel Type A516 corrosion products and intact fuel, $\mathrm{pH}$ values will be held to near neutral by the surface properties of the corrosion products (the most abundant proton donor or acceptor in the package). Over longer time periods, when the degraded waste form will consist of schoepite, dissolving steels, and possibly HLWG, the $\mathrm{pH}$ will be anchored near neutral by dissolution reactions of schoepite and steel which consume protons at acidic $\mathrm{pH}$ and release them at alkaline $\mathrm{pH}$ values. Extremely unlikely scenarios involving degradation of individual components are required to overcome the intrinsic capacity of the degraded waste form to control its ambient $\mathrm{pH}$ to near neutral.

\subsubsection{Temperature}

Temperature affects surface equilibria, aqueous speciation, and dissolution rates and for this reason might be expected to affect $\mathrm{pH}$ excursion limits (maximum and minimum $\mathrm{pH}$ ). In the absence of a schoepite solubility model, it is unreasonable to speculate about the location of the 
high temperature schoepite solubility minimum. The $\mathrm{pH}_{\mathrm{zpc}}$ of hematite changes from roughly 9.1 to 7.7 (with a temperature shift of $5^{\circ} \mathrm{C}$ to $75^{\circ} \mathrm{C}$ ) (Stumm 1992 [DIRS 141778], p. 76), which suggests a downward $\mathrm{pH}$ shift of possibly 1.5 units in goethite surface equilibria with an increase in temperature from $25^{\circ} \mathrm{C}$ to $90^{\circ} \mathrm{C}$. Site densities might decrease if higher temperatures favor formation of lower surface area materials. There are not enough high-temperature surface chemistry data to advance more than a qualitative model for corrosion product surface behavior at higher temperatures.

The $\mathrm{pH}$ below which steel dissolves to $\mathrm{HCrO}_{4}{ }^{-}$, and above which it dissolves to $\mathrm{CrO}_{4}{ }^{2-}$, is 6.5 at $25^{\circ} \mathrm{C}, 6.7$ at $50^{\circ} \mathrm{C}$, and 6.9 at $100^{\circ} \mathrm{C}$. Higher temperatures might, therefore, be expected to raise the upper-limit basic-pH range due to HLWG dissolution to $\sim 7$.

The above discussion addresses the thermal effects on chemistry portion of the subject matter of "Included" FEP 2.1.11.08.0A (Thermal effects on chemistry and microbial activity in the EBS) and indicates how that subject matter has been included and addressed within TSPA-LA. The microbial activity in the EBS subject matter is described in FEP 2.1.10.01.0A and documented in Engineered Barrier System Features, Events, and Processes (BSC 2004 [DIRS 169898]).

\subsection{SURFACE COMPLEXATION DEMONSTRATION}

The effects of ferric (hydr)oxide surfaces on $\mathrm{pH}$, as defined in Section 6.7, are demonstrated in this section using PHREEQC version 2.3. PHREEQC is a USGS geochemical code capable of performing surface complexation reactions in aqueous systems. The DTNs generated for the surface complexation demonstration are solely intended to build confidence in the surface complexation model discussed in Section 6.3.2, and are not actual technical products of this model. These DTNs include: MO0403SPASURCR.000, MO0403SPAYMPR3.000, and MO0403MWDSRFCC.000.

The purpose of the PHREEQC surface complexation calculations in this section is to build confidence in the analytical model developed in Section 6.7. Additional complexity in surface complexation calculations is afforded by PHREEQC due to its ability to include effects of surface charge, ionic strength, and a much larger assortment of surface complexation reactions. However, as the calculations demonstrate, this increased complexity does not result in $\mathrm{pH}$ predictions largely different from those made by the simplified analytical model in Section 6.7. Unlike the results of the analytical model, the PHREEQC calculations are not passed on to TSPA-LA.

Surface complexation calculations are calculations of equilibrium adsorption reactions. Similar to aqueous reactions, each adsorption reaction is represented by a specific chemical reaction and an associated equilibrium constant. The primary difference between aqueous reactions in bulk water and adsorption reactions is that surface sites have fixed locations and densities relative to one another. As a result, adsorption and desorption of protons and other ions from these sites cause the surface to take on an electrostatic charge, which in turn, affects the behavior of nonadsorbed ions in the vicinity of the surface. Therefore, equilibrium surface complexation calculations incorporate equations that simulate the effects of surface charge. 
The particular surface complexation model chosen for these calculations is from Dzombak and Morel's (1990 [DIRS 105483], Chapter 2) generalized two-layer model, which is based on the Gouy-Chapman theory of the electrical double layer. In this model, there is one layer associated with the surface charge (affected by site-specific adsorption) and a diffuse layer between the surface layer and the bulk solution that contains counter-charged ions. Details of the mathematical representation of surface effects are provided by Dzombak and Morel (1990 [DIRS 105483], Chapter 2) and the PHREEQC 2.3 user manual (BSC 2001 [DIRS 154877]).

The surface complexation calculations presented below require several inputs. These inputs include a thermodynamic database (Section 6.8.1), surface properties (Section 6.8.2), and initial water and gas compositions (Section 6.8.3). Results of this demonstration are presented in Section 6.8.4.

\subsubsection{Surface Complexation Reaction Databases}

The surface complexation database was taken primarily from Surface Complexation Modeling, Hydrous Ferric Oxide (Dzombak and Morel 1990 [DIRS 105483]), which develops and documents a broad, self-consistent database of surface complexation reactions for hydrous ferric oxide (HFO) based on the generalized two-layer model. Two additional reactions for carbonate adsorption are included in work by Appelo et al. (2002 [DIRS 168168]). These reactions were derived by Appelo et al. (2002 [DIRS 168168], p. 3097) to be consistent with the Dzombak and Morel (1990 [DIRS 105483]) database.

In this report, two variations of this database are used for the surface complexation calculations. The first database, YMP_R3.dat, is developed in Section 6.3.2.1 and documented in DTN: MO0403SPAYMPR3.000. The other, YMP_R3mr.dat, is identical to the first, but includes all reactions in Table 6-12, which are estimated using linear free-energy relationships. These estimated reactions are of sufficient accuracy for the intended use of the surface complexation calculations in this report.

For YMP_R3mr.dat, all reactions from Table 6-12 were entered exactly as displayed, with the exception of arsenite and silica. To conform to the PHREEQC representation of the uncharged aqueous arsenite species $\left(\mathrm{HAsO}_{2}\right)$, the arsenite adsorption reaction was changed to:

$$
\mathrm{HFO}_{-} \mathrm{wOH}+\mathrm{HAsO}_{2}=\mathrm{HFO} \_\mathrm{wH}_{2} \mathrm{AsO}_{3}
$$

The $\log \mathrm{K}$ for this reaction was not changed because addition of $\mathrm{H}_{2} \mathrm{O}$ to both sides of the equation has a negligible effect on the $\log \mathrm{K}$ at ionic strengths below 1 molal. In addition, because the PHREEQC database does not include ${\mathrm{S} \mathrm{SiO}_{3}}^{2-}$ aqueous species, the silica adsorption reactions were changed to:

$$
\mathrm{HFO} \_\mathrm{wOH}+\mathrm{SiO}_{2}=\mathrm{HFO}_{-} \mathrm{wSiO}_{3^{-}}+\mathrm{H}+
$$

and

$$
\mathrm{HFO} \_\mathrm{wOH}+\mathrm{SiO}_{2}+\mathrm{H}_{2} \mathrm{O}=\mathrm{HFO}_{-} \mathrm{wOHSiO}_{3}{ }^{2-}+2 \mathrm{H}+
$$


with $\log \mathrm{K}$ values of -7.06 and -14.66 , respectively. These reactions and $\log \mathrm{K}$ values were calculated by combining the silica reactions from Table 6-12.

\subsubsection{Surface Properties}

As presented in Section 6.7, goethite is the representative iron product of each steel corrosion reaction. Because goethite is a major product of these reactions and it has a relatively large surface area and adsorption site density, goethite is the surface used in the surface complexation calculations. The rationale for using goethite surface areas in combination with the HFO thermodynamic database is discussed in detail in Sections 6.3.2, 6.6.11, and 6.7.

The surface properties of goethite are provided in Table 4-10. Multiplying the site concentration of $0.00135 \mathrm{~mol} / \mathrm{g}$ by the molecular weight of goethite $(88.85 \mathrm{~g} / \mathrm{mol})$ gives a site concentration of $0.120 \mathrm{~mol} / \mathrm{mol}$ of goethite. This site concentration is equivalent to a specific surface area of $49 \mathrm{~m}^{2} / \mathrm{g}$ with a specific site density of 16.6 sites $/ \mathrm{nm}^{2}$, as well as equivalent to a specific surface area of $160 \mathrm{~m}^{2} / \mathrm{g}$ with a specific site density of 5 sites $/ \mathrm{nm}^{2}$. These values largely span the general ranges listed in Table 4-10 for these parameters. For the calculations below, the lower value of $49 \mathrm{~m}^{2} / \mathrm{g}$ specific surface area is considered so as to not over estimate the potential buffering effects.

Between 10 and 40 moles of ferric (hydr)oxides are calculated to form per kilogram of water (Section 6.3.2). For the calculations presented below, the molality of goethite is set at 10 moles per kg water, though thin film conditions could lead to much higher molalities. Multiplying this molality by the molecular weight of goethite implies approximately 900 grams of goethite per $\mathrm{kg}$ water, a value used in the PHREEQC input files to quantify the abundance of the adsorbent. Multiplying this value by the site concentration from Table 4-10 in Section 6.3.2 $(0.00135 \mathrm{~mol} / \mathrm{g})$ results in a surface site molality of 1.2 . Because the database (Dzombak and Morel 1990 [DIRS 105483]) divides the total number of sites into strong and weak sites, whereby the concentration of strong sites is $2.5 \%$ of the weak site concentration, the molalities of weak and strong sites were set at 1.2 and 0.03 , respectively.

The electric double layer thickness is the only other surface parameter necessary for the PHREEQC runs. This was estimated by solving Equation 2.4 in Surface Complexation Modeling, Hydrous Ferric Oxide (Dzombak and Morel 1990 [DIRS 105483], p. 11 and 12) for $1 / \kappa$, which is the double-layer thickness (in meters):

$$
1 / \kappa=\sqrt{\frac{\varepsilon \varepsilon_{o} R T}{2 F^{2} I \cdot 10^{3}}}
$$

where,

$$
\begin{aligned}
& \varepsilon=\text { dielectric constant of water }(78.5), \\
& \varepsilon_{\mathrm{o}}=\text { permittivity of free space }(8.853 \mathrm{E}-12 \mathrm{C} / \mathrm{V}-\mathrm{m}), \\
& \mathrm{R}=\text { universal gas constant }(8.314 \mathrm{~J} / \mathrm{mol}-\mathrm{K}),
\end{aligned}
$$




$$
\begin{aligned}
& \mathrm{T}=\text { temperature }(298.13 \mathrm{~K}), \\
& \mathrm{F}=\text { Faraday constant }(96,485 \mathrm{C} / \mathrm{mol}), \text { and } \\
& \mathrm{I}=\text { ionic strength in molality. }
\end{aligned}
$$

Ionic strength in these calculations is on the order of $0.01 \mathrm{~mol} / \mathrm{L}$. Thus, the double-layer thickness is on the order of $3 \times 10^{-9} \mathrm{~m}$. This value was held constant for all runs because its effect on the calculated final $\mathrm{pH}$ is small compared to uncertainties in other parameters, such as the total site concentration.

\subsubsection{Water and Gas Compositions}

A total of four water compositions were equilibrated with the goethite surface, each at three different fugacities of carbon dioxide: $10^{-1.5}, 10^{-3.0}$, and $10^{-5.0}$ bars. The four water compositions came from DTN: MO0403SPAIPCHM.004 and include:

- Seepage water reacted with CSNF at 35 years (C31J25)

- Distilled water reacted with CSNF at 35 years (CS_comp3)

- Seepage water reacted with codisposal package at 60 years (D23N25)

- Distilled water reacted with codisposal package at 54 years (CD_comp7).

These compositions are summarized in SCM modeling summary.xls, Appendix F. The initial $\mathrm{pH}$ values of these waters, listed in Table 6-19, are low because they represent the effects of corrosion of Carbon Steel Type A516 and ignore the effects of surface complexation. Only those components whose concentrations exceeded 1.00E-08 molal were included in the simulations, with the exception of $\mathrm{Fe}$, which was always included regardless of its concentration. Components with total concentrations below 1.00E-08 molal have negligible effects on $\mathrm{pH}$ in these waters.

Table 6-19. Initial pH of Waters Prior to Surface Complexation Calculations

\begin{tabular}{|l|l|c|c|}
\hline \multicolumn{1}{|c|}{ Water } & \multicolumn{1}{c|}{ Model } & Year & pH \\
\hline C31J25 & Liquid influx & 35 & 3.29 \\
\hline CS_comp3 & Vapor Influx & 35 & 3.29 \\
\hline D23N25 & Liquid Influx & 60 & 4.70 \\
\hline CD_comp7 & Vapor Influx & 54 & 3.34 \\
\hline
\end{tabular}

Source: Appendix F, Surface_Complexation_initial_water_comps3.x/s).

\subsubsection{Surface Complexation Calculations}

The surface-complexation calculations were performed using the inputs in Sections 6.8.1 through 6.8.3 and several mineral constraints. Consistent with Table 6-11, gibbsite, hematite, and pyrolusite were allowed to precipitate to saturation. The surface complexation model uses the site concentrations for HFO, which is justified in Section 6.7, but the model demonstration precipitates hematite in order to be consistent with the EQ6 model. Section 6.6.11 examines the impact of forming hematite versus goethite. In addition, calcite and $\mathrm{PuO}_{2}$ (hydr,aged) were 
allowed to precipitate to saturation. Calcite only precipitated in the D23N25 seepage run at 60 years and at $\log f \mathrm{CO}_{2}$ of -1.5 . The only mineral allowed to dissolve was schoepite that was allowed to dissolve to saturation due to its abundance in the waste packages. Because the molalities of the various phases forced to saturation were low compared to the surface site molalities, the predicted $\mathrm{pH}$ values were insensitive to the minerals allowed to precipitate (e.g., $\mathrm{PuO}_{2}, \mathrm{PuO}_{2}$ (hydr,aged), boltwoodite-Na).

The $\mathrm{pH}$ values resulting from the surface complexation calculations are presented in Table 6-20. The non-parenthetical $\mathrm{pH}$ values were calculated using the YMP_R3mr.dat database, which contains all surface complexation reactions in Tables 4-9 and 6-12. Those in parentheses were calculated using the YMP_R3.dat database developed in Section 6.3.2 and documented in DTN: MO0403SPAYMPR3.000. These runs and the YMP_R3mr.dat database are documented in Appendix F (PHREEQC files).

The $\mathrm{pH}$ values of the initial waters in Table 6-19 are for waters in equilibrium with a fugacity of carbon dioxide of $10^{-3}$ bars. As a result, the effects of surface complexation are best evaluated by comparing these $\mathrm{pH}$ values with the $\mathrm{pH}$ values in the " $10^{-3.0}$ bars $\mathrm{CO}_{2}$ " column in Table 6-20. The 3.3 to 4.7 range of initial $\mathrm{pH}$ values (Table 6-19) is buffered by surface complexation reactions to a $\mathrm{pH}$ range of approximately 7.1 to 8.3 (Table 6-20). There are two reasons for this effect. First, the surface acts as a $\mathrm{pH}$ buffer (Section 6.7), and second, the surface sites have a high concentration per mass of water (Section 6.8.2). The low $\mathrm{pH}$ values of the initial waters in Table 6-17 should never exist because corrosion of the steel is accompanied by the generation of iron (hydr)oxide corrosion products that counteract the acidity generated by corrosion.

$\mathrm{pH}$ values increase with decreasing $\mathrm{CO}_{2}$ fugacity and decrease with increasing $\mathrm{CO}_{2}$ fugacity, as predicted in Table 6-18. Based on the results using the expanded YMP_R3mr.dat database, at $10^{-1.5}$ bars the $\mathrm{pH}$ is calculated to fall as low as about 6.5 , while at $10^{-5.0}$ bars, it increases to a maximum around 9.0, depending on the waste package type and initial water composition. The abridged YMP_R3.dat database calculations give a slightly different $\mathrm{pH}$ range of 6.4 to 8.2 . The similarity in the $\mathrm{pH}$ values predicted by each database suggests that the abridged database contains the generally dominant surface complexation reactions.

The differences between YMP_R3.dat and YMP_R3mr.dat $\mathrm{pH}$ calculations are due to the expanded surface complexation database in $Y M \bar{P} R 3 m r$.dat. The additional adsorbates in YMP R3mr.dat are $\mathrm{Ba}^{2+}, \mathrm{Co}^{2+}, \mathrm{Hg}^{2+}, \mathrm{Mg}^{2+}, \mathrm{Mn}^{2+}, \overline{\mathrm{N}} \mathrm{O}_{2}{ }^{2+}, \mathrm{PuO}_{2}{ }^{2+}, \mathrm{UO}_{2}{ }^{2+}, \mathrm{AsO}_{4}{ }^{3-}, \mathrm{AsO}_{3}{ }^{3-}, \mathrm{F}^{-}$, $\mathrm{PO}_{4}{ }^{3-}$, and $\mathrm{SiO}_{3}{ }^{2-}$. While the expanded database allows consideration of additional surface complexation reactions, the representations of these reactions in the database are not verified for accuracy, as are the surface complexation reactions in the abridged database (YMP_R3.dat).

The $\mathrm{pH}$ ranges predicted in these calculations and presented in Table 6-20 are slightly larger than the range predicted by the analytical model in Table 6-18. There are several reasons for this. First, the range in Table 6-20 covers four different corrosion fluids. Table 6-18 covers corrosion of Carbon Steel Type A516 only. Second, the analytic model neglected ionic strength corrections for the primary surface equilibria and ignored exchange of other sorbing ions for protons or hydroxyls, except for carbonate. However, the first-order agreement between the analytic and the full surface complexation model suggests that the primary mechanisms controlling $\mathrm{pH}$ are adequately captured in Table 6-18. 
According to the results of the YMP_R3mr.dat calculations, the following adsorbates account for $1 \%$ or more of all surface species in at least one of the simulations: $\mathrm{H}^{+}, \mathrm{CO}_{3}{ }^{2-}, \mathrm{UO}_{2}{ }^{2+}, \mathrm{Ni}^{2+}$, $\mathrm{CrO}_{4}{ }^{2-}, \mathrm{Ca}^{2+}, \mathrm{PO}_{4}{ }^{3-}$, and $\mathrm{SO}_{4}{ }^{2-}$. Concentrations of adsorbed $\mathrm{UO}_{2}{ }^{2+}$ are always around $15 \%$ to $25 \%$ of the concentration of all surface species. Percentages of surface sites adsorbing $\mathrm{CO}_{3}{ }^{2-}$ are a strong function of $\mathrm{CO}_{2}$ fugacity. At $10^{-1.5}$ bars, around $50 \%$ to $60 \%$ of all surface sites involve $\mathrm{CO}_{3}{ }^{-2}$ adsorption. This percentage range drops to approximately $15 \%$ to $25 \%$ at $10^{-3.0}$ bars and to less than $1 \%$ at $10^{-5.0}$ bars.

$\mathrm{UO}_{2}{ }^{2+}$ is the only adsorbate not included in YMP R3.dat calculated to occupy at least $5 \%$ or more of the surface sites in the YMP_R3mr.dat calculations. Thus, $\mathrm{UO}_{2}{ }^{2+}$ adsorption may be largely responsible for the differences between the $\mathrm{pH}$ calculations within each cell in Table 6-20. This relationship can be assessed by suppressing only the $\mathrm{UO}_{2}{ }^{2+}$ adsorption reactions from the YMP R3mr.dat database and rerunning the simulations. Suppression of $\mathrm{UO}_{2}{ }^{2+}$ adsorption has the important repercussion of reducing schoepite dissolution, which also affects $\mathrm{pH}$ (Section 6.7).

Table 6-20. Equilibrium pH Predicted in Surface Complexation Calculations

\begin{tabular}{|l|l|l|l|l|l|l|l|}
\hline Water & Model & Year & $\begin{array}{l}\text { Log fCO } \\
=-1.5\end{array}$ & $\begin{array}{l}\text { Log fCO } \\
=-3.0\end{array}$ & $\begin{array}{l}\text { Log fCO } \\
=-5.0\end{array}$ & $\begin{array}{c}\text { Input } \\
\text { Filenames }\end{array}$ & $\begin{array}{c}\text { Output } \\
\text { Filenames }\end{array}$ \\
\hline C31J25 & $\begin{array}{l}\text { Liquid } \\
\text { influx }\end{array}$ & 35 & $\begin{array}{l}6.60 \\
(6.59)\end{array}$ & $\begin{array}{l}7.54 \\
(7.56)\end{array}$ & $\begin{array}{l}7.98 \\
(7.93)\end{array}$ & $\begin{array}{l}\text { cs35-15 } \\
\text { cs35-30 } \\
\text { cs35-50 }\end{array}$ & $\begin{array}{l}\text { cs35-15.out } \\
\text { cs35-30.out } \\
\text { cs35-50.out }\end{array}$ \\
\hline CS_comp3 & $\begin{array}{l}\text { Vapor } \\
\text { Influx }\end{array}$ & 35 & $\begin{array}{l}6.49 \\
(6.45)\end{array}$ & $\begin{array}{l}7.16 \\
(7.37)\end{array}$ & $\begin{array}{l}7.53 \\
(7.69)\end{array}$ & $\begin{array}{l}\text { cd35-15 } \\
\text { cd35-30 } \\
\text { cd35-50 }\end{array}$ & $\begin{array}{l}\text { cd35-15.out } \\
\text { cd35-30.out } \\
\text { cd35-50.out }\end{array}$ \\
\hline D23N25 & $\begin{array}{l}\text { Liquid } \\
\text { influx }\end{array}$ & 60 & $\begin{array}{l}7.05 \\
(6.96)\end{array}$ & $\begin{array}{l}8.06 \\
(7.95)\end{array}$ & $\begin{array}{l}8.31 \\
(8.17)\end{array}$ & $\begin{array}{l}\text { co60-15 } \\
\text { co60-30 } \\
\text { co60-50 }\end{array}$ & $\begin{array}{l}\text { co60-15.out } \\
\text { co60-30.out } \\
\text { co60-50.out }\end{array}$ \\
\hline CD_comp7 & $\begin{array}{l}\text { Vapor } \\
\text { Influx }\end{array}$ & 54 & $\begin{array}{l}7.11 \\
(6.96)\end{array}$ & $\begin{array}{l}8.24 \\
(7.85)\end{array}$ & $\begin{array}{l}9.05 \\
(8.16)\end{array}$ & $\begin{array}{l}\text { cod54-15 } \\
\text { cod54-30 } \\
\text { cod54-50 }\end{array}$ & $\begin{array}{l}\text { cod54-15.out } \\
\text { cod54-30.out } \\
\text { cod54-50.out }\end{array}$ \\
\hline
\end{tabular}

NOTE: $\quad{ }^{1}$ Values in parentheses are calculated using the abridged YMP_R3.dat. Preceding values are calculated using the expanded YMP_R3mr.dat.

\subsection{APPLICATION OF SURFACE COMPLEXATION MODEL TO THE BATCH REACTOR MODEL RESULTS}

The surface complexation model is applied only to the CSNF model. Corrosion product surfaces represent an important $\mathrm{pH}$ buffer that tends to anchor $\mathrm{pH}$ values near neutral. Its effect is most important to consider when $\mathrm{pH}$ values are otherwise predicted to depart substantially from neutral. For this reason it was applied for CSNF calculations. The $\mathrm{pH}$ values of CDSP effluents are not predicted to be as extreme as those for the CSNF waste packages, so the explicit surface complexation calculation was not included in the model, although buffering of $\mathrm{pH}$ will certainly occur.

The low-pH trend observed during the initial 600 years was caused by the dissolution of Carbon Steel Type A516 where sulfur contained in the steel was oxidized and formed sulfuric acid. This period is also characterized by the formation of ferric (hydr)oxide corrosion products; hematite was allowed to form in the simulations because of its long term stability. Runs in which goethite 
was allowed to form are documented in Section 6.7 and show much the same behavior in the $\mathrm{pH}$ profile. It is during this period that the surface complexation model (Section 6.7) is applied in the $\mathrm{pH}$ abstraction.

Because the surface complexation effects are accounted for by modifying the $\mathrm{pH}$ after the batch reactor results are presented, there is no feedback from the surface complexation model to the batch reactor model. Therefore, the impact of the modified $\mathrm{pH}$ on the batch reactor runs must be examined. All of the metal alloys use linear corrosion rates, which are unaffected by $\mathrm{pH}$. The CSNF rate law is a function of $\mathrm{pH}$ and tends toward lower values in the neutral $\mathrm{pH}$ range. During the first six hundred years, the period when the surface complexation model is employed, the CSNF total degradation rate, from Figure A-1, decreases from approximately $2 \mathrm{E}-13 \mathrm{~mol} / \mathrm{sec}_{-} \mathrm{cm}^{2}$ at $\mathrm{pH} 4$ to $7 \mathrm{E}-14 \mathrm{~mol} / \mathrm{sec}-\mathrm{cm}^{2}$ at $\mathrm{pH} 7$, a decrease of less than a factor of three. Thus, a factor of three less CSNF would dissolve during the first six hundred years, and the total duration that CSNF would be present in the waste package would be extended. The influence on the chemistry of the system would be minimal because schoepite, the primary CSNF degradation product, would still form just in smaller quantities.

During the period when the surface complexation is implemented, the redox potential of the system will vary in accordance with the $\mathrm{pH}$ predicted by the surface complexation model. Section 6.10.6 derives Eh as a function of temperature, oxygen partial pressure, and $\mathrm{pH}$; thus, the $\mathrm{pH}$ predicted from the surface complexation model will be used to calculate the redox potential for the initial 600 years, and will likely be different from that displayed in the 0 - to 600 -year period in Figures 6-10 and 6-11. This raises the question whether the low pH and Eh for the first six hundred years are different than displayed in Figures 6-10 and 6-11 and will result in the same mineral assemblage under the new conditions. This question was investigated by using EQ6 and reducing the sulfur of the Carbon Steel Type A516 composition. Sulfur was identified as the cause of the observed $\mathrm{pH}$ low in the model output, and its removal, or use of more realistic sulfur oxidation states, would create a $\mathrm{pH}$ similar to that predicted by the surface complexation model.

The results of this exercise showed that during the 0- to 200-year period when the Carbon Steel Type A516 was corroding, the system $\mathrm{pH}$ values varied between 5 and 8 . This is the same $\mathrm{pH}$ as was predicted by the surface complexation model (Section 6.7), and the same set of minerals form as did when the $\mathrm{pH}$ was controlled by the sulfur contained in the Carbon Steel Type A516. A plot of the minerals and the $\mathrm{pH}$ is provided in Appendix A, Figure A-10. This exercise lends confidence to the argument that although the batch reactor model and the surface complexation model are decoupled, the surface complexation model's effect on $\mathrm{pH}$ would not influence the corrosion product mineral assemblage. Furthermore, since the Eh is a function of $\mathrm{pH}$, and the $\mathrm{pH}$ shown in Figure A-10 is in the same range as that for the surface complexation model (Section 6.7), it follows that there is no impact on the Eh from the decoupling of the models.

These same concepts apply to the period when the surface complexation model is active. During this time, dissolved ions will complex with the surfaces of the ferric (hydr)oxides minerals and deviations in ionic concentrations in the bulk fluid for various input water compositions will be slight for elements that do not originate from in-package materials. Therefore, it is expected that the input water composition will have the same effect on the in-package chemistry with surface complexation as it does when surface complexation is not active. 
The mineral assemblages for the base case and for the same base case with a $\mathrm{pH}$ moderated to a minimum of 4.5 (by using 10× less sulfur in the Carbon Steel Type A516) are shown in Figures 6-68 and 6-69. All of the major minerals are the same. The only differences are slight and include the timing of the formation of certain minerals as well as small changes in the quantities of kaolinite, baddeleyite, barite, and $\mathrm{Fe}_{2}\left(\mathrm{MoO}_{4}\right)_{3}$ This comparison shows that the lack of feedback from the surface complexation model to the batch reactor model has minimal affect on the minerals that form.

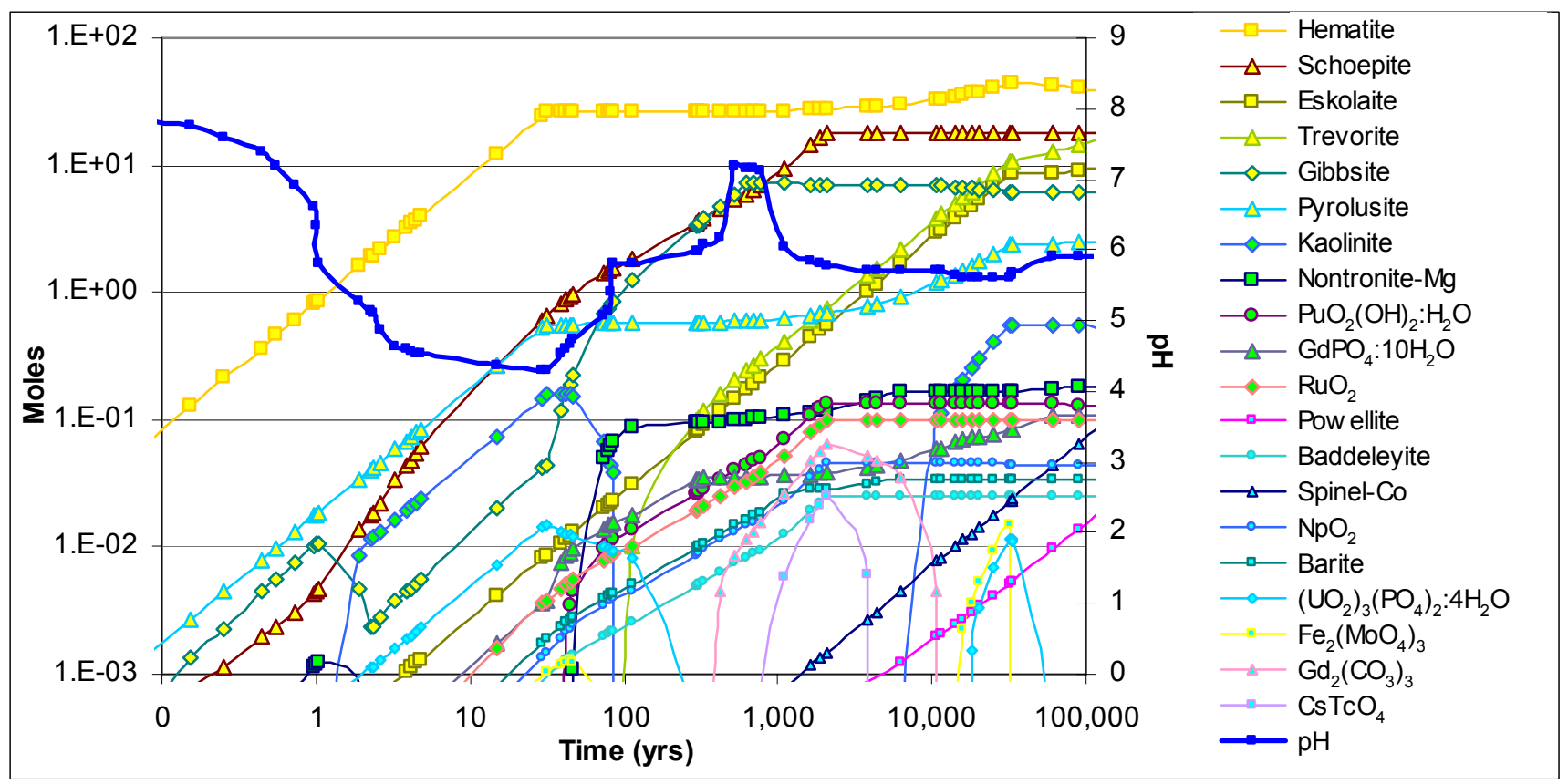

Source: $\quad$ CSNF Liquid Influx Model Output.x/s (Appendix F ISpreadsheets)

Note: $\quad$ Time refers to time after waste package breach ( 0 on the $x$-axis refers to 0.1 years).

Figure 6-68. Mineral Assemblage for Base Case 


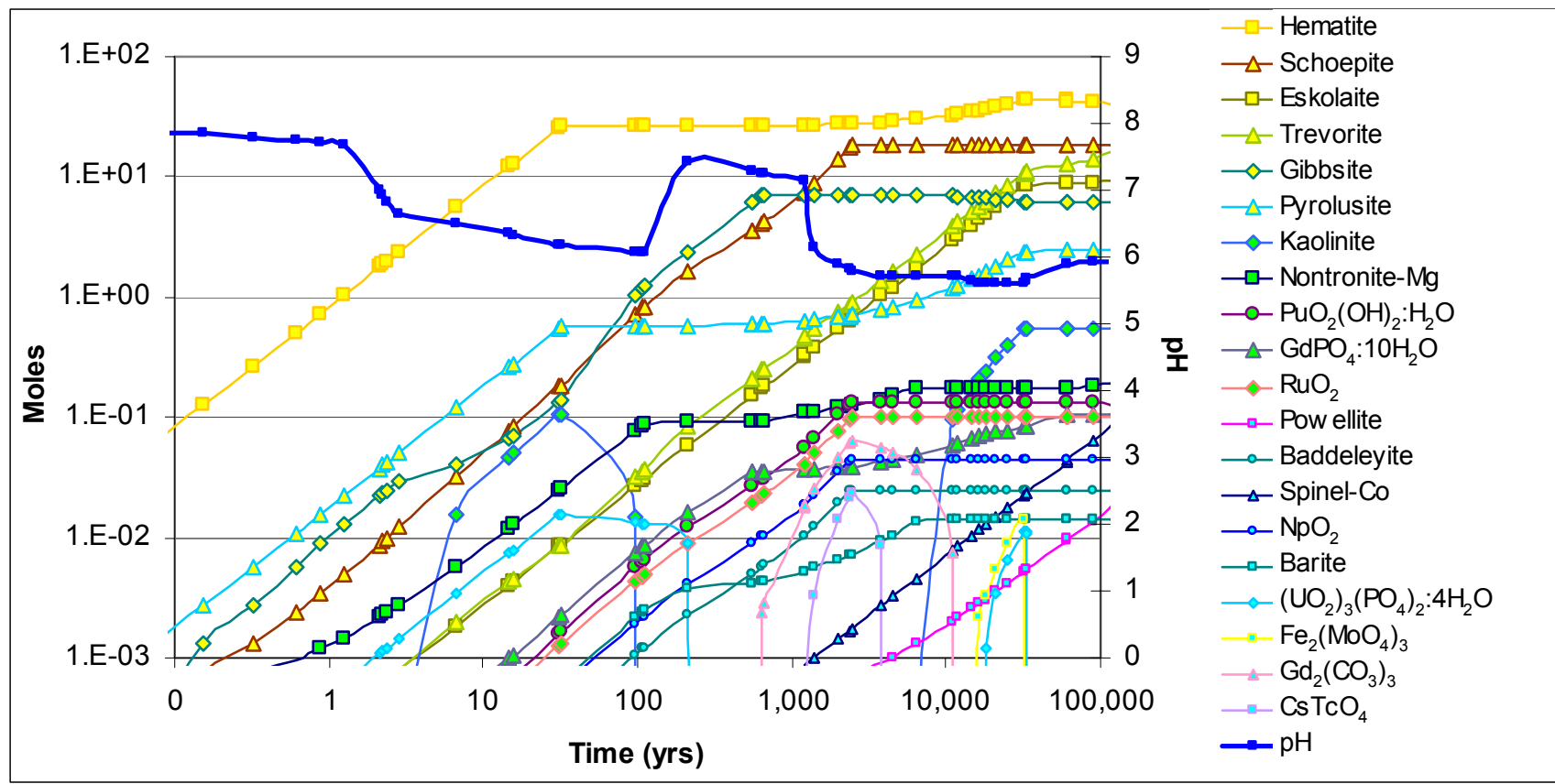

Source: CSNF Liquid Influx Model Output.xIs (Appendix F ISpreadsheets).

NOTE: $\quad$ Time refers to time after waste package breach ( 0 on the $x$-axis refers to 0.1 years).

Figure 6-69. Mineral Assemblage for Moderated pH Case

\subsection{MODEL ABSTRACTION}

The in-package chemistry model is activated within TSPA-LA once the waste package has been breached and the interior temperature of the waste package is below the boiling temperature of water. All references to time within this report refer to the time after waste package breach and after the waste package cools to temperatures lower than $100^{\circ} \mathrm{C}$ where liquid water is stable. The in-package chemistry model is applicable over the water volumetric flux (hereafter referred to as "flux") range from $0.001 \mathrm{~L} / \mathrm{yr}$ to $1000 \mathrm{~L} / \mathrm{yr}$ per waste package (Section 6.6.5), a temperature range from $25^{\circ} \mathrm{C}$ to $100^{\circ} \mathrm{C}$ (Section 6.6.6), a carbon dioxide partial pressure range of $10^{-5}$ to $10^{-1.5}$ atmospheres (Section 6.6.4), and an oxygen partial pressure up to 0.2 atmospheres (Section 6.6.4). Spatially, the applicability of the in-package chemistry model is limited to the waste package interior.

In the CSNF vapor-influx model, there are no fluoride or chloride abstractions because these elements are not a constituent of the water vapor or in any of the waste package components. Therefore, only the $\mathrm{pH}$ and ionic strength are abstracted from the CSNF vapor-influx model; the total carbonate and Eh are calculated as functions of $\mathrm{pH}$ and $f \mathrm{CO}_{2}$. The mapping of batch reactor cases to the abstractions is presented in Table 6-21. 
Table 6-21. Mapping of Batch Reactor Cases to Abstractions

\begin{tabular}{|c|c|}
\hline Batch Reactor Cases & Developed Abstractions \\
\hline CSNF Vapor-Influx Case & $\mathrm{pH}$ and ionic strength \\
\hline CSNF Liquid-Influx Case & $\mathrm{pH}$, ionic strength, fluoride and chloride concentrations \\
\hline CDSP Vapor-Influx Case & $\mathrm{pH}$, ionic strength, and fluoride concentrations \\
\hline CDSP Liquid-Influx Case & $\mathrm{pH}$, ionic strength, fluoride and chloride concentrations \\
\hline
\end{tabular}

\subsection{1 pH Abstractions}

The $\mathrm{pH}$ abstractions for the CSNF and CDSP waste packages are described in the following sections. The results of the single component runs were not used in the development of either abstraction, since the purpose of this section is to describe the bulk chemistry of the waste package. Because of the similarities between the vapor influx runs and liquid influx runs for both the CSNF and the CDSP waste packages (as shown in a single plot, Figure 6-20 for the CSNF waste package, and by comparing Figures 6-12 and 6-23 for the CDSP waste package), the CSNF and CDSP $\mathrm{pH}$ abstractions are applicable to both the vapor-influx case and the liquidinflux case. Additionally, due to these similarities, the full suite of runs varying all of the key inputs are conducted for the liquid-influx case, and are not repeated for the vapor-influx case. The trends observed by the liquid-influx case are applicable to the trends that would be observed in the vapor-influx case.

\subsubsection{CSNF pH Abstraction}

The CSNF $\mathrm{pH}$ abstraction is grouped into four abstractions: two time frames: 0 yrs to $600 \mathrm{yrs}$ and $600 \mathrm{yrs}$ to $20,000 \mathrm{yrs}$, and two flux conditions: flux less than or equal to $150 \mathrm{~L} / \mathrm{yr}$ and flux greater than $150 \mathrm{~L} / \mathrm{yr}$.

The $\mathrm{pH}$ history for the full suite of CSNF liquid-influx cases is presented in Figure 6-70 (excluding the cases which vary in the water influx rates, which are shown in Figure 6-41).

As described in Sections 5.2, 6.3.2, and 6.7.1, the long-term condition of the surfaces of the waste package components is uncertain enough that the most realistic approach to anticipating in-package $\mathrm{pH}$ values is to simply allow it to vary between the limits set by the surface complexation model and batch reactor model, independent of time. However, Section 6.7.1 states that it is only appropriate to apply the surface complexation model for the first 600 years, thus making the model dependent on time. This time dependence is only a function of when the surface complexation model is applied, and is not a function of the time series $\mathrm{pH}$ values calculated by EQ3/6.

For the CSNF waste package, during the period when the surface complexation model is implemented ( 0 to 600 years), the $\mathrm{pH}$ ranges are defined by the surface complexation model as a function of the fugacity of carbon dioxide gas in Table 6-18 (values using 0.1 moles of sites per mole $\mathrm{Fe}$ ). The maximum $\mathrm{pH}$ values for the 0 - to 600 -year period are the same as the values calculated in Section 6.7.1 (Table 6-18), with no additional uncertainty added. Likewise, the 
minimum $\mathrm{pH}$ value should also correspond to the values in Table 6-18, however, to account for any uncertainty in when the surface complexation model might really be in effect, the $\mathrm{pH}$ minimum was set by the long-term $\mathrm{pH}$ minimum of 4.5. Applying a $\mathrm{pH}$ minimum of 4.5 for both the 0- to-600-year time frame and the long term also accounts for the uncertainty associated with the steel and alloy corrosion rates. As shown in Figure 6-56, depending on the corrosion rates used, the $\mathrm{pH}$ minimum can occur anywhere between 10 and 200 years. This $\mathrm{pH}$ is also based on the $90^{\circ} \mathrm{C}$ simulation displayed in Figure 6-46, where for times greater than 600 years, $\mathrm{pH}$ stabilizes around 4.5. Allowing the $\mathrm{pH}$ to be sampled down to the long-term $\mathrm{pH}$ minimum, which is lower than the $\mathrm{pH}$ minimum predicted by the surface complexation model, provides TSPA-LA with a broader $\mathrm{pH}$ range intended to capture uncertainty in corrosion rates and the surface areas available for corrosion. In addition, sampling the long-term $\mathrm{pH}$ minimum also removes any time dependence on the EQ6 results. As was discussed in Section 6.7.3, there is little surface chemistry data at high temperatures; however, the data that are available support the trend of decreasing $\mathrm{pH}$ with increased temperature observed in Figure 6-46. Each distribution should be uniformly sampled, $\mathrm{pH}$ values for intermediate values of $\log f \mathrm{CO}_{2}$ may be linearly interpolated between nearest neighbor values, and no uncertainty term should be added to the sampled value.

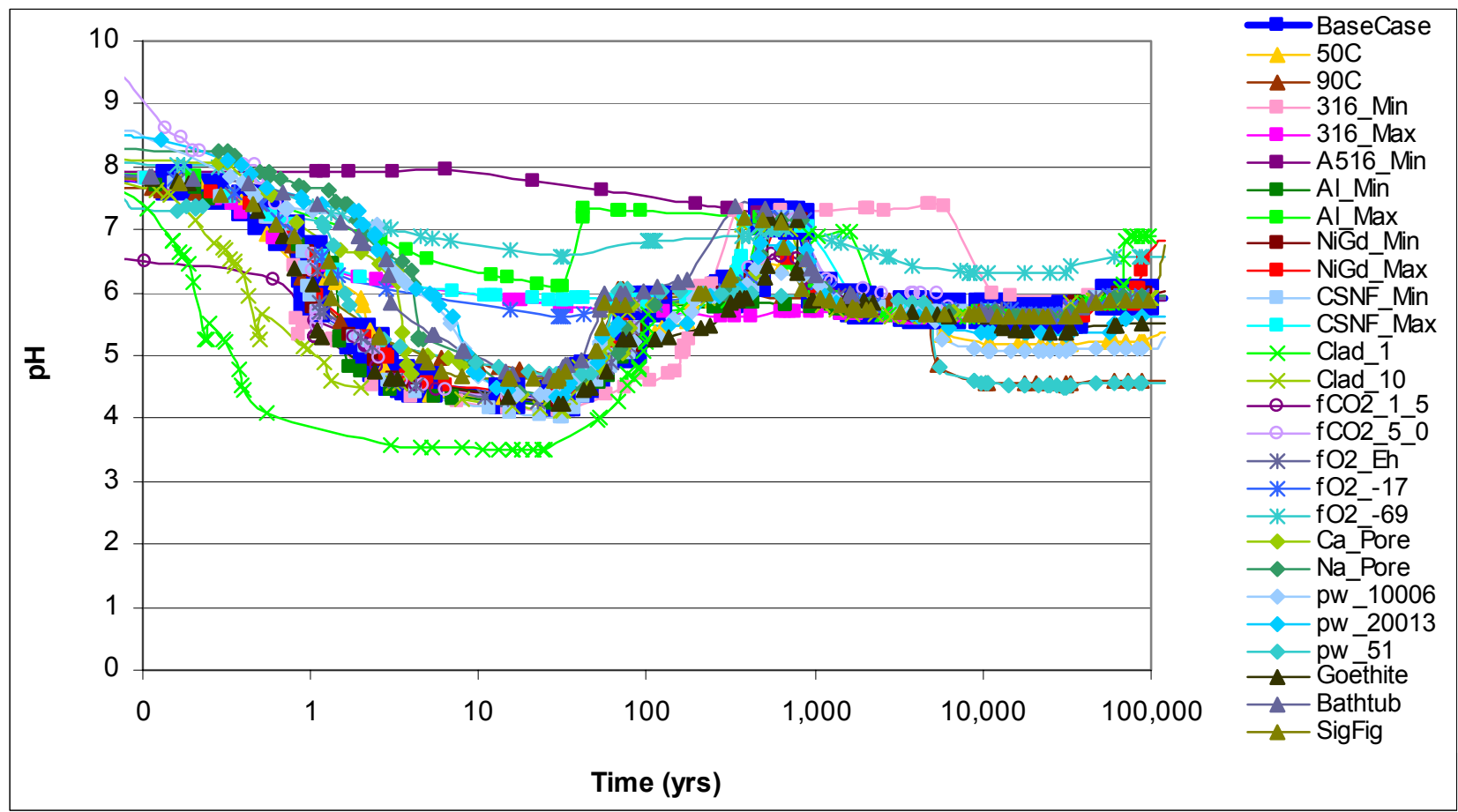

Source: $\quad$ CSNF Liquid Influx Model Output.xls (Appendix F ISpreadsheets).

NOTE: $\quad$ Time refers to time after waste package breach ( 0 on the $x$-axis refers to 0.1 years). The surface complexation model has not yet been applied to these results.

The maximum rate for the $\mathrm{A} 516$ is the same as the mean rate.

Figure 6-70. CSNF Liquid-Influx Model pH Results

For the CSNF waste packages for the period from 600 to 20,000 years, the $\mathrm{pH}$ should be uniformly sampled between $\mathrm{pH} 4.5$ and 7. The $\mathrm{pH}$ minimum is based on the $\mathrm{Cr}(\mathrm{VI})$ sensitivity that shows a lower $\mathrm{pH}$ at late times (Section 6.6.3, Figure 6-33) due to the degrading stainless 
steel which is the major source of $\mathrm{Cr}$. Though the model uses $\mathrm{Cr}$ (III), there is still the potential for some of the $\mathrm{Cr}$ to oxidize to $\mathrm{Cr}(\mathrm{VI})$, so the $\mathrm{pH}$ minimum of 4.5 accounts for that potential. This $\mathrm{pH}$ minimum is supported by the long-term $\mathrm{pH}$ observed in the high temperature runs Figure 6-46). Though the minimum long-term $\mathrm{pH}$ is more likely to be closer to 5.5 or 6 , based on all of the $25^{\circ} \mathrm{C}$ runs shown in Figure 6-70, and considering the fact that the repository will have cooled significantly by late times, the $\mathrm{pH}$ minimum of 4.5 was retained so as to not minimize risk. A lower $\mathrm{pH}$ is more conservative in most respects; it results in higher dissolved concentrations as well as high CSNF dissolution rates. The $\mathrm{pH}$ maximum of 7 is based on long-term $\mathrm{pH}$ observed for the higher liquid-influx cases in Figure 6-41 and the low- $f \mathrm{O}_{2}$ case in Figure 6-37, with no additional uncertainty term added.

If the flux into a failed waste package exceeds $150 \mathrm{~L} /$ year, the maximum $\mathrm{pH}$ could reach that of the incoming water, as shown in Section 6.6.5. Therefore, for fluxes greater than $150 \mathrm{~L} /$ year, the maximum $\mathrm{pH}$ is set at 8.5 for 0 to 600 years, and for 600 to 20,000 years to coincide with the maximum reasonable water that could enter a waste package for a significant duration, based on Figure 6-70. (The $\mathrm{pH}$ for the $\log f \mathrm{CO}_{2}=-5.0$ case is not considered, because the initial high $\mathrm{pH}$ is only a function of the solution being equilibrated with that low $f \mathrm{CO}_{2}$ ). The reason for the flux dependence is that at high flux values, there is less opportunity for reactions to occur and the $\mathrm{pH}$ of the water more closely reflects the $\mathrm{pH}$ of the incoming water. The $\mathrm{pH}$ minimum is set to 4.5 to coincide with the minimum $\mathrm{pH}$ observed in Figure 6-41 or with a reasonable water that could enter a waste package for a significant duration, based on Figures 6.13-2 and 6.13-15 of the Physical and Chemical Environment (BSC 2004 [DIRS 169860]). There is no additional uncertainty term added. Figure 6-45 shows that $\mathrm{pH}$ increases with increasing liquid influx; therefore, the high influx and the low influx $\mathrm{pH}$ abstractions should be sampled in a similar manner, meaning if a high $\mathrm{pH}$ is sampled for a low liquid influx, a corresponding high $\mathrm{pH}$ should be sampled for a high liquid influx.

For late times ( $>40,000$ years), the $\mathrm{pH}$ would be less affected by the processes inside the waste package and would be more a function of the incoming water $\mathrm{pH}$. By 40,000 years, most of the reactants that strongly impact the chemistry have degraded, and only the NiGd remains, which has a slow degradation rate. Figure 6-70 shows the long term $\mathrm{pH}$ to be between 4.5 and 7, but the runs showing a low $\mathrm{pH}$ are the high temperature runs that are modeled at $90^{\circ} \mathrm{C}$ or above (cases 90C and pw_51). According to Figure 6.3-67 of BSC 2005 [DIRS 173944] the repository has cooled to below $60^{\circ} \mathrm{C}$ by 20,000 years, so these high temperature cases are not relevant at these late times. Therefore, the expected $\mathrm{pH}$ minimum for times greater than 40,000 years is 6 , and the expected $\mathrm{pH}$ maximum would be set by that of the incoming water.

For naval waste packages that do not contain Carbon Steel Type A516 in their design, the expected $\mathrm{pH}$ profiles ( $\mathrm{pH}$ between 5 and 8) would be near those displayed in Figure 6-55. The naval nuclear propulsion program provides a release rate from naval spent nuclear fuel based on this $\mathrm{pH}$ range. The use of the CSNF $\mathrm{pH}$ abstraction for the transport of the radionuclides from naval spent nuclear fuel is justified because the CSNF $\mathrm{pH}$ abstraction encompasses the range of expected in-package $\mathrm{pH}$ conditions for naval fuel. In addition, the naval waste packages comprise 300 waste packages compared to 7,772 CSNF packages (BSC 2004 [170022], Table 42 ), any consequence of modeling naval fuel as $\mathrm{CSNF}$, resulting in a $\mathrm{pH}$ range extending $0.5 \mathrm{pH}$ units is not likely to be significant. 


\subsubsection{CDSP pH Abstraction}

The CDSP $\mathrm{pH}$ abstraction is grouped into two flux conditions, flux less than or equal to $150 \mathrm{~L} / \mathrm{yr}$ and flux greater than $150 \mathrm{~L} / \mathrm{yr}$.

The $\mathrm{pH}$ history for the full suite of CDSP liquid-influx cases is presented in Figure 6-71 (excluding the cases which vary in the water influx rates, which are shown in Figure 6-43).

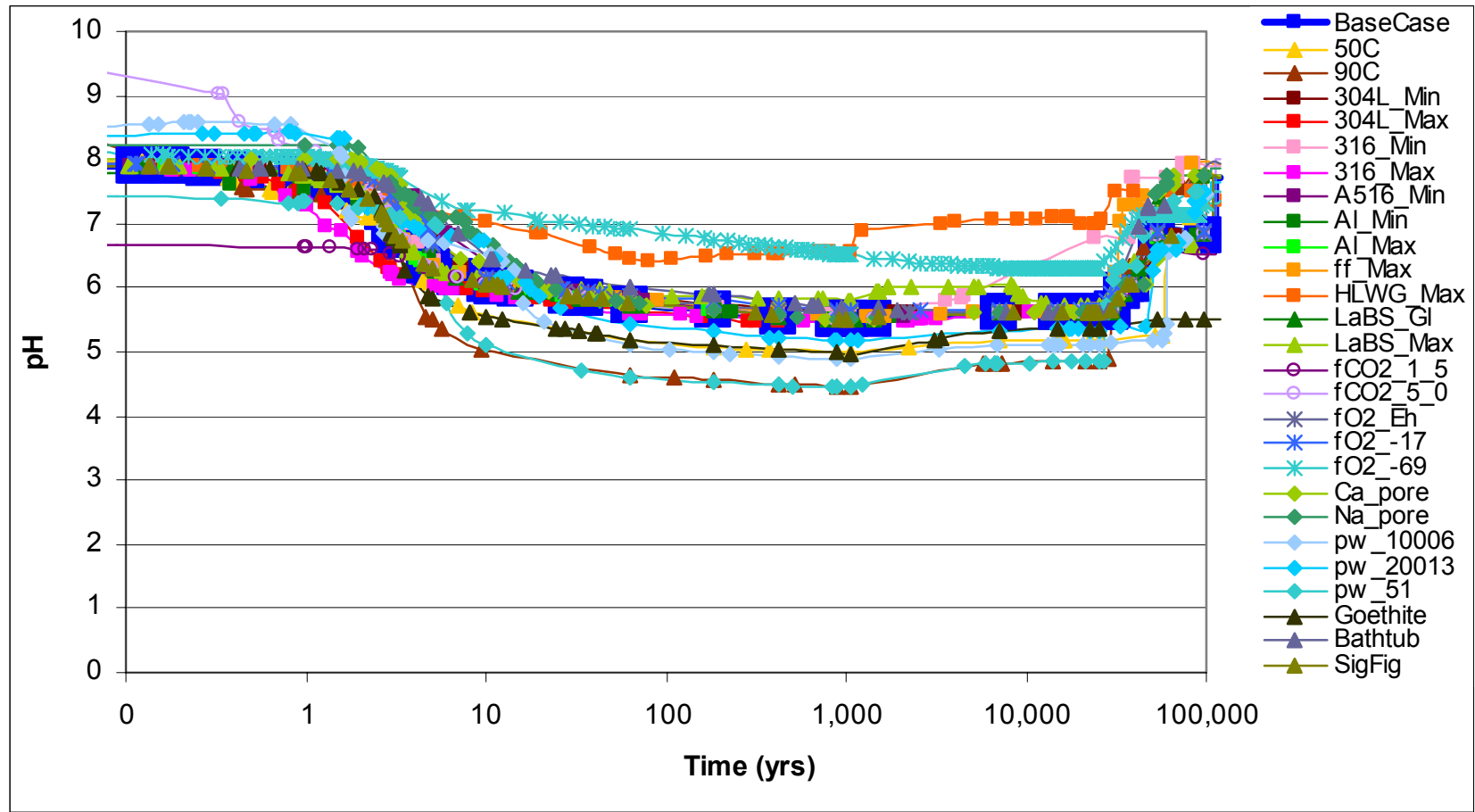

Source: $\quad$ CDSP Liquid Influx Model Output.xls (Appendix F ISpreadsheets).

NOTE: $\quad$ Time refers to time after waste package breach ( 0 on the $x$-axis refers to 0.1 years).

The maximum rate for the $\mathrm{A} 516$ is the same as the mean rate.

Figure 6-71. CDSP Liquid-Influx Model pH Results

For the CDSP waste package, the surface complexation model is not implemented, and the $\mathrm{pH}$ ranges for the entire regulatory timeframe should be uniformly sampled between a minimum and maximum $\mathrm{pH}$. The minimum $\mathrm{pH}$ is 4.5 is based on the $\mathrm{Cr}(\mathrm{VI})$ sensitivity that shows a lower $\mathrm{pH}$ at late times (Section 6.6.3, Figure 6-35) due to the degrading stainless steels which is the major source of $\mathrm{Cr}$. Though the model uses $\mathrm{Cr}(\mathrm{III})$, there is still the potential for some of the $\mathrm{Cr}$ to oxidize to $\mathrm{Cr}(\mathrm{VI})$, so the $\mathrm{pH}$ minimum of 4.5 accounts for that potential. Though the minimum long-term $\mathrm{pH}$ is more likely to be closer to 5.5 or 6 , based on the lower temperature runs shown in Figure 6-71, and considering the fact that the repository will have cooled significantly by late times, the $\mathrm{pH}$ minimum of 4.5 was retained so as to not minimize risk. A lower $\mathrm{pH}$ is more conservative in most respects; it results in higher dissolved concentrations as well as high HLWG dissolution rates. The maximum $\mathrm{pH}$ is dependent on the liquid influx rate. As shown in Figure 6-43, at flow rates higher than $150 \mathrm{~L} / \mathrm{yr}$, the $\mathrm{pH}$ increases back towards that of the incoming water. Therefore, for low flow rates $(\mathrm{Q} \leq 150 \mathrm{~L} / \mathrm{yr}$ ), the maximum $\mathrm{pH}$ is 7.0 (Figure 6-39 for the low $\mathrm{fO}_{2}$ case). 
If the flux into a failed waste package exceeds $150 \mathrm{~L} /$ year, the maximum $\mathrm{pH}$ could reach that of the incoming water, as shown in Section 6.6.5. Therefore, the maximum $\mathrm{pH}$ is set at 8.5 to coincide with the maximum reasonable water that could enter a waste package for a significant duration, based on Figure 6-71. (The $\mathrm{pH}$ for the $\log f \mathrm{CO}_{2}=-5.0$ case is not considered, because the initial high $\mathrm{pH}$ is only a function of the solution being equilibrated with that low $f \mathrm{CO}_{2}$ ). The $\mathrm{pH}$ minimum is set to 4.5 to coincide with a reasonable water that could enter a waste package for a significant duration, based on Figures 6.13-2 and 6.13-15 of the Physical and Chemical Environment (BSC 2004 [DIRS 169860]). The reason for the flux dependence is that at high flux values, there is less opportunity for reactions to occur and the $\mathrm{pH}$ of the water more closely reflects the $\mathrm{pH}$ of the incoming water. There is no additional uncertainty term added. Figure 643 shows that $\mathrm{pH}$ increases with increasing liquid influx; therefore, the high influx and the low influx $\mathrm{pH}$ abstractions should be sampled in a similar manner, meaning if a high $\mathrm{pH}$ is sampled for a low liquid influx, a corresponding high $\mathrm{pH}$ should be sampled for a high liquid influx.

For late times ( $>40,000$ years), the $\mathrm{pH}$ would be less affected by the processes inside the waste package and would be more a function of the incoming water $\mathrm{pH}$. By 40,000 years, most of the reactants that strongly impact the chemistry have degraded, and only the HLWG remains, which has a slow degradation rate. Figure 6-71 shows the long term $\mathrm{pH}$ to be between 4.5 and 7, but the runs showing a low $\mathrm{pH}$ are the high temperature runs that are modeled at $90^{\circ} \mathrm{C}$ or above (cases 90C and pw_51) and the run that allows goethite to form. According to Figure 6.3-67 of BSC 2005 [DIRS 173944] the repository has cooled to below $60^{\circ} \mathrm{C}$ by 20,000 years, so these high temperature cases are not relevant at these late times. In addition, at these late times, the consideration of goethite becomes more questionable, since the more thermodynamically stable hematite will likely dominate. Therefore, the expected $\mathrm{pH}$ minimum for times greater than 40,000 years is 6.5 , and the expected $\mathrm{pH}$ maximum would be set by that of the incoming water.

\subsubsection{Comparison of CSNF and CDSP pH Abstractions}

The in-package chemistry is highly dependent on the waste package type; therefore, there is no correlation between CSNF and CDSP $\mathrm{pH}$ abstractions.

The $\mathrm{pH}$ profiles for the CSNF and CDSP abstractions are different from one another because of the different materials used in two waste package types, as shown in Table 4-6. Figure 6-72 shows the $\mathrm{pH}$ profiles for liquid-influx base case for both CSNF and CDSP waste packages. 


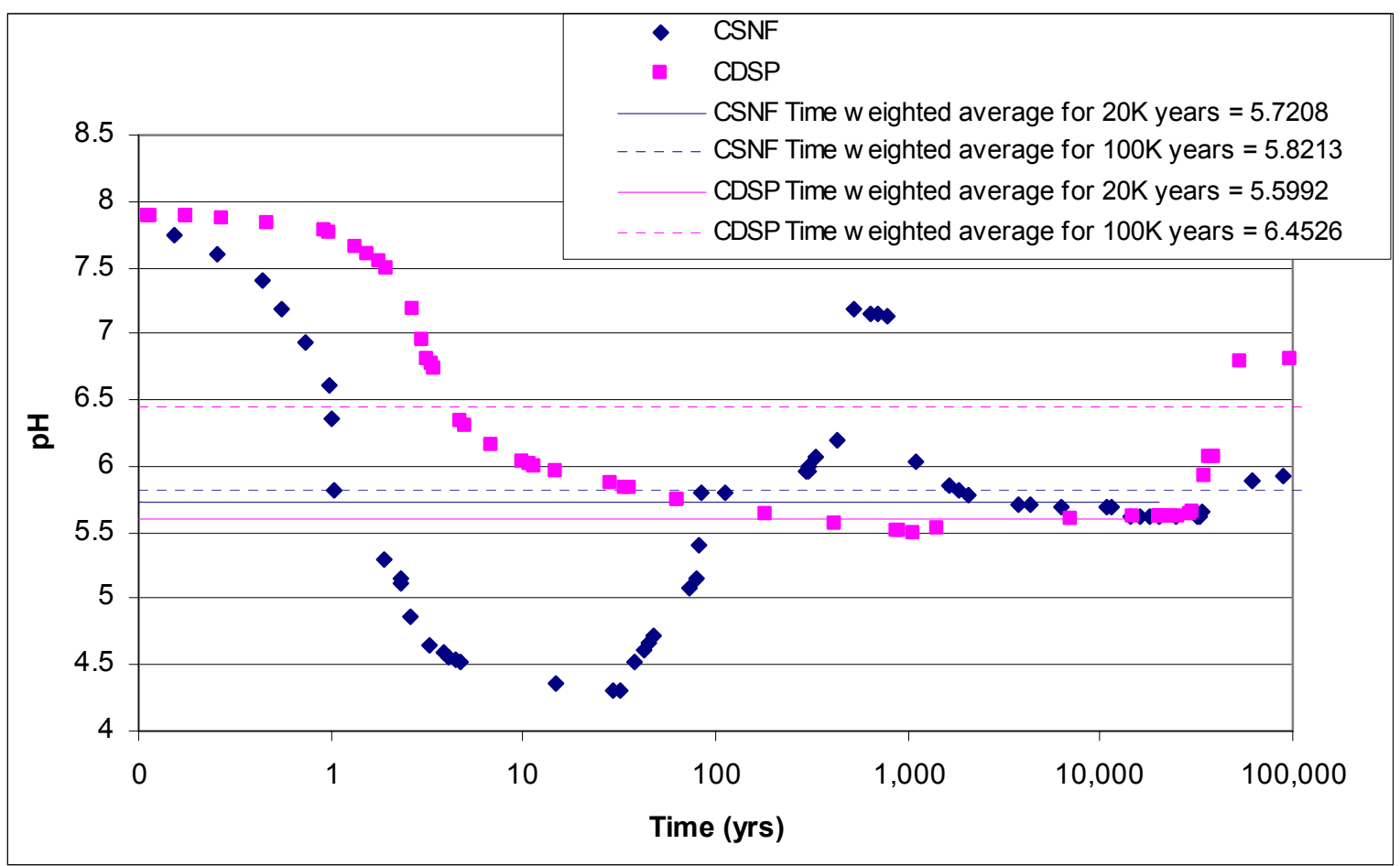

Source: $\quad$ pH Comparison for CSNF and CDSP.xls (Appendix F).

NOTE: $\quad$ Time refers to time after waste package breach ( 0 on the $x$-axis refers to 0.1 years).

Figure 6-72. Comparison of CSNF and CDSP Liquid-Influx pH Profiles

A counter-intuitive observation on the $\mathrm{pH}$ profiles is that the CDSP 20,000-year time-weighted $\mathrm{pH}$ is lower than that for the CSNF. The dissolution of HLWG elevates $\mathrm{pH}$, as shown in Figure 6-22, but when all the CDSP waste package components are combined in a single run, the resulting $\mathrm{pH}$ for the first 20,000 years is actually lower than the CSNF $\mathrm{pH}$ for the same duration, due to the low degradation rate of the HLWG and the presence of more stainless steel (higher quantities of 316 than the CSNF waste package and the additional 304L stainless steel not present in the CSNF waste package). For later times, the $\mathrm{pH}$ trends are reversed, and the 100,000 year time weighed average $\mathrm{pH}$ for the CDSP waste package is higher than that for the CSNF waste package, due to the effects of the HLWG dissolution becoming more of a factor as the other reactants are depleted.

\subsubsection{Ionic Strength Abstractions}

Based on previous versions of this model, it is known that the most significant factor affecting ionic strength is water flux. Therefore, ionic strength abstractions are calculated as a function of flux. The ionic strength abstraction is a triangular distribution between a minimum, a mode, and a maximum function of ionic strength versus flux. Based on the full suite of EQ6 runs, three cases are selected to represent the minimum, the mode, and the maximum, and these three cases are then run with the entire range of liquid or vapor fluxes. The resulting time-weighted ionic strength for each case is calculated and then abstracted as a function of the base ten logarithm of either the seepage flux or vapor flux, using linear regression in Microsoft Excel using "Add Trendline" from the "Chart" submenu to fit the exponential function to the data (the resulting trendline is shown in Figures 6-74, 6-76, 6-79, and 6-80 as the "Power" function). 
The ionic strength results predicted using the EQ6 model were based on water ratios that were adjusted to avoid exceeding the ionic strength limit of the aqueous model; thus, the ionic strength boundary condition was set by the model itself. Compounding this issue are three points. First is the fact that at early times, the ratio of water to reactants is initially small and increases with time, so the ionic strength will initially be high and decrease with time as more water enters the system. Second is the fact that the corrosion rates used in the modeling consume water faster than the liquid or vapor influx rate, resulting in higher ionic strengths. This water consumption (shown in Figure 6-75 for liquid influx and Figure 6-77 for vapor influx) indicates that there is not sufficient water to sustain the maximum corrosion rates examined, or even the average rates in some cases. When there is insufficient water to support corrosion, the corrosion process slows down. Third is that this model does not account for evaporative processes. The principal solutes following evaporation will be those of soluble salts like $\mathrm{Cl}, \mathrm{Na}, \mathrm{Mg}$, which could increase the ionic strength of the in-package solution.

These three effects are not necessarily captured in the EQ6 model, but are accounted for in the broad uncertainty applied to the ionic strength abstraction. In contrast to the factors above, the ionic strengths predicted by EQ6 are likely to be high as the underlying calculations do not account for removal of dissolved salts from solution by corrosion product sorption or the lower oxidation state the system, which impacts important materials in the waste package. However, the complexities involved with predicting the exact identities and abundances (hence site densities) of the corrosion products over long periods of time, prevents estimation of the magnitude of the effect. For example, complete conversion of corrosion products to low site density hematite over time would lead to ionic strengths closer to the EQ6 prediction.

The possibility of ionic strength being higher than was possible to model with the batch reactor model, or being lower due to sorption reactions or lower oxidation states, is dealt with because the ionic strength abstractions capture extreme ionic strengths by including high water influx rates and high corrosion rates, as described in Sections 6.10.2.1 and 6.10.2.2. The results of the ionic strength abstractions are shown in Figure 6-74, Figure 6-76, Figure 6-79, Figure 6-80.

Unlike the batch reactor conceptual model (Section 6.3.1.1), under vapor influx conditions, the interior of the waste package is dry at the moment of waste package breach. With time, the humidity of the interior of the waste package will equilibrate to the ambient drift conditions and water will begin to adsorb or condense to the interior waste package components. The ratio of water to reactants is initially small and increases with time, so the ionic strength will initially be high and decrease with time as more water enters the system. This is an effect that is not captured by the vapor influx EQ6 model. Therefore, the ionic strength data that show a linear increase as a function of time, $<30$ years (Figure 6-73 for example), is appropriately weighted by using a time-weighted average for the ionic strength values. The potentially high-ionic strength solutions that could occur based on the low ratio of water to reactants at early times, but not captured in the EQ6 model, are captured by the broad ionic strength abstraction that encompasses high ionic strengths, as shown in the abstractions developed in the following sections.

The ionic strength abstraction for late times is also based on a time-weighted average ionic strength. This approach is justified for the liquid-influx cases because a single TSPA timestep can be much longer than the short-lived (I) peaks shown in Figures 6-73 and 6-78. Also the 
uncertainty associated with the timing and duration of the ionic strength peak is difficult to quantify, and is a factor of the stainless steel rates and the surface area of the stainless steels; therefore, it is appropriate to make the abstraction time independent. The use of a time-weighted average ionic strength for the vapor-influx case is justified for these same reasons, and also because the vapor-influx rate is only sampled once per realization, so the abstracted ionic strength is only calculated once per realization, and it would be inappropriate to apply a shortlived ionic strength peak to the entire realization. The time-weighted average ionic strength is further justified in Section 6.10.2.4.

Further complicating the effect of increasing water content is the role of corrosion products and surface complexation on ionic strength. Increasing water content and surface complexation have the same potential impact of decreasing the ionic strength. The applied broad uncertainty range covers this effect. It was demonstrated that the waste package becomes filled with water and mineral phases by about 5,000 to 7,000 years (WP_volume.xls, Appendix F). This has no impact on the ionic strength abstraction because the colloid threshold ionic strength, $0.05 \mathrm{~mol} / \mathrm{L}$ (BSC 2004 [DIRS 170025]), occurs well before this time around 10 to 30 years. The significance of the quantity of water in the model is discussed in more detail in Section 6.10.2.4.

Low ionic strengths $(<0.05 \mathrm{~mol} / \mathrm{L})$ are conservative for TSPA-LA relative to colloid stability because colloids are stable and can transport radionuclides when the ionic strength is less than $0.05 \mathrm{~mol} / \mathrm{L}$ (BSC 2004 [DIRS 170025]). High ionic strengths ( $>1$ molal) are conservative for TSPA-LA relative to the dissolved concentrations of radionuclides because TSPA-LA increases the uncertainty applied to the Dissolved Concentration Limits of Radioactive Elements (BSC 2005 [DIRS 173873]), increasing the concentrations of radionuclides in solution. Ionic strengths between 0.05 and 1 molal are the least conservative to TSPA-LA relative to the transport of radionuclides. Therefore, the uncertainty applied to the ionic strength should be broad enough to encompass extreme ionic strengths resulting in an overall representative output to TSPA-LA that does not minimize risk.

One of the limitations in the model relevant to the ionic strength abstraction is the B-dot limitation, described in Sections 1 and 6.3.1.1. Because the colloidal suspensions are only stable at ionic strength values below $0.05 \mathrm{~mol} / \mathrm{L}$ (BSC 2004 [DIRS 170025]), there is no significance in exceeding the 4 molal limits of the B-dot activity coefficient equation. For the Dissolved Concentration Limits of Radioactive Elements model (BSC 2005 [DIRS 173873]), TSPA-LA applies an additional uncertainty term to the concentrations if the ionic strengths is greater than one molal, so the significance of exceeding the 4 molal limits of the B-dot activity coefficient equation is already captured.

Because of the similarities between the vapor influx runs and liquid influx runs for both the CSNF and CDSP waste packages, (as shown in Figure 6-21 for CSNF waste packages), the full suite of runs varying all of the possible inputs conducted for the liquid-influx case is sufficient to show the model response, and is not repeated again for the vapor-influx case. This similarity also shows that the ionic strength abstraction for the vapor-influx case should take the same form as the liquid-influx case.

The ionic strength abstractions developed in Sections 6.10.2.1 through 6.10.2.2 are summarized and tabulated for use by the TSPA-LA in Section 6.10.2.3. 


\subsubsection{CSNF Ionic Strength Abstractions}

\subsection{Liquid Influx Abstraction}

The ionic strength histories for the full suite of CSNF liquid-influx cases are presented in Figure 6-73 (excluding the cases which vary in the water influx rates, which are shown in Figure 6-42). Because there are so many inputs, each with several values associated with them, each input is varied individually, while keeping the base-case value for the other inputs. The CSNF liquid-influx base case is defined in Section 6.5.1.1. For example, the cases that examine different incoming water compositions, all use the base-case values for flux, corrosion rates for all of the alloys and fuels, cladding exposure, $\log f \mathrm{CO}_{2}=-3$, and $\log f \mathrm{O}_{2}=-0.7$.

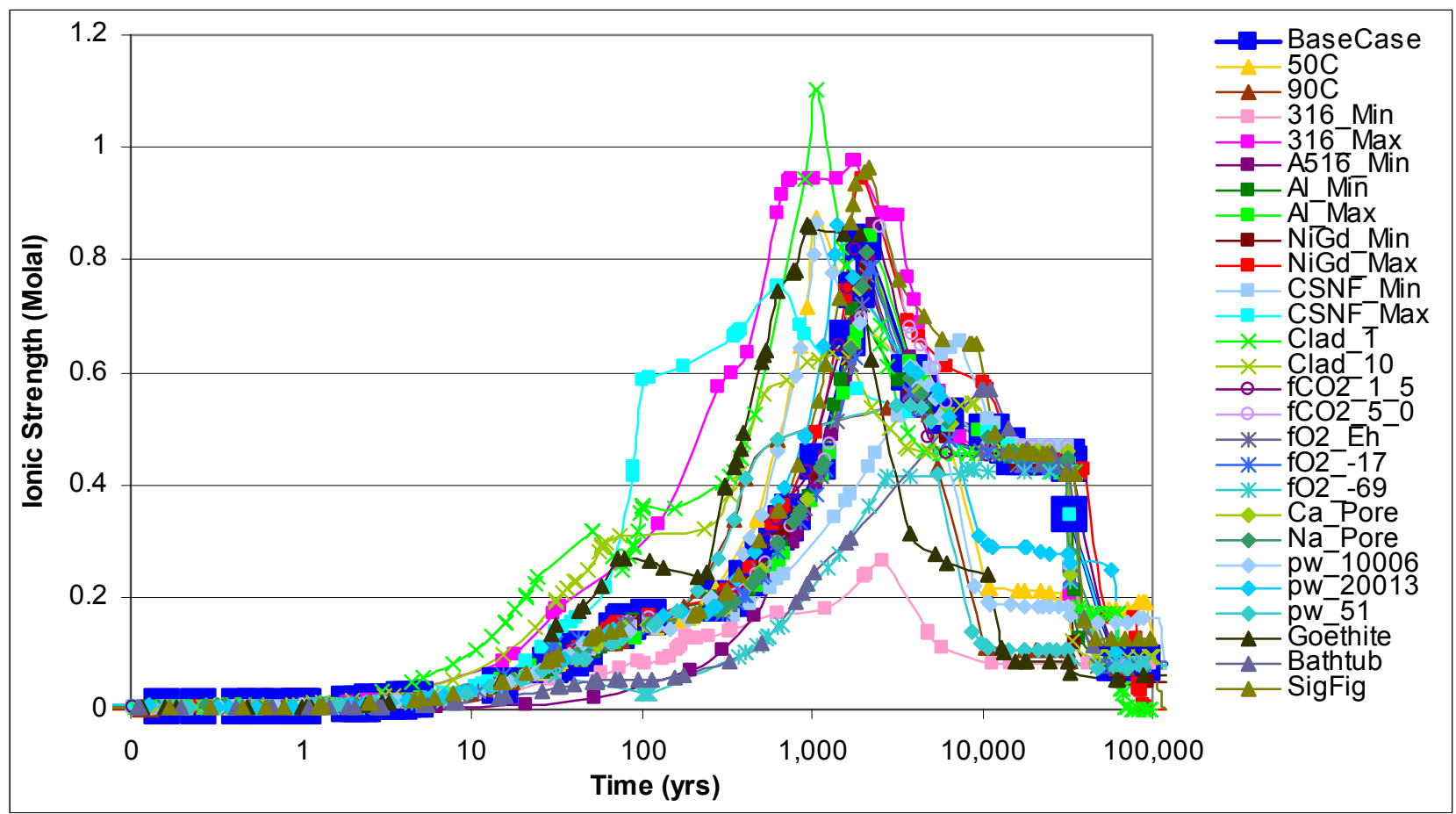

Source: $\quad$ CSNF Liquid Influx Model Output.xls (Appendix F).

NOTE: Time refers to time after waste package breach ( 0 on the $x$-axis refers to 0.1 years).

The maximum rate for the $\mathrm{A} 516$ is the same as the mean rate.

Figure 6-73. CSNF Liquid-Influx Model lonic Strength Profiles

The runs shown in Figure 6-73 were all conducted at a flux of $1 \mathrm{~L} / y e a r$. The point of this figure is to determine which other factors are important in selecting the minimum, maximum and mode cases, and this figure clearly shows that the next most significant factor in ionic strength is the corrosion rates used for the A516 and 316 steels (from Table 6-5). The cases that examine lower fuel exposures (1\% and 10\% cladding failure) also have higher ionic strengths, but this is an artifact of the scaling used. The quantity of water is scaled to the reactants based on the surface area, so for the lower fuel exposures, more of the remaining reactants are exposed, such as the A516 and 316. Since the degradation rate is the product of the kinetic rate, and the surface area exposed (Section 6.3.1.3.2), the lower fuel exposure cases model essentially the same as the increased degradation rate cases. 
The ionic strength for each of the three cases is calculated as a function of the liquid influx by linear regression, and the results are shown in Figure 6-74, which shows the base-case results as the time-weighted average ionic strength, and the two extreme cases show both the maximum ionic strength for the entire run as well as a time-weighted ionic strength.

These abstractions, were all generated by plotting in Microsoft Excel the time-weighted average ionic strength versus the base ten logarithm of seepage flux and then using "Add Trendline" from the "Chart" submenu to fit the exponential function to the data (the resulting trendline is shown in Figure 6-74, Figure 6-76, Figure 6-79, and Figure 6-80 as the "Power" function).

For the liquid-influx cases, the flux is varied from 0.001 to $1,000 \mathrm{~L} / \mathrm{yr}$.

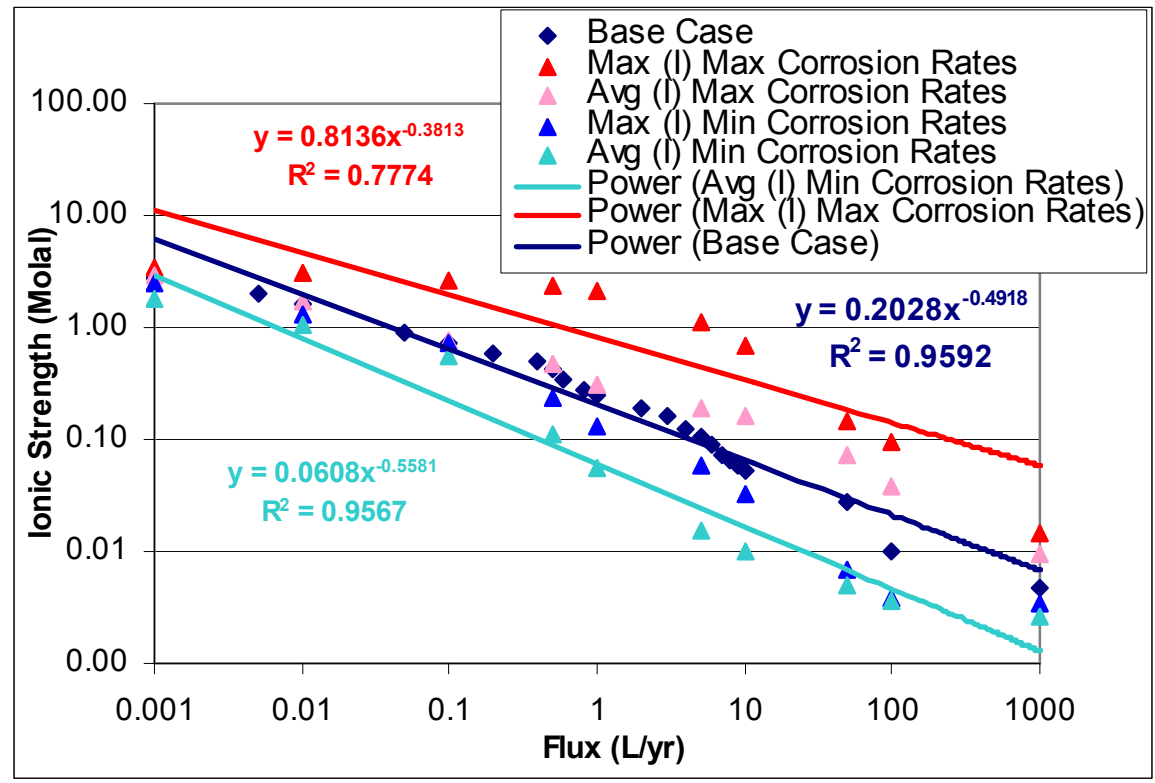

Source: (I) CSNF_Liquid Influx Model Output.xls (Appendix F).

Figure 6-74. CSNF Liquid-Influx Model Ionic Strengths as a Function of Flux

There is some question about the appropriateness of using the maximum corrosion rate case, because as Figure 6-75 shows, there is not sufficient water in the system to sustain the high corrosion rates (or even the average corrosion rates). The corrosion process consumes water, and if there is no water available, the corrosion process slows down. The EQ6 model is scaled to 1 liter of water $(1 \mathrm{~kg})$, but as the water is consumed faster than the influx rate, the mass of the solvent decreases below $1 \mathrm{~kg}$. Therefore, the use of the maximum corrosion rate case over estimates the ionic strength. Section 6.10.2.4 discusses the quantity of water in the EQ6 runs as it pertains to the ionic strength abstractions.

The relationship between ionic strength and flux becomes less linear with very high corrosion rates. The reason for this trend is that even with very high corrosion rates, the ionic strength at high fluxes is overwhelmed by the low ionic strength of the incoming water. If the runs had extended out to greater than 1000 liters per year, the ionic strength for all of the cases would converge on the ionic strength of the incoming water. At lower fluxes, the ionic strength for the 
high corrosion rate case is not as high as would be expected because the higher concentrations in solution tend to cause minerals to precipitate.

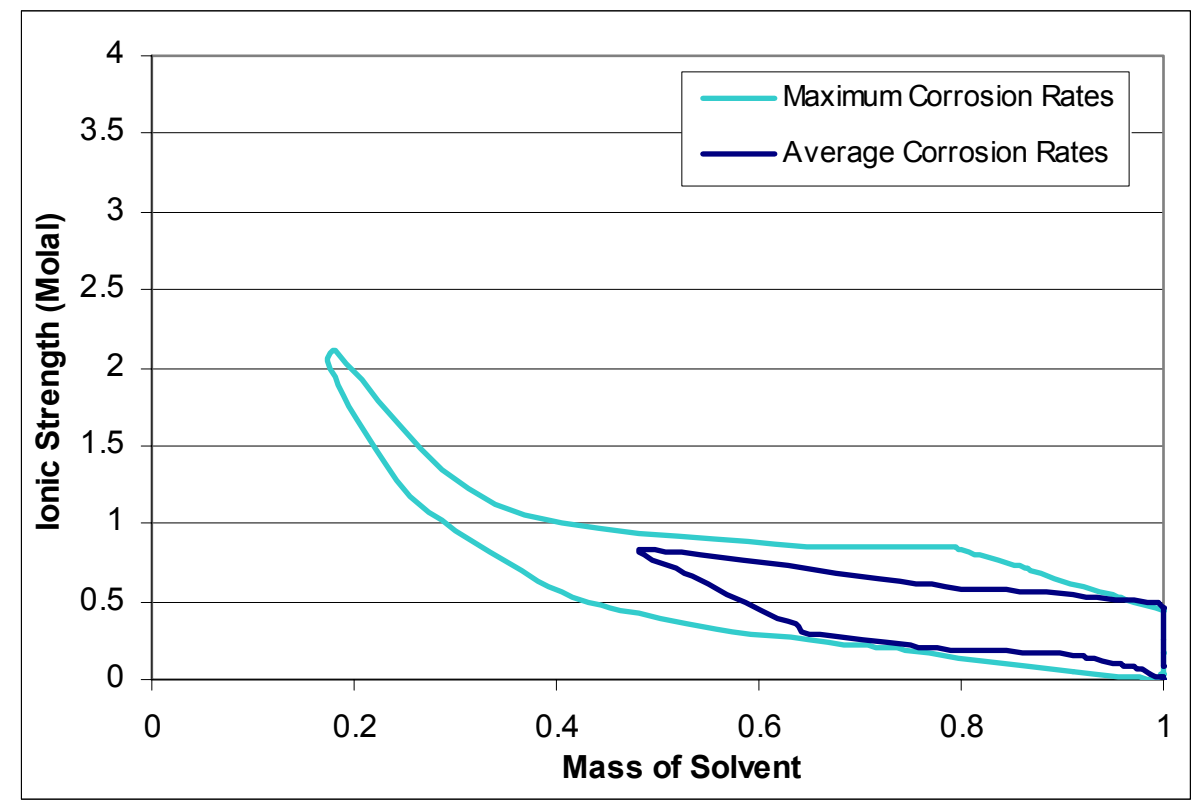

Source: (I) Abstraction CSNF Liquid Influx.xls (Appendix F).

Figure 6-75. CSNF Liquid-Influx Model lonic Strengths as a Function of Mass of Solvent

\subsection{Vapor Influx Abstraction}

Because of the similarities between the vapor-influx and liquid-influx runs for the CSNF waste packages (as shown in Figure 6-21), the ionic strength abstraction for the vapor-influx case should take the same form (base case $=$ mode; maximum corrosion rates $=$ maximum; minimum corrosion rates $=$ minimum) as the liquid-influx case. However, the EQ6 model is based on 1 liter of water (as described in Sections 6.3.1.1 and 6.10.2.4); this water is available to react with the various components being modeled and can be consumed by corrosion processes. If too much of the water is consumed, due to very high corrosion rates, the remaining quantity of water becomes so low, the system is no longer modeling a dilute aqueous environment, and the range of validity of the model has been exceeded (i.e., when ionic strength exceeds 4 molal). In a real system, if there is not sufficient water to sustain an aqueous environment, the corrosion processes slow down. To model this slowing down of the corrosion rates, the abstraction is based on the average corrosion rates rather than the high corrosion rates that cannot be sustained by the quantity of water available to react. Figures 6-75 and 6-77 show that the maximum corrosion rate case consumes far more water than the average corrosion rate case, artificially driving up the ionic strength. Therefore, the average corrosion rate case is a more reasonable case to use for the ionic strength abstraction.

For the vapor-influx case, the flux is varied from 0.1 to $10 \mathrm{~L} / \mathrm{yr}$. 


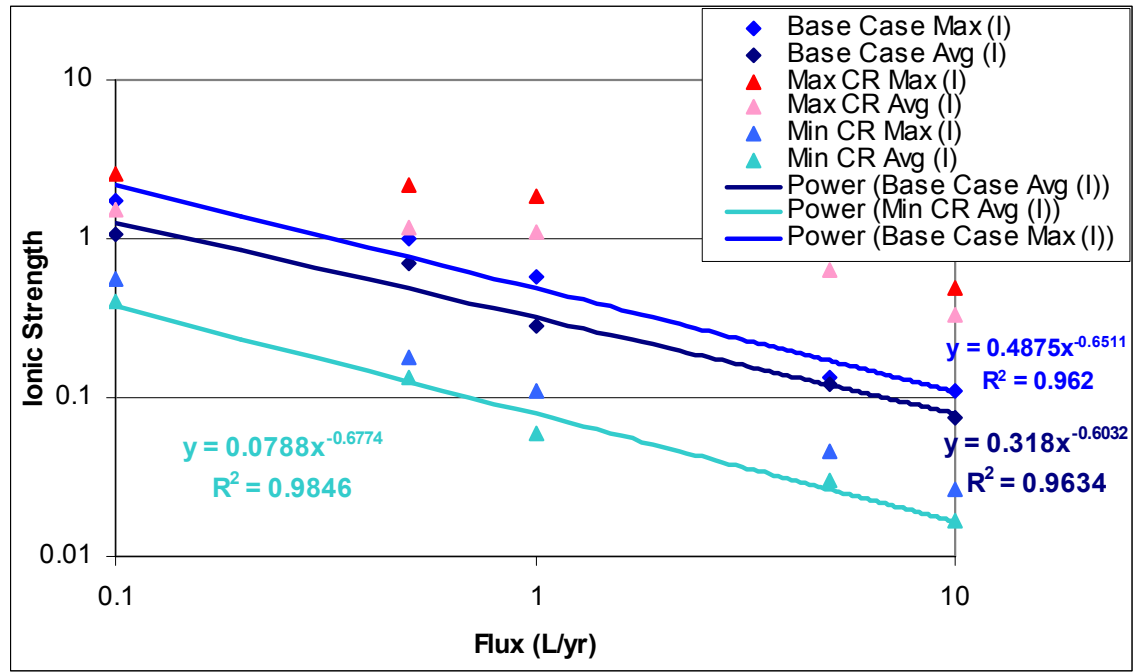

Source: (I) CSNF Vapor Influx Model Output.xls (Appendix F).

Figure 6-76. CSNF Vapor-Influx Model Ionic Strengths as a Function of Flux

For the vapor-influx case, the maximum ionic strength was determined from the maximum ionic strength value for the base case, unlike the liquid-influx model, that uses the maximum corrosion rate case. As shown for the liquid-influx case, the maximum corrosion rates consume more water than is available to react, and this effect is shown in Figure 6-77. For the vapor case with high corrosion rates, the high ionic strengths occur when the mass of solvent is well below $1 \mathrm{~kg}$ (1 liter), while for the average corrosion rate case, the maximum ionic strength value occurs when the mass is at $1 \mathrm{~kg}$. For the liquid case, both the ionic strength maximums for the maximum corrosion rate case and the average corrosion rate case, occur when the mass of solvent is well below $1 \mathrm{~kg}$ (1 liter), as shown in Figure 6-75.

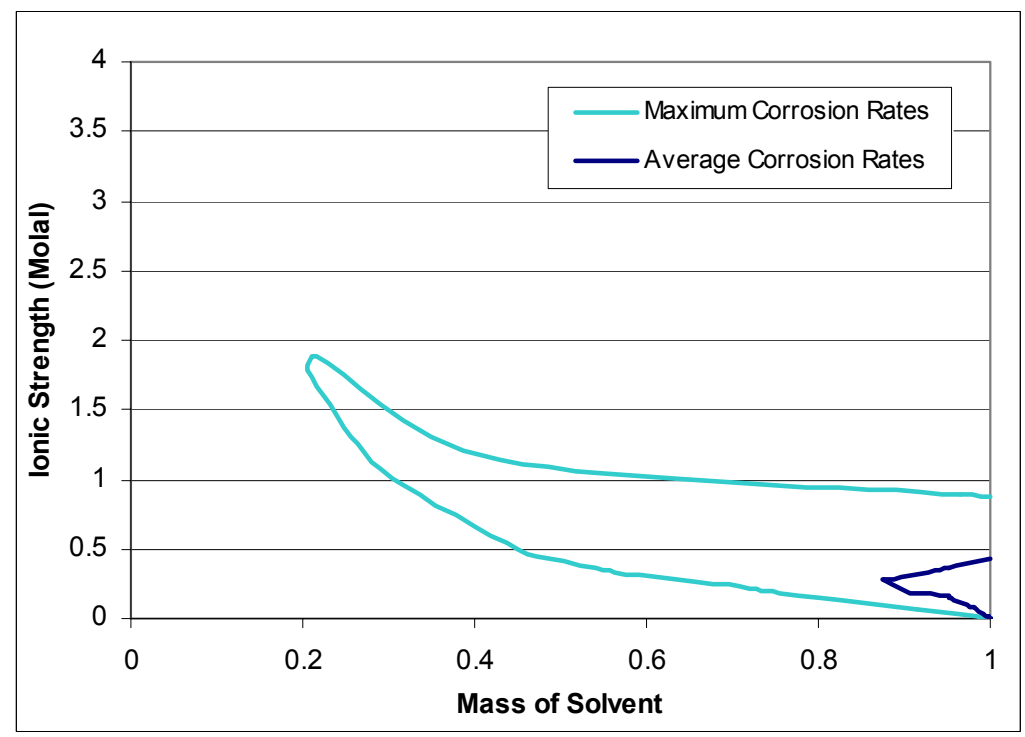

Source: (I) Abstraction CSNF Vapor Influx.xls (Appendix F).

Figure 6-77. CSNF Vapor-Influx Model lonic Strengths as a Function of Mass of Solvent 


\subsubsection{CDSP Ionic Strength Abstractions}

\subsection{Liquid Influx Abstraction}

The ionic strength histories for the full suite of CDSP liquid-influx cases are presented in Figure 6-78 (excluding the cases which vary in the water influx rates, which are shown in Figure 6-44). Because there are so many inputs, each with several values associated with them, each input is varied individually, while keeping the base-case value for the other inputs. The CDSP liquid-influx base case is defined in Section 6.5.1.2. For example, the cases that examine different incoming water compositions, all use the base-case values for flux, corrosion rates for all of the alloys and fuels, cladding exposure, $\log f \mathrm{CO}_{2}=-3$, and $\log f \mathrm{O}_{2}=-0.7$.

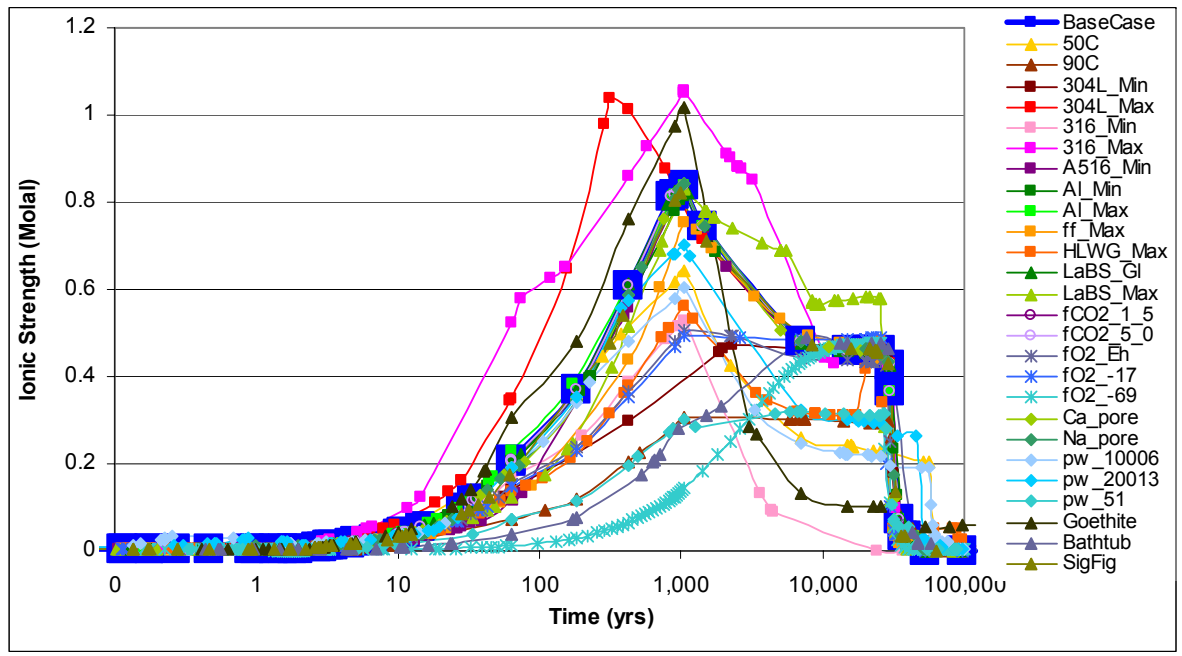

Source: (I) CDSP Liquid Influx Model Output.xls (Appendix F).

Note: $\quad$ Time refers to time after waste package breach ( 0 on the $x$-axis refers to 0.1 years). The maximum rate for the A516 is the same as the mean rate.

Figure 6-78. CDSP Liquid-Influx Model lonic Strength Profiles

As described in Section 6.10.2.1, the most significant factor affecting ionic strength is flux. The runs shown in Figure 6-78 were all conducted at a flux of $1 \mathrm{~L} / y e a r$. The point of this figure is to determine which other factors are important for selecting which case to represent the minimum, the mode and the maximum, and this figure clearly shows that the next most significant factor in ionic strength is the corrosion rates used for the A516 and 316 steels (from Table 6-5).

Therefore, the liquid influx and vapor influx ionic strength abstractions take the base-case run, the run with the minimum corrosion rates, and the case with the maximum corrosion rates, and simulates these three cases over the full range of influx rates. The ionic strength for each of the three cases is then calculated as a function of the liquid influx by linear regression. These results are shown in Figure 6-79; for the base-case results, the ionic strength is the time-weighted average ionic strength, and the two extreme cases show both the maximum ionic strength for the entire run as well as a time-weighted ionic strength. The abstracted ionic strength is given as a function of the liquid influx for the base case. The maximum abstracted ionic strength is given as a function of the liquid influx for the case using the maximum corrosion rates, and the 
minimum abstracted ionic strength is given as a function of the liquid influx for the case using the minimum corrosion rates.

These abstractions, were all generated by plotting in Microsoft Excel the time-weighted average ionic strength versus the base ten logarithm of seepage flux and then using "Add Trendline" from the "Chart" submenu to fit the exponential function to the data.

For the liquid-influx cases, the flux is varied from $0.001 \mathrm{~L} / \mathrm{yr}$ to $1,000 \mathrm{~L} / \mathrm{yr}$.

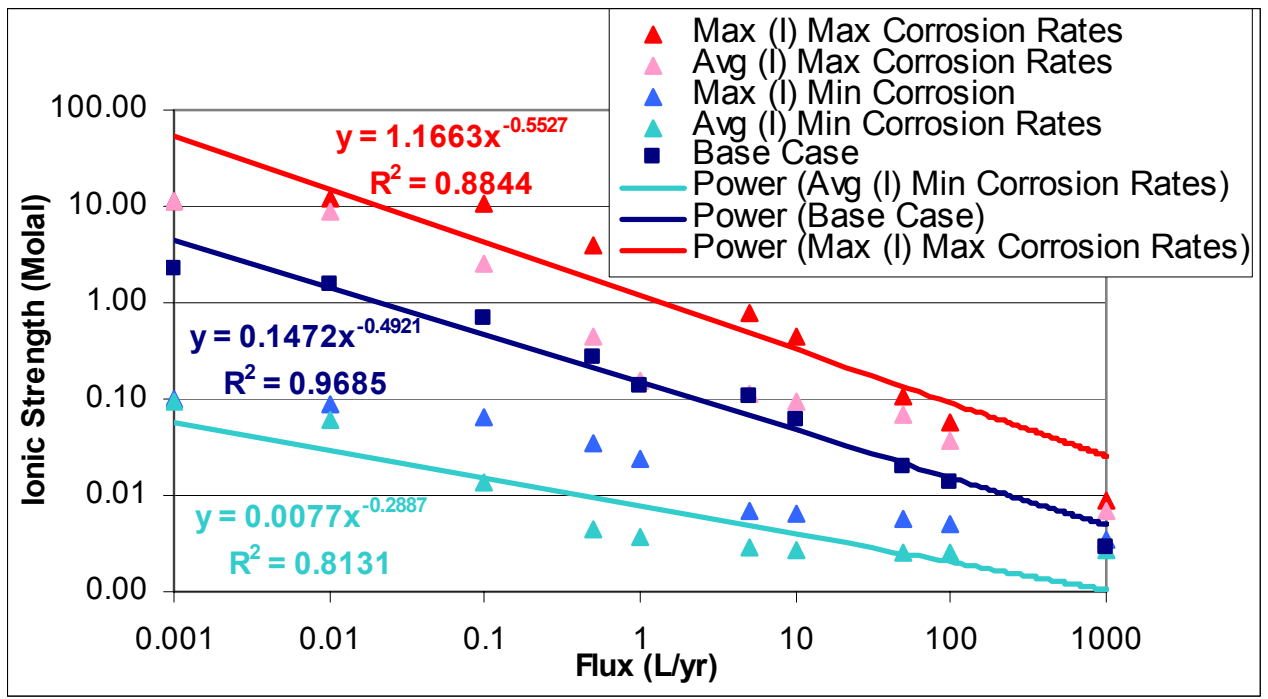

Source: (I) CDSP Liquid Influx Model Output.xls (Appendix F).

Figure 6-79. CDSP Liquid-Influx Model Ionic Strengths as a Function of Flux

Like the CSNF liquid-influx case, there is some question about the appropriateness of using the maximum corrosion rate case, because as Figure 6-75 shows, there is not sufficient water in the system to sustain the high corrosion rates. The corrosion process consumes water, and if there is no water available, the corrosion process slows down. The EQ6 model is scaled to 1 liter of water $(1 \mathrm{~kg})$, but as the water is consumed faster than the influx rate, the mass of the solvent decreases below $1 \mathrm{~kg}$. Therefore, the use of the maximum corrosion rate case over estimates the ionic strength. For the stability of colloids (transport of radionuclides), a low ionic strength is conservative, but since the maximum corrosion rates were used to develop the maximum ionic strength, the colloid threshold of $0.05 \mathrm{~mol} / \mathrm{L}$ has already been exceeded.

The relationship between ionic strength and flux becomes less linear with very high corrosion rates. The reason for this trend is that even with very high corrosion rates, the ionic strength at high fluxes is overwhelmed by the low ionic strength of the incoming water. If the runs had extended out to greater than 1,000 liters per year, the ionic strength for all of the cases would converge on the ionic strength of the incoming water. At lower fluxes, the ionic strength for the high corrosion rate case is not as high as would be expected because the higher concentrations in solution tend to cause minerals to precipitate. 


\subsection{Vapor Influx Abstraction}

Because of the similarities between the vapor influx runs and liquid influx runs (as shown in Figure 6-21), the ionic strength abstraction for the vapor-influx case should take the same form (base case $=$ mode; maximum corrosion rates $=$ maximum; minimum corrosion rates $=$ minimum) as the liquid-influx case. However, as described in Section 6.10.2.1.2, the maximum corrosion rate case consumes far more water than the average corrosion rate case, artificially driving up the ionic strength. Therefore, the average corrosion rate case is a more reasonable case to use for the ionic strength abstraction.

For the vapor-influx case, the flux is varied from 0.1 to $10 \mathrm{~L} / \mathrm{yr}$.

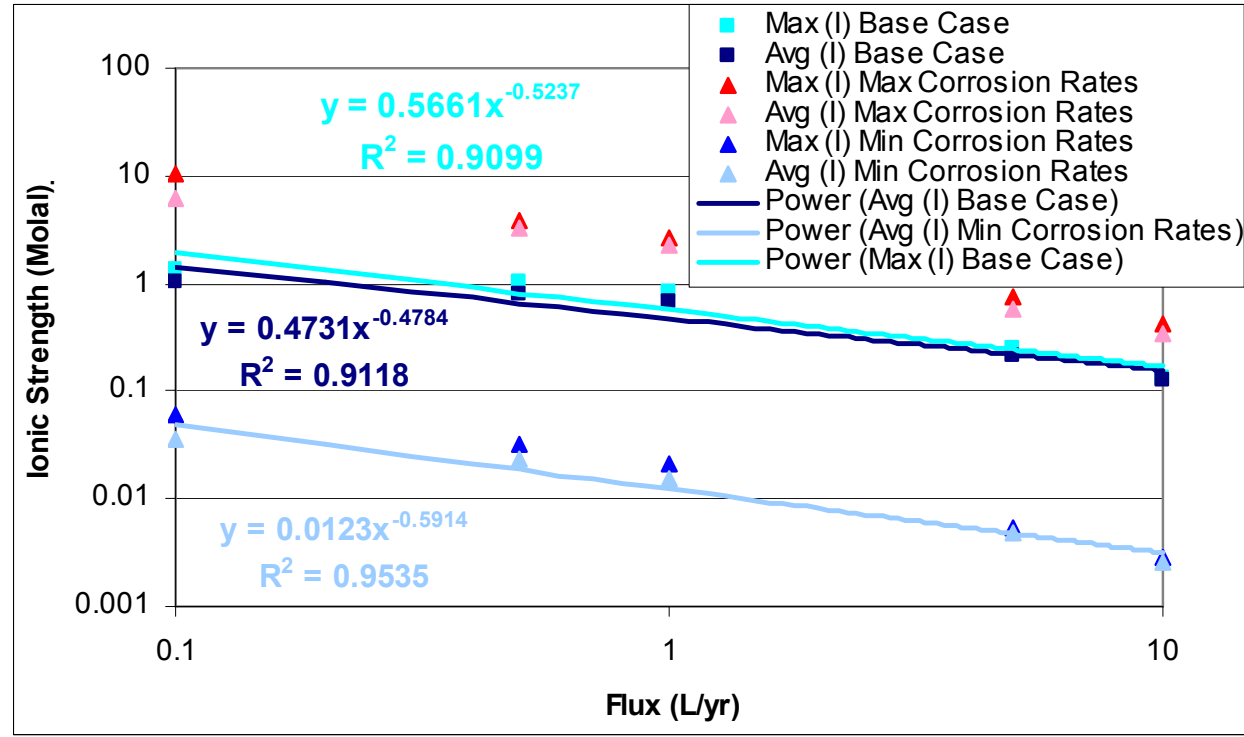

Source: (I) CDSP Vapor Influx Model Output.xls (Appendix F).

Figure 6-80. CDSP Vapor-Influx Model lonic Strengths as a Function of Flux

As with the CSNF vapor-influx case, the maximum ionic strength was determined from the maximum ionic strength value for the base case, unlike the liquid-influx model, that uses the maximum corrosion rate case. As shown for the CSNF liquid-influx case, the maximum corrosion rates consume more water than is available to react, and this effect is even more prominent for the vapor-influx case, as shown in (I) CDSP Vapor Influx Model Output.xls (Appendix F).

\subsubsection{Form of the Ionic Strength Abstractions}

The ionic strength abstractions are a function of the liquid or vapor influx, and take the following form:

where:

$$
y=e \cdot x^{f}
$$

$$
\mathrm{y}=\text { ionic strength (moles } / \mathrm{kg})
$$


$\mathrm{e}, \mathrm{f}=$ constants (specific to waste package type)

$\mathrm{x} \quad=$ liquid or vapor flux (L/yr)

The abstraction uses a Log Triangular Distribution:

and:

$$
\mathrm{y} \sim \log \operatorname{tri}\left(\mathrm{a}_{\min }, \mathrm{c}_{\text {mode }}, \mathrm{b}_{\max }\right)
$$

$$
\begin{gathered}
\mathrm{a}_{\text {min }}=\mathrm{e}_{\min } \cdot \mathrm{x}^{\mathrm{f}_{\text {min }}} \\
\mathrm{c}_{\text {mode }}=\mathrm{e}_{\text {mode }} \cdot \mathrm{x}^{\mathrm{f}_{\text {mode }}} \\
\mathrm{b}_{\text {max }}=\mathrm{e}_{\text {max }} \cdot \mathrm{x}^{\mathrm{f}_{\text {max }}}
\end{gathered}
$$

The e and $\mathrm{f}$ constants for each influx scenario and waste package type are provided in Figures 6-73, 6-76, 6-79, and 6-80.

If the liquid influx rate drops below the sampled vapor influx rate, the vapor-influx model should be used for that case.

For flow rates greater than 1,000 L/yr, the model should be used with a flow rate of 1,000 L/yr.

For the vapor-influx case, the vapor mass flow rate is similar for both the CSNF and CDSP waste packages because the conditions that control the vapor mass flow rate, temperature and $\mathrm{RH}$, are similar throughout the drift where the different waste packages are located. Differences in the CSNF waste package and CDSP waste package temperatures and relative humidities could cause a potential difference in the vapor flux rate because of the temperature dependence of the diffusion coefficient. This difference is expected to be insignificant considering that the sampled flux rate is applied for the entire realization in the TSPA-LA model and, therefore, does not account for reductions in the vapor diffusion rate as the repository cools and differences between CSNF and CDSP temperatures and relative humidities are much smaller. For this reason the same vapor flux rate applied in the CSNF waste package ionic strength abstraction can be applied to the CDSP waste package ionic strength abstraction. For the vapor-influx case, the ionic strength uncertainty is calculated once per realization, since the flux is only sampled once per realization.

For the liquid-influx case, the liquid mass flow rate is output from Abstraction of Drift Seepage (BSC 2004 [DIRS 169131]), and is different for each waste package type, because it is dependent on location within the drift, and is calculated with time-dependent variables. For the liquid-influx case, the ionic strength uncertainty is recalculated with each timestep, as a function of the flux, which is calculated with time-dependent variables. However, the random number sampled between 0 and 1 that TSPA-LA uses to sample between the minimum and maximum uncertainty is only sampled once per realization. So, if a given realization applies a high uncertainty (the random number is close to 1), the ionic strength uncertainty will remain high for that entire realization.

The uncertainty treatment of the ionic strength abstraction is broad in order to address the two intended uses of the ionic strength abstractions within TSPA-LA, determining colloids stability and the solubility of radionuclides. Low ionic strengths $(<0.05 \mathrm{~mol} / \mathrm{L})$ are conservative for 
TSPA-LA relative to colloid stability because colloids are stable and can transport radionuclides when the ionic strength is less than $0.05 \mathrm{~mol} / \mathrm{L}$ (BSC 2004 [DIRS 170025]). High ionic strengths ( $>1$ molal) are conservative for TSPA-LA relative to the dissolved concentrations of radionuclides because TSPA-LA increases the uncertainty applied to the Dissolved Concentration Limits of Radioactive Elements (BSC 2005 [DIRS 173873]), increasing the concentrations of radionuclides in solution.

\subsubsection{Significance of Quantity of water}

Using a bulk chemistry model to simulate thin films of water is appropriate, as justified in Section 5.1, but there are ramifications to doing so, particularly relating to modeling ionic strength (as shown in Section 6.6.1, the quantity of water in the EQ6 model has minimal impact on $\mathrm{pH})$. The vapor-influx cases are modeled such that water enters the waste package but does not flow out (to simulate the scenario where water vapor condenses and forms a film of water over the reactants with no advective flow), which is reasonable if the water is consumed by the corrosion processes at the same rate it enters, so there is no accumulation of water. The vapor diffusion into a waste package is calculated (in Section 6.4.3) based on the assumption that once the water enters the waste package, it is immediately consumed by corrosion products, thereby maintaining a strong driving force for more water vapor to diffuse into the waste package. In the EQ6 modeling however, due to the various materials with different degradation rates, and the difficulty in varying the incoming water (or vapor) flux rate within a given run, sometimes water does accumulate (referred to here as "code-induced water accumulation", where EQ6 calculates that the water influx rate is higher than the rate of consumption of water by corrosion products) or the opposite occurs, and the quantity of water decreases below the liter of water used as the basis for the EQ6 model (EQ6 is an aqueous model scaled to 1 liter of water).

When the ionic strength output from the vapor-influx cases is assessed, the total quantity of water is considered, and for cases where there is "code-induced water accumulation", the ionic strength values calculated after that point are discounted. These values are discounted for two reasons: first, the values will be artificially low because of the "code-induced water accumulation", and second, the model has started to model water vapor continuing to diffuse into the waste package and accumulate faster than it is consumed by corrosion, which is a nonphysical process for which there is no driving force. For the CSNF vapor-influx base case, the "code-induced water accumulation" begins at about 1,300 years (Appendix F, (I) Abstraction CSNF Vapor Influx.xls). For the corresponding CSNF liquid-influx case, the maximum ionic strength is not realized until about 2,000 years (Figure 6-9), which means that the ionic strength for the vapor base case does not reach the same maximum value as the corresponding liquid base case. However, the ionic strength abstraction for the vapor-influx case is higher than the abstraction for the liquid-influx case, because the vapor-influx case is based only on the ionic strength values between 0 yrs and 1,300 yrs, and does not include the lower ionic strengths that are modeled in the later years with "code-induced water accumulation."

The potential impact of cutting the results short is that the abstracted ionic strength for the vaporinflux case for a given flux is higher than for the corresponding liquid-influx case. However, this is justified because the lower ionic strengths that might occur at later times, due to the depletion of reactants that generate high ionic strengths, are not justified because the run can not sustain those high water fluxes (the water is not being consumed, therefore, there is no driving force for 
water to continue in at that rate). So, basing the ionic strength abstraction for a high vapor flux on early times is appropriate because those are the only times during which high water fluxes are possible (while the A516 and other components are degrading fast enough to consume the entire entering flux). For the ionic strength abstraction for lower flux cases, the runs continue out until 18,000 years for the $0.1 \mathrm{~L} / \mathrm{yr}$ flux, which shows that this flux is reasonable for the entire regulatory timeframe and the time-weighted averaged ionic strength includes that entire time frame.

For the CDSP vapor-influx base case (1 liter per year), "code-induced water accumulation" does not occur until 2,300 years (Appendix F, (I) Abstraction CDSP Vapor Influx.xls). Unlike the CSNF case, the maximum ionic strength for the liquid-influx case occurs around 1,000 years, well before the "code-induced water accumulation" in the vapor-influx case, so the abstracted ionic strength for the CDSP vapor-influx case captures the maximum ionic strength.

\subsubsection{Fluoride Abstractions}

The fluoride profiles for the CSNF liquid-influx model simulations are plotted in Figure 6-81. Other than the input seepage compositions, there are no other sources of fluorine in the CSNF waste package. The dip in fluoride concentration at about one year (Figure 6-81) is the result of fluorapatite precipitation with subsequent dissolution as the concentration recovers to approximately 1E-04 molal. This early fluoride minimum was not considered for the abstraction because the abstraction only applies a maximum value to the fluoride concentration. The maximum fluoride concentrations correspond to the cases with different porewater composition, which contain more fluoride than $\mathrm{J}-13$. It is possible that surface complexation reactions could decrease the effective fluoride concentration of the waste package solutions; however, the surface complexation model was not used to generate the fluoride abstraction. Not using the surface complexation model to moderate the fluoride concentrations is justified because higher fluoride concentrations are conservative to the downstream model (BSC 2005 [DIRS 173873]) that uses this output. 


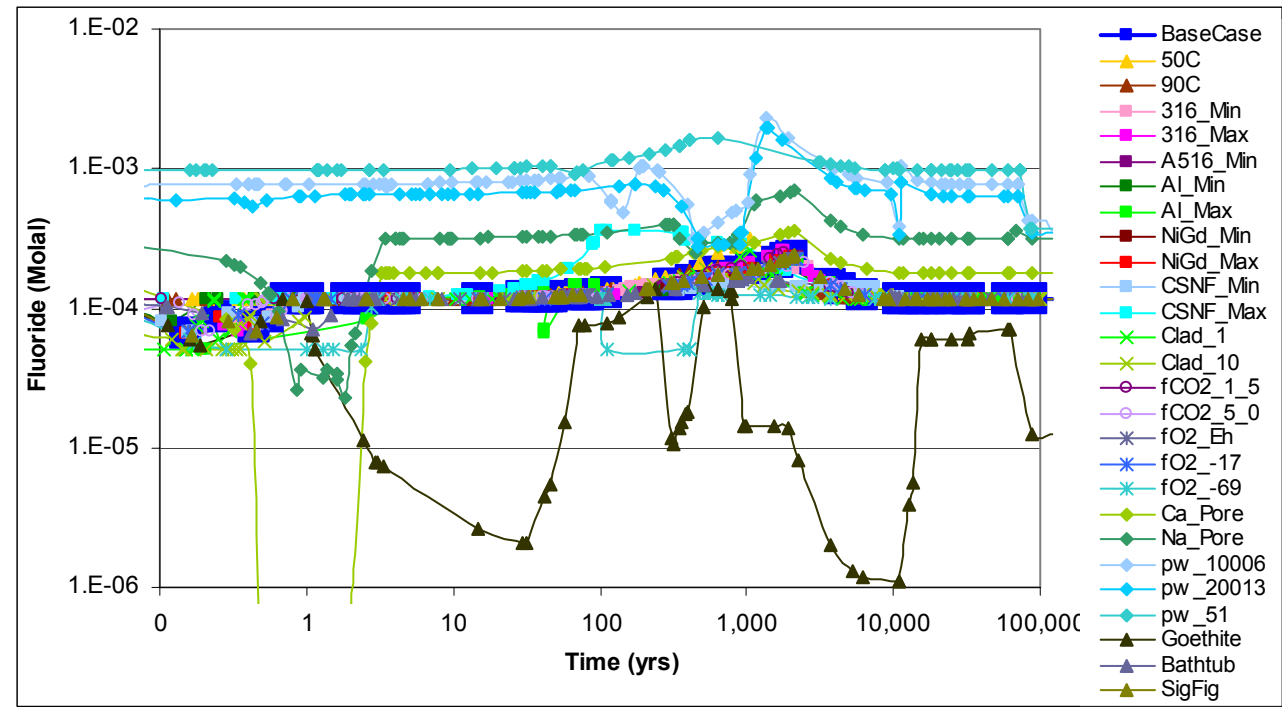

Source: CSNF Liquid Influx Model Output.xIs (Appendix F ISpreadsheets).

NOTE: $\quad$ Time refers to time after waste package breach ( 0 on the $x$-axis refers to 0.1 years).

Figure 6-81. CSNF Liquid-Influx Model Fluoride Profiles

To cover the maximum fluoride concentrations in the CSNF waste package, based on the values in Figure 6-81, the maximum fluoride concentration is set at 3E-03 molal. This value is greater than any of the values in Figure 6-81, so it is not necessary to apply an uncertainty value to the fluoride value.

Although there is no dissolved fluoride in the water vapor, the HLWG contains fluorine (Table 4-5); therefore, a fluoride abstraction is provided for the CDSP vapor-influx model.

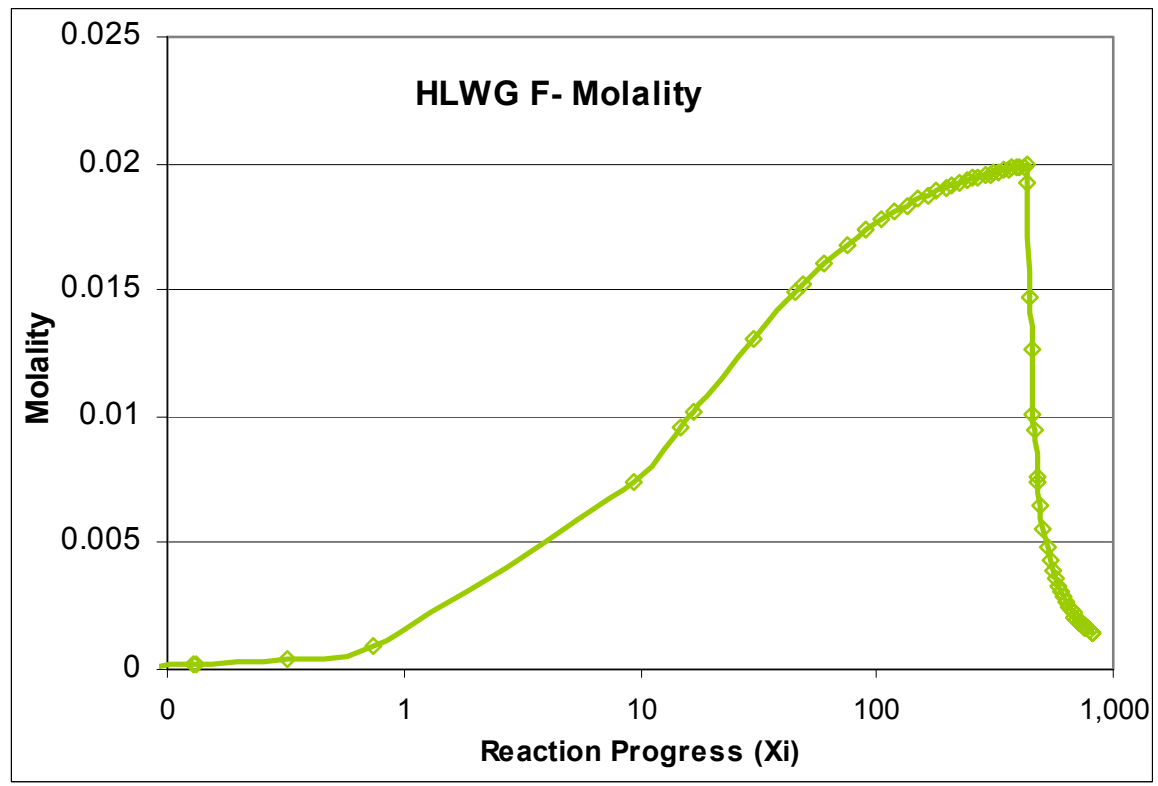

Source: $\quad C D S P$ Vapor Influx Model Output.xIs (Appendix F ISpreadsheets).

NOTE: 0 on the $\mathrm{x}$-axis refers to $0.1 \mathrm{Xi}$.

Figure 6-82. CDSP Vapor-Influx Model Fluoride Profiles 
The fluoride profile for the CDSP vapor-influx model simulation is plotted in Figure 6-82. In the vapor-influx model, the only source of the fluoride is in the glass, so the HLWG single component run is used for this abstraction. To cover the maximum fluoride concentrations in the CDSP waste package, based on the values in Figure 6-82, the maximum fluoride concentration is set at 2E-02 molal.

The CDSP liquid-influx model simulations are plotted in Figure 6-83. The variation in the fluoride concentration (Figure 6-83) is due to precipitation/dissolution reactions of minor fluoride bearing phases (fluorite and fluorapatite) at early times (note the dip in fluoride concentrations around 1 year), and the depletion of the HLWG at later times. It is possible that surface complexation reactions could decrease the effective fluoride concentration of the waste package solutions; therefore, the values provided should be considered maximums. The minimum fluoride spike at about 5 years was not included in the abstraction because of its short duration. Compared to CSNF fluoride profiles (Figure 6-81), CDSP fluoride profiles are much more complex because the $\mathrm{pH}$-dependent HLWG dissolution, of which fluoride is a component, controls aqueous fluoride concentration (Table 6-8). It is possible surface complexation reactions could decrease the effective fluoride concentration of the waste package solutions; therefore, the values provided should be considered maximums.

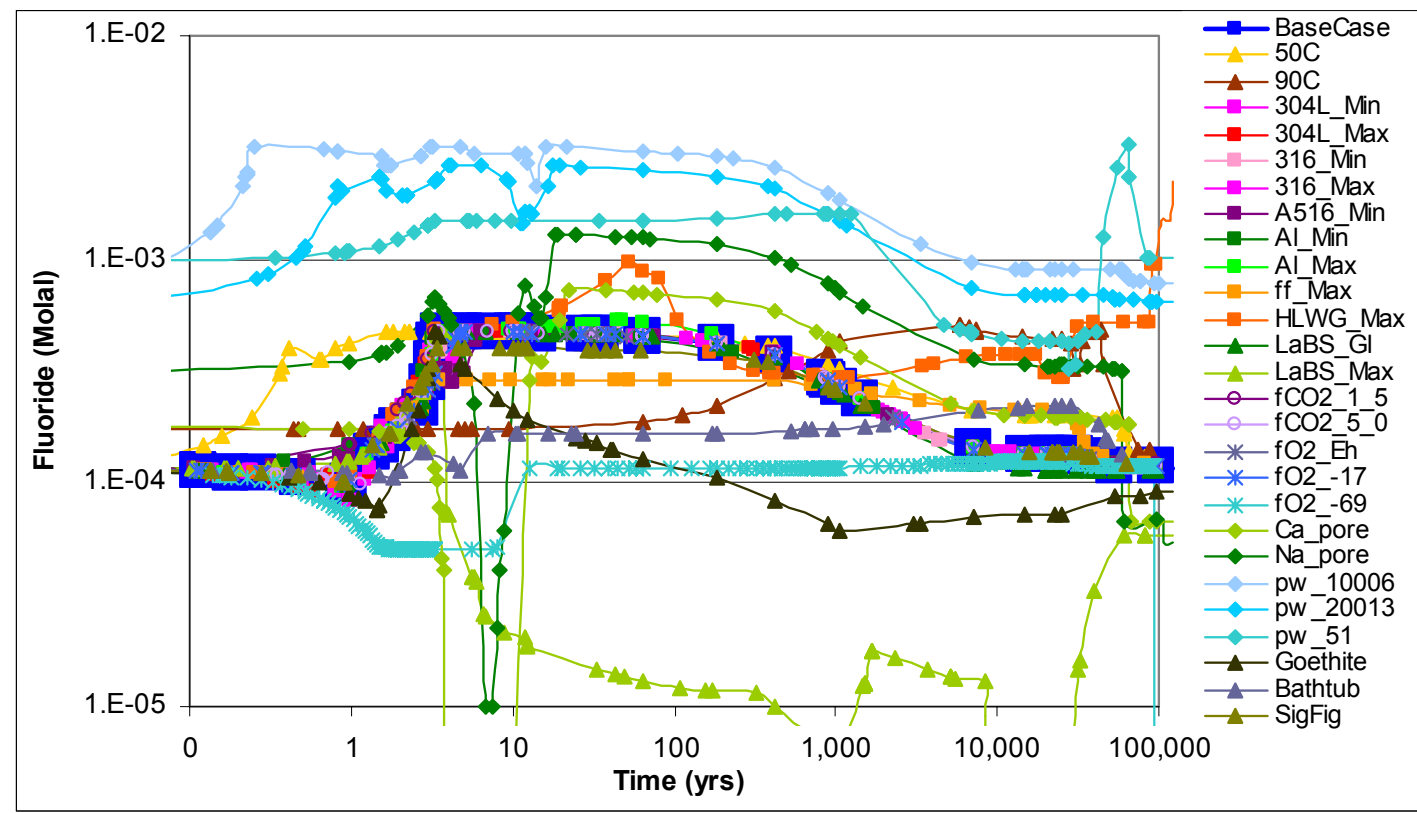

Source: CDSP Liquid Influx Model Output.xIs (Appendix F ISpreadsheets).

NOTE: $\quad$ Time refers to time after waste package breach ( 0 on the $x$-axis refers to 0.1 years).

Figure 6-83. CDSP Liquid-Influx Model Fluoride Profiles

To cover the maximum fluoride concentrations in the CDSP waste package, based on the values in Figure 6-83, the maximum fluoride concentration is set at 4E-03 molal. This value is greater than any value in Figure 6-83 therefore; it is not necessary to apply an uncertainty value to the fluoride value. 


\subsubsection{Chloride Abstractions}

Figure 6-84 shows the CSNF liquid-influx model chloride profiles. It is possible that surface complexation reactions could decrease the effective chloride concentration of the waste package solutions; therefore, the values provided should be considered maximums.

CDSP liquid-influx model chloride profiles are plotted in Figure 6-85. It is possible that surface complexation reactions could decrease the effective chloride concentration of the waste package solutions; therefore, the values provided should be considered maximums.

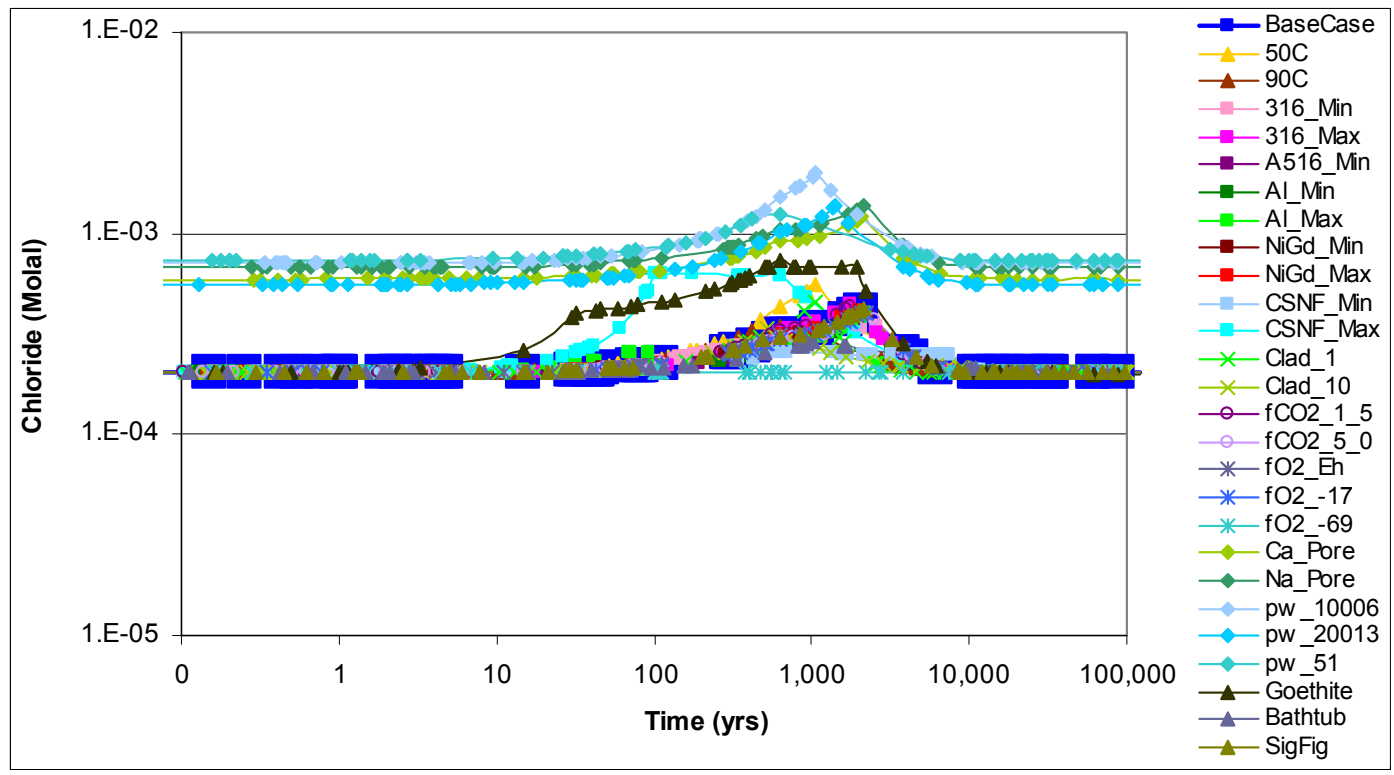

Source: CSNF Liquid Influx Model Output.xIs (Appendix F ISpreadsheets).

NOTE: $\quad$ Time refers to time after waste package breach ( 0 on the $x$-axis refers to 0.1 years).

Figure 6-84. CSNF Liquid-Influx Model Chloride Profiles

To cover the maximum chloride concentrations in the CSNF waste package, based on the values in Figure 6-84, the maximum chloride concentration is set at 3E-03 molal. This value is greater than any value in Figure 6-84 therefore; it is not necessary to apply an uncertainty value to the chloride value. 


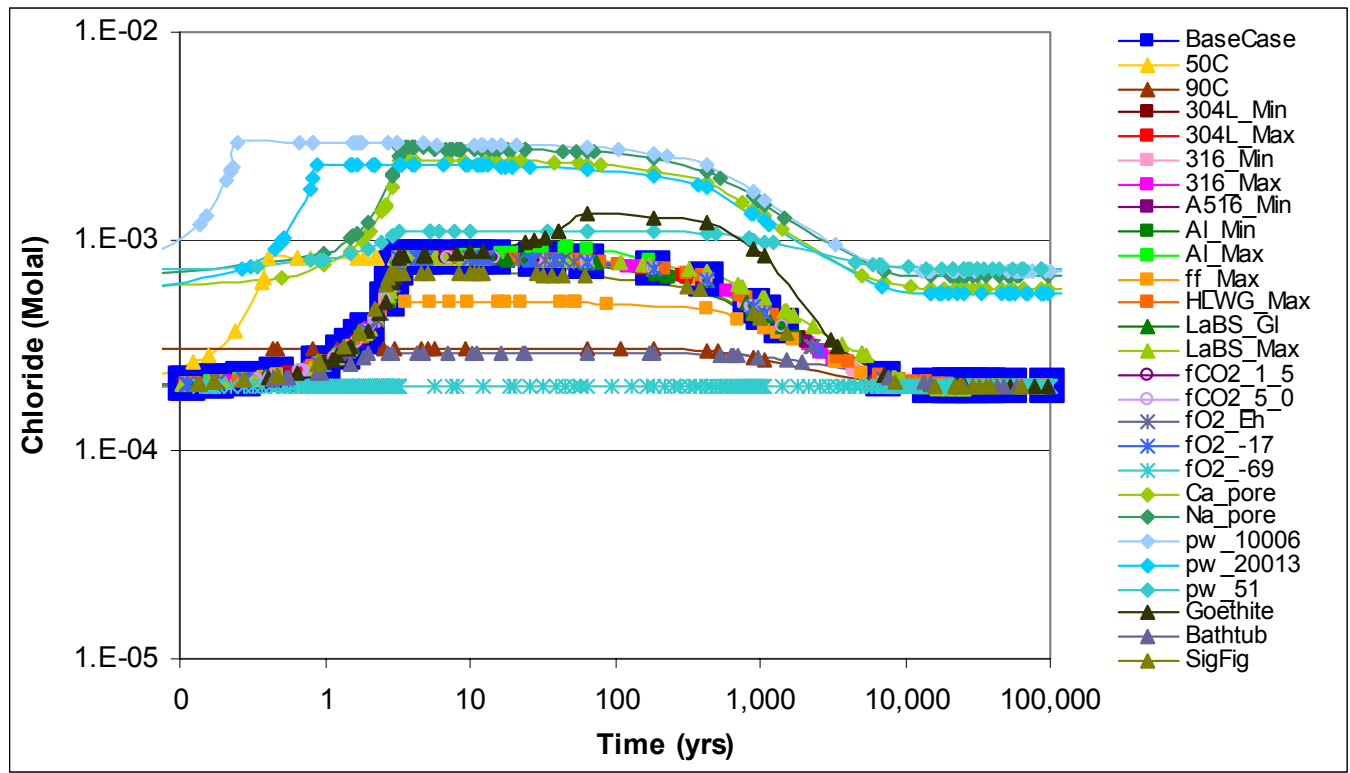

Source: CDSP Liquid Influx Model Output.xls (Appendix F ISpreadsheets).

NOTE: $\quad$ Time refers to time after waste package breach ( 0 on the $x$-axis refers to 0.1 years).

Figure 6-85. CDSP Liquid-Influx Model Chloride Profiles

To cover the maximum chloride concentrations in the CDSP waste package, based on the values in Figure 6-85, the maximum chloride concentration is set at 4E-03 molal. This value is greater than any value in Figure 6-85 therefore; it is not necessary to apply an uncertainty value to the chloride value.

\subsubsection{Total Carbonate Abstraction}

Total carbonate is used in the kinetic rate expression for the dissolution of CSNF; therefore, abstracted values are needed for the TSPA-LA. The bulk solution total carbonate concentration should not be effected by carbonate surface complex reactions because of the large reservoir of atmospheric carbon dioxide available will maintain equilibrium with the bulk solution. In a system where the partial pressure of carbon dioxide $\left(\mathrm{CO}_{2}\right)$ is constant over the modeled period and the $\mathrm{pH}$ and temperature known, the total carbonate can be calculated using the equilibrium mass action expressions.

Where the total carbonate $(0<\mathrm{pH}<14)$ is equal to:

$$
\begin{array}{lll} 
& \multicolumn{1}{c}{=\left[\mathrm{CO}_{2}(\mathrm{aq})\right]+\left[\mathrm{HCO}_{3}{ }^{-}\right]+\left[\mathrm{CO}_{3}{ }^{2-}\right]} \\
\mathrm{CO}_{2}(\mathrm{~g}) \Leftrightarrow \mathrm{CO}_{2}(\mathrm{aq}) & \log =k_{1} \quad\left[\mathrm{CO}_{2}(\mathrm{aq})\right]=\mathrm{PCO}_{2}(\mathrm{~g}) 10^{k_{1}} \\
\mathrm{CO}_{2}(\mathrm{aq}) \Leftrightarrow \mathrm{H}^{+}+\mathrm{HCO}_{3}^{-} \quad \operatorname{logK}=k_{2} \quad\left[\mathrm{HCO}_{3}^{-}\right]=\left(\mathrm{PCO}_{2}(\mathrm{~g}) 10^{k_{1}} 10^{k_{2}}\right) / 10^{-\mathrm{pH}} \\
\mathrm{HCO}_{3}{ }^{-} \Leftrightarrow \mathrm{H}^{+}+\mathrm{CO}_{3}{ }^{2-} & \operatorname{logK}=k_{3} \quad\left[\mathrm{CO}_{3}{ }^{2-}\right]=\left[\left(\mathrm{PCO}_{2}(\mathrm{~g}) 10^{k_{1}} 10^{k_{2}}\right) / 10^{-\mathrm{pH}}\right] 10^{k_{3}} / 10^{-\mathrm{pH}} \quad \text { (Eq. 6-29c) }
\end{array}
$$


Note : $\mathrm{PCO}_{2}$ is the partial pressure of $\mathrm{CO}_{2}$ (which is equivalent to $\mathrm{CCO}_{2}$ for the purposes of this report).

Combining terms and substituting back into expression (Eq. 6-29), the total carbonate for the system is equal to the expression in Table 6-22.

Table 6-22. Total Carbonate as a Function of $\mathrm{pH}$

\begin{tabular}{|c|c|}
\hline & $\begin{array}{l}\text { Equation of Total Carbonate } \\
(\mathrm{mol} / \mathrm{kg})\end{array}$ \\
\hline \multicolumn{2}{|c|}{ Total $\mathrm{C}=\mathrm{PCO}_{2}\left(10^{k_{1}}+10^{\left(\mathrm{pH}+k_{1}+k_{2}\right)}+10^{\left(2 \mathrm{pH}+k_{1}+k_{2}+k_{3}\right)}\right)$} \\
\hline Source: & Total Carbonate and Eh Abstractions.xls (Appendix F ISpreadsheets). \\
\hline NOTE: & $\begin{array}{l}k \text { is defined as } \operatorname{logK} \text {, and } \mathrm{PCO}_{2} \text { is the partial pressure of } \mathrm{CO}_{2} \text { (in } \\
\text { atmospheres). For the purposes of this report and ranges of this model } \\
\left(25^{\circ} \mathrm{C} \text { to } 100^{\circ} \mathrm{C} \text { and up to } 4 \mathrm{molal}^{\circ} \text { solutions), mol/L is considered }\right. \\
\text { equivalent to } \mathrm{mol} / \mathrm{kg} \text {, and } \mathrm{PCO}_{2} \text { is equivalent to } \mathrm{fCO}_{2} \text {. }\end{array}$ \\
\hline
\end{tabular}

Since the equilibrium constants for the carbonate species vary as a function of temperature, it is possible to derive expressions for $\mathrm{K}_{1}, \mathrm{~K}_{2}$, and $\mathrm{K}_{3}$ that include this functionality. The thermodynamic data from $0^{\circ} \mathrm{C}$ to $100^{\circ} \mathrm{C}$ for the carbonate species was extracted from data0.ymp.R4 (DTN: SN0410T0510404.002 [DIRS 172712]) and is compiled in Table 6-23. $\mathrm{K}_{1}$ (Table 6-23) is the result of combined expressions.

Table 6-23. Log K Values for the Carbonate Species at Temperature

\begin{tabular}{|c|c|c|c|c|c|}
\hline \multirow[b]{2}{*}{$\mathbf{K}$} & \multirow[b]{2}{*}{ Reaction } & \multicolumn{4}{|c|}{ Log $\mathrm{K}$ at Temperature } \\
\hline & & $0^{\circ} \mathrm{C}$ & $25^{\circ} \mathrm{C}$ & $60^{\circ} \mathrm{C}$ & $100^{\circ} \mathrm{C}$ \\
\hline $\mathrm{K}_{1}$ & $\begin{array}{l}\mathrm{CO}_{2}(\mathrm{~g})+\mathrm{H}_{2} \mathrm{O}=\mathrm{H}^{+}+\mathrm{HCO}_{3}^{-} \\
\underline{\mathrm{HCO}_{3}^{-}}{ }^{-}+\mathrm{H}^{+}=\mathrm{CO}_{2} \\
\mathrm{CO}_{2}(\mathrm{~g})=\mathrm{CO}_{2}(\mathrm{aq})+\mathrm{H}_{2}\end{array}$ & $\begin{array}{r}-7.6765 \\
+6.5804 \\
-1.0961\end{array}$ & $\begin{array}{r}-7.8136 \\
+6.3447 \\
-1.4689\end{array}$ & $\begin{array}{r}-8.0527 \\
+6.2684 \\
-1.7843\end{array}$ & $\begin{array}{r}-8.3574 \\
+6.3882 \\
-1.9692\end{array}$ \\
\hline $\mathrm{K}_{2}$ & $\mathrm{CO}_{2}(\mathrm{aq})+\mathrm{H}_{2} \mathrm{O}=\mathrm{HCO}_{3}^{-}+\mathrm{H}^{+}$ & -6.5804 & -6.3447 & -6.2684 & -6.3882 \\
\hline $\mathrm{K}_{3}$ & $\mathrm{HCO}_{3}^{-}=\mathrm{CO}_{3}{ }^{2-}+\mathrm{H}^{+}$ & -10.6241 & -10.3288 & -10.1304 & -10.0836 \\
\hline
\end{tabular}

Source: DTN: SN0410T0510404.002 [DIRS 172712]

Log $\mathrm{K}$ temperature expressions were derived by plotting the $\log \mathrm{K}$ values from $0^{\circ}$ to $100^{\circ} \mathrm{C}$ (Table 6-24) versus their respective temperatures and fitting a polynomial to the data in Microsoft Excel. This is the same method used by the EQPT code when it compiles the log K grid of an EQ3/6 data0 file (Daveler and Wolery 1992 [DIRS 103803], p. 12). Therefore, consistency is maintained between the approach used in the model report and that used in EQ3/6.

Plots of the $\log \mathrm{K}$ temperature interpolations are included in Total Carbonate and Eh Abstraction.xls (Appendix F $\backslash$ Spreadsheets). The expressions in Table 6-23 are valid for temperatures in the range of $0^{\circ} \mathrm{C}$ to $100^{\circ} \mathrm{C}$. This range is larger than that for the $\mathrm{pH}$ abstractions $\left(25^{\circ} \mathrm{C}\right.$ to $\left.100^{\circ} \mathrm{C}\right)$ in Section 6.10.1. 
Table 6-24. Log K Temperature Interpolation Functions for Total Carbonate Abstraction

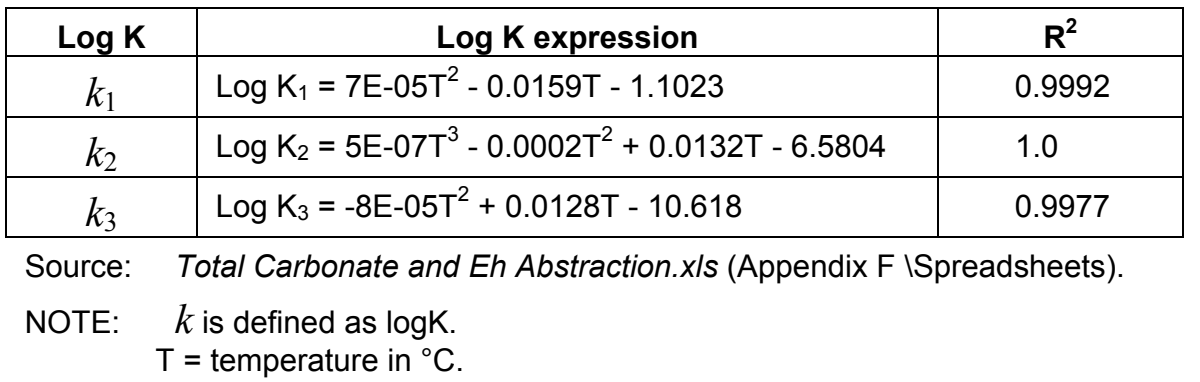

Three feeds are required for the total carbonate abstraction, as it should be implemented in TSPA-LA. The first feed is the temperature required to calculate the appropriate $\log \mathrm{K}$ values. The second feed is the in-package $\mathrm{pH}$ estimated using the relationships and conditions specified in Section 6.10.1. The third input is $\mathrm{PCO}_{2}$. Once the $\log \mathrm{K}$ values and in-package $\mathrm{pH}$ are calculated, they can be used to calculate the total carbonate via the expression in Table 6-22.

Since the $\mathrm{pH}$ abstractions account for uncertainty, there is no need to introduce further uncertainty at the level of the total carbonate abstraction. Therefore, the carbonate abstraction can be used as is with no uncertainty term added to it.

Figure 6-86 shows the carbonate abstraction calculated at three temperatures

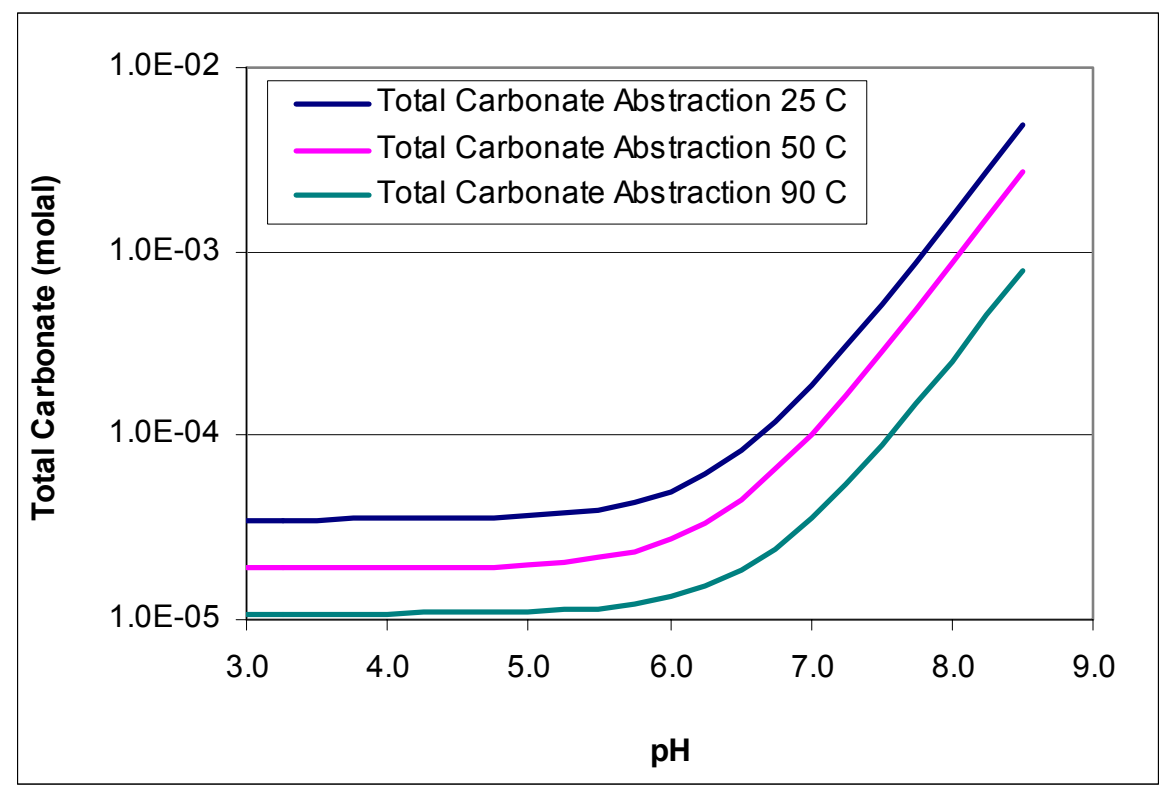

Source: $\quad$ Total Carbonate and Eh Abstraction.xls (Appendix F ISpreadsheets).

Note: $\quad \log \mathrm{fCO}_{2}=-3.0$

Figure 6-86. Total Carbonate Abstraction at Three Temperatures 


\subsubsection{Eh Abstraction}

In aqueous systems in equilibrium with a constant partial pressure of oxygen, the Eh may be calculated directly from the $\mathrm{pH}$. For the formation of water, the $\mathrm{pE}^{\circ}$ may be calculated from the following expression, where $\Delta \mathrm{G}^{\circ}$ is the Gibbs energy of formation, $\mathrm{F}$ is the Faraday constant (23.06 kcal/volt-gram equivalent), Eh is the electron activity expressed in units of volts, and $\mathrm{pE}$ is the negative log base 10 of electron activity.

$$
1 / 2 \mathrm{O}_{2}+2 \mathrm{H}^{+}+2 \mathrm{e}^{-}=\mathrm{H}_{2} \mathrm{O}
$$

$\Delta \mathrm{G}^{\circ}=-56.688 \mathrm{kcal} / \mathrm{mol}(\mathrm{DTN}: \mathrm{SN0410T0510404.002}$ [DIRS 172712])

$$
\Delta \mathrm{G}^{\circ}=-\mathrm{nFEh}^{\circ}
$$

(Drever 1982 [DIRS 100725], p. 254, Equation 11-6)

$$
\mathrm{pE}=\mathrm{F} /(2.303 \mathrm{RT}) \mathrm{Eh}
$$

(Drever 1982 [DIRS 100725], p. 254)

Solving Equation 6-32 for Eh and substituting into Equation 6-31 results in Equation 6-33, establishing a relationship between $\Delta \mathrm{G}^{\circ}$ and $\mathrm{pE}^{\circ}$ :

$$
\Delta \mathrm{G}^{\circ}=-2.303 n R T\left(\mathrm{pE}^{\circ}\right)
$$

Where, $\mathrm{n}=$ number of electrons [2], $\mathrm{R}=$ Gas Constant $(1.987 \mathrm{E}-03 \mathrm{kcal} / \mathrm{mol} \cdot \mathrm{K}), \mathrm{PO}_{2}$ is the partial pressure of oxygen (in atmospheres), and $\mathrm{T}=$ absolute temperature (Kelvin).

Solving for $\mathrm{pE}^{\circ}$ with temperature dependency results in:

$$
\mathrm{pE}^{\circ}=6193.973 / \mathrm{T}
$$

Thus, for the formation of water in terms of one electron mole:

$$
\begin{gathered}
1 / 4 \mathrm{O}_{2}+\mathrm{H}^{+}+\mathrm{e}^{-}=1 / 2 \mathrm{H}_{2} \mathrm{O} \\
\mathrm{pE}=\mathrm{pE}^{\circ}+\log \left(\mathrm{PO}_{2}{ }^{1 / 4}\left[\mathrm{H}^{+}\right]\right) \\
\mathrm{pE}=6,193.973 / \mathrm{T}-\mathrm{pH}+0.25 \log \left(\mathrm{PO}_{2}\right)
\end{gathered}
$$

Converting to Eh gives the expression in Table 6-25. The expression for Eh as a function of $\mathrm{pH}$, oxygen partial pressure, and temperature (Table 6-25) is applicable for both CSNF and CDSP waste packages. The temperature should be input in degrees Kelvin, and the output is in volts. 
Table 6-25. Eh as a Function of $\mathrm{pH}, \mathrm{PO}_{2}$, and Absolute Temperature

\begin{tabular}{|c|c|}
\hline \multicolumn{1}{c|}{$\begin{array}{c}\text { Equation of Eh } \\
\text { (volts) }\end{array}$} \\
\hline $\mathrm{Eh}=2.303 \mathrm{R} \mathrm{T} / \mathrm{F}\left(6193.973 / \mathrm{T}-\mathrm{pH}+0.25 \log \mathrm{PO}_{2}\right)$ \\
\hline Source: & $\begin{array}{l}\text { Total Carbonate and Eh Abstractions.x/s } \\
(\text { Appendix } \mathrm{F} \text { ISpreadsheets). } \\
\mathrm{PO}_{2} \text { is the partial pressure of } \mathrm{O}_{2} \text { (in atmospheres) }\end{array}$
\end{tabular}

Figure 6-87 shows the Eh abstraction function plotted. Again, fluids are expected to be uniformly oxidizing. Variations in Eh come from $\mathrm{pH}$ shifts. Like the carbonate abstraction, uncertainty is built into the Eh abstraction by virtue of the input $\mathrm{pH}$, which already has associated uncertainty.

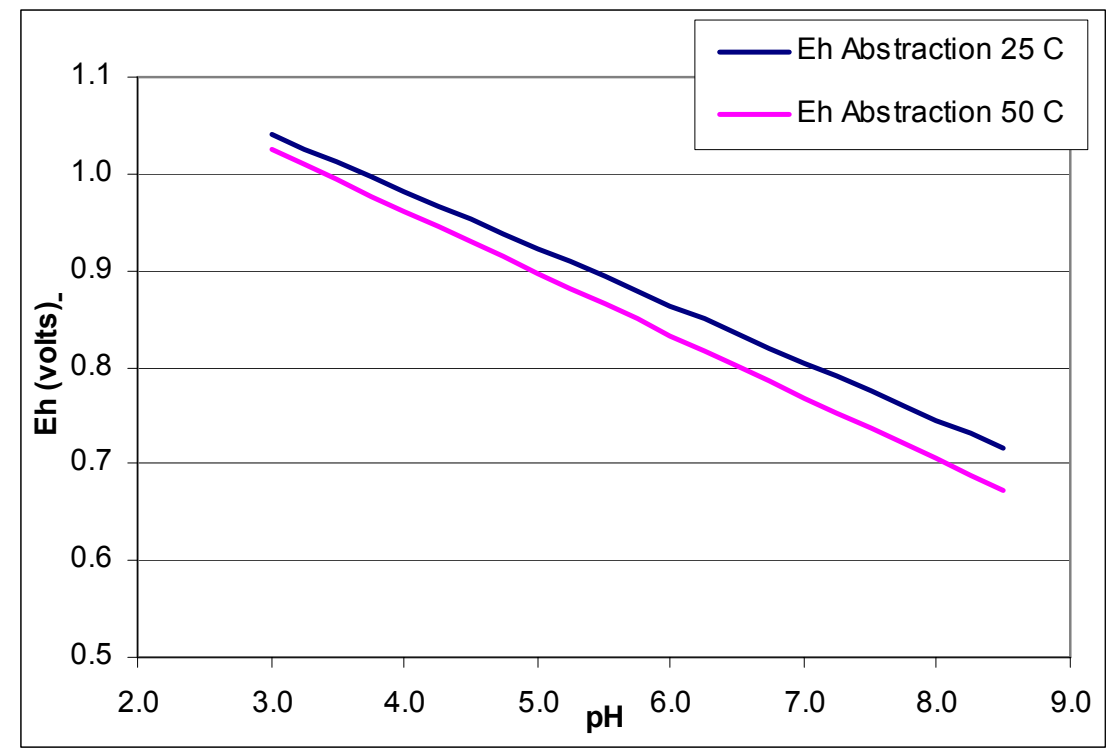

Source: $\quad$ Total Carbonate and Eh Abstraction.xls (Appendix F ISpreadsheets).

Figure 6-87. Eh Abstraction at Two Temperatures

\subsubsection{Linking the Vapor-Influx and Liquid-Influx Models for TSPA-LA}

In a potential repository situation, one could imagine a scenario where a waste package could be breached under vapor influx conditions, and then at some future time, it is possible that seepage might also enter this same waste package and react with the remaining materials. The opposite sequence might also occur, where seepage enters a waste package and at some future time, the seepage might cease and vapor influx conditions would prevail. This would be a scenario where the vapor-influx and the liquid-influx models would need to be linked. In Section 6.5.2, it was demonstrated that the initial composition of the seepage entering a breached waste package did not exert a significant influence on the resulting in-package chemistry. As Figures 6-20 and 6-21 demonstrate, the results of the liquid-influx model follow similar behavior as the ensemble outputs from the vapor-influx model. 
Based on the comparison of the results in Figure 6-20 and Figure 6-21, it is recommended that for the purposes of TSPA-LA, should it be necessary to link the vapor-influx model and the liquid-influx model, the change from one model to the other should occur synchronously. If a package is initially receiving water vapor and at some later time, seepage begins to enter the package, then the vapor influx abstraction should cease and the seepage abstraction should begin at that point in time.

\subsubsection{Output Uncertainty}

The in-package chemistry model combines two approaches to model uncertainty: (1) application of a factorial design approach to account for known large potential variations in model input (reactant combinations, water flux, fuel exposure, temperature, and seepage composition); and (2) sensitivity analysis of lesser known, not as well-defined input variations (carbon dioxide partial pressure, Carbon Steel Type A516 sulfur content, corrosion rates, and extreme temperatures and flux values). Where (1) provided the functional basis of the in-package chemistry model abstraction, (2) provided the uncertainty ranges of the abstracted parameters. Thus, the information to be used in TSPA-LA directly incorporates uncertainty exterior to the in-package environment (1) and interior to the in-package environment in a form that can be readily implemented in TSPA-LA (i.e., model uncertainty is propagated through the abstractions). Thus, the only restrictions on the subsequent use of the in-package chemistry model abstraction in TSPA-LA are that all of the abstractions presented in Section 6.10 must be applied within the stated limits (flux, temperature, $f \mathrm{CO}_{2}$, and fuel exposure) as specified in this report.

\subsubsection{Model Abstraction Conclusions}

The inputs to the batch reactor model are scaled according to their surface area, and the base case considers the waste package void space to be approximately half filled with water. The other half of the void space is filled with air in equilibrium with the drift atmosphere (Section 6.3.1). Sensitivity studies were conducted that varied the ratio of water to air (Section 6.6.1) and the composition of the air in contact with the water (Section 6.6.4). Therefore, the chemical effects of the void space (composition and quantity) have been investigated and incorporated into the model.

The batch reactor model generally considers the redox potential to be fully oxidizing, and this modeling assumption is discussed in Section 6.3.1.1. The redox potential is varied in a sensitivity analysis in Section 6.6 .4 by using lower fixed $f \mathrm{O}_{2}$ values, including the adjusted Eh model used in the Dissolved Concentration Limits of Radioactive Element model (BSC 2005 [DIRS 173873]), all the way down to $\log f \mathrm{O}_{2}=-69$. The sensitivity shows that the $\mathrm{pH}$ and ionic strength results are sensitive to the $\mathrm{OO}_{2}$ values, so the results of this sensitivity were used to develop the $\mathrm{pH}$ and ionic strength limits.

The batch reactor model generally allows reactions to reach thermodynamic equilibrium, and this modeling assumption is discussed in Section 6.3.1.1 and the most important species, chromium species, are examined in more detail in Section 6.6.3. This sensitivity examines the impact of allowing kinetics to control the oxidation state, allowing only $\mathrm{Cr}$ (III) species to form. The sensitivity shows that the ionic strength results are sensitive to the oxidation state of chromium. 
The sensitivity studies involving changes in design (Sections 6.6.7, 6.6.8, 6.6.9, and Appendix A) show that minor changes to the waste package or waste form design will not impact the results of this model. This conclusion applies to the design changes that call for the replacement of Neutronit with a NiGd alloy, or the addition of a purge port.

The above discussion addresses the subject matter of "Included" FEPs 2.1.01.02.0B (Interactions between co-disposed waste), 2.1.02.09.0A (Chemical effects of void space in waste package), 2.1.09.01.0B (Chemical characteristics of water in waste package), 2.1.09.06.0A (Reduction-oxidation potential in waste package), 2.1.09.07.0A (Reaction kinetics in waste package), 2.1.09.02.0A (Chemical interaction with corrosion products), 2.1.11.08.0A (Thermal effects on chemistry and microbial activity in the EBS), and 2.2.08.12.0B (Chemistry of water flowing into the waste package) and indicates how that subject matter has been included and addressed within TSPA-LA. 


\section{VALIDATION}

The purpose of the in-package chemistry model and the in-package chemistry model abstraction is to predict the bulk chemistry inside of a breached waste package and to provide simplified expressions of that chemistry for use in TSPA-LA. The in-package chemistry model is made up of two main models: the batch reactor model, and the surface complexation model. The batch reactor model is made up of two water-influx models, the liquid-influx and the vapor-influx models, and several other component submodels, including the fuel-degradation and the steeldegradation submodels. Based on these models, several output model abstractions were generated in Section 6.10, including: the total carbonate, fluoride, chloride, and Eh models. The technical work plan (BSC 2005 [DIRS 173246], Table 2-3) states that the postdevelopment validation of the model will focus on the three submodels. The fuel-degradation submodel will be validated by comparison with results from laboratory experiments published in refereed journals or literature. The types of minerals formed and the aqueous concentrations predicted by the model will be compared to experimental results to quantify the uncertainty range of the model. The steel-degradation submodel will be validated based on results published from laboratory experiments on man-made analog materials. The surface complexation model will be validated by technical review. The technical work plan (BSC 2005 [DIRS 173246]) does not contain validation criteria for three additional model outputs, so this model deviates from the technical work plan by providing these criteria in Table $7-1$.

Typical validation efforts outlined in the technical work plan and cited above were subsequently considered to provide insufficient confidence for predicting in-package chemistry over the much longer time spans to which the model is to be applied. Consequently, in addition to the validation methods outlined in the technical work plan, model validation efforts focused on natural analogue observation that might provide confidence in model predictions over near geologic time spans.

The primary outputs of the in-package chemistry model abstraction to total system performance assessment are ranges of $\mathrm{pH}$ and ionic strength. Adequate validation of the in-package chemistry model, therefore, entails showing on the basis of natural analogue evidence that the $\mathrm{pH}$ and ionic strength ranges are comparable.

The salient critical features of the in-package chemistry model are:

1. Alkaline waters ( $\mathrm{pH}>7$, HLWG from Figure 6-22) formed by interaction of dilute solutions with waste form glass dissolution

2. Acidic waters ( $\mathrm{pH}<7$, Figure 6-17 and Figure 22) formed by interaction of incoming solutions with certain waste package components

3. Production of high ionic strength solutions (greater than $1 \mathrm{M}$ ) and low ionic strength solutions (less than $0.05 \mathrm{M}$ ) by reaction with waste form and waste package components (Section 6.10.2)

4. Buffering to intermediate $\mathrm{pH}$ values via interaction of fluids with corrosion products, (i.e., surface complexation) (Table 6-18). 


\subsection{DOCUMENTED DECISIONS AND ACTIVITIES IMPLEMENTED DURING MODEL DEVELOPMENT PROCESS}

The technical work plan (BSC 2005 [DIRS 173246], Table 2-3) indicates that the in-package chemistry model requires a medium level of confidence (Level II) because of the impact of $\mathrm{pH}$, one of the main outputs of the in-package chemistry model, on plutonium and neptunium solubility.

Achieving Level I criteria requires a single postdevelopment model validation method. Achieving Level II criteria requires satisfying Level I criteria and providing rationale for the selection of that postdevelopment model validation method.

Satisfying Level I criteria entails demonstrating that the model development efforts include:

(a) Evaluating and selecting input parameters and data: Section 4.1 provides the inputs used in the in-package chemistry model, which include waste package design information, material compositions, atomic weights, densities, water compositions, waste form compositions, corrosion or reaction rates, and thermodynamic data. These inputs were chosen to best represent all of the components of the in-package chemistry model. Therefore, this criterion has been met for all of the salient features.

(b) Formulating defensible assumptions and simplifications: Sections 5, 6.3.1, and 6.3.2 provide the assumptions (Section 5) and simplifications (Sections 6.3.1 and 6.3.2) used in the in-package chemistry model. All model assumptions and simplifications have been shown to be either conservative or captured within the uncertainty of the model. Therefore, this criterion has been met for all of the salient features of the model.

(c) Ensuring consistency with physical principles, such as conservation of mass, energy, and momentum: Sections 6.3, 6.3.1, and 6.3.2 provide brief discussions of the EQ6 geochemical modeling software used for the in-package chemistry model simulations. EQ6 conserves mass, both of solids and water; therefore, the in-package chemistry model also conserves these properties. This criterion has been met for all of the salient features.

(d) Representing important future state (aleatoric), parameter, and alternative model uncertainties: Unexpected random (aleatoric) events are outside of the realm of the in-package chemistry model. However, the in-package chemistry model was designed to be robust enough to handle large changes in temperature, flux, and seepage composition. Alternative conceptual models were discussed in Section 6.4 and the current in-package chemistry model robustness eliminates the need for these alternative conceptual models. Therefore, this criterion has been met for all of the salient features.

(e) Ensuring simulation conditions have been set up to span the range of intended use and the avoidance of inconsistent outputs: Sections 6.3.1 and 6.3.2 outline the wide range of inputs (flux, fuel exposure, temperature, reactant combinations) that were used in the in-package chemistry model. These conditions span the range of intended use in TSPA-LA for which the in-package chemistry model will be used. Therefore, this criterion has been met for all of the salient features. 
(f) Ensuring that model predictions (performance parameters) adequately represent the range of possible outcomes, consistent with important uncertainties: Sections 6.3.1 and 6.3.2 provide the input conditions that span the range of the intended use of the model; thus, logic dictates that the range of outputs (performance parameters) also represents the range of possible outcomes. Additionally, sensitivity analyses have been performed to expand the performance parameters to values consistent with important conditional uncertainties. Therefore, this criterion has been met for all of the salient features.

\subsection{POST-MODEL DEVELOPMENT VALIDATION METHODS}

Level II validation includes one method of postmodel development validation consistent with a model of moderate importance to mean annual dose and documentation of the rationale for selection of postmodel development activities.

\subsection{RATIONALE FOR SELECTION OF VALIDATION METHODS}

The technical work plan (BSC 2005 [DIRS 173246], Table 2-3) names three methods for validation, different methods for different aspects of the model report, and these methods are listed in Table 7-1. This model deviated from the TWP (BSC 2005 [DIRS 173246]) for the validation of the fluoride, chloride, Eh and total carbonate model. The TWP does not list any validation criteria for these models, so new validation criteria are provided for them in Table 7-1.

Table 7-1. Validation Criteria, Activities, and Metrics

\begin{tabular}{|c|c|}
\hline Validation Criteria / Activities & Metric / Criteria \\
\hline $\begin{array}{l}\text { Is the fuel-degradation model consistent with results from laboratory } \\
\text { experiments published in refereed journals or literature? (VA } 1,3)\end{array}$ & \multirow{4}{*}{$\begin{array}{l}\text { The criteria for meeting all of the } \\
\text { corroborating validation activities will be } \\
\text { qualitative }\end{array}$} \\
\hline $\begin{array}{l}\text { Are the types of minerals formed and the aqueous concentrations } \\
\text { predicted by the model consistent with experimental results? (VA 1) }\end{array}$ & \\
\hline $\begin{array}{l}\text { Is the steel-degradation model consistent with results from laboratory } \\
\text { experiments on man-made analog materials? (VA 1) }\end{array}$ & \\
\hline $\begin{array}{l}\text { Because the output will be applied over geologic time spans, are the } \\
\text { specific outputs of this model (pH, ionic strength) consistent with natural } \\
\text { analogue observation (rather than experimental)? (VA 3) }\end{array}$ & \\
\hline $\begin{array}{l}\text { The surface-complexation portion of the model will be validated by } \\
\text { independent technical review, and this review will address the following } \\
\text { two points: (VA 5) } \\
\text { - Is the surface complexation modeling approach technically } \\
\text { correct? } \\
\text { - Does it adequately capture the likely processes in the degraded } \\
\text { waste form and in the waste package internal components? }\end{array}$ & $\begin{array}{l}\text { Independent technical review: } \\
\text { assessment of the validation activities will } \\
\text { be qualitative, and considered successful } \\
\text { if deemed defendable by the reviewer }\end{array}$ \\
\hline Is the fluoride model output consistent with experimental data? (VA 1) & \multirow{3}{*}{$\begin{array}{l}\text { The criteria for meeting all of the } \\
\text { corroborating validation activities will be } \\
\text { qualitative, and considered successful if } \\
\text { the model is consistent with and / or } \\
\text { bounds the corroborating data }\end{array}$} \\
\hline $\begin{array}{l}\text { Is the total carbonate model output consistent with published literature? } \\
\text { (VA 3) }\end{array}$ & \\
\hline Is the Eh model output consistent with experimental data? (VA 1) & \\
\hline
\end{tabular}

NOTE: $\quad$ VA is validation activity as defined in LP-SIII.2Q-BSC, Section 5.3.

For the fuel-degradation and the steel-degradation portion of the model, the results were compared to experimental data from laboratories because the laboratory experiments were 
conducted in various environments intended to capture the possible range of conditions anticipated to exist in the repository.

Comparison of the existing data with information about either natural or man-made analogs was determined to be the most appropriate method to validate the model results regarding the types of minerals that are anticipated to form in the waste package prior to and following any postulated breaches. This selection was based on the conclusion that data regarding the long-term environmental performance (i.e., 10,000 or more years) addressed by the model would be difficult to duplicate in the laboratory and the use of analogs presented the best opportunity to provide a meaningful comparison with the model outputs of interest (i.e., $\mathrm{pH}$, ionic strength data) that are developed and discussed in Section 6.10.

The validation of the surface complexation model introduces additional challenges due to the relatively new analytical approach to buffering $\mathrm{pH}$ that is used in the model. The surface complexation model is based in large part on the most readily available experimental data regarding this subject, and the limited, if any, availability of information regarding the surface complexation of natural or man-made analogs. As a result, the use of an independent technical review by an individual with appropriate expertise was deemed to be the most appropriate method of validation for the surface complexation model. Dr. Yifeng Wang, Principal Member of Technical Staff, Sandia National Laboratories, a recognized expert in the field of geochemistry, with a Ph.D. from the Dept. of Geological Sciences, Indiana University, was selected to review and report on the model developed herein. Dr. Wang's independent review was conducted in accordance with the requirements of Technical Work Plan for Postclosure Waste Form Modeling (BSC 2005 [DIRS 173246]) and the results are reported in Appendix E.

For the fluoride, chloride, Eh and total carbonate portions of the model, the results were compared to experimental data from laboratories because the laboratory experiments were conducted in various environments intended to capture the possible range of conditions anticipated to exist in the repository.

\section{4 pH AND IONIC STRENGTH VALIDATION}

\subsubsection{Abstraction Validation}

This abstraction model uses mathematical relationships and statistical distributions to fit product output (i.e., product output is used as input for the abstraction). Thus, product output was used to generate the abstraction model (i.e., to generate the mathematical relationships and statistical distributions that will be used in TSPA-LA). Therefore, the acceptance criterion, for the abstraction relationships, is that they reflect the product output used in their generation. In other words, validation of the abstraction model requires comparison of abstracted parameter values to their corollary product output parameter values. It must be emphasized that this does not constitute validation of the product output, but only that the abstraction can reproduce a subset of the process model output through the use of mathematical relationships.

The abstracted $\mathrm{pH}$ is plotted with the model output for the CSNF waste package in Figure 7-1, which shows that the model abstraction accurately captures the model behavior. Note that the $\mathrm{pH}$ extends outside the abstracted range between 0-600 years, because the effects of surface complexation are not included in the batch reactor results. 
The abstracted $\mathrm{pH}$ is plotted with the model output for the CDSP waste package in Figure 7-2. Figure 7-2 shows that the model abstraction accurately captures the model behavior. Note that the $\mathrm{pH}$ extends above the abstracted range between 0-10 years, because of the incoming water composition, but this effect is quickly overwhelmed by the corrosion of the waste package internals. Because TSPA-LA samples a $\mathrm{pH}$ value once per simulation, it would not be appropriate to allow a transient $\mathrm{pH}$ value (the high $\mathrm{pH}$ values lasting less than 1 year) to be sampled. The $\mathrm{pH}$ also extends above the abstracted range, but this occurs well past the 10,000-year regulatory period. Also, for high flux cases, the abstracted $\mathrm{pH}$ maximum extends up to 8.5 .

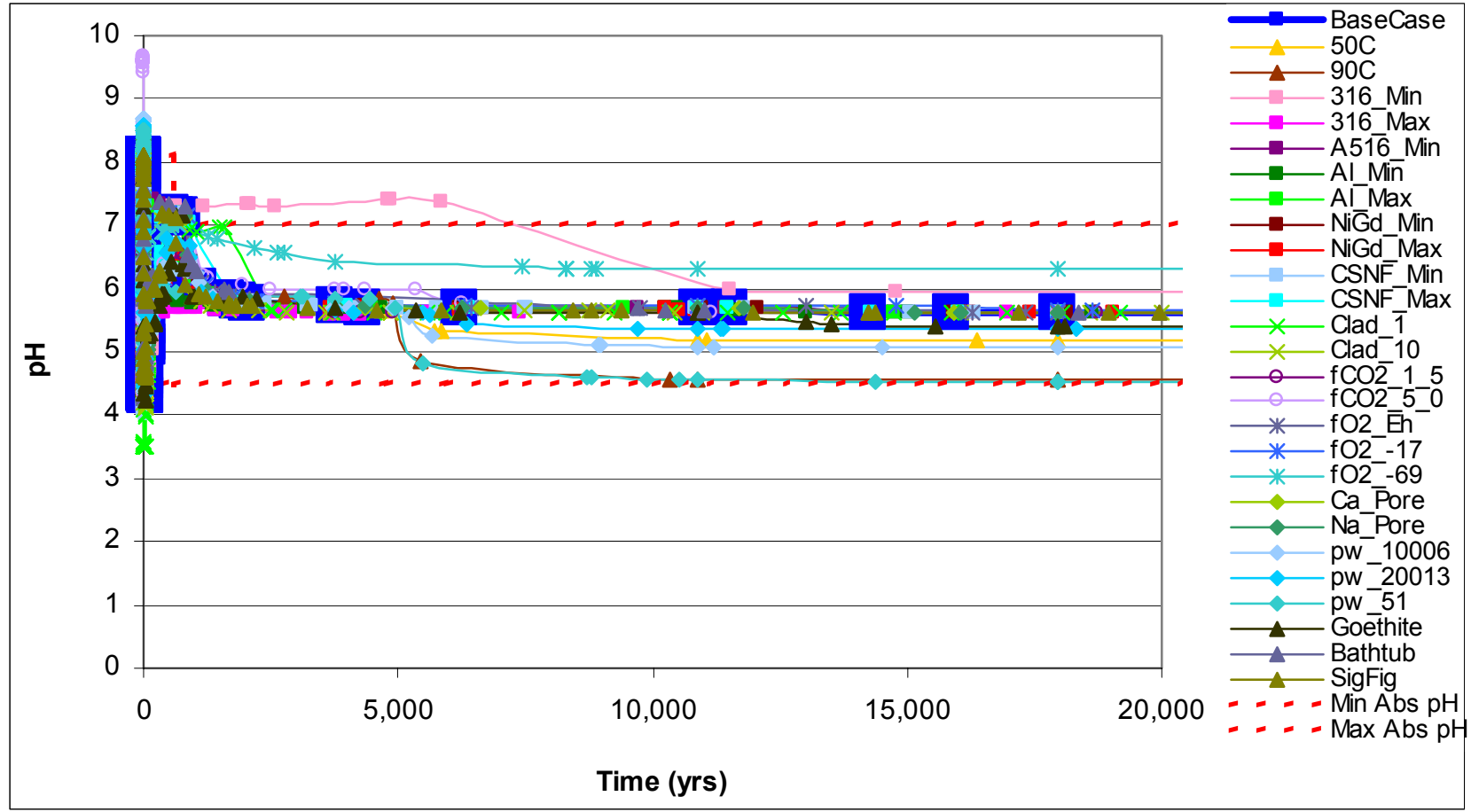

Source: $\quad$ CSNF Liquid Influx Model Output.xIs (Appendix F ISpreadsheets).

Note: $\quad$ Time refers to time after waste package breach ( 0 on the $x$-axis refers to 0.1 years). The maximum rate for the A516 is the same as the mean rate.

Figure 7-1. CSNF pH Abstraction Compared to Model Output 


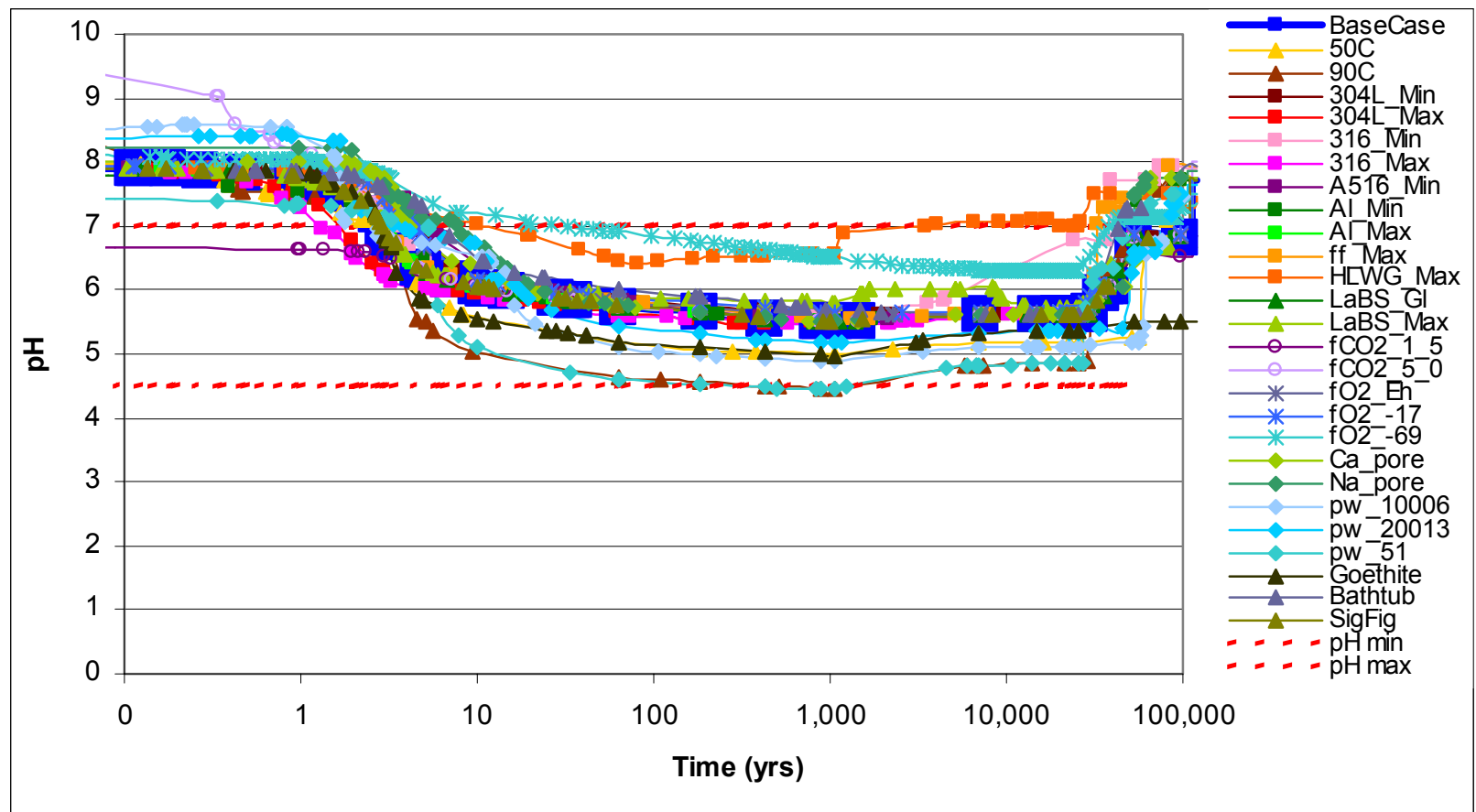

Source: $\quad$ CDSP Liquid Influx Model Output.xls (Appendix F ISpreadsheets).

Note: $\quad$ Time refers to time after waste package breach ( 0 on the $x$-axis refers to 0.1 years). The maximum rate for the A516 is the same as the mean rate.

Figure 7-2. CDSP pH Abstraction Compared to Model Output

Comparisons of the model abstraction to the model output for the high flux $\mathrm{pH}$ abstractions are shown in the following figures.

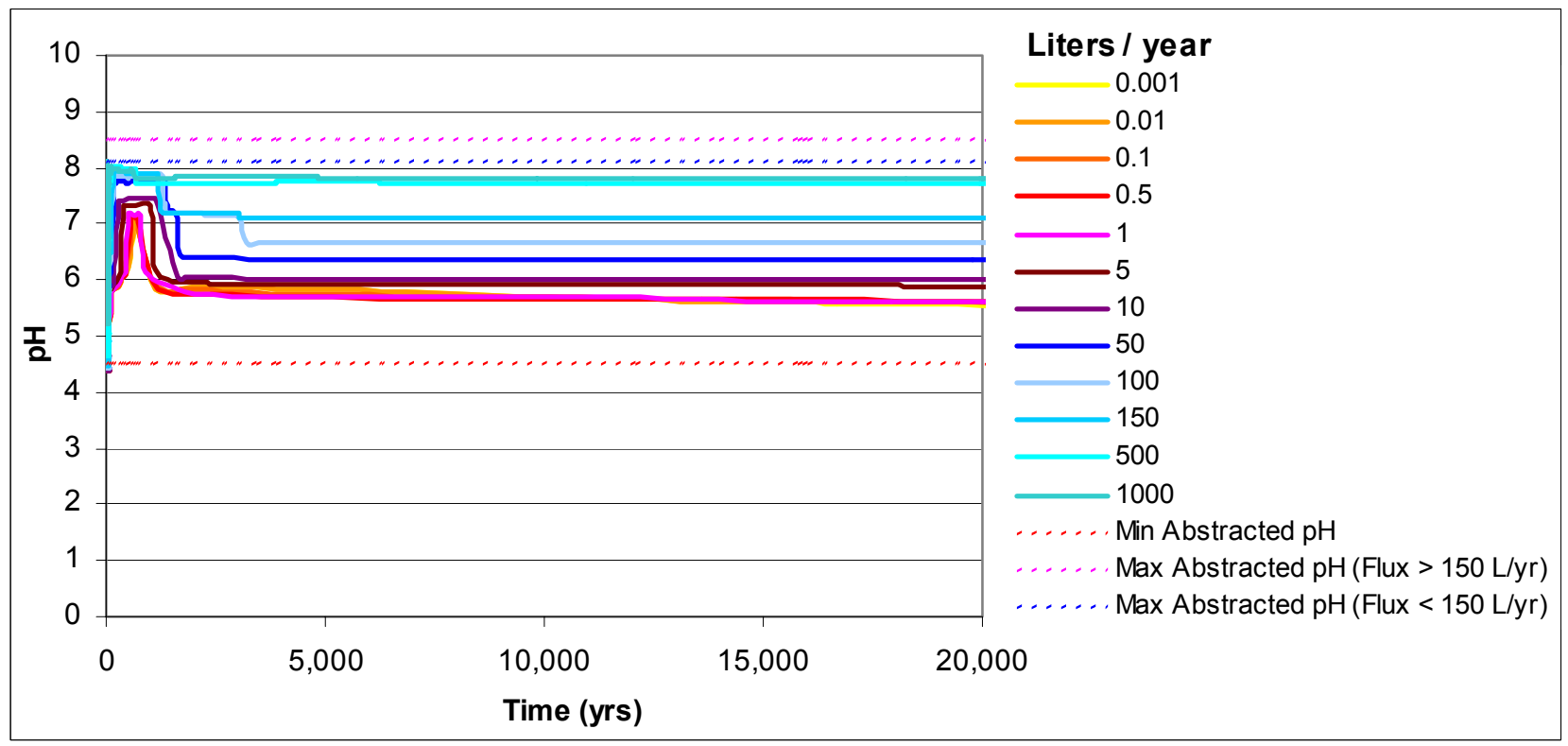

Source: (I) Abstraction CSNF Liquid Influx.xIs (Appendix F ISpreadsheets).

NOTE: $\quad$ Time refers to time after waste package breach ( 0 on the $x$-axis refers to 0.1 years).

Figure 7-3. CSNF pH Abstraction for High Flux Compared to Model Output 


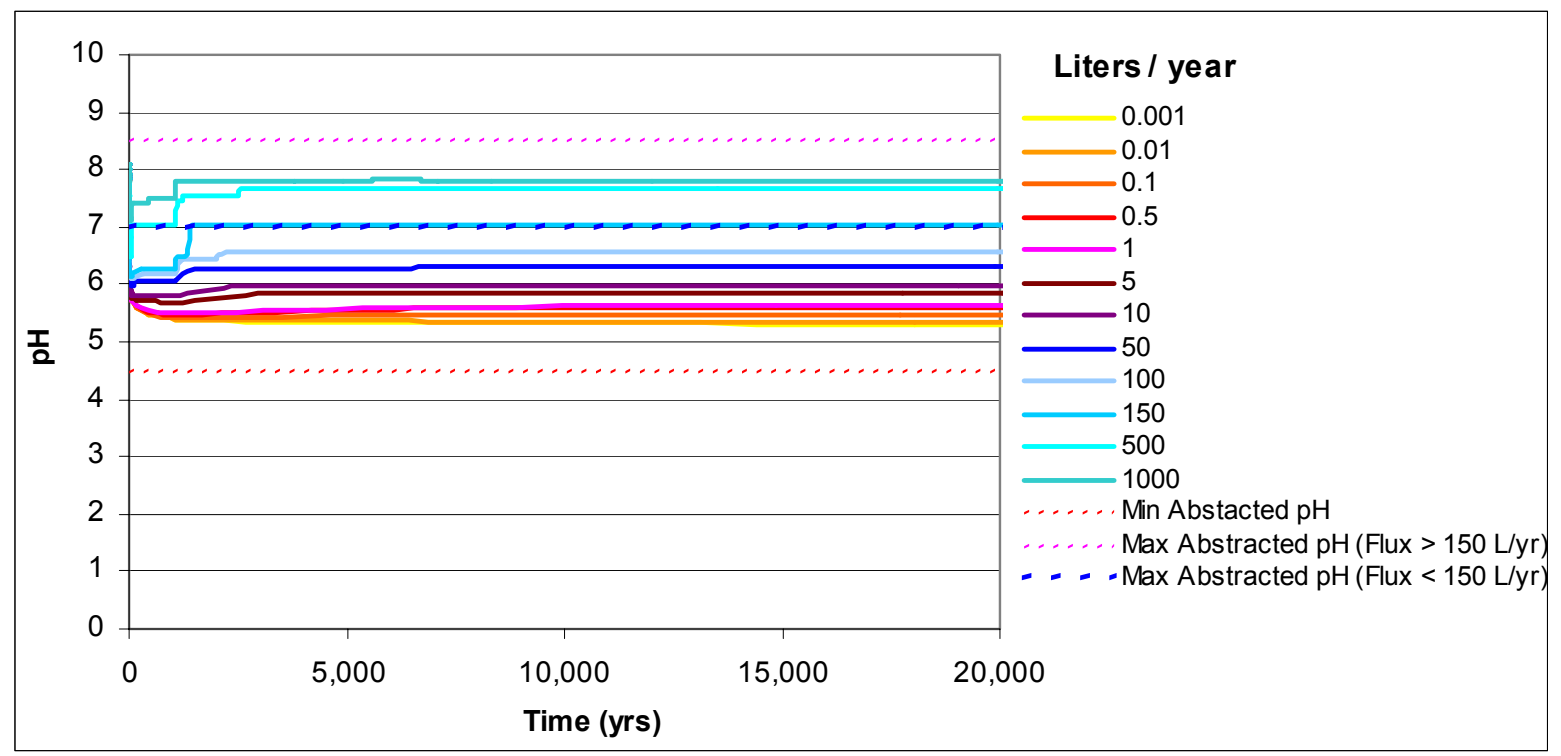

Source: (I) Abstraction CDSP Liquid Influx.xIs (Appendix F ISpreadsheets).

NOTE: $\quad$ Time refers to time after waste package breach ( 0 on the $x$-axis refers to 0.1 years).

Figure 7-4. CDSP pH Abstraction for High Flux Compared to Model Output

Comparisons of the model abstraction to the model output for the ionic strength abstractions are shown in the following figures.

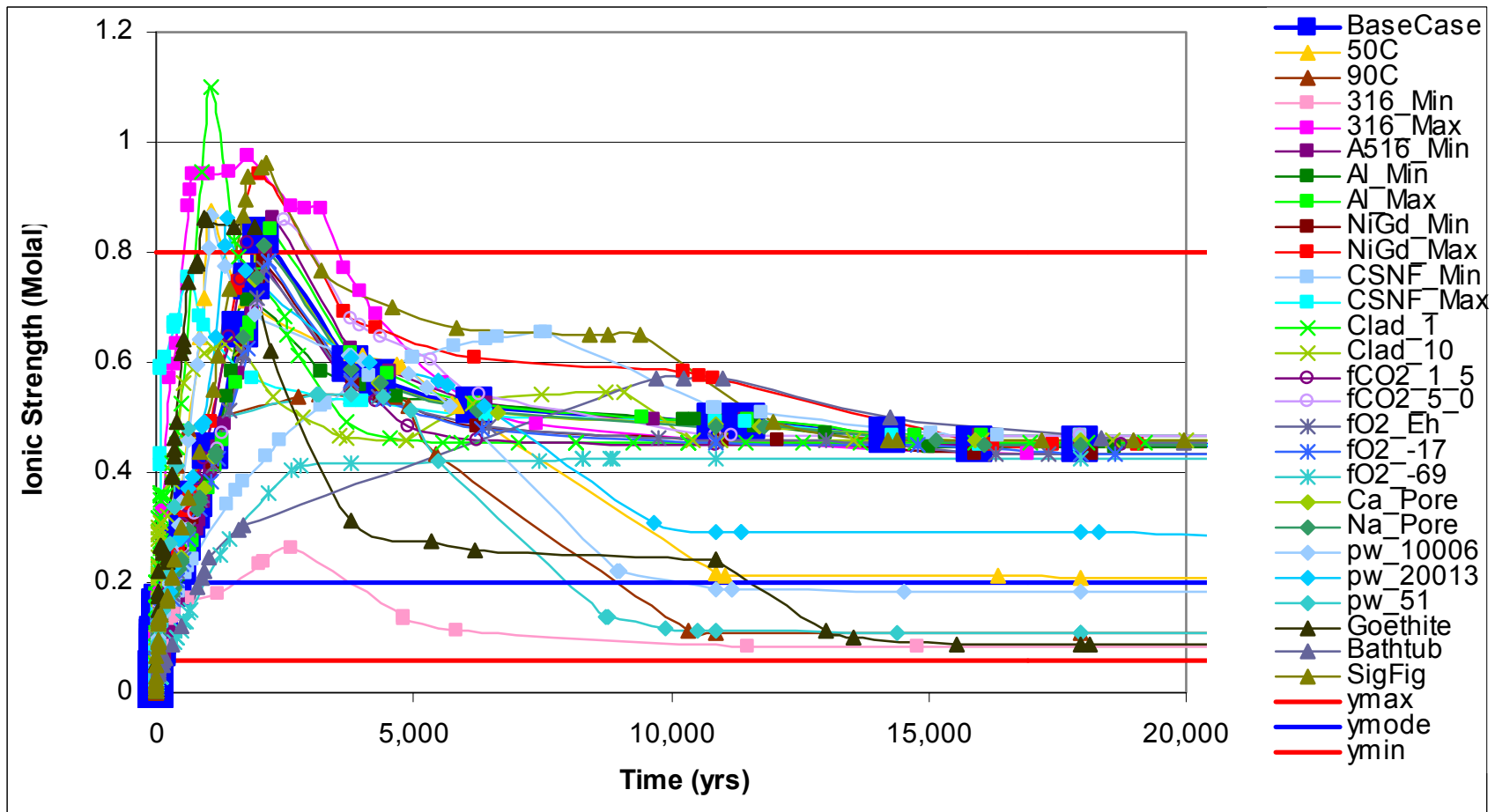

Source: $\quad$ CSNF Liquid Influx Model Output.xls (Appendix F ISpreadsheets).

NOTE: $\quad$ Time refers to time after waste package breach ( 0 on the $x$-axis refers to 0.1 years).

Figure 7-5. CSNF Ionic Strength Abstraction Compared to Model Output (1 L/yr) 


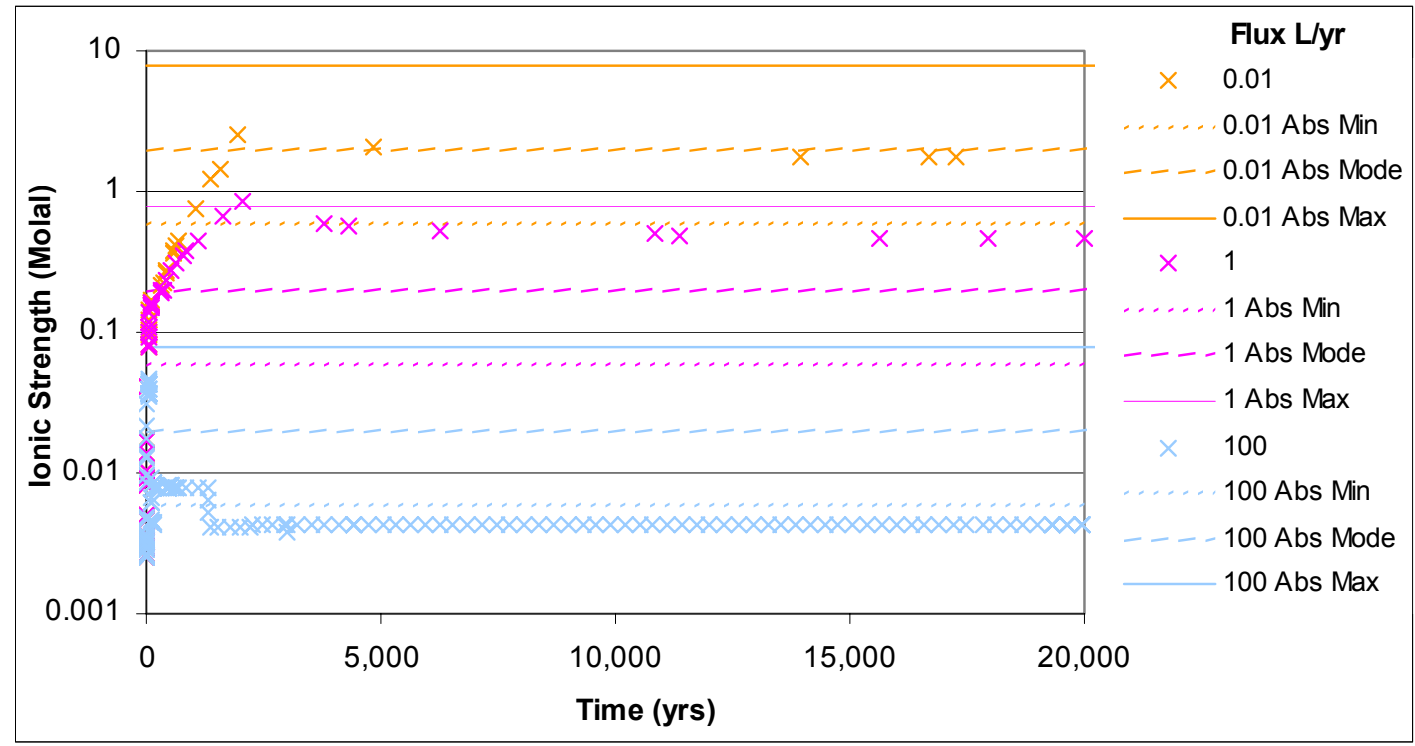

Source: (I) CSNF_Liquid Influx Model Output.xls (Appendix F ISpreadsheets).

NOTE: Time refers to time after waste package breach ( 0 on the $x$-axis refers to 0.1 years).

Figure 7-6. CSNF Ionic Strength Abstraction Compared to Model Output for Various Fluxes

As shown in Figure 7-5, the abstracted ionic strength captures the majority of the model output. The abstraction is based on the time-weighted averages of the ionic strength values, so for this reason, some of the maximum ionic strength values fall outside of the abstraction. Because TSPA-LA time steps can be quite large, it would not be appropriate to allow the sampled ionic strength to go above the time-weighted average ionic strength for the most extreme case.

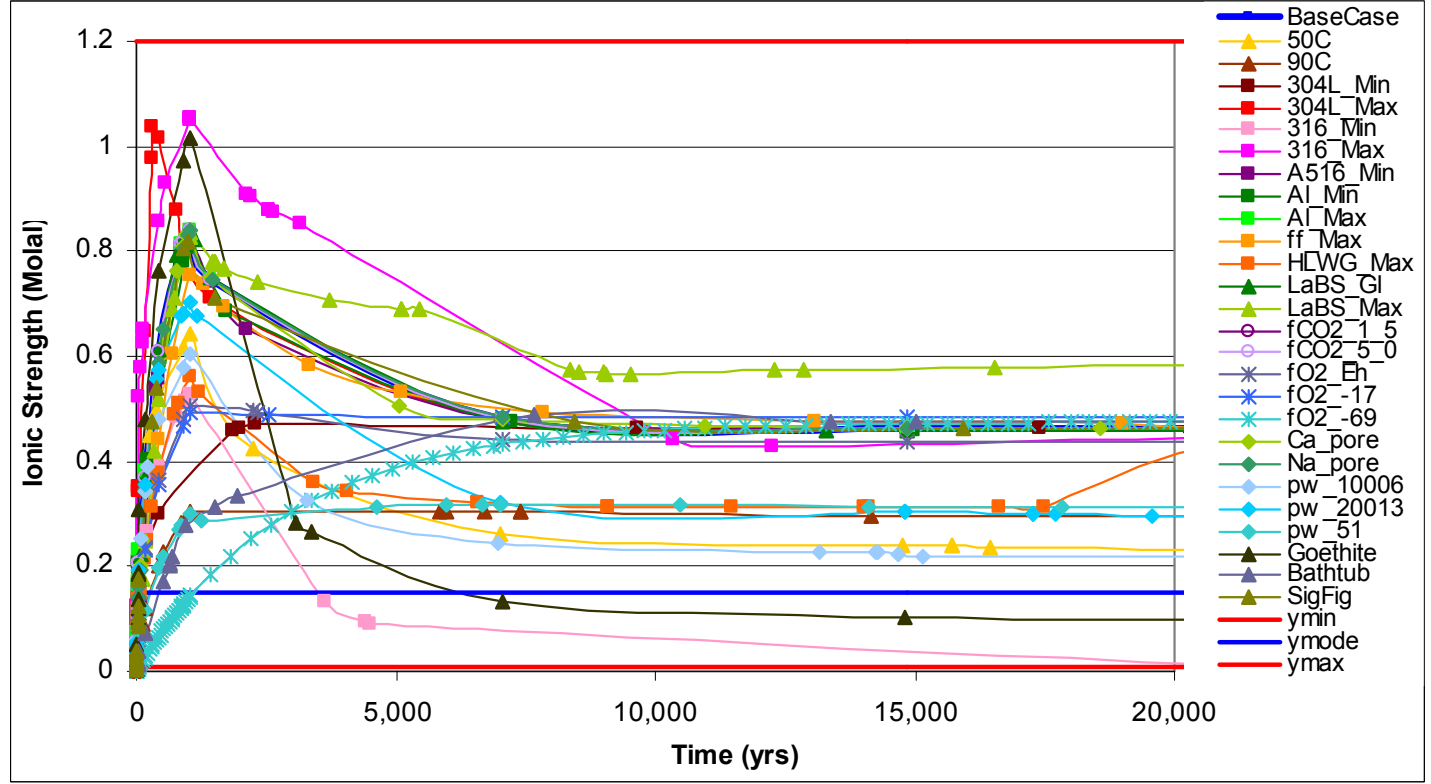

Source: CDSP Liquid Influx Model Output.xIs (Appendix F ISpreadsheets).

NOTE: Time refers to time after waste package breach ( 0 on the $x$-axis refers to 0.1 years).

Figure 7-7. CDSP Ionic Strength Abstraction Compared to Model Output (1 L/yr) 


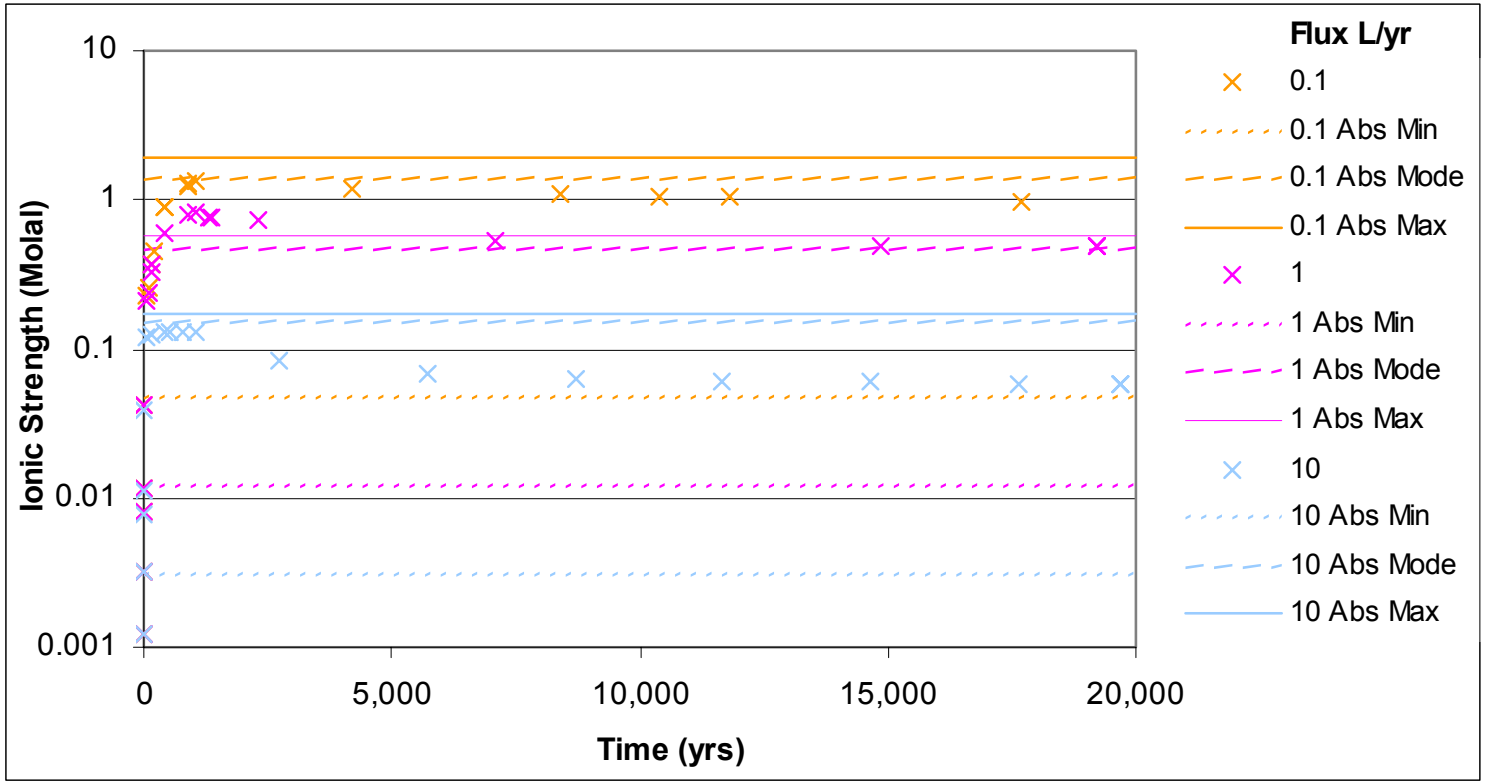

Source: (I) CDSP_Liquid Influx Model Output.xls (Appendix F ISpreadsheets).

NOTE: Time refers to time after waste package breach ( 0 on the $x$-axis refers to 0.1 years).

Figure 7-8. CDSP Ionic Strength Abstraction Compared to Model Output for Various Fluxes

Figure 7-7 shows that the CDSP ionic strength abstraction captures the model output. For the CDSP model, the time-weighted average of the most extreme case does bound the maximum ionic strengths for all of the runs. The reason that the time-weighted average of the most extreme case for CDSP is higher than all of the runs is because unlike the CSNF waste package that contains Stainless Steel Type316 only, the CDSP waste package contains Stainless Steel Types 316 and 304L. It is the degradation of the stainless steels that generates the high ionic strength; therefore, it is appropriate that the maximum ionic strength for the CDSP waste package is higher than for the CSNF waste package.

As shown in Figures 6-20 and 6-21, the liquid influx and the vapor influx results are similar; therefore, the liquid influx results are indicative of the vapor influx results also capturing the model results.

The validation process used for the $\mathrm{pH}$ abstractions was a comparison of the abstracted $\mathrm{pH}$ for each time period to the product output value for a given set of input parameters. The response surfaces are mathematical constructs whose limits were set by the process models inputs and outputs. The ionic strength abstractions represent a best fit to the process model data, and are, therefore, able to reproduce the process model output for a given set of input conditions within a range of uncertainty; thus, rendering them self validating.

The $\mathrm{pH}$ is used by TSPA-LA to determine the dissolved concentration of radionuclides, and the degradation rate of the CSNF; therefore, the $\mathrm{pH}$ abstraction should reasonably represent the in-package $\mathrm{pH}$. Likewise, the ionic strength is used by TSPA-LA to determine the stability of colloids and the dissolved concentrations of radionuclides (for ionic strengths $>1$ molal, additional uncertainty is added); therefore, the ionic strength abstractions should reasonably represent the in-package ionic strength. 


\subsubsection{Fuel-Degradation Model Consistent with Results from Laboratory Experiments}

The fuel degradation model was derived from laboratory experiments done by DOE contractors, which are themselves consistent with results published in refereed journals and literature (BSC 2004 [DIRS 169987]). In particular, the CSNF degradation rate law is broadly consistent with that proposed by Grambow (1989 [DIRS 113233]). The HLW glass degradation model is consistent with experimental and literature data (BSC 2004 [DIRS 169988], Table 7-1). The DSNF degradation model is consistent with experimental data (BSC 2004 [DIRS 172453], Section 6.1.7).

\subsubsection{Types of Minerals Formed Consistent with Experimental Results}

The primary phases predicted to form in the model are ferric oxyhydroxides (hematite, goethite, etc.) from steel corrosion, and schoepite from the degradation of spent fuel. Steel is observed in nature and in experiments to corrode to metal oxides whose specific identities depend upon the particular conditions of corrosion and the composition of the steel. Hematite and goethite are routinely observed as the most common iron oxides in soil (Schwertmann and Taylor 1995 [DIRS 105959]). Schoepite is observed as an alteration product in experiments (BSC 2004 [DIRS 169987]) and at the Pena Blanca natural analogue (Langmuir 1997 [DIRS 100051], p. 512). The aqueous concentrations of, respectively, $\mathrm{Fe}$ and $\mathrm{U}$ in fluids in contact with ferric hydroxides and schoepite tend to be fixed by the presence of these solids (Langmuir 1997 [DIRS 100051]; Stumm and Morgan 1996 [DIRS 125332]).

\subsubsection{Steel-Degradation Model Consistent with Results from Laboratory Experiment}

The steel degradation rates were derived from a compilation of laboratory experiments and are therefore implicitly consistent. Moreover, this range of rates, 4 to $131 \mu \mathrm{m} / \mathrm{yr}$ for low carbon steel, is somewhat higher but otherwise broadly consistent with the rates determined from iron archeological artifacts, 0.1 to $10 \mu \mathrm{m} / \mathrm{yr}$ (Miller et al. 2000 [DIRS 156684], p. 101). The latter probably saw lower temperatures than the data from which the rate model was derived. The stainless steel degradation rates cover a broad range of rates and are consistent with many experimental results documented in Aqueous Corrosion Rates for Waste Package Materials (BSC 2004 [DIRS 169982]).

Recent experimental work was conducted on "corrosion of miniature waste packages" (Zarrabi et al. 2003 [DIRS 171238]) in bathtub and flow-through configurations. The miniature waste packages were fabricated from carbon steel with similar interior geometry as Codisposal waste packages. The x-ray diffraction (XRD) analysis of the corrosion products revealed a variety of iron oxyhydroxide minerals formed, regardless of the chemical conditions of inflow water to the miniature waste packages. The corrosion products were mainly goethite $(\mathrm{FeO}(\mathrm{OH}))$, lepidiocrocite $(\mathrm{FeO}(\mathrm{OH}))$, magnetite $\left(\mathrm{FeFe}_{2} \mathrm{O}_{4}\right)$, and maghemite- $\mathrm{C}\left(\mathrm{Fe}_{2} \mathrm{O}_{3}\right)$. Hematite was not observed, likely due to the short duration of the experiment. But, these minerals are consistent with other experimental work that did see the formation of hematite (Pednekar 1987 [DIRS 159329]).

In dynamic systems (bathtub and flow-through configurations), formation of goethite is favored over hematite (Zarrabi et al. 2003 [DIRS 171238]). However, the thermodynamic stability of 
these two minerals, in the presence of water, is similar. The mineral that actually begins to form typically depends on the nature of the substrates upon which the mineral begins to grow. Once started, that mineral will generally persist, even though it may not be the most stable. These results are consistent with many available "natural analogs" that point in the same direction. For example, Angus et al. 1962 [DIRS 167071] used electron diffraction to determine that corrosion products, taken from piles of buried Roman nails found in England were mainly $\mathrm{Fe}_{2} \mathrm{O}_{3}$ containing some Mn (bixbyite), which is similar to the composition of hematite.

In the study of "miniature waste packages" (Zarrabi et al. 2003 [DIRS 171238]), changes in pH and conductivity of several inflow solutions with different compositions were monitored. In one case, the $\mathrm{pH}$ of the inflow was adjusted to 2.1, and the outflow $\mathrm{pH}$ increased for the first week to 4.9 and then stabilized at a $\mathrm{pH}$ of 4.2. In the same experiment, conductivity of the effluent decreased from its original value of about 4,030 $(\mu \mathrm{S})$ to about 1,950 $(\mu \mathrm{S})$ and remained low for the duration of the experiment. This indicates the steady-state buffering and sorption capacity of carbon steel corrosion products.

In summary, this experiment validates the types of corrosion products that form from steel corrosion and also supports the $\mathrm{pH}$ trends used in the surface complexation model.

\subsection{5 pH and Ionic Strength Consistent with Natural Analogue Observation}

Because the output will be applied over geologic time spans, the specific outputs of this model ( $\mathrm{pH}$, ionic strength) are compared to natural analogue observation (rather than experimental data).

\subsubsection{Production of Alkaline Waters by Glass Dissolution}

Glass dissolution causes $\mathrm{pH}$ values greater than 7 when protons from solution exchange with alkalis, typically $\mathrm{Na}^{+}, \mathrm{K}^{+}$, or $\mathrm{Ca}^{2+}$, present at the dissolving glass-solution interface, e.g.:

$$
\text { Glass- } \mathrm{Na}^{+}+\mathrm{H}^{+} \leftrightarrow \mathrm{Na}^{+}+\text {Glass- } \mathrm{H}^{+}
$$

The general link between dissolution of alkali-bearing silicate minerals and glasses with acidity destruction (alkalinity production) is amply documented in the peer-reviewed scientific literature. Typically, large-scale weathering of alkali-bearing silicates ultimately leads to high pH values in alkali lakes (Berner and Berner 1987 [DIRS 161746], pp. 280 to 281). Experiments seeking to mimic interaction of seawater with basaltic glass on the ocean floor occasionally observe alkaline $\mathrm{pH}$ values (note that basaltic glass is generally considered to be an appropriate natural analogue for nuclear waste glass (Ewing and Haaker 1979 [DIRS 161749]).

Because basaltic glass is an appropriate analog for waste glass, the alkaline, long-term $\mathrm{pH}$ values calculated for glass-bearing packages should be similar to those of ground waters from basalt formation and other rock types of basaltic composition. In his authoritative review of the chemistry of natural waters, Hem (1995 [DIRS 115670]) gives the analyses of two basalt ground waters and one water from a tuff containing the basaltic mineral olivine. The basalt waters have pH values of 7.8 and 7.9 (Hem 1995 [DIRS 115670], Table 12, Analyses 4 and 5) and water from an olivine tuff has a pH of 8.2 (Hem 1995 [DIRS 115670], Table 16, Analysis 3). 
Besides saturated environments, such as lakes and deep groundwater mentioned above, increases in $\mathrm{pH}$ due to degradation of glass have also been observed in unsaturated environments that are more analogous to repository conditions. A study of the natural alteration of ancient vitreous slags (the glassy refuse that remains after the smelting of metallic ore) found that all samples (100 to 4,000 years old) had a first stage of weathering in which the solution $\mathrm{pH}$ increased due to the reaction of the protons of the solution in the acid environment with the vitreous slags. This was found for different chemical compositions of glass and for different weathering environments, from open-air stacks to underground conditions. If sufficient oxygen exists, such as in the case of the open-air samples, the second stage involves further increases in $\mathrm{pH}$ toward a neutral to moderately basic environment, as the dissolution of the glass skeleton proceeds (Mahé-Le Carlier et al. 2000 [DIRS 171509]).

In short, the high-end $\mathrm{pH}$ values predicted by the single component HLWG runs in the in-package chemistry model are corroborated by natural observations documented in the peer-reviewed literature. This, in tandem with the satisfaction of Level I criteria (a) through (f), therefore, provides sufficient justification for a Level II validation for this particular feature of the in-package chemistry model. On the basis of meeting the criteria for this feature, the level of confidence has been met.

\subsubsection{Lower Limits to pH Inside the Package}

The $\mathrm{pH}$ values inside the degrading waste form are predicted to be between 4.5 and 8.5 . The chemical makeup of the waste form corrosion products will be dominated by metal oxides and hydroxides similar to natural soils. The $\mathrm{pH}$ values in natural waters typically only become more acidic than 4.5 when high levels of organic acids are present, or when reduced sulfur is oxidized. Hem (1995 [DIRS 115670], Table 13, Analyses 1 and 4; Table 14, Sample 7) gives analyses of natural waters with $\mathrm{pH}$ values of $4.0,3.8$, and 3.0, respectively. These waters all contain relatively high proportions of dissolved sulfate, indicating that the source of their acidity is the oxidation of reduced sulfur. Oxidation of reduced sulfur is also a major source of acidity in waters corroding waste package materials, particularly the low carbon steel. The levels of reduced sulfur in the waste package are too low to exceed the pH-buffering capacity of the corrosion products themselves (Section 6.7.1). Given a relative absence of high levels of organic acids and reduced sulfur, the in-package chemistry model predicts low-end $\mathrm{pH}$ values of 4.5. This low-end $\mathrm{pH}$ value is similar to the $\mathrm{pH}$ values of natural waters that contain little dissolved organic acids, and which are not influenced by sulfide oxidation, such as those described in Hem (1995 [DIRS 115670]), validating the model predictions of low-end $\mathrm{pH}$ values.

\subsubsection{Neutralization of Alkaline and Acidic Waters}

This section describes the neutralization of the alkaline waters produced by the dissolution of the HLWG (Section 7.2.5.1) and the acidic waters produced by the oxidation of the sulfur in the low carbon steels (Section 7.2.5.2). This neutralization is shown by comparing the $\mathrm{pH}$ values generated by the single components of the CDSP waste package in Figure 6-22 with the combined reactants shown in Figure 6-23. The concept of acids and bases neutralizing one another is a generally accepted fact and does not require validation. 


\subsubsection{Production of Extreme Ionic Strength Solutions}

High ionic strength solutions ( $>1$ molal) are predicted to form when low volumes of fluid remain in contact with soluble waste form and waste package components for long periods of time. This observation is validated by the observation that older geologic fluids tend to be saltier than younger ones that have had less time to react with solids (Drever 1982 [DIRS 100725]).

Low ionic strength solutions $(<0.05 \mathrm{~mol} / \mathrm{L})$ are predicted to form when high volumes of water flow past the waste form and waste package components or when water only contacts the HLWG and aluminum alloy without contacting any other waste package materials. These low ionic strengths are conservative for colloid stability and thus result in the greatest radionuclide release in advective flow conditions, and therefore do not require validation.

\subsubsection{Relationship Between Ionic Strength and Flow Rate}

Freeze and Cherry (1979 [DIRS 101173], Figure 7.17(b)) show the relationship between groundwater flow rate and concentration of solution for a constant reaction rate. The plot shows that water flowing at a higher flow rate, but same degradation rate and same flow distance will have a lower concentration than water flowing at a lower flow rate. For the in-package system, this is equivalent to saying that if water is flowing through the waste package, the water with the highest flow rate will exit the waste package with the lowest ionic strength. This behavior is exhibited in this model as shown in Figures 6-74 and 6-76 for CSNF, and Figures 6-79 and 6-80 for CDSP.

\subsubsection{Surface Complexation Model}

A technical review of the surface complexation model was conducted and is documented in Appendix E. The reviewer, Yifeng Wang, who was independent of the development and checking of the document, concluded:

A simplified version of surface complexation model, described by an analytic equation, is used in the package chemistry. I have checked the derivation of the equation, and no error has been found. The prediction of the equation has been confirmed by PHREEQC calculations.

In general, the surface complexation model developed for in-package chemistry is adequate for its intended use, i.e., to provide a more realistic prediction of in-package $\mathrm{pH}$.

Therefore, the surface complexation model has been validated by means of a technical review.

\subsection{FLUORIDE VALIDATION}

The fluoride abstractions are plotted in Figures 7-9 through 7-11, along with the model output. 


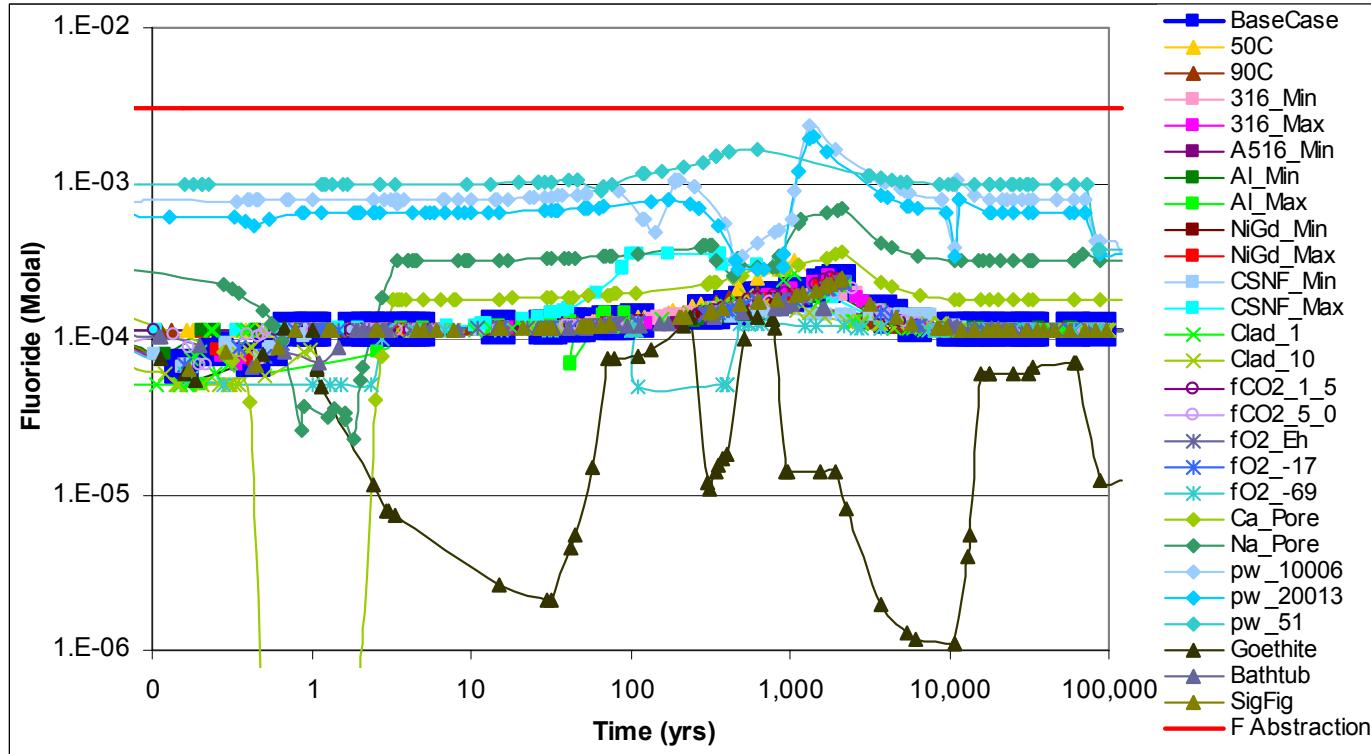

Source: $\quad$ CSNF Liquid Influx Model Output.xIs (Appendix F ISpreadsheets).

NOTE: $\quad$ Time refers to time after waste package breach ( 0 on the $x$-axis refers to 0.1 years).

Figure 7-9. CSNF Fluoride Abstraction Compared to Model Output

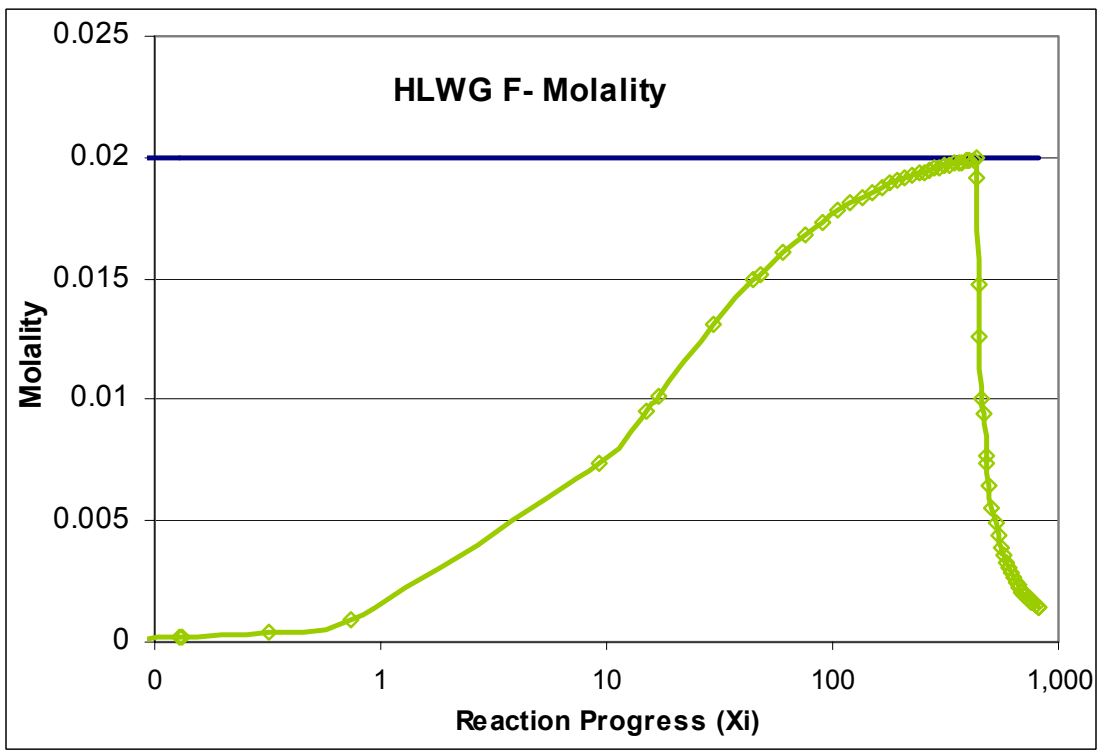

Source: CDSP Vapor Influx Model Output.xIs (Appendix F ISpreadsheets).

NOTE: 0 on the $\mathrm{x}$-axis refers to $0.1 \mathrm{Xi}$.

Figure 7-10. CDSP Vapor-Influx Fluoride Abstraction Compared to Model Output

These figures illustrate that the abstraction adequately bounds the model output. 


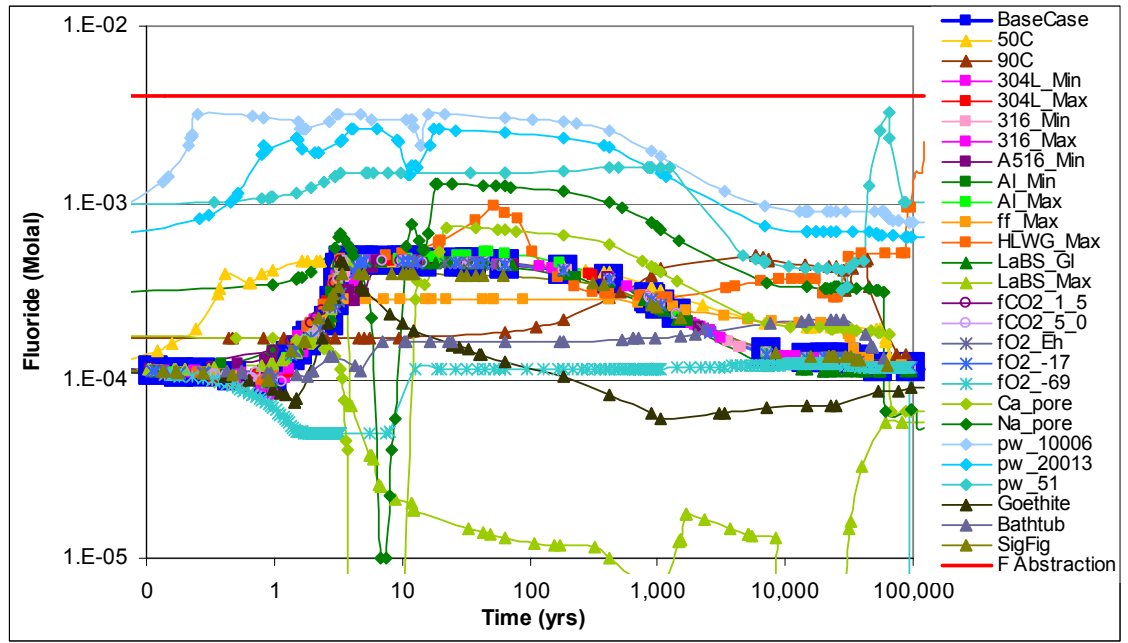

Source: CDSP Liquid Influx Model Output.xIs (Appendix F ISpreadsheets).

NOTE: Time refers to time after waste package breach ( 0 on the $x$-axis refers to 0.1 years).

Figure 7-11. CDSP Liquid Influx Fluoride Abstraction Compared to Model Output

The experimental data used to validate these models is shown in Figure 7-12 and is from three sets of experiments: Wronkiewicz et al. 1992 [DIRS 100493] and LL020709923142.023 [DIRS 161677], and LL980710551022.012. The Wronkiewicz et al. 1992 [DIRS 100493] data comes from unsaturated testing of $\mathrm{UO}_{2}$, and the LL020709923142.023 [DIRS 161677] data comes from the testing of hydrological boreholes. Coupons of candidate waste package materials were placed at strategic locations such as hot/dry locations near heaters and warm/wet regions in the condensation zones in hydrological boreholes and in the heated drift. These coupons consisted of one of three materials (Alloy 22, carbon steel, and Monel-400). LL980710551022.012 [DIRS 173475] contains data from the unsaturated drip condition testing of spent fuel and unsaturated dissolution tests of glass.

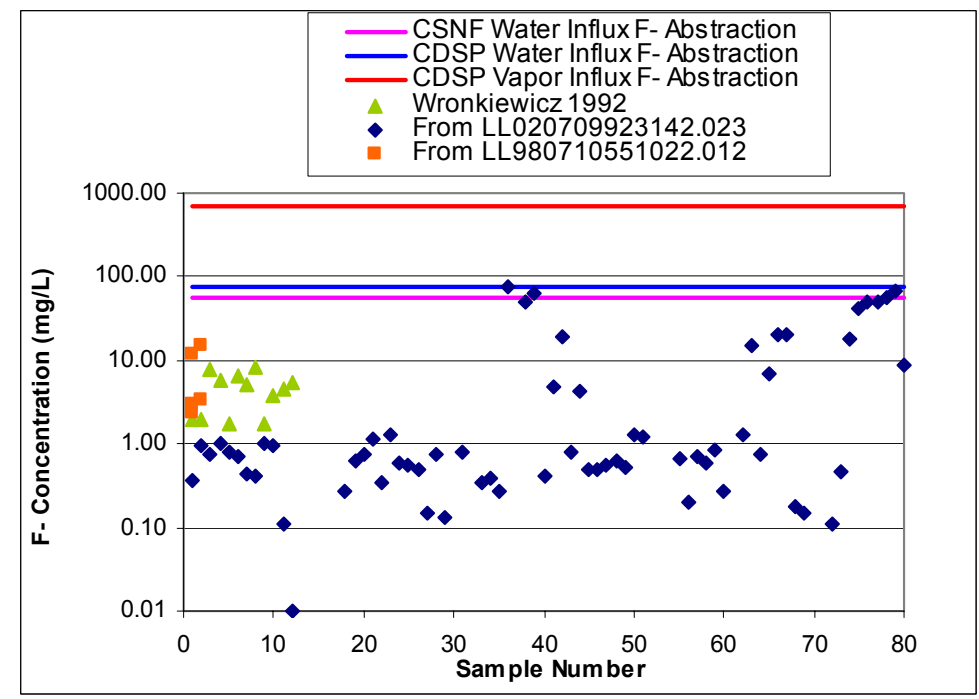

Source: $\quad F$ and $\mathrm{Cl}$ Abstractions.xls (Appendix F ISpreadsheets).

Figure 7-12. CSNF and CDSP Fluoride Abstractions Compared to Experimental Data 
The fluoride model is used by the Dissolved Concentration Limits of Radioactive Elements Model (BSC 2005 [DIRS 173873]). High fluoride concentrations increase dissolved concentrations of radionuclides; therefore, higher fluoride values are conservative. The fact that the model is consistent with the experimental data, and bounds the vast majority of the experimental data shows that this model is valid for its intended use.

\subsection{CHLORIDE VALIDATION}

The chloride abstraction is plotted in Figures 7-13 and 7-14, along with the model output.

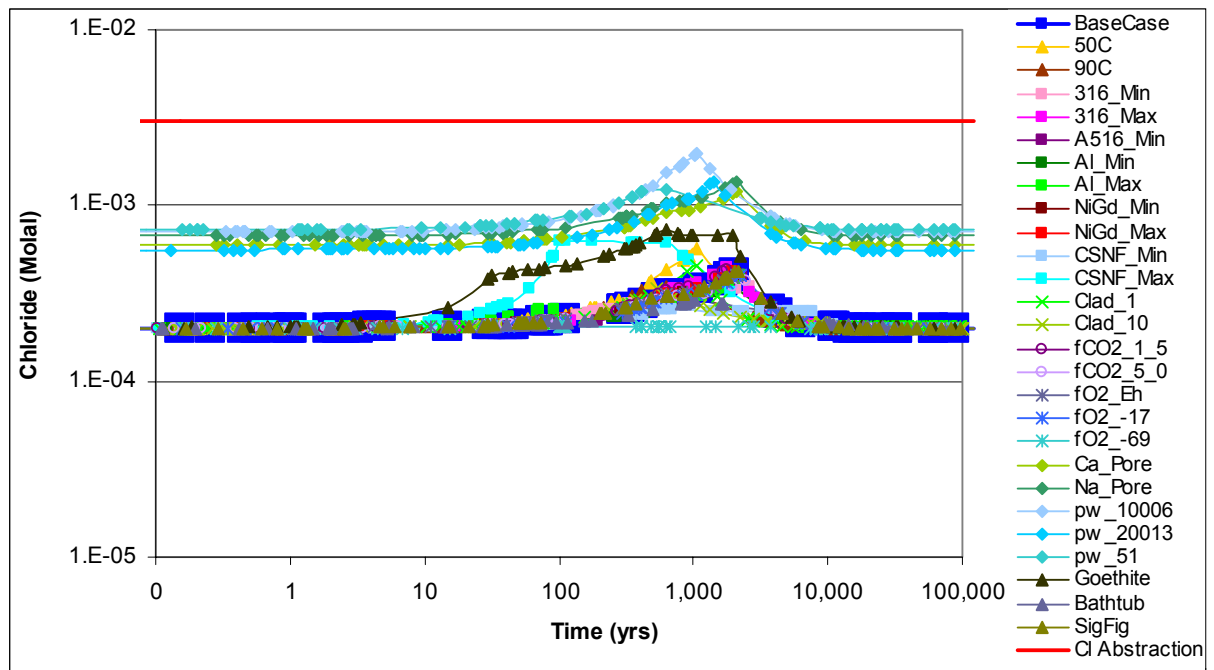

Source: $\quad$ CSNF Liquid Influx Model Output.xIs (Appendix F ISpreadsheets).

NOTE: $\quad$ Time refers to time after waste package breach ( 0 on the $x$-axis refers to 0.1 years).

Figure 7-13. CSNF Chloride Abstraction Compared to Model Output

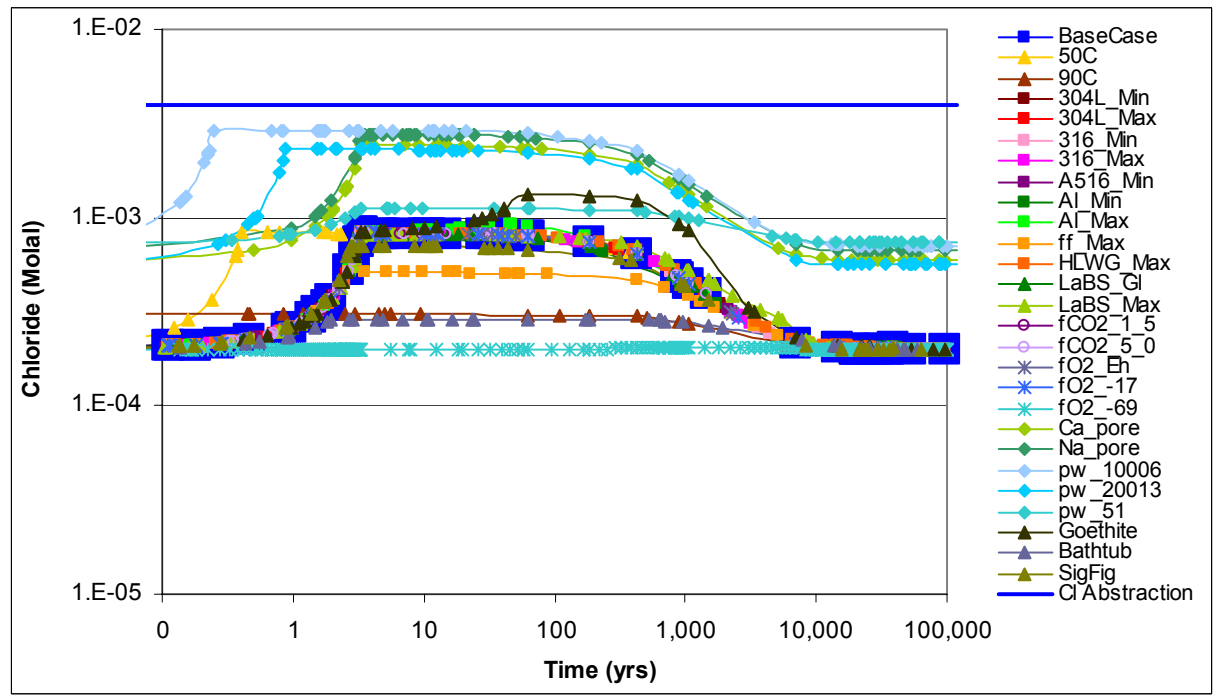

Source: CDSP Liquid Influx Model Output.xIs (Appendix F ISpreadsheets).

NOTE: $\quad$ Time refers to time after waste package breach ( 0 on the $x$-axis refers to 0.1 years).

Figure 7-14. CDSP Chloride Abstraction Compared to Model Output 
These figures illustrate that the abstraction adequately bounds the model output.

The experimental data used to validate these models is shown in Figure 7-15 and is from three sets of experiments: Wronkiewicz et al. 1992 [DIRS 100493] and LL020709923142.023 [DIRS 161677], and LL980710551022.012. The Wronkiewicz et al. 1992 [DIRS 100493] data comes from unsaturated testing of $\mathrm{UO}_{2}$, and the LL020709923142.023 [DIRS 161677] data comes from the testing of hydrological boreholes. Coupons of candidate waste package materials were placed at strategic locations such as hot/dry locations near heaters and warm/wet regions in the condensation zones in hydrological boreholes and in the heated drift. These coupons consisted of one of three materials (Alloy 22, carbon steel, and Monel-400). LL980710551022.012 [DIRS 173475] contains data from the unsaturated drip condition testing of spent fuel and unsaturated dissolution tests of glass.

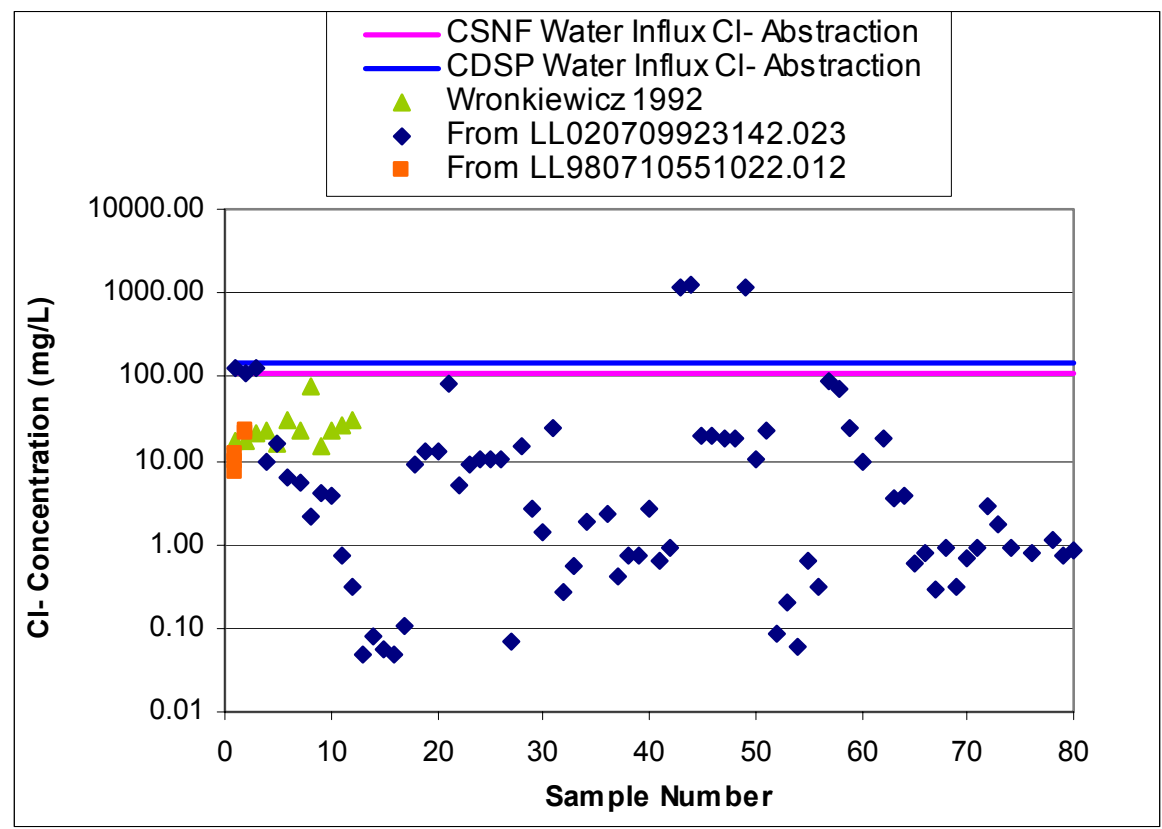

Source: $\quad F$ and $\mathrm{Cl}$ Abstractions.xls (Appendix F ISpreadsheets).

Figure 7-15. CSNF and CDSP Chloride Abstractions Compared to Experimental Data

The intended use of the chloride model had been by the Pitting Model for Zirconium-Alloyed Cladding, BSC 2004 [DIRS 170043] for the determination of whether the conditions for Zirconium pitting exist in the waste package. High chloride concentrations are more likely to cause pitting; therefore, higher chloride values are conservative. However, the pitting model no longer uses this model, so the level of validation required for this model is low. The fact that the model is consistent with the experimental data, and bounds the vast majority of the experimental data shows that this model is valid for its intended use. Even though the chloride model is no longer used, it is retained as validated output of this model to maintain consistency with previous versions and to be available for future potential use. 


\subsection{TOTAL CARBONATE VALIDATION}

The TSPA model calculates total carbonate (Total C) using the equation given in Table 6-22. The variables and parameters in this equation are the $\mathrm{PCO}_{2}$ and $\mathrm{pH}$, and the temperaturedependent values of three chemical equilibrium constants. The $\mathrm{PCO}_{2}$ and $\mathrm{pH}$ values are established by the TSPA model. The values of the equilibrium constants are calculated by the TSPA model using the equations given in Table 6-24 and the temperature corresponding to the TSPA realization.

The equation for Total $\mathrm{C}$ in Table 6-22 is based on the laws of equilibrium thermodynamics. The equations for the temperature-dependent equilibrium constants are polynomial fits to data from the thermodynamic database (DTN: SN0410T0510404.002 [DIRS 172712]) used in the EQ3/6 calculations supporting this report.

An equation for Total $\mathrm{C}$ and temperature-dependent values of parameters required for its solution can be taken from standard textbooks of aqueous geochemistry and used to validate the Total C calculations of this report. One such textbook, Stumm and Morgan (1996 [DIRS 125332]) discusses carbonate chemistry in Chapter 4. Substituting equations 2 and 3 into equation 5 of Table 4.2 of that chapter leads to the following expression for Total C:

$$
\text { Total } \mathrm{C}=\mathrm{PCO}_{2}\left(\mathrm{k}_{\mathrm{H}}+\mathrm{k}_{\mathrm{H}} \mathrm{k}_{1} /\left[\mathrm{H}^{+}\right]+\mathrm{k}_{\mathrm{H}} \mathrm{k}_{1} \mathrm{k}_{2} /\left[\mathrm{H}^{+}\right]^{2}\right)
$$

In this equation, $\left[\mathrm{H}^{+}\right]$is the $\mathrm{H}^{+}$ion concentration, $\mathrm{k}_{1}$ and $\mathrm{k}_{2}$ are temperature-dependent constants of equations 2 and 3 , and $\mathrm{k}_{\mathrm{H}}=\left[\mathrm{H}_{2} \mathrm{CO}_{3}{ }^{*}\right] / \mathrm{PCO}_{2}$ where $\left[\mathrm{H}_{2} \mathrm{CO}_{3}{ }^{*}\right]=\left[\mathrm{CO}_{2}(\mathrm{aq})\right]+\left[\mathrm{H}_{2} \mathrm{CO}_{3}\right]$. Stumm and Morgan (1996 [DIRS 125332]) give values for the negative logs of these constants for several temperatures in their Table 4.3.

Table 7-2 shows values of Total $\mathrm{C}$ calculated at various temperatures, $\mathrm{PCO}_{2}$ and $\mathrm{pH}$ values using the abstraction equation of Table 6-22, and the equations for the temperature dependent parameters from Table 6-24, and compares them with values calculated using Eq. 7-2 and the parameter values from Stumm and Morgan (1996 [DIRS 125332] Table 4.3).

Table 7-2. Comparison of Total Carbonate Model

\begin{tabular}{|c|c|c|c|c|c|}
\hline $\begin{array}{c}\text { Temperature } \\
\left({ }^{\circ} \mathbf{C}\right)\end{array}$ & $\begin{array}{c}\text { Partial Pressure } \\
\text { of } \mathbf{C O}_{2} \\
\left(\mathbf{P C O}_{2}\right)\end{array}$ & $\mathbf{p H}$ & $\begin{array}{c}\text { Total Carbonate } \\
\text { from } \\
\text { Equation in } \\
\text { Table 6-22 }\end{array}$ & $\begin{array}{c}\text { Total Carbonate } \\
\text { fromEq. 7-2 }\end{array}$ & $\begin{array}{c}\text { Difference } ~ \\
\text { Mean (\%) }\end{array}$ \\
\hline 25 & 0.010 & 8.0 & $1.54 \mathrm{E}-02$ & $1.55 \mathrm{E}-02$ & -0.8 \\
\hline 25 & 0.010 & 6.0 & $5.00 \mathrm{E}-04$ & $4.90 \mathrm{E}-04$ & 2.0 \\
\hline 25 & 0.001 & 4.0 & $3.51 \mathrm{E}-05$ & $3.40 \mathrm{E}-05$ & 3.2 \\
\hline 25 & 0.001 & 6.0 & $5.00 \mathrm{E}-05$ & $4.90 \mathrm{E}-05$ & 2.0 \\
\hline 25 & 0.001 & 8.0 & $1.54 \mathrm{E}-03$ & $1.55 \mathrm{E}-03$ & -0.8 \\
\hline 40 & 0.010 & 8.0 & $1.11 \mathrm{E}-02$ & $1.05 \mathrm{E}-02$ & 5.3 \\
\hline 40 & 0.010 & 6.0 & $3.44 \mathrm{E}-04$ & $3.31 \mathrm{E}-04$ & 3.8 \\
\hline 40 & 0.001 & 4.0 & $2.38 \mathrm{E}-05$ & $2.30 \mathrm{E}-05$ & 3.2 \\
\hline 40 & 0.001 & 6.0 & $3.44 \mathrm{E}-05$ & $3.31 \mathrm{E}-05$ & 3.8 \\
\hline 40 & 0.001 & 8.0 & $1.11 \mathrm{E}-03$ & $1.05 \mathrm{E}-03$ & 5.3 \\
\hline 100 & 0.010 & 8.0 & $1.88 \mathrm{E}-03$ & $3.76 \mathrm{E}-03$ & -66.5 \\
\hline
\end{tabular}


Table 7-2. Comparison of Total Carbonate Model (Continued)

\begin{tabular}{|c|c|c|c|c|c|}
\hline $\begin{array}{c}\text { Temperature } \\
\left({ }^{\circ} \mathrm{C}\right)\end{array}$ & $\begin{array}{c}\text { Partial Pressure } \\
\text { of } \mathrm{CO}_{2} \\
\left(\mathrm{PCO}_{2}\right)\end{array}$ & $\mathrm{pH}$ & \begin{tabular}{|c}
$\begin{array}{c}\text { Total Carbonate } \\
\text { from } \\
\text { Equation in } \\
\text { Table } 6-22\end{array}$ \\
\end{tabular} & $\begin{array}{l}\text { Total Carbonate } \\
\text { fromEq. } 7-2\end{array}$ & $\begin{array}{c}\text { Difference I } \\
\text { Mean (\%) }\end{array}$ \\
\hline 100 & 0.010 & 6.0 & 1.19E-04 & $1.39 \mathrm{E}-04$ & -14.9 \\
\hline 100 & 0.001 & 4.0 & 1.02E-05 & 1.03E-05 & -0.7 \\
\hline 100 & 0.001 & 6.0 & 1.19E-05 & 1.39E-05 & -14.9 \\
\hline 100 & 0.001 & 8.0 & $1.88 \mathrm{E}-04$ & 3.76E-04 & -66.5 \\
\hline
\end{tabular}

This table illustrates that at $25^{\circ} \mathrm{C}$ the differences between the two sets of calculations are not more than $2 \%$, at $40^{\circ} \mathrm{C}$ they are less then $6 \%$, but at $100^{\circ} \mathrm{C}$, the differences can be as much as $66 \%$. It is likely the precision could be improved if more significant figures were displayed in the parameters in Table 6-24 for the temperature dependence of the $\mathrm{K}$ values. The total carbonate abstraction (along with the $\mathrm{pH}$ abstraction) is used in the TSPA-LA as an input to the CSNF degradation rate. The CSNF degradation rate is fairly insensitive to total carbonate; therefore, the abstraction equation for the TSPA and the supporting table of temperature dependencies are adequate for their purposes.

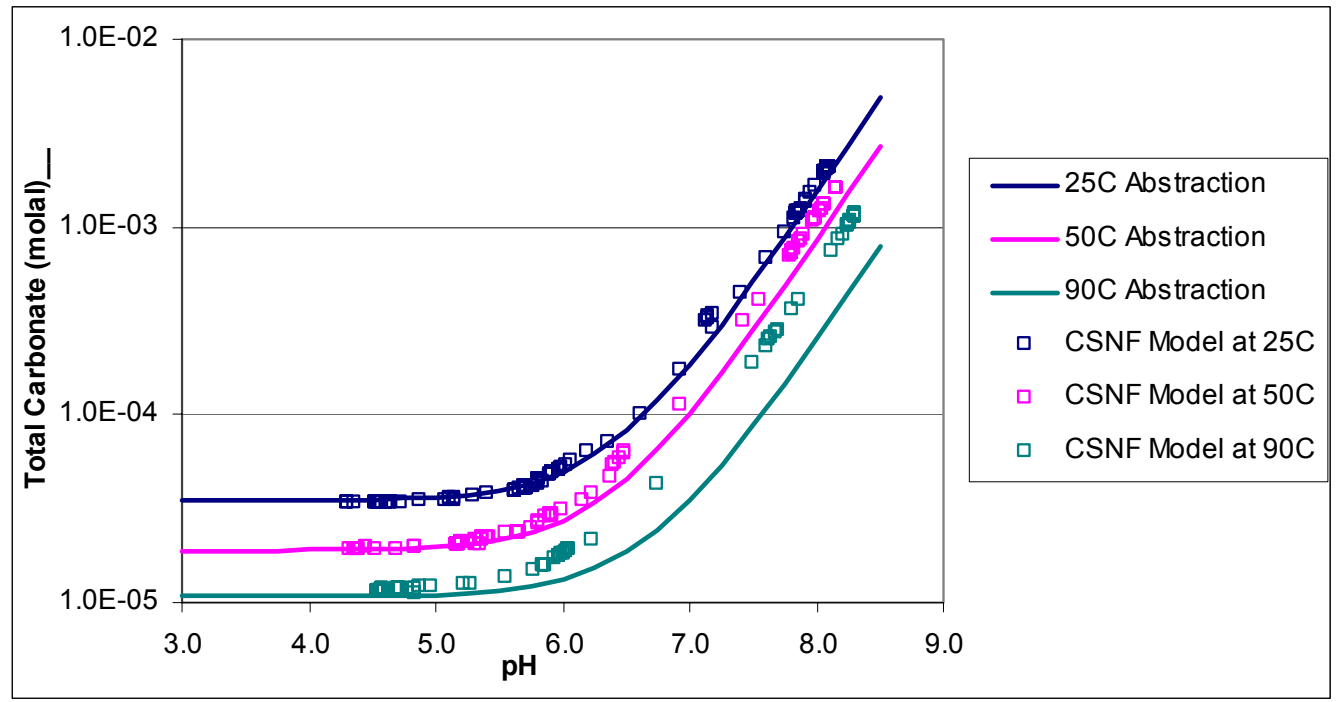

Source: $\quad$ Total Carbonate and Eh Abstraction.xls (Appendix F ISpreadsheets).

Note: $\quad \log \mathrm{PCO}_{2}=-3.0$

Figure 7-16. Total Carbonate Abstraction Compared to Model Output 


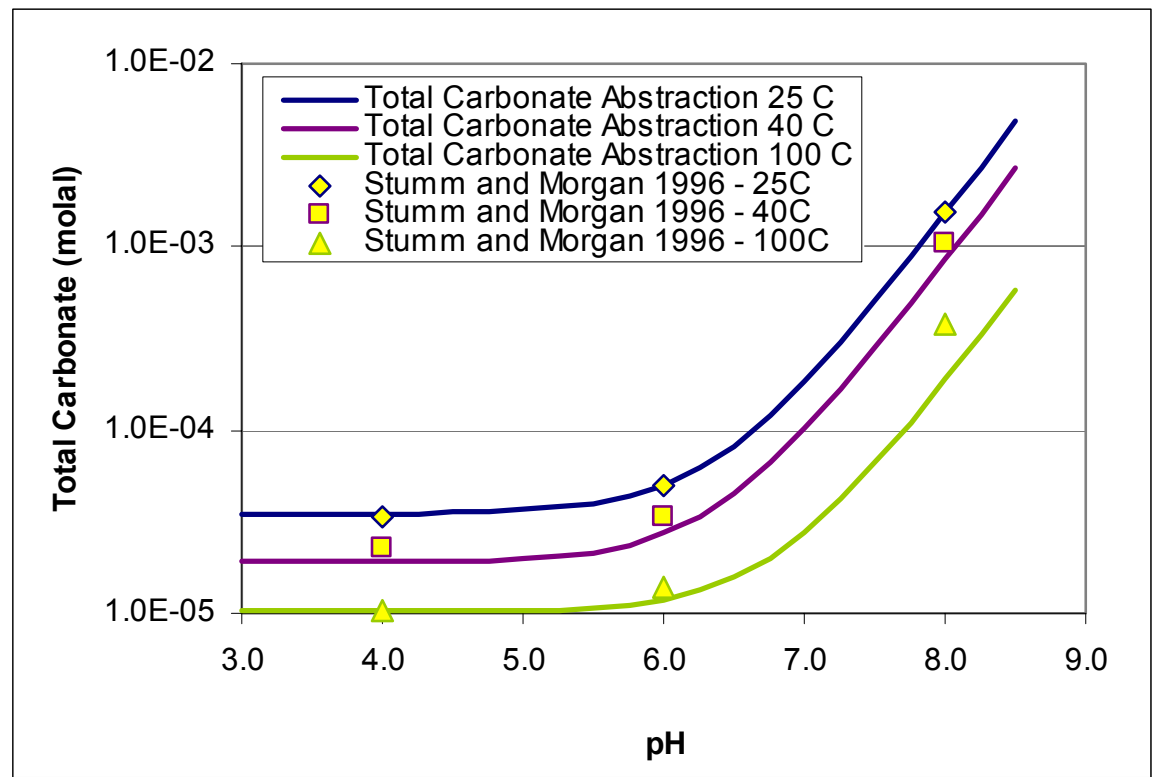

Source: $\quad$ Total Carbonate and Eh Abstraction.xls (Appendix F ISpreadsheets).

Note: $\quad \log \mathrm{PCO}_{2}=-3.0$

Figure 7-17. Total Carbonate Abstraction Compared to Validation Data

Figure 7-16 shows the agreement of the model abstraction and the model output, which illustrates that the abstraction adequately reproduces the model output. Figure 7-17 shows the model abstraction with validating data from the report by Stumm and Morgan (1996 [DIRS 125332]), which also shows agreement. The total carbonate model is used in the kinetic rate expression for the dissolution of CSNF within TSPA-LA. The fact that the model is consistent with the literature data shows that this model is valid for its intended use.

\subsection{EH VALIDATION}

The Eh abstraction is plotted in Figure 7-18, along with the model output and experimental data. The experimental data used to validate this model is from the report by Rai (1984 [DIRS 122768]). 


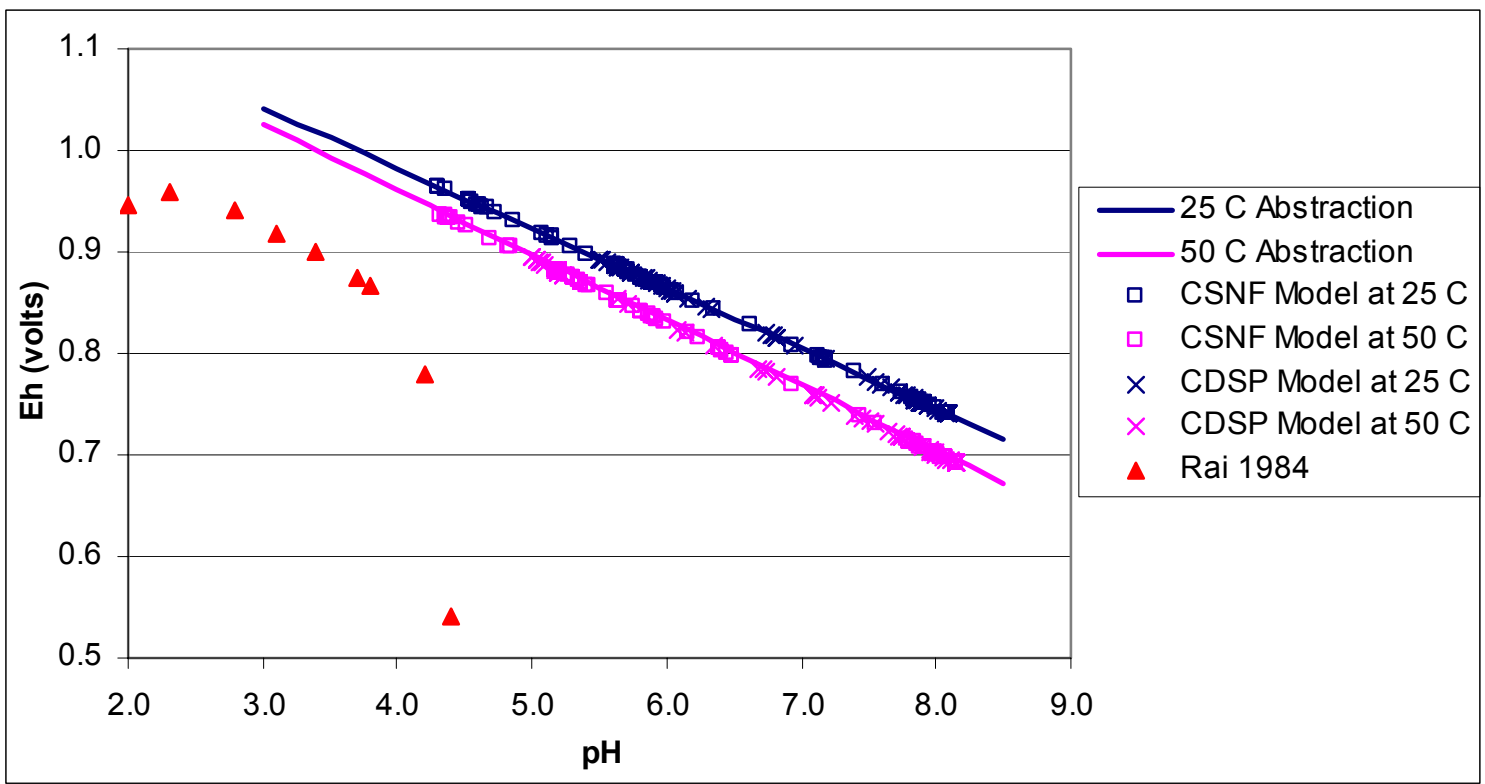

Source: Total Carbonate and Eh Abstraction.xls (Appendix F ISpreadsheets).

Figure 7-18. Eh Abstraction Compared to Model Output and Experimental Data

The close agreement of the abstraction and the model output illustrates that the abstraction adequately reproduces the model output. The intended use of the Eh model had been by Pitting Model for Zirconium-Alloyed Cladding, BSC 2004 [DIRS 170043] for the determination of the corrosion potential, $\mathrm{E}_{\text {corr }}$. However, the pitting model no longer uses this Eh model, so the level of validation required for this model is low. The fact that the model is consistent with the experimental data, and bounds the experimental data shows that this model is valid for its intended use. Even though the Eh model is no longer used, it is retained as validated output of this model to maintain consistency with previous versions and to be available for future potential use.

\subsection{SUMMARY}

To summarize, the in-package chemistry model is a numerical titration of water with acid-producing solids (steel components), alkali-producing solids (glass), and $\mathrm{pH}$ buffering via iron (hydr)oxide surface complexation. The outputs are ionic strength trajectories and $\mathrm{pH}$ distributions. Documenting that these are within the bounds of $\mathrm{pH}$ values and ionic strengths observed in natural situations, as done in the peer-reviewed literature, where similar processes prevail is critical to model validation of the in-package chemistry model. Additionally, the surface complexation model was validated via a technical review to determine if the approach and application were technically sound. Yifeng Wang (Appendix E) agrees that the surface complexation conceptual model and its formulation are adequate for intended use.

Achieving a sufficient level of confidence required documenting:

1. Fuel and steel degradation models

2. Formation of corrosion products

3. Production of low-pH waters by steel degradation 
4. Production of high-pH waters by glass degradation

5. Production of ionic strength extremes

6. $\mathrm{pH}$ buffering via surface complexation.

This model requires Level II validation (BSC 2005 [DIRS 173246]). In addition to satisfying Level I criteria (a) through (f), the evidence above collectively provides broad justification for assignment of a Level II validation for the in-package chemistry model. In addition, the requirement for Level II validation is to provide rationale for the selection of the validation methods used. This justification is provided in Section 7.3. The validation of the in-package chemistry model meets the requirements for implementation in the TSPA-LA and does not require any further validation. 


\section{CONCLUSIONS}

The in-package chemistry process models are developed and documented in Section 6 and Appendix B. The in-package chemistry model is made up of two main models: the batch reactor model, and the surface complexation model. The batch reactor model is made up of two waterinflux models, the liquid-influx and the vapor-influx models, and several other component submodels, including the fuel-degradation and the steel-degradation submodels. Based on these models, several output model abstractions were generated in Section 6.10, including: the total carbonate, fluoride, chloride, and Eh models. Based on the results of the in-package chemistry process models, it may be concluded that the following inputs or processes have only minor impact on the model response such that they were not explicitly carried forward into the abstractions.

- Initial water composition

- Partial pressure of carbon dioxide and oxygen

- Radiolysis (Appendix B)

- Modifications to waste package design configuration (including the replacement of Neutronit with NiGd alloy, or the addition of a purge port)

- Sulfur content of Carbon Steel Type A516 waste package components

- Composition and fracturing of the HLW glass log

- Oxidation state of chromium

- Waste package component degradation rates

- Controlling iron mineral (hematite versus goethite)

- CDSP waste package configuration (2-MCO/2-DHLW versus 5-DHLW/DOE SNF).

The effect of the above factors on the model response is finite and accounted for in the abstractions via applied uncertainty terms. The following variables have a large influence on the in-package chemistry:

- Waste package type (CSNF versus codisposed)

- Water flux

- Temperature.

These variables are used as input to the in-package chemistry abstractions (i.e., the abstractions are functions of these variables). Therefore, in TSPA-LA the in-package chemistry is implemented as a function of external variables that directly links the in-package chemistry to the repository environment. 


\subsection{MODEL OUTPUT}

The output of this model includes abstracted values for $\mathrm{pH}$, ionic strength, total carbonate, Eh, fluoride, and chloride concentrations. The uncertainties for these abstracted values are also presented.

The output of this model starts once the waste package has been breached and once the temperature of the waste package has dropped to $100^{\circ} \mathrm{C}$. The range of applicability (restrictions for subsequent use) for the output of this model is provided in Table 8-1. The output of the model is provided below and in the output DTN: MO0502SPAINPCA.000 [DIRS 172893].

Table 8-1. Range of Applicability

\begin{tabular}{|l|l|l|l|}
\hline & \multicolumn{1}{|c|}{ Value } & \multicolumn{1}{c|}{ Units } & \multicolumn{1}{c|}{ Source } \\
\hline Oxygen Fugacity & up to $10^{-0.7}$ & atm & Section 6.6 .4 \\
\hline Carbon Dioxide Fugacity & $10^{-5.0}$ to $10^{-1.5}$ & atm & Section 6.6 .4 \\
\hline Temperature & 25 to 100 & ${ }^{\circ} \mathrm{C}$ & Section 6.6.6 \\
\hline Water Flux & 0.001 to 1,000 & L/yr & $\begin{array}{l}\text { Sections } 6.6 .5 \text { and } \\
6.10 .2\end{array}$ \\
\hline
\end{tabular}

\subsection{1 pH Abstraction}

Table 8-2 shows the TSPA-LA pH abstraction.

Table 8-2. TSPA-LA pH Abstraction

\begin{tabular}{|c|c|c|c|c|c|c|c|c|c|}
\hline $\begin{array}{c}\text { Water } \\
\text { Entry Case }\end{array}$ & $\begin{array}{c}\text { Waste } \\
\text { Package } \\
\text { Type }\end{array}$ & $\begin{array}{l}\text { Period } \\
\text { (yrs) }\end{array}$ & $\begin{array}{c}\text { Temp } \\
\left({ }^{\circ} \mathrm{C}\right)\end{array}$ & $\begin{array}{c}\text { Flux } \\
\text { (L/yr per } \\
\text { Waste } \\
\text { Package) }\end{array}$ & $\begin{array}{l}\log \\
\mathrm{fCO}_{2}\end{array}$ & $\begin{array}{l}\text { Min } \\
\mathrm{pH}\end{array}$ & $\begin{array}{c}\text { Max } \\
\text { pH }\end{array}$ & Distribution & Uncertainty \\
\hline \multirow{13}{*}{$\begin{array}{l}\text { Liquid Influx } \\
\quad \text { and } \\
\text { Vapor Influx }\end{array}$} & \multirow{11}{*}{ CSNF } & \multirow{9}{*}{0 to 600} & \multirow{9}{*}{$\begin{array}{c}25 \text { to } \\
100\end{array}$} & \multirow{8}{*}{$Q \leq 150$} & -5.0 & 4.5 & 8.1 & \multirow{13}{*}{ Uniform } & \multirow{13}{*}{$\begin{array}{l}\text { No } \\
\text { Additional } \\
\text { Uncertainty }\end{array}$} \\
\hline & & & & & -4.5 & 4.5 & 8.1 & & \\
\hline & & & & & -4.0 & 4.5 & 8.0 & & \\
\hline & & & & & -3.5 & 4.5 & 7.9 & & \\
\hline & & & & & -3.0 & 4.5 & 7.7 & & \\
\hline & & & & & -2.5 & 4.5 & 7.5 & & \\
\hline & & & & & -2.0 & 4.5 & 7.3 & & \\
\hline & & & & & -1.5 & 4.5 & 7.0 & & \\
\hline & & & & $Q>150$ & $\mathrm{~N} / \mathrm{A}$ & 4.5 & 8.5 & & \\
\hline & & \multirow{2}{*}{$\begin{array}{l}600 \text { to } \\
20,000\end{array}$} & \multirow{2}{*}{$\begin{array}{c}25 \\
\text { to } 100\end{array}$} & $Q \leq 150$ & $\mathrm{~N} / \mathrm{A}$ & 4.5 & 7.0 & & \\
\hline & & & & $Q>150$ & $\mathrm{~N} / \mathrm{A}$ & 4.5 & 8.5 & & \\
\hline & \multirow{2}{*}{ CDSP } & \multirow{2}{*}{$\begin{array}{c}0 \text { to } \\
20,000\end{array}$} & \multirow{2}{*}{$\begin{array}{c}25 \text { to } \\
100\end{array}$} & $Q \leq 150$ & N/A & 4.5 & 7.0 & & \\
\hline & & & & $Q>150$ & $\mathrm{~N} / \mathrm{A}$ & 4.5 & 8.5 & & \\
\hline
\end{tabular}

Source: Section 6.10.1.

NOTE: The CDSP pH abstraction is not dependent on log $\mathrm{fCO}_{2}$. 
As shown in Figure 6-41 for CSNF, as flux rate increases, $\mathrm{pH}$ values increase. Therefore, in the CSNF $\mathrm{pH}$ abstraction, the in-package $\mathrm{pH}$ value was developed with a flux dependence. At early times (less than or equal to 600 years) at lower-flux conditions, less than or equal to $150 \mathrm{~L} / \mathrm{yr}$, the $\mathrm{pH}$ inside a failed CSNF waste package is sampled uniformly from the range, 4.5 to 8.1, depending $f \mathrm{CO}_{2}$. At late times, the $\mathrm{pH}$ is sampled from a uniform distribution between 4.5 and 7.0. For higher flux conditions, greater than $150 \mathrm{~L} / \mathrm{yr}$, the sampled uncertainty range is expanded from the same minimum, 4.5, to a maximum value of 8.5. To enforce the trend in higher $\mathrm{pH}$ values at higher flow rates observed in Figure 6-41, sampling the low- and high-flux distributions should not be independent. Sampling the distributions independently could yield a sampled value for the high-flux condition $\mathrm{pH}$ that is lower than the sampled value of the low-flux condition $\mathrm{pH}$. This is contrary to the results plotted in Figure 6-41. Therefore, it is recommended that correlation be applied when sampling the two flux-dependent distributions. Because the low- and high-flux distribution types are the same and use the same minimum value, and the high-flux condition maximum $\mathrm{pH}$ value is always greater than the low-flux condition maximum $\mathrm{pH}$, regardless of $f \mathrm{CO}_{2}$, a higher high-flux condition $\mathrm{pH}$ is always obtained if these two distributions are sampled with perfect correlation (i.e., a correlation factor of 1). The same flux correlation applies to the CSNF late-time $\mathrm{pH}$ abstraction (based on Figure 6-41) and the CDSP pH abstraction (based on Figure 6-43).

There is no correlation between the CSNF and CDSP $\mathrm{pH}$ abstraction. For the CSNF abstraction, there is no correlation between the early and late times.

The expected $\mathrm{pH}$ minimum value for times greater than 40,000 years is 6 for CSNF and 6.5 for CDSP, and the expected $\mathrm{pH}$ maximum value would be set by that of the incoming water.

\subsubsection{Ionic Strength Abstraction}

The ionic strength abstraction is a function of the liquid or vapor influx, and takes the following form:

where:

$$
y=e \cdot x^{f}
$$

$$
\begin{array}{ll}
\mathrm{y} & =\text { ionic strength }(\text { moles } / \mathrm{kg}) \\
\mathrm{e}, \mathrm{f} & =\text { constants }(\text { specific to waste package type) } \\
\mathrm{x} & =\text { liquid or vapor flux }(\mathrm{L} / \mathrm{yr})
\end{array}
$$

For the vapor case, the flux, $\mathrm{x}$, is a uniform distribution from 0.1 to $10 \mathrm{~L} / \mathrm{yr}$. For the liquid case, the flux is calculated by TSPA.

The abstraction uses a Log Triangular Distribution:

and:

$$
\mathrm{y} \sim \log \operatorname{tri}\left(\mathrm{a}_{\min }, \mathrm{c}_{\text {mode }}, \mathrm{b}_{\max }\right)
$$




$$
\begin{gathered}
\mathrm{a}_{\text {min }}=\mathrm{e}_{\min } \cdot \mathrm{x}^{\mathrm{f}_{\text {min }}} \\
\mathrm{c}_{\text {mode }}=\mathrm{e}_{\text {mode }} \cdot \mathrm{x}^{\mathrm{f}_{\text {mode }}} \\
\mathrm{b}_{\text {max }}=\mathrm{e}_{\max } \cdot \mathrm{x} \mathrm{f}_{\text {max }}
\end{gathered}
$$

The e and f constants for each influx scenario and waste package type are provided in the table below.

Table 8-3. Constants for TSPA-LA lonic Strength Abstraction

\begin{tabular}{|c|c|c|c|c|c|c|c|c|}
\hline \multirow{2}{*}{} & \multicolumn{4}{|c|}{ Liquid Influx } & \multicolumn{4}{c|}{ Vapor Influx } \\
\cline { 2 - 9 } & \multicolumn{2}{|c|}{ CSNF } & \multicolumn{2}{c|}{ CDSP } & \multicolumn{2}{c|}{ CSNF } & \multicolumn{2}{c|}{ CDSP } \\
\cline { 2 - 9 } & e & f & e & f & e & f & e & f \\
\hline Minimum & 0.061 & -0.55 & 0.008 & -0.29 & 0.079 & -0.68 & 0.012 & -0.59 \\
\hline Mode & 0.20 & -0.49 & 0.15 & -0.49 & 0.32 & -0.60 & 0.47 & -0.48 \\
\hline Maximum & 0.81 & -0.38 & 1.17 & -0.55 & 0.49 & -0.65 & 0.57 & -0.52 \\
\hline
\end{tabular}

Source: Section 6.10.2.

If the liquid influx rate drops below the sampled vapor influx rate, the vapor-influx model should be used for that case.

For flow rates greater than $1,000 \mathrm{~L} / \mathrm{yr}$, the model should be used with a flow rate of 1,000 L/yr.

For the vapor-influx case, the vapor mass-flow rate is similar for the CSNF and CDSP waste packages because the conditions that control the vapor mass-flow rate, temperature, and relative humidity are similar throughout the drift where the different waste packages are located. Differences in the CSNF and CDSP waste package temperatures and relative humidities could cause a potential difference in the vapor-flux rate because of the temperature dependence of the diffusion coefficient. This difference is expected to be insignificant considering that the sampled flux rate is applied for the entire realization in the TSPA-LA model and, therefore, does not account for reductions in the vapor diffusion rate as the repository cools and differences between CSNF and CDSP temperatures and relative humidities are much smaller. For this reason the same vapor-flux rate applied in the CSNF waste package ionic strength abstraction can be applied to the CDSP waste package ionic strength abstraction. For the vapor-influx case, the ionic strength uncertainty is calculated once per realization, since the flux is only sampled once per realization.

For the liquid influx case, the liquid mass flow rate is output from Abstraction of Drift Seepage (BSC 2004 [DIRS 169131]), and is different for each waste package type, because it is dependent on location within the drift, and is calculated with time-dependent variables. For the liquid influx case, the ionic strength uncertainty is recalculated with each timestep, as a function of the flux, which is calculated with time-dependent variables. However, the random number sampled between 0 and 1 that TSPA-LA uses to sample between the minimum and maximum uncertainty is only sampled once per realization. So if a given realization applies a high uncertainty (the random number is close to 1), the ionic strength uncertainty will remain high for that entire realization. 


\subsubsection{Total Carbonate Abstraction}

Table 8-4. TSPA-LA Total Carbonate Abstraction

\begin{tabular}{|c|l|c|}
\hline \multicolumn{3}{|c|}{ Equation of Total Carbonate (mol/kg) } \\
\hline \multicolumn{2}{|c|}{ Total $\mathrm{C}=\mathrm{PCO}_{2}\left(10^{k_{1}}+10^{\left(\mathrm{pH}+k_{1}+k_{2}\right)}+10^{\left(2 \mathrm{pH}+k_{1}+k_{2}+k_{3}\right)}\right)$} \\
\hline Log K & \multicolumn{1}{|c|}{ K expression } & $\mathbf{R}^{\mathbf{2}}$ \\
\hline $\boldsymbol{k}_{\mathbf{1}}$ & $\log \mathrm{K}_{1}=7 \mathrm{E}-05 \mathrm{~T}^{2}-0.0159 \mathrm{~T}-1.1023$ & 0.9992 \\
\hline $\boldsymbol{k}_{\mathbf{2}}$ & $\log \mathrm{K}_{2}=5 \mathrm{E}-07 \mathrm{~T}^{3}-0.0002 \mathrm{~T}^{2}+0.0132 \mathrm{~T}-6.5804$ & 1.0 \\
\hline $\boldsymbol{k}_{\mathbf{3}}$ & $\log \mathrm{K}_{3}=-8 \mathrm{E}-05 \mathrm{~T}^{2}+0.0128 \mathrm{~T}-10.618$ & 0.9977 \\
\hline
\end{tabular}

Source: Section 6.10.5.

NOTE: $\quad$ Temperature is in ${ }^{\circ} \mathrm{C}$.

$k$ is defined as $\log \mathrm{K}$, and $\mathrm{PCO}_{2}$ is the partial pressure of $\mathrm{CO}_{2}$ (in atmospheres). For the purposes of this report and ranges of this model $\left(25^{\circ} \mathrm{C}\right.$ to $100^{\circ} \mathrm{C}$ and up to 4 molal solutions), $\mathrm{mol} / \mathrm{L}$ is considered equivalent to $\mathrm{mol} / \mathrm{kg}$, and $\mathrm{PCO}_{2}$ is equivalent to $\mathrm{fCO}_{2}$.

\subsubsection{Eh Abstraction}

Table 8-5. TSPA-LA Eh Abstraction

\begin{tabular}{|c|}
\hline Equation of Eh (volts) \\
\hline $\mathrm{Eh}=2.303 \mathrm{RT} / \mathrm{F}\left(6193.973 / \mathrm{T}-\mathrm{pH}+0.25 \log \mathrm{PO}_{2}\right)$ \\
\hline
\end{tabular}

Source: Section 6.10.6

NOTE: Temperature is in $\mathrm{K}$.

$\mathrm{PO}_{2}$ is the partial pressure of $\mathrm{O}_{2}$ (in atmospheres)

\subsubsection{Fluoride and Chloride Abstraction}

Table 8-6. TSPA-LA Fluoride and Chloride Abstraction

\begin{tabular}{|c|c|c|c|c|}
\hline Water Entry Case & $\begin{array}{c}\text { Waste Package } \\
\text { Type }\end{array}$ & $\begin{array}{c}\text { Period } \\
\text { (yrs) }\end{array}$ & Max F' (Mol/kg) & $\operatorname{Max~} \mathrm{Cl}^{-}(\mathrm{Mol} / \mathrm{kg})$ \\
\hline \multirow[t]{2}{*}{ Vapor Influx } & CSNF & 0 to 20,000 & $\mathrm{~N} / \mathrm{A}$ & $\mathrm{N} / \mathrm{A}$ \\
\hline & CDSP & 0 to 20,000 & 2E-02 & $\mathrm{N} / \mathrm{A}$ \\
\hline \multirow[t]{2}{*}{ Liquid Influx } & CSNF & 0 to 20,000 & 3E-03 & 3E-03 \\
\hline & CDSP & 0 to 20,000 & 4E-03 & 4E-03 \\
\hline
\end{tabular}

Source: Sections 6.10.3 and 6.10.4.

NOTE: The CSNF waste package does not contain any $\mathrm{F}^{-}$or $\mathrm{Cl}^{-}$, so for the vapor-influx case that condenses pure water onto the waste package materials, there are no $\mathrm{F}^{-}$or $\mathrm{Cl}^{-}$abstractions. The CDSP waste package contains $\mathrm{F}^{-}$, but no $\mathrm{Cl}^{-}$.

The mapping of batch reactor cases to the abstractions is presented in Table 6-21. 


\subsection{YMRP CRITERIA}

The following acceptance criteria are from Section 2.2.1.3.3 of Yucca Mountain Review Plan, Final Report (NRC 2003 [DIRS 163274]) and are based on the requirements of 10 CFR 63.114 (a)-(c) and (e)-(g) [DIRS 173273].

\section{Acceptance Criterion 1 - System Description and Model Integration Are Adequate}

(1) TSPA adequately incorporates important design features, physical phenomena and couplings and uses consistent and appropriate assumptions throughout the quantity and chemistry of water contacting waste packages and waste forms abstraction process;

This model accurately reflects the design features of the repository, including the design of the waste package and waste form, as discussed in Sections 4.1.3 and 4.1.4, and the design of the drift as it impacts the incoming quantity and chemistry of water, as discussed in Section 4.1.2. The physical phenomena and couplings important to the process of possible degradation of the waste package and waste form, are discussed in Section 5 and in the conceptual models in Sections 6.3.1 and 6.3.2. The use of assumptions in this document is consistent throughout this document and with assumptions used in other reports, as discussed in Sections 5, 6.3.1, and 6.3.2. An example of one of these assumptions includes the oxidation state considered in this report, which is fully oxidizing for the base case, but a sensitivity study was included in Section 6.6.4, which examines the impact of using a slightly lower oxidation state used in Dissolved Concentration Limits of Radioactive Elements (BSC 2005 [DIRS 173873]). A second example is the incoming waters used in this report and is discussed in Section 4.1.2. These waters are considered in a sensitivity study in Section 6.6.2. These compositions were taken from Drift-Scale THC Seepage Model (BSC 2005 DIRS 172862]). The seepage water compositions used as input to the calculations of Engineered Barrier System: Physical and Chemical Environment Model (BSC 2004 [DIRS 169860]) are also based on the results of the THC model. A third example is the use of surface properties for iron minerals, described in Section 6.3.2 and 6.7, which are potentially different than the sorption portion of $E B S$ Radionuclide Transport (BSC 2004 [DIRS 169868]). To address this potential difference, a sensitivity study was conducted in this report using various site densities in Section 6.7.

(2) The abstraction of the quantity and chemistry of water contacting the waste packages and waste forms uses assumptions, technical bases, data and models that are appropriate and consistent with other related DOE abstractions.

The abstraction of the in-package water is described in Section 6.10, and uses assumptions, technical bases, data and models listed in Sections 5, 6.3.1, 6.3.2, and 4.1, respectively, which are consistent with other model abstractions.

The seepage rates and compositions selected as input for this model (Section 4.1.2) are consistent with Abstraction of Drift Seepage (BSC 2004 [DIRS 169131])., Physical and Chemical Environment (BSC 2004 [DIRS 169860]), and Drift-Scale THC Seepage Model (BSC 2005 [DIRS 172862]). Other models use the chemistry of the water determined in this report within the TSPA-LA and are, therefore, consistent; these models include: Waste Form and In-Drift 
Colloids (BSC 2004 [DIRS 170025]), Dissolved Concentration Limits of Radioactive Elements (BSC 2005 [DIRS 173027173873]), CSNF Waste Form Degradation (BSC 2004 [DIRS 169987]), and Defense HLW Glass Degradation (BSC 2004 [DIRS 169988]).

The significance of the quantity of water modeled as contacting the waste packages in this model is described in Section 6.10.2.4. Some assumptions in this model related to the quantity of water contacting the waste package, described in Section 6.3.1.1, could potentially differ from other TSPA-LA models, such as the quantity of water associated with the thin films described in $E B S$ Radionuclide Transport (BSC 2004 [DIRS 169868]), or the quantity of water required to fill the rind volumes associated with degraded CSNF fuel and degraded HLWG, described in CSNF Waste Form Degradation (BSC 2004 [DIRS 169987]) and Defense HLW Glass Degradation (BSC 2004 [DIRS 169988]), so the impact of these assumptions is analyzed in Section 6.6.1 and accounted for in the abstracted model in Section 6.10.2.

(3) Important design features, such as waste package design and material selection, backfill, drip shield, ground support, thermal loading strategy, and degradation processes are adequate to determine the initial and boundary conditions for calculations of the quantity and chemistry of water contacting waste packages and waste forms.

Throughout this model, information is presented related to the design of the waste package (Section 4.1.4) and waste form (Section 4.1.3), degradation processes (Sections 4.1.4 and 6.3.1.1), physical phenomena (Section 6.3.1.1), and couplings that may affect the degradation of the engineered barriers (Section 6.3.1.1). These descriptions are consistent with the information delineated elsewhere in other reports and are adequate for their intended purposes (i.e., to enable the modelers to develop and implement appropriate models and to enable the reviewer to understand the bases for the analytical activities performed by the applicant and those results)

(4) Spatial and temporal abstractions appropriately address physical couplings (thermal-hydrologic-mechanical-chemical).

The spatial abstraction for the batch reactor model is described in Section 6.3.1.1 and appropriately addresses physical couplings. The temporal abstractions appropriately address physical couplings by using degradation rates that account for coupled processes for the waste package materials and the waste forms (Sections 4.1.3 and 4.1.4). Additionally, the incoming water compositions (Section 4.1.2) are consistent with Drift-Scale THC Seepage Model (BSC 2005 [DIRS 172862]), which accounts for coupled processes.

(5) Sufficient technical bases and justification are provided for TSPA assumptions and approximations for modeling coupled T-H-M-C effects on seepage and flow, the waste package chemical environment, and the chemical environment for radionuclide release. The effects of the distribution of flow on the amount of water contacting the waste package and waste form are consistently addressed in all relevant abstractions. 
The incoming water compositions (Section 4.1.2) are consistent with Drift-Scale THC Seepage Model (BSC 2005 [DIRS 172862]), which accounts for coupled processes. The amount of water contacting the waste package and waste form is an input consistent with Abstraction of Drift Seepage (BSC 2004 [DIRS 169131]), which provides the incoming seepage rates for this report. This model does not explicitly model evaporation, which is consistent with Abstraction of Drift Seepage (BSC 2004 [DIRS 169131]), but is potentially different from other models, specifically Engineered Barrier System: Physical and Chemical Environment Model (BSC 2004 [DIRS 169860]). The justification for this difference is described in Sections 4.1.2 and 6.3.1.1, and the impacts of this potential difference are addressed in the model abstraction, as described in Section 6.10. The vapor-influx rates used in this report (Section 4.1.2), could potentially be different than other TPSA-LA models, as described in Section 6.10.2.4, including EBS Radionuclide Transport (BSC 2004 [DIRS 169868]); therefore, the impact of the rate of flow is examined in Section 6.6.5, and the results are incorporated into the abstracted results in Section 6.10. The vapor-influx rates used in this model are independent of drift conditions, as currently implemented in the TSPA-LA, which is different than Engineered Barrier System: Physical and Chemical Environment Model (BSC 2004 [DIRS 169860]), which uses in-drift environmental conditions to determine the chemistry of the water for the purposes of colloid stability. Calculation of the vapor influx rates as a function of the drift conditions is examined in an alternative conceptual model in EBS Radionuclide Transport (BSC 2004 [DIRS 169868]) as well as in this model (Section 6.4.3), and both calculations support the range of vapor influx rates selected as input to this report. The impact of varying these rates is incorporated into the ionic strength abstraction (Section 6.10.2), where the vapor influx rate is varied from 0.1 to 10 liters per year. The alternative conceptual model (Section 6.4.3) shows an alternative implementation for the TSPA-LA to calculate the vapor-influx rate based on the in-drift temperature and relative humidity.

(6) The expected ranges of environmental conditions within the waste package emplacement drifts, inside of breached waste packages, and contacting the waste forms and their evolution with time are identified. These ranges may be developed to include: (i) the effects of drip shield and backfill on the quantity and chemistry of water; (ii) conditions that promote corrosion of engineered barriers and degradation of waste forms; (iii) irregular wet and dry cycles; (iv) gamma-radiolysis; and (v) size and distribution of penetrations of waste packages.

This report uses the expected ranges of environmental conditions of the drift as inputs (Sections 4.1.2 and 6.3.1.1) and then determines the resulting ranges of environmental conditions inside the waste package (Section 6.10). The quantity of water entering the waste package is dependent upon the condition of the drip shield and waste package and the size and distribution of penetrations of waste packages, and this model varies the quantity to encompass a broad range of conditions, as described in Section 6.3.1.3. The liquid-influx rates used in this model come from Abstraction of Drift Seepage (BSC 2004 [DIRS 169131]), and vapor-influx rates come from an alternative conceptual model in EBS Radionuclide Transport (BSC 2004 [DIRS 169868]), which is enhanced in Section 6.3.4. These influx rates are calculated based on the expected environmental conditions and the conditions of the waste package and drip shield. Other environmental conditions considered in this model include $f \mathrm{CO}_{2}, f \mathrm{O}_{2}$, and temperature, which are varied across the possible range in the emplacement drifts in Sections 6.6.4 $\left(f \mathrm{CO}_{2}\right.$ and 
$\left.f \mathrm{O}_{2}\right)$ and 6.6.6 (temperature), and these results are incorporated into the abstracted results in Section 6.10. This model specifically studies the effects of gamma radiolysis on water composition, as presented in Appendix B.

(7) The model abstraction for quantity and chemistry of water contacting the waste packages and waste forms is consistent with the detailed design information on waste package design and other engineered features.

This model uses the design of the waste package and the waste package materials as input, as described in Section 4.1.4, and the input files for the model are based on this design information.

(8) Adequate technical bases are provided, including activities such as independent modeling, laboratory or field data, or sensitivity studies, for inclusion of any T-H-M-C couplings and features, events and processes;

This model is validated by laboratory data that studies coupled processes, as described in Section 7.2.2. The corrosion rates used by this model were determined by laboratory and field data, which include couplings, as described in Sections 4.1.3 and 4.1.4. This report addresses eight FEPs considered appropriate, as is discussed in Section 6.2. Table 6-1 includes a detailed listing of where within this report the specific FEPs are discussed and addressed. The technical information contained in Sections 4, 5, 6, and 7 is sufficient to provide the basis for the inclusion or exclusion decisions related to these FEPs.

(9) Performance affecting processes that have been observed in thermal-hydrologic tests are included in the TSPA.

The effects observed in thermal-hydrologic tests and experiments (from the drift scale test) are used for validation purposes in Drift-Scale THC Seepage Model (BSC 2005 [DIRS 172862], Section 7.1), and the incoming water compositions (Section 4.1.2) are consistent with that model.

(10) Likely modes for container corrosion are identified and considered in determining the quantity and chemistry of water entering the waste packages and contacting the waste forms.

The quantity of water entering the waste package is dependent upon the condition of the drip shield and waste package and the size and distribution of penetrations of waste packages, and this model varies the quantity to encompass a broad range of conditions, as described in Section 6.3.1.3. Section 6.10 determines the chemistry of the water within the waste package is a function of the degradation of the waste package materials and waste forms. These degradation processes are described in Sections 6.3.1 and 6.3.2.

(11) The abstraction of the in-package criticality or external-to-package criticality within the emplacement drifts provides an adequate technical basis for screening these events. If either event is included in the TSPA, then the DOE uses acceptable technical bases for selecting the design criteria that mitigate the potential impact of in-package criticality on the repository performance; identifies the FEPs that may increase the reactivity of the system inside the waste package, identifies the configuration classes and configurations that have the 
potential for nuclear criticality; and includes changes in thermal conditions and degradation of engineered barriers in the abstraction of the quantity and chemistry of water contacting waste packages and waste forms.

The subject of potential criticality is discussed in other reports. This criterion is considered not to be applicable to this report.

(12) Guidance in NUREG 1297 and NUREG 1298 (Altman et al. 1988 a, b) or other acceptable approaches is followed.

The information contained in this report is based on established physical models, justified assumptions and previously qualified input data. As a result, there was no need to use the guidance of NUREG 1297 and/or NUREG 1298 in the development of this report.

\section{Acceptance Criterion 2 - Data Are Sufficient For Model Justification}

(1) Geological, hydrological and geochemical values used in the License Application are adequately justified. Adequate description of how the data were used, interpreted and appropriately synthesized into the parameters is provided.

The sources for the geological, hydrological, and geochemical data are justified in Sections 4.1.1 through 4.1.6 and 6.3.1.3 describes how the data were used and converted into values appropriate for the model input files. The chemical thermodynamic database used in the modeling was developed specifically for the project and is consistent with the thermodynamic data being used by other reports.

(2) Sufficient data were collected on the characteristics of the natural system and engineered materials to establish initial and boundary conditions for conceptual models of T-H-M-C coupled processes that affect seepage and flow and the waste package environment;

The sources for the geological, hydrological, and geochemical data (Sections 4.1.1 through 4.1.6) come from a broad body of data collected on the characteristics of the natural system and engineered materials. Section 6.3.1.3 describes how the data were used to establish initial and boundary conditions.

(3) Thermo-hydrologic tests were designed and conducted with the explicit objective of observing $T$ - $H$ processes for the temperature ranges anticipated in the repository and making measurements for mathematical models. Data are sufficient to verify that $T-H$ conceptual models address important $T-H$ phenomena;

Natural system data are used to develop Drift-Scale THC Seepage Model (BSC 2005 [DIRS 172862]), which is consistent with the water composition input to this model (Section 6.6). The natural system data are used to establish initial and boundary conditions that affect seepage and flow and are discussed in Section 6.3.1.1. 
(4) Sufficient information to formulate the conceptual approaches for analyzing water contact with the drip shield, waste packages and waste forms is provided;

The conceptual model for water contacting the waste package materials and waste forms is provided in Section 6.3.1.1.

(5) Sufficient data are provided to complete a nutrient and energy inventory calculation, if it has been used to justify the inclusion of the potential for microbial activity affecting the waste package chemical environment and chemical environment for radionuclide release. As necessary, data are adequate to support determination of the probability for microbially induced corrosion and microbial effects, such as the production of organic by-products and microbially enhanced dissolution of the high-level radioactive waste glass form.

Microbially influenced corrosion is not addressed in this report.

\section{Acceptance Criterion 3 - Data Uncertainty is Characterized and Propagated Through the Model Abstraction}

Most of the input values were treated as variables and were varied over a wide range of possible values for the base case (Sections 6.3.1 and 6.3.2). In addition, many sensitivity analyses (Section 6.6) were run, which varied additional parameters, as well as expanded range of values that were used in the base case. The results of these analyses were used in the abstraction of the model to ensure that the model output captured the full possible range of variability (Section 6.10). In this way, the results of this model capture the expected behavior and the most extreme possibilities, so do not underrepresent the estimate of risk.

(1) Models use parameter values, assumed ranges, probability distributions and/or bounding assumptions that are technically defensible, reasonably account for uncertainties and variabilities, and do not result in under-representation of the risk estimate.

Each of the models developed in this report use parameter values, assumed ranges, probability distributions or bounding assumptions, or both, that are technically defensible, reasonably account for uncertainties and variabilities, and do not result in underrepresentation of the risk estimate. In each situation, discussion and consideration of the uncertainties associated with specific data are addressed in detail. The treatment of uncertainty is explicitly addressed in Section 6.10.8 and specific sections throughout the document including Sections 6.6 and 6.10.2..

(2) Parameter values, assumed ranges, probability distributions and bounding assumptions used in the TSPA calculations of quantity and chemistry of water contacting waste packages and waste forms are technically defensible and reasonable based on data from the Yucca Mountain region (e.g., results from large block and drift-scale heater and niche tests) and a combination of techniques that may include laboratory experiments, field measurements, natural analog research and process modeling studies. 
The models developed and discussed in this AMR use three different input water compositions for the base case, two of which are based on waters obtained from core samples proximal to the repository. The model uses three additional water compositions from Drift-Scale THC Seepage Model (BSC 2005 [DIRS 172862]) in a sensitivity analysis in Section 6.6.2. This subject is discussed in detail in Sections 4.1.2 and 6.3.1.3.1.

(3) Input values used in the TSPA calculations of quantity and chemistry of water contacting engineered barriers (e.g., drip shield and waste package) are consistent with the initial and boundary conditions and the assumptions of the conceptual models and design concepts for the Yucca Mountain site. Correlations between input values are appropriately established in the DOE TSPA. Parameters used to define initial conditions, boundary conditions and computational domain in sensitivity analyses involving coupled T-H-M-C effects on seepage and flow, the waste package chemical environment, and the chemical environment for radionuclide release, are consistent with available data. Reasonable or conservative ranges of parameters or functional relations are established.

The inputs to this model (Section 4.1.1 through 4.1.6) are consistent with initial boundary conditions and design concepts for the Yucca Mountain site because they come from various design documents and other related model reports. The results of this model (and others) are validated by comparison with laboratory data and natural analog, as described in Section 7.2. The model abstraction, developed in Section 6.10, uses reasonable and conservative abstractions to capture the range of output.

(4) Adequate representations of the uncertainties in the characteristics of the natural systems and engineered materials is provided in the parameter development for conceptual models, process level models, and alternative conceptual models. The DOE may constrain these uncertainties using sensitivity analyses or conservative limits.

Most of the input values were treated as variables and were varied over a wide range of possible values for the base case (Section 6.3.1 and 6.3.2). In addition, many sensitivity analyses (Section 6.6) were run, which varied additional parameters, as well as expanded range of values that were used in the base case. The results of these analyses were used in the abstraction of the model to ensure that the model output captured the full possible range of variability (Section 6.10). In this way, the results of this model capture the expected behavior and the most extreme possibilities, so do not under-represent the estimate of risk.

(5) If criticality is included in the TSPA, then the DOE uses an appropriate range of input parameters for calculating the effective neutron multiplication factor;

The subject of possible criticality either in or external to the waste package is not discussed in this report. As such, this criterion is considered not to be applicable to this report. 
(6) Where sufficient data do not exist, the definition of parameter values and conceptual models is based on appropriate use of other sources, such as expert elicitation conducted in accordance with NUREG-1563.

The information contained in this report is based on established physical models, justified assumptions and previously qualified input data. As a result, there was no need to use other sources, such as expert elicitation conducted in accordance with NUREG-1563, in the development of this report.

\section{Acceptance Criterion 4 - Model Uncertainty is Characterized and Propagated Through the Model Abstraction}

Uncertainties in inputs and in the methodology are considered in the development of the conceptual model (Sections 6. 3) and output parameters (Section 6.10). Discussion of uncertainty in the conceptual model appears in various places throughout the report. The model uncertainty is consistent with available site data, laboratory experiments and natural analog as described in Section 7. The use of the output of the model by TSPA-LA was analyzed and the uncertainty treatment was altered so as to lead to the most conservative results with respect to colloid stability and radionuclide solubility and thus resulted in over-representation of the risk estimate.

(1) Alternative modeling approaches of FEPs are considered and are consistent with available data and current scientific understanding; and the results and limitations are appropriately considered in the abstraction.

This report explicitly addresses alternative conceptual models related to the makeup of the water entering the waste package after postulated breach and the manner in which this water transits the waste package following entry in Section 6.4. Although due consideration was given to the use of these models, it was determined that the selected "base-case" model and selected input data is sufficient, robust and adequate for its intended purpose and that the use of the alternative conceptual models was not warranted.

(2) Alternative modeling approaches are considered and the selected modeling approach is consistent with available data and current scientific understanding. A description that includes a discussion of alternative modeling approaches not considered in the final analysis and the limitations and uncertainties of the chosen model is provided

This report explicitly addresses alternative conceptual models related to the make-up of the water entering the waste package after postulated breach and the manner in which this water transits the waste package following entry in Section 6.4. Although due consideration was given to the use of these models, it was determined that the selected "base-case" model and selected input data is sufficient, robust and adequate for its intended purpose and that the use of the alternative conceptual models was not warranted.

(3) Consideration of conceptual model uncertainty is consistent with available site characterization data, laboratory experiments, field measurements, natural 
analog information, and process-level modeling studies; and the treatment of uncertainty does not result in under-representation of the risk estimate.

Each of the models developed in this report use parameter values, assumed ranges, probability distributions or bounding assumptions that are consistent with available site characterization data, technically defensible, reasonably account for uncertainties and variabilities, and do not result in underrepresentation of the risk estimate. In each situation, discussion and consideration of the uncertainties associated with specific data are addressed in detail. The treatment of uncertainty is explicitly addressed in Section 6.10.8 and specific sections throughout the document, including Sections 6.6 and 6.10.2..

(4) Adequate consideration is given to the effects of thermal-hydrologic-mechanical-chemical coupled processes in the assessment of alternative conceptual models.

Alternative Conceptual Model I (Section 6.4.1) considers the effects of a nonhomogenous system as a result of coupled processes, such as the effects of gas and changes in boundary conditions. Alternative Conceptual Model II (Section 6.4.2) considers the composition of seepage entering a waste package is likely to vary as a function of changing conditions in the unsaturated zone and drift environments.

(5) If the DOE uses an equivalent continuum model for the TSPA abstraction, the models produce conservative estimates of the effects of coupled THMC processes on calculated compliance with post-closure public health and environmental standards.

The subject of an equivalent continuum model is not discussed in this report. As such, this criterion is considered not to be applicable to this report.

\section{Acceptance Criterion 5 - Model Abstraction Output is Supported By Objective Comparisons}

The output of the model abstraction was compared with laboratory experiments and natural analog as described in Section 7.2. There are no confirmatory actions, such as compliance runs, additional sensitivity runs, and neutralization runs associated with this report.

(1) The models implemented in this TSPA abstraction provide results consistent with output from detailed process level models and/or empirical observations (laboratory and field testings and/or natural analogues);

The results of models implemented in this total system performance assessment abstraction were compared with results from detailed process-level models and or empirical observations (laboratory and field testing, or natural analogs) to ensure consistency. The results of such comparisons are addressed in Section 7 and Appendix E.

(2) Abstracted models for coupled THMC effects on seepage and flow and the waste package chemical environment, as well as on the chemical environment for radionuclide release, are based on the same assumptions and approximations 
demonstrated to be appropriate for process level models or closely analogous natural or experimental systems.

The model abstraction is validated in Section 7.3, and is based on the same assumptions and approximations used in other reports.

(3) Accepted and well-documented procedures are used to construct and test the numerical models that simulate coupled THMC effects on seepage and flow, waste package chemical environment, and the chemical environment for radionuclide release. Analytical and numerical models are appropriately supported. Abstracted model results are compared with different mathematical models to judge robustness of results.

Accepted and well-documented procedures contained in the quality assurance program (Section 2) governed the development of this report and the work it documents. This model was constructed, supported, and documented according to LP-SIII.2Q-BSC. Test and validation methods (Section 7), including comparison of abstracted output with that of other relevant models, also comply with LP-SIII.2Q-BSC, as well as with applicable written guidance. This report was generated according to the requirements of Technical Work Plan for Postclosure Waste Form Modeling (BSC 2005 [DIRS 173246]) as directed by LP-2.29Q-BSC, Planning for Science Activities. 
INTENTIONALLY LEFT BLANK 


\section{INPUTS AND REFERENCES}

\subsection{DOCUMENTS CITED}

159372 Allen, B.L. and Hajek, B.F. 1995. "Mineral Occurrence in Soil Environments." Chapter 5 of Minerals in Soil Environments. 2nd Edition. Dixon, J.B. and Weed, S.B., eds. SSSA Book Series, No. 1. Madison, Wisconsin: Soil Science Society of America. TIC: 237222.

$171707 \quad$ Allison, J.D.; Brown, D.S.; and Novo-Gradac, K.J. 1991. MINTEQA2/PRODEFA2, A Geochemical Assessment Model for Environmental Systems: Version 3.0 User's Manual. EPA/600/3-91/021. Athens, Georgia: U.S. Environmental Protection Agency, Office of Research and Development. TIC: 240804.

168734 Allison, J.M. 2004. "Request for Referenceable Information on High-Level Waste (HLW) Radionuclide Inventories in Support of Preparation of the Yucca Mountain Project License Application (Your Letter, JCP-0445, 1/28/04)." Memorandum from J.M. Allison (DOE/SR) to J. Arthur, III (OCRWM), February 26, 2004, 0303040661, with attachment. ACC: MOL.20040317.0265.

167071 Angus, N.S.; Brown, G.T.; and Cleere, H.F. 1962. "The Iron Nails from the Roman Legionary Fortress at Inchtuthil, Perthshire." Journal of The Iron and Steel Institute, 200, 956-957. London, England: Iron and Steel Institute. TIC: 255544.

172038 Appelo, C.A.J. and Postma, D. 1999. Geochemistry, Groundwater and Pollution. Brookfield, Vermont: A.A. Balkema. TIC: 250797.

168168 Appelo, C.A.J.; Van der Weiden, M.J.J.; Tournassat, C.; and Charlet, L. 2002. "Surface Complexation of Ferrous Iron and Carbonate on Ferrihydrite and the Mobilization of Arsenic." Environmental Science \& Technology, 36, (14), 3096-3103. Washington, D.C.: American Chemical Society. TIC: 255581.

149625 Audi, G. and Wapstra, A.H. 1995. Atomic Mass Adjustment, Mass List for Analysis. Upton, New York: Brookhaven National Laboratory, National Nuclear Data Center. TIC: 242718.

104439 B\&W Fuel Company 1991. Final Design Package Babcock \& Wilcox BR-100 100 Ton Rail/Barge Spent Fuel Shipping Cask. Volume 2. 51-1203400-01. DBABE0000-00272-1000-00014 REV 00. Lynchburg, Virginia: B\&W Fuel Company. ACC: MOV.19960802.0083.

163015 Ball, J.W. and Nordstrom, D.K. 1998. "Critical Evaluation and Selection of Standard State Thermodynamic Properties for Chromium Metal and its Aqueous Ions, Hydrolysis Species, Oxides, and Hydroxides." Journal of Chemical \& Engineering Data, 43, (6), 895-918. Washington, D.C.: American Chemical Society. TIC: 254015. 
106164 Baxter, R.G. 1988. Defense Waste Processing Facility Wasteform and Canister Description. DP-1606, Rev. 2. Aiken, South Carolina: E.I. du Pont de Nemours \& Company, Savannah River Plant. TIC: 8704.

161746 Berner, E.K. and Berner, R.A. 1996. Global Environment: Water, Air, and Geochemical Cycles. Upper Saddle River, New Jersey: Prentice Hall. TIC: 253965.

103524 Bird, R.B.; Stewart, W.E.; and Lightfoot, E.N. 1960. Transport Phenomena. New York, New York: John Wiley \& Sons. TIC: 208957.

154467 Brady, P.V. 1992. "Silica Surface Chemistry at Elevated Temperatures." Geochimica et Cosmochimica Acta, 56, 2941-2946. New York, New York: Pergamon Press. TIC: 235218.

$157873 \quad$ Bricker, O. 1965. "Some Stability Relations in the System $\mathrm{Mn}-\mathrm{O}_{2}-\mathrm{H}_{2} \mathrm{O}$ at $25^{\circ}$ and One Atmosphere Total Pressure." American Mineralogist, 50, 1296-1354. Washington, D.C.: Mineralogical Society of America. TIC: 238855.

$154880 \quad$ BSC 2001. Software Management Report (SMR) for transl V.2.0. 10251-SMR-2.0-00. Las Vegas, Nevada: Bechtel SAIC Company. ACC: MOL.20010813.0419.

154877 BSC 2001. User Manual (UM) for PHREEQC Version 2.3. SDN: 10068-UM-2.3-00. Las Vegas, Nevada: Bechtel SAIC Company. ACC: MOL.20010525.0172.

$169110 \quad$ BSC 2003. PWR Assembly End-Effect Reactivity Evaluation. CAL-UDC-NU-000006 REV 00, with 01 errata. Las Vegas, Nevada: Bechtel SAIC Company. ACC: MOL.20010412.0158; DOC.20031014.0007.

$170710 \quad$ BSC 2004. 21-PWR Waste Package Configuration. 000-MW0-DSU0-00403-000-00D. Las Vegas, Nevada: Bechtel SAIC Company. ACC: ENG.20040708.0005.

172553 BSC 2004. 21-PWR Waste Package with Absorber Plates Loading Curve Evaluation. CAL-DSU-NU-000006 REV 00C. Las Vegas, Nevada: Bechtel SAIC Company. ACC: DOC.20041220.0002.

169131 BSC 2004. Abstraction of Drift Seepage. MDL-NBS-HS-000019, Rev. 01. Las Vegas, Nevada: Bechtel SAIC Company.

169982 BSC 2004. Aqueous Corrosion Rates for Waste Package Materials. ANL-DSD-MD-000001 REV 01. Las Vegas, Nevada: Bechtel SAIC Company. ACC: DOC.20041012.0003. 
170019 BSC 2004. Clad Degradation - FEPs Screening Arguments. ANL-WIS-MD-000008 REV 02. Las Vegas, Nevada: Bechtel SAIC Company. ACC: DOC.20041020.0014.

169987 BSC 2004. CSNF Waste Form Degradation: Summary Abstraction. ANL-EBS-MD-000015 REV 02. Las Vegas, Nevada: Bechtel SAIC Company. ACC: DOC.20040908.0001.

169988 BSC 2004. Defense HLW Glass Degradation Model. ANL-EBS-MD-000016 REV 02. Las Vegas, Nevada: Bechtel SAIC Company.

ACC: DOC.20041020.0015.

168199 BSC 2004. Design and Engineering, Interface Ring. 000-MW0-MGR0-00201-000-00A. Las Vegas, Nevada: Bechtel SAIC Company. ACC: ENG.20040309.0013.

168253 BSC 2004. Design and Engineering, Spread Ring Sub-Assembly. 000-MW0-MGR0-01801-000-00A. Las Vegas, Nevada: Bechtel SAIC Company. ACC: ENG.20040309.0022.

172453 BSC 2004. DSNF and Other Waste Form Degradation Abstraction. ANL-WISMD-000004 REV 04. Las Vegas, Nevada: Bechtel SAIC Company. ACC: DOC.20041201.0007.

169868 BSC 2004. EBS Radionuclide Transport Abstraction. ANL-WIS-PA-000001, Rev. 01. Las Vegas, Nevada: Bechtel SAIC Company. ACC: DOC.20041118.0006.

169898 BSC 2004. Engineered Barrier System Features, Events, and Processes. ANL-WIS-PA-000002, Rev. 03. Las Vegas, Nevada: Bechtel SAIC Company. ACC: DOC.20041122.0008.

169860 BSC 2004. Engineered Barrier System: Physical and Chemical Environment. ANL-EBS-MD-000033 REV 03. Las Vegas, Nevada: Bechtel SAIC Company. ACC: DOC.20041201.0001; DOC.20050411.0004.

172017 BSC 2004. Gamma and Neutron Radiolysis in the 21-PWR Waste Package from Ten to One Million Years. 000-00C-DSU0-00700-000-00A. Las Vegas, Nevada: Bechtel SAIC Company. ACC: ENG.20041013.0008.

169984 BSC (Bechtel SAIC Company) 2004. General Corrosion and Localized Corrosion of Waste Package Outer Barrier. ANL-EBS-MD-000003 REV 02. Las Vegas, Nevada: Bechtel SAIC Company. ACC: DOC.20041004.0001.

170022 BSC 2004. Initial Radionuclide Inventories. ANL-WIS-MD-000020 REV 01. Las Vegas, Nevada: Bechtel SAIC Company. ACC: DOC.20040921.0003. 
170043 BSC 2004. Pitting Model for Zirconium-Alloyed Cladding. MDL-WIS-MD-000001 REV 01. Las Vegas, Nevada: Bechtel SAIC Company. ACC: DOC.20040827.0009.

171916 BSC 2004. Qualification of Thermodynamic Data for Geochemical Modeling of Mineral-Water Interactions in Dilute Systems. ANL-WIS-GS-000003 REV 00. Las Vegas, Nevada: Bechtel SAIC Company. ACC: DOC.20041129.0006.

170025 BSC 2004. Waste Form and In-Drift Colloids-Associated Radionuclide Concentrations: Abstraction and Summary. MDL-EBS-PA-000004 REV 01. Las Vegas, Nevada: Bechtel SAIC Company. ACC: DOC.20041028.0007.

172214 BSC 2004. Waste Package Masses. 000-00C-MGR0-01100-000-00C. Las Vegas, Nevada: Bechtel SAIC Company. ACC: ENG.20040927.0001.

$170020 \quad$ BSC 2004. Waste-Form Features, Events, and Processes. ANL-WIS-MD-000009 REV 02. Las Vegas, Nevada: Bechtel SAIC Company. ACC: DOC.20041028.0006.

$173501 \quad$ BSC 2005. IED Waste Package Configuration [Sheet 1 of 1]. 800-IED-WIS0-00601-000-00A. Las Vegas, Nevada: Bechtel SAIC Company. ACC: ENG.20050406.0005.

173873 BSC 2005. Dissolved Concentration Limits of Radioactive Elements. ANL-WIS-MD-000010 REV 04. Las Vegas, Nevada: Bechtel SAIC Company. ACC: DOC.20050525.0003.

174225 BSC 2005. DOE and Commercial Waste Package System Description Document. 000-3YD-DS00-00100-000-006. Las Vegas, Nevada: Bechtel SAIC Company. ACC: ENG.20050620.0002.

172862 BSC 2005. Drift-Scale THC Seepage Model. MDL-NBS-HS-000001 REV 04. Las Vegas, Nevada: Bechtel SAIC Company. ACC: DOC.20050218.0001.

173944 BSC (Bechtel SAIC Company) 2005. Multiscale Thermohydrologic Model. ANLEBS-MD-000049 REV 03. Las Vegas, Nevada: Bechtel SAIC Company. ACC: DOC.20050711.0001.

171190 BSC 2005. Q-List. 000-30R-MGR0-00500-000-001. Las Vegas, Nevada: Bechtel SAIC Company. ACC: ENG.20050217.0010.

173246 BSC 2005. Technical Work Plan for Postclosure Waste Form Modeling. TWP-WIS-MD-000014 REV 01. Las Vegas, Nevada: Bechtel SAIC Company. ACC: DOC.20050407.0008. 
161921 Christensen, H. 1995. "Remodeling of the Oxidant Species During Radiolysis of High-Temperature Water in a Pressurized Water Reactor." Nuclear Technology, 109, 373-382. La Grange Park, Illinois: American Nuclear Society.

TIC: 253765.

161918 Christensen, H. and Bjergbakke, E. 1982. Radiolysis of Ground Water from Spent Fuel. SKB TR-82-18. Stockholm, Sweden: Svensk Kärnbränsleförsörjning A.B. TIC: 205896.

161919 Christensen, H.; Sunder, S.; and Shoesmith, D.W. 1994. Development of a Kinetic Model to Predict the Rate of Oxidation and Dissolution of Nuclear Fuel $\left(\mathrm{UO}_{2}\right)$ by the Radiolysis of Water. AECL-11102. Pinawa, Manitoba, Canada: Atomic Energy of Canada Limited. TIC: 242350.

164025 Cornell, R.M.; Giovanoli, R.; and Schneider, W. 1992. "The Effect of Nickel on the Conversion of Amorphous Iron(III) Hydroxide into More Crystalline Iron Oxides in Alkaline Media." Journal of Chemical Technology and Biotechnology, 53, (1), 73-79. Oxford, England: Blackwell Scientific Publishing. TIC: 254448.

$102824 \quad$ CRWMS M\&O 1997. Criticality Evaluation of Degraded Internal Configurations for the PWR AUCF WP Designs.

BBA000000-01717-0200-00056 REV 00. Las Vegas, Nevada: CRWMS M\&O. ACC: MOL.19971231.0251.

100222 CRWMS M\&O 1997. Degraded Mode Criticality Analysis of Immobilized Plutonium Waste Forms in a Geologic Repository. Predecisional Document. A00000000-01717-5705-00014 REV 01. Las Vegas, Nevada: CRWMS M\&O. ACC: MOL.19980422.0911.

104440 CRWMS M\&O 1998. Summary Report of Commercial Reactor Criticality Data for Crystal River Unit 3. B00000000-01717-5705-00060 REV 01. Las Vegas, Nevada: CRWMS M\&O. ACC: MOL.19980728.0189.

151947 CRWMS M\&O 2000. Source Terms for HLW Glass Canisters. CAL-MGR-NU-000002 REV 01. Las Vegas, Nevada: CRWMS M\&O. ACC: MOL.20000823.0004.

153263 CRWMS M\&O 2001. EQ6 Calculations for Chemical Degradation of N Reactor (U-metal) Spent Nuclear Fuel Waste Packages. CAL-EDC-MD-000010 REV 00. Las Vegas, Nevada: CRWMS M\&O. ACC: MOL.20010227.0017.

163339 Cutlip, M.B. and Shacham, M. 2000. Problem Solving in Chemical Engineering with Numerical Methods. Upper Saddle River, New Jersey: Prentice Hall.

TIC: 254281. 
103803 Daveler, S.A. and Wolery, T.J. 1992. EQPT, A Data File Preprocessor for the EQ3/6 Software Package: User's Guide and Related Documentation (Version 7.0). UCRL-MA-110662 PT II. Livermore, California: Lawrence Livermore National Laboratory. TIC: 205240.

154436 Davis, J.A.; Coston, J.A.; Kent, D.B.; and Fuller, C.C. 1998. "Application of the Surface Complexation Concept to Complex Mineral Assemblages."

Environmental Science \& Technology, 32, (19), 2820-2828. Washington, D.C.: American Chemical Society. TIC: 249656.

168855 Davis, J.A.; Payne, T.E.; and Waite, T.D. 2002. "Simulating the $\mathrm{pH}$ and $\mathrm{pCO}_{2}$ Dependence of Uranium(VI) Adsorption by a Weathered Schist with Surface Complexation Models." Chapter 4 of Geochemistry of Soil Radionuclides. SSSA Special Publication Number 59. Zhang, P-C. and Brady, P.V., eds. Madison, Wisconsin: Soil Science Society of America. TIC: 253952.

102773 Deer, W.A.; Howie, R.A.; and Zussman, J. 1966. An Introduction to the Rock-Forming Minerals. New York, New York: John Wiley \& Sons. TIC: 245492.

159374 Dixon, J.B. 1995. "Kaolin and Serpentine Group Minerals.” Chapter 10 of Minerals in Soil Environments. 2nd Edition. Dixon, J.B. and Weed, S.B., eds. SSSA Book Series, No. 1. Madison, Wisconsin: Soil Science Society of America. TIC: 237222.

150095 DOE (U.S. Department of Energy) 2000. N Reactor (U-Metal) Fuel Characteristics for Disposal Criticality Analysis. DOE/SNF/REP-056, Rev. 0. Washington, D.C.: U.S. Department of Energy, Office of Environmental Management. TIC: 247956.

102812 DOE (U.S. Department of Energy) 1992. Characteristics of Potential Repository Wastes. DOE/RW-0184-R1. Volume 1. Washington, D.C.: U.S. Department of Energy, Office of Civilian Radioactive Waste Management.

ACC: HQO.19920827.0001.

152658 DOE 2000. Review of Oxidation Rates of DOE Spent Nuclear Fuel, Part 1: Metallic Fuel. DOE/SNF/REP-054, Rev. 0. Washington, D.C.: U.S. Department of Energy. TIC: 248978.

158405 DOE 2002. DOE Spent Nuclear Fuel Information in Support of TSPA-SR. DOE/SNF/REP-047, Rev. 2. Idaho Falls, Idaho: U.S. Department of Energy, Idaho Operations Office. TIC: 252089.

168434 DOE 2004. Interim Report on the Corrosion Performance of a Neutron Absorbing Ni-Cr-Mo-Gd Alloy. DOE/SNF/REP-086, Rev. 0. Idaho Falls, Idaho: U.S. Department of Energy, Idaho Operations Office.

ACC: DOC.20040412.0001. 
170071 DOE 2004. Packaging Strategies for Criticality Safety for “Other” DOE Fuels in a Repository. DOE/SNF/REP-090, Rev. 0. Idaho Falls, Idaho: U.S. Department of Energy, Idaho Operations Office. ACC: MOL.20040708.0386.

100725 Drever, J.I. 1982. The Geochemistry of Natural Waters. Englewood Cliffs, New Jersey: Prentice Hall. TIC: 240706.

105483 Dzombak, D.A. and Morel, F.M.M. 1990. Surface Complexation Modeling, Hydrous Ferric Oxide. New York, New York: John Wiley \& Sons.

TIC: 224089.

105780 Eary, L.E. and Rai, D. 1987. "Kinetics of Chromium(III) Oxidation to Chromium(VI) by Reaction with Manganese Dioxide." Environmental Science \& Technology, 21, (12), 1187-1193. Washington, D.C.: American Chemical Society. TIC: 243224.

161749 Ewing, R.C. and Haaker, R.F. 1979. Naturally Occurring Glasses: Analogues for Radioactive Waste Forms. PNL-2776. Richland, Washington: Pacific Northwest Laboratory. ACC: NNA.19900315.0277.

145442 Finch, R.J. and Murakami, T. 1999. "Systematics and Paragenesis of Uranium Minerals." Chapter 3 of Uranium: Mineralogy, Geochemistry and the Environment. Burns, P.C. and Finch, R.J., eds. Reviews in Mineralogy Volume 38. Washington, D.C.: Mineralogical Society of America.

TIC: 247121.

106357 Firsching, F.H. and Brune, S.N. 1991. "Solubility Products of the Trivalent Rare-Earth Phosphates." Journal of Chemical Engineering Data, 36, 93-95. Washington, D.C.: American Chemical Society. TIC: 240863.

$173728 \quad$ Franks, F. 1975. Water, A Comprehensive Treatise. Volume 5 of Water in Disperse Systems. New York, New York: Plenum Press. TIC: 257268.101173

Freeze, R.A. and Cherry, J.A. 1979. Groundwater. Englewood Cliffs, New Jersey: Prentice-Hall. TIC: 217571.

113233 Grambow, B. 1989. Spent Fuel Dissolution and Oxidation: An Evaluation of Literature Data. SKB TR-89-13. Stockholm, Sweden: Svensk Kärnbränsleförsörjning A.B. TIC: 208579.

109691 Gray, W.J. and Einziger, R.E. 1998. Initial Results from Dissolution Rate Testing of N-Reactor Spent Fuel Over a Range of Potential Geologic Repository Aqueous Conditions. DOE/SNF/REP-022, Rev. 0. Washington, D.C.: U.S. Department of Energy. TIC: 245380.

164947 Hamel, W.F. 2003. "Waste Treatment and Immobilization Plant (WTP) High-Level Waste (HLW) Canister Production Estimates to Support Analyses by the Yucca Mountain Project." Memorandum from W.F. Hamel (DOE) to W.J. Taylor, June 26, 2003, with attachment. ACC: MOL.20030828.0080. 
100814 Harrar, J.E.; Carley, J.F.; Isherwood, W.F.; and Raber, E. 1990. Report of the Committee to Review the Use of J-13 Well Water in Nevada Nuclear Waste Storage Investigations. UCID-21867. Livermore, California: Lawrence Livermore National Laboratory. ACC: NNA.19910131.0274.

115670 Hem, J.D. 1985. Study and Interpretation of the Chemical Characteristics of Natural Water. 3rd Edition. Geological Survey Water-Supply Paper 2254. Washington, D.C.: U.S. Government Printing Office. ACC: NNA.19940427.0181.

173263 Housiadas, C.; Papanicolaou, E.; and Drossinos, Y. 2002. "Combined Heat and Mass Transfer in Laminar Flow Diffusion Nucleation Chambers.” Journal of Aerosol Science, 33, 797-816. [New York, New York]: Pergamon. TIC: 257126.

105875 Hsu, P.H. 1995. "Aluminum Hydroxides and Oxyhydroxides." Chapter 7 of Minerals in Soil Environments. 2nd Edition. Dixon, J.B. and Weed, S.B., eds. SSSA Book Series, No. 1. Madison, Wisconsin: Soil Science Society of America. TIC: 237222.

$158974 \quad$ HydroGeoLogic and Allison Geoscience Consultants. 1999. MINTEQA2/PRODEFA2, A Geochemical Assessment Model for Environmental Systems: User Manual Supplement for Version 4.0. Athens, Georgia: U.S. Environmental Protection Agency, National Exposure Research Laboratory. TIC: 252456.

150560 IAEA (International Atomic Energy Agency) 1998. Waterside Corrosion of Zirconium Alloys in Nuclear Power Plants. IAEA-TECDOC-996. Vienna, Austria: International Atomic Energy Agency. TIC: 248234.

105878 Johnson, C.A. and Xyla, A.G. 1991. "The Oxidation of Chromium (III) to Chromium (VI) on the Surface of Manganite (MnOOH)." Geochimica et Cosmochimica Acta, 55, 2861-2866. New York, New York: Pergamon Press. TIC: 243616.

$161606 \quad$ Kerr, P.F. 1977. Optical Mineralogy. 4th Edition. New York, New York: McGraw-Hill. TIC: 252886.

105907 Klein, C. and Hurlbut, C.S., Jr. 1985. Manual of Mineralogy. 20th Edition. New York, New York: John Wiley \& Sons. TIC: 242818.

$107760 \quad$ Kügler, A. 1996. Böhler Neutronit A976 Sheet and Plate for Nuclear Engineering. Murzzuschlag, Austria: Böhler Bleche GmbH. TIC: 240558.

$100051 \quad$ Langmuir, D. 1997. Aqueous Environmental Geochemistry. Upper Saddle River, New Jersey: Prentice Hall. TIC: 237107. 
159034 Li, G.; Peacor, D.R.; Coombs, D.S.; and Kawachi, Y. 1997. "Solid Solution in the Celadonite Family: The New Minerals Ferroceladonite, $\mathrm{K}_{2} \mathrm{Fe}_{2}{ }^{2}+\mathrm{Fe}_{3}{ }^{2}+\mathrm{Si}_{8} \mathrm{O}_{20}(\mathrm{OH})_{4}$, and Ferroaluminoceladonite, $\mathrm{K}_{2} \mathrm{Fe}_{2}{ }^{2}+\mathrm{Al}_{2} \mathrm{Si}_{8} \mathrm{O}_{20}(\mathrm{OH})_{4}$." American Mineralogist, 82, (5-6), 503-511. Washington, D.C.: Mineralogical Society of America. TIC: 252472.

171509 Mahé-Le Carlier, C.; Le Carlier de Veslud, C.; Ploquin, A.; and Royer, J-J. 2000. "Natural Weathering of Archaeo-Methallurgical Slags: An Analog for Present Day Vitrified Wastes." Earth and Planetary Sciences, 330, 179-184. New York, New York: Elsevier. TIC: 256502.

172949 Marra, J. and Ebert, W. 2003. Accounting for a Vitrified Plutonium Waste Form in the Yucca Mountain Repository Total System Performance Assessment (TSPA). WSRC-TR-2003-00530. Aiken, South Carolina: Westinghouse Savannah River Company. ACC: MOL.20050308.0057.

165219 McKenzie, J.M. 2002. Naval Nuclear Propulsion Program Technical Baseline Compliance Document, Revision 1, October 2002. Letter from J.M. McKenzie (DOE) to J. Williams (DOE/OCRWM), November 19, 2002, NR:RA:RWIshihara U\#02-2852, with enclosure. ACC: HQO.20030502.0028; HQO.20030502.0029.

$156684 \quad$ Miller, W.; Alexander, R.; Chapman, N.; McKinley, I.; and Smellie, J. 2000. Geological Disposal of Radioactive Wastes \& Natural Analogues, Lessons from Nature and Archaeology. Waste Management Series, Volume 2. New York, New York: Pergamon. TIC: 251762.

$105911 \quad$ Milnes, A.R. and Fitzpatrick, R.W. 1995. "Titanium and Zirconium Minerals." Chapter 23 of Minerals in Soil Environments. 2nd Edition. Dixon, J.B. and Weed, S.B., eds. SSSA Book Series, No. 1. Madison, Wisconsin: Soil Science Society of America. TIC: 237222.

119707 Notz, K.J.; Welch, T.D.; Moore, R.S.; and Reich, W.J. 1990. Preliminary Waste Form Characteristics (Draft). ORNL TM-11081. Oak Ridge, Tennessee: Oak Ridge National Laboratory. ACC: HQX.19901003.0018.

$163274 \quad$ NRC (U.S. Nuclear Regulatory Commission) 2003. Yucca Mountain Review Plan, Final Report. NUREG-1804, Rev. 2. Washington, D.C.: U.S. Nuclear Regulatory Commission, Office of Nuclear Material Safety and Safeguards. TIC: 254568.

163604 Palache, C.; Berman, H.; and Frondel, C. 1944. Elements, Sulfides, Sulfosalts, Oxides. Volume I of The System of Mineralogy of James Dwight Dana and Edward Salisbury Dana, Yale University 1837-1892. 7th Edition. New York, New York: John Wiley \& Sons. TIC: 209331. 
162280 Palache, C.; Berman, H.; and Frondel, C. 1951. Halides, Nitrates, Borates, Carbonates, Sulfates, Phosphates, Arsenates, Tungstates, Molybdates, Etc. Volume II of The System of Mineralogy of James Dwight Dana and Edward Salisbury Dana, Yale University 1837-1892. 7th Edition. New York, New York: John Wiley \& Sons. TIC: 209332.

159511 Parkhurst, D.L. and Appelo, C.A.J. 1999. User's Guide to PHREEQC (Version 2)-A Computer Program for Speciation, Batch-Reaction, One-Dimensional Transport, and Inverse Geochemical Calculations. Water-Resources Investigations Report 99-4259. Denver, Colorado: U.S. Geological Survey. TIC: 253046.

103896 Parrington, J.R.; Knox, H.D.; Breneman, S.L.; Baum, E.M.; and Feiner, F. 1996. Nuclides and Isotopes, Chart of the Nuclides. 15th Edition. San Jose, California: General Electric Company and KAPL, Inc. TIC: 233705.

168860 Payne, T.E. and Waite, T.D. 1991. "Surface Complexation Modelling of Uranium Sorption Data Obtained by Isotope Exchange Techniques." Radiochimica Acta, 52/53, 487-493. München, Germany: R. Oldenbourg Verlag. TIC: 255999.

159329 Pednekar, S.P. 1987. Final Report on Corrosion of Carbon Steel in Aqueous Environments at Temperatures Below Boiling - A Literature Review to Electric Power Research Institute, February 24, 1987. Columbus, Ohio: Battelle, Columbus Division. TIC: 224492.

172869 Praga, A.N. 1998. MCO Loading and Cask Loadout Technical Manual. HNF-2169, Rev. 0. Richland, Washington: Duke Engineering and Services Hanford. TIC: 253692.

155635 Punatar, M.K. 2001. Summary Report of Commercial Reactor Criticality Data for Crystal River Unit 3. TDR-UDC-NU-000001 REV 02. Las Vegas, Nevada: Bechtel SAIC Company. ACC: MOL.20010702.0087.

122768 Rai, D. 1984. "Solubility Product of Pu(IV) Hydrous Oxide and Equilibrium Constants of $\mathrm{Pu}(\mathrm{IV}) / \mathrm{Pu}(\mathrm{V}), \mathrm{Pu}(\mathrm{IV}) / \mathrm{Pu}$ (VI), and $\mathrm{Pu}(\mathrm{V}) / \mathrm{Pu}(\mathrm{VI})$ Couples." Radiochimica Acta, 35, 97-106. Munchen, Germany: R. Oldenbourg Verlag. TIC: 219109.

112060 Rai, D. and Ryan, J.L. 1982. "Crystallinity and Solubility of Pu(IV) Oxide and Hydrous Oxide in Aged Aqueous Suspensions." Radiochimica Acta, 30, 213-216. Munchen, Germany: R. Oldenbourg Verlag. TIC: 219107.

107105 Roberts, W.L.; Campbell, T.J.; and Rapp, G.R., Jr. 1990. Encyclopedia of Minerals. 2nd Edition. New York, New York: Van Nostrand Reinhold. TIC: 242976. 
144800 Runde, W. 1999. "Letter Report on Plutonium Thermodynamic Database." Letter from W. Runde (LANL) to P. Dixon (LANL), August 1, 1999, with attachments. ACC: MOL.19991214.0624.

113307 Sandino, A. 1991. Processes Affecting the Mobility of Uranium in Natural Waters. Ph.D. thesis. Stockholm, Sweden: Royal Institute of Technology. TIC: 246941.

144629 Schwertmann, U. and Cornell, R.M. 1991. Iron Oxides in the Laboratory: Preparation and Characterization. New York, New York: VCH Publishers. TIC: 237942.

105959 Schwertmann, U. and Taylor, R.M. 1995. "Iron Oxides." Chapter 8 of Minerals in Soil Environments. 2nd Edition. Dixon, J.B. and Weed, S.B., eds. SSSA Book Series, No. 1. Madison, Wisconsin: Soil Science Society of America. TIC: 237222.

162970 Sequeira, C.A.C. 2000. "Corrosion of Copper and Copper Alloys." Chapter 42 of Uhlig's Corrosion Handbook. 2nd Edition. Revie, R.W., ed. New York, New York: John Wiley \& Sons. TIC: 248360.

162976 Smith, W.H. and Purdy, G.M. 1995. "Chromium in Aqueous Nitrate Plutonium Process Streams: Corrosion of 316 Stainless Steel and Chromium Speciation." Waste Management, 15, (7), 477-484. New York, New York: Pergamon. TIC: 254034.

103804 Spahiu, K. and Bruno, J. 1995. A Selected Thermodynamic Database for REE to be Used in HLNW Performance Assessment Exercises. SKB TR-95-35. Stockholm, Sweden: Svensk Kärnbränsleförsörjning A.B. TIC: 225493.

127253 Sposito, G. 1984. The Surface Chemistry of Soils. New York, New York: Oxford University Press. TIC: 217687.

141778 Stumm, W. 1992. Chemistry of the Solid-Water Interface, Processes at the Mineral-Water and Particle-Water Interface in Natural Systems. New York, New York: John Wiley \& Sons. TIC: 237213.

125332 Stumm, W. and Morgan, J.J. 1996. Aquatic Chemistry, Chemical Equilibria and Rates in Natural Waters. 3rd Edition. New York, New York: John Wiley \& Sons. TIC: 246296.

126175 Taylor, W.J. 1997. "Incorporating Hanford 15 Foot (4.5 Meter) Canister into Civilian Radioactive Waste Management System (CRWMS) Baseline." Memorandum from W.J. Taylor (DOE) to J. Williams (Office of Waste Acceptance Storage and Transportation), April 2, 1997.

ACC: HQP.19970609.0014. 
126924 Waber, N. 1991. Mineralogy, Petrology and Geochemistry of the Pocos de Caldas Analogue Study Sites, Minas Gerais, Brazil. II. Morro do Ferro. SKB TR-90-12. Stockholm, Sweden: Svensk Kärnbränsleförsörjning A.B.

TIC: 206350.

168856 Waite, T.D.; Davis, J.A.; Fenton, B.R.; and Payne, T.E. 2000. "Approaches to Modelling Uranium(VI) Adsorption on Natural Mineral Assemblages." Radiochimica Acta, 88, (9-11), 687-693. München, Germany: Oldenbourg Wisenschaftsverlag. TIC: 255860.

106266 Weast, R.C., ed. 1977. CRC Handbook of Chemistry and Physics. 58th Edition. Cleveland, Ohio: CRC Press. TIC: 242376.

137607 Wilson, C.N. and Bruton, C.J. 1989. Studies on Spent Fuel Dissolution Behavior Under Yucca Mountain Repository Conditions. PNL-SA-16832. Richland, Washington: Pacific Northwest Laboratory. ACC: HQX.19890918.0047.

100493 Wronkiewicz, D.J.; Bates, J.K.; Gerding, T.J.; Veleckis, E.; and Tani, B.S. 1992. "Uranium Release and Secondary Phase Formation During Unsaturated Testing of UO2 at $90^{\circ}$ C." Journal of Nuclear Materials, 190, 107-127. Amsterdam, The Netherlands: North-Holland Publishing Company. TIC: 236558.

$100194 \quad$ Yang, I.C.; Rattray, G.W.; and Yu, P. 1996. Interpretation of Chemical and Isotopic Data from Boreholes in the Unsaturated Zone at Yucca Mountain, Nevada. Water-Resources Investigations Report 96-4058. Denver, Colorado: U.S. Geological Survey. ACC: MOL.19980528.0216.

105963 Zachara, J.M.; Girvin, D.C.; Schmidt, R.L.; and Resch, C.T. 1987. "Chromate Adsorption on Amorphous Iron Oxyhydroxide in the Presence of Major Groundwater Ions." Environmental Science \& Technology, 21, (6), 589-594. Easton, Pennsylvania: American Chemical Society. TIC: 243613.

171238 Zarrabi, K.; McMillan, S.; Elkonz, S.; and Cizdziel, J. 2003. Corrosion and Mass Transport Processes in Carbon Steel Miniature Waste Packages. Document TR-03-003, Rev. 0. Task 34. Las Vegas, Nevada: University of Nevada, Las Vegas. ACC: MOL.20040202.0079.

173729 Zhang, J. and Grischkowsky, D. 2004. "Waveguide Terahertz Time-Domain Spectroscopy of Nanometer Water Layers." Optics Letter, 29, (4), 1617-1619. [Washington, D.C.]: Optical Society of America. TIC: 257234.

\subsection{CODES, STANDARDS, REGULATIONS, AND PROCEDURES}

100475 48 FR 28194. 10 CFR Part 60 Disposal of High-Level Radioactive Wastes in Geologic Repositories Technical Criteria. Readily available.

17327310 CFR 63. 2005 Energy: Disposal of High-Level Radioactive Wastes in a Geologic Repository at Yucca Mountain, Nevada. ACC: MOL.20050405.0118. 
104189 ASTM A 20/A 20M-95a. 1995. Standard Specification for General Requirements for Steel Plates for Pressure Vessels. West Conshohocken, Pennsylvania: American Society for Testing and Materials. TIC: 240026.

165003 ASTM A 240/A 240M-03b. 2003. Standard Specification for Chromium and Chromium-Nickel Stainless Steel Plate, Sheet, and Strip for Pressure Vessels and for General Applications. West Conshohocken, Pennsylvania: American Society for Testing and Materials. TIC: 254845.

162723 ASTM A 516/A 516M-01.2001. Standard Specification for Pressure Vessel Plates, Carbon Steel, for Moderate- and Lower-Temperature Service. West Conshohocken, Pennsylvania: American Society for Testing and Materials. TIC: 253997.

154062 ASTM A 887-89 (Reapproved 2000). 2000. Standard Specification for Borated Stainless Steel Plate, Sheet, and Strip for Nuclear Application. West Conshohocken, Pennsylvania: American Society for Testing and Materials. TIC: 249544.

144744 ASTM B 209-96. 1996. Standard Specification for Aluminum and Aluminum-Alloy Sheet and Plate. West Conshohocken, Pennsylvania: American Society for Testing and Materials. TIC: 247078.

168403 ASTM B 932-04. 2004. Standard Specification for Low-Carbon Nickel-Chromium-Molybdenum-Gadolinium Alloy Plate, Sheet, and Strip. West Conshohocken, Pennsylvania: American Society for Testing and Materials. TIC: 255846.

105725 ASTM C 1174-97. 1998. Standard Practice for Prediction of the Long-Term Behavior of Materials, Including Waste Forms, Used in Engineered Barrier Systems (EBS) for Geological Disposal of High-Level Radioactive Waste. West Conshohocken, Pennsylvania: American Society for Testing and Materials. TIC: 246015.

103515 ASTM G 1-90 (Reapproved 1999). 1999. Standard Practice for Preparing, Cleaning, and Evaluating Corrosion Test Specimens. West Conshohocken, Pennsylvania: American Society for Testing and Materials. TIC: 238771.

LP-SIII.2Q-BSC, Rev. 0, ICN 0. Qualification of Unqualified Data. Washington, D.C.: U.S. Department of Energy, Office of Civilian Radioactive Waste Management. ACC: DOC.20050119.0002.

LP-SIII.10Q-BSC, Rev. 0, ICN 1. Models. Washington, D.C.: U.S. Department of Energy, Office of Civilian Radioactive Waste Management.

ACC: DOC.20050203.0009. 
LP-SI.11Q-BSC, Rev. 0, ICN 0. Software Management. Washington, D.C.: U.S. Department of Energy, Office of Civilian Radioactive Waste Management. ACC: DOC.20040225.0007.

\subsection{SOFTWARE CODES}

153964 Software Code: EQ3/6. V7.2b. UCRL-MA-110662 (LSCR198).

159731 Software Code: EQ6. 7.2bLV. PC. 10075-7.2bLV-02. Windows NT, 2000.

173680 Software Code: GetEQData. V1.0.1. PC w/Windows 2000. 10809-1.0.1-00.

157837 Software Code: PHREEQC. V2.3. PC. 10068-2.3-01.

155029 Software Code: transl. V2.0. PC Windows98. 10251-2.0-00.

\subsection{SOURCE DATA, LISTED BY DATA TRACKING NUMBER}

160899 GS020408312272.003. Collection and Analysis of Pore Water Samples for the Period from April 2001 to February 2002. Submittal date: 04/24/2002.

161677 LL020709923142.023. Aqueous Geochemistry of Borehole Waters Collected in the Heating Phase of the DST. Submittal date: 07/26/2002.

173475 LL980710551022.012. Unsaturated Drip Condition Testing of Spent Fuel and Unsaturation Dissolution Tests of Glass. Submittal date: 08/11/1998.

151029 MO0006J13WTRCM.000. Recommended Mean Values of Major Constituents in J-13 Well Water. Submittal date: 06/07/2000.

160229 MO0210SPATHDYN.000. Themodynamic Data Input Files - DATA0.YMP.R2. Submittal date: 10/02/2002.

161756 MO0302SPATHDYN.000. Thermodynamic Data Input Files - Data0.YMP.R2. Submittal date: 02/05/2003.

162385 MO0302PNLDUFTD.000. Flowthrough Dissolution Data. Submittal date: $02 / 28 / 2003$.

162551 MO0303MWDSCMAB.000. THC Seepage Chemistry Model Abstraction Binning EQ3 Input, Pickup and Output Files. Submittal date: 03/06/2003.

170760 MO0407SEPFEPLA.000. LA FEP List. Submittal date: 07/20/2004.

170618 MO0407SEPUDISR.000. Uranium Dissolution Rates from Uranium Dioxide. Submittal date: 07/01/2004.

172097 MO0407SPAPCEML.005. EBS P\&CE Model Longevity of Materials Evaluation. Submittal date: 07/02/2004. 
172059 MO0409SPAACRWP.000. Aqueous Corrosion Rates For Non-Waste Form Waste Package Materials. Submittal date: 09/16/2004.

172244 MO0411SPAMOICA.000. Model Output for In-Package Chemistry Abstraction. Submittal date: 11/04/2004.

172712 SN0410T0510404.002. Thermodynamic Database Input File for EQ3/6 DATA0.YMP.R4. Submittal date: 11/01/2004.

\subsection{OUTPUT DATA, LISTED BY DATA TRACKING NUMBER}

MO0502SPAINPCA.000. In-Package Chemistry Abstraction. Submittal date: $02 / 25 / 2005$.

MO0403SPASURCR.000. Surface complexation reactions in PHREEQC format from the surface complexation demonstration (Section 6.8).

MO0403SPAYMPR3.000. Surface complexation demonstration (Section 6.8) thermodynamic database for PHREEQC (YMP_R3.dat) with abridged surface complexation reactions.

MO0403MWDSRFCC.000. Surface complexation demonstration (Section 6.8) input and output PHREEQC files, and the expanded PHREEQC database (YMP_R3mr.dat), which contains surface complexation reactions.

MO0312SPAICSCR.002. Developed in Appendix B, and documents the effect of radiolysis on the in-package chemistry. 
INTENTIONALLY LEFT BLANK 
APPENDIX A

ADDITIONAL IN-PACKAGE CHEMISTRY DISCUSSION AND PLOTS 
INTENTIONALLY LEFT BLANK 


\section{A. ADDITIONAL IN-PACKAGE CHEMISTRY DISCUSSION AND PLOTS}

\section{A.1 CSNF WATER CHEMISTRY EVOLUTION}

This section provides a detailed discussion of the chemistry evolution of the CSNF base case. This discussion is specific to the base case and the time steps, degradation rates and quantities of materials used. However, the trends observed in this base case are representative of the CSNF waste package in general.

The discussion begins at 31.7 years when A516 has been completely degraded. The oxidation of $\mathrm{S}$ and $\mathrm{P}$ as A516 degrades rapidly are the principle acid-producing reactions of waste package degradation. Additional acid is produced by the oxidation of S, P and Mo in the NiGd and 316 components of the package, but these degrade at lower rates. The initial, rapid degradation of A516 drives the $\mathrm{pH}$ down and it has reached its minimum value, 4.39, at 31.7 years when A516 degradation ceases. Note that this value is modeled without considering the effects of $\mathrm{H}^{+}$ sorption on Fe reaction products. This sorption buffers the $\mathrm{pH}$ at higher values as discussed in Section 6.3.2.

After 31.7 years, the $\mathrm{pH}$ begins to increase from its minimum value. With increasing $\mathrm{pH}$, the concentrations of several elements also change. For example, elements including Ti (below concentrations shown in figure), $\mathrm{Zr}, \mathrm{Fe}, \mathrm{Cr}, \mathrm{Mn}, \mathrm{Zn}, \mathrm{Al}, \mathrm{Np}$ and $\mathrm{U}$ that are controlled by oxide and hydroxide solids begin to decrease: $\mathrm{Gd}$ also decreases because it is controlled by $\mathrm{GdPO}_{4}: 10 \mathrm{H}_{2} \mathrm{O}$ solubility. With increasing $\mathrm{pH}$, phosphate hydrolysis decreases, increasing the activity of $\mathrm{PO}_{4}{ }^{3-}$ and lowering $\mathrm{Gd}$ activity to maintain $\mathrm{GdPO}_{4}: 10 \mathrm{H}_{2} \mathrm{O}$ equilibrium. Ba enters the solution as CSNF continues to degrade precipitating barite $\left(\mathrm{BaSO}_{4}\right)$ and lowering the total $\mathrm{S}$ concentration. With both the decreasing total $\mathrm{S}$ and $\mathrm{Al}$ and increasing $\mathrm{pH}$, the previously-precipitated alunite $\left(\mathrm{KAl}_{3}(\mathrm{OH})_{6}\left(\mathrm{SO}_{4}\right)_{2}\right)$ begins to dissolve increasing the $\mathrm{K}$ concentration. At this time, the Mo concentration is controlled by $\mathrm{Fe}_{2}\left(\mathrm{MoO}_{4}\right)_{3}$. As Fe decreases, total Mo increases to maintain equilibrium with this solid.

During this gradual $\mathrm{pH}$ increase, several additional solids begin to precipitate. At 37.7 years, $\mathrm{PuO}_{2}(\mathrm{OH})_{2}: \mathrm{H}_{2} \mathrm{O}$ precipitation begins causing the $\mathrm{Pu}$ concentration to decrease. At 42.1 years, spinel-Co $\left(\mathrm{Co}_{3} \mathrm{O}_{4}\right)$ begins to precipitate and the Co concentration falls. At 43.6 years, powellite $\left(\mathrm{CaMoO}_{4}\right)$ begins to form, which causes the $\mathrm{Ca}$ concentration to drop. At 47.0 years, nontronite- $\mathrm{Mg}\left(\mathrm{Mg}_{0.165} \mathrm{Fe}_{2} \mathrm{Al}_{0.33} \mathrm{Si}_{3.67} \mathrm{H}_{2} \mathrm{O}_{12}\right)$ forms and the $\mathrm{Mg}$ concentration decreases. At 72.6 years, the dissolving alunite is exhausted so the $\mathrm{K}$ concentration levels off.

At 78.0 years the $\mathrm{Fe}_{2}\left(\mathrm{MoO}_{4}\right)_{3}$, which has begun to dissolve as Mo is taken up by powellite, is exhausted. The $\mathrm{pH}$ then rises sharply to 5.82 at 83.7 years accompanied by decreases in $\mathrm{Fe}, \mathrm{Cr}$, $\mathrm{Mn}, \mathrm{Zn}, \mathrm{Gd}, \mathrm{Co}, \mathrm{Al}, \mathrm{Np}, \mathrm{U}$ and $\mathrm{Mg}$. During this period, precipitation of antlerite $\left(\mathrm{Cu}_{3}\left(\mathrm{SO}_{4}\right)(\mathrm{OH})_{4}\right)$ begins at 81.3 years causing $\mathrm{Cu}$ to drop. At 83.7 years, precipitation of trevorite $\left(\mathrm{NiFeO}_{4}\right)$ begins and the $\mathrm{pH}$ becomes virtually constant at 5.82. At 115 years, kaolinite $\left(\mathrm{Al}_{2} \mathrm{Si}_{2} \mathrm{O}_{5}(\mathrm{OH})_{4}\right)$, which has been dissolving since nontronite-Mg precipitation began at 47.0 years, is exhausted and the $\mathrm{pH}$ begins to rise once more.

From 115 years the $\mathrm{pH}$ increases gradually reaching 6.14 at 312 years. With the increasing $\mathrm{pH}$, the concentrations of $\mathrm{Fe}, \mathrm{Cr}, \mathrm{Mn}, \mathrm{Zn}, \mathrm{Co}, \mathrm{Al}, \mathrm{Np}, \mathrm{U}, \mathrm{Cu}$ and $\mathrm{Ni}$ decrease. At 220 years, tenorite 
$(\mathrm{CuO})$ begins to precipitate taking up $\mathrm{Cu}$ and causing antlerite to dissolve. At 226 years, the antlerite is exhausted.

The uranium solids schoepite $\left(\mathrm{UO}_{3}: 2 \mathrm{H}_{2} \mathrm{O}\right)$ and $\left(\mathrm{UO}_{2}\right)_{3}\left(\mathrm{PO}_{4}\right)_{2}: 6 \mathrm{H}_{2} \mathrm{O}$ form early in the waste degradation process. At 31.7 years as the $\mathrm{pH}$ begins to rise, $\left(\mathrm{UO}_{2}\right)_{3}\left(\mathrm{PO}_{4}\right)_{2}: 6 \mathrm{H}_{2} \mathrm{O}$ begins to dissolve in favor of schoepite. Between 226 and 312 years with the rising $\mathrm{pH}$, the total $\mathrm{P}$ decreases until at 312 years, $\left(\mathrm{UO}_{2}\right)_{3}\left(\mathrm{PO}_{4}\right)_{2}: 6 \mathrm{H}_{2} \mathrm{O}$ is exhausted. Because of the decreasing total $\mathrm{P}$ the $\mathrm{Gd}$ concentration rises steeply to maintain equilibrium with $\mathrm{GdPO}_{4}: 10 \mathrm{H}_{2} \mathrm{O}$.

The $\mathrm{pH}$ rises sharply beginning at 312 years until it levels off at 7.31 at 388 years. At 322 years with the $\mathrm{pH}$ at 6.22 , the precipitation of $\mathrm{Gd} 2(\mathrm{CO} 3) 3$ begins. As the $\mathrm{pH}$ increases, equilibrium with this solid sharply lowers the Gd concentration which in turn increases the total $\mathrm{P}$ content to maintain equilibrium with GdPO4:10H2O.

At 388 years, precipitation of the saponite-tri solid solution $\left(\mathrm{Ca}_{0.5}, \mathrm{H}, \mathrm{K}, \mathrm{Mg}_{0.5}, \mathrm{Na}\right)_{0.33} \mathrm{Mg}_{3}$ $\mathrm{Al}_{0.33} \mathrm{Si}_{3.67} \mathrm{O}_{10}(\mathrm{OH})_{2}$ begins. This solids persists until 984 years and maintains the $\mathrm{pH}$ between 7.31 and 7.32 until it disappears. During this period, concentrations of all elements are also virtually constant except those in the solid solution (e. g. $\mathrm{K}$ ) and $\mathrm{Ba}$ and total $\mathrm{S}$. Ba continues to increase as CSNF degrades causing total $\mathrm{S}$ to decrease to maintain equilibrium with barite. At 634 years, the Al_6061 component of the package is exhausted. In the absence of a continuing source of Al to the solution, the saponite-tri solid begins to dissolve to maintain gibbsite $(\mathrm{Al}(\mathrm{OH}) 3)$ equilibrium. This continues until 984 years when the saponite-tri is exhausted.

The $\mathrm{pH}$ drops from 984 to 2221 years during which time no changes in reaction mechanisms occur. The diagrams show points at 1112, 1659 and 2189 years during this period, but these result from the printing constraints imposed on EQ6, not because of any change in reactions.

At 2221 years, the degrading CSNF is exhausted. Ba is no longer being added to the solution, but with continuing $\mathrm{NiGd}$ and 316 dissolution, $\mathrm{S}$ continues to be oxidized adding $\mathrm{SO}_{4}{ }^{-2}$ to the solution. With increasing $\mathrm{SO}_{4}{ }^{-2}, \mathrm{Ba}$ decreases to maintain equilibrium with barite. $\mathrm{Mg}$ decreases with continuing nontronite-Mg precipitation until 2336 years when kaolinite begins to precipitate and Mg stabilizes.

From 2336 until the end of the calculation is reached at 18752 years, the $\mathrm{pH}$ remains close to 5.9. No changes in reactants or products occur until 17786 years when $\mathrm{Gd} 2(\mathrm{CO} 3) 3$ is exhausted. At this point, $\mathrm{Gd}$ decreases and total $\mathrm{P}$ increases until, at 18492 years, $\left(\mathrm{UO}_{2}\right)_{3}\left(\mathrm{PO}_{4}\right)_{2}: 6 \mathrm{H}_{2} \mathrm{O}$ begins to form once again. 


\section{A.2 ADDITIONAL PLOTS}

The computer files for the following plots are included in DTN: MO0411SPAMOICA.000 [DIRS 172244]. These plots were not updated from Rev 03 of this report, so for these cases $\mathrm{Cr}(\mathrm{VI})$ was allowed to form instead of $\mathrm{Cr}(\mathrm{III})$. The impact of using $\mathrm{Cr}(\mathrm{III})$ versus $\mathrm{Cr}(\mathrm{VI})$ is examined in Section 6.6.3. Because the purpose of these plots is to observe the model response to varying certain inputs, as long as all of the cases being compared are consistent in their treatment of chromium, the cases from Rev 03 using $\operatorname{Cr}(\mathrm{VI})$ are still valuable for showing the model response. The source for the input to these sensitivities is documented in Rev 03 of this report.

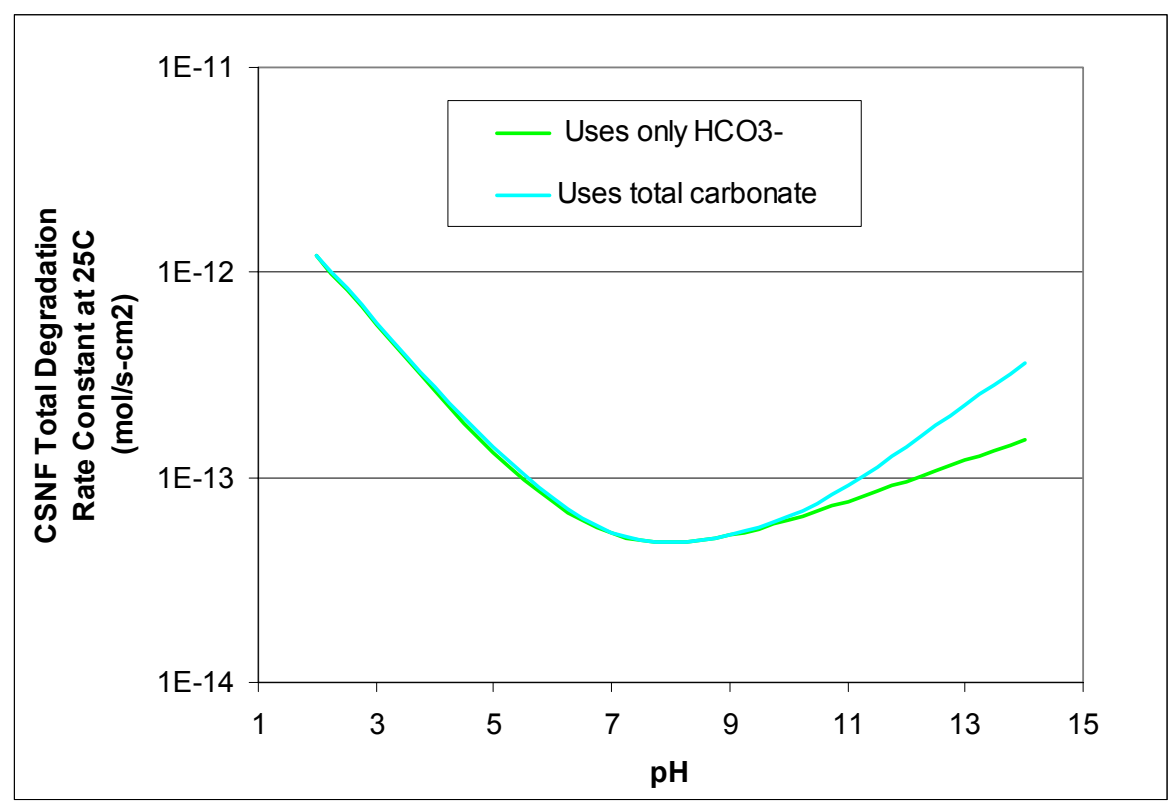

Source: CSNF.xIs (Appendix F ISpreadsheets)

Figure A-1. CSNF Total Degradation Rate Constant as a Function of pH 


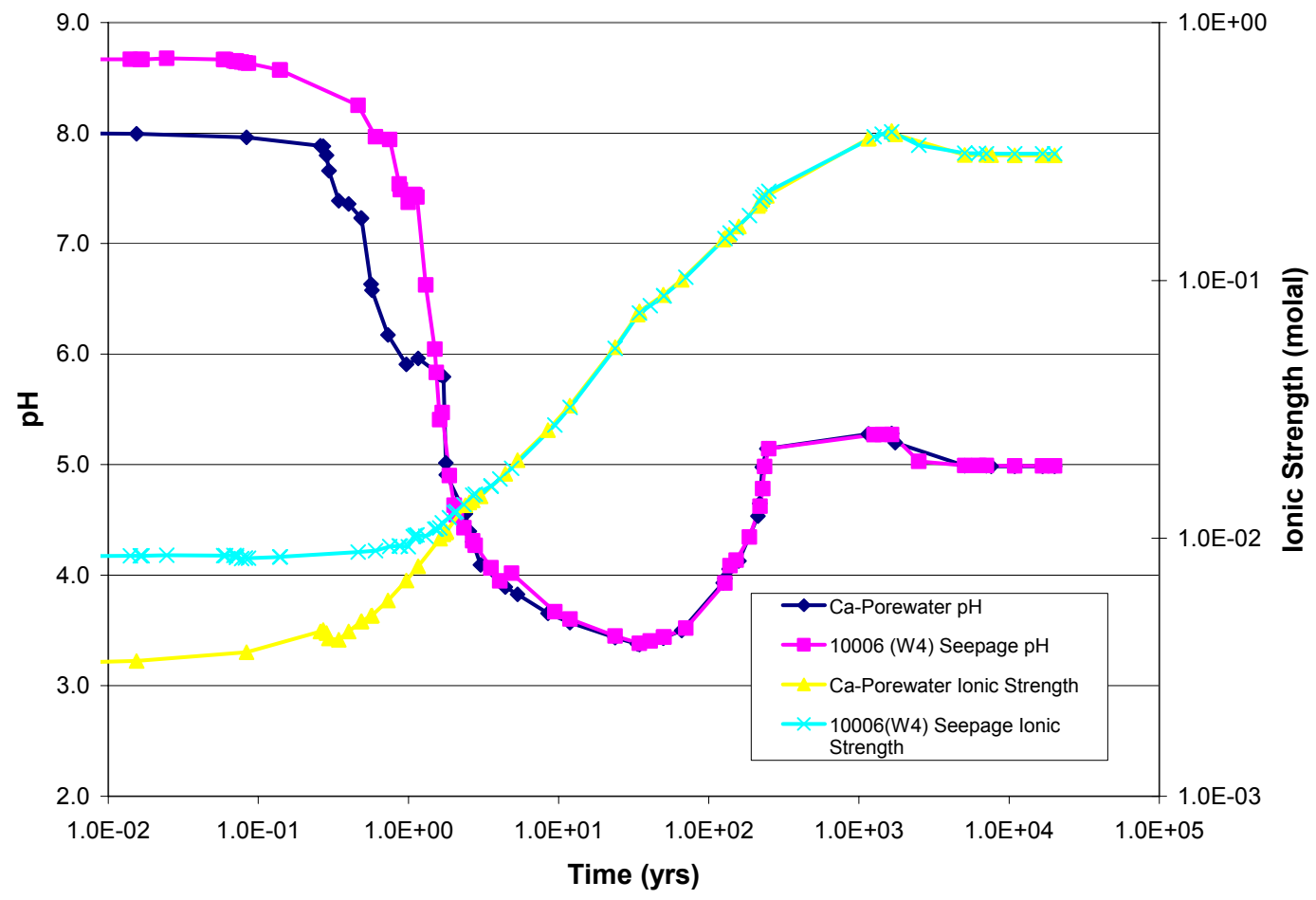

Source: CSNF_P\&CE_fluids.xIs in DTN: MO0411SPAMOICA.000 [DIRS 172244].

Figure A-2. Thermally Perturbed Composition 10006 (W4) with Ca-porewater (W5) for CSNF

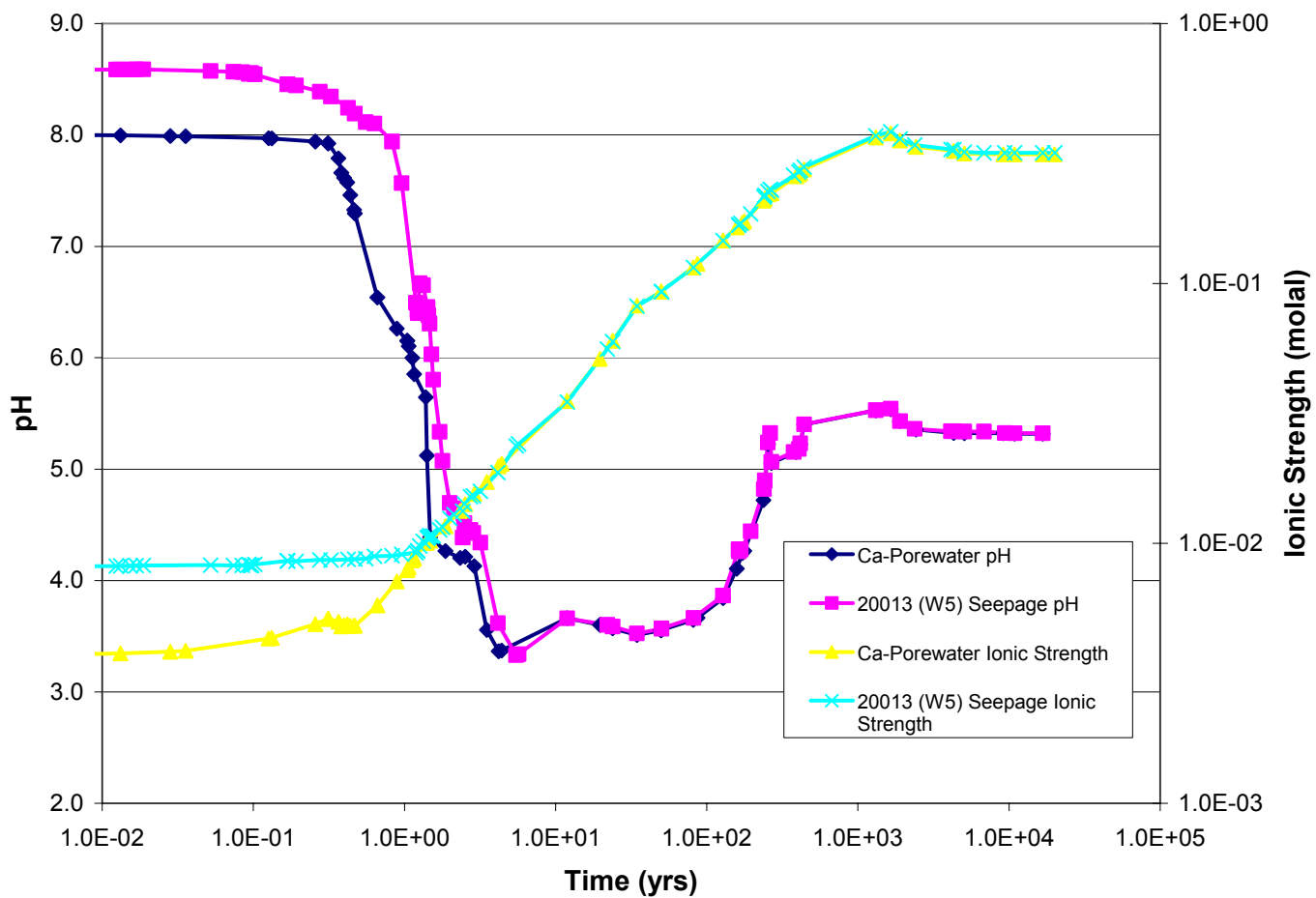

Source: CSNF_P\&CE_fluids.xIs in DTN: MO0411SPAMOICA.000 [DIRS 172244].

Figure A-3. Thermally Perturbed Composition 20013 (W5) with Ca-porewater (W5) for CSNF 


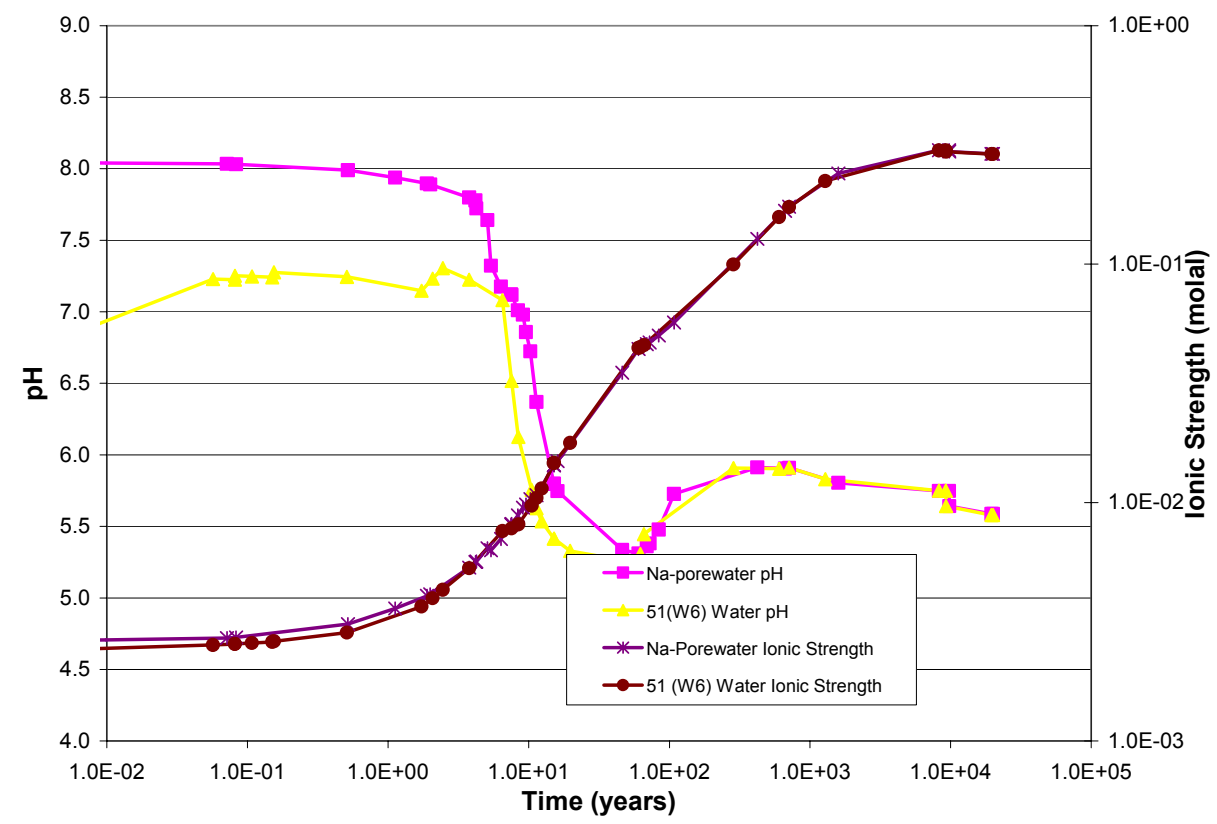

Source: CDSP_P\&CE_fluids.x/s in DTN: MO0411SPAMOICA.000 [DIRS 172244].

Figure A-4. Thermally Perturbed Composition 51 (W6) with Na-porewater (W5) for CDSP

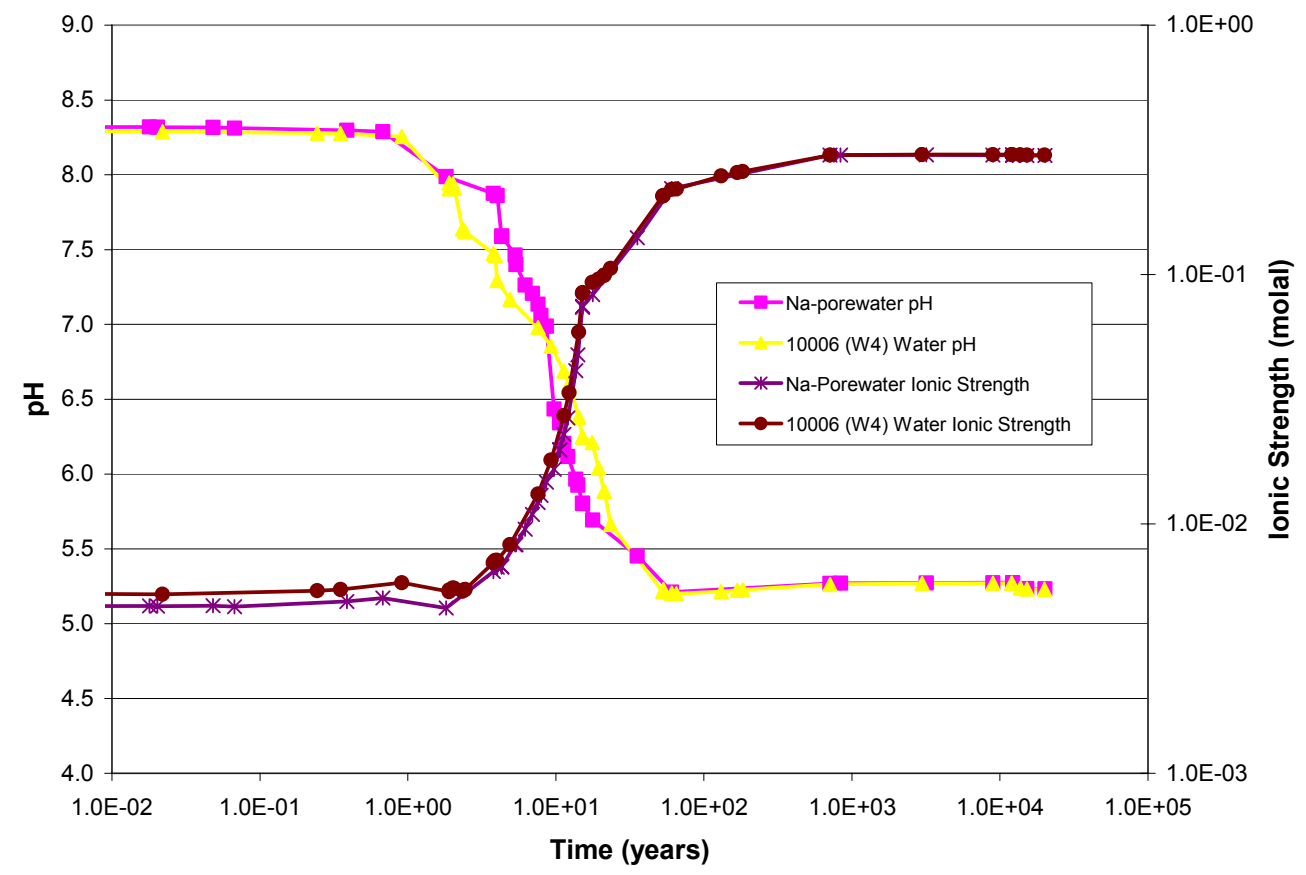

Source: CDSP_P\&CE_fluids.x/s in DTN: MO0411SPAMOICA.000 [DIRS 172244].

Figure A-5. Thermally Perturbed Composition 10006 (W4) with Na-porewater (W5) for CDSP 


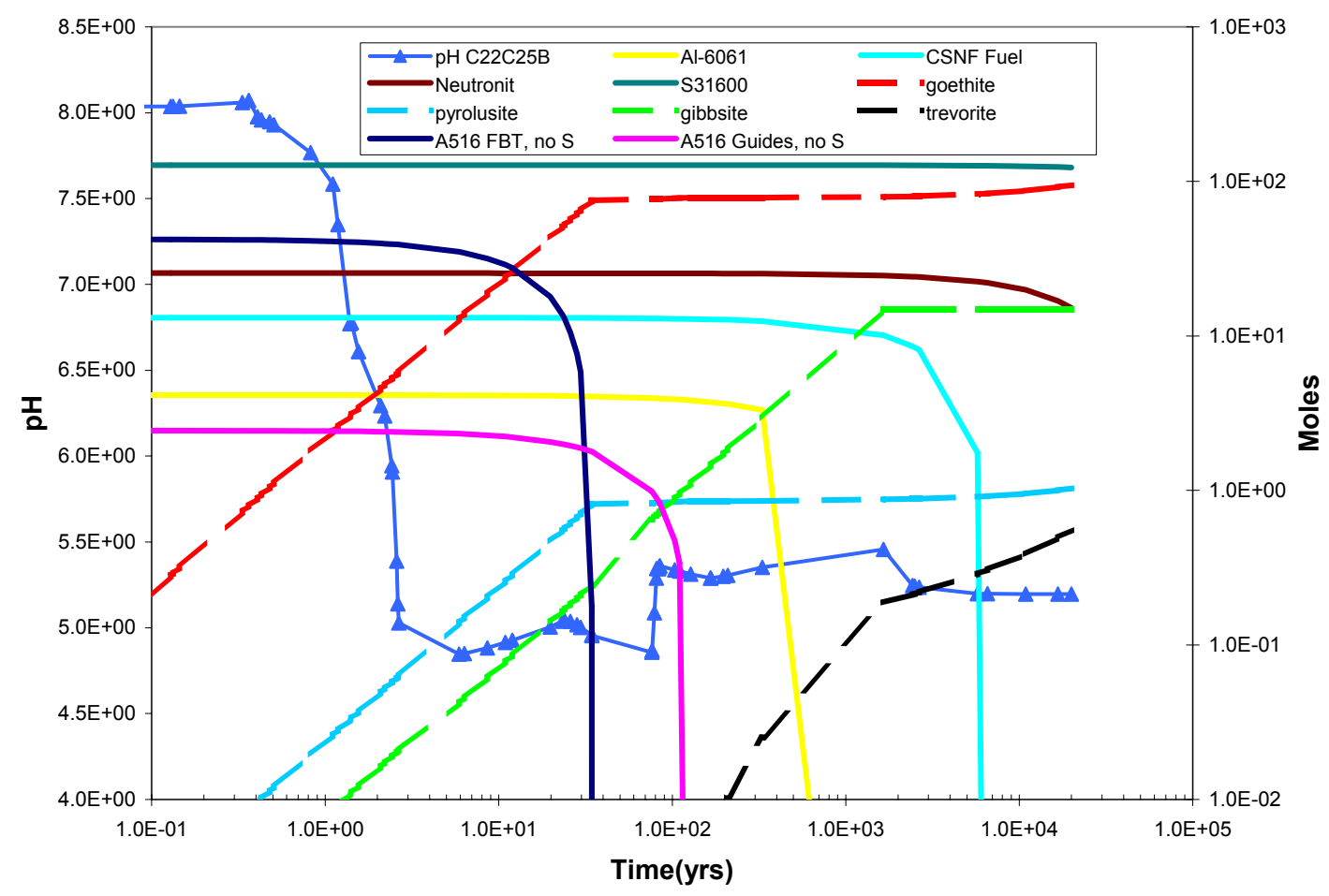

Source: CSNF_Water Influx_25.x/s in DTN: MO0411SPAMOICA.000 [DIRS 172244].

Figure A-6. Corrosion Products and pH with no Sulfur in the Carbon Steel Type A516 Composition

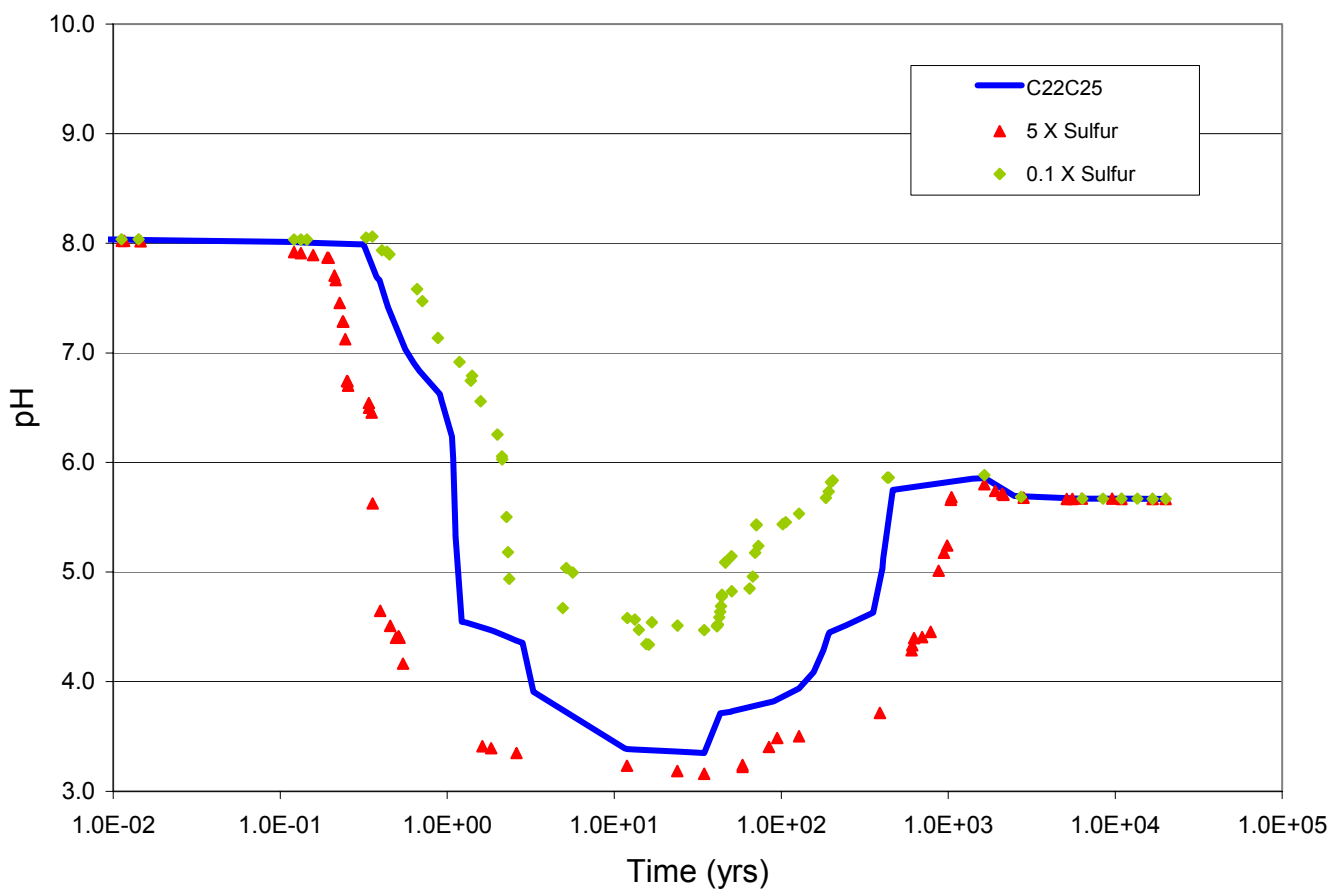

Source: DTN: MO0411SPAMOICA.000 [DIRS 172244], CSNF_Sensitivity.xls.

Figure A-7. Effect of Varying Sulfur Content in Carbon Steel Type A516 on pH 


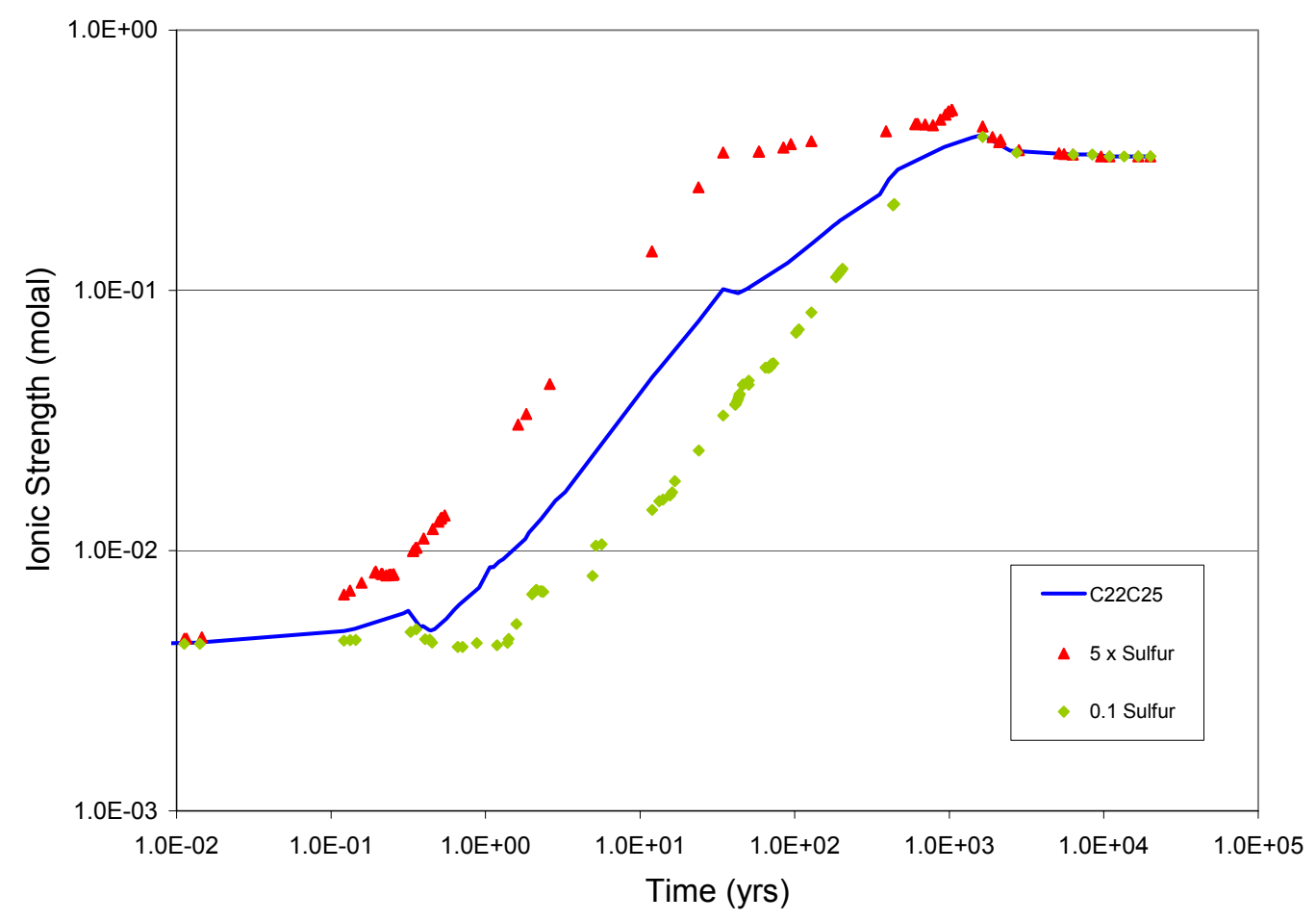

Source: DTN: MO0411SPAMOICA.000 [DIRS 172244], CSNF_Sensitivity.xls.

Figure A-8. Effect of Varying Sulfur Content in Carbon Steel Type A516 on lonic Strength

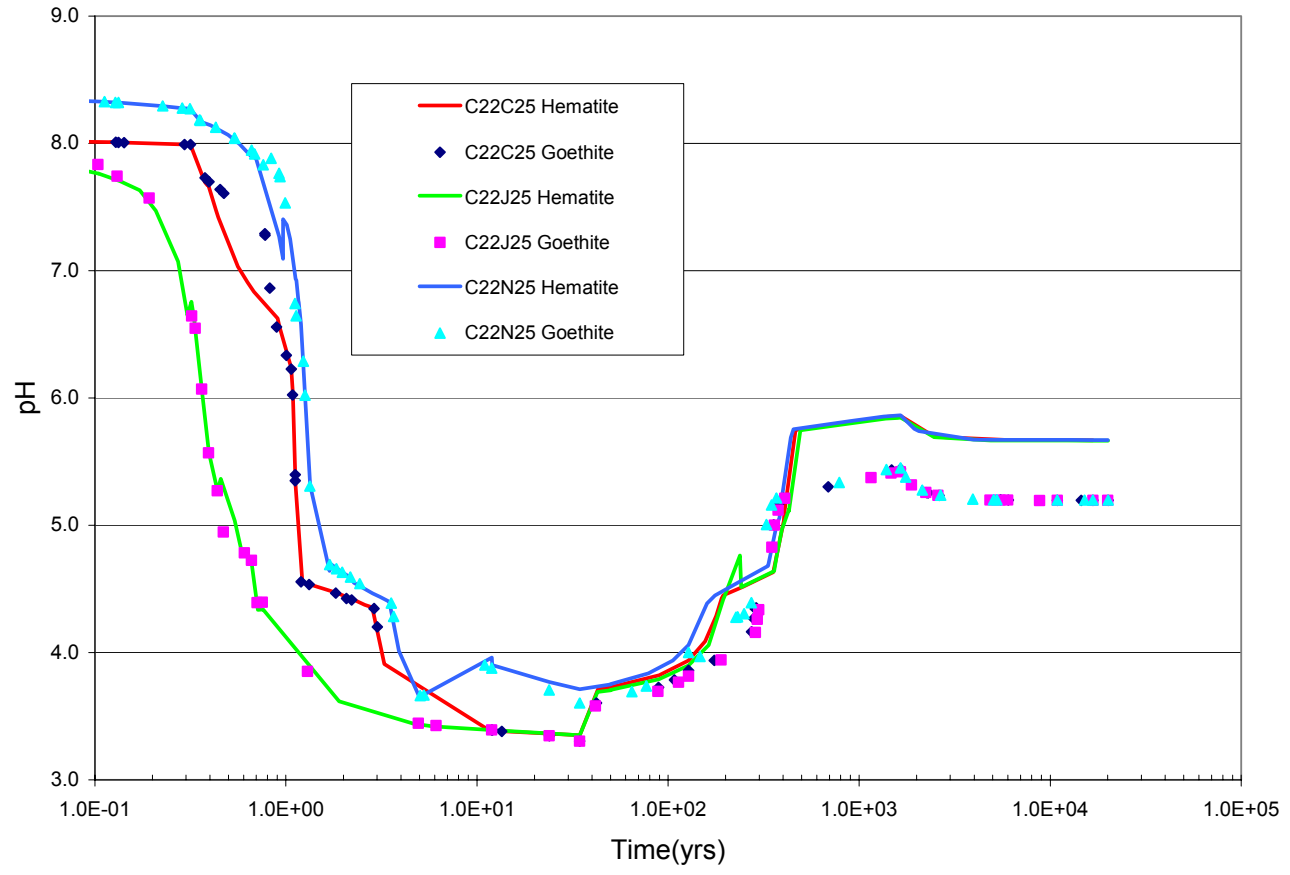

Source: DTN: MO0411SPAMOICA.000 [DIRS 172244], CSNF_Water Influx_25.x/s.

Figure A-9. Effect of Goethite and Hematite on $\mathrm{pH}$ 


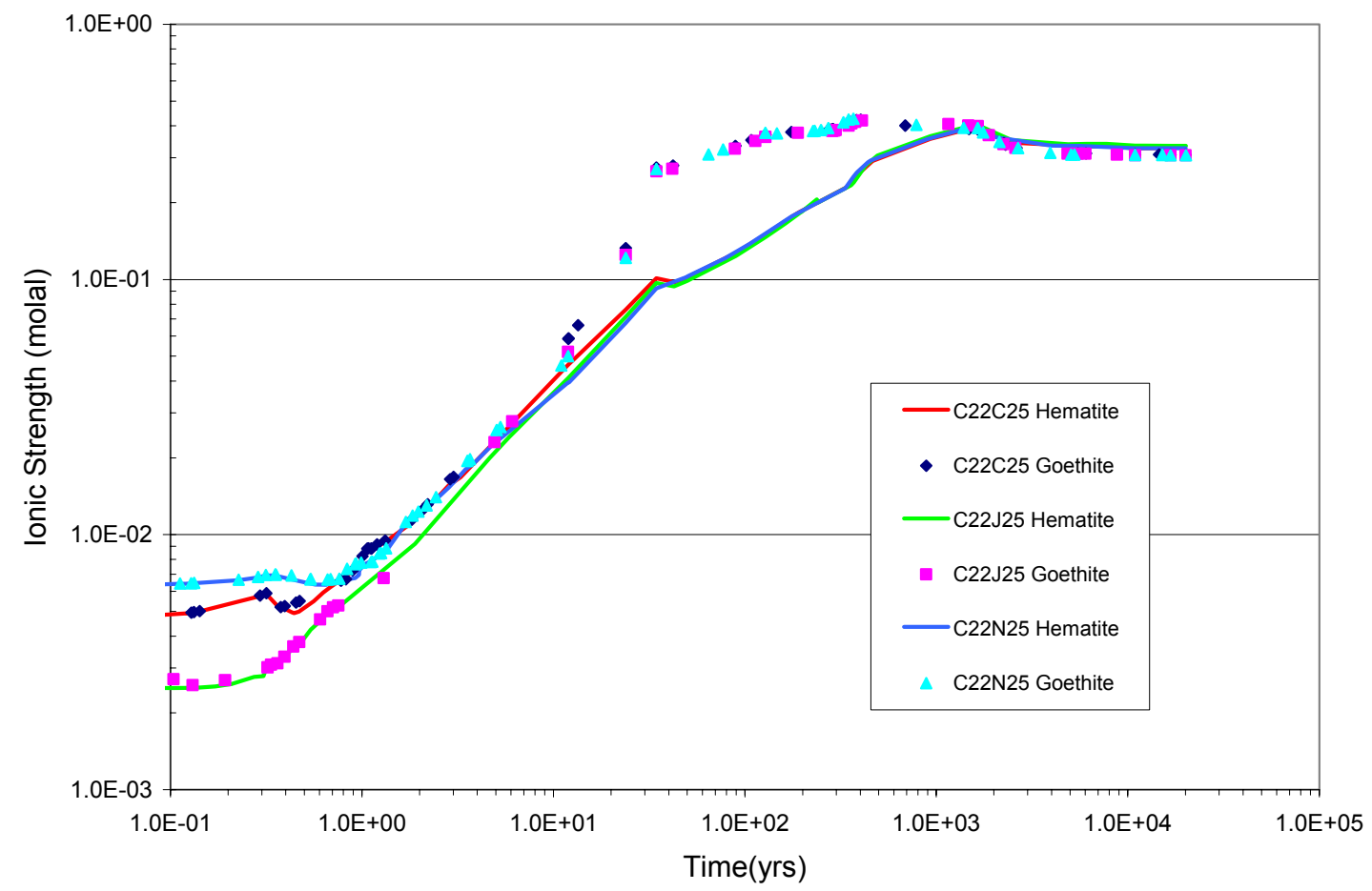

Source: DTN: MO0411SPAMOICA.000 [DIRS 172244], CSNF_Water Influx_25.x/s.

Figure A-10. Effect of Goethite and Hematite on lonic Strength

Table A-1. Minor Input Inconsistencies in the EQ3 and EQ6 Input Files

\begin{tabular}{|l|l|l|l|}
\hline \multicolumn{1}{|c|}{ Input } & \multicolumn{1}{|c|}{ Base Value } & \multicolumn{1}{c|}{ Alternate Value } & \multicolumn{1}{c|}{ Justification } \\
\hline Log $\mathrm{fO}_{2}$ value & -0.7 & -0.818 (for J-13.3i files) & $\begin{array}{l}\text { The difference is due to the number of } \\
\text { significant figures copied over from } \\
\text { previous input files, but is so minor that } \\
\text { it will not impact the results. }\end{array}$ \\
\hline N-Reactor Rate & $\begin{array}{l}10 \times \text { higher rate for } \\
\text { higher temperatures }\end{array}$ & Used base-case rate. & $\begin{array}{l}\text { The base-case rate is already high, so } \\
\text { the difference is so minor, it will not } \\
\text { impact the results. }\end{array}$ \\
\hline $\begin{array}{l}\text { Molar Volume of } \\
\text { igd }\end{array}$ & 11.42 & 12.88 & $\begin{array}{l}\text { The molar volume of Neutronit was } \\
\text { used in the input file, but this value is } \\
\text { only used to calculate the volume of } \\
\text { material, which is not used in this } \\
\text { report. }\end{array}$ \\
\hline Soddyite & Not suppressed & Suppressed & $\begin{array}{l}\text { This mineral was suppressed in the } \\
\text { runs used to develop the ionic strength } \\
\text { abstraction, but was not suppressed in } \\
\text { the base-case runs. This difference is } \\
\text { justified because the mineral did not } \\
\text { form in the base-case runs, indicating } \\
\text { that suppressing it has no impacts on } \\
\text { the results. }\end{array}$ \\
\hline
\end{tabular}




\section{APPENDIX B}

\section{IN-PACKAGE RADIOLYSIS ANALYSES}


INTENTIONALLY LEFT BLANK 


\section{B. IN-PACKAGE RADIOLYSIS ANALYSES}

\section{B.1 RADIOLYSIS CONTRIBUTION TO IN-PACKAGE CHEMISTRY}

Radiolysis is an important process that could influence the results of the in-package chemistry model. A nonmechanistic treatment in the form of a sensitivity analysis is provided here to examine how radiolysis could affect the $\mathrm{pH}$ and concentration of certain aqueous species. All of the pertinent input files may be found in DTN: MO0411SPAMOICA.000 [DIRS 172244], and the output files in DTN: MO0312SPAICSCR.002.

These appendix was not updated from Rev 03 of this report, so for these cases $\mathrm{Cr}(\mathrm{VI})$ was allowed to form instead of $\mathrm{Cr}$ (III). The impact of using $\mathrm{Cr}$ (III) versus $\mathrm{Cr}(\mathrm{VI})$ is examined in Section 6.6.3. The source for the input to this appendix is documented in Rev 03 of this report.

\section{B.2 DATA AND PARAMETERS}

- Gamma and Neutron Radiolysis in the 21-PWR Waste Package from Ten to One Million Years (BSC 2004 [DIRS 172017]). Nitric acid $\left(\mathrm{HNO}_{3}\right)$ production rate at 500 years (assuming waste package breach) is $3.60 \mathrm{E}+13$ molecules $/ \mathrm{yr}-\mathrm{cm}^{3}$ (air) (BSC 2004 [DIRS 172017], Table 21, p. 33). This time was selected because it is the earliest breach, representing juvenile failure of the waste package. Figure 5 of this reference shows that the production is constant after 500 years, so the selection of this time is not critical.

- Geometry of CSNF waste package: Volume $=4,968,751 \mathrm{~cm}^{3}, 10 \%$ fuel exposed surface area $=3,297,160 \mathrm{~cm}^{2}$, void volume with $0.25-\mathrm{cm}$ thick water layer $=4,144,461 \mathrm{~cm}^{3}$, from CSNF.xls, DTN: MO0411SPAMOICA.000 [DIRS 172244].

- Surface area normalization factor for $10 \%$ fuel exposure $=1.213 \mathrm{E}-03$, from $C S N F . x l s$, DTN: MO0411SPAMOICA.000 [DIRS 172244].

- G value for nitric acid production is 1.5 molecules/100 ev energy deposition (BSC 2004 [DIRS 172017], p. 27). The $G$ value represents the number of molecules formed from radiolysis in a material and is linear with energy deposition. This number is used to calculate hydrogen peroxide $\left(\mathrm{H}_{2} \mathrm{O}_{2}\right)$ generation by scaling (first bullet).

- Density of moist air $\left(40 \%\right.$ relative humidity, $\left.30^{\circ} \mathrm{C}\right)$ is $1.16 \mathrm{E}-3 \mathrm{gm} / \mathrm{cm}^{3}$ (DTN: MO0312SPAICSCR.002, csnf_radiolysis.xls, Sheet MoistAir, Cell H14). This number is used to calculate hydrogen peroxide generation by scaling the first bullet, above.

- G value for hydrogen peroxide production is 0.72 molecules/100 ev energy deposition. This value is presented in Waterside Corrosion of Zirconium Alloys in Nuclear Power Plants (IAEA 1998 [DIRS 150560], Table 8.2, p. 214) and corroborated by Christensen (1995 [DIRS 161921], p. 375, Table II), Christensen et al. (1994 [DIRS 161919], p. 6, Table 1) and Christensen and Bjergbakke (1982 [DIRS 161918], Table 1, p.16). G value is 0.72 molecules/100 ev energy. 
Other accepted engineering numbers:

- Avogadro constant $=6.02 \mathrm{E}+23$ molecules $/$ Mole

- Density of water at $27^{\circ} \mathrm{C}=1 \mathrm{gm} / \mathrm{cm}^{3}$.

\section{B.3 ASSUMPTIONS}

The following assumptions are made for this report:

- Nitric acid production and hydrogen peroxide production is represented by the production rates at 500 years. This assumption is conservative because 500 years is the earliest waste package breach time because of early failures and radiolysis generally decreases with time. Figure 5 of Gamma and Neutron Radiolysis in the 21-PWR Waste Package from Ten to One Million Years (BSC 2004 [DIRS 172017]) shows that gamma dose and, therefore, most of the radiolysis is nearly constant after 500 years. This assumption needs no further validation.

- Nitric acid produced in the humid air by radiolysis is absorbed into the layers of water on the fuel and does not escape the waste package through the corrosion patches. This assumption is conservative because it is the upper limit of the amount of nitric acid that can be absorbed on the fuel. This assumption is necessary because modeling of chemical diffusion rates on this scale is not available. This assumption is conservative and needs no further validation.

- Radiolysis production in the outer eleven fuel assemblies of the 21-PWR design can be approximated by the radiolysis in the middle nine assemblies. Gamma and Neutron Radiolysis in the 21-PWR Waste Package from Ten to One Million Years (BSC 2004 [DIRS 172017]) provides analysis of the production in the center assembly of the waste package only. Radiation fluxes and, therefore, radiolysis production rates are less in the outer assemblies. This assumption is conservative and needs no further validation.

- Other than the generation of nitric acid and hydrogen peroxide, there are no other collateral chemical effects on the in-package environment. This assumption is justified because $\mathrm{HNO}_{3}$ and $\mathrm{H}_{2} \mathrm{O}_{2}$ have the greatest potential to alter the in-package chemistry.

\section{B.4 MODEL DISCUSSION}

When radiation passes through a material, some energy is deposited in the medium and chemical reactions can occur from the local deposition of energy (radiolysis). The $\mathrm{G}$ value represents the number of molecules of a substance that is formed when $100 \mathrm{ev}$ of energy is deposited in the media. When gamma and fast neutron energy pass through moist air, nitric acid is produced. Gamma and Neutron Radiolysis in the 21-PWR Waste Package from Ten to One Million Years (BSC 2004 [DIRS 172017]) predicts the amount of nitric acid that is produced per $\mathrm{cm}^{3}$ of humid air in the waste package $\left(3.6 \mathrm{E}+13\right.$ molecules $/ \mathrm{yr}-\mathrm{cm}^{3}$ at 500 years $)$. The amount of nitric acid formed in the waste package is calculated in EQ6 compatible input units via:

$\mathrm{HNO}_{3}$ production rate $=3.6 \mathrm{E}+13$ molecules $/ y r-\mathrm{cm}^{3} \times($ void volume waste package $)$ 


$$
\begin{aligned}
& =3.6 \mathrm{E}+13 \text { molecules } / \mathrm{yr}-\mathrm{cm}^{3} \times\left(4,144,461 \mathrm{~cm}^{3}\right) \\
& =1.49 \mathrm{E}+20 \text { molecules } / \text { yr-waste package } \times(1 \text { mole } / 6.02 \mathrm{E}+23 \text { molecules }) \\
& =2.48 \mathrm{E}-04 \mathrm{~mol} / \mathrm{yr}-\text { waste package } \times(1.213 \mathrm{E}-03) \times(1 \text { year } / 3.16 \mathrm{E}+07 \\
& \text { seconds }) \\
& =9.53 \mathrm{E}-15 \text { moles } / \text { second }
\end{aligned}
$$

where 1.213E-03 is the normalization factor from CSNF.xls, DTN: MO0411SPAMOICA.000 [DIRS 172244].

When gamma and fast neutron energy pass through water, hydrogen peroxide is produced. The production rate for hydrogen peroxide $\left(\mathrm{H}_{2} \mathrm{O}_{2}\right)$ in water is calculated by adjusting the nitric acid production rate by the ratio of $\mathrm{G}$ values and densities and converting to EQ6 compatible input units:

$\mathrm{H}_{2} \mathrm{O}_{2}$ Production Rate $=\mathrm{PR}_{\mathrm{HNO} 3} \times\left(\mathrm{G}_{\mathrm{H} 2 \mathrm{O} 2} / \mathrm{G}_{\mathrm{HNO} 3}\right) \times($ density water/density air $)$

$$
\begin{aligned}
& =3.6 \mathrm{E}+13 \mathrm{molecules} / \mathrm{yr}-\mathrm{cm}^{3} \times(0.72 / 1.5) \times\left(1.0 \mathrm{gm} / \mathrm{cm}^{3} / 1.16 \mathrm{E}-3 \mathrm{gm} / \mathrm{cm}^{3}\right) \\
& =1.5 \mathrm{E}+16 \text { molecules } / \mathrm{yr}-\mathrm{cm}^{3} \times\left(4,144,461 \mathrm{~cm}^{3}\right) \\
& =6.22 \mathrm{E}+22 \mathrm{molecules} / \mathrm{yr}-\text { waste package } \times(1 \mathrm{~mol} / 6.02 \mathrm{E}+23 \text { molecules }) \\
& =1.03 \mathrm{E}-01 \mathrm{~mol} / \mathrm{yr}-\text { waste package } \times(1.213 \mathrm{E}-03) \times(1 \mathrm{year} / 3.16 \mathrm{E}+07 \mathrm{~seconds}) \\
& =3.97 \mathrm{E}-12 \mathrm{~mol} / \text { second }
\end{aligned}
$$

where 1.213E-03 is the normalization factor from CSNF.xls, DTN: MO0411SPAMOICA.000 [DIRS 172244].

\section{B.5 EQ6 IMPLEMENTATION}

The effect of radiolysis on the in-package chemistry was handled in a nonmechanistic manner (i.e., EQ6 does not have the facility to model the radiolysis process directly; therefore, only the products of radiolysis are included as inputs in EQ6 simulations). However, EQ6 does have the capability to model the effect of $\mathrm{H}_{2} \mathrm{O}_{2}$ and $\mathrm{HNO}_{3}$ on the in-package chemistry.

A series of runs were performed where nitric acid and hydrogen peroxide were included as inputs in EQ6 runs and the results of these simulations were compared to their nonradiolysis counterparts.

Two base-case runs (C12C25 and $\mathrm{C} 22 \mathrm{C} 25$, Section 6.3.1) were used to test the effects of radiolysis. These runs were chosen because they represent the median fuel exposure (clad failure) value and the low and median flux values. It would be expected that the effects of nitric acid and hydrogen peroxide additions would be greater at the low end of the flux range. 
Two simulations were performed for each file, the first using the base-case nitric acid and hydrogen peroxide rates listed above, and a second where the $\mathrm{HNO}_{3}$ and $\mathrm{H}_{2} \mathrm{O}_{2}$ rates were multiplied by a factor of ten. An additional run was completed using the $\mathrm{C} 12 \mathrm{C} 25$ input file where the $\mathrm{HNO}_{3}$ and $\mathrm{H}_{2} \mathrm{O}_{2}$ rates were multiplied by a factor of ten and the sulfur content of the Carbon Steel Type A516 waste package components was increased by a factor of 20. The EQ6 inputs are listed in Table B-1.

Table B-1. EQ6 File Names and Nitric Acid and Hydrogen Peroxide Production Rates

\begin{tabular}{|c|c|c|}
\hline EQ6 Input File & $\mathrm{HNO}_{3}$ Rate $(\mathbf{m o l} / \mathbf{s})$ & $\mathbf{H}_{2} \mathrm{O}_{2}$ Rate $(\mathrm{mol} / \mathbf{s})$ \\
\hline $\mathrm{C} 22 \mathrm{C} 25$ & 0.0 & 0.0 \\
\hline $\mathrm{C} 22 \mathrm{CBC}$ & $9.53 \mathrm{E}-15$ & $3.97 \mathrm{E}-12$ \\
\hline $\mathrm{C} 22 \mathrm{BC} 10$ & $9.53 \mathrm{E}-14$ & $3.97 \mathrm{E}-11$ \\
\hline $\mathrm{C} 12 \mathrm{C} 25$ & 0.0 & 0.0 \\
\hline $\mathrm{C} 12 \mathrm{CBC}$ & $9.53 \mathrm{E}-15$ & $3.97 \mathrm{E}-12$ \\
\hline C12BC10x & $9.53 \mathrm{E}-14$ & $3.97 \mathrm{E}-11$ \\
\hline C12C10x_S20x & $9.53 \mathrm{E}-14$ & $3.97 \mathrm{E}-11$ \\
\hline
\end{tabular}

\section{B.6 RESULTS}

The results of the simulations are displayed in Figure B-1, where the $\mathrm{pH}$ profiles for the various runs are displayed versus time. These results show that neither the base case nor the $10 \times$ base-case generation rates of $\mathrm{HNO}_{3}$ and $\mathrm{H}_{2} \mathrm{O}_{2}$ had an impact on the in-package $\mathrm{pH}$. Therefore, it may be concluded that if radiolysis only affects the chemistry via $\mathrm{HNO}_{3}$ and $\mathrm{H}_{2} \mathrm{O}_{2}$ generation, then it will not be a significant process with regard to influencing the in-package chemistry.

The additional run $\left(\mathrm{C} 12 \mathrm{C} 10 \mathrm{x} \_\mathrm{S} 20 \mathrm{x}\right)$ with twenty times the sulfur in the carbon steel drives the $\mathrm{pH}$ of the system to a low of about $\mathrm{pH}=2.2$ (Figure B-1).

Table B-2 provides the minimum $\mathrm{pH}$, chloride, nitrate, hydrogen peroxide, and ferric iron maximum concentrations for the simulations. Again, the runs with $\mathrm{HNO}_{3}$ and $\mathrm{H}_{2} \mathrm{O}_{2}$ input show little deviation compared to the runs without $\mathrm{HNO}_{3}$ and $\mathrm{H}_{2} \mathrm{O}_{2}$.

Table B-2. Chloride, Ferric Iron, and Hydrogen Peroxide Molality

\begin{tabular}{|l|c|c|c|c|c|}
\hline \multicolumn{1}{|c|}{ EQ6 Input File } & $\begin{array}{c}\text { Minimum } \\
\mathbf{p H}\end{array}$ & $\mathbf{C l}$ & $\mathbf{N O}_{3}{ }^{-}$ & $\mathbf{H}_{2} \mathbf{O}_{2}$ (aq) & $\mathbf{F e}^{3+}$ \\
\hline C22C25 & 3.7 & $6.8 \mathrm{E}-04$ & $8.5 \mathrm{E}-04$ & $3.7 \mathrm{E}-19$ & $5.1 \mathrm{E}-11$ \\
\hline $\mathrm{C} 22 \mathrm{CBC}$ & 3.5 & $6.6 \mathrm{E}-04$ & $1.5 \mathrm{E}-03$ & $3.7 \mathrm{E}-19$ & $8.5 \mathrm{E}-11$ \\
\hline $\mathrm{C} 22 \mathrm{BC} 10 \mathrm{x}$ & 3.5 & $6.5 \mathrm{E}-04$ & $3.0 \mathrm{E}-03$ & $3.7 \mathrm{E}-19$ & $8.5 \mathrm{E}-11$ \\
\hline $\mathrm{C} 12 \mathrm{C} 25$ & 3.7 & $9.7 \mathrm{E}-04$ & $5.5 \mathrm{E}-03$ & $3.7 \mathrm{E}-19$ & $5.3 \mathrm{E}-11$ \\
\hline $\mathrm{C} 12 \mathrm{CBC}$ & 3.7 & $9.6 \mathrm{E}-04$ & $7.8 \mathrm{E}-03$ & $3.7 \mathrm{E}-19$ & $5.3 \mathrm{E}-11$ \\
\hline C12BC10x & 3.7 & $9.2 \mathrm{E}-04$ & $1.9 \mathrm{E}-02$ & $3.7 \mathrm{E}-19$ & $5.4 \mathrm{E}-11$ \\
\hline C12C10x_S20x & 2.2 & $9.7 \mathrm{E}-04$ & $1.6 \mathrm{E}-02$ & $3.7 \mathrm{E}-19$ & $3.8 \mathrm{E}-06$ \\
\hline
\end{tabular}

Source: Output DTN: MO0312SPAICSCR.002.

Based on this nonmechanistic approach to modeling the effects of radiolysis on in-package chemistry it may be stated that radiolysis will not affect the in-package chemistry in a manner 
that would impact TSPA-LA. The results of these analyses are compiled in DTN: MO0312SPAICSCR.002. Surface complexation, which is not accounted for by this radiolysis analyses, would further moderate the $\mathrm{pH}$ of this system in a manner similar to that discussed in Section 6.8.

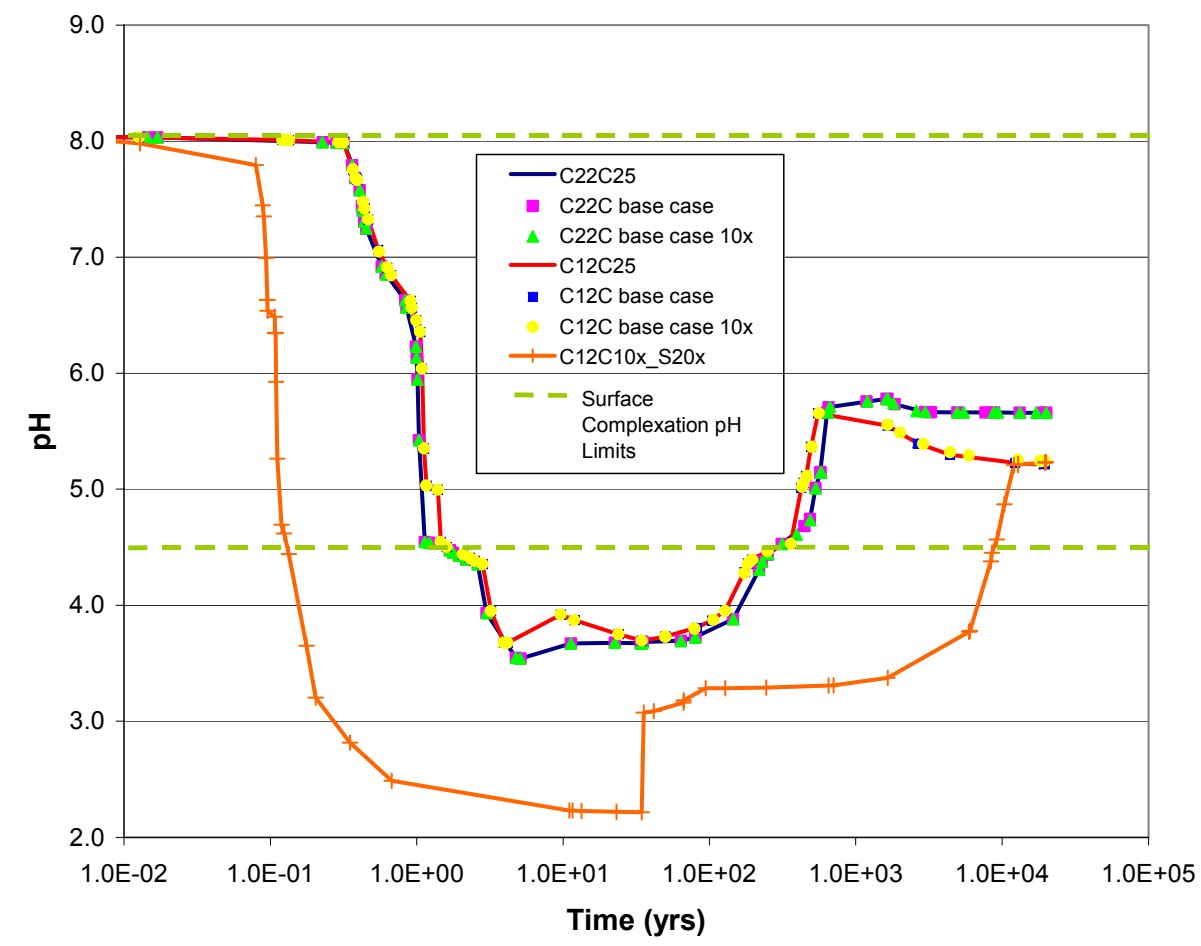

Source: csnf_radiolysis_ICN01.xls, Output DTN: MO0312SPAICSCR.002.

Figure B-1. pH Profiles Showing Radiolysis Impacts on pH 
INTENTIONALLY LEFT BLANK 


\section{APPENDIX C}

DATA QUALIFICATION PLAN 
INTENTIONALLY LEFT BLANK 


\section{DATA QUALIFICATION PLAN}

\begin{tabular}{|l|l|l|}
\hline \multirow{2}{*}{ BSC } & DATA QUALIFICATION PLAN & QA:QA \\
\cline { 3 - 3 } & Page 1 of 1 \\
\hline
\end{tabular}

\begin{tabular}{|c|c|c|}
\hline \multicolumn{3}{|l|}{ Section I. Organizational Information } \\
\hline \multicolumn{3}{|l|}{ Qualification Title: } \\
\hline \multicolumn{3}{|c|}{ Qualification of Data that Supports In-Package Chemistry Abstraction (ANL-EBS-MD-000037, Rev. 03) } \\
\hline \multicolumn{3}{|l|}{ Requesting Organization: } \\
\hline \multicolumn{3}{|l|}{ Engineered Systems } \\
\hline \multicolumn{3}{|c|}{ Section II. Process Planning Requirements } \\
\hline \multicolumn{3}{|l|}{ 1. List of Unqualified Data to be evaluated: } \\
\hline \multicolumn{3}{|c|}{$\begin{array}{l}\text { Sources of data that provide direct input to ANL-EBS-MD-000037 and that have not been qualified for all uses will be } \\
\text { evaluated. The Document Input Reference System (DIRS) assigns to these sources the following numbers: } 106164 \text {, } \\
100051,163015,168168 \text {, and } 105483 \text {. Authoritative sources will not be qualified. BSC/OCWRM documents will be } \\
\text { justified within the text of the document. }\end{array}$} \\
\hline \multicolumn{3}{|c|}{$\begin{array}{l}\text { 2. Type of Data Qualification Method(s) [Including rationale for selection of method(s) (Attachment 3) and qualification } \\
\text { attributes (Attachment 4) }\end{array}$} \\
\hline \multicolumn{3}{|c|}{$\begin{array}{l}\text { The method of technical assessment was chosen because documentation or proof of proper information acquisition } \\
\text { in unavailable for review for most data inputs }\end{array}$} \\
\hline \multicolumn{3}{|c|}{$\begin{array}{l}\text { The method of corroborating data was chosen for one of the methods of qualification because corroborating data are } \\
\text { available for comparison and inferences can be clearly identified, justified, and documented }\end{array}$} \\
\hline \multicolumn{3}{|c|}{$\begin{array}{l}\text { The qualification attribute: extent to which the data demonstrate the properties of interest, and one or more of the } \\
\text { following qualification attributes (taken from AP-SIII.2Q, Attachment } 4 \text { ) will be considered: }\end{array}$} \\
\hline $\begin{array}{l}\text { - Qualifications of personnel or } \\
\text { - Erior peer or other professiona } \\
\text { - Extent and quality of corrobor }\end{array}$ & $\begin{array}{l}\text { ing the information. } \\
\text { nation and their results. } \\
\text { se in conjunction with technical asses }\end{array}$ & \\
\hline \multicolumn{3}{|c|}{$\begin{array}{l}\text { - Extent and quality of corroborating information (for use in conjunction with technical assessment). } \\
\text { 3. Data Qualification Team and Additional Support Staff Required }\end{array}$} \\
\hline \multicolumn{3}{|l|}{$\begin{array}{l}\text { Emma Thomas - Chairman } \\
\text { William Downs }\end{array}$} \\
\hline \multicolumn{3}{|l|}{ 4. Data Evaluation Criteria } \\
\hline \multicolumn{3}{|c|}{$\begin{array}{l}\text { The following data evaluation criteria are based on and in this case identical to the attributes in block } 2 \text { : } \\
\text { - The extent to which the data demonstrate the properties of interest. } \\
\text { - Qualifications of personnel or organizations generating the information. } \\
\text { - Prior peer or other professional reviews of the information and their results. } \\
\text { - Extent and quality of corroborating information (for use in conjunction with technical assessment). }\end{array}$} \\
\hline \multicolumn{3}{|l|}{ 5. Identification of Procedures Used } \\
\hline \multicolumn{3}{|l|}{ AP-SIII.2Q, AP-SIII.9Q, and AP-3.15Q } \\
\hline \multicolumn{3}{|l|}{ Section III. Approval } \\
\hline Qualification Chairperson Printed Name & Qualification Chairperson Signature & Date \\
\hline Emma Thomas & & \\
\hline Responsible Manager Printed Name & Qualification Manager Signature & Date \\
\hline Neil Brown & & \\
\hline
\end{tabular}


INTENTIONALLY LEFT BLANK 


\section{APPENDIX D}

\section{QUALIFICATION OF DATA THAT SUPPORTS IN-PACKAGE CHEMISTRY}

\section{ABSTRACTION}


INTENTIONALLY LEFT BLANK 


\section{QUALIFICATION OF DATA THAT SUPPORTS IN-PACKAGE CHEMISTRY ABSTRACTION}

\section{D.1 PURPOSE}

This document relies on data that may not have been collected under an approved quality assurance program that meets the requirements of 10 CFR Part 63, Subpart G [DIRS 173273] or its predecessor, 10 CFR Part 60 (48 FR 28194 [DIRS 100475]). This appendix qualifies the data that this model report uses as direct input. The appendix was prepared according to the LP-SIII.2Q-BSC, Qualification of Unqualified Data. This qualification is being performed under the plan presented in Appendix C.

\section{D.2 METHODS AND CRITERIA}

LP-SIII.2Q-BSC offers five methods by which data may be qualified. As many of the methods were used as could be justified by the available supporting records. Technical assessment was considered as the strongest argument as documentation or proof of the quality and care of data acquisition is unavailable for review for most data inputs (e.g., laboratory quality plan unavailable for most older data collection activities). According to LP-SIII.2Q-BSC (Attachment 3 ), this confirmation comprises 1) "a discussion and justification that the data collection methodology used was appropriate for the type of data under consideration," 2) "a discussion and justification that the data acquisition and/or subsequent data development discussed in source documentation was appropriate for the type of data under consideration," or 3) "discussion and documentation that the data have been used in applications that are similar to those for which the data will be used." Option 1 was used for the qualification process in this appendix.

In addition to corroborating data and technical assessment, the qualification process considers the extent to which the data demonstrate the properties of interest and at least one of the qualification process attributes of LP-SIII.2Q-BSC (Attachment 4).

- Qualifications of personnel or organizations generating the information

- Prior peer or other professional reviews of the information and their results

- Extent and quality of corroborating information (for use in conjunction with technical assessment).

These criteria also serve as the "data evaluation criteria" on which the data qualification team will provide judgments (LP-SIII.2Q-BSC, Section 5.1.2 (b)(4)).

The team comprises two members: Emma Thomas, model originator, chairs the team and William Downs, Ph.D., who is technically competent in data collection and qualification, assists. As the analysis originator, Emma Thomas is not independent of the information to be qualified (LP-SIII.2Q-BSC, Section 5.1.2 (b)(3)). However, the procedure requires that the originator chair the team "... when the qualification is performed within the Analysis or Model Report" (LP-SIII.2Q-BSC, Section 5.1.1). William Downs did not participate in the acquisition, but was a reviewer of the analysis. 


\section{D.3 QUALIFICATION OF DATA}

LP-SIII.2Q-BSC does not apply to "established fact" or numerical data obtained from an established or authoritative data source. Because some of the data comes from authoritative sources (other than the U.S. Department of Energy, Office of Civilian Radioactive Waste Management), it does not need to be qualified. The remaining data are qualified only for its intended use.

Table D-1 lists the sources of data that are being qualified for their use in this report and designates the attributes or criteria that are used, in conjunction with the corroborating data and technical assessment, to qualify the information.

Table D-1. Sources of Data and Criteria Used to Qualify the Information

\begin{tabular}{|c|c|}
\hline Source & Criteria \\
\hline \multicolumn{2}{|c|}{ Data Sources to be Qualified } \\
\hline $\begin{array}{l}\text { Defense Waste Processing Facility Wasteform and } \\
\text { Canister Description (Baxter } 1988 \text { [DIRS 106164]) }\end{array}$ & $\begin{array}{l}\text { Technical assessment/acceptable methodology } \\
\text { Corroborating Data Personnel/organization qualifications } \\
\text { Demonstrate properties of interest }\end{array}$ \\
\hline $\begin{array}{l}\text { Aqueous Environmental Geochemistry (Langmuir } 1977 \\
\text { [DIRS 100051] }\end{array}$ & $\begin{array}{l}\text { Technical assessment/acceptable methodology } \\
\text { Corroborating Data } \\
\text { Personnel/organization qualifications } \\
\text { Demonstrate properties of interest }\end{array}$ \\
\hline $\begin{array}{l}\text { "Critical Evaluation and Selection of Standard State } \\
\text { Thermodynamic Properties for Chromium Metal and its } \\
\text { Aqueous lons, Hydrolysis Species, Oxides, and } \\
\text { Hydroxides" (Ball and Nordstrom } 1998 \text { [DIRS 163015]) }\end{array}$ & $\begin{array}{l}\text { Technical assessment/acceptable methodology } \\
\text { Corroborating Data } \\
\text { Personnel/organization qualifications } \\
\text { Demonstrate properties of interest }\end{array}$ \\
\hline $\begin{array}{l}\text { "Surface Complexation of Ferrous Iron and Carbonate on } \\
\text { Ferrihydrite and the Mobilization of Arsenic." (Appelo et } \\
\text { al. } 2002 \text { [DIRS 168168] }\end{array}$ & $\begin{array}{l}\text { Technical assessment/acceptable methodology } \\
\text { Personnel/organization qualifications } \\
\text { Demonstrate properties of interest }\end{array}$ \\
\hline $\begin{array}{l}\text { Surface Complexation Modeling, Hydrous Ferric Oxide } \\
\text { (Dzombak and Morel } 1990 \text { [DIRS 105483]) }\end{array}$ & $\begin{array}{l}\text { Technical assessment/acceptable methodology } \\
\text { Personnel/organization qualifications } \\
\text { Demonstrate properties of interest }\end{array}$ \\
\hline
\end{tabular}

The discussions above and in the next section fulfill requirements of LP-SIII.2Q-BSC to discuss the data for qualification, the method of qualification, and the evaluation criteria (LP-SIII.2Q-BSC, Section 5.3.1, paragraphs (a)(1) through (3)).

A discussion of the remaining requirements follows:

- LP-SIII.2Q-BSC, Section 5.3.1 (a)(4) - the team considers the information technically correct because it has undergone a technical assessment and it fulfills at least one of the qualification process attributes of LP-SIII.2Q-BSC (Attachment 4).

- LP-SIII.2Q-BSC, Section 5.3.1 (a)(5)—no data are generated by this evaluation. 
- LP-SIII.2Q-BSC, Section 5.3.1 (a)(6) - the team finds that the information is qualified for its use within In-Package Chemistry Model Abstraction ANL-EBS-MD-000037, Rev. 03.

- LP-SIII.2Q-BSC, Section 5.3.1 (a)(7) - the team recommends that the information be given the status of "qualified data."

- LP-SIII.2Q-BSC, Section 5.3.1 (a)(8) - the team did not "abandon" any qualification method.

- LP-SIII.2Q-BSC, Section 5.3.1 (a)(9) - the data are qualified only for use in this document. It is not qualified for other potential users.

- LP-SIII.2Q-BSC, Section 5.3.1 (a)(10)—supporting or corroborating information is identified in Appendix $\mathrm{C}$ when used in the qualification effort.

- LP-SIII.2Q-BSC, Section 5.3.1 (a)(11) — the qualification was performed under the data qualification plan presented in Appendix C.

\section{D.3.1 Qualification of Baxter, R.G. 1988 [DIRS 106164]}

Technical Assessment/Acceptable Methodology: This report describes the physical and chemical stability characteristics of the defense high-level waste form borosilicate glass that was developed at the DOE Savannah River National Laboratory, Aiken, South Carolina. The value of interest for this report is the density of the waste glass at $25^{\circ} \mathrm{C}$ is $2.85 \mathrm{~g} / \mathrm{cm}^{3}$. This value is the mean of several calculated densities based on percentages of radionuclide containing sludges and glass constituents.

Personnel/organization qualifications: The author and his organization are nationally recognized as the developers and testors of the borosilicate glass waste form. These data are comparable to "vendor data" for qualification purposes.

Corroborating Data: In order to check the validity of the density of the borosilicate glass waste form, the data were compared to similar data measured on other borosilicate glass samples by scientists at the Oak Ridge National Laboratory, Oak Ridge, Tennessee. The data agreed within $6 \%$ at $25^{\circ} \mathrm{C}$ (Notz et al. 1990 [DIRS 119707]).

Demonstrate properties of interest: The estimates were made for materials selected for use in the repository.

\section{D.3.2 Qualification of Langmuir 1997 [DIRS 100051]}

Technical Assessment/Acceptable Methodology: This publication is a textbook that contains empirical data for numerous thermodynamic and physicochemical parameters. The original source for these data are publications in peer-reviewed journals that have been used in numerous investigations and modeling efforts. These data have been included in virtually all of the equilibrium geochemistry simulation codes (e.g., PHREEQEC, MINTEQA2, etc.) since they were originally published and have been accepted by the scientific community. 
Personnel/organization qualifications: The author is a Professor Emeritus at the Colorado School of Mines and has dozens of publications in the area of thermodynamics of dissolved species and mineral phases.

Corroborating Data: The table, from which the goethite surface data (sites per unit area and surface area per unit mass) were taken, contained data from several sources that demonstrated that the data selected were well within the range of measured data. In addition, similar data in agreement were calculated from basic crystal chemistry models and solvation theory.

Demonstrate properties of interest: The corrosion models for the iron bearing alloys used as either structural elements or waste casks have specified that the corrosion products include goethite $-\gamma$-FeOOH. This selection is considered conservative as the corrosion products include ferrihydrite $\left(\mathrm{Fe}[\mathrm{OH}]_{3}\right)$, goethite $(\gamma-\mathrm{FeOOH})$, and hematite $\left(\alpha-\mathrm{Fe}_{2} \mathrm{O}_{3}\right)$ as aging of the corrosion products proceeds with time. Ferrihydrite has a much larger surface area and would suggest adsorption of more elevated levels of species from solution but will dehydrate to goethite.

\section{D.3.3 Qualification of Ball and Nordstrom 1998 [DIRS 163015]}

Technical Assessment/Acceptable Methodology: This article comes from a peer-reviewed journal, Journal of Chemical \& Engineering Data, that is a major source for thermodynamic data. The authors selected a method to achieve consistency and minimize error that include maintaining thermodynamic relationships, determine the most direct path for derived thermodynamic quantities, and compare derived thermodynamic quantities with empirical data where ever possible. For compounds and species where multiple measurements have been made, statistical analyses were conducted to determine the aleatory dispersion about the mean. The rigor of the methods used to develop these data is compatible with the requirements of the OCRWM quality program.

Personnel/organization qualifications: The authors of this article are nationally recognized specialists in the field of geochemistry and both of them have numerous publications in the field of geochemistry. The junior author, Dr. Kirk Nordstrom, is the coauthor (with J.L. Munoz) of Geochemical Thermodynamics, a text used by numerous universities for advanced courses in the field.

Corroborating Data: The article contains comparisons of the solubilities of key minerals calculated from the generated thermodynamic data with empirical data. In addition, the thermodynamic data for chromium species and compounds were compared and evaluated with data that had been generated and published by other researchers.

Demonstrate properties of interest: Because the various waste packages contain stainless steel as structural members and hexavalent chromium, $\mathrm{Cr}^{6+}$, represents a risk to human health and the environment, the solubility and sorption characteristics of chromium dissolved species and solids are necessary for assessing the performance of the repository.

\section{D.3.4 Qualification of Appelo et al. 2002 [DIRS 168168]}

Technical Assessment/Acceptable Methodology: This article comes from a peer-reviewed journal, Environmental Science \& Technology, which is a major source for thermodynamic data. 
The authors selected a method to achieve consistency and minimize error that include maintaining thermodynamic relationships, determine the most direct path for derived thermodynamic quantities, and compare derived thermodynamic quantities with empirical data where ever possible. The rigor of the methods used to develop these data is compatible with the requirements of the OCRWM Quality Program.

Personnel/organization qualifications: Dr. C A J Appelo received his PhD from the Vrije Universiteit, Amsterdam, NL, in 1978. He is a hydrochemical consultant providing consulting and educating for water resources, water quality and water pollution, and has presented short courses in hydrogeochemistry and hydrogeochemical transport modeling in Finland, France, the Netherlands, Portugal, South Africa, and Switzerland. He has over 35 publications in peer-reviewed technical journals and is an author of a widely used textbook on groundwater geochemistry and pollution and geochemical modeling (Appelo and Postma 1999 [DIRS 172038]). His collaboration with U. S. Geological Survey research scientists led to the development of the geochemical modeling code, PHREEQC, and its database.

Dr. Cristophe Tournassat recently received his $\mathrm{PhD}$ in environmental geochemistry from the University of Grenoble-I, FR. He is now a research scientist with the French Government environment organization BRGM in Orleans.

Dr. Laurent Charlet is a Full Professor in the Earth and Planetary Sciences Department at the University of Grenoble-I, FR. He received his PhD in 1986 from the University California at Riverside in Soil and Environmental Sciences, was a Postdoctoral Fellow at the Swiss Institute of Aquatic Sciences (EAWAG), and a Research Associate in the Department of Chemistry, University of Bern, Switzerland. His present research interests include mineral-water interface chemistry, atomic-scale environmental chemistry, biogeochemistry and the relationship between contamination and public health. He is author of more than 60 refereed publications in technical journals.

Professor Charlet's professional activity includes service in the Fundamental Environmental Chemistry section of the International Union of Pure and Applied Chemistry (IUPAC); membership in a review panel on nuclear waste confinement for the CNWRA, San Antonio; direction of the European Union (EU) project on "Mercury in French Guyana;" and service as associate editor of Aquatic Chemistry and Advances in Environmental Science, and as guest editor of Geochimica et Cosmochimica Acta.

Demonstrate properties of interest: The value given by Appelo et al. (2002 [DIRS 168168], Table 1, p. 3,097) is the value for the equilibrium constant for reactions given in Table 4-9. These are precisely the data that are required for parameterizing the surface complexation model. The surface complexation model (Section 6.7) is used to calculate the $\mathrm{pH}$ values fixed by surface complexation reactions on ferric oxyhydroxides (hydrous ferric oxides) formed within the waste package as a function of $\mathrm{CO}_{2}$ fugacity $\left(f \mathrm{CO}_{2}\right)$. In its development, this model requires values for the equilibrium constants of several chemical reactions. Some of these reactions are between dissolved species or between gases and dissolved species. Equilibrium constants for these reactions are taken from the qualified thermodynamic database data0.ymp.R4 (DTN: SN0410T0510404.002 [DIRS 172712]). Equilibrium constants for surface complexation reactions are also required for the surface complexation model but are not included in the 
database Data0.YMP.R4. Appelo et al. (2002 [DIRS 168168], Table 1, p. 3,097) provide values for one of the constants needed.

\section{D.3.5 Qualification of Dzombak and Morel 1990 [DIRS 105483]}

Technical Assessment/Acceptable Methodology: This publication is a textbook that contains data for surface complexation parameters. This textbook is considered the handbook for this type of material by those in the field. The original source for these data are publications in peer-reviewed journals that have been used in numerous investigations and modeling efforts. These data have been included in virtually all of the equilibrium geochemistry simulation codes (e.g., PHREEQEC, MINTEQA2, etc.) since they were originally published and have been accepted by the scientific community.

Personnel/organization qualifications: Dr. David A Dzombak is professor in the Department of Civil and Environmental Engineering at Carnegie Mellon University, Pittsburgh, PA and a registered Professional Engineer in Pennsylvania. His research and professional interests include: aquatic chemistry, especially interactions of aqueous chemical species with mineral surfaces; fate and transport of chemicals in surface and subsurface waters; water and wastewater treatment; in situ and ex situ soil treatment; hazardous waste site remediation; abandoned mine drainage remediation; river and watershed restoration; and public communication of environmental science. In addition to this book containing the data to be qualified, he has published more than 50 articles in leading, peer-reviewed, environmental engineering and science journals and numerous book chapters.

Professor Dzombak's professional service activity has included service on the EPA Science Advisory Board (2002 to present); the Committee on Bioavailability of Contaminants in Soils and Sediments, National Research Council (2000 to 2002); editorial board of Water Environment Research (1993 to 1998) and Ground Water (1991 to 1993); Board of Directors and Officer (Treasurer) of the Association of Environmental Engineering and Science Professors (1996 to 1999); chair of committees for the American Academy of Environmental Engineers, American Society of Civil Engineers, and Water Environment Federation; and advisory committees for Allegheny County and the Commonwealth of Pennsylvania.

Dr. François M. M. Morel is the Albert G. Blanke Professor of Geosciences and Princeton University, Director, Princeton Environmental Institute and Director, Center for Environmental Bioinorganic Chemistry. His professional activities include teaching, as instructor of undergraduate and graduate subjects in aquatic chemistry element cycles, surface phenomena and biogeochemistry, and research as: Principal Investigator of projects on: (i) coordination chemistry, surface chemistry and photochemistry of trace elements in natural waters; (ii) interactions between the chemistry and microbiota in aquatic systems, (iii) trace metal nutrition and toxicity in phytoplankton; and (iv) environmental bioinorganic chemistry. He is author of four books, 14 book chapters, and more than 135 articles in peer-reviewed engineering and science journals.

Professor Morel's professional service activity has included service on the National Research Council Panel on Marine Mineral Technology (1976 to 1977), Committee on Ocean Waste Transportation (1982 to 1984) and Committee on Irrigation-Induced Water Quality Problems 
(1985 to 1988). He has also served on the Advisory Board of Environmental Science and Technology (1978 to 1983) and as associate editor (1980), on the Editorial Board of Limnology and Oceanography (1980 to 1983) and as special editor (1990) and is on the editorial board of Biogeochemistry, Geobiology, Aquatic Sciences and Environmental Microbiology. He serves Institut National de l'Environnement Industriel et des Risques, as Membre du Conseil Scientifique (1991 to present), and Nancie Centre International De L'eau as membre du Conseil d'Orientation (1995 to present).

Since its publication in 1990, this book by Dzombak and Morel has become a standard source for equilibrium constants surface complexation reactions. Data from it are cited in widely used textbooks on aqueous geochemistry including those by Langmuir (1997 [DIRS 100051]) and Stumm and Morgan (1996 [DIRS 125332]). These data are also included in the databases accompanying the broadly distributed, U. S. Geological Survey geochemical modeling code PHREEQC (BSC 2001. [DIRS 154877]); Parkhurst and Appelo (1999 [DIRS 159511]) and the widely used U.S. Environmental Protection Agency geochemical assessment model MINTEQA2 (Allison et al. 1991 [DIRS 171707]); HydroGeoLogic; Allison Geoscience Consultants (1999 [DIRS 158974]).

Demonstrate properties of interest: Values provided by Dzombak and Morel (1990 [DIRS 105483], Table 5.7) are for the equilibrium constants for reactions in Table 4-9. These are precisely the data that are required for parameterizing the surface complexation model. The surface complexation model (Section 6.7) is used to calculate the $\mathrm{pH}$ values fixed by surface complexation reactions on ferric oxyhydroxides (hydrous ferric oxides) formed within the waste package as a function of $\mathrm{CO}_{2}$ fugacity $\left(f \mathrm{CO}_{2}\right)$. In its development, this model requires values for the equilibrium constants of several chemical reactions. Some of these reactions are between dissolved species or between gases and dissolved species. Equilibrium constants for these reactions are taken from the qualified thermodynamic database data0.ymp.R4 (DTN: SN0410T0510404.002 [DIRS 172712]). Equilibrium constants for surface complexation reactions are also required for the surface complexation model but are not included in database Data0.YMP.R4. Dzombak and Morel (1990 [DIRS 105483], Table 5.7) provide values for two of the needed constants.

\section{D.4 CONCLUSION}

In conclusion, all of the data from the articles or books listed above are qualified for their intended use in this model report. 
INTENTIONALLY LEFT BLANK 
APPENDIX E

EVALUATION OF IN-PACKAGE CHEMISTRY SURFACE COMPLEXATION MODEL 
INTENTIONALLY LEFT BLANK 


\section{E. EVALUATION OF IN-PACKAGE CHEMISTRY SURFACE COMPLEXATION MODEL}

The following evaluation was performed by Yifeng Wang, Principal Member of Technical Staff, Sandia National Laboratories, a recognized expert in the field of geochemistry, with a Ph.D. from the Department of Geological Sciences, Indiana University. This review was conducted on 7/23/2004 in accordance with the requirements of Technical Work Plan for Postclosure Waste Form Modeling (BSC 2005 [DIRS 173246]). In his report on his evaluation, Dr. Wang raised several questions. The report and the responses by Patrick Brady to the raised questions are provided below:

The in-package chemistry model is developed to predict the chemistry (e.g., pH and ionic strength) of inside a breached waste package. The surface complexation model is included as a part of model to provide realistic estimates of in-package $\mathrm{pH}$ values by accounting for the effect of surface protonation and deprotonation on solution $\mathrm{pH}$. This review is focused only on the surface complexation model.

The corrosion of Carbon Steel Type A516 and the oxidation of elemental sulfur contained in the steel will generate a certain quantity of $\mathrm{H}_{2} \mathrm{SO}_{4}$ acid that could potentially lead to a low in-package $\mathrm{pH}$. In reality, this low $\mathrm{pH}$ is likely to be buffered by surface protonation on corrosion products, given the factors that only a trace amount of elemental sulfur (1000 times less than Fe on a molal basis) is contained in Carbon Steel Type A516 and that Fe oxyhydroxides as a corrosion product are practically insoluble and have a high surface adsorption capability with the point of zero charge close to neutral $\mathrm{pH}$. Therefore, the general concept of using a surface complexation mechanism to constrain a more realistic in-package $\mathrm{pH}$ is scientifically sound.

It is generally recognized that there are a large uncertainties associated with the equilibrium constants of surface complexation reactions, which are usually model-dependent. However, the equilibrium constants used in the in-package chemistry model seem reasonable. First of all, the surface complexation constants are relatively well established for $\mathrm{Fe}$ oxides as compared to other minerals. Second, the actual values used in the model are from a carefully compiled and widely accepted data sources (e.g., Dzombak and Morel 1990 [DIRS 105483]).

A simplified version of surface complexation model, described by an analytic equation, is used in the package chemistry. I have checked the derivation of the equation, and no error has been found. The prediction of the equation has been confirmed by PHREEQC calculations.

In general, the surface complexation model developed for in-package chemistry is adequate for its intended use (i.e., to provide a more realistic prediction of in-package $\mathrm{pH}$ ). 
Specific comments:

- In the model abstraction, the in-package chemistry model implies a well-mixed cell for a whole waste package. This assumption is not consistent with the EBS transport model, which assumes two cells in a waste package. Steel corrosion is assumed to be present only in cell 1 . It seems to me that the surface complexation model should be applied only to cell 1 .

Response-Spent fuel will reside inside of a matrix of steel and corrosion products. In the EBS transport model the fuel is referred to as domain 1. Steel and its corrosion products are referred to as domain 2. Water that moves into domain 1 must move first through domain 2 where the corrosion products reside and where the SCM is used to calculate the $\mathrm{pH}$. Water carrying fuel components out of domain 1 must move through domain 2 as well. It is, therefore, reasonable to apply the SCM in domains 2 and 1.

- The technical basis for selection of goethite as a representative corrosion product is not fully justified.

Response-Corrosion product formation is complex and depends upon time, temperature, relative humidity, salt identity and concentrations and so on. It is impossible to fully justify the selection of a single corrosion product such as goethite. For this reason, goethite - a corrosion product that is commonly observed, with mid-range site density and surface areas - was chosen to represent what in all likelihood will be an evolving collection of iron corrosion products. For the purposes of this calculation, the technical basis is believed sufficient.

- Low pH could be also caused by the release of Cr(VI) from Stainless Steel Type 304L. But I am not sure the same surface complexation model can apply to this condition.

Response-Stainless Steel Type 304L can, in theory, cause low pH values. Because the molal dissolution rate of Stainless Steel Type 304L is quite low, the resulting proton production occurs over long time spans and will tend to be diluted by the steady influx of seepage or condensate.

- There are other uncertainties associated with the surface complexation model. The temperature effect on surface complexation has not been well established in general.

Response-Yes, the temperature effect on surface complexation remains an area of active study. There is no evidence in the evolving subject literature that temperature effects on surface complexation will lead to materially different $\mathrm{pH}$ trajectories though. The competition of other ions on surface protonation and deprotonation could affect on the predicted $\mathrm{pH}$, although the PHREEQC calculations have shown such an effect may be not significant. Competition could affect the $\mathrm{pH}$, but again the PHREEQC provides sufficient confidence that the large-scale features are captured in the analytical mode. 
APPENDIX F

CD-ROM 
INTENTIONALLY LEFT BLANK 
APPENDIX G

LISTING OF FILES ON COMPACT DISC 
INTENTIONALLY LEFT BLANK 


\section{G. LISTING OF FILES ON COMPACT DISC}

This attachment contains the name and size of the zip file placed on the electronic media (Attachment I). Winzip 7.0 was used to compress the files.

Volume in drive D is $050707 \quad 1657$

Volume Serial Number is E32 F-2BC4

Directory of D:

$\begin{array}{rrrl}\text { 07/07/2005 } & 08: 51 \mathrm{a} & 1,313,984 & \text { Alternative Conceptual Model.zip } \\ \text { 07/07/2005 } 09: 09 \mathrm{a} & 296,094,110 & \text { EQ6 Runs.zip } \\ \text { 07/07/2005 } 08: 51 \mathrm{a} & 2,648,657 & \text { SCM.zip } \\ \text { 07/07/2005 } 04: 19 \mathrm{p} & 7,720,991 & \text { Spreadsheets.zip } \\ & & \\ 4 \text { File(s) } & 307,777,742 & \text { bytes }\end{array}$

Total Files Listed:

4 File(s) 307,777,742 bytes

$0 \operatorname{Dir}(\mathrm{s}) \quad 0$ bytes free

The zip files contain files of various types:

Excel files (extensions $=\mathbf{x l s})$.

Mathcad files $($ extensions $=$ mcd $)$.

EQ3/6 input files $($ extension $=3 i$ or $6 i)$.

ASCII text file: provides input parameters for EQ3/6.

EQ3/6 output files (extension $=30$ or 60$)$.

ASCII text file: provides detailed information about the system at each print point, which is specified by the user in the input file.

EQ3/6 pickup files (extension $=3$ p or $6 p)$.

ASCII text file: provides a description of the system at the end of that run to be used as an input file for a continuation run.

EQ6 Tab-delimited text files $($ extension $=\mathbf{t x t})$.

*.elem_aqu: total aqueous moles of elements.

*.elem_min: total moles of elements in minerals.

*.elem_tot: total moles of elements (aqueous + mineral). 
*.min_info: moles of each mineral.

EQ6 binary output file (extension = bin).

Binary file: provides detailed information about the system at the full numerical precision for every time step.

EQPT input files (data0.cr3 and data0.ert)

EQPT output files (data1.cr3 and data.ert)

transl input file (data0.ymp.R2)

transl output file (extension $=$ dat $)$

PHREEQC input file (no extension)

PHREEQC output file (extension = out)

Batch files (extension $=$ bat) used to start EQ6 runs.

Winzip files (extension $=$ zip). 
The following figure illustrates the directory structure within the zip files listed above.

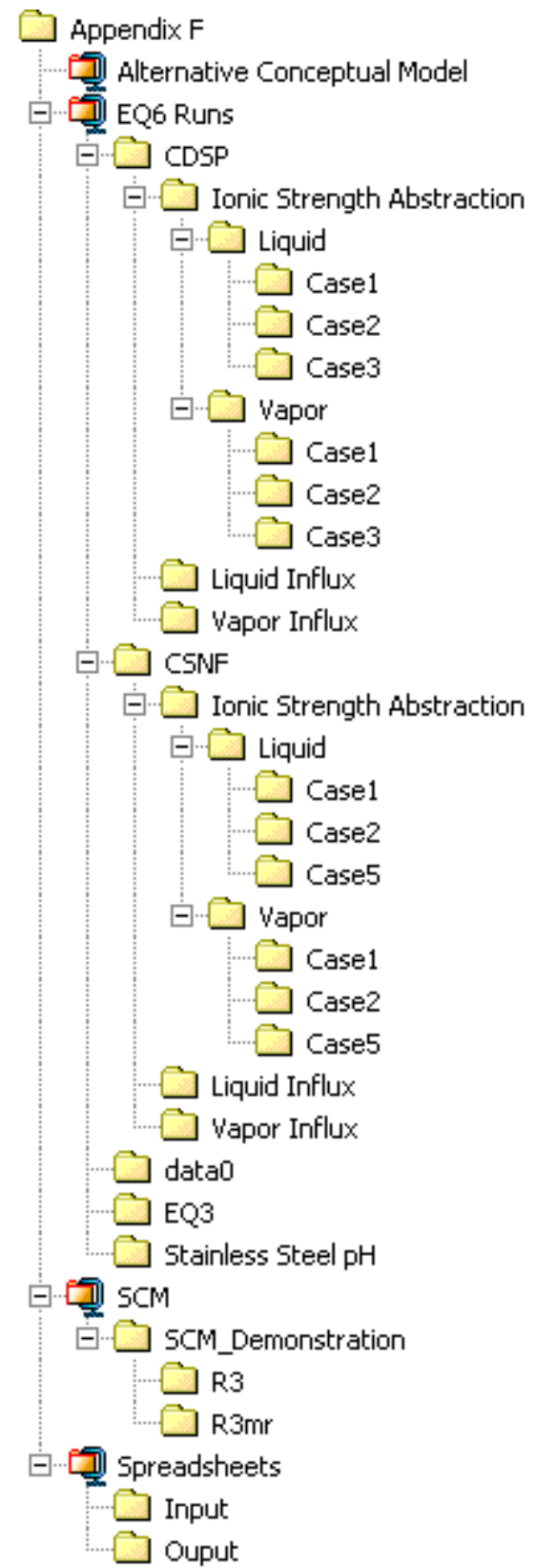

Figure G-1. Directory Structures for Appendix F Zip Files 
INTENTIONALLY LEFT BLANK 
APPENDIX H

WATER-VAPOR FLUX INTO THE WASTE PACKAGE BASED ON

FICK'S FIRST LAW AND STEFAN TUBE EQUATIONS 
INTENTIONALLY LEFT BLANK 


\section{H. WATER-VAPOR FLUX INTO THE WASTE PACKAGE BASED ON FICK'S FIRST LAW AND STEFAN TUBE EQUATIONS}

\section{H.1 WATER VAPOR DIFFUSION FLUX FICK'S FIRST LAW CALCULATION}

This sheet calculates the water-vapor flux (q) into the waste package through the stress corrosion cracks in the waste package outer lid based on Fick's First Law. The technical basis for this calculation was taken from EBS Radionuclide Transport Abstraction (BSC 2004 [DIRS 169868], Section 6.6.2). The flux is calculated over a temperature range (specified by the index, i) for a specified relative humidity. Fick's First Law is based on the assumption that the calculated flux is due to a concentration gradient, and that the change in the gradient is constant with regard to distance between the source and sink. In the case presented, it is also assumed that the relative humidity is zero inside the waste package. The justification of this assumption is that water vapor will be consumed in the formation of corrosion products and secondary minerals. In addition, this assumption is conservative as it maximizes the vapor diffusion flux into the waste package. Fick's First Law does not evaluate the contribution of the advective (convective) component to flux.

The mathematical expression of Fick's First Law is (BSC 2004 [DIRS 169868], Equation 6.6.2-8):

$$
q=D_{A B} A_{S C C} \frac{\partial C_{W V}}{\partial x}
$$

where $q=$ flux, $D_{A B}=$ binary diffusion coefficient, $A_{S C C}=$ cross-sectional area of the stress corrosion cracks through which water vapor can diffuse, $\partial C_{w v}=$ the change in water vapor concentration from the source to the sink, and $\delta x$ is the distance of the travel path (thickness of the waste package outer lid $=2.54 \mathrm{~cm}$ ).

This appendix was prepared using Mathcad, Version 11 (Table 3-1). This sheet calculates the flux $\left(q\right.$ Temp $\left._{i}\right)$ in an iterative manner for the temperature range $30^{\circ} \mathrm{C}$ to $96^{\circ} \mathrm{C}$, for a selected value of relative humidity $(R H)$. The temperature range from $30^{\circ} \mathrm{C}$ to $96^{\circ} \mathrm{C}$ was selected as $30^{\circ} \mathrm{C}$ is approximately room temperature, and $96^{\circ} \mathrm{C}$ is when water will stop boiling at the site elevation.

In Equation H.1-2, adapted from EBS Radionuclide Transport Abstraction (BSC 2004 [DIRS 169868], Equation 6.2.2-2), the vector $i=1 . .67$ defines the range of the iteration, Temp $_{i}$ sums 29 with the vector i to define the temperature range $30^{\circ} \mathrm{C}$ to $96^{\circ} \mathrm{C}$, and pwfTemp defines a function that calculates the saturated partial pressure of water vapor over the temperature range $30^{\circ} \mathrm{C}$ to $96^{\circ} \mathrm{C}$. Equations for pwfTemp are taken from the report by Singh et al. (2002 [DIRS 161624], Equations 1a and 1b).

$$
\begin{gathered}
i:=1 . .67 \\
\text { Temp }_{i}:=29+i
\end{gathered}
$$




$$
\text { pwfTemp(Temp) }:=\mid \begin{aligned}
& 610.78 \cdot \exp \left[\frac{17.269 \cdot(\text { Temp })}{237.3+(\text { Temp })}\right] \text { if }(0 \leq \text { Temp }) \cdot(\text { Temp }<63) \\
& 610.78 \cdot \exp \left[\frac{17.269 \cdot(\text { Temp })}{236.3+1.01585 \cdot(\text { Temp })}\right] \text { if }(63 \leq \text { Temp }) \cdot(\text { Temp }<110)
\end{aligned}
$$

(Eq. H.1-2)

Note: $\quad$ The symbol : = denotes a definition in Mathcad.

From the saturated partial pressure of water vapor (pwfTemp) the partial pressure of water dependent on the relative humidity (RH) can be determined (BSC 2004 [DIRS 161624], Equation 6.6.2-1):

$$
\begin{gathered}
p w \text { Temp }_{i}:=p w f \operatorname{Temp}\left(\text { Temp }_{i}\right) \\
R H:=0.95 \\
\text { pTemp }_{i}:=\left(\text { pwTemp }_{i}\right) \cdot R H
\end{gathered}
$$

where pwTemp $_{i}$ is vapor pressure of water calculated in the function $p w f T e m p$ for the temperature range 30 to $96^{\circ} \mathrm{C}$. $R H$ is the relative humidity. By changing the value for $R H$ the flux is calculated over the range of temperatures specified by the vector $i$. pTemp $p_{i}$ is the partial pressure of water dependent on the relative humidity.

Next, the molal humidity is calculated. In this example it is calculated for $50^{\circ} \mathrm{C}$ and 95 percent relative humidity (BSC 2004 [DIRS 161624], Equation 6.6.2-4):

$$
\operatorname{HmTemp}_{i}:=\frac{p \operatorname{Temp}_{i}}{101325-p \operatorname{Temp}_{i}}
$$

where $\mathrm{HmTemp}_{i}$ is the molal humidity $\left(\mathrm{mol} \mathrm{H}_{2} \mathrm{O} / \mathrm{mol}\right.$ wet air). Pressure for dry air is 1 atm $=$ $101,325 \mathrm{~Pa}$, from equation $\mathrm{H} .1-2$ at $50^{\circ} \mathrm{C}$ the partial pressure of water $\left(\mathrm{p}_{\mathrm{w}}\right)$ was calculated $\mathrm{p}_{\mathrm{w}}=12,344 \mathrm{~Pa}$. So the partial pressure at $R H=0.95$ is $\mathrm{p}_{\mathrm{w}}=11,717 \mathrm{~Pa}$. Then the molal humidity of water vapor in wet air (molar fraction of water vapor in wet air) can be calculated by dividing $11,717 \mathrm{~Pa} / 101,325 \mathrm{~Pa}=0.1156 \mathrm{~mol} \mathrm{H}^{2} \mathrm{O} \mathrm{mol}^{-1}$ wet air.

The concentration of water vapor at $50^{\circ} \mathrm{C}$ and 95 percent relative humidity can then be calculated (BSC 2004 [DIRS 161624], Equation 6.6.2-5):

$$
C_{w v} \text { Temp }_{i}:=\frac{\text { HmTemp }_{i}}{22414 \cdot\left(\frac{273.15+\text { Temp }_{i}}{273.15}\right)}
$$

where $C_{w v}$ Temp $_{i}$ is the concentration of water vapor in the air $\mathrm{mol} \mathrm{H} \mathrm{H}_{2} \mathrm{O} / \mathrm{cm}^{3}$. 
To calculate the binary diffusion coefficient the following equation is used (Bird et al. 1960 [DIRS 103524] Equation 16.3-1; BSC 2004 [DIRS 161624], Equations 6.6.2-6 and 6.6.2-7):

DABTemp $:=3.64 \cdot 10^{-4} \cdot\left(\frac{273.15+\mathrm{Temp}_{\mathrm{i}}}{\sqrt{647.25 \cdot 132}}\right)^{2.334} \cdot(218.3 \cdot 36.4)^{\frac{1}{3}} \cdot(647.25 \cdot 132)^{\frac{5}{12}} \cdot\left(\frac{1}{18.01528}+\frac{1}{28.964}\right)^{\frac{1}{2}} \cdot(1)^{-1}$

(Eq. H.1-6)

DAB is the binary diffusion coefficient $\left(\mathrm{cm}^{2} \mathrm{~s}-1\right), \mathrm{a}=3.64 \times 10-4$ for $\mathrm{H}_{2} \mathrm{O}$, Tempi $=$ temperature (C) converted into absolute temperature $(\mathrm{K}), \mathrm{TcA}=647.25 \mathrm{~K}, \mathrm{TcB}=132 \mathrm{~K}, \mathrm{pcA}=218.3 \mathrm{~atm}$, $\mathrm{pcB}=36.4 \mathrm{~atm}, \mathrm{MA}=18.01528 \mathrm{~g} / \mathrm{mol}, \mathrm{MB}=28.964 \mathrm{~g} / \mathrm{mol}$, and $\mathrm{p}-1=1 \mathrm{~atm}$.

Then the water-vapor flux (qTemp) that enters through the aperture of the stress corrosion cracks can be calculated (BSC 2004 [DIRS 161624], Equation 6.6.2-8):

$$
\text { qTemp }:=\frac{\text { DABTemp } \cdot(1.93) \cdot \text { CwvTemp }}{2.54}
$$

The value $1.93 \mathrm{~cm}^{2}$ is the stress corrosion crack cumulative aperture as it is expected that there will be 25 stress corrosion cracks (BSC 2004 [DIRS 169996]) and each will have an aperture of $7.7 \times 10^{-6} \mathrm{~m}^{2} / \mathrm{scc}$ (BSC 2004 [DIRS 169868] Section 6.3.3.1.2.1). Therefore, to calculate the cumulative aperture $\left(7.7 * 10^{-6} \mathrm{~m}^{2} / \mathrm{scc}\right) *(25 \mathrm{scc}) *(100 \mathrm{~cm})^{2} / \mathrm{m}^{2}=1.93 \mathrm{~cm}^{2}$. The waste package outer lid (BSC 2004 [DIRS 167394] Detail A) thickness is $2.54 \mathrm{~cm}$.

This calculates the vapor flux per second that enters the waste package. However, the vapor flux per year into the package is the value of interest. The following converts the flux from $\mathrm{mol} / \mathrm{sec}$ to mol/year:

$$
\text { QTempi }:=\text { qTemp } \cdot 60 \cdot 60 \cdot 24 \cdot 365.2 \text {. }
$$

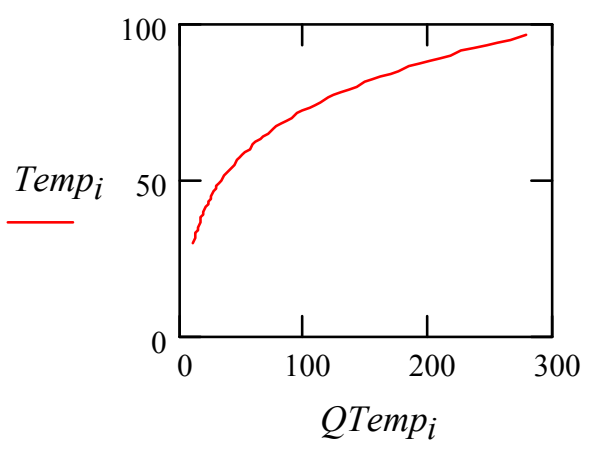

Figure H.1-1. Water Vapor Flux (QTemp $)$ That Enters the Waste Package, Calculated Based on Fick's First Law and for 95 Percent Relative Humidity 


\begin{tabular}{|c|c|c|c|}
\hline Temp $_{i}=$ & $p w$ Temp $_{i}=$ & & QTemp $_{i}=$ \\
\hline 30 & $4.242 \cdot 10^{3}$ & \multirow[t]{6}{*}{ I } & 10.75 \\
\hline 31 & $4.492 \cdot 10^{3}$ & & 11.46 \\
\hline 32 & $4.754 \cdot 10^{3}$ & & 12.22 \\
\hline 33 & $5.029 \cdot 10^{3}$ & & 13.01 \\
\hline 34 & $5.318 \cdot 10^{3}$ & & 13.86 \\
\hline 35 & $5.622 \cdot 10^{3}$ & & 14.76 \\
\hline
\end{tabular}

Table H.1-1. Water Vapor Flux (mol/yr) Calculated from Fick's First Law

\begin{tabular}{|c|c|c|c|c|c|c|c|c|c|}
\hline $\begin{array}{l}\text { Relative } \\
\text { Humidity } \\
\end{array}$ & 0.30 & 0.40 & 0.50 & 0.60 & 0.70 & 0.80 & 0.90 & 0.95 & 1.00 \\
\hline Temp. $\left({ }^{\circ} \mathrm{C}\right)$ & \multicolumn{9}{|c|}{ Flux(mol/yr) } \\
\hline 30 & 3.26 & 4.35 & 5.43 & 6.52 & 7.61 & 8.69 & 9.78 & 10.32 & 10.87 \\
\hline 31 & 3.47 & 4.62 & 5.78 & 6.93 & 8.09 & 9.25 & 10.40 & 10.98 & 11.56 \\
\hline 32 & 3.69 & 4.91 & 6.14 & 7.37 & 8.60 & 9.83 & 11.06 & 11.67 & 12.29 \\
\hline 33 & 3.92 & 5.22 & 6.53 & 7.83 & 9.14 & 10.44 & 11.75 & 12.40 & 13.05 \\
\hline 34 & 4.16 & 5.55 & 6.93 & 8.32 & 9.71 & 11.09 & 12.48 & 13.17 & 13.86 \\
\hline 35 & 4.42 & 5.89 & 7.36 & 8.83 & 10.30 & 11.77 & 13.25 & 13.98 & 14.72 \\
\hline 36 & 4.69 & 6.25 & 7.81 & 9.37 & 10.93 & 12.49 & 14.06 & 14.84 & 15.62 \\
\hline 37 & 4.97 & 6.63 & 8.28 & 9.94 & 11.60 & 13.25 & 14.91 & 15.74 & 16.57 \\
\hline 38 & 5.27 & 7.03 & 8.78 & 10.54 & 12.30 & 14.05 & 15.81 & 16.69 & 17.57 \\
\hline 39 & 5.59 & 7.45 & 9.31 & 11.17 & 13.03 & 14.89 & 16.76 & 17.69 & 18.62 \\
\hline 40 & 5.92 & 7.89 & 9.86 & 11.84 & 13.81 & 15.78 & 17.75 & 18.74 & 19.73 \\
\hline 41 & 6.27 & 8.36 & 10.44 & 12.53 & 14.62 & 16.71 & 18.80 & 19.85 & 20.89 \\
\hline 42 & 6.63 & 8.85 & 11.06 & 13.27 & 15.48 & 17.69 & 19.90 & 21.01 & 22.11 \\
\hline 43 & 7.02 & 9.36 & 11.70 & 14.04 & 16.38 & 18.72 & 21.06 & 22.23 & 23.40 \\
\hline 44 & 7.43 & 9.90 & 12.38 & 14.85 & 17.33 & 19.80 & 22.28 & 23.52 & 24.75 \\
\hline 45 & 7.85 & 10.47 & 13.09 & 15.70 & 18.32 & 20.94 & 23.56 & 24.87 & 26.17 \\
\hline 46 & 8.30 & 11.07 & 13.83 & 16.60 & 19.37 & 22.13 & 24.90 & 26.28 & 27.67 \\
\hline 47 & 8.77 & 11.69 & 14.62 & 17.54 & 20.46 & 23.39 & 26.31 & 27.77 & 29.23 \\
\hline 48 & 9.26 & 12.35 & 15.44 & 18.52 & 21.61 & 24.70 & 27.79 & 29.33 & 30.87 \\
\hline 49 & 9.78 & 13.04 & 16.30 & 19.56 & 22.82 & 26.08 & 29.34 & 30.97 & 32.60 \\
\hline 50 & 10.32 & 13.76 & 17.20 & 20.64 & 24.08 & 27.52 & 30.96 & 32.69 & 34.41 \\
\hline 51 & 10.89 & 14.52 & 18.15 & 21.78 & 25.41 & 29.04 & 32.67 & 34.48 & 36.30 \\
\hline 52 & 11.49 & 15.31 & 19.14 & 22.97 & 26.80 & 30.63 & 34.46 & 36.37 & 38.28 \\
\hline 53 & 12.11 & 16.15 & 20.18 & 24.22 & 28.25 & 32.29 & 36.33 & 38.35 & 40.36 \\
\hline 54 & 12.76 & 17.02 & 21.27 & 25.53 & 29.78 & 34.03 & 38.29 & 40.41 & 42.54 \\
\hline 55 & 13.45 & 17.93 & 22.41 & 26.89 & 31.38 & 35.86 & 40.34 & 42.58 & 44.82 \\
\hline 56 & 14.16 & 18.88 & 23.60 & 28.32 & 33.05 & 37.77 & 42.49 & 44.85 & 47.21 \\
\hline 57 & 14.91 & 19.88 & 24.85 & 29.82 & 34.79 & 39.76 & 44.73 & 47.22 & 49.70 \\
\hline 58 & 15.69 & 20.93 & 26.16 & 31.39 & 36.62 & 41.85 & 47.08 & 49.70 & 52.31 \\
\hline 59 & 16.51 & 22.02 & 27.52 & 33.03 & 38.53 & 44.03 & 49.54 & 52.29 & 55.04 \\
\hline 60 & 17.37 & 23.16 & 28.95 & 34.74 & 40.53 & 46.32 & 52.11 & 55.00 & 57.90 \\
\hline 61 & 18.26 & 24.35 & 30.44 & 36.53 & 42.61 & 48.70 & 54.79 & 57.83 & 60.88 \\
\hline
\end{tabular}


Table H.1-1. Water Vapor Flux (mol/yr) Calculated from Fick's First Law (Continued)

\begin{tabular}{|c|c|c|c|c|c|c|c|c|c|}
\hline $\begin{array}{l}\text { Relative } \\
\text { Humidity }\end{array}$ & 0.30 & 0.40 & 0.50 & 0.60 & 0.70 & 0.80 & 0.90 & 0.95 & 1.00 \\
\hline Temp. $\left({ }^{\circ} \mathrm{C}\right)$ & \multicolumn{9}{|c|}{ Flux(mol/yr) } \\
\hline 62 & 19.20 & 25.60 & 32.00 & 38.39 & 44.79 & 51.19 & 57.59 & 60.79 & 63.99 \\
\hline 63 & 20.17 & 26.90 & 33.62 & 40.35 & 47.07 & 53.79 & 60.52 & 63.88 & 67.24 \\
\hline 64 & 21.19 & 28.25 & 35.31 & 42.37 & 49.44 & 56.50 & 63.56 & 67.09 & 70.62 \\
\hline 65 & 22.25 & 29.66 & 37.08 & 44.49 & 51.91 & 59.32 & 66.74 & 70.44 & 74.15 \\
\hline 66 & 23.35 & 31.13 & 38.92 & 46.70 & 54.48 & 62.27 & 70.05 & 73.94 & 77.83 \\
\hline 67 & 24.50 & 32.67 & 40.83 & 49.00 & 57.17 & 65.34 & 73.50 & 77.59 & 81.67 \\
\hline 68 & 25.70 & 34.27 & 42.84 & 51.40 & 59.97 & 68.54 & 77.10 & 81.39 & 85.67 \\
\hline 69 & 26.95 & 35.94 & 44.92 & 53.90 & 62.89 & 71.87 & 80.86 & 85.35 & 89.84 \\
\hline 70 & 28.25 & 37.67 & 47.09 & 56.51 & 65.93 & 75.35 & 84.76 & 89.47 & 94.18 \\
\hline 71 & 29.61 & 39.48 & 49.35 & 59.22 & 69.10 & 78.97 & 88.84 & 93.77 & 98.71 \\
\hline 72 & 31.03 & 41.37 & 51.71 & 62.05 & 72.39 & 82.74 & 93.08 & 98.25 & 103.40 \\
\hline 73 & 32.50 & 43.33 & 54.16 & 64.99 & 75.83 & 86.66 & 97.49 & 102.90 & 108.30 \\
\hline 74 & 34.03 & 45.37 & 56.71 & 68.06 & 79.40 & 90.74 & 102.10 & 107.80 & 113.40 \\
\hline 75 & 35.62 & 47.50 & 59.37 & 71.24 & 83.12 & 94.99 & 106.90 & 112.80 & 118.70 \\
\hline 76 & 37.28 & 49.71 & 62.13 & 74.56 & 86.99 & 99.41 & 111.80 & 118.10 & 124.30 \\
\hline 77 & 39.00 & 52.00 & 65.01 & 78.01 & 91.01 & 104.00 & 117.00 & 123.50 & 130.00 \\
\hline 78 & 40.80 & 54.39 & 67.99 & 81.59 & 95.19 & 108.80 & 122.40 & 129.20 & 136.00 \\
\hline 79 & 42.66 & 56.88 & 71.10 & 85.32 & 99.54 & 113.80 & 128.00 & 135.10 & 142.20 \\
\hline 80 & 44.59 & 59.46 & 74.32 & 89.19 & 104.10 & 118.90 & 133.80 & 141.20 & 148.60 \\
\hline 81 & 46.60 & 62.14 & 77.67 & 93.21 & 108.70 & 124.30 & 139.80 & 147.60 & 155.30 \\
\hline 82 & 48.69 & 64.92 & 81.15 & 97.39 & 113.60 & 129.80 & 146.10 & 154.20 & 162.30 \\
\hline 83 & 50.86 & 67.82 & 84.77 & 101.70 & 118.70 & 135.60 & 152.60 & 161.10 & 169.50 \\
\hline 84 & 53.11 & 70.82 & 88.52 & 106.20 & 123.90 & 141.60 & 159.30 & 168.20 & 177.00 \\
\hline 85 & 55.45 & 73.93 & 92.42 & 110.90 & 129.40 & 147.90 & 166.30 & 175.60 & 184.80 \\
\hline 86 & 57.87 & 77.17 & 96.46 & 115.70 & 135.00 & 154.30 & 173.60 & 183.30 & 192.90 \\
\hline 87 & 60.39 & 80.52 & 100.60 & 120.80 & 140.90 & 161.00 & 181.20 & 191.20 & 201.30 \\
\hline 88 & 63.00 & 84.00 & 105.00 & 126.00 & 147.00 & 168.00 & 189.00 & 199.50 & 210.00 \\
\hline 89 & 65.70 & 87.60 & 109.50 & 131.40 & 153.30 & 175.20 & 197.10 & 208.10 & 219.00 \\
\hline 90 & 68.51 & 91.34 & 114.20 & 137.00 & 159.80 & 182.70 & 205.50 & 216.90 & 228.40 \\
\hline 91 & 71.41 & 95.22 & 119.00 & 142.80 & 166.60 & 190.40 & 214.20 & 226.10 & 238.00 \\
\hline 92 & 74.42 & 99.23 & 124.00 & 148.80 & 173.70 & 198.50 & 223.30 & 235.70 & 248.10 \\
\hline 93 & 77.54 & 103.40 & 129.20 & 155.10 & 180.90 & 206.80 & 232.60 & 245.60 & 258.50 \\
\hline 94 & 80.77 & 107.70 & 134.60 & 161.50 & 188.50 & 215.40 & 242.30 & 255.80 & 269.20 \\
\hline 95 & 84.12 & 112.20 & 140.20 & 168.20 & 196.30 & 224.30 & 252.40 & 266.40 & 280.40 \\
\hline 96 & 87.58 & 116.80 & 146.00 & 175.20 & 204.40 & 233.60 & 262.70 & 277.30 & 291.90 \\
\hline
\end{tabular}




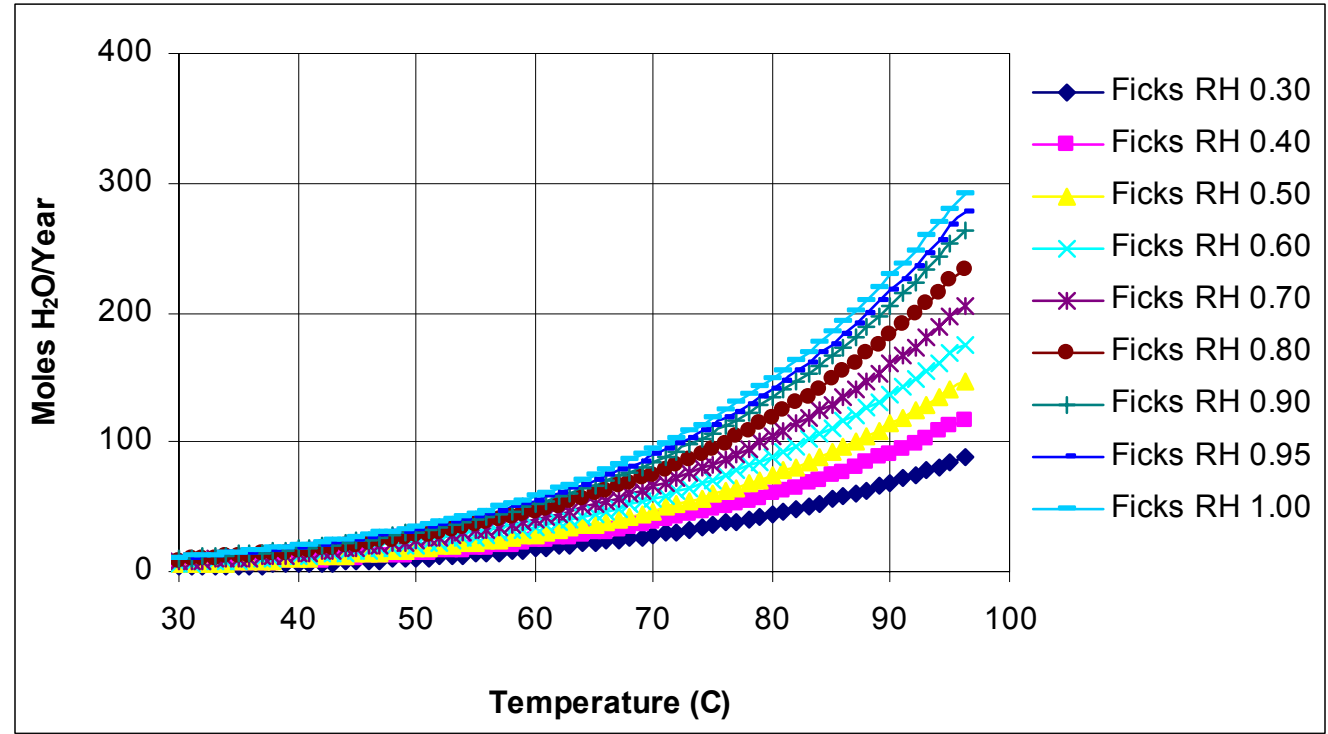

Figure H.1-2. Water Vapor Flux Calculated Based on Fick's First Law

\section{H.2 WATER VAPOR DIFFUSION FLUX STEFAN TUBE ANALYTIC SOLUTION}

The purpose of this sheet is to calculation of the water vapor flux into the waste package through the Stress Corrosion Cracks on the outer lid based on the Stefan Tube equations. In contrast to Fick's First Law that calculates the flux solely due to diffusion a Stefan Tube calculation determines flux based on diffusion and advection (Cutlip and Shacham 2000 [DIRS 163339], Equation 7-3).

$$
\begin{gathered}
N_{A}=D_{A B} C \frac{d x_{A}}{d z}+\frac{C_{A}}{C}\left(N_{A}+N_{B}\right) \\
\text { flux }=\text { diffusion }+ \text { bulk flow (convection) }
\end{gathered}
$$

where $\mathrm{D}_{\mathrm{AB}}$ is the molecular diffusivity of $\mathrm{A}$ in $\mathrm{B}\left(\mathrm{cm}^{2} / \mathrm{s}\right), \mathrm{C}$ is the total concentration $\left(\mathrm{mole} / \mathrm{cm}^{3}\right)$, $\mathrm{C}_{\mathrm{A}}$ is the concentration of $\mathrm{A}(\mathrm{mole} / \mathrm{m} 3), \mathrm{N}_{\mathrm{A}}$ is the flux of A relative to stationary coordinates (mole $/ \mathrm{m}^{2}{ }^{*} \mathrm{~s}$ ) and $\mathrm{N}_{\mathrm{B}}$ is the flux of $\mathrm{B}\left(\mathrm{mole} / \mathrm{m}^{2} * \mathrm{~s}\right)$. For this problem, the total gas concentration $\mathrm{C}$ in constant and component $\mathrm{B}$ is stagnant. Thus $\mathrm{N}_{\mathrm{B}}$ is zero. The mole fraction of $\mathrm{A}$ in the gas mixture, $x_{A}$, can be used to replace $\mathrm{C}_{\mathrm{A}} / \mathrm{C}$. The modified expression for this equation can be written as (Cutlip and Shacham 2000 [DIRS 163339], Equation 7-4):

$$
N_{A}=-D_{A B} \frac{d C_{A}}{d z}+x_{A} N_{A}
$$

Solving for $\mathrm{N}_{\mathrm{A}}$ and rearranging Equation H.2-2 yields (Cutlip and Shacham 2000 [DIRS 163339], Equation 7-5): 


$$
\frac{d x_{A}}{d z}=\frac{\left(1-x_{A}\right) N_{A}}{D_{A B} C}
$$

At constant temperature and pressure for ideal gases, the total concentration $\mathrm{C}$ and binary diffusivity $\mathrm{D}_{\mathrm{AB}}$ may be considered constant. Based on this information an analytical solution can be derived and is provided below (Cutlip and Shacham 2000 [DIRS 163339], Equations 7-7 and 7-8):

$$
\begin{gathered}
\mathrm{N}_{\mathrm{Az} \mid \mathrm{z}=\mathrm{z} 1}=\frac{\mathrm{D}_{\mathrm{AB}} \mathrm{C}}{\left(\mathrm{z}_{2}-\mathrm{z}_{1}\right)\left(\mathrm{X}_{\mathrm{B}}\right) 1 \mathrm{~m}}\left(\mathrm{X}_{\mathrm{A} 1}-\mathrm{X}_{\mathrm{A} 2}\right) \\
\left(\mathrm{X}_{\mathrm{B}}\right)_{1 \mathrm{~m}}=\frac{\left(\mathrm{X}_{\mathrm{A} 1}-\mathrm{X}_{\mathrm{A} 2}\right)}{\ln \left[\left(1-\mathrm{X}_{\mathrm{A} 2}\right) /\left(1-\mathrm{X}_{\mathrm{A} 1}\right)\right]}
\end{gathered}
$$

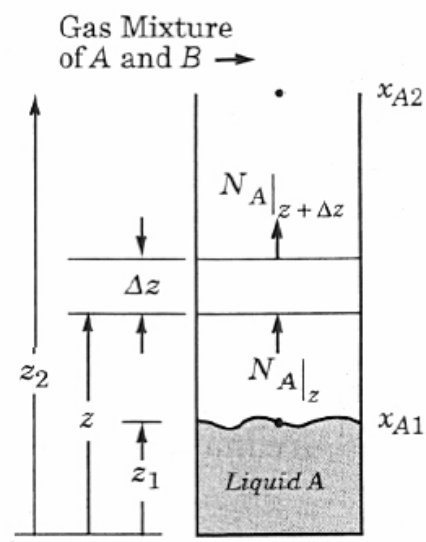

Source: Cutlip and Shacham 2000 [DIRS 163339], Figure 7-1.

Figure H.2-1. Gas Phase Diffusion of $A$ through Stagnant $B$

where $\mathrm{z}_{1}$ is the location above the liquid interface, $\mathrm{z}_{2}$ is the location at the end of the tube, $\mathrm{X}_{\mathrm{A} 1}$ is the mole fraction of $\mathrm{A}$ at location 1 , and $\mathrm{X}_{\mathrm{A} 2}$ is the mole fraction of $\mathrm{A}$ at location 2 . The geometry of the locations and the corresponding mole fractions are illustrated in Figure 7-1 of the study by Cutlip and Shacham (2000 [DIRS 163339]). This figure is reproduced above. It should be remembered that a flux is dependent on the aperture or area of the opening. It is implicitly assumed (although not stated) by Cutlip and Shacham (2000 [DIRS 163339]) that the area of opening is 1 meter square. This can be shown by performing a dimensional analysis by assigning and calculating with the dimensional units. This was done for "Diffusion flux - Stefan Tube Anal. Soln (indexed- units).mcd."

In Equation H.2-6, as adapted from EBS Radionuclide Transport Abstraction (BSC 2004 [DIRS 169868], Equation 6.2.2-2), the vector $\mathrm{i}=1 . .67$ defines the range of iteration, Temp $p_{i}$ sums 29 with the vector $\mathrm{i}$ to define the temperature range of the calculation $p w f T e m p\left(30^{\circ} \mathrm{C}\right.$ to $96^{\circ} \mathrm{C}$ ), and pwfTemp defines a function that calculates the saturated partial pressure of water 
vapor over the temperature range (Temp) of $30^{\circ} \mathrm{C}$ to $96^{\circ} \mathrm{C}$. Equations for $p w f T e m p$ are from Singh et al. (2002 [DIRS 161624], Equations 1a and 1b).

$$
\begin{gathered}
i:=1 . .67 \\
\text { pwfTemp }(\text { Temp }):=\left\lfloor\begin{array}{c}
\text { Temp }_{i}:=29+i \\
610.78 \cdot \exp \left[\frac{17.269 \cdot(\text { Temp })}{237.3+(\text { Temp })}\right] \text { if }(0 \leq \text { Temp }) \cdot(\text { Temp }<63) \\
610.78 \cdot \exp \left[\frac{17.269(\text { Temp })}{236.3+1.01585(\text { Temp })}\right] \text { if }(63 \leq \text { Temp }) \cdot(\text { Temp }<110)
\end{array}\right.
\end{gathered}
$$

(Eq. H.2-6)

Again, from the saturated partial pressure of water vapor (pwfTemp) the partial pressure of water dependent on the relative humidity (RH) can be determined (BSC 2004 [DIRS 169868], Equation 6.6.2-1):

$$
\begin{gathered}
\text { pwTemp }_{i}:=\operatorname{pwfTemp}\left(\text { Temp }_{i}\right) \\
R H:=0.95 \\
\text { pTemp }_{i}:=\left(\text { pwTemp }_{i}\right) \cdot R H
\end{gathered}
$$

where pwTempi $(\mathrm{Pa})$ the saturation vapor pressure of water. It is calculated in the function pwfTemp over the temperature range $30^{\circ} \mathrm{C}$ to $96^{\circ} \mathrm{C} . P a=N / M^{2} . R H$ is the relative humidity. Changing the RH calculate the flux over the previously defined temperature range. pTempi (Pa) is the partial pressure of water dependent on the relative humidity.

Next, the molal humidity is calculated. In this example it is calculated for $50^{\circ} \mathrm{C}$ and 95 percent relative humidity (BSC 2004 [DIRS 169868], Equation 6.6.2-4):

$$
\text { HmTemp }_{i}:=\frac{p \text { Temp }_{i}}{101325-p \text { Temp }_{i}}
$$

where HmTemp $p_{i}$ is the molal humidity $\left(\mathrm{mol} \mathrm{H}_{2} \mathrm{O} / \mathrm{mol}\right.$ wet air). Pressure for dry air is 1 atm $=$ $101325 \mathrm{~Pa}$, from equation $\mathrm{H} .1-2$ at $50^{\circ} \mathrm{C}$ the partial pressure of water $\left(\mathrm{p}_{\mathrm{w}}\right)$ was calculated $\mathrm{p}_{\mathrm{w}}=$ $12,344 \mathrm{~Pa}$. So the partial pressure at $\mathrm{RH}=0.95$ is $\mathrm{pw}=11,717 \mathrm{~Pa}$. Therefore, the molal humidity (mole fraction) of water vapor under these conditions is $0.1156 \mathrm{~mol} \mathrm{H}_{2} \mathrm{O} \mathrm{mol}^{-1}$ wet air.

Next, the concentration of water vapor at $50^{\circ} \mathrm{C}$ and 95 percent relative humidity can be calculated (BSC 2004 [DIRS 169868], Equation 6.6.2-5): 


$$
\text { CwvTemp }_{i}:=\frac{\text { HmTemp }_{i}}{22414\left(\frac{273.15+\text { Temp }_{i}}{273.15}\right)}
$$

where $\mathrm{CwvTemp}_{i}$ is the concentration of water vapor in the air $\left(\mathrm{mol} \mathrm{H} 2 \mathrm{O} \mathrm{cm}^{-3}\right)$.

To calculate the binary diffusion coefficient, the following equation is used (Bird et al. 1960 [DIRS 103524] Equation 16.3-1; BSC 2004 [DIRS 169868], Equations 6.6.2-6 and 6.6.2-7):

DABTemp $_{i}:=3.64 \cdot 10^{-4} \cdot\left(\frac{273.15+\text { Temp }_{i}}{\sqrt{647.25 \cdot 132}}\right)^{2.334} \cdot(218.3 \cdot 36.4)^{\frac{1}{3}} \cdot(647.25 \cdot 132)^{\frac{5}{12}} \cdot\left(\frac{1}{18.01528}+\frac{1}{28.964}\right)^{\frac{1}{2}} \cdot(1)^{-1}$

(Eq. H.2-10)

where $D_{A B}$ is the binary diffusion coefficient $\left(\mathrm{cm}^{2} \mathrm{~s}^{-1}\right), a=3.64 \times 10^{-4}$ for $\mathrm{H}_{2} \mathrm{O}$, Temp $_{i}=$ temperature $(\mathrm{C})$ converted into absolute temperature $(\mathrm{K}), T_{c A}=647.25 \mathrm{~K}, T_{c B}=132 \mathrm{~K}, p_{c A}=$ $218.3 \mathrm{~atm}, p_{c B}=36.4 \mathrm{~atm}, M_{A}=18.01528 \mathrm{~g} / \mathrm{mol}, M_{B}=28.964 \mathrm{~g} / \mathrm{mol}$, and $p^{-1}=1 \mathrm{~atm}$.

$X B_{i}$ is one of the two equations for the analytical Stefan Tube equations and is based on the concentrations of gas $\mathrm{A}$ and $\mathrm{B}$ and the configuration illustrated in Figure H.2-1. Note: $X B_{i}$ is dimensionless as its units are (Pa/Pa) (Cutlip and Shacham 2000 [DIRS 163339], Equation 7.8):

$$
X B_{i}:=\frac{\left(\frac{p \text { Temp }_{i}}{101325}-0\right)}{\ln \left[\frac{(1-0)}{\left(1-\frac{p T e m p}{1}\right)}\right]}
$$

Once the value for $X B_{i}$ has been determined, the water vapor flux into the waste package can be determined by solving the following equation (Cutlip and Shacham 2000 [DIRS 163339], Equation 7.8):

$n_{A z_{i}}:=\frac{\text { DABTemp }_{i} \cdot C w v \operatorname{Temp}_{i}}{(2.54-0) \cdot X B_{i}} \cdot\left(\frac{p \operatorname{Temp}_{i}}{101325}-0\right) 1.93$

$1.93 \mathrm{~cm}^{2}$ is the aperture of the SCC from EBS Radionuclide Transport Abstraction (BSC 2004 [DIRS 169868], p. 6-181).

$$
\begin{gathered}
N_{A z_{i}}:=n_{A z_{i}} \cdot 60 \cdot 60 \cdot 24 \cdot 365.2 \\
N_{A z_{21}}=4.466
\end{gathered}
$$


$\mathrm{N}_{\mathrm{Azi}}$ converts $\mathrm{n}_{\mathrm{Az}}$ from $\mathrm{mol} / \mathrm{sec}$ to $\mathrm{mol} / \mathrm{yr}$.

Temp $i$
\begin{tabular}{|r|}
\hline 30 \\
\hline 31 \\
\hline 32 \\
\hline 33 \\
\hline 34 \\
\hline 35 \\
\hline 36 \\
\hline 37 \\
\hline 38 \\
\hline 39 \\
\hline 40 \\
\hline 41 \\
\hline 42 \\
\hline 43 \\
\hline 44 \\
\hline 45 \\
\hline 46 \\
\hline
\end{tabular}

${ }^{A z_{i}}=$
\begin{tabular}{|r|}
\hline $1.473 \cdot 10^{-8}$ \\
\hline $1.661 \cdot 10^{-8}$ \\
\hline $1.871 \cdot 10^{-8}$ \\
\hline $2.106 \cdot 10^{-8}$ \\
\hline $2.369 \cdot 10^{-8}$ \\
\hline $2.662 \cdot 10^{-8}$ \\
\hline $2.99 \cdot 10^{-8}$ \\
\hline $3.356 \cdot 10^{-8}$ \\
\hline $3.763 \cdot 10^{-8}$ \\
\hline $4.217 \cdot 10^{-8}$ \\
\hline $4.723 \cdot 10^{-8}$ \\
\hline $5.286 \cdot 10^{-8}$ \\
\hline $5.912 \cdot 10^{-8}$ \\
\hline $6.607 \cdot 10^{-8}$ \\
\hline $7.38 \cdot 10^{-8}$ \\
\hline $8.238 \cdot 10^{-8}$ \\
\hline $9.191 \cdot 10^{-8}$ \\
\hline
\end{tabular}

$N_{A z}=$

\begin{tabular}{|r|}
\hline 0.465 \\
\hline 0.524 \\
\hline 0.59 \\
\hline 0.665 \\
\hline 0.747 \\
\hline 0.84 \\
\hline 0.944 \\
\hline 1.059 \\
\hline 1.188 \\
\hline 1.331 \\
\hline 1.491 \\
\hline 1.668 \\
\hline 1.866 \\
\hline 2.085 \\
\hline 2.329 \\
\hline 2.6 \\
\hline 2.9 \\
\hline
\end{tabular}

Table H.2-1. Water Vapor Flux (mol/yr) Calculated by the Stefan Tube Equation

\begin{tabular}{|c|c|c|c|c|c|c|c|c|c|}
\hline $\begin{array}{l}\text { Relative } \\
\text { Humidity }\end{array}$ & 0.30 & 0.4 & 0.50 & 0.60 & 0.70 & 0.80 & 0.90 & 0.95 & 1.00 \\
\hline $\begin{array}{l}\text { Temp. } \\
\left({ }^{\circ} \mathrm{C}\right)\end{array}$ & \multicolumn{9}{|c|}{ Flux (mol/yr) } \\
\hline 30 & 0.04 & 0.07 & 0.12 & 0.17 & 0.23 & 0.30 & 0.38 & 0.42 & 0.47 \\
\hline 31 & 0.05 & 0.08 & 0.13 & 0.19 & 0.26 & 0.33 & 0.42 & 0.47 & 0.52 \\
\hline 32 & 0.05 & 0.09 & 0.15 & 0.21 & 0.29 & 0.38 & 0.48 & 0.53 & 0.59 \\
\hline 33 & 0.06 & 0.11 & 0.16 & 0.24 & 0.32 & 0.42 & 0.54 & 0.60 & 0.67 \\
\hline 34 & 0.07 & 0.12 & 0.18 & 0.27 & 0.36 & 0.48 & 0.60 & 0.67 & 0.75 \\
\hline 35 & 0.07 & 0.13 & 0.21 & 0.30 & 0.41 & 0.54 & 0.68 & 0.76 & 0.84 \\
\hline 36 & 0.08 & 0.15 & 0.23 & 0.34 & 0.46 & 0.60 & 0.76 & 0.85 & 0.94 \\
\hline 37 & 0.09 & 0.17 & 0.26 & 0.38 & 0.51 & 0.67 & 0.86 & 0.95 & 1.06 \\
\hline 38 & 0.10 & 0.19 & 0.29 & 0.42 & 0.58 & 0.76 & 0.96 & 1.07 & 1.19 \\
\hline 39 & 0.12 & 0.21 & 0.33 & 0.47 & 0.65 & 0.85 & 1.07 & 1.20 & 1.33 \\
\hline 40 & 0.13 & 0.23 & 0.37 & 0.53 & 0.72 & 0.95 & 1.20 & 1.34 & 1.49 \\
\hline 41 & 0.15 & 0.26 & 0.41 & 0.59 & 0.81 & 1.06 & 1.35 & 1.50 & 1.67 \\
\hline 42 & 0.16 & 0.29 & 0.46 & 0.66 & 0.90 & 1.18 & 1.51 & 1.68 & 1.87 \\
\hline 43 & 0.18 & 0.33 & 0.51 & 0.74 & 1.01 & 1.32 & 1.68 & 1.88 & 2.09 \\
\hline 44 & 0.20 & 0.36 & 0.57 & 0.82 & 1.13 & 1.48 & 1.88 & 2.10 & 2.33 \\
\hline 45 & 0.23 & 0.40 & 0.63 & 0.92 & 1.26 & 1.65 & 2.10 & 2.34 & 2.60 \\
\hline 46 & 0.25 & 0.45 & 0.71 & 1.02 & 1.40 & 1.84 & 2.34 & 2.61 & 2.90 \\
\hline 47 & 0.28 & 0.50 & 0.79 & 1.14 & 1.56 & 2.05 & 2.60 & 2.91 & 3.23 \\
\hline
\end{tabular}


Table H.2-1. Water Vapor Flux (mol/yr) Calculated by the Stefan Tube Equation (Continued)

\begin{tabular}{|c|c|c|c|c|c|c|c|c|c|}
\hline $\begin{array}{l}\text { Relative } \\
\text { Humidity }\end{array}$ & 0.30 & 0.4 & 0.50 & 0.60 & 0.70 & 0.80 & 0.90 & 0.95 & 1.00 \\
\hline $\begin{array}{l}\text { Temp. } \\
\left({ }^{\circ} \mathrm{C}\right)\end{array}$ & \multicolumn{9}{|c|}{ Flux(mol/yr) } \\
\hline 48 & 0.31 & 0.56 & 0.87 & 1.27 & 1.73 & 2.28 & 2.90 & 3.24 & 3.60 \\
\hline 49 & 0.35 & 0.62 & 0.97 & 1.41 & 1.93 & 2.54 & 3.23 & 3.61 & 4.01 \\
\hline 50 & 0.38 & 0.69 & 1.08 & 1.57 & 2.15 & 2.82 & 3.59 & 4.02 & 4.47 \\
\hline 51 & 0.43 & 0.76 & 1.20 & 1.74 & 2.38 & 3.14 & 4.00 & 4.47 & 4.97 \\
\hline 52 & 0.47 & 0.85 & 1.33 & 1.93 & 2.65 & 3.48 & 4.44 & 4.97 & 5.52 \\
\hline 53 & 0.52 & 0.94 & 1.48 & 2.14 & 2.94 & 3.87 & 4.93 & 5.52 & 6.14 \\
\hline 54 & 0.58 & 1.04 & 1.64 & 2.38 & 3.26 & 4.29 & 5.48 & 6.13 & 6.82 \\
\hline 55 & 0.64 & 1.15 & 1.81 & 2.63 & 3.61 & 4.76 & 6.08 & 6.80 & 7.57 \\
\hline 56 & 0.71 & 1.27 & 2.01 & 2.92 & 4.00 & 5.28 & 6.74 & 7.54 & 8.40 \\
\hline 57 & 0.79 & 1.41 & 2.22 & 3.23 & 4.43 & 5.85 & 7.47 & 8.37 & 9.32 \\
\hline 58 & 0.87 & 1.56 & 2.46 & 3.57 & 4.91 & 6.47 & 8.28 & 9.27 & 10.33 \\
\hline 59 & 0.96 & 1.72 & 2.71 & 3.95 & 5.43 & 7.17 & 9.17 & 10.27 & 11.45 \\
\hline 60 & 1.06 & 1.90 & 3.00 & 4.36 & 6.00 & 7.93 & 10.15 & 11.38 & 12.68 \\
\hline 61 & 1.17 & 2.09 & 3.31 & 4.82 & 6.64 & 8.77 & 11.23 & 12.59 & 14.04 \\
\hline 62 & 1.28 & 2.31 & 3.65 & 5.32 & 7.33 & 9.70 & 12.43 & 13.94 & 15.54 \\
\hline 63 & 1.41 & 2.55 & 4.03 & 5.87 & 8.10 & 10.71 & 13.74 & 15.42 & 17.20 \\
\hline 64 & 1.56 & 2.80 & 4.44 & 6.47 & 8.93 & 11.83 & 15.19 & 17.04 & 19.02 \\
\hline 65 & 1.71 & 3.09 & 4.89 & 7.14 & 9.85 & 13.06 & 16.78 & 18.83 & 21.03 \\
\hline 66 & 1.88 & 3.39 & 5.38 & 7.86 & 10.86 & 14.41 & 18.52 & 20.81 & 23.25 \\
\hline 67 & 2.07 & 3.73 & 5.92 & 8.66 & 11.97 & 15.89 & 20.45 & 22.98 & 25.69 \\
\hline 68 & 2.27 & 4.10 & 6.51 & 9.53 & 13.19 & 17.52 & 22.57 & 25.38 & 28.38 \\
\hline 69 & 2.49 & 4.51 & 7.16 & 10.48 & 14.52 & 19.31 & 24.90 & 28.01 & 31.34 \\
\hline 70 & 2.74 & 4.95 & 7.86 & 11.53 & 15.99 & 21.28 & 27.47 & 30.92 & 34.62 \\
\hline 71 & 3.00 & 5.43 & 8.64 & 12.68 & 17.59 & 23.45 & 30.30 & 34.13 & 38.23 \\
\hline 72 & 3.29 & 5.95 & 9.48 & 13.93 & 19.35 & 25.82 & 33.41 & 37.66 & 42.21 \\
\hline 73 & 3.60 & 6.53 & 10.41 & 15.30 & 21.29 & 28.44 & 36.84 & 41.55 & 46.61 \\
\hline 74 & 3.94 & 7.16 & 11.42 & 16.81 & 23.41 & 31.31 & 40.62 & 45.84 & 51.47 \\
\hline 75 & 4.32 & 7.84 & 12.52 & 18.46 & 25.73 & 34.47 & 44.78 & 50.58 & 56.83 \\
\hline 76 & 4.72 & 8.58 & 13.73 & 20.26 & 28.28 & 37.94 & 49.37 & 55.81 & 62.76 \\
\hline 77 & 5.16 & 9.40 & 15.05 & 22.23 & 31.08 & 41.75 & 54.43 & 61.58 & 69.33 \\
\hline 78 & 5.64 & 10.28 & 16.49 & 24.39 & 34.15 & 45.95 & 60.01 & 67.97 & 76.59 \\
\hline 79 & 6.17 & 11.25 & 18.06 & 26.75 & 37.52 & 50.57 & 66.17 & 75.03 & 84.65 \\
\hline 80 & 6.73 & 12.30 & 19.77 & 29.34 & 41.21 & 55.65 & 72.98 & 82.85 & 93.58 \\
\hline 81 & 7.35 & 13.45 & 21.65 & 32.17 & 45.27 & 61.25 & 80.51 & 91.51 & 103.51 \\
\hline 82 & 8.02 & 14.69 & 23.69 & 35.26 & 49.72 & 67.43 & 88.85 & 101.12 & 114.56 \\
\hline 83 & 8.75 & 16.05 & 25.92 & 38.65 & 54.61 & 74.23 & 98.08 & 111.81 & 126.88 \\
\hline 84 & 9.54 & 17.53 & 28.35 & 42.36 & 59.98 & 81.75 & 108.33 & 123.70 & 140.64 \\
\hline 85 & 10.40 & 19.14 & 31.01 & 46.43 & 65.89 & 90.05 & 119.72 & 136.97 & 156.04 \\
\hline 86 & 11.33 & 20.89 & 33.91 & 50.88 & 72.40 & 99.23 & 132.41 & 151.80 & 173.34 \\
\hline 87 & 12.35 & 22.79 & 37.08 & 55.76 & 79.56 & 109.40 & 146.56 & 168.41 & 192.83 \\
\hline 88 & 13.44 & 24.86 & 40.54 & 61.11 & 87.45 & 120.68 & 162.39 & 187.09 & 214.87 \\
\hline
\end{tabular}


Table H.2-1. Water Vapor Flux (mol/yr) Calculated by the Stefan Tube Equation (Continued)

\begin{tabular}{|c|c|c|c|c|c|c|c|c|c|}
\hline $\begin{array}{c}\text { Relative } \\
\text { Humidity }\end{array}$ & $\mathbf{0 . 3 0}$ & $\mathbf{0 . 4}$ & $\mathbf{0 . 5 0}$ & $\mathbf{0 . 6 0}$ & $\mathbf{0 . 7 0}$ & $\mathbf{0 . 8 0}$ & $\mathbf{0 . 9 0}$ & $\mathbf{0 . 9 5}$ & $\mathbf{1 . 0 0}$ \\
\hline $\begin{array}{c}\text { Temp. } \\
\text { ('0) }\end{array}$ & \multicolumn{9}{|c|}{ Flux(mol/yr) } \\
\hline 89 & 14.64 & 27.12 & 44.31 & 66.99 & 96.16 & 133.21 & 180.14 & 208.17 & 239.91 \\
\hline 90 & 15.93 & 29.57 & 48.44 & 73.43 & 105.77 & 147.16 & 200.11 & 232.06 & 268.52 \\
\hline 91 & 17.33 & 32.24 & 52.95 & 80.51 & 116.40 & 162.73 & 222.68 & 259.26 & 301.45 \\
\hline 92 & 18.85 & 35.15 & 57.87 & 88.29 & 128.18 & 180.15 & 248.30 & 290.45 & 339.68 \\
\hline 93 & 20.49 & 38.31 & 63.26 & 96.85 & 141.24 & 199.70 & 277.54 & 326.49 & 384.55 \\
\hline 94 & 22.28 & 41.75 & 69.16 & 106.28 & 155.77 & 221.72 & 311.17 & 368.55 & 438.02 \\
\hline 95 & 24.21 & 45.50 & 75.61 & 116.69 & 171.96 & 246.63 & 350.17 & 418.29 & 503.02 \\
\hline 96 & 26.31 & 49.58 & 82.68 & 128.18 & 190.04 & 274.98 & 395.93 & 478.14 & 584.37 \\
\hline
\end{tabular}

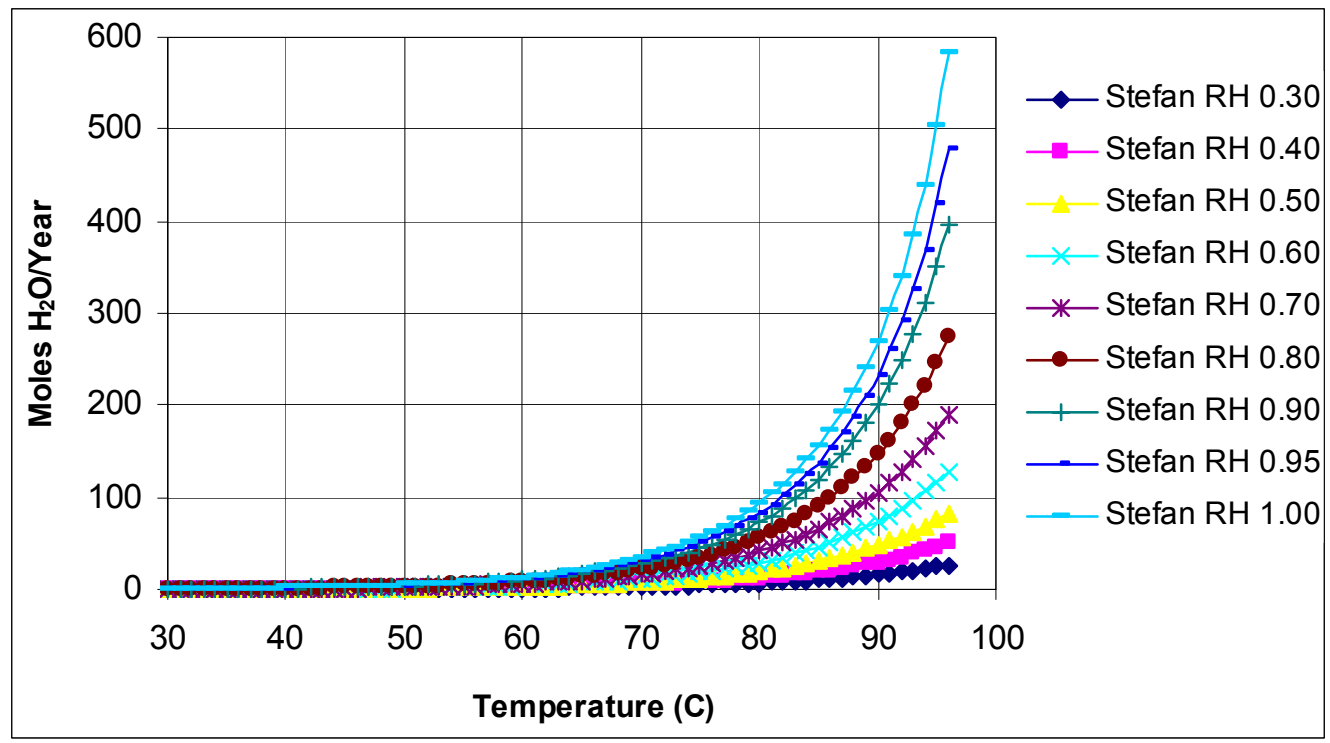

Figure H.2-2. Water Vapor Flux Calculated Based on Stefan Tube Equations 